2.

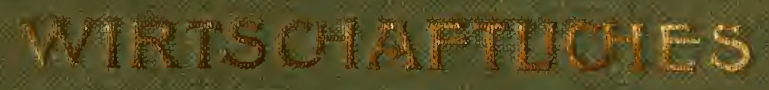

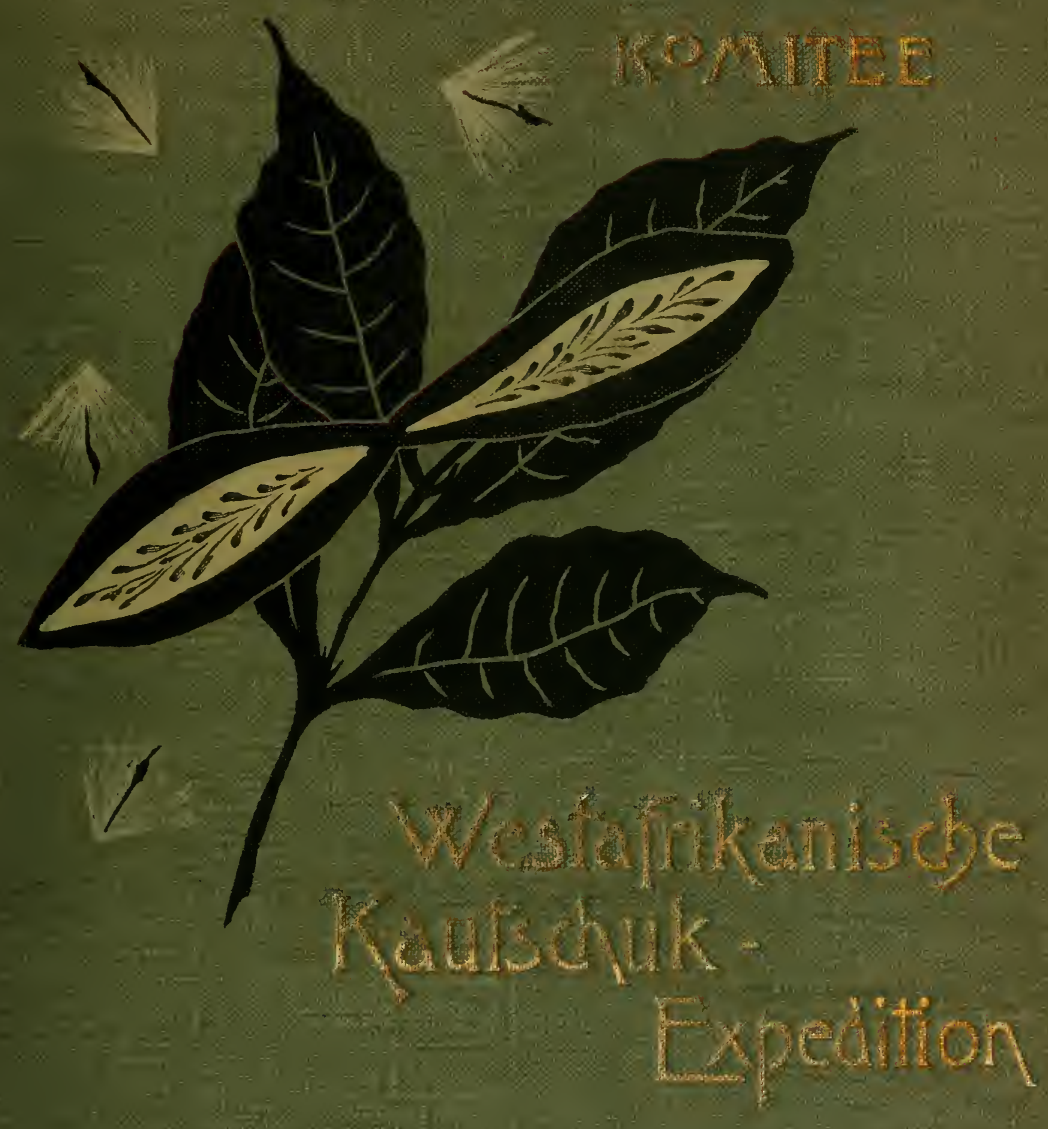

P. SemiechTER 
畓 (19)

4.

1, thit

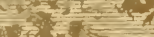

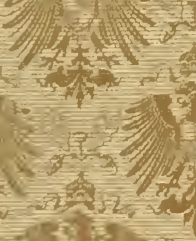
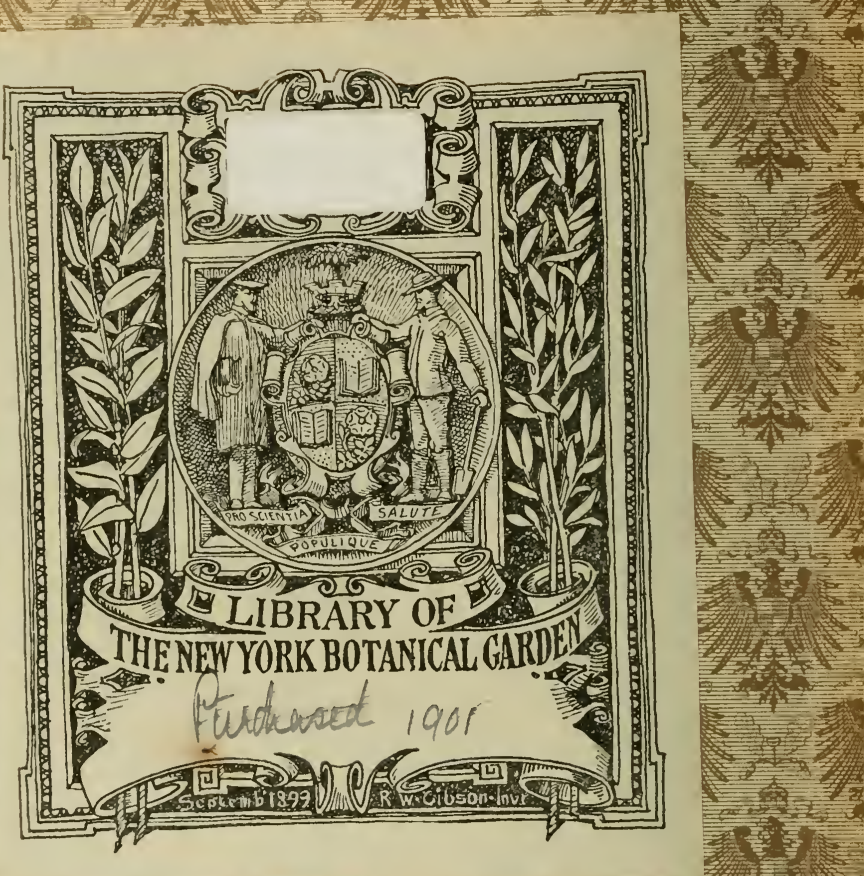

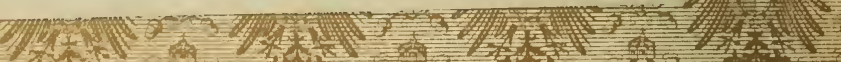

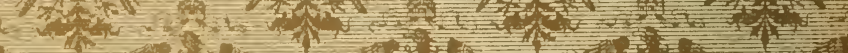

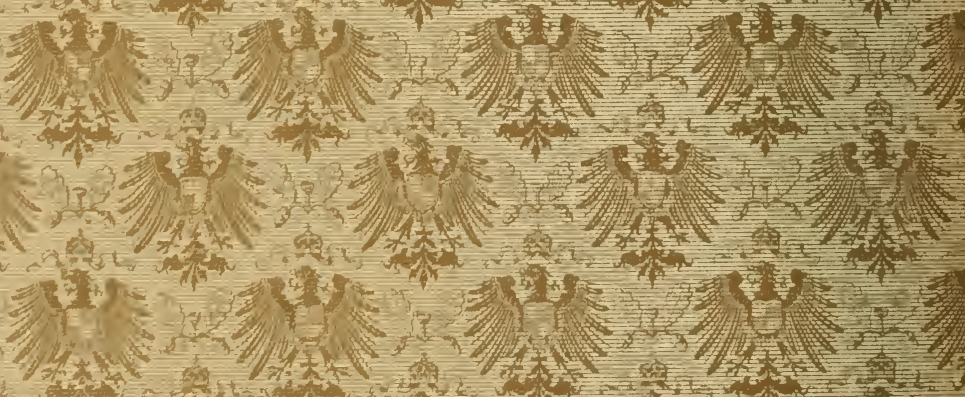





\section{UUestafrikanische Rautschuk=Expedition.}

(R. schlechter.)

$1899 / 1900$. 



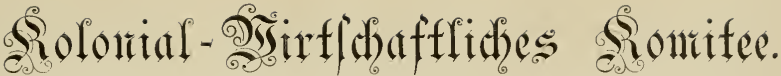

\section{(Uestafrikanische Rautschuk=Expedition. \\ (R. Schlechter.) \\ $1899 / 1900$.}

Mĩt 13 Tafeln uns it 21bbiloungen in Tert.

Berlin 1900.

Verlag des Kolonial-Wirtschaftlichen Komitees, Berlin NW., Unter den Linden 40.

(Preis 12 Mark.)

In Kommission bei der Königlichen Hofbuchhandlung von E. S. Mittler \& Sohn, Berlin, Kochstrasse $68-71$. 


$$
\begin{aligned}
& 56 \\
& 290 \\
& 535
\end{aligned}
$$




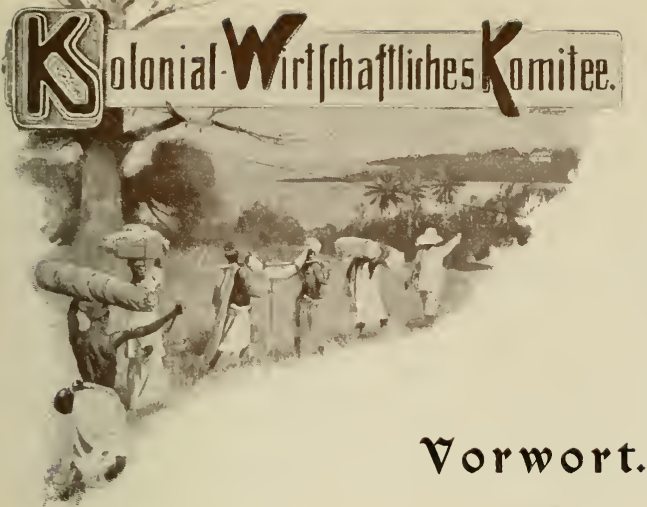

Die gefäbrdete Lage des Kautschukmarktes, hervorgerufen durch den Niedergang der Produktion infolge des Raubbaues der Eingeborenen und durch den in ungeabnter raleise sich steigernden Bedarf der modernen, insbesondere der elektrotechnischen, fahrrad- etc. Industrien sowie die Aussicht auf reichen Gewinn, der dem Nationalvermögen durch Einführung einer Kautschukgrolskultur in deutschen Kolonien zufliełsen könnte, veranlafste das Kolonial-飞airtschaftliche Komitee, im frübjabr 1899 cine Kautschuk-Expedition nach खalestafrika unter fübrung des Botanikers und Kautsshukexperten Бerrn Rudolf Schlechter zu entsenden, mit der Hufgabe,

die besten Kautschukvarietäten aus fremden Kolonien nach den deutschen Schutzgebieten $z u$ überfübren und eine geregelte Kautschuk-Grorskultur in Kamerun und Cogo in die đalege zu leiten.

Das Komitee ist in der Lage, feststellen zu können, dais die Expedition ihren $Z$ weck erreicht und insbesondere durch Einführung der Kautschuk-Grolskultur in den Kameruner Plantagen, u. a. der "Moliwe-Pflanzungsgesellschaft", der "đalestafrikanischen Dflanzungsgesellschaft Bibundi", der "Kamerun-Land- und Plantagengesellschaft", praktische $E_{r}$ gebnisse erzielt bat.

Der Kolonialabtheilung des Huswärtigen Amtes und den Goupernements bon Kamerun und Cogo ist das Komitee zu Dank verpflichtet für auggiebigen Schutz und thatkräftige Anterstützung der Expedition.

Den unter dem Präsidium Seiner Бoheit des БerzogRegenten Jobann Flbrecht von Mecklenburg-Sebwerin vereinten Instituten der Zaloblfabrtslotterie zu Zwecken der 
deutschen Schutzgebiete und der Deutschen Kolonialgesellschaft verdankt das Komitec cine nambafte finanziclle Beibülfe, durch welehe die Busfübrung des gemeinnützigen Anternehmens und die Ђerausgahe des vorliegenden Xalerkes erst ermöglieht wurde.

Den Interessentengruppen der Dflanzungsgesellschaften und Industricllen schuldet das Komitee Dank für bewährten Rat und materielle förderung der Expedition und zwar den firmen: Kabelwerk, Nieder-Schöneweide - Emil Arntz, Gummiwaren-Fabrik, Höxter Asbest- und Gummiwerke Alfred Calmon Akt.-Ges., Hamburg-Uhlenhorst Berlin-Rixdorfer Gummiwarenfabrik Franz Schumann, Berlin-Rixdorf - Blödner \& Vierschrodt, Gotha - Centralverein Deutscher Kautschukwaren-Fabriken, Berlin Continental Caoutschouc- und Guttapercha-Compagnie, Hannover Deutsche Gummi- und Guttaperchawaren-Fabrik Akt.-Ges. vorm. Volpi \& Schlüter, Berlin - Felten \& Guilleaume, Carlswerk, Mühlheim a. Rh. - François Fonrobert, Gummiwaren-Fabrik, Finsterwalde - Gesellschaft Süd-Kamerun, Hamburg - Handelskammer, Breslau - Hannoversche Aktien-Gummiwaren-Fabrik, Hannover - Harburger Gummi-Kamm.Co., Dr. Heinr. Traun, Hamburg S. Herz, Berlin -- Kamerun Land- und Plantagen-Gesellschaft, Hamburg Gebr. Körtıng, Hannover - Lange \& Pöhler, Arnstadt - Leipziger Gummiwaren-Fabrik vorm. Julius Marx, Hein \& Co., Leipzig Metzeler u. Co., München - Mitteldeutsche Gummıwaren-Fabrik Louis Peter, Frankfurt a. M. Moliwe-Pfianzungs-Gesellschaft, Hamburg - Münden-Hildesheimer Gummiwaren-Fabriken Gebr. Wetzell, Akt.-Ges., Hildesheim - Geh. Kommerzienrat Dr. Oechelhäuser, Dessau - Phıl. Penin, Gummiwaren-Fabrik, Aktien-Gesellschaft, Leipzig-Plagwitz - Rheinısche Gummiwaren-Fabrik Franz Clouth, Köln-Nippes - H. Rost \& Co., Hamburg -- Russian-American India Rubber Co., St. Petersburg - Carl Schwanitz, Gummiwaren-Fabrik, Berlin - H. Schwieder, Gummiwaren-Fabrik, Dresden-Neustadt - South-West-Africa Comp. Ltd., Berlin Vereinigte Berlin-Frankfurter Gummiwaren-Fabrik, Berlin - Vereinigte Gummiwaren-Fabriken Harburg-Wien, vorm. Menier-J. N. Reithoffer, Harburg a. E. - Westafrikanische Pflanzungs-Gesellschaft „Bibundi“, Hamburg.

Möge das vorliegende Ergebnis der westafrikanischen Kautschuk-Expedition cine daucrnde kraftvolle Entwickelung der Kautschuk- Dlantagen und Volkskulturen Deutsch-飞alestafrikas $z$ ur folge haben und den deutschen Kolonien, deren Kautschuk-Produktion beute kaum den zwanzigsten Ceil des deutschen Konsums beträgt, mit der Zeit cinen nennenswerten Hnteil an dem lobnenden Kautsehukhandel sichern zum Nutzen unserer Kolonien und zum Nutzen unserer Volkswirtschaft.

Berlin, im Dezember 1900. Linter de.n Linden 40.

Kolonial-Wirtschaftliches Komitee. 


\section{Inhaltsverzeichnis.}

1. Kapitel Vorbereitungen zur Reise, Ausreise nnd Yornba-Expedition Seite

2. " Aufenthalt in Kamernn. Reise nach und anf dem Congo. . . 29

3. "Sanga-Ngoko-Reise und Rückreise nach Kamerun . . . . 80

4. . Kamerm- and Bakossi-Expedition . . . . . . . . . . 135

5. - Togo-Reise und Heimreise . . . . . . . . . . . . . 181

6. $\quad$ Allgemeines nnd Untersnchungen . . . . . . . . . . . . 227

Anhang I. Denkschrift des Herrn Prof. Dr. O. Warburg

zur Begrïndung der Kautschuk-Expedition . 250)

, II. Gutachten über die von Lagos eingesandten

Kautschukproben des ehemischen Lahoratoriums für Handel und Industrie (Dr. Robert Henriques) Berlin.

7. . Die hotanischen Ergebnisse der Expedition.

\section{Verzedelunis der Abhildungen.}

Mlesser und Beile zum Anzapfen der Kantschnkpflanzen nebst Bechern zum Anffangen des Milehsaftes . . . . . . . . . . . . . . . . 2

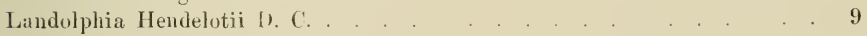

Ficus Vogelii Miq. . . . . . . . . . . . . . . . . . . . . . 11

Fetischmasken, schnhe Fächer mnd Lanzen ans dem Yoruba-Lande . . . 14

Carpodinns lanceolatus K. Sch. . . . . . . . . . . 52

Costus Lukanusianus K. Seh. . . . . . . . . . . . . . . . 65

Landolphia floridat Bth. . . . . . . . . . . . . . . . . . . 68

Landolphia Klainei Pierre . . . . . . . . . . . . . . . . . . 83

Kickxia elastica Prenss . . . . . . . . . . . . . . . . . . . . . . . 99

Kickxia latifolia Stapf . . . . . . . . . . . . . . . . . . . 125

Landolphia owariensis P. Beauv. . . . . . . . . . . . . . . . 128

Die „Cyelop-Grotte" bei Kriegsschiffhafen . . . . . . . . . . . . 136

Kickxia-Bänme in Mundame . . . . . . . . . . . . . . . . 164

Kokospalmen in Gr. Batanga . . . . . . . . . . . . . . . . . . 174

Elf Monate alte Kiekxia auf der C'ampo-Plantage . . . . . . . . . . 176

Rast der Expeclition unter einem Fieus Vogelii-Kantschuklaum in Dorfe

Lolobi . . . . . . . . . . . . . . . 196

R. Schlechter vor seinem Zelt in Kadyebi . . . . . . . . . . . . . . 203

Die Expedition in Kadyebi . . . . . . . . . . . . . . . . 208

Fetischhäuschen im Dorfe Bevi . . . . . . . . . . . . . . . . 212

Feigenbäume im Dorfe Bevi . . . . . . . . . . . . . . 216

Eingeborene von Wangata . . . . . . . . . . . . . . . . 230

Kickxia africana Bth. . . . . . . . . . . . . . . . . . . . . 238

Ceara-Kantschnkliam in Fr. Batanga . . . . . . . . . . . . . . 252

Pflanzungen der Victorianer-Neger anf den Wege nach Kriegsschiffhafen . 260

Junge Kakaoanpflanzung am Vorwerk Wasserfall der Kriegssehiffhafen-

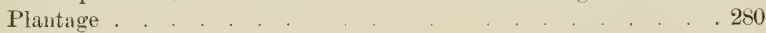

Landolphia humilis K. Sch. n. sp. . . . . . . . . . . . . . . 288

Carpodinus Schlechteri K. Sch. n. sp. . . . . . . . . . . . . . . . 305 


\section{Kapitel.}

\section{Vorbereitungen zur Reise, Ausreise und Yoruba - Expedition.}

Im Oktober des Jahres 1898 wurde vou seiten des KolonialWirtschaftlichen Komitees, insbesondere der Herren Karl Supf und Professor Dr. O. Warburg, der Plan gefalst, eine Expedition zur Erforschung der Kautschukverhältnisse in unseren Kolonien nach Westafrika zu entsenden. Es sollte Aufgabe der Expedition sein, die Kautschukpflanzen anderer Kolonien nach Kamerun zu überführen und dort, wenn möglich, zum Anbau derselben anzuregen, ebenso die in den fremden Kolonien gewonnenen Erfahrungen der Entwickelung der Kautschukindustrie unseren Kolonien zur Verfügung zu stellen. Ich wurde mit der Leitung der Expedition betrant.

Sobald durch Eingehen der dazu nötigen Gelder die Ausführung der Expedition gesichert war, begann ich mit meinen Vorbereitungen. Es war unterdessen schon der Monat Dezember herangekommen, so dafs ich, da die Ausreise auf Anfang Februar 1899 festgesetzt war, keine Zeit zu verlieren hatte. Aufser Anschaffung der zum persönlichen Gebrauch nötigen Kleidungsstücke und allgemeinen Expeditionsausrüstungen hatte ich anch die zur Ausführung meiner Aufgabe nötigen Chemikalien und Apparate, von denen umstehend einige abgebildet sind, zu beschaffen.

Da die Eingeborenen beim Anzapfen der Lianen und Bäume meist durch zu tiefes Einschneiden grofsen Schaden anrichten, liefs ich für die mitgenommenen Messer und Beile Scheiden anfertigen, welche ein zu tiefes Eindringen der Schneide in die Rinde verhüten sollten. Diese Scheiden waren aus starkem Blech bergestellt und kounten den betreffenden Instrumenten vor Gebrauch derselben aufgeschoben werden.

Auskunft über die zu bereisenden Länder erhielt ich, soweit dieses möglich war, bereitwilligst von vielen Seiten; auch war Herr Dr. Mertens, der Direktor der Graphischen Anstalt in Berlin, so freundlich, mir Auskunft über Photographieren in den Tropen zu geben, und den von mir für die Expedition angeschafften photographischen Apparat zu prüfen.

R. Schlechter, Westafrikanische Kautschuk-Expedition. 
Kurz vor meiner Abreise ron Berlin traf noch Dr. Preufs, der Leiter des botanischen Gartens ron Victoria, ein mit der freudigen Nachricht, dafs es ihm gelungen sei, die echte Kickxia im Kamerun-Geliet nachzuweisen, und dafs es sich um zwei spezifisch rollständig rerschiedene Arten handele, von denen die eine guten Kantschuk liefere, die andere dagegen wertlos sei. Auch ihm verdanke ich viele wichtige Angaben und Vorschläge, die mir bei Ausführung meiner Expedition von grofsem Vorteile waren. Er erklärte sich anch bereit, etwaige von mir nach Kamerun gebrachte Kautschukpflanzen im botanischen Garten zu Victoria in Kultur zu nehmen und später an die Pflanzungen zu verteilen, wodurch natürlich die Einführung fremder Kautschukpflanzen in Kamerun bedeutend erleichtert werden konnte.

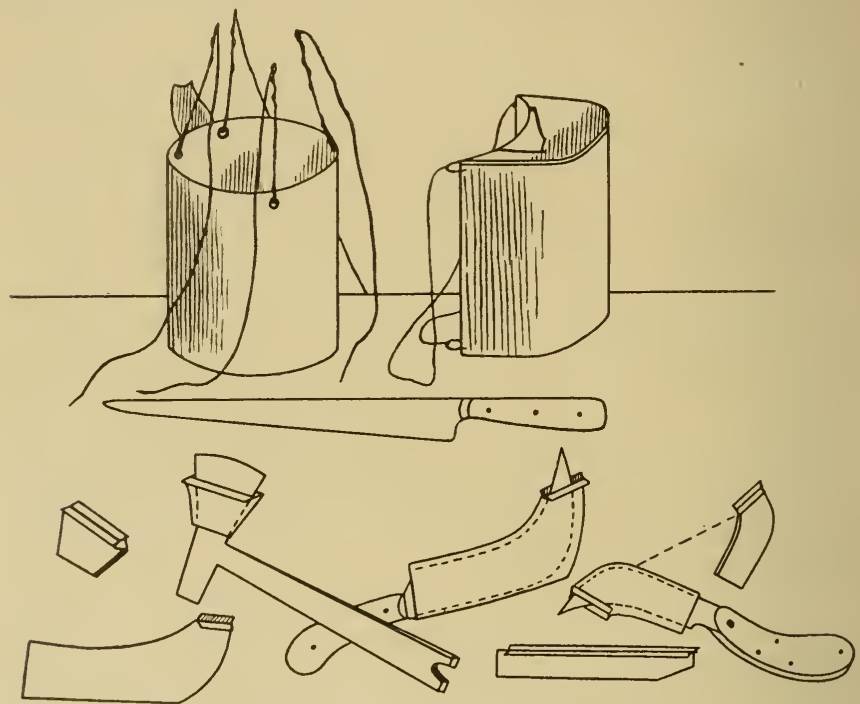

Messer und Beile zum Anzapfen der Kautschukpflanzen nebst Bechern zum Auffangen des Milchsaftes.

Am 7. Februar 1899 war ich mit den Vorbereitungen fertig und konnte somit am 8. Februar meine Abreise von Berlin ausführen. Da der I)ampfer erst am 11. Februar abfahren sollte, hatte ich auch in Hamburg noch Zeit genug, die Herren, an welche ich Empfehlungsschreiben hatte, zu besuchen. Auch hier erfuhr ich noch manches, das für meine Reise wertvoll war; so habe ich besonders den Herren Thormählen, Jantzen und Rhode noch für das 
Interesse zu danken, welches sie meiner Expedition entgegenbrachten. Der Zufall wollte es, dafs damals auch der ehemalige Gouverneur von Kamerun, Excellenz v. Soden, Geheimrat Prof. Dr. Wohltmann und Herr Upmann sich in Hamburg aufhielten, von denen ganz besonders die beiden erstgenannten Herren in der Lage waren, mich tiefer in die Verhältnisse Kameruns einzuweihen, und dank ihrer Liebenswürdigkeit sollte ich noch später viel daron profitieren.

Endlich, am 11. Februar, lichtete der Dampfer „Adolph Woerunann", mit dem ich zunächst bis Lagos reisen sollte, seinen Anker; am Abend konnten wir noch einmal einen letzten Blick auf die deutsche Küste an der Elbe-Mündung werfen, und dann ging es hinaus in die See. Wie wünschte ich damals, dafs es mir rergönnt sein möge, meine Aufgaben zu erfüllen und mit reichen Erfolge nach Abschlufs der Expedition in das Vaterland zurückkehren zu können.

Am-ersten Abend war die Stimmung an Bord natürlich zum Teil sehr gedrückt, so manch einer der Mitreisenden verliefs seine Lieben zu Haus zum ersten Male auf längere Zeit, und ein jeder wul'ste, dafs manchem nicht das Glück blühen würde, seine Heimat wiederzusehen.

Je weiter wir uns vom Vaterlande entfernten, desto mehr verschwanden die trüben Gedanken, um den Hoffnungen auf Erfolg Platz zu machen. Die Passagiere lernten sich näher kennen, und schon nach wenigen Tagen herrschte die fröhlichste Stimmung an Bord.

Am 13. Februar fuhren wir in den Kanal ein. Ein plötzliches tiefes Fallen des Barometers schien Sturm anzuzeigen, so dafs der Kapitän es für geraten hielt, vorsichtig zu manövrieren; doch auch diese Gefahr war bald vorüber.

Dank der Liebenswürdigkeit unseres Kapitäns J ensen vergingen die Tage schnell, und alles war froh und guter Dinge. Zudem erhielten wir gutes Essen, was um so mehr in Betracht kam, als durch die Seeluft unser Appetit bedeutend gereizt wurde.

Als wir uns am 19. Februar der Insel Madeira näherten, waren die kalten Winde, welche uns ziemlich weit nach Süden begleitet hatten, bereits verschwunden, und das angenehmste Frühlingswetter brachte uns in freudige Stimmung. Fast alle benutzten daher den Aufenthalt vor Funchal zu einer Exkursion, denn gerade hier ist Madeira am schönsten. Mit einigen Mitreisenden unternahm ich eine kleine Fahrt mit der Zahnradbahn auf die Berge im Rücken der Stadt. Nachdem wir von einer Kirche daselbst eine der schönsten Aussichten genossen hatten, welche die Erde wohl bietet, und uns durch ein Gläschen Madeiraweines gestärkt hatten, ging es im rasenden Tempo auf Holzschlitten, wie sie hier bei derartigen Touren üblich sind, den Berg hinunter. 
Man konnte dabei nicht umhin, die Geschicklichkeit der beiden Lenker zu bewundern, welche selbst bei plötzlichen Biegungen der steilabfallenden Strafsen den dahinsausenden Schlitten sicher führten. Nach kurzem Spaziergange durch den Stadtgarten, der durch wundervolle Exemplare von Palmen sich auszeichnet, kehrten wir nach dem Dampfer zurück. Noch vor Mitternacht wurde der Anker wieder gelichtet, und weiter ging es unserm Ziele entgegen.

$\mathrm{Al}_{s}$ wir am nächsten Morgen erwachten, lagen wir im. Hafen von Las Palmas. Da wir nur wenige Stunden hier blieben, war es keinem der Passagiere gestattet, das Schiff zu verlassen, denn noch vor Mittag fuhren wir auch wirklich wieder ab. Mit jedem Tage wurde es nun merklich wärmer, so dafs alle Passagiere sich schon vor Ankunft des Dampfers in Monrovia ihrer Tropen- und Sommerkleidung bedienten. Monrovia, die Hauptstadt der Negerrepublik Liberia, konnten wir leider vom Dampfer aus kaum erkennen, denn die Stadt selbst ist von der See kaum zu erblicken, da sie zum grofsen Teile durch einen dicht mit Urwald bedeckten Hügel verhorgen wird. Die Vegetation ist sehr üppig, eine Folge der riesigen Niederschläge, durch welche sich Liberia und das benachbarte Sierra Leone-Gebiet auszeichnen und wie sie ähnlich oder sogar nocb stärker nur noch in einem Teile unseres Schutzgebietes von Kamerun sich wiederholen. Als wir am 27. Februar Monrovia verliefsen, sah es an Bord unseres Dampfers bedeutend lebendiger aus als zuvor, wir hatten nämlich eine grölsere Anzahl Cruneger und Weyboys an Bord bekommen, welche nun, wie es hier an der Küste allgemein üblich ist, die Scheuerarbeiten und das Aus- und Einladen der Fracht zu besorgen hatten.

Viele der westafrikanischen Küstenplätze zeichnen sich durch eine sehr hohe, unregelmälsige und daher häufig sehr gefährliche Brandung aus, und hier besonders bewähren sich die Cruneger und Weyboys in erster Linie. Es ist kaum zu glauben, mit welcher Geschicklichkeit sie die Boote, welche zum Löschen der Ladung verwendet werden, durch die Brandung hindurchschaffen. Natürlich lassen sich hier ïberhaupt nur die eigens zu dem Zwecke von dem Dampfer mitgeführten scharfkieligen Brandungsboote verwenden. Überschlägt sich solch ein Boot einmal an einem hohen Brecher, so lassen sich die Neger, welche übrigens alle wie die Fische schwimmen können, so weit durch die hereinbrechenden Wellen an Land tragen, bis sie festen Boden unter sich fühlen, einen geeigueten Moment benutzend, ehe die Wellen zurücklaufen, retten sie sich dann fast stets.

Am 28. Februar erreichten wir Cape Palmas, das durch den Tod unseres ehemaligen deutschen Konsuls in Westafrika, des wohl- 
bekannten Erforschers des Sudan-Gebietes, Dr. Gustav Nachtigal, eine traurige Berühmtheit erlangt hat. Der Ort ist nicht so bedeutend wie Monrovia, steht jenem aber nicht weit nach. Der Handel liegt fast ausschliefslich in deutschen Händen, wie überhaupt die Republik Liberia vornehmlich ihre Güter aus Deutschland bezieht.

Von nun an erreichten wir täglich einen neuen Hafen, vor denen wir jedoch uns meist zu kurze Zeit auflielten, um das Land besuchen zu können. So konnten wir am 2. März das englische Fort CapeCoast-Castle, von dem aus vor wenigen Jahren die Expedition gegen die Ashantis nach Kumassi abgegangen war, leider nur vom Schiffe aus bewundern. Auf der Weiterfahrt blieben wir nun immer mehr oder minder in Sicht der Küste. Die Orte Salt-Pond, Appun und Winnebah konnten wir deutlich vom Dampfer aus erkennen. Unterdessen verliessen uns immer mehr Passagiere. Als wir am ¿. März am Nachmittage in Accra ankamen, hatten wir bereits dem fünften Herrn Lebewohl zu sagen. Auch er sollte weiter ins Innere der englischen Gold-Coast-Kolonie hinein, um mit den Eingeborenen Handel zu treiben. In Ada, einer kleineren Handelsniederlassung in der Nähe der Volta-Mündung, traf'en wir mit Tagesanbruch am 3. März ein, aber nur um Passagiere abzusetzen, es ging daher sofort nach Quitta weiter, wo wir um 10 $\frac{1 / 2}{\mathrm{Uhr}}$ eintrafen. $\mathrm{Zn}$ allgemeinem Bedauern verliefs uns hier Herr Oloff, ein Bremer Kaufmann, der bier in Westafrika seine Handelsniederlassungen inspizieren wollte. Noch un $2 \mathrm{Uhr}$ desselben Tages langteu wir vor Lome, der Hauptstadt unseres Schutzgebietes Togo, an; da wir für diesen Ort eine gröfsere Menge Ladung hatten, so bätte manch einer gern einmal wieder auf dentschem Boden gelustwandelt, doch war die Brandung eine derartige, dafs nur diejenigen Herren an Land gingen, welche dazu gezwungen waren. Wiederholt wurden einige unserer Brandungsboote umgeworfen. Da auch am nächsten Tage die Brandungsverhältnisse nicht günstiger zum Löschen der Ladung waren, so kam es, dais wir erst gegen $5 \mathrm{Uhr}$ wieder die Anker lichten konnten. Unser Kurs lief nicht allzufern von der Küste, so dafs wir auch noch rom Schiffe aus Klein-Popo und Bagida gut seben konnten. Ich war natürlich in froher Stimmung, denn am nächsten Morgen sollten wir ja in Lagos eintreffen.

Früh war ich schon am Morgen des 5. März an Deck. Wir waren eben auf der Rhede von Lagos angekommen. Zusammen mit uns lagen noch 5 andere Dampfer hier, von denen zwei, der "Ogun" und der "Teck", die sogenannten Barrendampfer der Woermann-Linie waren. Diese Dampfer übernehmen auf der See, aufserhalb der Barre, 
welche vor dem Ausflusse der Lagos-Lagune liegt, die Ladung der grofsen Passagier- und Frachtdampfer und bringen dieselbe dann bei Hochwasser über die Barre hinweg nach Lagos hinein. Dafs diese Fahrten nicht immer glücklich ablaufen, beweisen die gestrandeten Dampfer, welche auf der Barre ror Lagos liegen.

Erst gegen Abend bot sich mir Gelegenheit dar, mit dem "Ogun" nach Lagos hineinzufahren. Die Fahrt über die Barre verlief glücklich, bald langten wir an der Signalstation an und fubren nun den Lagunenarm hinauf, worauf wir in kurzer Zeit die Stadt Lagos erblicken konnten. Gegen 7 Uhr laudete ich zusammen mit Herrn Fritsch, dem Tertreter der Firma Geyser \& Co., welcher auch auf dem "Ogun" angekommen war und mir in freundlichster Weise Aufnahme in seinem Hause angeboten hatte Da hier für Europäer kein Hotel existierte, machte ich gern von seiner Liebenswürdigkeit Gebrauch und erhielt ein vorzügliches Unterkommen. Gerade ibm habe ich es auch zum grofsen Teile zu verdanken, dafs ich schon nach verhältnismälsig kurzer Zeit ins Innere aufbrechen konnte.

Am nächsten Tage machte ich mich zunächst auf den Weg zum stellvertretenden deutschen Konsul Herrn Meier, der zugleich Ver. treter der Firma Witt \& Büsch war, an welche ich ein Empfehlungsschreiben erhalten hatte. Am Nachmittage hatte mein liebenswürdiger Wirt mir angeboten, mir den Botanischen Garten zu zeigen. Derselbe liegt auf der Nordseite der Lagos-Lagune hinter der "Iddo-Insel" bei Ebute-Meta. In dem Garten war nichts von besonderem Interesse zu sehen. Einige Ficus elastica und eine Anzahl abgestorbener Manihot Glaziovii-Stämme waren aufser sebr kleinen Kickxiasämlingen die einzigen rorhandenen Kautschukpflanzen. Da kein Europäer dem Garten vorstand, war es nicht zu verwundern, dafs derselbe einen recht verwahrlosten Eindruck machte. Nicht einmal Näheres konnte ich erfahren, wo die KickxiaSämlinge herstammten. Dafs es Kautschukpflanzen waren, davou hatte keiner der anwesenden Neger auch nur die geringste Abnung:

Die nächsten Tage meines Aufenthaltes gebrauchte ich nun dazu, Erkundigungen über das Hinterland einzuziehen. Herr Fritsch war selbst einmal bis Ife im Yoruba-Lande gewesen und konnte mir daher viel über Land und Leute berichten. Bereitwilligst stellte er mir auch seine Reisenotizen zur Verfügung. Sehr schwierig schien anfangs die Trägerfrage zu sein. Die Lagos-Leute wollten nicht gern fort oder wenigstens nicht in Begleitung eines Europäers. Doch auch hier kam bald Rat. Dr. Randle, ein eingeborener Arzt, welcher in England studiert hatte und hier auch bei den Europäern einen sehr guten Ruf als Arzt besitzt, erbot sich, mir einen geeig- 
neten "Headman" zu schicken. Diese "Headmen" sind Eingeborene, welche eine Anzahl von Leuten um sich sammeln, die dann unter ihrer Leitung Arbeiten irgend welcher Árt verrichten. Es scheint selten vorzukommen, dafs sich einer dieser Eingeborenen gegen seinen Headman auflehnt, solange der letztere einigermalsen versteht, sich Respekt zu erhalten. Seinem Versprechen gemäls schickte Dr. Randle mir auch sehr bald einen Mann, der behauptete, genügend Leute beschaffen zu können. Derselbe beanspruchte fürr sich zwar ein sehr hohes Gehalt, doch wurden wir nach längeren Unterhandlungen schliefslich darin einig, dafs er pro Tag 3 sh., die Träger je $1 \mathrm{sh}$. erhalten sollten, dagegen Essen sich selbst besorg'en mufsteu. Ich packte nun meine Sachen zu Trägerlasten um, um zu sehen, wie vieler Träger ich bedurfte. Am 12. März erschien der "Headman" mit den gewünschten Leuten, so stand also meinem Aufbruche ins Innere nichts mehr im Wege.

Am Morgen des 13. März fehlten natürlich wieder einige 'Träger; ich hatte dies aber schon vorausgesehen und deshalb die Leute bereits vor 6 Uhr antreten lassen. Als nach geraumer Zeit die fehlenden Leute endlich erschienen, wurde das Gepäck auf die "Daddy", die Barkasse der Firma Geyser \& Co., rerladen, welche Herr Fritsch mit der ihm eigenen Liebenswürdigkeit mir zu dem Zwecke zur Verfügung gestellt hatte. Um 8 Uhr war alles bereit zur Abfahrt. Herr Fritsch begleitete mich bis zum Landungsplatze bei Ikorodu. Die Fahrt ïler die Lagune ging glücklich von statten, es war zwar sehr heifs auf dem spiegelglatten Wasser, doch lief das kleine Fahrzeug vorzüglich, so dafs wir um 11 Uhr schon vor dem Landungsplatze von Ikorodu eintrafen. Da wir in ziemlicher Entfernung von dem Strande liegen bleiben mufsten, und die Ladung in kleinen Canoes hinüberzuschaffen war, wurde es doch 12 Uhr, ehe alles Gepäck an Land war. Sogleich liefs ich die Lasten verteilen und jedem Träger die Verantwortlichkeit für die von ihm getragenen Gegenstände ans Herz legen. Wie ich es schon bei früheren Expeditionen zur Genüge kennen geler'ut hatte, glaubte natürlich ein jeder, dafs seine Last für ihn zu schwer sei, und es kam Klage au Klage; stillschweigend hörte ich dies anfänglich an, dann warnte ich die Leute, und als dann noch einige murrten, liefs ich für diese die schwersten Lasten heraussuchen. Das half, keiner beschwerte sich jetzt mehr. Un 12/2 Uhr gab ich den Befehl zum Aufbruch, und nach einem letzten Grufs zur "Daddy" hinüber ging es hinein in die Wildnis.

Der Ort, an dem wir gelandet waren, ist ungefähr $1 \frac{1}{2}$ Stunden rou der Ortschaft Ikorodu entfernt und wird als Marktplatz rerwendet. Bei dieser Gelegenheit sollen dann daselbst häutig über 
100000 Eingeborene zusammenkommen. Der in gutem Zustande gehaltene Weg ron dem Marktplatze nach der Ortschaft Ikorodu führte durch Urwaldgebiet, welches durch kleinere, von den Eingeborenen unter Kultur gesetzte Lichtungen unterbrochen wurde. Ölpalmen sah man allenthalben. Dieselben werden von den Eingeborenen sehr geschont, da sie den hauptsächlichsten Handelsartikel liefern. Noch bevor wir lkorodu erreichten, sah ich rereinzelte Exemplare von Landolphia Heudelotii, welche aber noch zu schwach waren, um Kautschuk liefern zu können. Ikorodu ist ein recht stattliches Dorf, das einige hundert Häuser besitzt; kurz vor dem Dorfe liegt das. Haus des englischen Residenten für das Djibu-Land, welcher zufällig auf Reisen war, als ich das Dorf passierte. In Ikorodu gab ieh meinen Leuten eine Viertelstunde Zeit, um sich Essen zu kaufen, denn bis dahin hatten sie noch keine Gelegenheit dazu gehabt. Um unseren Lagerplatz entwickelte sich nun bald ein reges Leben, alte Weiber brachten alle möglichen Elswaren herbei, am meisten begehrt war ein dicker Bohnenbrei, welcher mit einer Miesmuschelschale abgemessen und pro Portion für 5 Kauris verkauft wurde. Wenn man dabei bedenkt, dals der Preis der Kauris ein sehr niedriger war, d. h. 4000 Stück für 1 Shilling galten, so ist es erklärlich, wie billig die Eingeborenen hier leben. Eine der Hauptnahrungen der Eingeborenen ist eine aus Maniot und aus Yams hergestellte Masse, welche fast glasig aussieht. Dieselbe wird in Marantaceenblätter eingewickelt und in dieser Weise auf den Märkten feilgeboten. Um 21/2 Uhr waren wir trotz der drückenden Hitze wieder auf dem Marsche. Da der Weg sehr breit ausgeschlagen war, kam uns nicht einmal der Urwaldschatten zu gute. Das Terrain war ziemlich eben. Gegen $5^{1 / 2}$ Uhr erreichten wir einige Schutzhütten, welche von Marktweibern längs des Weges hier sowohl wie im Yoruba- und EkbaLande häufig aufgestellt werden. Ich liefs hier das Lager aufschlagen. Da meine Leute noch nicht mit dem Aufstellen des Zeltes vertraut waren, dauerte es ziemlich lange, ehe alles fertig war, obgleich ich alle hatte antreten lassen. Das Essen war unterdessen auch schon hergestellt, und befriedigt konnte ich mich etwas ausruhen. Bis in die Nacht hinein safsen die Leute noch am Feuer nmher, ersichtlich ihre Meinungen über den neuen Weifsen austauschend, von dem sie nicht verstehen konnten, weshalb er sich offenbar zweeklos ins Innere ihres Landes begeben wolle.

Um 4 $4^{1 / 2}$ Uhr liefs ich am nächsten Morgen schon die Leute antreten. Das Zusammenpacken der Lasten und Abbrechen des Zeltes ging bei den noch ungeschulten Leuten uur langsam vor sich, so dafs erst um $5^{1 / 2}$ alles zum Aufbruch fertig war. Ich setzte nun 


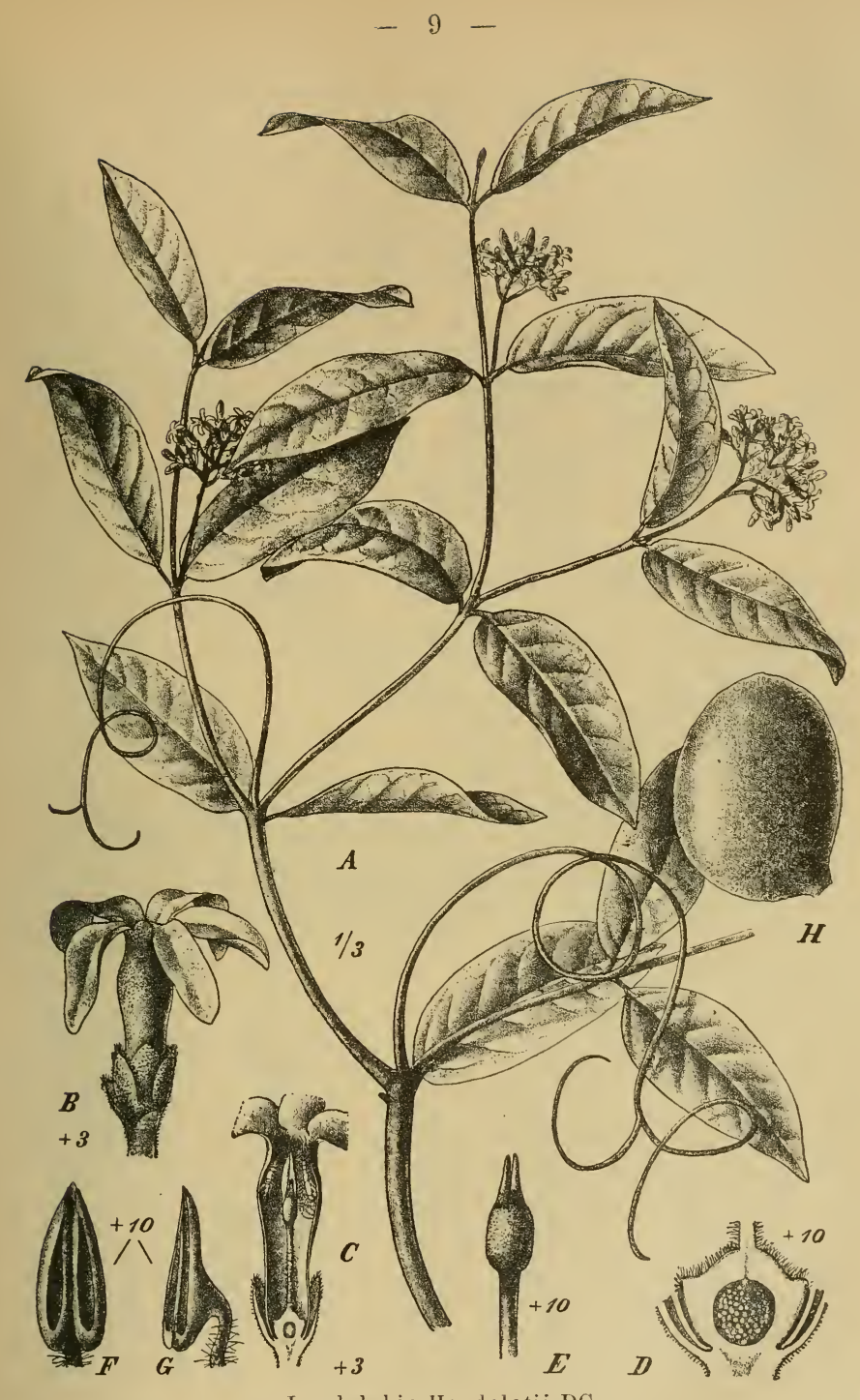

Landolphia Heudelotii DC.

A Zweig. B Blüte, C Längsschnitt durch dieselbe, D Längsschmitt durch den Fruchtknoten, E Griffelkopt, F Anthere von vorn, G dieselbe von der Seite. 
meinem Headman auseinander, weshalb ich gekommen sei, und rersprach demjenigen, welcher mir den ersten Ire-Baum (Kickxia elastica) zeigen würde, eine Belohnung. Das T'errain war dicht bewaldet. Schon nach kurzem Marsche sahen wir verschiedene abgestorbene Kickxiastämme, welche an der von Schnitten nach allen Richtungen verletzten Rinde unschwer zu erkennen waren, ron lebenden Bäumen war jedoch noch nichts zu sehen. Die Eingeborenen versicherten mir, dafs früher viel Kickxia hier vorhanden gewesen sei, dafs aber die Fantis in kurzer /eit das Land in einer solchen Weise ausgeräubert hätten, dals man selten lebende Bäume zu Gesicht bekomme.

Gegen \& Uhr erreichten wir einen kleinen Weiler, welcher kaum ein Dutzend Hütten zählte. Die Eingeborenen nannten ihn Ihraye. Da hier auffallend viele Kolabäume im Walde standen, gab ich den Leuten Zeit, sich bei den unter Schutzhütten sitzenden Weibern Nahrungsmittel zu kaufen, welche hier vorzugsweise aus Bananen bestanden. Die Kolanüsse waren den Leuten offenbar zu teuer; sie wurden für ungefähr $5 \mathrm{Pf}$. angeboten. Es wäre mir interessant gewesen, zu erfahren, ob die Kolastämme hier wirklich wild wuchsen oder ob sie angepflanzt waren, doch verweigerten die Iseute jede Auskunft darüber. Da ich den Baum auch sonst am Wege noch beobachtete, möchte ich das Erstere vermuthen, hier bei Ihraye war er aber in solchen Mengen vorhanden, dals man fast annehmen mufste, es handle sich um eine Kultur.

Auf dem Weitermarsche nach Ishagamo war der Weg insofern beschwerlicher, als das Terrain hügelig war, zudem brannte die Sonne sehr stark. Kurz vor dem Dorfe erreichten wir das Ende des breit geschlagenen Weges. Auf einem von Eingeborenen einigermafsen gut gehaltenen Urwaldwege ging es weiter, bis wir Ishagamo um 5 Uhr erreichten. Hier war eine kleine Truppe von Polizeisoldaten einquartiert. Ein englischer Missionar erschien kurz nach meinem Eintreffen auf dem Lagerplatze; als er sah, dafs ich mein Zelt aufschlagen liefs, machte er mich auf ein Logierhaus aufmerksam, das von der Regierung für Durchreisende hier erbaut ist. Es war dies eine mir sehr willkommene Nachricht, da ich mich nach den ungewohnten langen Märschen nicht recht wohl fühlte. Ich siedelte natürlich nun in das geräumige, reingehaltene Gebäude über. Auf den Plätzen des Dorfes bemerkte ich hier eine grofsblättrige Ficusart, welche nach einigen Versuchen sich zu meiner grofsen Freude als gummiliefernd entpuppte. Wie alle Ficusarten heifst sie hier im Lande Abbá. Ich liefs von meinen Leuten Latex des Baumes sammeln, welche äufserst reichlich flofs. Da sich die Pflanze sehr leicht vermehren läfst und schöne grofse Blätter besitzt, würde 


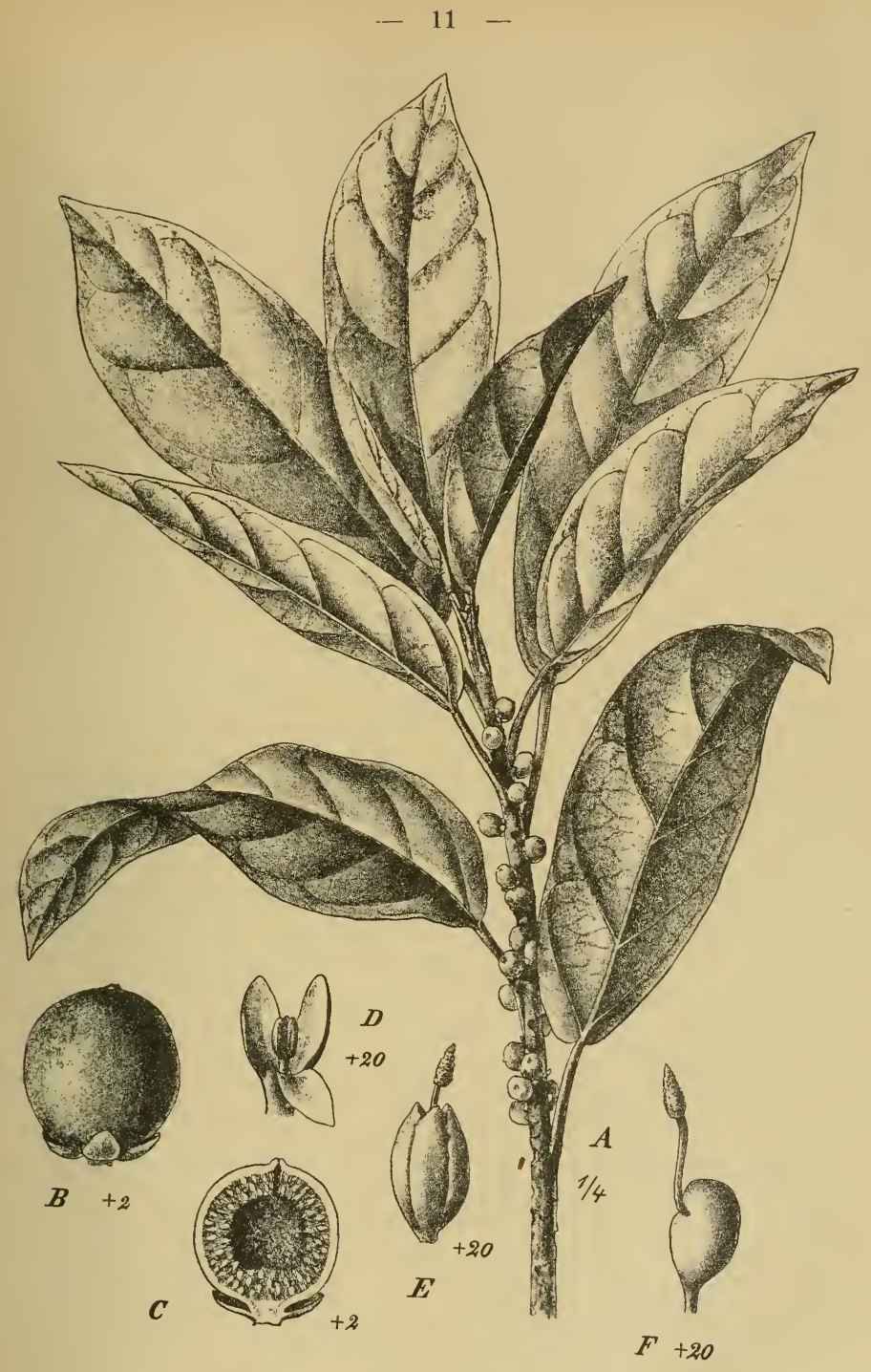

Fiens Vogelii Miq.?

A Zweig, B Feige, C Längsschnitt durch dieselbe, D männliche Blïte, E weibliche Blüte, F Fruchtknoten mit Griffel. 
sie sich in trockneren Gegendeu an sonnigen Strafsen als Schattenbaum sehr empfehlen. Der gewonnene Kautschuk war von geringerer Qualität und würde wohl auf $3 \mathrm{Mk}$. pro Kilo taxiert werden können, doch ist bei der reichlichen Saftproduktion der Pflanze ein rentables Ausbeuten des Kautschuks selbst bei dem niedrigen Preise sehr wahrscheinlich. Ich glaube, dafs ein solcher Ficusstamm jährlich gegen 10 Pfund Kautschuk liefern würde.

Den Abend in Ishagamo verbrachte ich in angenehmer Unterhaltung in Gesellschaft des liebenswürdigen englischen Missionar's.

Gegen 6 Uhr am folgenden Morgen war unsere Karawane wieder auf dem Marsche. Der Weg führte kurz hinter dem Dorfe über einen kleinen, fast ausgetrockneten Bach. Da wir uun auf schattigen, meist breit ausgetretenen Waldwegen marschierten, empfanden wir die Hitze nicht mehr so wie an den beiden vorhergehenden Tagen. Allenthalben sah man im Walde die abgestorienen Ire-Stämme und am Wege hin und wieder auch einige Kolabäumchen. Als wir um $7 \frac{1}{2}$ Uhr in Iperu anlangten, liefs ich Rast zum Frühstïck machen. Hier war der ganze Ort von furcht. barem Lärm erfüllt, da ein alter Mann gestorben war. Unglücklicherweise war der einzige schattige Lagerplatz im Dorfe in der Nähe der Behausung des Toten, wir hatten daher das Geheul aus nächster Nähe anzuhören. Die Weiber schienen sich im Geheule abzulösen, eine Kolonne kam nach der andern im Gänsemarsch vorüber gezogen, fortwährend wurde geschossen. Das ganze Dorf schien an der Trauerfeierlichkeit beteiligt zu sein. Um unseren Lagerplatz sammelte sich bald wieder eine Menge Neugieriger, war ich den Leuten doch eine äufserst interessante Persönlichkeit, denn erstens hatten sie fast noch nie erlebt, dafs ein Weifser, der ja doch sicher viel Geld haben mulste, den ganzen Weg mit seinen Leuten zusammen marschiert, statt sich in einer Hängematte tragen zu lassen, dafs dieser Weifse aber noch Pflanzen sammelte und trocknete, offenbar um "Fetisch" daraus zu machen, war noch nicht vorher vorgekommen. Es ist natürlich erklärlich, dafs ich bei diesen Leuten, welche so gänzlich an ihrem Fetischglauben hängen, mit einer geheimeu Furcht beobachtet wurde.

Das Fetischtum steht gerade in diesen Ländern, südlich rom Niger, noch in höchster Blüte. Fast an jedem Wege, der nach einer Farmstätte führt, auf Feldern, in jedem Hause, an vielen Bäumen sind Fetische anzutrefien, sei es einfach in Form eines verzauberten Blattbüschels, oder als Erdklumpen mit Kauris geschmückt, oder als rohe Lehmfiguren, die Nachbildungen meuschlicher Körper darstellen. Nicht selten stölst man aufserhalb der Dörfer auf Gefälse an den Wegen, welche Palmenöl, Kauris oder 
andere Kostbarkeiten enthalten; dies sind Opfer, welche den Fetischen dargebracht werden, nie wird ein Neger wagen, etwas davon zu stehlen. Selbst die sogenannten getauften und civilisierten" Neger besitzen doch noch immer eine derartige Schen vor dem Fetisch, dafs sie sich wohl hüten, durch Zerstören der Fetischabzeichen oder Opfergaben den Zorn desselben zu erregen. Sicheres über die Arten der Verehrung des Fetisch sowie über den Charakter derselben zu erfahren, ist äufserst schwierig, das Volk wird durch die allmächtigen und gefürchteten Fetischpriester durch Grausamkeiten derartig eingeschüchtert, dafs es selten jemand wagt, sein Wissen dem Weilsen zu verraten.

Während wir in Iperu waren, wurden Unmengen ron Palmenwein hereingebracht. Die meisten Calebassen wanderten in das Haus des Toten; denn keine Festlichkeit darf ohne Geniefsen von Palmenwein vor sich gehen. Dabei betrinkt sich die ganze Gesellschaft derartig, dafs es nicht selten zu grauenhaften Ausschreitungen kommt. Der Wein wird hier ansnahmslos von der Ölpalme gewonnen.

Iper'u verliefsen wir gegen $2 \mathrm{Uhr}$ am Nachmittage. Während des Marsches durch den dichten Wald trafen wir Tausende ron Menschen, welche, aus dem Innern kommend, nach dem IkoroduMarkt wanderten, um Landeserzeugnisse zu verkaufen und dafür mit europäischen Waren nach Hause zurückzukehren. Die Karawanen, welche dicht hintereinander folgten, bildeten einen langen Zug, der kaum zu Ende war, als wir unser Abendquartier erreichten. Hier konnte man sehen, wie dicht bevölkert diese Gebiete sind. Hinter Iperu latten wir das Djibu-Land verlassen und befanden uns nun im Yoruba-Lande. Das erste Dorf, welches wir am Nachmittage um $t$ Uhr erreichten, wurde von meinen Lenten Odi genannt. Die Bauart der Hütten unterschied sich hier keineswegs ron der in Djibu-Lande üblichen. Hier wie dort waren die Dächer der in mehrere Räume geteilten, langen, viereckigen Häuser mit Gras gedeckt. Einige Häuser waren sogar weifslich angetüncht. Die Stralsen, wenn man überhaupt von solchen reden kann, schlängeln sich zwischen den Häusern dahin. Da der Boden hier in Odi sehr thonig war, waren sie bei der hügeligen Umgebung vom Regen ganz tief ausgewaschen. Dicht hinter Odi hatten wir über ein hügeliges, hauptsächlich mit Busch bewachsenes Terrain zu marschieren. Da die Sonne stark brannte, ermüdeten die Träger mit ihren zum Teil recht schweren Lasten zusehends, so dals wir nur langsam vorwärts kommen konnten. Kurz nach 5 Uhr erreichten wir endlich Ishara, ein Dorf, welches ich als Nachtquartier in Aussicht genommen hatte. 
Ishara ist kleiner und viel unbedeutender als Ishagamo. Es ist mit seinen für Yoruba-Verhältnisse recht weit voneinander stehenden Häusern auf einem Hügel erbaut. Die Wege waren auch hier wieder vom Regen tief ansgewaschen, ja an einigen Stellen so tief, dafs man zwischen den Häusern vermuten kounte, man befände sich in einem Festungsgraben. Auf der Spitze des Ishara-Hügels befindet sich eine Aufsenstation der englischen Mission in Ishagamo, welcher ein farbiger Lehrer vorsteht. In der Nähe des Schulhanses
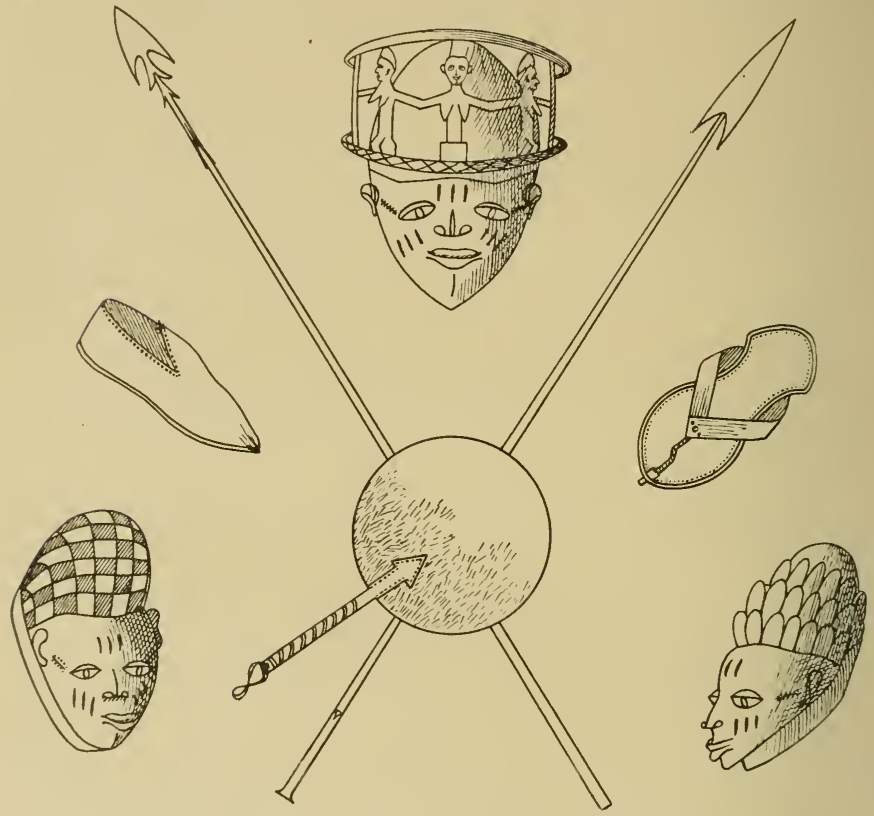

Fetischmasken, Schuhe, Fïcher und Lanzen aus dem Yoruba-Lande.

liefs ich das Lager aufschlagen. Da der Boden ron kleinen Steinen durchsetzt war, war es keine Kleinigkeit, die Zeltpflöcke zu befestigen. Für meine Leute erwirkte ich von dem Lehrer die Erlaubnis, während der Nacht im Schulhause zu schlafen.

Da sich gegen Morgen am 16. März ein ziemlich heftiger Sturm erhob, wachte ich schou früh auf. Das Zusammenpacken der Lasten sowie Abbrechen des Zeltes ging jetzt schon recht schnell bei den nun etwas geübten Leuten. Noch vor $5 \frac{1}{1} / 2$ Uhr liefs ich aufbrechen. Der heutige Vormittagsmarsch brachte mir insofern eine grofse Genugthuung, als wir die ersten lebenden Kickxiastämme fanden, wenn- 
gleich dieselben auch angeschnitten waren. Da ich von unten Blïten entdecken konnte, schickte ich einen meiner Leute anf den Baum hinauf. Aber o weh! Kaum war derselbe über die erste Hälfte des Staınmes hinaus emporgeklettert, da wurde er derartig von einer grofsen roten Ameisenart überfallen, dafs er schleunigst zurückkehrte. natürlich war nun erst nach Angebot eines Geschenkes ein anderer bereit, einige $Z$ weige für mich herunterzuholen. Ich versuchte die Bäumchen anzuzapfen, erhielt aber nur sehr wenig. Milch, immerhin aber genug, um mich zu überzeugen, dafs sie einen rorzüglichen Kautschuk lieferten. Der Boden des Waldes, in dem ich hier die Kickxia antraf, bestand ans verwittertem Glimmerschiefer. Auf dem Weitermarsche erreichten wir gegen $7 \frac{1}{2}$ Uhr ein kleines Dorf, Ascha. Dasselbe zeichnete sich durch Schmutz und drückende Hitze aus. Da nach Angaben der dortigen Einwohner die nächste Ortschaft sehr weit entfernt sein sollte, liefs ich, obgleich ungern, hier Halt machen. Während meine Leute sich ausruhten, machte ich eine kleine Exkursion, um so doch wenigstens im Walde im Schatten zu sein, den ich um so mehr wünschte, als sich grofse IIengen von Fliegen an unserem Lagerplatze einstellten. Nachdem wir gefrühstückt hatten, nahmen wir den \arsch wieder auf. Auch meine Träger waren froh, diesem von Fliegen und anderem Ungeziefer wimmelnden Schmntzhaufen den Rücken kehren zu könneu. Der Wald wurde nun immer interessanter und schöner. Während des Nachmittages entdeckte ich die ersten fruchttragenden Kickxien. Teils durch Belohnung, teils durch Drohung gelang es mir, einige meiner Leute zu bewegen, trotz der Ameisen Früchte herunterzuholen. Sehr gern hätte jch hier für einige Zeit ein Lager aufgeschlagen, doch war dieses unmöglich, da kein Wasser in der Nähe vorhanden war. Gegen 6 Uhr abends erreichten wir endlich eine Wasserstelle in der Nähe des kleinen Dorfes Omi. Fast wäre es dabei noch zu argen Zwistigkeiten zwischen meinen Trägern und den Omi-Lenten gekommen, da diese ihnen nicht gestatten wollten, von ihrem Wasser zu schöpfen. Wir schlugen unser Lager unter einer riesigen Alstonia auf, einem Baume, welcher auch häufig als kautschukliefernd aufgeführt wird. Durch verschiedene Experimente, welche ich noch am Abend vornahm, konnte ich mich davon überzengen, dafs die aus der Latex des Baumes gewonnene Masse kein Kautschuk und auch nicht als solcher zu verwenden sei.

Schon während des Tages hatten sich einige Träger gemeldet, welche über kranke Füfse klagten, während andere behaupteten, ihre Lasten seien zu schwer. Am Abend liefs ich dieselben wieder vortreten. Ich überzeugte mich dann, dafs zwei derselben wirklich 
durchgelaufene Füfse hatten, während die anderen sich nur das Leben etwas leichter hatten machen wollen. Um sogleich ein Exempel zu statuieren, liefs ich den letzteren die schwersten Lasten für die nächsten Tage anweisen, die Kranken erhielten dagegen die leichtesten. Seit dieser Zeit kam es selten vor, dafs sich jemand über seine Last beschwerte, es sei denn, dafs er wirklich krank war.

Am 17. März liefs ich die Leute um $5 \frac{1}{2} 2 \mathrm{Uhr}$ antreten. Da ich hoffte, noch heute Ibadan, die bedeutendste Stadt des Yoruba-Landes, zu erreichen, batten wir lange Märsche zu machen. Am Vormittage sahen wir viele Kickxiastämme, von denen jedoch der gröfste Teil durch übermälsiges Anzapfen getötet war. Ich zählte nicht weniger als 238 in dieser Weise zu Grunde gerichtete Bäume. Wenn man nun sieht, was die Eingeborenen in diesen Gebieten noch an Wald niederbrennen, um ihre Farmen anzulegen, so wird die Zahl der dem Verderben geweihten Kickxiastämme noch bedeutend vergröfsert. Es war auch gerade an jenem Tage, dafs mir besonders in die Augen fiel, wieviel Wald die Eingeborenen niedergeschlagen und abgebrannt hatten, um einige Bananen und Maniok zu pflanzen.

In Fawi, einem kleinen Dorfe, welches wir gegen $10 \mathrm{Uhr}$ erreichten, liefs ich eine kurze Rast machen. Bald darauf traten wir aus dem Walde heraus. Über hügeliges Terrain, zwischen niedrigem Gebüsch, unter brenmender Hitze marschierten wir nun auf einem recht schlechten Wege weiter, bis wir kurz vor Odi eine schöne breite Strafse erreichten, welche nach Djib-Ode, der Hauptstadt des Djib-Landes, führen soll. Als wir kurz darauf in Odi, einem Marktflecken südlich von Ibadan, eintrafen, liefs icb wieder eine kurze Rast machen, da sich hier auf dem sehr regen Markte für meine Leute Gelegenheit bot, Nahrungsmittel zu kaufen.

Man konnte hier ein äufserst interessantes, reges Leben bewundern. Sudan-Sklaven, aus weit entfernten Gegenden, feilschten und handelten mit den Haussa-Leuten um die Wette. Sogar die Fullah fehlten nicht, von denen sich besonders die Franen durch schönen Körperbau und regelmälsige Gesichtszüge auszeichneten. Es war ein so reger Verkehr hier, wie ich ihn bis dahin noch nie in Afrika unter den Eingeborenen gesehen hatte. Auffallend war, dals alles einen äufserst geregelten Gang zu gehen schien, wirklich ernsten Streit beobachtete ich nicht, trotz des furchtbaren Lärmes, der über den Marktplatz wogte. Meine Leute hatten sich bald mit dem nötigen Proviant versehen, so dafs wir gegen 3 Uhr nach Ibadan zu weiter marschieren komnten.

Das Land, welches sich vor uns ausbreitete, bestand aus Hügeln, die mit kurzer Gras- oder Strauchvegetation bedeckt waren. Längs der Thäler und der Wasserläufe hatten sich kleine Galleriewälder 
gebildet, die sich durch äufserst üppige Vegetation auszeicheten. Die Stralse nach Ibadan war in vorzüglichem Zustande. Sie wimmelte geradezu von Menschen, welche teils von Ibadan kamen, teils dorthin gingen. Da wir nun nicht mehr durch den Wald geschützt waren, machte sich bald eine äufserst angenehme Brise bemerkbar. Selbst die ermüdeten Träger bekamen nenen Mut, und frischer als zuvor ging es auf unser nächstes Ziel los. Als wir eben über einen Hügelrücken marschierten, machte mich mein Headman auf einen merkwürdigen Anblick aufmerksam. Direkt vor uns, sich über mehrere Hügel erstreckend, war ein immenser grauer Fleck zu sehen. Anfangs glaubte ich thatsächlich, es hier mit regetationslosen Felsenhügeln zu thun zu haben; mein Headman aber belehrte mich eines Besseren: es war die Stadt Ibadan.

Bevor wir die Thore der Stadt erreichten, hatten wir noch ein kleines Flüfschen zu überschreiten, in welchem sich meine Leute schleunigst zum Bade gestürzt hatten, um möglich rein in die grofse Stadt einzuzichen. Ich liefs die Karawane hier sich noch einmal sammeln, un dann geschlossen zur Stadt zu marschieren. Gegen $4^{1 / 2}$ Uhr erreichten wir das erste Thor. Es war viereckig gebant, ähnlich wie die Häuser der Yoruba, aber bedentend höher. Die Mauer, welche um die Stadt führt, ist niedriger und stellenweise wie in allen Städten des Landes vollständig verfallen. Eineu Schutz für etwaige feindliche Angriffe würde sie also nicht gewähren. Unter den Thoren sitzen die Zöllner; welche von jedem kommenden Neger ein kleines Kopfgeld erhalten, sofern er nicht zur Stadt gehört oder in Begleitung eines Weifsen ist. Aus letzterem Grunde hatte sich vor der Stadt meiner Karawane eine Anzahl von Leuten angeschlossen, welche sich so das Kopfgeld zu ersparen hofften. Kaum waren wir innerhalb der Stadt, als einer meiner Leute zusammenbrach. Wohl oder übel mufste ich halten lassen und seine Last auf die übrigen verteilen. Den Maun liefs ich zurück und befahl ihm, sobald als möglich nach meinem Lager anf der anderen Seite der Stadt nachzukommen.

Die Häuser standen, mit Ausnahme der an felsigen Orten gebauten, dicht zusammen. Es schien mir kaum glaublich, als ich sab, eine wie grofse Menschenmenge hier zusammengepfercht wohnt. Aufserdem dieses interessante rege Leben, die Webereien und Färbereien, man mochte fast glauben zu träumen. Wir gebrauchten nicht weniger als $3 / 4$ Stunde, lis wir das andere Thor erreichten. Über zwei grofse Marktplätze zogen wir, auf denen sich ein mir ganz fremdes Bild von Verkehr und Regsamkeit entrollte. Es wurden da die verschiedensten Gegenstände feilgeboten. Von gedörrten Hunden und Eidechsen bis zum Zwirnfaden, alles war zu 
finden. Selbst europäische Stofle und andere Artikel desselben Ursprunges waren reichlich vertreten. Lebensmittel spielten natürlich eine grolse Rolle, ebenso Töpferwaren. Auch schön geschnitzte, aus Kürbissen angefertigte Schalen waren zu einem äufserst billigen Preise zu erstehen. Die Haussa boten schöne Lederarbeiten dar, besonders Geldtäschchen, Sandalen, Schuhe, Fächer aus Rinderfell hergestellt, Scheiden für Schwerter und Messer, ja sogar Sättel. Perlen wurden von Fullah- und YorubaWeibern verkauft, die eben von der Küste zurückgekehrt waren. Dazu der Lärm der handelnden Eingeborenen und der uns begleitenden schwarzen Jugend der Stadt, es war zum Betäuben. Die Marktplätze waren mit Abá- (Ficus-) Bäumen bepflanzt, unter deren Schatten es stets angenehm kühl ist. Diese Ficusbäume werden ganz allgemein in diesen Gegenden auf freien Plätzen in den Dörfern angepflanzt. Häufig sind sie die einzigen Bäume, welche in den Dörfern vorhanden sind. Unter ihrem Schatten versammeln sich die Männer zum Plaudern, wenn sie nicht sonst durch Schlafen oder Arbeiten verhindert sind. Unter ihnen werden die Ratsversammlungen alogehalten und wird vom Häuptling Recht gesprochen.

Direkt aufserhalb der Stadt trafen wir in dem hier von der englischen Regierung hingestellten Haussa-Posten ein und erreichteu gleich darauf das Wohnhaus des englischen Residenten vom YorubaLande. Ich wurde hier von den anwesenden vier Europäern sehr herzlich aufgenommen. Mein Lager schlug ich dicht neben der Wohnung der beiden hier stationierten englischen Offiziere auf, um mich so behaglich einzurichten, als es eben die Umstände erlaubten. Meine erschöpften Leute konnten eine Rast von zwei Tagen sehr wohl gebrauchen; da aufserdem in deu Wäldern östlich der Stadt Kickxia vorhanden sein sollte, glaubte ich am besten von hier Leute zum Sammeln von Früchten ausschicken zu können.

Am nächsten Morgen liefs ich die Träger antreten und schickte die Hälfte derselben fort zum Einsammeln von Kickxiafrüchten und -Milch. Ich versprach den betreffenden Leuten eine Belohnung für jede 25 Früchte, denn das hatte ich eingesehen, dafs ich ohne Belohnung keine Kickxiafrucht erhalten würde, schon da die Eingeborenen eine furchtbare Angst vor den sich auf den Kickxien aufhaltenden Ameisen haben. Dafs diese Furcht nicht unbegründet war, konnte ich an der Brust eines meiner Träger sehen, welcher in der That von diesen Tieren arg bearbeitet war.

Die Abwesenheit meiner Leute benutzte ich dazu, mich über die Wege nach Abeokuta im Ekba-Lande und über die Kautschukverhältnisse des Protektorates zu orientieren. Von dem vorsichtigen und offenbar sehr national gesinnten englischen Residenten war 
nicht sehr viel in Erfahrung zu bringen. Derselbe war zwar äufserst liebenswürdig und zuvorkommend, schien es aber doch nicht gern zu sehen, dafs ich als Deutscher mich im Yoruba-Lande aufhalte. Der englische Doktor und die beiden Offiziere waren zu wenig über die Verhältuisse im Lande unterrichtet, um etwas Näheres angeben zu können, es blieben mir also nur noch die Eingeborenen übrig. Ich schickte meine Leute daher täglich in die Stadt, um Erkundigungen einzuziehen. Der Weg nach Abeokuta war sehr bald in Erfahrung gebracht. Betreffs des Kautschuks und der Kickxia hörte ich, dafs letztere in den östlich von Ife gelegenen Wäldern in bedeutend gröfseren und dickeren Stämmen vorhanden sein solle; im westlichen Teile des Yoruba-Landes wie im Djibu-Lande seien alle gröfseren Stämme bereits vernichtet worden, ja, in einigen früher an Kickxien sehr reichen Gegenden seien sie ganz verschwunden. Der englische Resident erklärte mir, dafs er auf Grund des von den Eingeborenen rücksichtslos betriebenen Raubbaus sich bewogen gefühlt habe, eine Verordnung zu erlassen, wonach Kickxien in seinem Bezirke vier Jahre hindurch nicht angetastet werden sollten. Da im ganzen Yoruba-Lande höchstens zwölf Europäer waren und somit eine Kontrolle ausgeschlossen war, so ist es natürlich, dafs sich kein Eingeborener um diese Verordnung kümmerte. Selbst an dem Hauptwege hatten wir auf der Reise von Ishagamo bis Ibadan frisch angeschnittene Kickxien gesehen, das Verbot wurde also offenkundig übergangen. In deu Wäldern des Yoruba-Landes sind auch einige Landolphien zu finden, welche guten Kautschuk liefern. Die Milch derselben wird entweder mit Kickxiamilch vermischt, oder allein nach Zusatz von Citronensaft durch Kochen koaguliert. Im ersteren Falle geht sie im Handel natürlich mit unter dem Namen "Silkrubber" und wird in grofsen Kuchen auf den Markt gebracht. Allein koaguliert wird sie in kleinen Bällchen geknetet als „Lagos-Bälle“ auf dem europäischen Markt verkauft. Häufig wird von den Eingeboremen der Silkrubber durch Zusatz von Ficusmilch gefälscht, wobei besonder's eine in den dortigen Wäldern häufige Art aus der Verwandtschaft der Ficus salicifolia in Betracht kommt; doch soll auch die Milch der von mir in Ishagamo gefundenen Ficusart zu demselben Zwecke verwendet werden. Die verbreitetste Art des Koagnlierens der Kautschukmilch ist die des Kochens. Da Citronen allenthalben im Lande zu haben sind, bedienen sich die Eingeborenen der Säure derselben, um die Koagulation zu beschleunigen. Seltener wird auch Kautschukmilch durch Reiben auf der Handfläche koaguliert, eine Methode, welche nur bei Landolphia angewendet wird. 
Da die ausgeschickten Leute, welche Kickxiafrüchte sammeln sollten, erst am 19. März wiederkamen, mufste ich meine beabsichtigte Weiterreise auf den 20. März verschieben. Ich hatte doch auf diese Weise eine nicht unbedeutende Menge von Kicksiasamen zusammengebracht, obgleich gegen die Verordnung des englischen Residenten. Die erste Aufgabe der Expedition war also somit erfüllt, und ich konnte meinen Rückmarsch zur Küste antreten. Da mir wenig daran gelegen sein konnte, dieselben Gegenden noch einmal zu durchziehen, hatte ich die etwas längere Route über Abeokuta durch das Ekba-Land gewählt.

Am Vormittage des 20. März liefs ich die Träger ảurchmustern und alle nicht gesunden Leute durch neue ersetzen. In der so volkreichen Stadt war dieses nicht so schwer, besonders da ich nach Lagos zurück wollte. Am Nachmittag brach die Karawane auf. Der Marsch durch die Stadt dauerte jetzt noch länger als der am 17. März. Nach Schätzungen soll dieselbe ungefähr 300000 Einwohner haben, wäre demnach wohl die grölste Stadt des afrikanischen Kontinentes. Über Hügel und Thal marschierten wir zwischen den eng aneinander gebauten Häuserreihen hin, gefolgt von neugierigen Weibern und lärmenden mackten Kindern.

Beror wir noch das westliche Thor der Stadt erreicht hatten, brach einer der Träger zusammen. Derselbe schien ebenso wie sein Brucler, den ich am Morgen entlassen hatte, schwindsüchtig zu sein. Da ich mich nicht dadurch aufhalten lassen wollte, entliefs ich den Mann sofort und liefs seine Last auf die übrigen verteilen, denn ohne Aufenthalt war kein neuer Träger zu beschaffen. Der Tag war furchtbar heifs und schwül, kein Lüftchen regte sich, so dafs es mich denn auch nicht überraschte, als ich in der Ferne schwarze Regenwolken aufsteigen sah. Meine Leute wollten gern noch innerhall) der Stadt Rast machen, ich jedoch war nicht damit einverstanden, da ich wufste, welche Schwierigkeiten es am nächsten T'age machen würde, die Leute zum Aufbruch zusammenzubringen. Trotz des Murrens mufsten die Träger weiter. Etwa $1 \frac{1}{2}$ Stunden, nachdem wir aus der Stadt herausgetreten waren, erhob sich ein furchtbarer Tornado. Nun hiefs es sobald als möglich Schutz zu suchen. Im Laufschritt vorwärts. Der Wind peitschte furchtbar die Blätter der Ölpalmen. Es war ein Sturm, wie ich ihn nicht vorher erlebt hatte. Nach etwa $1 / 2$ Stunde Laufschritt wurde es ganz finster, obgleich es noch nicht $6 \mathrm{Uhr}$ abends war.' Zu unserer Freude erreichten wir das Farmdorf Otimbale, als eben der Regen begann. Die Lasten konnten also noch trocken untergebracht werden. In strömendem Regen wurde das Zelt aufgestellt, welches zu meiner grofsen Freude selbst bei diesem Sturm fest standhielt. Nachdem 
die übliche Rinne um das Zelt gelegt war, gelang es auch den Boden vollständig trocken zu legen, so dafs ich noch vollständig trocken mich schlafen legen konnte. Die Träger quartierten sich in den Häusern der Eingeborenen ein.

Meinen Leuten schien der Abschied von lbadan nicht besonders leicht geworden zu sein, denn am nächsten Tage schien niemand rechte Lust zum Packen und Marschieren zu haben. Erst um $6 \mathrm{Uhr}$ waren wir auf dem Wege. Zunächst hatten wir noch grasige Hügel mit Gebüsch und einigen Borassuspalnen zu durchziehen. Um $7^{1 / 4}$ liefs ich eine kurze Rast in dem Farmdorfe Okovin machen. Kurz rorher hatten wir den fast trockenen Odoona-Bach zu überschreiten

Gegen 8 Uhr langten wir in der Ortschaft Bodeibo an. Auch hier war das System der Kopfgeld-Erhebung, wie ich es von Ibadan geschildert, eingeführt. Bald darauf erreichten wir den Waldgürtel, der hier an der Nordgrenze einige Zungen in die Grasländer hineinschiebt. Der Wald war hier üppiger als ich ihn vorher im YorubaLande gesehen, Kickxien schienen jedoch wenige vorhanden zu sein. Nach Aussage der Eingeborenen sollen sie aber früher auch hier sehr zahlreich gewesen sein. Überall hörte man dieselbe Klage der Eingeborenen, die Fantis hätten ihnen alle „Rubbersticks" ausgeschlagen und getötet. Um 9 Uhr erreichten wir einen kleinen Farmweiler, Okradjo genannt. Hier war ein Lager der "Eisenbahn-Surveyer" aufgeschlagen, welche die Route der von Abeokuta nach Ibadan in Aussicht genommenen Eisenbahn ausstecken sollten. Die Europäer waren nicht anwesend, als ich mit meiner Karawane eintraf. Während der Frülstücksrast, welche ich den Lenten hier gab, wurden wir derartig von kleinen Fliegen gepeinigt, dafs ich es sehr bald vorzog, eine kleine Exkursion in den Wald zu unternehmen. Hier fand ich aufser einigen Orchideen (zwei Angraecum-Arten) auch einige Apocynaceen, deren Milchsaft ich untersuchte. Landolphien waren hier reichlicher vorhanden, aber keine blühend, so dals ich die Arten nicht feststellen konute.

Unter meinen Trägern brach hier ein kleiner Aufstand aus, der mich zwang, den Rädelsführer zu strafen. Da die Leute aber bald einsahen, dafs sie doch den Kürzeren gezogen hatten, beruhigten sie sich wieder und gaben sich sogar am Nachmittage Mühe, möglichst flott zu marschieren.

Der Nachmittagsmarsch führte uns durch dichten Wald, in dem sich hin und wieder Spuren ron Kickxia fanden. Es war ein sehr heifser Tag ohne jeden Wind, so dafs den Trägern ihre Lasten nicht gerade leicht wurden; die kleine Aufmunterung, welche sie vorher erhalten, kam mir daher sehr zul statten. Um $3^{1 / 2}$ Uhr stiefsen wir plötzlich auf das Hauptlager der Eisenhahn- 
Ingenieure. Hier liefs ich eine kurze Rast machen. Mr. Berger, der Chef-Ingenieur, war so freundlich, mir einen Träger zur Verfügung zu stellen, da ich durchans einen Mann mehr gebrauchte, an Stelle dessen, der in Ibadan zusammengebrochen war, und mir einen Empfehlungsbrief für den Eisenbahn-Doktor, in dessen Lager ich zu übernachten gedachte, mitzugeben. Bis Ilugn hatten wir einen sehr angenehmen Marsch durch ein sehr schönes, schattiges Waldgebiet, in dem ich viel Landolphia sah. Längs des Weges beobachtete ich hier einige Häuflein etwa armlang geschnittener Landolphiazweige, die die Eingeborenen geschnitten, um dann in ihren Häusern die darin noch enthaltene Milch zu samineln und zu Kautschuk zu verarbeiten. Dafs diese Milch nicht vorher koaguliert, ist dadurch zu erklären, dafs die beim Anschneiden heraustretende Milch sofort an der Luft koaguliert und somit die ganze Schnittfläche luftlicht verschlossen wird. Dicht hinter Ilugu erreichten wir das Lager des Eisenbahn-Doktors, der mich sehr höflich aufnahm. Noch bis in die Nacht hinein safsen wir daselbst gemütlich zusammen, uns über Lagos und die von mir zuletzt bereisten Gegenden unterhaltend.

Da ich keine Zeit zu verlieren hatte, um noch zur rechten Zeit zur Abfahrt des Dampfers nach Kamerun in Lagos einzutreffen, hiefs es nun, den Marsch möglichst zu beschleunigen. Ich brach daher am 22. März schon vor $5^{\mathrm{I}} / 2$ Uhr auf. Auf einem ziemlich schlechten Waldwege, auf dem die Träger häufig über Wurzeln stolperten, liefs ich nun in schnellem Tempo marschieren. Der Headman, welcher nach meiner Marschordnung stets hinter dem letzten Träger ging, feuerte die Leute immer wieder an. So kam es, dafs wir schon um 8 Uhr in Abuleode eintrafen. Der Aufenthalt hier wurde uns wieder durch die Scharen der kleinen Fliegen, welche in die Augen, Ohren und Nase hineinflogen und sich an jedem nicht bedeckten Körperteile festsetzten, um den Schweifs aufzusaugen, rollständig verleidet. Da sonst nichts Interessantes hier zu finden war, beschäftigte ich mich mit Fangen ron Schmetterlingen. Zu diesem Zwecke liefs ich durch meine Leute an einer sonnigen Stelle im Wege wiederholt Wasser ausgiefsen, bis der Boden dort vollständig durchnälst war. Es dauerte gar nicht lange, bis sich die ersten Papilio dort niedersetzten, um die Feuchtigkeit aufzusaugen. Nach kurzer Zeit wurde die betreffende Stelle von Dutzenden umschwärmt. Die saugenden Tiere konnte ich dann einfach mit der Hand aufuehmeu und durch Zerdrücken des Brustkastens töten. Etwa lädierte Exemplare legte ich mit ausgebreiteten Flügeln wieder zurïck, damit sie durch die leuchtende blaue Färbung der Flügel nun immer wieder neue Tiere anzogen. Es gelang mir so, in einer Stunde nicht 
weniger als 63 guter Exemplare habhaft zu werden, ohne einmal den Käscher zu gebrauchen. Grofse Feinde aller Insektensammlungen in den Tropen sind die Ameisen, welche sofort über dieselben herfallen, sollte man es einmal wagen, frisch gefangene Sachen über Nacht frei stehen zu lassen, ohne sie durch Naphthalin oder Kampfer zu schützen.

Um $2^{1} / 2$ Uhr liefs ich wieder aufbrechen. Teils über offenes Terrain, teils durch dichte Wälder führte uns nun unser Weg. Die Hitze war kaum mehr zn ertragen, dazu kamen die uns stets umschwärmenden Fliegen. Gegen $4^{1 / 2}$ Uhr erreichten wir ein Dorf, für welches mir die Eingeboreneu den Namen Adawó angaben. Als ich weiterziehen wollte, kamen die Lente und behaupteten, es sei vor uns auf einer sehr langen Strecke kein Dorf mehr vorhanden. $\mathrm{Da}$ ich in der Nacht Regen befürchtete und daher meine Lente gern in Hütten schlafen lassen wollte, blieb mir nichts anderes übrig, als hier über Nacht zu bleiben. Ich liefs mein Lager unter grofsen Ficusbäumen aufschlagen. Da es noch sehr früh war und die Leute sonst nichts zu thun hatten, schickte ich die ganze Gesellschaft aus und liefs Milch der Ficusart sammeln, um damit zu experimentieren. Diese Milch verhielt sich nun insofern sehr merkwürdig, als sie weder durch Kochen noch durch Säurezusatz zur Koagulation zu bringen war. Ich liefs einen Topf unter beständigem Fener etwa eine halbe Stunde scharf kochen, und selbst dadurch erzielte ich keine Koagulation. Eine andere Ficusart, welche grolse lederige Blätter besitzt, ergab auch nur ein klebriges Produkt, das kaun verwendbar sein würde, höchstens zur Erzielung von Wasserdichtigkeit bei Stoffen. Die Kosten des Einsammelns würden jedoch wohl kaum durch den Wert des erhaltenen Produktes gedeckt werden, wenn sich nicht etwa neue Verwendbarkeiten für dasselbe finden liefsen. Es sind mir zwar schon hohe Preise genannt worden, welche für ein derartiges Produkt bezahlt worden sein sollen, doch bin ich der festen Überzeugung, dafs diese nicht als Marktpreise gelten können. Es würde nämlich viel billiger sein, guten Kautschuk zu kaufen und denselben mit der gewünschten Quantität Harz zu rermischen. Die Nacht in Adawô war sehr unangenehm, erstens ting es an zu regnen, zweitens aber gab es Moskitos in Mengen. Ich erwähne dieses besonders, da es im Yoruba-Lande auffallend ist, dafs die Moskitos in der Periode des heginnenden Regens so äufserst selten sind. Es ist daher das Reisen in diesen Gegenden bedeutend angenehmer als z. B. im Congostaate, in dem einem nur allzu häufig die Nächte durch diese höchst unangenehme Zugabe rerleidet werden. 
An 23. März waren wir bereits um $4^{1}{ }^{1}$ Uhr auf dem Wege. Es war herrlich, bei dem eben hereinbrechenden Morgenlichte durch den Urwald zu marschieren. Gegen $6 \mathrm{Uhr}$ trafen wir mit zwei Haussa-Soldaten und vier Trägern zusammen, welche aus dem nördlich gelegenen Shaka kamen und mich um Erlaubnis baten, sich meiner Karawane anschliefsen $z$ dürfen. Ich sollte es nicht bereuen, dafs wir bereits so früh aufgebrochen waren, demn bald traten wir gänzlich aus dem Urwald heraus und hatten nun auf teilweise sebr sandigem Boden über ein heifses Steppengebiet zu ziehen. Die Leute lechzten nach Wasser, das nicht zu bekommen war. Gegen 9 Uhr langten wir in Ayetoro an, einem Ilorfe, das einige hundert Häuser zählen dürfte. Ich selbst war furchtbar durstig geworden auf dem Marsche durch die staubige Steppe, sebr gelegen kam mir daher ein Trunk Palmenwein, den mir der Häuptling des Dorfes als Geschenk schickte. Ich gab den Trägern hier Zeit zum Essen und Trinken und machte unterdessen einen Spaziergang durch das Dorf. Merkwürdige Fetische waren hier zu beobachten, zum Teil nur aus einem Pflanzenbüschel bestehend, der an einem langen Stab befestigt war. Einem derselben schien eine ganz besondere Macht beigemessen zu werden, denn der Platz um den Stab herum war sehr schön gesäubert, im Kreise herum standen Schalen mit Palmenöl und -Kernen, Kauris, Efswaren aller Art und vielem anderen. Ich sah hier übrigens viele Haussa-Leute, welche nach Abeokuta gehen wollten. Einer derselben war der Abgesandte eines Haussa-Häuptlings im Innern, er trug ein wundervolles Schwert in einer prachtvoll gearbeiteten Lederscheide an einem dicken, runden, kirschroten, aus Seide hergestellten Gurte, welcher um die eine Schulter hing. Dieses Schwert war, wie er mir erklärte, ihm von seinem Herrn als Zeichen seiner Vollmacht mitgegeben worden.

Abeokuta selbst sollte nach Angaben der Eingeborenen noch ssehr weit" sein. Ich liefs daher um $1 \mathrm{Uhr}$ wieder aufbrechen. Weiter ging es über Steppengebiet; bei der immensen Hitze nicht gerade ein sehr angenehmer Spaziergang, dazu kam noch, dafs die Eingeborenen jetzt bei Beginn der Regen einen Teil der Steppe abgebrannt hatten, um für ihr Vieh frisches Gras zu erhalten. Ja, wir hatten selbst einmal zehn Minuten lang am Rande einer brennenden Fläche, die sich am Wege dahinzog, entlang zu geben. Die ganze Karawane setzte sich sehr bald in Laufschritt, um der furchtbaren Hitze möglichst bald zu entgehen.

Die Eingeborenen, welche aufserhalb der Waldzone wohnen, betreiben etwas Viehzucht, weiter nach Norden zu soll sogar viel Vieh vorhanden sein. Die Tsetsefliege scheint hier also nicht so weit ins Innere zu gehen wie dieses leider in unserer Togo-Kolonie 
der Fall zu sein scheint. Ackerbau wird in beschränktem Mafse getrieben. Hauptsächlich wird dann Manihok angepflanzt, stellenweise auch Bataten. Yams sah jch selten, ebenso Baumwolle.

Gegen $3^{1 / 2}$ Uhr sahen wir in der Ferne die riesigen F'elsen, auf welchen Abeokuta zum Teil erbaut ist. Je mehr wir uns der Stadt näherten, desto reicher war das Land kultiviert und desto besser wurden die Wege. Plötzlich waren wir am Thore angelangt. Dasselbe war ähnlich wie die Thore von Ibadan erbaut; auch hier sals die Thorwache und nahm Kopfgeld von den passierenden Fremden. Als meine Träger kamen und nicht zahlten, schienen die Leute sie anhalten zu wollen, als sie aber den Weifsen dahinter sahen, stauden sie davon ab. Ein Kopfgeld schienen sie jedoch auch zu erwarten. Ich liefs daher durch meinen Headman sagen, dafs ich nichts bezahlen werde, da ich auch in den anderen Städten nicht bezahlt habe. Daraufhin schienen sie sich zu beruhigen.

Anfangs führte unser Weg noch zwischen Feldern hin, dann zeigten sich die ersten Häuser, die zerstreut auf und zwischen mächtigen Felsen standen, bis wir schliefslich das Panorama dieser riesigen Felsenstadt ganz vor uns hatten.

Abeokuta ist eine der merkwürdigsten Städte, welche ich je gesehen. Ein grofser Teil der Häuser steht derartig zwischen und auf den Felsen, dals man sich unwillkürlich die Frage vorlegt: „Warum baut nur der so träge Eingeborene sein Haus hierher, wo er es doch wur nach mühevollem Klettern erreichen kann?" Das Wasser und das Holz müssen von unten weither geholt werden, so dals die Frauen und Mädchen die beschwerlichen Kletterpartien mindestens jedeu Tag einmal zu machen haben. Unser Weg führte oft über mächtige, schräge Felsen hin, die dann plötzlich jäh in die Tiefe abfielen. Ein Ausgleiten hätte genügt, um den Tod des dann Abstürzenden herbeizuführen. Für die Eingeborenen mit ihren nackten Fülsen sind diese Wege natürlich weniger gefahrvoll als für den beschuhten Europäer. Die Stadt soll auch gegen 200000 Einwohner besitzen. Wie mir meine Träger mitteilten, sollen die Einwohner jetzt jedoch häufig auswandern, da der Weifse mit seiner Eisenbahn, die jetzt bereits über Abeokuta hinausgefülırt ist, ihnen nun zu nahe ist.

Nach dreiviertelstündigem Marsche erreichten wir das westliche Stadtthor, das in der Nähe des Ogun-Flusses liegt. Da ich noch an demselben Tage den Endpunkt der damals im Bau begriffenen Eisenbahn erreichen wollte, um mir die Erlaubnis zu erwirken, mit meiner Karawane bis Ebute-Meta die Güterzüge benutzen zu dürfen, überschritten wir trotz der eintretenden Dämmerung den Ogun und marschierten dann auf das Lager des hier befindlichen Chef-Ingenieurs 
zu. Dasselbe war damals acht englische Meilen südlich von Abeokuta gelegen. Unterwegs brach mein Headman zusammen, ebenso waren die Träger so ermüdet, dafs die meisten für heute marschunfähig waren. Ich gab daher dem Headman Befehl, sich einige Zeit auszuruhen und dann mir $\mathrm{zu}$ folgen. Ich marschierte allein im Mondscheine weiter. Um 11 Uhr langte ich im Lager des ChefIngenieurs, Mr. Horse, an. Hier war glücklicherweise noch njemand schlafen gegangen. Ich wurde sehr freundlich empfangen und erhielt sofort die Erlaubnis zur Benutzung der Baln. Um $3 \mathrm{Uhr}$ nachts langte schliefslich auch meine Karawane an.

Um $4^{1} / 2$ Uhr am Morgen des folgenden Tages liefs ich alles zum Aufbruch nach dem Terminus der Eisenbahnlinie rüsten. Längs des frisch aufgeworfenen Eisenbahndammes hatten wir $4^{1 / 2}$ Meilen zu marschieren. Endlich dort angekommen, sahen wir weder von einem Zuge noch von einer Lokomotive ein Anzeichen. Die arbeitenden Eingeborenen konnten mir auch keine Auskunft geben. Da kein Europäer in der Nähe war, machte ich mich daran, die Häuser derselben aufzusuchen, fand aber alle leer, erst um $9 \mathrm{Uhr}$ traf ich einen Europäer, mit dem ich wun nach seiner Behausung fuhr. Meinen Leuten gab ich den Befehl, dorthin nachzukommen. Um 101/2 Uhr endlich kam ein Zug. Mit diesem konnten wir um $11^{1} / 2 \mathrm{Uhr}$ eine kurze Strecke weiterfahren, mufsten dann aber aussteigen, da der Zug erst am nächsten Tage nach Ebute-Meta fahren sollte. Gegen 1 Uhr traf ganz unerwartet zu unserem Glück eine Lokomotive ein, welche noch am selbigen Tage nach Ebute-Meta zurück sollte Da nur ein Wagen zur Beförderung meiner Karawane angehängt worden war, hatte ich die Genugthuung, dafs wir sehr schnell fuhren. Es war allerdings fast unerträglich heifs, denn zu der Sonnenhitze gesellte sich noch die der Lokomotive, und was das Schlimmste für uns war, es flogen uns beständig die Funken, welche mit dem Rauch ansgestolsen wurden, ins Gesicht und auf die Kleider. Für die zum Teil recht dürftig bekleideten Träger war dieses natürlich doppelt unangenehm. Gegen $7 \mathrm{Uhr}$ langten wir am Abend in Ebute-Meta an. Sogleich schickte ich Leute aus, welche einige grofse Canoes besorgen sollten, damit wir sofort über die Lagos-Lagune nach der Stadt hinüber könnten. Nach langem Handeln liefsen sich endlich einige Eingeborene bewegen, uns in Canoes nach Ebute-Ero ïberzusetzen. Es war eine prachtvolle Fahrt in hellem Mondschein über die Lagos-Lagune. Meine Leute saugen Iustige Lieder, als sie Ebute-Ero wieder vor sich salen, und erzählten den Canoeleuten alle möglichen Geschichten, welche während der Expedition passiert sein sollten. 
In Ebute-Ero begrülste ich zunächst die Herren in der Gayserschen Zweigfaktorei: dann ging es nach Lagos hinüber. Ich hatte hier eine Hängematte erhalten und liefs mich nun nach der Hauptfaktorei in Lagos tragen. Um $9 \mathrm{Uhr}$ traf ich dort ein. Herr Fritsch nahm mich wieder freundlichst auf.

Am folgenden Tage löhnte ich die Träger ab und begann nun mit den Vorbereitungen zur Weiterreise nach Kamerun. Vor allen Dingen hatte ich die Kickxiasamen richtig anszutrocknen und die gesammelten Pflanzen einzupacken, ebenso waren die Trägerlasten wieder derartig in Kisten zu verpacken, dals sie auf dem Dampfer nach Kamerun weitertransportiert werden konnten. Es war ursprünglich meine Absicht gewesen, einige Lagos-Leute, welche bereits als Gummisammler in den Wäldern des Yoruba-Landes Kickxia ausgebeutet hatten, für die spätere Congo- und Sanga-Reise zu engagieren. Das, was ich während meiner Reise im Hinterlande von Lagos gesehen, hatte mich aber immer mehr von diesem Plane abgebracht, denı hätte ich solche Lagos-Leute in die Sanga-NgokoRegion hineingebracht, so würde ich damit auch dort den Raubbau eingeführt haben, wie er hier im Yoruba-Lande verbreitet ist, und die Kickxiabestände, welche ich späterhin dort feststellen konnte, würden in Kürze demselben Schicksal verfallen sein, wie die im Djibu- und Yoruba-Lande einst so reichlich vorhandenen.

Während der wenigen Tage, welche ich noch in Lagos verbringen mufste, bis der Dampfer eintraf, hatten wir wiederholt starke Gewitterregen. Bei einem derselben wurden leider meine ganzen Pflanzensammlungen gehörig durchnälst, so dafs ich grofse Mühe hatte, dieselben wieder zu trocknen. Diese Regen erscheinen hier an der westafrikanischen Küste häufig so plötzlich, dafs man nicht immer die nötigen Vorsichtsmafsregeln dagegen treffen kann.

Ein für mich in Lagos äufserst interessanter Tag war der Markttag. Ich ging zusammen mit dem bereits oben genannten Dr. Randle an einem solchen Tage einmal dorthin, wo die Frauen die im Lande angewendeten Medizinen verkauften. Dieselben bestanden vorzugsweise aus Pflanzen. Da meines Wissens eine Liste solcher Pflanzen aus dieser Region nie reröffentlicht worden ist, dürfte eine solche, wie ich sie hier zusammengestellt habe, von einigem Interesse sein. Dr. Randle war so freundlich, die Namen der Eingeborenen für die betreffenden Arten hinzuzufügen.

\begin{tabular}{lll}
\multicolumn{1}{c}{ Botanischer Name } & & Yoruba-Name \\
Sanseviera guineensis . . . & Pason-Koko \\
Xanthosoma esculentum . & . & Ogiri-sako \\
Dicliptera spec. . . . . . . & Kusu-mope \\
Cleome spec. . . . . . . & Ay-tare
\end{tabular}




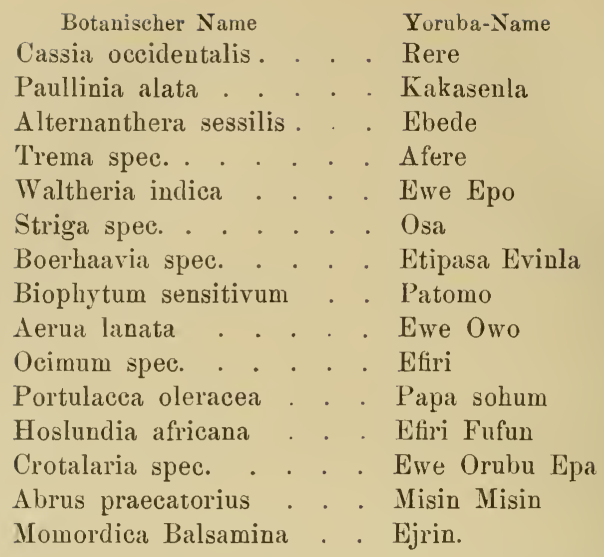

Der Dampfer "Aline Woermann", mit dem ich nun nach Kamerun weiterfahren wollte, traf unerwarteterweise äufserst pünktlich am 1. April vor Lagos ein. Ich hatte kaum noch Zeit genug, meine Sachen vollständig fertig zu machen. $\mathrm{Zu}$ meinem Glücke waren die Barrenverhältnisse zu ungünstig, um den Barrendampfern noch an demselben Tage die Durchfahrt zu gestatten. Dadurch gewann ich noch genügend Zeit. Am nächsten Tage, dem 1. Osterfeiertage, fuhr ich nun in Begleitung der Herren Fritsch und Schurmann auf dem Barrendampfer "Teck" hinaus und stieg dann auf die "Aline Woermann“ über. Bis zum Abend blieben wir noch vor Lagos, da die aus Europa kommende Ladung nun erst auf die Barrendampfer übertragen werden mufste. Endlich um $7 \mathrm{Uhr}$ ertönte das Signal zur Abfahrt. 


\section{Kapitel.}

\section{Aufenthalt in Kamerum, Reise nach und auf dem Congo.}

Während der kurzen Fahrt von Lagos nach der Kamerun-Küste hatten wir vorzügliches Wetter. Die See war spiegelglatt, kein Lüftchen regte sich. Am Morgen des 4. April tanchte plötzlich der Kamerunberg vor unseren Augen auf, als sich die Nebel, welche umherhingen, etwas lüfteten. Seine Spitze war leider nicht, zu sehen. Doch dessenungeachtet war ein jeder der Passagiere entzückt ron dem Anblick, welcher sich uns bot, als wir uns der Küste bei Bibundi näherten. Die tropische Fülle und Üppigkeit der Vegetation überstieg alle Erwartungen. Der dichte Urwald, welcher das Land bedeckte, soweit wir im stande waren, es zu sehen, machte mit seinen riesigen Bäumen, die von Epiphyten aller Art bedeckt waren, einen gewaltigen Eindruck auf einen jeden der Beschaner.

Gegen 7 Uhr am Morgen warfen wir Anker vor Bibundi. Natürlich konnte niemand der Passagiere seinen Wunsch bezwingen, dieses tropische Paradies zu sehen. Alle gingen mit der nächsten Gelegenheit an Land. Mit verschiedenen anderen Herren ging ich nun nach der Kakaoplantage der Bihundi-Gesellschaft. Herr Rackow, der damalige Leiter, enpfing uns bereits am Strande. Da es in meiner Absicht lag, mit Herrn Rackow betreff's Kickxiakulturen zu sprechen, so benutzte ich diese dazu günstige Gelegenheit, fand allerdings bis jetzt nicht viel Gehör für Einführung einer neuen Kultur, um so weniger, als wir auch auf dem Schiffe einen Pflanzer aus Sunatra mitgebracht hatten, der hier in Bibundi eine Tabakplantage anlegen sollte. So konnte ich denn diesen meinen ersten Besuch in Bibundi nur zur allgemeinen Orientierung verwenden. Ich besprach daher mit Herrn Rackow meinen Plan, dafs ich in einiger Zeit von Victoria nach Bibundi zurückkehren wollte, um dann einige Tage dort zu verweilen. Auch Herrn Oberleutnant v. Carnap traf ich hier in Bibundi. Derselbe war mit einer gröfseren Truppe von Arbeitern, welche er im Rio-del-Rey- 
Gebiete angeworben hatte, vor kurzem dort eingetroffen, und wollte nun die Gelegenheit wahrnehmen, um mit unserem Dampfer die Leute nach Kriegsschiffhafen zu bringen. Da das Anbordbringen der Leute ziemlich langsam vor sich gehen konnte, denn wir hatten in beträchtlicher Entfernung von der Küste Anker geworfen, so konnten wir erst um 5 Uhr wieder in See gehen. Längs der wunderrollen Kïste fuhren wir num an der Ambas-Bai mit Victoria und den beiden Inseln Mundule und Ambas vorbei, um die AffenHalbinsel herum in die prachtvolle Bucht von Kriegsschiff bafen hinein. Noch in der Dunkelheit wurden die neuangeworbenen Arbeiter, 214 an der Zahl, gelandet. Mit Tagesanbruch am 5. April wurden die Anker wieder gelichtet. Um $5^{1} / 2$ Uhr waren wir vor Tictoria.

Es war ein prachtroller Morgen; der im Hintergrunde aufsteigende Kamerumberg war bis zur Spitze des Engelberges mit Nebel bedeckt. Darunter die dunklen, dicht bewaldeten Hügel, im Gegensatz zu den weifsgetünchten Häusern ron Victoria: ein Bild, wie man es an der ganzen westafrikanischen Küste nicht wieder sehen kaun.

Zusammen mit Herrn Oberleutnant v. Carnap fuhr ich an Land. Da ich die Absicht hatte, mich einige Zeit in dem VictoriaBezirke aufzuhalten, quartierte ich mich in dem Hotel der AmbasBay Trading Comp. ein. Dank des Entgegenkommens, welches ich von seiten des damaligen Bezirksamtmannes, Herrn Assessor Hor'n, fand, und vor allen Dingen des regen Interesses, welches Herr Oberleutnant v. Carnap meinen Unternehmungen entgegenbrachte, waren die Gepäckstiicke und sonstigen Expeditionsgüter bald in einem Schuppen der Ambas-Bay Trading Comp. untergebracht.

Nach dem Essen machte ich mich sogleich auf den Weg zum botanischen Garten und besprach dort mit dem anwesenden Gärtner die Möglichkeit, meine Kickxiasamen zum Teil dort aussäen zu lassen. Es wurden sogleich auch Beete hergerichtet, so dafs schon am 7. April die Samen ausgesät werden konnten. Auch die Ficusstecklinge, welche ich aus Lagos mitgebracht hatte, konnteu zu derselben Zeit in den Boden eingesteckt werden.

Während der nächsten Tage machte ich mit Herrn Oberleutnant v. Carnap zusanmen rerschiedene kleine Exkursionen und Ausflüge, um mich über die Verhältnisse und die Vegetation etwas zu orientieren.

Am 9. April fuhr ich zusammen mit den Herren Assessor Horn und Oberleutnant v. Carnap nach Kriegsschifthafen zil Herru Frederici, mit dem ich auch die Möglichkeit einer Kickxiaanlage daselbst besprechen wollte. Die Fahrt dorthin unternahmen wir in einem Regierungsboote. Gegen $10^{1 / 2}$ Uhr langten wir bei Herrn 
Frederici an, der uns äulserst liebenswürdig aufnahm. Schon auf dem Wege ron dem Landungsplatze bis zum Wohnhause des Herrn Frederici konnte man sehen, dafs hier eine peinliche Ordnung allenthalben herrschte. Die Gebäude waren solide und praktisch aufgeführt, kurzum man sah, dafs Herr Frederici nicht umsonst als Muster eines Plantagenleiters in Kamerun gilt.

Als ich im Laufe der Unterhaltung Herrn Frederici fragte, wie er sich zur Frage des Anbaues von Kautschukbäumen stelle, äufserte er sich, entschieden dagegen zu sein. Als ich ilım nuu die Vorteile einer solchen Anlage im Falle des Gedeihens der Kickxia vor Augen führte, gelang es mir zu meiner nicht geringen Freude, ihn vollständig umzustimmen, so dafs er sich sofort bereit erklärte, eine solche Pflanzung anzulegen. Da ich schon allenthalben von der Tüchtigkeit dieses äufserst praktischen Mannes gehört hatte, lag mir viel daran, vor allen Dingen ihn für meine Sache zu gewinnen; es war natürlich nun eine grofse Genugthuung für mich, dafs es mir gelang. Am Nachmittage machten wir einen längeren Spaziergang, um die Plantage zu besichtigen. Bei dieser Gelegenheit stellten wir auch gleich einen Platz fest, welcher zur Anlage der Saatbeete für die Kickxia reserviert werden sollte, ebenso die Lokalitäten, auf denen dann später die Kickxia in der von mir vorgeschlagenen Weiše ausgepflanzt werden sollten. Zur Anlage dieser Kickxianpflanzungen wählten wir die Hügel, welche sonst für Kakaokulturen weniger geeignet sind.

Es war eine Freude, zu sehen, wie alle Bestände in wundervoller Ordnung gehalten wurden, besonders die von Herrn Frederici in nenerer Zeit angelegten. Beständig waren neue Pflanzen an Stelle etwaiger kranker oder abgestorbener Bäume eingesetzt worden, so dafs nur wenige Lücken in den Beständen vorhanden waren. Da, wo von Herrn Fredericis Vorgänger die eiuzelnen Stämme zu dicht gepflanzt waren, wurde allmählich mehr Luft geschafft. Schöne breite Wege, die in vorzüglichem Zustande waren, durchschnitten die Plantage nach allen Seiten. Die Wasserläufe waren durch schöne massive Brücken passierbar gemacht. Besonders gut gefiel mir das von Herrn Frederici erst unlängst angelegte Vorwerk "Wasserfall". Hier hatte Herr F. die Erfahrungen, welche er im Laufe der Jahre gesammelt hatte, alle verwerten können. Hier sah man die regelmäfsigsten Bestände. Dieselben bestanden zwar meist nur aus jüngeren Pflanzen, versprachen aber, sich prachtvoll zu entwickeln. Die Anlagen zum Gären und Dörren des Kakaos waren entschieden die praktischsten, welche ich gesehen. Die letzteren waren ganz ähnlich den Dörrhäusern, welche Dr. Preufs in seinen Berichten an das Kolonial-Wirtschaftliche Komitee aus Südamerika abgebildet und beschrieben hat. 
Am Abend kehrte Herr Assessor Horn nach Victoria allein zurück, Herr Oberleutnant v. Carnap und ich blieben über Nacht bei Herrn Frederici, uщ am nächsten Morgen erst auf dem Landwege nach Victoria zurückzugehen. Unser Weg von Kriegsschiff hafen nach Tictoria führte durch das Vorwerk Wasserfall über eine Hügelkette. Sobald wir die Grenze der Kriegsschiffhafen-Plantage überschritten hatten, wurde er schmaler und war mehr vernachlässigt, stellenweise war er vollständig nit Unkraut bewachsen. Der prachtrolle Urwald zu beiden Seiten wurde hin und wieder von Anpflanzıngen der Tictoria-Neger unterbrochen. Die Kakaobestände derselben waren häufig zu dicht bewachsen, sonst wurden hauptsächlich Bananen und I'lanten, letztere eine nicht sülse, grolse Bananenart, gepflanzt. Stellenweise sah man etwas Maniok (Kassada) und Xantosoma esculentum (Koko).

Am Morgen des 11. April brach ich mit zwei Trägern (MajumbaLeuten) und einem Jungen nach Buea auf, um mich dem Herrn Gouverneur v. Puttkamer vorzustellen. Der schöne, weit gehaltene Weg führte über den Limbe-Bach hinüber durch einige Vorwerke der "Victoria"-Plantagengesellschaft. Die Kakaobestände daselbst standen zum grofsen Teile nicht schlecht, doch war der Boden stellenweise so steinig, dafs man sich unwillkürlich fragen mufste, ob denn die Bäumchen hier für längere Zeit sich würden halten können. Hinter dem Limbe-Vorwerk stieg der Weg allmählich nach Bomana zu an. Er war an den steileren Stellen besonders dicht mit Basalt- und Lavageröll bedeckt. Da die Sonne unterdessen schon etwas höher gestiegen war, konnten die Träger mit den schweren Koffern nicht. mehr so schnell vorwärts. Ich ging daher mit dem Jungen voraus. Oberhalb Bomana traten in dem Urwalde stellenweise schon offenere Partien auf, welche mit Elefantengras bewachsen waren. Dieses letztere ist eine riesige Pennisetumart, welche nicht selten eine Höhe vou $3 \mathrm{~m}$ erreicht. Gegen $11^{1} / 2$ Uhr erreichte ich den Rand des oberen Plateaus, auf dem Buea gelegen ist. Dasselbe liegt 800 bis $900 \mathrm{~m}$ über dem Meeresspiegel. Dichter Urwald war hier nicht ınehr vorhanden. Whe ich die Station Buea, den Sitz des Herrn Gouverneurs v. Puttkamer, erreichte, hatte ich noch durch einen Teil der „Günther-Soppo-Pflanzung“ zu marschieren. Die Kaffeebäumchen dasellost sahen meist nicht sehr vielversprechend aus, viele waren eingegangen, andere schienen zu kränkeln. Offenbar behagte ihnen die kalte, nebelige Luft dieses Plateaus nicht mehr. Kakao gedeiht so boch oben am Kamerunberge auch nicht mehr. Gegen $12^{1 / 2}$ Uhr traf ich auf der Station Buea ein. Ich meldete mich hier bei dem Stationschef, Herrn Leuschner, welcher mit seiner Gemahlin mich sehr liebenswürdig aufnahm und mir in dem Logierhaus, welches für 
Durchreisende und nene Ankömmlinge sowie für Rekonvaleszenten, welche etwa aus der mörderischen Küstenzone heraufkommen sollten, gebaut ist, ein Zimmer anwiesen. Die Station liegt direkt am Fufse des Gipfelkegels des Kamerun-Gebirges. Zur Zeit meiner damaligen Ankunft bestand sie aus etwa 15 Häusern. Das Klima ist hier für Europäer gesund, besonders da Fieber hier nicht mehr vorzukommen scheint, doch werden infolge der häutigen Nebel die Europäer leicht von Rheumatismus befallen. Da die Eingeborenen der Umgebung jetzt vollständig beruhigt sind, wird hier nur eine kleine Polizeisoldatentruppe gehalten, welche hauptsächlich Ordonnanzdienște zu verrichten hat.

Am Nachmittage empfing mich der Gouverneur Herr v. Puttkamer. Er brachte meiner Expedition, wie überhaupt allen Dingen, welche die Entwickelung des Schutzgebietes fördern könnten, ein sehr reges Interesse entgegen und versprach, meine Pläne in jeder Weise zu unterstïtzen. Dals dies nicht leere Versprechungen waren, hatte ich in Zukunft genug Gelegenheit, wahrzunehmen. Ich kann daher dem Herrn Gouverneur v. Puttkamer nicht genug Dank wissen für die Art, in welcher er die Interessen meiner. Expedition gefördert hat.

Bei seiner letzten Rückkehr aus Europa hatte Herr Gouverneur v. Puttkamer eine Anzahl Algäuer Kübe nach Kamerun hinüberfïhren und nach Buea auf die Station bringen lassen. Dieselben haben sich hier sehr gut entwickelt und geben reichlich Milch. Leider aber scheint das Futter des Kamerun-Gebirges nicht genügend kräftig zu sein, so dals ein nicht geringer T'eil desselben für die Tiere noch immer aus Europa importiert werden muls. Man hatte auch bereits Versuche gemacht, Kreuzungen zwischen dem Algäuer Vieh und eingeborenen Kamerun-Kühen zu erziehen, so dals es nicht ausgeschlossen ist, dafs dadurch die einheimischen Rinder bedeutend rerbessert werden.

In Buea hielt ich mich bis zum 13. April auf. Ich rerbrachte die Zeit daselbst, so gut es ging, mit Sammeln von Pflanzen, Exkursionen, und vor allen Dingen Besuchen nach der Günther-SoppoPlantage. Herr Günther latte nämlich eine kleine Landolphiapflanzung angelegt, welche wohl die erste in unserem Schutzgebiete sein dürfte. Die Pflänzchen schienen sich an den Bäumchen, an deren Fufse sie angepflanzt waren, recht wohl zu befinden, einige waren bereits gegen $2 \mathrm{~m}$ hoch. Doch trotz dieses guten Gedeihens scheint mir eine solche Anlage, wenn sie in dieser Weise noch einer gewissen Pflege bedarf, nicht rentabel genug zu sein. Vor dem 15. Jahre dürften die Lianen wohl kaum anzapfbar sein, und da dieselben nur sehr wenig Latex abgeben, würden die Unkosten 
wohl in keinem annehmbaren Verhältnisse zu dem Gewinne stehen. Während eines Streifzuges auf dem Boden der Soppo-Plantage fand ich eine Ficusart, aus der Verwandtschaft der P. Preufsii Warb., deren Milch nach der Koagulation ein ganz ähnliches Produkt ergab, als die der Ficusart aus dem Yoruba-Lande. Natürlich kann ich über diese Art daher nur dasselbe sagen, wie von der YorubaArt. Man mufs mit solchen Dingen natürlich sehr vorsichtig sein, da sich für ein so minderwerthiges Material erst allmählich ein Absatz auf dem Kautschukmarkte erzielen lälst. Ändern würde sich diese Sachlage natürlich dadurch, dafs sich eine neue Verwendung für solche Produkte finden liefse. Der Kakao auf der SoppoPlantage stand da, wo er nicht in zu hoher Lage ausgepflanzt war, nicht schlecht; dennoch machte die ganze Plantage einen etwas verwahrlosten Eindruck, obgleich die Wege recht gut gehalten waren. Herr Günther schrieb dieses dem Mangel an Arbeiterund Aufseherpersonal zu, das lange nicht ausreiche, um die unter Kultur gesetzten Ländereien in Ordnung zu halten.

Am Nachmittage des 13. April verabschiedete ich mich bei dem so äufserst zuvorkommenden und liebenswürdigen Herrn v. Puttkamer und trat nun meinen Rückmarsch nach Victoria an. Um $2 \mathrm{Uhr}$ verliefs ich Buea; auf einem direkteren, aber steileren Wege stieg ich ab, so schnell es in dem Lavageröll ging. Um $6^{1 / 4}$ Uhr traf ich in Victoria ein. Hier bezog ich wieder mein altes Quartier in dem Ambas-Bay-Hotel bei Herrn Lange. Von der Ficusart, welche ich bei Soppo gefunden hatte, brachte ich auch Stecklinge für den botanischen Garten in Victoria mit.

Während einiger Tage blieb ich nun in Victoria, um zunächst einige Versuche mit der Milch der Ficus elastica zu machen. Im botanischen Garten waren einige ältere Stämme, welche zum Anzapfen durchaus geeignet schienen. Das Resultat dieser Untersuchungen deckte sich genau mit den Ergebnissen der Experimente, welche ich kurze Zeit später in Bibundi anstellte, es konnte kaum zufriedenstellend genannt werden. Der Kautschuk war entschieden ron inferiorer Qualität, obgleich etwas besser als der der Ficusarten aus dem Yoruba-Lande und von Buea.

Zusammen mit Herrn Oberleutnant v. Carnap besuchte ich damals auch die Moliwepflanzung, welche unter der tüchtigen Leitung des Herrn Stammler eben zu entstehen begann. Die zu jener Zeit zur ersten Anlage ausgesuchte Lokalität befand sich etwa $3 / 4$ Stunde von Victoria entfernt. Dort angekommen, überzeugte ich mich sofort, dafs es unter den damals waltenden Umständen für Herru Stammler vollständig unmöglich war, sofort Kickxiasaat zu übernehmen. Da er sich aber entschlossen hatte, Kickxia anzupflanzen, 
so machte ich ihm einen Vorschlag, auf den er nur zu gern einging. Ich wollte dem botanischen Garten in Victoria die für die Moliwepflanzung bestimmten Kickxiasamen zur Aussaat ïbergeben. Herr S tammler mufste sich verpflichten, dieselben bis zum 1. August 1899 spätestens abzuholen, sonst verfielen die Pflänzchen dem botanischen Garten als Eigentum. In dieser Weise wurde denv auch alles arrangiert. Herr Assessor Horn, der gewissermafsen Herrn Dr. Preufs während seiner Abwesenheit vertrat, gab seine Einwilligung dazu. Somit wurden der Moliwepflanzung auch einige tausend Kickxiapflänzchen gesichert.

Da ich, wie ich schon oben angegeben, die Absicht hatte, noch einmal Bibundi zu besuchen, um Kickxiasamen dorthin zu bringen, so benutzte ich, mit Genehmigung des Herrn Gouverneurs v. Puttkamer, eine Gelegenheit, dorthin zu gelangen, welche sich am 17. April bot. Der Regierungsdampfer "Nachtigal" sollte Herrn Hauptmann v. Besser nach Bibundi bringen, wo er die Grenze zwischen der Sanje- und der Bibundi-Plantage festlegen wollte. Ich begleitete daher Herrn Hauptmann v. Besser nach Bibundi. Als wir gegen $10^{1 / 2}$ Uhr dort eintrafen, war leider Herr Rackow ebeu im Begriff, nach Victoria abzureisen. Ich konnte also nur das Nötigste mit ihm besprechen. Von Frau Rackow wurden wir in der freundlichsten Weise aufgenommen. Diese Dame, welche hier in der Halbcivilisation unermüdlich ihrem Haushalte vorstand, ist ein Segen für die sich in Bibundi aufbaltenden Europäer gewesen. Wo es nur immer in Krankheitsfällen etwas zu helfen gab, hat sie stets für die betreffenden Herren in der edelmütigsten Weise gesorgt. Auch uns wufste sie hier das Leben recht angenehm zu machen; wenn nur jemand einen Wunsch äufserte, wurde er sogleich erfüllt, wenn dies irgend möglich war.

Wie ich mit Herru Rackow rerabredet hatte, liefs ich unter meiner Aufsicht für die Kickxiasamen hier Saatbeete anlegen und zwar in derselben Weise, wie ich es bereits auf Kriegsschiffhafen und im botanischen Garten zu Victoria vorgeschlagen hatte.

Die vier Tage meines Aufenthaltes in Bibundi suchte ich nun soweit als möglich anszunutzen. Am Nachmittage des 17. April machte ich mit Herrn Hauptmann v. Besser einen Besuch auf der Sanje-Plantage. Herr Becker, der Leiter derselben, war eben dabei, eine gröfsere Fläche für Kakaokulturen zu reinigen. Die Lage der Plantage in einer grofsen, mäfsig feuchten und äufserst fruchtbaren Ebene, auf der zur Anlage der Anpflanzungen eigentlich nur wenig Wald wegzuschlagen sein wird, stellt bei guter Betriebsleitung für das Unternehmen eine grofse Zukunft in Aussicht. Auf dem Gebiete der Sanje-Gesellschaft sind noch einige alte Kakao- 
gärten eines ehemaligen Elefantenjägers vorhanden, welche ron der Gesellschaft übernommen worden waren. Diese Gärten waren recht gut in Pflege gehalten und mit grofsem Geschick angelegt, so dal's Her Becker sehr recht that, indem er diese Anlagen sogleich fortsetzen liefs.

Auch hier in Bibundi waren bei dem Wohnhause des Herrn Rackow einige Ficus elastica-Stämme von genügender Stärke rorhanden, so dafs ich Versuche damit anstellen konnte. Ich liefs zu dem Zwecke Milch derselben einsammeln, kam aber bei ineinen Experimenten zu demselben Schlusse wie in Victoria. Der Kautschuk war entschieden ein minderwertiges Produkt, jedoch nicht gänzlich unbrauchbar.

Am 20. April begleitete ich Herrn Hauptmann v. Besser auf einer seiner Vermessungstouren, $1 \mathrm{~m}$ die Flora des Gebirgswaldes hier kennen zu lernen. Wir drangen längs der östlichen Grenzlinie des Bibundi-Gebietes ziemlich tief in den Urwald ein. Das Ergebnis dieser Exkursion war für mich nicht anders als ich erwartete. Es fanden sich einige Landolphien, die wirklich Kautschuk lieferten, aber nicht zahlreich genug vorhanden zu sein schienen. um einen Abbau seitens der Europäer zu rechtfertigen. Von Kickxia war nichts zu entdecken, ebenso wenig ron kautschukliefernden Ficusarten.

Da ein längerer Aufenthalt in Bibundi für mich nur Zeitrerlust bedeutet hätte, weil ich doch jetzt nach der Aussaat der Kickxien in Abwesenheit des Herrn Rackow nichts ausrichten konnte, beschlols ich, am Morgen des 21. April mit einem Boote nach Victoria zurückzukehren. Einer der Herren ron Bibundi, Herr Iazat, welcher nach Kamerun wollte, begleitete mich. Erst um 9 Uhr kamen wir ron Bibundi fort, da sich natürlich im letzten Augenblicke immer wieder etwas Neues fand, was die Herren Bootsjungen noch zu besorgen hatten. Es herrschte eine grauenhafte Windstille, so dafs wir uns im Boote vor der Hitze kaum retten konnten. Natürlich kamen wir auch nur sehr langsam rorwärts, da wir nicht das Segel gebrauchen konnten. Wir fuhren um das Kap Debundja herum nach Isongo, wo wir bei dem Leiter dieses Vorwerkes der Bibundi-Pflanzung, Herrn Kundler, unser Mittagsmahl einnahmen. Es war gegen $2^{1 / 2}$ Uhr, als wir eintrafen. Die Kakaopflanzung stand hier recht gut und war schön rein gehalten. Bei den hier hesonders starken Regenfällen scheint sich dieser Ort für Kakao vorzüglich zu eignen, ebensowohl für Vanille, welche in neuerer Zeit dorthin eingeführt werden soll. Landschaftlich bietet Isongo ein reizendes Bild dar. Gegen $4 \mathrm{Uhr}$ brachen wir wieder von Isongo auf, un noch bis Mokindange fahren zu könnell. Eine 
Brise, welche sich plötzlich erhob, war für uns günstig. So kam es, dafs wir gegen unsere Erwartungen bereits um $6 \frac{1 / 2}{\mathrm{Uhr}}$ vor Mokindange waren. Es war eine gefährliche Fahrt hinein in die mit zerstreuten Felsen reich bedeckte Bucht, da aber Herr Mazat sowobl wie unsere Bootsleute häufig vorher hier gewesen waren, kamen wir endlich wohlbehalten bei Herrn Böklin, welcher der hiesigen Plantage rorsteht, an. Mokindange ist ebenso wie Isongo noch ein Vorwerk der Bibundi-Plantage. Die Plantage konnte ich leider nicht mehr besichtigen, da wir am nächsten Morgen bereits un 6 Uhr wieder abfuhren. Der Wind war wieder ungünstig für uns, so dals unsere Leute die ganze Strecke rudern mufsten. Wir fuhren bei dem Dorfe Bota vorbei, zwischen den merkwürdigen "Piraten"-Inseln und dem Festlande hindurch nach Victoria zu. Unterwegs liefen wir noch einmal an der Küste bei Herrn Weilers Besitz an, wo Herr Mazat noch einiges Geschäftliche zu arrangieren hatte. Gegen ? Uhr langten wir endlich bei strömendem Regen in Tictoria an.

Da sich der Monat nun seinem Ende zuneigte, benutzte ich die nächsten Tage meines Aufenthalts in Victoria dazu, die für meine Congo-Reise nötigen Lasten zusammenzustellen. Aufserdem setzte ich meine Experimente mit der Milch der Ficus elastica fort.

Einer Verabredung gemäls schickte Herr Frederici an 26. April von Kriegsschiffhafen ans ein Boot, um mich dorthin abzuholen, damit wir die Kickxien aussäen könnten. Noch an demselben Tage wurden die Saatbeete fertiggestellt und am nächsten Tage die Samen gleich in Abständen von $1 \mathrm{dm}$ einzeln eingesteckt. Zum Schntz gegen die Sonne mulste natürlich ein leichtes Dach von Wedeln der Ölpalme hergestellt werden, was einfach dadurch erzielt wurde, dals man diese Wedel auf dazu angebrachten Stellagen darüber legte.

Ich besichtigte nun während meines Aufenthalts die Plantage genauer als es mir vorher die Zeit erlaubt hatte. Auch das Vorwerk N'Bamba besuchte ich. Überall fand ich dieselbe Ordnung, überall die Anlagen praktisch und doch ohne grofsen Kostenaufwand aufgeführt. Wir unterzogen nun auch die für Kickxiabestände ausersehenen Hügeliücken einer Besichtigung. Ich fand hier dieselbe Urwaldvegetation wie in den Wäldern des Yoruba-Landes, wo ich Kickxia angetroffen hatte. Der Boden war zwar entschieden fruchtbarer und ron anderer Beschaffenheit, doch scheint dieser Umstand, wie meine späteren Reisen in das Bakossi-Gebiet bewiesen, von nicht so hoher Bedeutung zu sein.

Als ich am 22. Mai nach Victoria zurückkehren wollte, wollte es der Zufall, dals gerade der Dampfer "Adolph Woermann" auf 
seiner Rückreise nach Victoria Kriegsschifthafen anlief. Herr Kapitäu Jensen war so freundlich, mich nach Tictoria mitzunehmen. Dieser Umstand war mir besonders angenehm, da ich erfuhr, dafs Herr Küderling aus Campo, welcher als einziger bisher für Kickxiaplantagen im Schutzgebiete eingetreten war, sich an Bord befände. Ich hatte sonach Gelegenheit, mich eingehender mit ihm über die Kickxiakultur zu unterhalten, und gab ihm das Versprechen, nach meiner Rückkehr aus der Sanga-Ngoko-Region, auch seine Plantage am Campo-Flusse zu besuchen.

In Victoria sah ich zu meiner grofsen Freude, dals die Kickxiasamen bereits anfingen, anfzugehen. Kaum 5 pCt. der Samen schienen auszubleiben.

Da der "Woermanu-Dampfer", welcher nach dem Congo fahren sollte, nun jeden Tag in Kamerun erwartet wurde, fuhr ich am 7. Mai mit der "Nachtigal" nach Kamerun hinüber, um daselbst auf den Dampfer zu warten. Herr Gouverneur r. Puttkamer, welcher erst seit kurzem vom Congo zurückgekehrt war, war so liebenswürdig gewesen, mir Empfehlungen an die dortigen Behörden und andere Persönlichkeiten, welche mir von Nutzen sein konnten, mitzugeben. Ebenso hatte er mir viele Ratschläge erteilt, deren Nutzen ich sehr bald erkennen sollte.

In Kamerun nahm mich Herr Grofsberger für die Zeit meines Aufenthaltes daselbst in seiner Faktorei auf. Als bald die Nachricht von Europa kam, dals der für den Congo bestimmte Dampfer in der Elbe Schaden erlitten habe und daher durch einen anderen ersetzt werden solle, beschlols ich, mit dem anch schon erwarteten englischen Dampfer "Roquelle" zu fahren. Auch dieser hatte Verspätung und lief erst am 9. Mai im Kamerun-Flusse ein. Da mir der Kapitän versicherte, dafs er nicht vor dem 12. Mai wieder abfahren könne, benutzte ich die Gelegenheit, mich in Kamerun näher umzusehen.

Kamerun, die Hauptstadt des gleichnamigen Schutzgebietes, liegt an dem durch Zusammenfluis des Mungo und des Wuri gebildeten breiten Kamerun-Flusse. Die Stadt der Europäer zieht sich längs der Ufer des Flusses hin; die Gourernementsgebäude bedecken einen Teil eines hinter und über der Europäerstadt gelegenen Hügelrückens, der unter dem Namen Yoss-Platte bekannt ist. Dieser Hügelrücken fällt nach dem Wuri zu allmählich ab. Auf ihm haben sich auch die Eingeborenen festgesetzt, welche hier die grofsen Dörfer Belltown, Deidotown etc. angelegt haben. Der Gesundheitszustand der Europäer scheint gerade hier ein bedeutend schlechterer zu seiu, als in den meisten anderen Niederlassungen unseres Schutzgebietes. Gerade in den letzten Jahren sind daselbst viele der 
dortigen Ansiedler dem mörderischen Klima erleg'en. Der Handel mit den Eingeborenen im Hinterlande wird anch jetzt noch meist durch Zwischenhändler aus dem Dualla-Stamme veruittelt. Da ein nicht unbedeutender Handel auf den Flufsläufen ans dem Hinterlande herunter kommt, so ist es nicht zu verwundern, dafs sich gerade hier so viele Kaufleute Faktoreien erworben haben. Ein solches Zusammentreffen vieler europäischer Kaufleute, von denen wohl die eine Hälfte Deutsche, die andere englische Unterthanen sind, hatte natürlich zur Folge, dafs die einzelnen Firmen höhere Preise für die Produkte, welche aus dem Innern kamen, zu zahlen hatten, als dies bei geringerer Konkurrenz der Fall gewesen wäre. Da diese Verhältnisse immer schlimmer wurden und die Kaufleute endlich einen inmer geringeren Verdienst ron ihren Waren erzielen konnten, so ist es nicht zu verwundern, dals die Entwickelung des Handels in Kamerun in den letzten Jahren nicht mit den anderen Niederlassungen in unserem Schutzgebiete Schritt halten konnte.

Noch am Abend des 11. Mai siedelte ich mit meinem ganzen Gepäck zur "Roquelle" über. Da die für die Fahrt nach dem Congo bestimmten Dampfer noch mehr Frachtdampfer, im eigentlicben Sinne des Wortes, sind als die, welche den allmonatlichen Postverkehr nach Kamerun von Hamburg vermitteln, so war es natürlich mit dem Komfort an Bord der "Roquelle" nicht weit her. Dessenungeachtet mufs ich sagen, dafs ich mich dennoch bald hier heimisch fühlte, trotz der Petroleumlämpchen, durch welche die Kabinen des Abends erleuchtet wurden. Der Kapitän und die Offiziere thaten hier entschieden ihr Möglichstes, um den Passagieren die Reise angenehm zu machen.

Gegen 8 Uhr morgens verliefs die "Roquelle“ am 12. Mai Kamerun. Es war ein prachtvoller Tag. Auf dem sonst meist sehr heifsen Kamerun-Flufs wehte eine angenehm kühlende Brise. Als sich dieselbe gegen Mittag legte, wurde es sogleich bedeutend heilser. Ich empfand die Hitze nicht besonders, fuhren wir doch ziemlich nahe an der Küste entlang, so dafs man die Niederlassungen der Europäer, wie Longji, Plantation und Kribi deutlich erkennen konnte und mein Interesse so stets rege gehalten wurde. Die bei Malimba ziemlich niedrige Küste wird nach dem Süden unseres Schutzgebietes hier allmählich hügeliger. Das ganze Land, soweit das Auge es erblicken kann, ist mit dichtem Urwalde bedeckt. Um $4^{1 / 2}$ Uhr kam Grofs-Batanga, unser nächster Bestimmungsplatz, in Sicht. Um 5 Uhr liefsen wir die Anker fallen. Da ich geschäftlich hier in der Woermannschen Faktorei zu thun hatte, benutzte ich die erste Gelegenheit, welche sich mir bot, an Land zu gehen. Unser Schiff lag in bedeutender Entfernung 
rom Lande, so dafs wir erst um 6 Uhr daselbst eintrafen, als eben die Dunkelheit anbrach. Da wir nur wenig Cargo für GrofsBatanga an Bord hatten, konnte ich mich nicht lange hier aufhalten, sondern mufste sogleich nach Erledigung meiner Geschäfte wieder an Bord zurück. Noch an demselben Abend fuhren wir weiter. Als ich am Morgen des nächsten Tages an Deck erschien, kam eben Batta in Sicht. Gegen 9 Uhr warfen wir daselbst Anker. Auch hier hielten wir uns nicht lange auf. Die Vertreter der wenigen Firmen, welche hier eine Faktorei besitzen, schickten zum Teil grofse Canoes zum Dampfer, um das Ausladen der Fracht zu beschleunigen. So konnten wir denn bereits um $11 \mathrm{Uhr}$ die Anker lichten. Die Küste ist hier der Südküste Kameruns sehr ähnlich. Die Stämme der Eingeborenen im Innern sollen den Europäern sehr feindlich gesinnt sein, so dafs bisher nur wenige Europäer ins lunere vordringen konnten. Der Kautschuk, welcher aus dem Jnnern an die Küste kommt, wird durch $\mathrm{Z}$ wischenhändler heruntergebracht. Die Letzteren sind hier vorzugsweise Gabnnesen. Unser Kurs lief nun weiter ron der Küste $a b$, wir steuerten direkt auf die Insel Corisko zu. Nachdem wir dieselbe am Nachmittage um 4 Uhr passiert hatten, kamen wir bald in Sicht der beiden Elobi-Inseln. Da das Fahrwasser nach Aussage unseres Kapitäns hier nicht besonders günstig ist und wir während der Nacht hier in spanischen Gebieten keine Fracht landen durften, zog der Kapitän es ror, über Nacht das Schiff vor Anker zu legen, um am frühen Morgen auf die Elobi-Inseln zuzusteuern.

Die Inseln Corisko sowie Grofs- und Klein-Elobi stehen unter spanischem Schutze. Die Küste von Batta bis zum Muni-Flusse, welcher sich in die Corisko-Bai ergielst, wird den Spaniern jetzt von den Franzosen streitig gemacht. Die letzteren haben aller Orten daselbst jetzt bereits die Polizeigewalt in Händen. Wenn dieses Gebiet dereinst im Innern mehr zugänglich sein wird, dann wird hier ein enormer Handelsaufschwung stattfinden, wenn nicht diese ganzen Küstengebiete auch noch von den Franzosen in Konzessionen zerteilt werden, wie es jetzt bereits im grölseren Teile des Congo français der Fall ist. Das Land ist sehr reich an Gummi. Es soll auch Kickxia etwa zwei Tagereisen entfernt von der Küste vorkommen. Bis jetzt liegen allerdings dafür noch nicht genügend Beweise vor.

Nachdem wir am folgenden Tage (14. Mai) mit dem Löschen unserer Ladung für Elobi fertig waren, stachen wir um 12 Uhr mittags wieder in See. Da sich kein Lüftchen regte, wurde die Hitze bald fast unerträglich. Gegen Abend war in der Ferne Gabun zu sehen; der Dunkelheit wegen fuhren wir nicht in die Bucht 
hinein, sondern warfen wieder Anker auf der offenen See. Bei Tagesanbruch fuhren wir nun am 15. Mai nach Gabun hinein und legten uns dicht bei der Stadt vor Auker. Da ich schon häufig Lobenswertes ïber den botanischen Garten dieses Ortes gehört hatte, machte ich mich sofort auf den Weg dorthin. Leider war der Kurator, Mons. Chalot, abwesend, auch sonst nur farbige Arbeiter anzutreffen, so dafs ich mich so gut es elsen ging, allein zurechtfinden mufste. Die in dem Garten vorhandenen Kautschukpflanzen interessierten mich natürlich am meisten. Es waren hier rorhanden Manihot Glaziovii, Ficus elastica, Herea spec., einige Landolphien und gegen 20 Exemplare der falschen Kickxia (africana Bth.). Die letzteren erklärten natürlich auch die früheren Behauptungen des Mons. Clalot, welche dahin gingen, dafs Kickxia keinen Kautschuk gebe. Ich lernte im Laufe des Tages hier noch einige Herren kennen, von denen mir fast ein jeder von einem nenen Kautschukbaume erzählen konnte, den er in der Nähe der Stadt entdeckt haben wollte. Guttapercha gab es nach Aussagen dieser Herren in Unmengen, doch wollte niemand sein Geheimnis verraten. Natïrlich sind dies alles Illusionen von Leuten, welche diese Produkte und die Zubereitung derselben nicht kennen. Wurde mir doch hier eine ganz gewöhnliche Ficusart, die vollständig wertlos ist, als äufserst kostbarer Guttaperchabaum gezeigt mit der Bitte, doch keinen Gebrauch von diesem Geheimnis zu machen. Der Kautschuk, welcher von hier aus verschifft wird, kommt bereits aus ziemlicher Entfernung aus dem Inneru oder durch den ComoFlufs, welcher in die Gabun-Bucht mündet, hinunter. Palmenkerne und Öl sowie Mahagoniholz sind die Hauptexportartikel des Ortes. Erstere werden in nicht zn grofser Entfernung von der Küste gewonnen, wie es ja bei so billigen Produkten kaum anders möglich ist, da die Transportkosten zu hoch sein wïrden. Das Mahagoniholz ist nur da abbaufähig, wo es in nächster Nähe des Meeres oder der Flüsse geschlagen werden kann; es wäre vollständig unmöglich, die riesigen Blöcke über grofse Entfernungen zu transportieren, während kleingeschnittene Stämme wertlos sind. Da das Mahagoniholz vorzüglich schwimmt, werden die Stämme zu Flöfsen rerkettet und in dieser Weise die Flüsse hinuntergeschwemmt und später durch Barkassen zu den Frachtdampfern hinübergeführt.

Im botanischen Garten sah ich aufser einigen allgemeiner verbreiteten Nutzpflanzen auch eine recht gut gedeihende Strophanthuskultur. Es waren verschiedene Arten vorhanden, die alle zur Zeit meiner Anwesenheit reichlich blühten und Früchte brachten. Ebenso waren einige mir damals noch unbekannte Coffea-Arten sehr reich mit Früchten besetzt. Da ich keinen Europäer im Garten finden 
konnte, war es damals nicht möglich, Samen dieser Coffea-Arten für den botanischen Garten in Kamerun zu bekommen. Ich mufste es daher auf spätere Zeiten rerschieben.

Unserm deutschen Konsul Herrn Gebauer konnte ich damals leider nur einen kurzen Besuch abstatten, da ich schor um 3 Uhr zum Dampfer zurück mufste.

Trotz der Eile, welche unser Kapitän anfangs hatte, konnten wir doch nicht Gabun vor 5 Uhr am Nachmittage verlassen. Noch bis in die Nacht hinein sahen wir auf der Weiterfahrt das herrliche Licht des Leuchtturmes von Gabun. Mit Tagesanbruch erreichten wir wieder einen neuen Landungsplatz, Cape-Lopez, eine kleine Niederlassung in der Nähe der Ogowe-Mündung, des Hauptstromes, welcher in dieser Gegend aus dem Innern kommt. Unter Jagdliebhabern ist Cape-Lopez berühmt wegen seiner Büffel- und Elefantenherden, welche zuweilen bis. in die Nähe der Häuser herankommen sollen. Mich als Botaniker interessierte die dortige Flora bedeutend mehr. Ich zog es daher vor, ohne Gewehr umberzustreifen und in den interessanten, kurzgrasigen Sümpfen und Sumpfwäldern hinter der Niederlassung nach Seltenheiten zu fahnden. Es mag sicher noch viele Novitäten hier zu entdecken geben. Ich konnte mich leider nur zu kurze Zeit aufhalten, um viel zu sammeln, aufserdem war die Jahreszeit ungünstig. Wenn ein Botaniker sich einige Wochen hier aufhalten könnte, so würde er sicher eine reiche Ausbeute zu erwarten haben. Ebenso dürfte ein Ichthyologe mit einem mehrwöchentlichen Aufenthalte zufrieden sein, denn das Meer wimmelt hier von den verschiedensten Fischen.

Während der nächsten beiden Tage legten wir an zwei Küstenplätzen an, wo wir uns auch wieder nur kurze Zeit aufhielten. Am 17. Mai in Sette-Kama, am 18. in Majumba, zwei Niederlassungen, welche wegen ihrer schlechten Brandungsverhältnisse berïchtigt sind. Auch wir hatten darunter zu leiden, da das Löschen der Ladung durch die hohe Brandung verlangsamt wurde. Salz wird bei solchen Gelegenheiten stets stark beschädigt, was um so bedauerlicher ist, als neben Gewehren und Pulver Salz in diesen Gegenden einer der Haupthandelsartikel ist.

Am 19. Mai warfen wir am Morgen vor Loango Anker. Dieses Städtchen ist der südlichste bedeutendere Ort an der Küiste des Congo français; es ist auf einem sandigen Hügel erbaut und dürfte damals etwa 50 europäische Einwohner gehabt haben. Unsere Boote grebrauchten beim Landen des Cargo eine volle Stunde, ehe sie vom Dampfer aus bis zur Stadt gelangen konnten. Vor der Einfahrt hat sich nämlich direkt vor der Stadt eine breite Sanddüne gebildet, um deren spitze man erst herumfahren uuls, ehe man ïber die 
Lagune zum Landungsplatze gelangen kann. Die aufsteigenden Strafsen der Stadt sind sehr sandig, so dafs ein Europäer mit seiner Fufsbekleidung sehr schnell ermüdet.

Da eben die Brutzeit der grauen Papageien vorüber war, wurden uns allenthalben junge Tiere zum Preise von 5 Franes angeboten. Diese Papageien von der Loango-Küste sollen sich besser in Europa halten als die der nördlicheren Gegenden, aufserdem wird behauptet, dafs sie schneller sprechen lernen; genug, sie sind in Europa die begehrtesten. Mit diesen Umständen rechnend, hatten sich einige der Offiziere unseres Schiffes vorgenommen, hier eine grölsere Anzahl der Vögel zu kaufen. Schon während der letzten Tage hatten die Zimmerleute auf dem Dampfer ihre ganze freie Zeit dazu benutzt, hölzerne Käfige zu bauen, damit in Loango alle Vögel untergebracht werden könnten. Da die Eingeborenen bald sahen, dals Papageienkäufer an Land gekommen waren, entstand in kurzer Zeit ein regelrechter Markt mit den Vögeln. Ein bestimmter Preis (5 Frcs.) wurde festgesetzt; wer seine Tögel dafür abgeben wollte, war willkommen. In walzenförmigen, aus Blättern der Ölpalmen geflochtenen Behältern von verschiedener Gröfse brachten die Eingeborenen ihre Papageien an. Einige hatten 20 bis 30 Stück. Als alles Geld der Käufer verbraucht war, wurden die ganzen Behälter in ein Boot gesetzt, und zurück ging es, dem Dampfer zu. Dort wurden die Tiere in die gröfseren und bequemeren Käfige untergebracht. Trotz aller Sorgfalt, mit welcher die Tiere an Bord der Schiffe behandelt werden, stirbt doch immer noch eine grofse Zahl derselben, so dafs eine solche Geldanlage seitens der Matrosen, Stewards etc., welche doch nichts dabei verlieren, sondern nur gewinnen wollen, immerhin mit einem gewissen Risiko verknüpft ist.

In Loango war sonst nichts von Bedeutung zu sehen. Es gab wenige Gärten hier, da in dem mageren, sandigen Boden nichts Besseres zu gedeihen scheint. Finige Manihot Glaziovii-Stämmchen waren von der Regierung längs der Strafsen ausgepflanzt und schienen sich wohl zu fühlen. Vielleicht würde man hier in dem sterilen Boden bei dem geringeren Feuchtigkeitsgehalte der Atmosphäre mit diesem Kautschukbaume bessere Resultate erzielen als in den feuchten nördlicheren Gebieten. Erwähnen will ich noch, dafs von Loango die grofse Karawanenstrafse nach Brazzaville am Stanley-Pool ausging. Dieselbe wurde früher von sämtlichen französischen Expeditionen, welche ins Innere gingen, benutzt, wird aber jetzt, nachdem der Congostaat seine Eisenbahn ron Matadi bis Leopoldville fertiggestellt hat, allmählich aufgegeben.

Am Morgen des 20. Mai trafen wir vor Landana ein. Unsere Fracht wurde hauptsächlich nach dem fünf Jinuten von Landana 
entfernten Chiloango gelandet. Die Brandung kanu anch hier gefährlich werden. Zusammen mit dem Vertreter des Schiffes besuchte ich die katholische Mission in Landana, wo ich einen recht schönen Garten vorfand. Es waren die meisten tropischen Obstarten in mehr oder minder guten Qualitäten vorhanden, ebenso Gemüse aller Art. Leider wimmelte der Platz ron Moskitos. Die Residenz des portugiesischen Untergouverneurs, welcher dem Gouverneur rom Angola untergeordnet ist, steht auf einem luftigen Hügel und ist weithin sichtbar. Gesundheitlich schienen sich die Europäer hier nicht zu beklagen.

Als wir um $4^{1 / 2}$ Uhr am Nachmittage weiter fuhren, hatten wir einen der Patres der Mission als Passagier für Kabinda mitgenommen. Ich rerwickelte mich bald in ein Gespräch mit ihm, da wir beide die einzigen Passagiere waren. Als natürlich auch das Gespräch auf Kautschuk kam, erzählte er mir von Kautschukbäumen, welche in der Mission von Kabinda kultiviert werden sollen. Natürlich war ich nur zu gern hereit, als er mich am nächsten Morgen, als wir um $5 \mathrm{Uhr}$ vor Kabinda ankamen, aufforderte, mir die Kautschukbäume in der Mission anzusehen. Nach seinen Erzählungen ging ich mit grofsen Erwartungen hin, doch was fand ich -- eine Ficusart, welche anch nur eine vogelleim-ähnliche Masse lieferte.

Die katholische Mission war etwa eine halbe Stunde von der Stadt entfernt, so dafs ich mich noch beeilen mufste, um rechtzeitig zur Abfahrt des Dampfers an Bord zu kommen.

Wenige Stunden Fahrt nach Süden brachten uns nun zur CongoMündung. Gegen 3 Uhr konnte man bereits die Spitze der Halbinsel, auf der Banana erbaut ist, sehen. Es waren Gefühle eigener Art, mit denen ich in den Congo hineinfuhr, sollte ich doch nun für lange Zeit vom Meere Abschied nehmen, vielleicht um es nie wieder zu sehen. Der schlechte Ruf, den das Klima des unteren Congo an der ganzen Westküste Afrikas hat, trug nicht gerade zu meiner Beruhigung bei. Bald aber waren alle trüben Gedanken verschwunden, als wir vor Banana Anker warfen. Zum ersten Male sah ich Lente vom oberen Congo hier, die mit ihrer zerschnittenen Stirn und der eigenartigen Haartracht einen höchst interessanten Anblick darboten. Von allen Seiten kamen Eingeborene in ihren kleinen Canoes herangefahren, um bemalte und geschnitzte Flaschenkürbisse, Muscheln und sonstige Kuriositäten feilzubieten.

Banana selbst besteht vornehmlich aus den Gebäuden der Handels. niederlassung der Nieuwe Afrikansche Handels-Vernootschap und einigen Gebäuden der Congostaat-Regierung. Ws sind aufserdem noch einige wenige kleinere Faktoreien errichtet worden, 
dieselben spielen aber alle eine ziemlich unbedeutende Rolle. Die Niederlassung ist auf einer sandigen, schmalen Landzunge aufgebant, welche stellenweise an der dem Binnenlande zugekehrten Seite mit Mangroven-Morästen bedeckt ist. Bei weitem gesunder scheint die dem Meere zugekehrte Seite zu sein, denn erstens besitzt dieselbe keine Mangroven, zweitens aber halten sich die Moskitos infolge der Seebrise von dieser Seite ziemlich fern, während sie auf der anderen Seite in Milliarden des Abends umherschwärmen. An der äufsersten Spitze der Halbinsel ist ein kleiner Leuchtturm erbaut worden, dessen Licht weithin sichtbar sein soll. Da wir erst mit Eintritt der Dunkelheit vor Banana eingelaufen waren, konnte ich leider nicht an Land gehen. Ebenso war am nächsten Morgen kaum Zeit dazu, da sich der Kapitän plötzlich entschlofs, weiterzufahren. Wir hätten vielleicht schon am selbigen Abend Banana verlassen, wenn die Congo-Regierung nicht das Fahren der Dampfer nach Eintritt der Dunkelheit verboten hätte.

Gegen 9 Uhr am Morgen des 22. Mai fuhren wir durch einige der Mündungsarme in den Hauptstrom hinein. Bei Kisanga waren wir dem portugiesischen (südlichen) Ufer des Stromes ziemlich nahe. Je mehr wir uns nun gegen Nachmittag Boma, der Hauptstadt des Congostaates, näherten, desto enger wurde der Strom und desto gelber die Färbung des Wassers. Endlich um 41/2 Uhr erreichten wir Boma. Hier wurde der Dampfer ganz dicht an das Ufer herangezogen, da die äufser'st günstigen Tiefenverhältnisse des Stromes dies gestatten. Es fing bereits an zu dunkeln, als wir das Land betreten konnten. Ich erledigte daher nur einige geschäftliche Gänge und verschob alles andere auf den folgenden Tag, da der Kapitän mir sagte, dafs er den nächsten Vormittag sicher hier verbleiben müsse, um den Cargo für Boma löschen zu können. Vor der Stadt lagen noch zwei kleine Regierungsdampfer, welche den Postverkehr zwischen Boma und Matadi wie Banana zu vermitteln haben.

Am Vormittage des nächsten Tages machte ich bei dem Gouverneur des Congostaates Herrn V anghermé Besuch. Dank des Einführungsschreibens des Herrn Gouverneurs v. Puttkamer wurde ich sehr liebenswürdig empfangen. In jeder Weise wurde mir gezeigt, dafs meine Expedition ins Innere von der Regierung unterstützt werden würde. Die Einfulur meiner Gewehre wurde mir sofort erlaubt, ebenso sollten meine ganzen Expeditionsgüter ohne Schwierigkeiten gelandet werden dürfen. Da ich das Landen derselben aber erst in Matadi vorzunehmen gedachte, versprach mir der Herr Gouverneur Vanghermé, eine diesbezïgliche Bestimmung zugleich mit Empfehlungsschreiben für die Beamten im Innern nach Matadi nachzuschicken. Hätte ich nicht von seiten der Congostaat-Regierung 
dieses liebenswürdige Entgegenkommen gefunden, so wäre es zum mindesten sehr fraglich gewesen, ob ich die Congo-Reise erfolgreich hätte durchführen können. Eine ebenso liebenswürdige Aufnahme wie bei dem Herrn Gourerneur fand ich anch bei dem Staatssekretär Herru van Damm, der in zurorkommendster Weise die Regelung meiner Papiere etc. reraulafste.

Wie unser Kapitän vorausgesagt hatte, fuhren wir wirklich recht pünktlich um $12 \mathrm{Uhr}$ mittags ab. Je mehr wir uns jetzt der auf dem portugiesischen Congo-Ufer gelegenen Ansiedlung Noki näherten, desto stärker wurde die Strömung. Die Ufer des Stromes werden bereits dicht hinter Boma höher und bilden schliefslich ziemlich hohe, felsige Hügel, welche oft jäh am Flusse abfallen. Die felsige Natur dieser Hügel bedingt es natürlich, dafs der Strom hier bedeutend eingeengt ist, so dafs sein Wasser in dem häufig gekrümmten Flufsbette schmeller dahinschiefst. An besonders scharfen Biegungen im Flufslaufe bilden sich dann leicht Strudel, welche für die Schiffahrt nicht ganz ungefährlich sind. Derartige Strudel sind z. B. bei Noki anzutreffen.

Noki, welches wir um $5^{1 / 2}$ Uhr gegen Abend erreichten, ist eine kleine, schön gelegene Niederlassung kurz vor Matadi. Die dort ansässigen Kaufleute sind fast alle Portugiesen. Da von hier auch eine nicht unbedeutende Handelsstrafse ins Innere der portugiesischen Besitzungen geht, so ist es nicht zu verwundern, dals die Einfubr von europäischen Stoffen und sonstigen Tauschartikeln für die Eingeborenen eine ziemlich grofse ist. So kam es auch, dafs wir $1^{1} / 2$ Tag hier liegen mufsten, um unseren Cargo zu löschen. Aus dem Innern wird hier Kautschuk gegen Ende des Jahres in ziemlichen Mengen heruntergebracht, besonders Wurzelkautschuk. Letzterer wird nach Angaben der Kaufleute hinter der ehemals sehr bedeutenden, jetzt allmählich verfallenden Stadt San-Salvador gewonnen. Unseren Aufenthalt in Noki benutzte ich zu einer kleinen Streiferei über die Hügel. Letztere sind sehr steinig und mit üppiger Grasvegetation bedeckt. An geschützteren Orten in den Thälern hat sich etwas Wald hier und dort angesiedelt, in dem Landolphien nicht selten anzutreffen sind. Die Vegetation dieser Hügel, welche alle wohl noch als Ausläufer der aus Angola kommenden Sierra do Cristal zu betrachten sind, erinnert lebhaft an die Vegetation Benguellas und Angolas. Die Savannen sind mit hohen AndropogonArten bedeckt, welche die Eingeborenen zum Decken ihrer Häuser verwenden; dazwischen finden sich niedere Kräuter und Halbsträucher aus den Familien der Leguminosen, Compositen, Polygalaceen, Gentianaceen, Melastomaceen etc. In den Sümpfen sind kleine Scrophulariaceen, Labiaten und prachtvolle Lissochilus -Arten verbreitet. 
Am 25. Mai morgens fuhren wir nach Matadi. Kurz hinter Noki hatten wir noch Stromschnellen zu passieren, welche schon verschiedene Schiffe zur Umkehr gezwungen haben sollen. Das Wasser schiefst hier zu einigen Jahreszeiten mit einer Geschwindigkeit von etwa 10 Knoten dahin. Allenthalben bilden sich kleine Strudel, welche für Boote entschieden gefährlich sein kömnen.

Da dicht hinter Noki die Grenze des portugiesischen Gebietes liegt, hatte die Congostaat-Regierung kurz hinter derselben die Telegraphenlinie, welche Boma mit Matadi verbindet, über den Strom führen lassen. $\mathrm{Zn}$ diesem $\mathrm{Z}$ wecke sind zwei riesige eiserne Gestelle aufgebaut worden, über welche der Drabt ïber den Strom gezogen ist.

Als wir in Matadi anlangten, fand ich auf der Post bereits die mir von Herrn Gouverneur Vanghermé versprochenen Briefe vor. Ich hatte nun keine Schwierigkeiten, meine Expeditionsgüter und Gewehre zu landen. Allenthalben kamen mir die Regierungsbeamten mit der gröfsten Liebenswürdigkeit entgegen. Da ich noch meine Angelegenheiten in Matadi zu ordnen hatte, beschlofs ich, erst an Montag, den 29. Mai, nach dem Stanley-Pool zu fahren. Ich quartierte mich nun jm französischen Hotel ein und konnte dann in Ruhe meine Vorbereitungen zur Abreise ins Innere treffen. Matadi (Felsenstadt) hatte zur Zeit meiner Ankunft daselbst nach Schätzungen dort ansässiger Europäer etwa 150 europäische Einwohner, von denen mindestens zwei Drittel geborene Belgier waren. Aufser den von ihren benachbarten Kolonien kommenden zahlreichen Portugiesen waren von anderen Nationen besonders Italiener zahlreich vorhanden, welche meist bei der Eisenbahn angestellt waren.

Wie ich beabsichtigt hatte, war ich mit meinen Vorbereitungen am Montag, den 29. Mai, vollständig fertig zur Abreise ins Innere.

Dreimal in der Woche schickt die Eisenbahnverwaltung durchgehende Züge nach dem Stanley-Pool, denen je ein Passagierwagen angehängt wird. Man darf sich diese Congo-Eisenbahn nicht etwa wie eine europäische vorstellen. Die Personenwagen bestehen ähnlich wie unsere Speisewagen aus einem einzigen Coupee, in dem etwa zehn Lehnstühle angebracht sind. Fenster sind nicht vorhanden, sondern der ganze Wagen ist offen; für die Tropen ja entschieden das Angenehmste. Um sich gegen Staub und Rauch der Lokomotive schützen zu können, sind leinene Vorhänge vorhanden, welche man nach Belieben herabziehen kann. Da unterwegs nur einmal, während des Nachtquartiers, Gelegenheit gegeben wird, zu essen, so mufs ein jeder sich bereits in Matadi mit dem nötigen Vorrate an Getränken und Nahrungsmitteln versorgen. Alle Passagiere erscheinen denn auch bei Abfabrt des Zuges mit einer Kiste voller Konserven. 
Der Preis für die zweitägige Fahrt bis Stanley-Pool beträgt 5u0 Fres., wofür ein jeder Passagier $100 \mathrm{~kg}$ Freigepäck mitzunehmen das Recht hat. Für das übrige Passagiergepäck mufs bis Leopoldrille ein Frachtsatz ron 1 Fre. pro Kilo bezahlt werden. Wenn man bedenkt, dal's die Entfernung von Matadi bis Leopoldville nur etwas über $400 \mathrm{~km}$ beträgt, so scheint dieser Frachtsatz ein immens hoher zu sein, dennoch wird er von den Leuten, welche die Verhältnisse des Landes vor Fertigstellung der Eisenbahn kannten, gern bezahlt, denn früher wurde durch die unsicheren Träger, welche sogar noch die Lasten bestahlen, der Transport einer Last von $30 \mathrm{~kg}$ bis Leopoldville auch auf 30 bis 40 Fres. angesetzt Die Eisenbahn befördert nun die ganzen Waren in zwei Tagen sicher zum StanleyPool, während man früher mindestens einen Monat für diese Reise rechuete. Auch für die Beförderung sämtlicher anderen Waren, welche ins Innere gebracht werden, mufs derselbe Frachtsatz bezahlt werden; eine Ausnahme hiervon machen nur Maschinenteile und einige damit rerwandte Artikel, sowie Salz, bei ersteren wird eine Reduktion von $40 \mathrm{pCt}$., bei letzterem von $50 \mathrm{pCt}$. erlaubt, vorausgesetzt, dafs es in geschlossenen Säcken (nicht in Barren) eingeführt wird. Die Frachtsätze von Leopoldville bis Matadi zurück sind andere. Ich werde späterhin darauf zurückkommen.

Am Montag, den 29. Mai, fuhr ich um $6 \frac{1}{2}$ Uhr morgens ron Matadi ab. Der Zug hatte anfangs eine sehr beschwerliche Fahrt, da er durch zwei Lokomotiven die Berge hinaufgezogen werden mufste, bis wir allmählich das Plateau erreichten Die Scenerie war grofsartig. Zuerst fuhren wir ein kleines Stückchen längs des Congo, zum Teil an steil abfallenden Gehängen rorüber. Immer höher ging es hinauf. Unten sah man den Strom dahinbransen über die Schnellen von Vivi, welche der Schiffahrt auf dem Flusse eine Grenze setzen. Auf einer Sandbank lag ein riesiges Krokodil, auf welches einer der Mitreisenden eben anlegen wollte, als es, durch den Zug erschreckt, sich träge ins Wasser fallen liefs. Ton der Station Kenge an vergrölserte sich die Fahrgeschwindigkeit luedeutend, da wir nunmehr über das Platean fuhren, auf welchem nur hin und wieder noch kleinere sanfte Steigungen vorbanden waren. Nach 10 Uhr wurle es in dem Wagen fast unerträglich, da wir allmählich vollständig mit Kohlenstaub bedeckt waren, aufserdem wurde es drückend heifs. Das Plateau, über welches wir dahinsausten, war meist mit hohen Andropogon- und stellenweise mit Pennisetum-Arten bedeckt. Dazwischen waren hier und dort kleine Sträucher und Gebüsche zu sehen, oder in den Thälern Sümpfe oder Wälder. Da gerade die Trockenzeit begann, als ich diese Reise machte, sah das ganze Gebiet ziemlich verbrannt und dürr 
aus. Von Blumen war recht wenig zu sehen. Nach etwa elfstündiger Fahrt, also gegen $5^{1 / 2} \mathrm{Uhr}$ abends, erreichten wir die Station Tumba, wo für die Nacht angehalten wurde, denn während der Nacht wird auf der Congo-Eisenbahn nicht gefahren. Die Passagiere hatten sich in den hier vorhandenen sogenannten Hotels ein Nachtquartier zu suchen, was damals durchaus nicht so einfach war. Die Einrichtung dieser "Hotels" ist äufserst primitiv. Gewöhnlich stehen mehrere Betten in jedem Schlafzimmer, so dafs man gezwungen ist, mit irgendwelchen wildfremden Menschen zu schlafen. Diebstähle sollen daher nicht selten sein. Das Essen, welches uns gegeben wurde, war nicht schlecht. Fs wurde an einer grofseu, langen Tafel eingenommen. Da der Grundsatz der meisten dieser freilebigen Belgier "Heute ist heut" ist, so kann man sich denken, dafs tüchtig getrunken wurde. Unteroffiziere salsen an demselben Tische mit Offizieren und schienen sich durchaus nicht dazu bewogen zu fühlen, sich ein wenig im Trinken und Lärmen zu mäfsigen. Die Schlimmsten waren entschieden die Italiener, welche offenbar auch zu Hause einer ziemlich niederen Kaste angehörten. Bis tief in die Nacht hinein dauerte das Lärmen dieser Leute. Man liefs sich allerdings nicht dadurch stören, sich nach der ermüdenden Eisenbahnfahrt bei der hier herrschenden kühleren Temperatur sogleich nach Beendigung der Mahlzeit in Morphens Arme zu werfen.

Um 7 Uhr am folgenden Tage setzte sich der Zug wieder in Bewegung. Wir fuhren weiter über das grasige Plateau dahin, welches sich allmählich nach dem Stanley-Pool hin etwas senkt. Die Vegetation blieb anfangs dieselbe wie am vorhergehenden Tage. Von Inkisi ab nach Kimuenza zu waren Waldungen wieder häufiger. Ton Kimuenza nach Dolo fuhren wir über eine sandige Ebene dahin. Hier hatte man eine Vegetation vor sich, welche entschieden an die der Hoogeveld-Steppen von Transvaal und von Huilla erinnert. Kurzes Gras bedeckte diese Ebene; dazwischen sah man Helichrysen, Buchnera-Arten, Indigoferen, Gentianeen, Asclepiadaceen etc. In den hier und dort sich hinziehenden Niederungen wuchsen hohe Cyperaceen im Gemisch mit Lissochilus-Arten, Melastomaceen, Hedyotis, Gladiolus, Eriocaulon und Utricularien. Kurzum, eine Vegetation, wie ich sie hier bei so geringer Meereshöhe in der Nähe des Äquators nie zu finden gedacht hätte. Schon bei der Fahrt über diese Ebene sah ich an sandigen Stellen eine Pflanze wachsen, in welcher ich Carpodinus lanceolatus erkannte, von der der Wurzelkautschuk, hier am Congo allgemein "Caoutchouc aux herbes" genannt, herstammen soll. Ich entschlofs mich daher, sobald als möglich hierher zurückzukehren, um diese Frage näher zu unter- 
suchen. Gegen $6^{1} / 2$ Uhr am Abend erreichten wir Kinchassa, das einige Kilometer vor Leopoldville am Stanley-Pool gelegen ist. Herr Dr. Briart, der Direktor der Societé Anonyme Bèlge, an den ich rom Herrn Gouverneur v. Puttkamer ein Empfehlungsschreiben erhalten hatte, nahm mich sehr liebenswürdig für einige Tage bei sich auf. Ihm sowohl wie besonders dem Sous-Directeur der Gesellschaft, Herrn Vaalbroek, bin ich zu grolsem Danke verpflichtet für das Interesse, welches sie meiner Reise entgegengebracht haben, und für die Unterstützung, welche ich bei ihnen gefunden babe.

Da ich möglichst wenig Zeit verlieren wollte, wachte ich mich am folgenden Tage sogleich auf den Weg nach Leopoldville, um mich dem Kommandanten von Leopoldville, Herrn Costermans, Inspecteur d'Etat, vorzustellen und ihn zu bitten, mir bei Anwerbnng ron Trägern behülflich zu sein. Ich fand mehr Unterstützung, als ich je zu erhalten zu hoffen gewagt hatte. Herr Costermans wollte selbst für die nötigen Träger sorgen. Ich solle nur ruhig nach Kinchassa zurückkehren, in zwei Tagen würden die Träger mit zwei Soldaten zu meiner Verfügung stehen. Froh darüber, dafs auch diese Trägerfrage erledigt sei, packte ich nun sogleich in Kinchassa die zu der kleinen Exkursion nach den sandigen Ebenen bei Dolo nötigen Lasten und wartete dann auf die Ankunft der 'Träger. In der Zwischenzeit hatte ich noch Gelegenheit, hier zu sehen, welche Unmengen von Kautschuk allein von dieser einen Gesellschaft exportiert werden. Herr Dr. Briart war so freundlich, mir die verschiedensten Proben zu zeigen und mich auf viele Einzelheiten aufmerksam zu machen. Tom oberen Congo und seinen Nebenflüssen kommt der Kautschuk in viereckigen Mattentaschen, welche etwa eine Last $(30 \mathrm{~kg})$ enthalten, hier an. Die Taschen werden dann hier aufgeschnitten und der sämtliche Kautschuk noch einmal durchgearbeitet. Dadurch wird er noch etwas mehr ausgetrocknet, was ein geringeres Oxydieren zur Folge hat. Der unter Leitung der Beamten des Staates hergestellte Kautschuk wird jetzt selten gefälscht, da die Missethäter sehr schwer bestraft werden, früher jedoch konnte man in den Bällen die verschiedensten Sachen finden. Herr Vaalbroek batte eine interessante Sammlung derartiger Fälschungen; Palnennüsse, Steine, kleine Messingstücke, ja selbst Zeugballen und Erde bildeten den Kern eines solchen Bällchens, um den dann selı geschickt eine Kautschukdecke gelegt war. Wehe dem Kaufmanu, der nicht erst durch Anschneiden der Bälle sich daron überzeugte, dafs er einen wirklichen Kautschukball und nicht Steine von den Eingeborenen erstand.

Da die mir versprochenen Träger bereits am Nachmittage des 1. Juni eingetroffen waren, so konnte ich, nachdem ich schnell eine 
Anzahl Lasten zu dem Zwecke gepackt hatte, am Freitag, den 2. Juni, bereits früh am Morgen meine Exkursion in die sandigen Steppen ron Dolo antreten. Welch ein erhebendes Gefülıl war es für mich, nun wieder frei hinauswandern zu können und mich ganz meiner Aufgabe und dem Studium jener Gebiete hingeben zu dürfen.

Nachdem wir die Eisenbahnstation Dolo passiert hatten, wo ich noch für einige 'Tage Proviant für mich von den "Magasins Genereaux ${ }^{66}$ mitnehmen liels, zogen wir erst nach den Ufern des Stanley-Pool hinüber. Nachdem wir einen kleinen Wasserlauf, welcher mit wundervollen blauen Seerosen (Nymphaea) und goldgelben Äschynomenen bedeckt war, in Canoes übergesetzt hatten, langten wir in sandigerem Terrain an und sahen uns bald darauf in der grofsen Ebene, in welcher ich Carpodinus lanceolatus, die Pflanze, welche den Wurzelkautschuk liefern soll, neulich beobachtet hatte. Nach einigen Kreuz- und Querzügen, welche ich zu unserer besseren Orientierung machen liefs, wählte ich schliefslich einen grofsen Strychnos-Baum in der Nähe eines Baches zu meinem Lagerplatze. Ich liefs sofort cämtliche Leute zum Reinigen des Platzes antreten, um wenigstens ein möglichst ungezieferfreies Lager für diese Tage zu haben. Dals diese Vorsichtsmafsregel nicht ganz umsonst war, zeigte sich sogleich, denn plötzlich raschelte es im Grase, und eine kleine Schlange suchte zu entfliehen. Ein Schlag mit dem Cutlas genügte, das Tier unschädlich zu machen. Nachdem die Leute einen gröfseren Platz gesäubert hatten, liefs ich das Zelt aufstellen. Das war nuu allerdings mit Schwierigkeiten verknüpft, da keiner der Leute ein Wörtchen Französisch verstand; die beiden Soldaten wulsten auch nicht Bescheid, und ich selbst kannte noch nicht mehr von dem hier als Verkehrssprache dienenden Bacongo als das eine Wörtlein „malu“ (schnell). Es war eine harte Geduldsprobe für wich, bis das Zelt fertig dastand. Nachdem ich nun die Lasten hatte unterbringen lassen und gesehen, dafs sonst alles richtig eingerichtet wurde, machte ich mich am Nachmittage daran, die Wurzelkautschukpflanze zu suchen. Bald hatte ich eine Stelle gefunden, an der ich das Gewünschte in Menge sah. Ich liefs eine grölsere Menge der Wurzelstöcke dem Boden entmehmen, um damit zu experimentieren. Wieder im Lager angelangt, fing ich etwas Milch der Wurzel in einem Reagenzglase auf, um es durch Erwärmen und Säurezusatz zu koagulieren. Das Resultat war ein sehr unbefriedigendes, denn ich erhielt nur eine klebrige, fast gar nicht elastische Masse. Diese Wurzelstöcke enthielten aufserdem so wenig Milchsaft, dal's das Auffangen sehr geringer Quantitäten schon an und für sich lange Zeit erforderte. Auch mit dem im Stengel und in den Blättern vorhandenen Milchsafte machte ich ähnlicheVersuche, deren Resultate mich ebenso wenig zufriedenstellen konnten. 


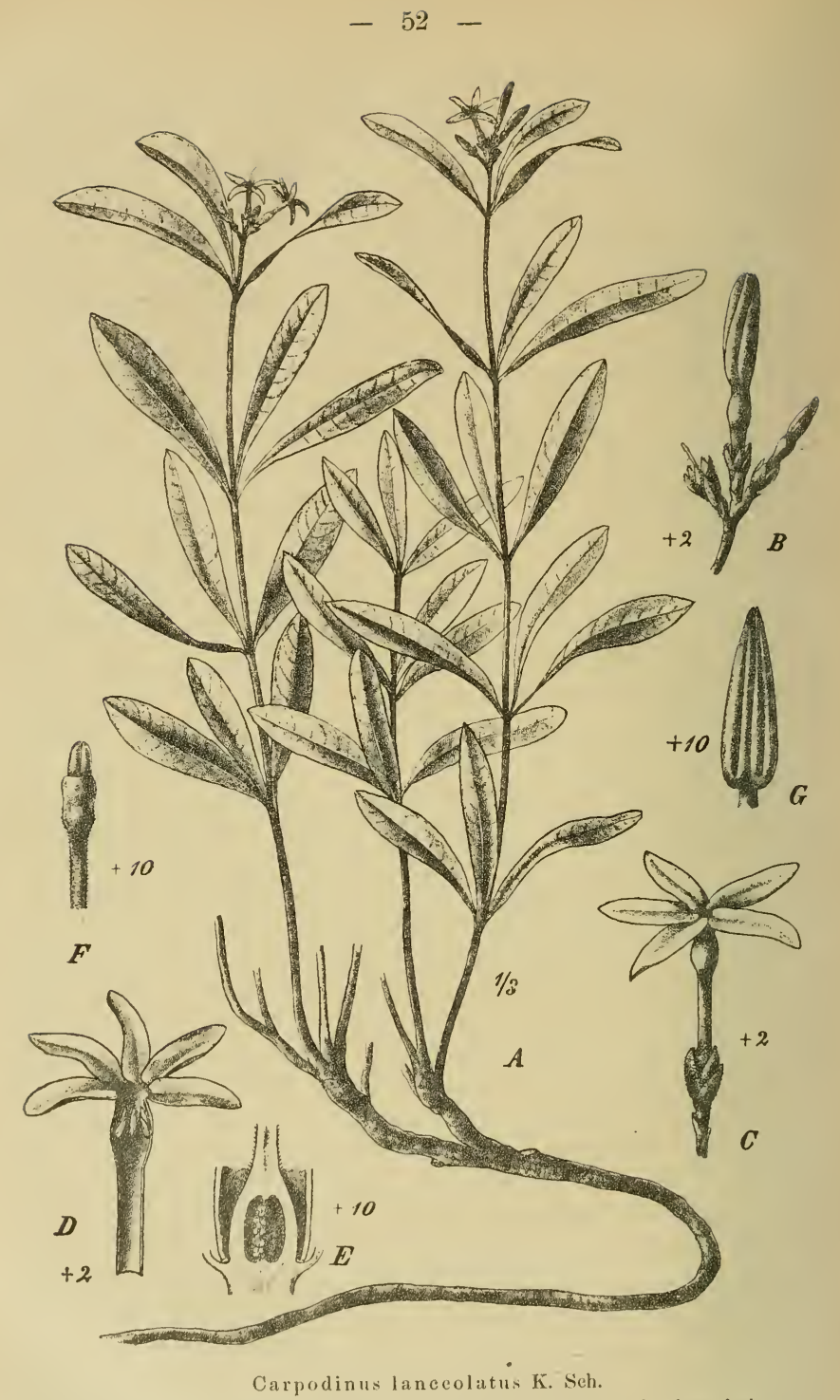

A Habitusbild, B Kusspen, C Blüte, D dieselbe geöffnet, E durelıgesclınittener Fruchtknoten, F Griffelkopf, G Anthere. 
Nach einer infolge der hier in Milliarden umherschwärmenden Moskitos sehlaflos verbrachten Nacht nahm ich am nächsten Tage meine Versuche wieder von neuem auf. Immer wieder liefs ich neues Material heranschaffen, um nun die verschiedensten Koagulationsmethoden zu probieren, alle mir zur Verfügung stehenden Säuren wendete ich an. Sämtliche Bemühungen blieben erfolglos. Von einem meiner Träger, welcher den Wurzelkautschuk zuzubereiten verstehen sollte, liefs ich nun nach der hier üblichen Methode die Wurzelstöcke zerschneiden und in Wasser setzen, um nach Eintritt der Fäulnis durch Schlagen den Kautschuk zu gewinnen. Das bei dieser Behandlung erzielte Produkt war zwar infolge seiner Vermischung mit Rindenstückchen und anderen Pflanzenteilchen fast gar nicht klebrig, war aber dennoch so minderwertig, dafs ich es für ausgeschlossen halten mulste, von dieser Lokalität aus Carpodinus lanceolatus Kautschuk zu erhalten. An Ort und Stelle liefs sich natürlich Weiteres über die Ursache dazu nicht feststellen. Nicht unwahrscheinlich ist es, dafs es auch hier zwei verschiedene einander ähnliche CarpodinusArten giebt, von denen nur eine brauchbaren Kautschuk liefert; nicht ausgeschlossen ist natürlich auch, dafs die chemische Zusammensetzung des Bodens eine nicht unbedeutende Rolle dabei spielt, um so mehr, als eine solche Einwirkung auf die Güte des Produktes bereits wiederholt bei Ficus elastica und bei Manibot Glaziovii festgestellt ist. Ich möchte das Studium dieser ebenso wichtigen wie interessanten Fragen den am Congo in den WurzelkautschukDistrikten ansässigen Europäern sehr warm ans Herz legen. Ich selbst wurde leider durch die Macht der Verhältnisse gezwungen, ron der Lösung dieser Frage abzustehen, denn für mich war die Zeit zu einer Expedition in die den Wurzelkautschuk liefernden Distrikte am Kwango zu kuapp bemessen. Wie ich auf meine eifrigen Erkundigungen bin kurz darauf in Kinchassa erfuhr, hatte man schon einmal versucht, in der Umgebung von Leopoldville aus der Carpodinus lanceolatus Kautschuk zu gewinnen, hatte aber ein ebenso ungünstiges Resultat erhalten wie ich selbst und infolgedessen bald darauf wieder davon Abstand genommen.

Am 5. Juni zog ich wieder aus jenen Gegenden fort, um dann nach kurzem Aufenthalte in Kinchassa noch am Nachmittage desselben Tages bis Leopoldville weiterzumarschieren. Da wir erst mit Anbruch der Dunkelheit in Leopoldville anlangten, liefs ich mein Lager in der Nähe der Eisenbahnstation aufschlagen in der Absicht, am folgenden Tage einen geeigneteren Lagerplatz zu suchen, um daselbst, bis zur Abfahrt des Dampfers nach dem oberen Congo, zu bleiben. 
Am nächsten Tage machte ich mich auf den Weg, um dem Distriktsvorsteher, Herrn Costermans, meine Rückkehr nach Leopoldville anzuzeigen und ihn um Erlaubnis zu bitten, mein Lager in die Nähe des Stanley-Pool verlegen zu dürfen. Natürlich wurde mir letzteres sofort gestattet, ebenso wurde ich aufgefordert, zur Terproviantierung meiner Leute zweimal in der Woche Schiquangas, $d$. h. grofse aus zerstampftem und gekochtem Maniok hergestellte, in Blätter eingewickelte Kuchen, von der Station abholen zu lassen. In jeder Weise bemühte sich also Herr Costermans, mich während meines Aufenthaltes in seinem Bezirke zu unterstützen. Ich erfuhr hier auch, dafs die „Hainaut", der I)ampfer, mit welchem ich den Congo hinaufzufahren gedachte, etwa am 10. Juni erwartet werde. Am Nachnittage liefs ich an meinem alten Lagerplatze wieder alles einpacken und das Zelt abbrechen, um dann an den Ufern des Stanley-Pool, dicht bei der englischen Mission, mein Lager wieder aufzubauen. Mit eintretender Dunkelheit war alles glücklich unter Dach und Fach gebracht. Die nächsten Tage meines Aufenthaltes bei Leopoldville benutzte ich nun dazu, die Umgebung botanisch zu erforschen und die Bacongo-Sprache, ohne welche ich hier nicht auskommen konnte, wenigstens soweit zu erlernen, als zur allgemeinen Verständigung mit den Eingeborenen nötig war. Besonders zu Dank verpflichteten mich bei dieser Gelegenheit die beiden damals dort sich aufhaltenden Missionare Mr. Woollings und Mr. Gilchrist, welche mich in jeder Weise darin zu unterstützen suchten. Auf verschiedenen Exkursionen hatte ich Gelegenheit, die Flora der Umgebung näher kennen zu lernen, fand aber sehr wenige Pflanzen, welche in irgend einer Weise von den Eingeborenen verwendet werden, sei es als Medizin oder als Nahrungsmittel, oder um zur Gewinnung von Kautschuk oder Kopal von Nutzen zu sein. Eine Dissotis- (Melastomaceae-) Art schieu bei Augenkrankheiten eine grofse Rolle zu spielen; die wenig fleischigen Blätter wurden auf der Handfláche zerrieben und der so erhaltene Brei dann auf die Augen gestrichen. Nach Angaben der Leute soll der in diesem Brei enthaltene Saft sehr scharf sein und häufig für kurze Zeit das betreffende Auge erst fast unbrauchbar werden, danach aber sehr schnell heilen. Einige Monate später hatte ich Gelegenheit, einen Europäer zu sprechen, welcher selbst an seinen Augen zur Heilung einer Krankbeit diese Medizin angewendet hatte und nun behauptete, dieselbe sei vorzüglich in solchen Fällen zu gebrauchen. Unter den als Nahrungsmittel verwendeten Pflanzen war es besonders eine Podostemonacee, welche mir interessant war. Diese unter Wasser auf Steineu bei den Stromschnellen in Stanley-Pool wachsende Pflanze wurde von meinen Leuten in ganzen Lasten herbeigetragen 
und dann teils roh, teils weichgekocht wit grofsem Gefallen verzehrt. Es fiel nir ïberhaupt auf, dals die Eingeborenen eine nicht geringe Quantität von gewissermafsen als Kohl gekochten Kräuteru und jungen Trieben von Sträuchern zu ihrer Ernährung verwendeten. War Palınenöl zur Hand, so wurden die meisten Nahrungswittel erst darin eingetaucht, so z. B. afsen alle mit Vorliebe ihre Schiquanga in dieser Weise.

Kopalbäume scheinen nur selten bis zum Stanley-Pool hinunterzukommen. Auf den Sandbänken hier im Mittellaufe fiudet man nicht selten Kopalstücke, doch stammen diese hauptsächlich oder fast nur von den im Oberlaufe häufigen Bäumen her und sind alle vom Strom hinuntergeschwemmt worden. Jch sah unterhalb der Müudung des Kassai nur sehr wenige Kopalbäume, so stand ein Exemplar z. B. in der Nähe meines Lagers am Stanley-Pool.

Kautschukbäume traten in der Umgebung von Leopoldville nur vereinzelt auf, also nirgendwo in zahlreicherer Menge. Eine eigenartige Landolphia ist in dem Steppengebiet dieser Gegend verbreitet, dieselbe hat nur dünne, kurze Zweige und besitzt etwa apfelgrolse orangegelbe Früchte. Nicht selten sendet sie auch nur etwa $1^{1 / 2}$ Fufs lange aufrechte Schöfslinge aus dem Boden, welche sich daun allmählich umlegen, aber doch die Fähigkeit des Kletterns der anderen Landolphien verloren zu haben scheiven. Diese zur Terwandtschaft der L. owariensis gehörende Art liefert keinen Kautschuk.

Die frauzösische Seite des Congo, gegenüber Leopoldville, hatte ich auch wiederholt zu besuchen, da ich meine Güter zur späteren Durchreise nach dem Ngoko zu deklarieren hatte. Im allgemeinen herrschen auf jener Seite dieselben Zustände wie auf cler Seite des Congostates. Da die französische Regierung den Eingeborenen bis jetzt aber zu viel Selbstregierung überlassen hat und daher noch weniger Erwerbsbetrieb unter denselben sich geltend gemacht hat, so finden sich Landolphien daselbst noch häufiger. Jetzt, nachdem die französische Regierung aber begonnen, sich etwas mehr um diese Gebiete zu kümmern und das Land zum grofsen Teile in Kommissionen anfgeteilt ist, deren Inhaber sich häufig bemühen, in möglichst rücksichtsloser Weise alle vorhandenen Naturprodukte auszubeuten, so wird auch hier bald die Kautschukliane bedeutend seltener werden. Die Gefahr einer vollständigen Ausrottung ist allerdings wohl weniger zu fürchten, da diese Lianen ein ziemlich zähes Leben haben und leicht wieder aus den zurückgebliebenen unterirdischen Teilen neu aussprossen, aufserdem aber in jedem Jahre reichlich Samen ansetzen, aus welchen, wenn auch nur ein geringer Prozentsatz, wieder neue Pflänzchen erstehen. In 
der Umgebung ron Victoria, wo vor Jahren durch dort ansässige schwedische Händler am Kamerum-Gebirge Kautschuk-Raubhau im wahrsten Sinne des Wortes betrieben worden sein soll, fangen die dort in den Wäldern vorhandenen Liauen jetzt wieder an, Kantschuk zu liefern, so dafs die Eingeborenen daselbst bereits hin und wieder einigeu Kautschuk zu den Kaufleuten bringen.

In Brazzaville, dem Regierungssitze des Hinterlandes des Congo français, hatte man in den Stralsen Manihot Glaziovii als Alleebäume (häufig abwechselnd mit Mangobäumen) angepflanzt. Als ich die Pflänzchen sah, waren dieselben etwa sechs Monate alt und hatten sich bereits sehr schön entwickelt. Als Schattenbaum würde ich Manihot Glaziovii entschieden nicht empfehlen, da die alten Blätter gegen Ende der Trockenzeit häufig fast alle alsfallen, ehe sich neue entwickelt haben, die Stämue also einige Zeit hindurch vollständig blattlos dastehen. Brauchbareu Kautschuk lief'ert der Baunı in der Umgebung des Stanley-Pool entschieden, wie ich an einigen Exemplaren bei Leopoldville feststellen konnte. Allerdings ist der Ertrag kein reichlicher, daher dürften natürlich keine grol'sen Unkosten rorhanden sein, um den Al,bau des Kautschuks rentabel zu machen. Dies würde nur in sonst wertlosen Steppengebieten bei einer von Eingeborenen betriebenen Kultur möglich, welche dann für die Zukunft sich selbst überlassen werden müfste. Der Baum würde. sich dann durch Samen leicht weiter fortpflanzen, wie ich es in Kamerun und an Stanley-Pool gesehen. Von den bei Leopoldville verwilderten Manihotstämmen liefs ich einige tausend Samen sammeln, um sie eventuell später an geeigneten Stellen in unseren schutzgebieten auszusäen.

Da die „Hainant" erst mit bedeutender Verspätung in Leopoldville eintraf, aufserdem infolge eines an Bord ansgebrochenen Feners reparaturbedürftig geworden war, so verzögerte sich meine Abreise immer mehr. Endlich, am 20. Juni, erhielt ich von dem. Kommandanten von Leopoldville die Nachricht, dafs ich mich zum 22. Juni morgens zur Abreise mit der „Hainant" bereithalten könnte. Natürlich packte ich sogleich meine sämtlichen Lasten zusammen und liefs alles fertig machen zum sofortigen Abbruch des Lager's, in dem wir alle uns nummehr recht heimisch zu fühlen begonnen hatten. Am 21. Juni liefs ich meine sämtlichen Lasten mit Ausnahme der allernötigsten Sachen, welche ich auch bis zum nächsten INorgen gebrauchte, an Bord der "Hainant" schaffen, um den Rest am nächsten Morgen in aller Frühe nachfolgen zu lassen. Bei der Regierung erfuhr ich zu meiner nicht geringen Überraschung, dafs man mir für die Träger sowie die Ernährung derselben nichts abnehmen wollte, ich solle mich auf meiner Reise nach dem Innern, 
solange ich auf dem Gebiete des Staates sei, als Gast desselben betrachten, man halte dieses für selbstrerständlich. Ein gröfseres Entgegenkommen, als ich es hier im Congostaate gefunden, wäre wohl kaum möglich gewesen. Ich kann der Regierung desselben daher nicht genug Dank für die Aufnahme sagen, welche ich erhalten, ohne Unterstützung der Regierung wäre die Expedition, soweit sie sich im Gebiete des Congostaates bewegte, sicher erfolglos rerlaufen.

Am frühen Morgen des 22. Juni schaffte ich noch den letzten Rest meiner Lasten zum Dampfer hinüber, da dieser bereits um 7 Uhr abfahren sollte. Auch hier sah ich wieder das Entgegenkommen der Regierung, denn man hatte mir meinen Platz in der besten Kabine angewiesen.

Um $7^{1} / 2$ Uhr ertönte endlich das Signal zur Abfahrt, in einem grofsen Bogen ging es, die Sandbänke und Felsen zu vermeiden, der Mitte des Stromes zu. Der Dampfer war vollständig besetzt, teils von Angestellten des Congostaates, teils von jungen Kaufleuten, welche auf die verschiedenen Handelsstationeu ins Innere geschickt wurden. Da die „Hainaut“ zu den gröfsten Dampfern gehört, welche den Congo befahren, war die Anzahl der Passagiere für die Verhältnisse im Congo keine geringe. Nach den mir gemachten Mitteilungen ist der Dampfer im stande, 150 Tonnen zu tragen, für einen Flufsdampfer auf dem Congo ein enormes Gewicht. Er ist natürlich sehr breit und flach gebant, wie die meisten Heckraddampfer. Für die Passagiere sind die Kabinen auf dem oberen Deck eingerichtet. Die Eingeborenen liegen zusammengepfercht in Scharen auf dem unteren Deck herum. Da die "Hainaut" deren immer eine sehr bedeutende Menge mitführt (wir hatten etwa 250 Mann), so hat sie bei den Stämmen am Strome den Namen "Bangala mingi“ (viele Menschen) erhalten.

Nach kurzer Fahrt legten wir noch einmal in Kinchassa an, wo wir noch eine gröfsere Menge von Gütern für die Handelsstationen im Innern mitnehmen mufsten, denn die Regierung verbietet einigen gröfseren Gesellschaften, welche selbst Dampfer besitzen, auf dem eigentlichen Congo für ihren eigenen Gebrauch Waren zu transportieren. Diese Mafsregel ist gewissermalsen als Abgabe für die Dampfer zu betrachten, da die Regierung durch den Transport der Waren für diese Handelsgesellschaften ihre bei der Fahrt stromauf sonst häufig leeren Dampfer füllen kann. Die Gesellschaften haben für den Transport ihrer Waren der Regierung pro Tonne eine bestimmte Abgabe zu zahlen. Die auf den Handelsstationeu im Innern erworbenen Produkte schaffen sie dann auf den eigenen Dampfern nach dem Stanley-Pool hinunter. Von Kinchassa 
fuhren wir erst gegen 1 Uhr fort, so dafs wir noch während des ganzen Nachmittags zu fahren hatten, ele wir aus dem Stanley-Pool hinauskamen. Oberhalb des Stanley-Pool wird der Congo infolge der hügeligen Natur seiner Ufer sehr bedeutend eingeengt. Die Scenerie ändert sich hier plötzlich, die Hügel sind im Flufsthale mit dichtem Walde bedeckt, während die Ufer des StanleyPool zum grofsen Teile Savannenflora zeigten. Elefanten soll es hier in woch grofsen Mengen geben. Da der Mond heute sehr hell schien, fuhren wir bis gegen $81 / 2$ Uhr am Abend, obgleich dies sonst nicht üblich ist. Unserem Kapitän lag aber sehr viel daran, um Zeit zu ersparen, noch den ersten Holzposten zu erreichen. Daselbst angelangt, mufsten sämtliche Eingeborenen das Schiff verlassen, um am Lande zu schlafen, denn der Aufenthalt wird ihnen über Nacht auf dem Schiffe nicht gestattet Die Holzposten sind in gewissen Abständen längs des Congo vom Staate errichtet worden, um die vorbeifahrenden Dampfer der Regierung mit Holz zu versehen, denn alle diese sind natürlich auf Holzfeuerung eingerichtet, da der Kohlentransport zu teuer sein würde. Während der Nacht werden die Dampfer dann stets, soweit dies möglich ist, wieder mit Holz gefüllt. $\mathrm{Zu}$ diesem $\mathrm{Zwecke}$ führen alle diese Schiffe auf dem Strome eine Anzahl von Holzschlägern und Holzträgern bei sich, welche auch in den Gegenden, wo sich keine Holzposten befinden, für den Dampfer Holz schlagen müssen. Infolge der grofsen Zahl der jetzt bereits auf dem Congo fahrenden Dampfer fängt in häufiger besuchten Stellen diese Holzfrage bereits an, für die Dampfer der Gesellschaften etwas kritischer Natur zu werden. Diese Dampfer haben nicht das Recht, auf den vom Staate eingerichteten Posten Holz einzunehmen, sondern müssen durch ihre Holzhacker jede Nacht dasselbe mühsam zusammensuchen lassen. Das in den Wäldern vorhanden gewesene tote $\mathrm{Holz}$ ist natürlich dann bald abgetragen, so dafs es den Dampfern oft schwer wird, die nötigen Quantitäten ohne zu grofsen Zeitverlust zusammenzubringen. Das grüne, lebende Holz der Bäume ist mit Ausnahme desjenigen vom Kopalbaume frisch natürlich nicht für Heizungszwecke $\mathrm{zu}$ verwenden.

Am nächsteu Tage fuhren wir früh mit Tagesanbruch weiter. Die Vegetation war im grofsen und ganzen dieselbe wie am vorhergehenden Tage, d. h. im Thale des Stromes Galeriewald mit abwechselnden kleineren und grölseren Savannen, welche nicht selten mit Hunderten von Borassuspalmen geschnückt waren. Die Spitzen der Hügel waren selten bewaldet, meist sogar nur mit kurzem Grase bedeckt, während die im Stromthale liegenden nicht selten mit riesigen Andropogon- oder Setaria-Arten bestanden waren. Der Strom blieb noch immer so eng, Inseln waren gar nicht vorhanden, 
böchstens hier und dort eine kleine Sandbank, welche infolge des enorm tiefen Wasserstandes zu Tage getreten war. Ohne anzulegen, fuhren wir den ganzen Tag hindurch bis gegen Abend, da wir dann gezwungen waren, uns wieder mit frischem $\mathrm{Holz} \mathrm{zu}$ versehen. In den Wäldern hier waren allenthalben Elefanten- und Büffelspuren zu sehen. Die Nacht war so empfindlich kalt gewesen, dafs ich mich, da ich unvorsichtig gewesen war, gehörig erkältete und am nächsten Tage mich durchaus nicht wohl fühlte. Eine tüchtige Schwitzkur half diesem Zustande jedoch bald ab, so dals ich schon am Nachmittage mich wieder vollständig in Ordnung fühlte. Als wir am nächsten Tage Kwamuth an der Mündung des Kassai erreichten, hatten wir zugleich das Ende des als "Kanal" gezeichneten eingeengten Teiles des Congo erreicht, denn von dort an erweitert sich der Strom allmählich immer mehr, bis er schliefslich bei Bumba an seinem Oberlaufe seine grölste Breite erreicht.

Den Posten Kwamuth besuchte ich zusammen mit dem Kommandanten Maréchal, welcher auf dem Dampfer Passagier war und nach dem Tanganyika wollte, um sich dem Baron Dhanis zur Disposition zu stellen. Der Ort ist auf einem Hügel an der Mündung des Kassai erbaut und ist, wie sämtliche Stationen im Innern, zugleich Militärposten. Man hatte hier ziemliche Plantagen von Coffea liberica angelegt, die eben in Blüte waren, es war ein prachtvoller Anblick. I) a sich bei uns an der Kamerun-Küste selbst Kaffeeplantagen nicht bezahlbar machen, so sollte man kaum annehmen, dafs es hier so weit im Innern der Fall sein dürfte. Allerdings arbeitet der Congostaat hier mit bedeutend billigerem Arbeitermaterial, doch ist dabei der Trausport nicht aufser Acht zu lassen, denn derselbe würde his zur Küste nicht unbedeutende Kosten verursachen, während wir in Kamerun von vielen Plantagen den Kaffee direkt auf die Dampfer verladen könnten. Die Eisenbahnfracht allein beträgt $17 \mathrm{Ctms.} \mathrm{pro}$ Kilo, bei den jetzt sehr niedrigen Preisen, welche der LiberiaKaffee erzielt, viel zu grolse Unkosten. Gegenüber dem. Posten Kwamuth liegt eine belgische Missionsstation, Berghe St. Marie, welche wohl die bedeutendste derartige Station im Innern sein dürfte. Gegen Mittag fuhren wir weiter. Noch immer wechselten savannen und Urwald, doch bald wurden die Ufer immer niedriger, und kurz daranf kamen die ersten Inseln in Sicht. Ton nun an bot der Congo ein ganz anderes Bild dar; allenthalben sah man dicht bewaldete Inseln aus dem Wasserspiegel hervorragen. Wo die Ufer zu sehen waren, ragten sie höchstens einige Fufs über dem Wasserspiegel hervor, Urwald trat häufiger und in grölseren Komplexen auf. An einer Insel von ziemlicher Ausdehnung warfen wir am Abend Anker, um wieder $\mathrm{Holz}$ schlagen zu lassen. 
Am Yormittage des 26. Juni erreichten wir die amerikanische Missionsstation Tschumbiri, welcher gegenüber wir inmitten des Fahrwassers etwa eine Stunde lang vor Anker liegen blieben, uı Post abzugeben und etwas Proviant zu kaufen. Nicht weit davon entfernt machten wir wieder an einem Holzposten Halt. Als wir dann gegen Mittag fort wollten, stellte sich heraus, dais der Dampfer ein kleines Leck bekommen habe, welches erst ausgebessert werden mufste. Wir waren daher gèzwungen, für den Rest des Tages hier zu verbleiben. Leider bot der Platz nichts Interessantes dar, nicht eine Laudolphia war zu sehen. Die neuen Ankömmlinge henutzten hier natürlich die Gelegenheit, ihren ersten Jagdeifer etwas zu stillen, ein Leguan (grofse $1^{1 / 2} \mathrm{~m}$ lange Eidechse) und einige Tauben waren das Resultat ihres Jagdzuges. Elefanten- und Büffelspuren waren reichlich zu sehen, loch schienen sich die Tiere wohl zu hüten, sich einer solchen Zahl von Nimroden zu zeigen.

Während der Fahrt am nächsten Tage sahen wir häufig Nilpferde, welche sich aber stets in zu grol'ser Entfernung vom Dampfer hielten, un eine sichere Zielscheibe zu bieten, ebenso waren die Krokodile sehr scheu. Es ist unglaublich, welche grofse Mengen ron Flufspferden hier noch im Congo vorhanden sind, obgleich jährlich eine grofse Zahl derselben geschossen und auch ron den Eingeborenen harpuniert wird. Meist halten sich die Tiere in kleinen Trupps von 5 bis 10 Stück auf und tauchen sogleich unter, wenn ein Dampfer sich ihnen nähert, um dann nur hin und wieder an der Oberfläche zu erscheinen, um Luft zu schöpfen. Sobald sich ein solches Tier in der Nähe des Dampfers zeigt, wird darauf geschossen, obgleich man die angeschossenen Tiere nur selten bekommen kann.

Als wir gegen Mittag an dem Posten Bolobo, eintrafen, hatten wir ein sehr lebendiges Bild vor uns; es wurde gerade Markt abgehalten. Die Eingeborenen aus der Umgebung waren zu diesem Zwecke recht reichlich zusammengekommen. Es wurden fast nur Efswaren feilgeboten, welche mit Mitakus, der hier üblichen Münze, d. h. Messingdrahtstücken ron ungefähr $20 \mathrm{~cm}$ Länge, zu kaufen waren. Die Verkaufenden standen hinter einem kleinen Zaune in einer eigens zu dem Zwecke aufgebauten Hürde, in welche der Kauflustige nicht hineinkommen durfte, sondern sich die gekauften Sachen über den Zaun hinwegreichen lassen mulste. Man hat diese Regelung des Marktverkehrs wohl hauptsächlich eingeführt, um die Verkäufer vor Diebstählen zu schützen, denn alle diese Congo-Völker gehören zu den gewandtesten Jieben, welche es giebt. Ton seiten unseres Schiffes wurden grofse Mengen von Lebensmitteln erstanden, welche teils mit Mitakus, teils mit Zeug, Salz oder sonstigen Tausch- 
artikeln erhandelt wurden. Noch am Nachmittage setzten wir unsere Reise fort. Wir waren jetzt vollständig im Bereiche der Congo-Inseln, welche zum grofsen Teile von Sümpfen mit Wassergräsern durchzogen waren und daher viele Nilpferde beherbergten. Es wurle natürlich auch jetzt wieder tüchtig auf die Tiere geschossen und einige auch vielleicht verwundet, doch konnten wir die Körper natïrlich nicht bekommen, da zum Jagen der rerwundeten Tiere viel Zeit gehört, welche uns nicht zur Verfügung stand. Als wir gegen $5^{1} / 2$ Uhr anlegten, um für die Nacht Holz schlagen zu lassen, benutzte ich die Gelegenheit wieder zu einer kleinen Exkursion, während der ich zwei Landolphien ohne Blüten sah, die beide aber keinen brauchbaren Kautschuk lieferten.

Mit jedem Tage wurde der Flufs nun breiter. so dafs wir häufig durch die Inseln, welche immer zahlreicher wurden, von einem oder gar von beiden Ufern nichts mehr sehen konnten. Die für die Dampfer mit grölserem Tiefgange wie die „Hainant" einzig mögliche Fahrstrafse schien stellenweise schon sehr gefährlich, da das Wasser in diesem Jahre bedeutend mebr gefallen war, als es sonst zu geschehen pflegte. Bei der Fahrt stromauf ist die Gefahr num allerdings nicht so grofs als im entgegengesetzten Falle, denn dann werden die Dampfer von der gewaltigen Strömung im Congo nicht mitgerissen und auf die Sandbänke gesetzt, wo sie sich dann, durch die Strömung getrieben, immer tiefer einbohren. Als wir am Nachmittage des 28. Juni wieder anlegten, um Holz schlagen zu lassen, betrat ich einen Wald, welcher trotz des niedrigen Wasserstandes noch immer stellenweise unter Wasser stand, dessen Bäume also sicher fast während des ganzen Jahres direkt im Wasser stehen, und dennoch wuchsen hier Kautschuk liefernde Landolphien. Viele der Bäume stehen ähnlich wie die Mangroven und Pandanus, welche letzteren hier übrigens auch auftraten, auf Stützwurzeln, so dafs dadurch die Stänme über Wasser gehalten werden.

Am 29. Juni befanden wir uns gegenüber der Sanga-Mündung, von der natürlich infolge der vielen davor gelagerten Inseln nichts $\mathrm{zu}$ sehen war. Der Flufs verengt sich von hier bis Coquilhatville wieder etwas und ist weniger inselreich als unterhalb und oberhalb dieser Strecke. Noch am Abend desselben Tages erreichten wir den Posten Lukulela, welcher infolge seiner prachtvollen Wälder und des daselbst gewonnenen Nutzholzes bekannt ist. Ich sah hier den schönsten Wald, welchen ich je in Congo zu beobachten Gelegenheit gehabt hatte. Leider war es damals schon zu dunkel, um die Anpflanzungen der Station in Augenschein nehmen zu können, doch tröstete ich mich damit, dafs ich wufste, bei meiner Rückkehr bessere Gelegenheit dazu zu haben. 
Wie gewöhnlich setzten wir am folgenden Tage mit Tagesanbruch unsere Reise stromaufwärts fort. Da ich sehr bald eingesehen, dafs ich später nicht im Lande umherreisen dürfte, ohne das Bangala, die hier übliche Verkehrssprache, zu verstehen, so begaun ich bereits auf dem Dampfer, tüchtig Vokabeln zu lernen, um mich wenigstens einigermafsen mit den Eingeborenen rerständigen zu können. Es wurde während der Mittagsstunden hier auf dem vollständig windstillen Congo so heifs, dafs ein jeder bei dem müfsigen Leben, welches man an Bord des Dampfers zu fübren gezwungen war, erschlaffen mulste; wie sehr sehnte ich daher das Ende der Fahrt herbei, um doch wenigstens wieder etwas thätig sein zu können.

Irebu war unser nächstes Ziel, welches wir noch am Abend desselben Tages erreichten. Hier befand sich ein Camp d'Instruction, in welchem die Soldaten, welche die verschiedenen Stämme für die Schutztruppe des Staates liefern müssen, vorgebildet und gedrillt werden. Es befanden sich damals etwa 400 dieser Soldaten auf Irebu. Kommandant Jouniaux, der Kommandant der Station, führte uns am nächsten Tage, als der Dampfer, um Holz einzunehmen, den Ausflufs des Tumba-Sees hinaufgefahren war, umher und zeigte uns die ziemlich bedeutenden Kaffeeplantagen, welche von der Regierung hier angelegt worden waren. Man stand gerade vor der Haupternte. Die Plantagen waren in gutem Zustande gebalten, was insofern für die Regierung nicht schwer fällt, als sie Arbeiter in Überzahl erhalten kann, indem sie einfach aus den umherliegenden Dörfern die nötigen Leute requiriert, welche dann für eine geringe Bezahlung und für ihre Beköstigung für éine gewisse Zeit Arbeiten zu leisten haben. Nach allem, was ich hier in Irebu wie auch später in Equateur sah, schienen sich die Leute bei dieser Behandlung durchaus wohl zu fühlen.

Auf der Weiterfahrt wurde gegen Mittag noch einmal Halt gemacht, um wieder $\mathrm{Holz}$ einzunehmen. Am Abend legten wir kurz unterhalb Wangata für die Nacht an, um dann in aller Frühe erst bis Wangata, der Hauptniederlassung der Société Anonyme Bèlge, weiterzufahren. Von Wangata bis Coquilhatville oder Equateurville hatten wir nur eine kurze Zeit zu fahren, so dafs wir hereits um 11 Uhr daselbst anlangten. Ich war watürlich froh, dals ich nun an meinem Ziele angelangt war und den Dampfer verlassen konnte. Am Nachmittage liefs ich meine Lasten in das mir angewiesene Haus hineinschaffen und richtete mich dann darin so behaglich ein, als es eben ging.

Coquilhatville ist eine der gröfsten Stationen im Innern und gehört wohl entschieden auch mit zu den wichtigsten; die Ein- 
geborenen in dem Distrikte sind immer mehr oder minder im Aufstande begriffen. Man hat auf der Station riesige Kaffeeplantagen angelegt, in denen eine sehr grolse Zabl von Arbeitern thätig ist. Der Chef des Cultures auf der Station schien sich nach seinen Berechnungen einen sehr grofsen Verdienst von den Kaffeeplantagen zu versprechen, doch wird man das Resultat abwarten müssen, denn der hier angepflanzte Liberia-Kaffee erzielt sehr geringe Preise auf dem europäischen Markte.

Zur Besichtigung der Kautschukpflanzungen unternahm ich in Begleitung des Chefs des Cultures eine Exkursion, auf welcher ich alles sah, was davon vorhanden war. Hevea hatte man meiner Meinung nach auf zu trockenem Terrain angepflanzt. die Pflanzen wuchsen zwar recht kräftig, doch ist zu befürchten, dals man mit ihnen dieselbe Erfahrung machen wird, wie es in Kamerun der Fall war. Manihot Glaziovii war auch in einigen hundert Exemplaren vorbanden und hatte sich stellenweise sogar schon selbst ausgesät. Von Kickxia latifolia Stapf hatte man eine Plantage von etwa 5000 Pflänzchen angelegt, welche auch sehr gut zu gedeihen schienen, doch giebt diese Art, wie ich bald festzustellen Gelegenheit hatte, ebenso wenig Kautschuk wie Kickxia africama Bth., ist also deshalb vollständig zu verwerfen. Von Castilhoa elastica war ein kleines Exemplar unter grofsen Schwierigkeiten und mit vieler Mühe hierher geschafft worden; dasselbe war erst vor einigen Tagen ausgepflanzt worden, so dafs man noch nicht einmal sehen konnte, wie sich die Pflanze entwickeln würde. In einem sumpfigen Walde hatte man das Unterholz etwas weggeschlagen und eine Landolphia-Anpflanzung begonnen. Die Pflänzchen waren in Abständen von 5 bis $7 \mathrm{~m}$ einzeln oder zu zweien am Fufse der Bäume ausgesetzt und schienen sich in diesem feuchten Boden recht wohl zu fühlen. Auch diese Anpflanzung war erst sehr jungen Datums, so dafs die Pflänzchen erst drei bis vier Blätter entwickelt hatten. Ich halte es nicht für möglich, dafs eine solche Landolphia-Anpflanzung in sechs bis sieben Jahren anzapfbar sein wird, wie häufig vermutet wird. Es ist nicht zu bestreiten, dals dieselbe, wenn sie erst einmal zum Anzapfen reif ist, einen gewissen Wert repräsentiert, doch wird trotz aller Vorsichtsmafsregeln in wenigen Jahren der Kautschukertrag derselben bedeutend herabsinken, da bei der äufserst runzeligen und ungleich dicken Rinde die Schnitte nur zu leicht bis in die Cambiumschichten hineindringen. Hier im Congostaate weicht die Landolphia mit der fortschreitenden Civilisation in erschrecklicher Weise zurück. In gröfseren Quantitäten finden sich Kautschuklianen an leichter zugänglichen Lokalitäten nur noch da, wo der Europäer noch nicht dem Eingeborenen den Wert des Kautschuks 
hat klarmachen können. Die Terordnungen, welche die Regierung erlassen hat, werden natürlich, da sie unbequem sind, bei jeder möglichen Gelegenheit umgangen, denn dadurch würde der Ertrag der Kautschnk-Liane bedeutend verringert werden, und der Neger würde verlieren.

Die Bossanga- oder, wie sie hier allgemein genannt wurde, Bossassangapflanze, sah ich auch in der Umgebung der Station, besonders am Rande der Wälder, sehr häufig. Wie ich vermutet hatte, waren es Costusarten, von denen ich zwei verschiedene Spezies unter diesem Namen feststellen kounte. Die bis acht Fufs hohen Stengel werden entblättert und dann in etwa fufslange Stücke geschnitten; durch Drehung und Auswringen dieser Stücke erhält man den Saft in reichlicher Menge, und kann ihn in diesem Zustande sofort bei der Koagulation der Kautschukmilch verwenden. Dieselben Costus-Arten hatte ich bereits in Kamerun viel gesehen und schon damals die Plantagenleiter darauf aufmerksam gemacht, dafs ich in ihnen die Bossangapflanze des Congo vermute. Zur Untersuchung in Europa liefs ich zwei Flaschen mit Bossassangasaft füllen; da derselbe sehr reichlich fliefst, war das eine Arbeit von einer halben Stunde.

Ich machte nun im Laufe der folgenden Tage einige Exkursionen in die Umgebung der Station, soweit dieses auf dem sumpfigen Terrain möglich war. Die Kautschuk liefernden Landolphien sind alle ausgeschlagen, so dafs man zu neuen Anpflanzungen nicht einmal genügend Samen erhalten kann. Einige Ficusarten und einen grolsen Stamm der Kickxia latifolia zapfte ich an, konnte aber trotz aller Versuche und Anwendung der verschiedensten Säuren keinen brauchbaren Kautschuk gewinnen. Es gelang mir auch, einige Früchte der Kickxia latifolia zu finden, die bis dahin noch nicht bekannt waren. Auch die Stämme der Manihot Glaziovii liẹs ich anzapfen und erhielt kleine Quantitäten guten Kautschuks, welche aber zu gering waren, um ein plantagenmäfsiges Anbauen hier zu rechtfertigen. Mit den mir häufig gerühmten Kautschuk-Anpflanzungen in Coquilhatville stand es also zur Zeit meines Aufenthalts keineswegs besser als in Kamerun, im Gegenteil sind wir den Belgiern durch unsere Kickxiaplantagen weit vorausgeeilt. Die LandolphiaAnpflanzungen in Soppo sind anch bedeutend weiter entwickelt, als die im Congo angelegten.

Man heganu auch im Equateur-Distrikte Kakaopflanzungen in gröfserem Mafsstabe anzulegen; inwieweit sich diese rentieren werden, mufs die Zukunft beweisen, es ist nicht unwahrscheinlich, dafs die Niederschläge zu unbedeutend sind, um eine gute Frucht erzielen zu können. Wie ich später von den katholischen Missio- 


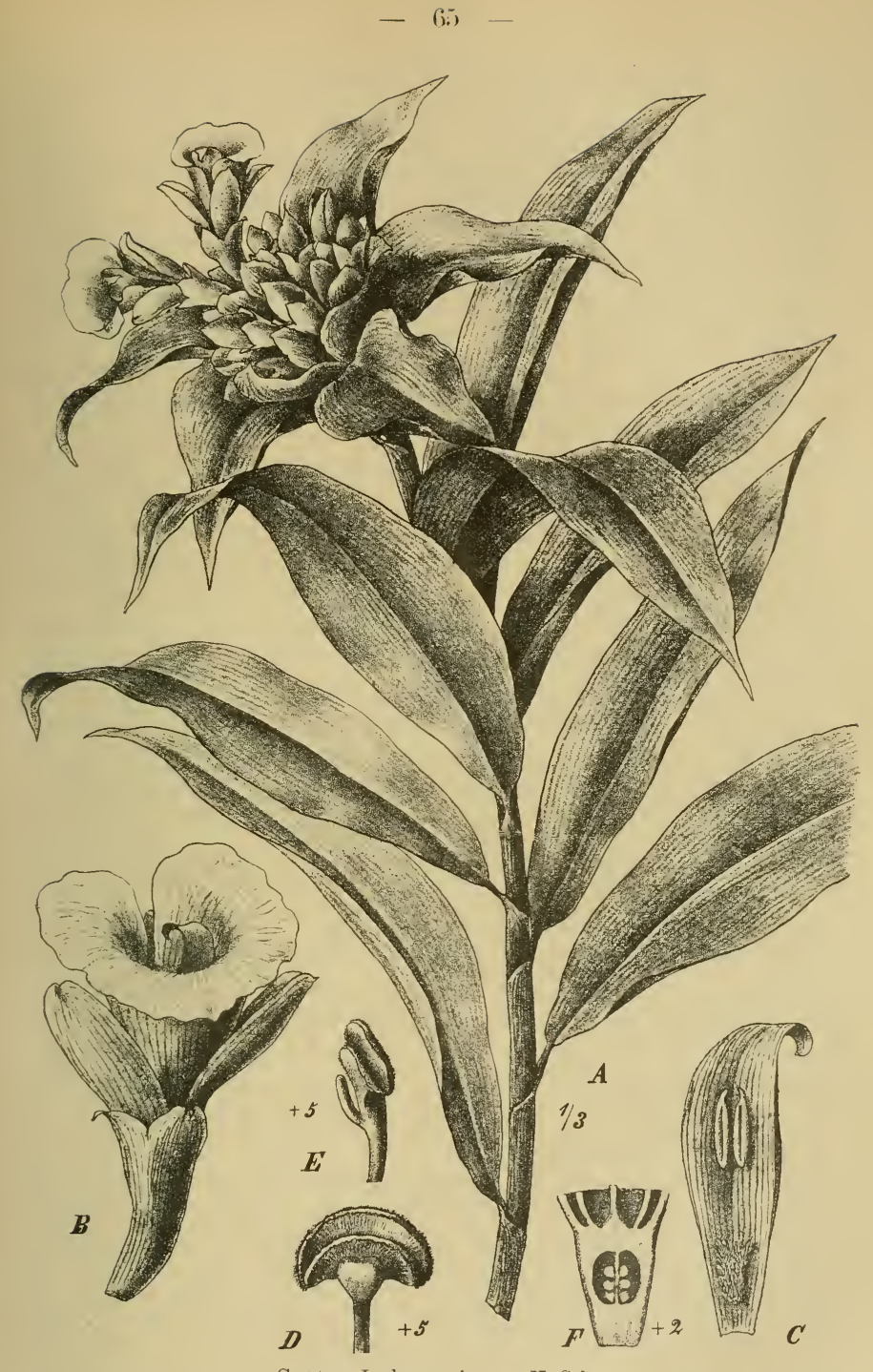

Costus Lukanusiauns K. Seh.

A Oberes Stengelstück, B Blüte, C Stanbhlatt, D Griffelkopf, E derselbe von der Seite, F Längssehnitt durch den Fruchtknoten.

R. Schlechter, Westafrikanische Kautschuk-Expedition. 
naren am Ruki horte, sollen Proben von Kakaobohnen, welche sie zur Begutachtung nach Europa geschickt hatten, als sehr minderwertig (.13. oder 14. Qualität") bezeichnet worden sein. Sei es nun, dafs die Fermentation oder das Dörren nicht richtig vor sich gegangen ist, sei es, dafs der Boden nicht fruchtbar genug oder die Spielart an und für sich minderwertig gewesen ist, dort hat man jedenfalls aufgehört, neue Pflanzungen anzulegen. Hier in Equateur versprach sich der Chef des Cultures ein gutes Resultat. Viel wird natürlich auch davon abhängen, welchen Frachtsatz die Eisenbahngesellschaft für den Transport vom Stanley-Pool bis Matadi ansetzen wird, demn für derartige Qualitäten würdeu die Transportunkosteu sehr leicht zu hoch werden.

Von Coquilhatville aus wollte ich gern eine kleive Expedition ins Innere nach der Gegend des Tumba-Sees machen, von wo eine nicht geringe Menge ron Kautschuk des Equateur-Distriktes kommt.

Da der Kommissar des Distriktes zur Zeit sich auf einem Zuge gegen die Eingeborenen jener Gegend befand, welche einen Aufstand begonnen hatten, glaubte sein Stellvertreter, mir nicht die nötigen Träger geben zu kömuen. So war ich deun gezwungen, bis zur Rückkehr des Kommissars zu warten.

Um meine Zeit möglichst auszufüllen, unternahm ich an 8. Juli eine Fahr in einem Canoe den Ruki hinauf nach der Missionsstation der Trappisten. Die Missionare hatten hier verschiedene Kulturen begonnen und waren eben dabei, die Station zu vergröfseru. Der Kaffee stand recht gut, Kakao war mit dem Kakao von Kamerun nicht zu vergleichen, doch waren die Pflanzungeu recht schön sauber gehalten, wie überhaupt die Station einen recht netten Eindruck machte. Diese Leute leben dort äufserst einfach und bleiben bis zu ihrem Tode in Afrika, wenn sie nicht etwa beständiger Krankheiten halber nach Europa zurückkehren müssen; doch das kommt selten vor. In dem mit der Missiousstation verbundenen Kloster lebten drei Nonueu, welchen die Erziehung der Mädchen oblag.

A u 9. Juli traf der Kommissar des Distrikts ein. Als ich ihn von meinem Wunsche in Kenntnis setzte, sprach er mir sein Bedauern aus, dafs er mir nicht erlauben dürfe, meine geplante Expedition ins Inwere auszuführen, da die Gegend zu unsicher sei, und er mir augenblicklich die zu meiner Expedition nötigen Soldaten nicht geben könne. Ich versuchte ihn umzustimmen, sah aber bald ein, dals es nichts half. Die Gründe zu dieser Weigerung sind mir unklar geblieben, genug, ich sah ein, dafs man mich nicht nach dem Tumba-See hineinlassen wollte, denn der Eingeborenen-Aufstand war damals schon erledigt. 
Da ich nun keinen Grund hatte, noch mehr Zeit zu verlieren, so packte ich meine Sachen bald ein, um dann am 11. Juli meine Reise nach der Sanga-Mündung den Congo hinunter anzutreten. Ich hatte ein grofses Canoe mit zwölf Ruderern bekommen, welches mich zunächst bis Irebu bringen sollte. Gern hätte ich selbst hier ein grölseres Canoe käuflich erworben, doch das war leider nicht möglich, da die sämtlichen grofsen Canoes der Eingeborenen von der Regierung in Beschlag genommen waren und die Leute nun natürlich keine grofsen Canoes mehr bauen wollten, um sich nicht noch einmal derselben Gefahr auszisetzen.

Nach etwa $1^{1 / 2}$ stündiger Fahrt erreichten wir die amerikanische Missionsstation bei Wangata, wo ich bei den sehr liebenswürdigen Missionaren mich eine kurze Zeit aufhielt. Auf der Weiterfahrt ging es über einige Stellen hinweg, welche infolge der starken Strömung eine grofse Zahl von Strudeln bildeten. Hier wurde dann immer das Kommando gegeben „koruka rnakessi“ (schnell rudern), um darüber hinwegzukommen und nicht vou den Strudeln mitgerissen zu werden. Längs der Ufer waren Kopalbäume in riesigen Mengen vorhanden. Der hier helle Kopal, welcher einer geringeren Qualität angebört, wird von den Eingeborenen meist im Wasser gesammelt oder bei niedrigem Wasserstande auf den Sandbänken, wo er oft in ziemlichen Mengen angeschwemmt wird. Man hat hin und wieder versucht, gröfsere Quantitäten nach Europa zu schicken, doch sollen die Transportkosten zu hoch sein, so dafs der Export den jetzt noch durch die hohen Verdienste am Kautschuk und Elfenbein verwöhnten Handelsgesellschaften noch nicht rentabel genug erscheint. Der Frachtsatz für diesen sogenannten "weifsen“ Kopal ist auf der Congo-Eisenbahn vom Stanley-Pool bis Matadi auf 18 Ctms. pro Kilo angesetzt worden; da hierzu noch die nicht unbedentenden Transportkosten auf den Dampfern bis Stanley-Pool kommen und ferner auch noch die Fracht von Matadi nach Europa nicht gering ist, so läfst sich natürlich verstelen, dafs ein grofser Verdienst bei minderwertigem Kopal nicht herauskommt.

Die keinen Kautschuk liefernde Landolphia florida, welche hier im Congo in einer besonder's schönen, grofsblütigen Varietät auftritt, war allenthalben längs der Ufer reichlich vorhanden. Ich stellte sowohl hier wie später in Bonga die möglichsten Versuche an, um Kautschuk daron zu gewinnen, doch alles war vergeblich, obgleich die Standorte häufig recht verschieden waren. Für mich ist die Frage für Kamerun und für den Congo so weit erledigt; Landolphia florida giebt daselbst keinen guten Kautschuk; wo andere Angaben vorhanden sind, dürften sie sich wohl anf einen Irrtum, sei es in der Art, sei es in der Bezeichnung des Produktes, 


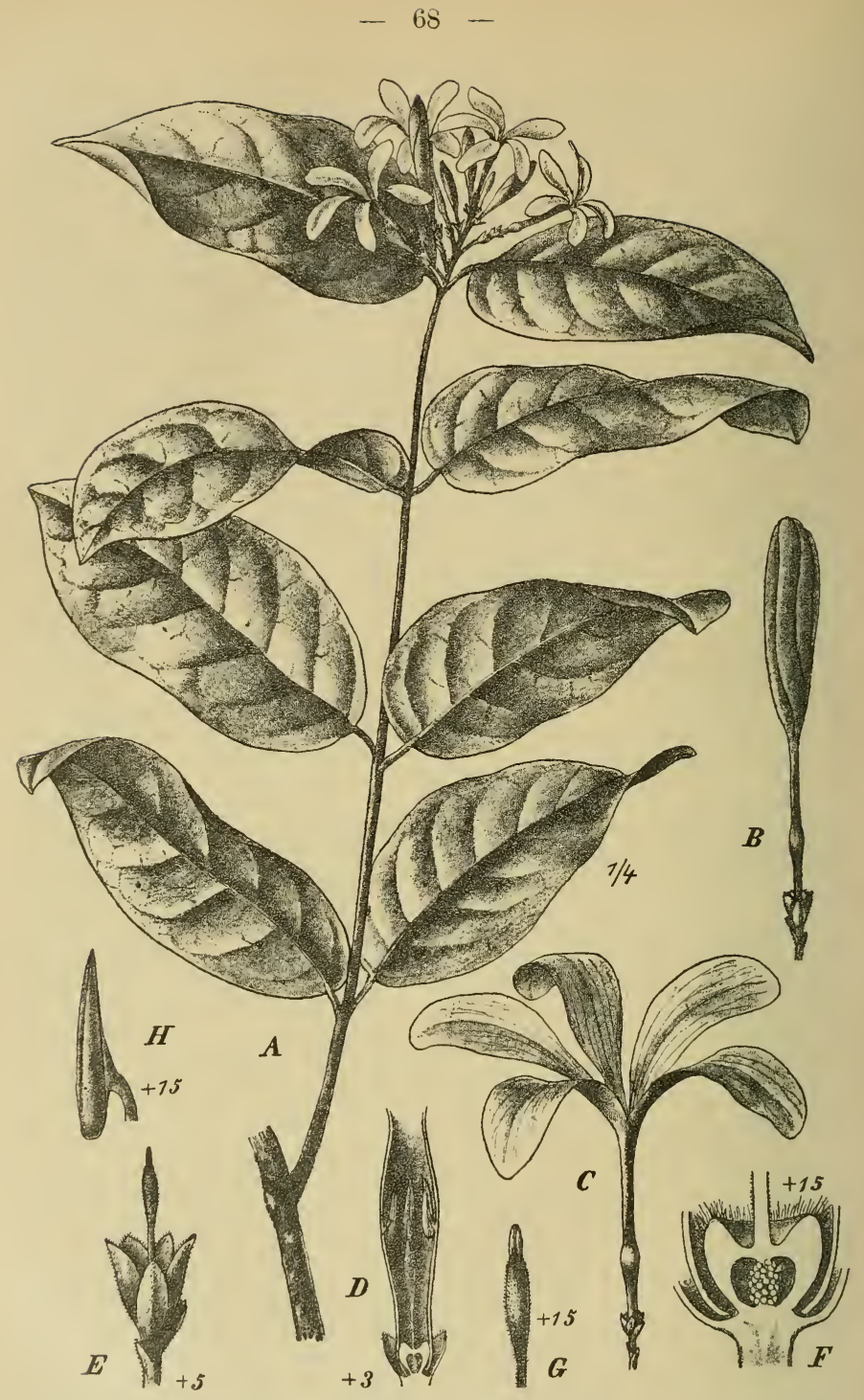

Landolphia florida Bth.

A Kweig, 13 Knospe, C Blüte, D Längssehnitt dureh den unteren Teil der Blüte, E Keleh und Griffel, F Querschnitt dureh den Frnehtknoten, G Griffelkopf, II Anthere. 
zurückführen lassen; da viele Laudolphien einander sehr ähnliche Blätter haben, so kann man sich leicht in der Art täuschen, zumal in den Wäldern häufig Kautschuk liefernde Arten mit anderen vermischt wachsen. Als Kautschuk sind mir häufig Produkte gezeigt worden, welche besser als Vogelleim bezeichnet werden würden; aufserdem neigt der Laie dazu, gern eine jede in den Tropen weifsen Milchsaft liefernde Pflanze, wie z. B. Ficusarten etc., als Kautschukpflanze anzusehen. Auch Asclepiadaceen stehen häufig bei Laien im Verdachte, Kautschuk zu liefern. So giebt Baillon nach aus dem Congo kommenden Notizen bei einer seiner neueu Tacazea-Arten an, dafs eine nicht geringe Quantität des CongoKautschuks von dieser Pflanze herstammen solle. Ich habe nach eigenen Versuchen sowie trotz eifriger Erkundigungen keine Tacazea-Art zu Gesicht bekommen, welche wirklich Kautschuk lieferte.

Der Congo und seine Nebenflüsse sind ungehener reich an Fischen, doch wird von den Eingeborenen, deren einzige Fleischnahrung lange Zeit hindurch die Fische bilden, der Fang derselben ziemlich vernachlässigt. Ein jeder kleine Wasserlauf bietet den Leuten eben eine so reichliche Ausbeute, dafs sie sich gar nicht dabei anstrengen brauchen. In vielen Gegenden wäre es für die Handelsgesellschaften vielleicht von grofsem Nutzen, wenn sie zur Ernährung ihrer eingeborenen Arbeiter durch Leute, welche den Fischfang wirklich kennen, täglich die nötigen Mengen fangen lassen würden, ganz besonders in solchen Gegenden, wo man vou den Eingeborenen nur schwerlich Nahrung erkaufen kann, wie z. B. im Sanga-Ngoko-Gebiete.

Am 11. Juni gegen Mittag erreichten wir lkenge, einen Holzposten des Staates, wo ich für meine Ruderer etwas Ḿais erstehen konnte, denn dieselben hatten seit dem Morgen noch nichts gegessen. Der Uferwald, welcher nur wenige Fufs über dem Niveau des jetzt ausnahmsweise tiefen Wasserstandes lag, war äufserst interessant. Wir hielten uns immer, soweit nur irgend möglich, an dem Ufer des Flusses, um uns nicht in den vielen Kanälen und Armen des Stromes zu verfahren. Affen und Wasservögel (Reiher, Enten und Wasserhühner) gab es in grofsen Mengen. Es gelang mir, verschiedene derselben für die Leute zu schiefsen, ebenso einige Affen, von denen ich auf der Fahrt bis Irebu allein fünf verschiedene Arten beobachtete. Im Wasser gab es viele Krokodile, doch konnte ich nicht zum Schufs kommen, da die Tiere ungemein scheu wareu. Nilpferde sahen wir gar nicht. Es war mir übrigens schon vorher aufgefallen, dafs wir auf der Reise von Irebu bis Coquilhatville nichts von den sonst so häufigen Tieren gesehen. An vielen Stellen, wo ich 
anlegen lassen konnte, benutzte ich die Gelegenheit, den Wald etwas zu untersuchen, fand aber immer dieselben Zustände: die Kautschuklianen waren alle ausgeschlagen. Calanusarten waren häufig, besonders am Flufsrande bildeten sie nicht selten undurchdringliches Gestrüpp. Ein jeder Tersuch, sich ohne Cutlas durch diese Gebüsche hindurchzuarbeiten, würde scheitern, die zurückgebogenen Haken an der verlängerten Blattspitze halten einen jeden Eindringling zurück. Da ich, wenn irgend möglich, am folgenden Tage in Irebu eintreffen wollte, so liefs ich bis gegen $7 \mathrm{Uhr}$ abends rudern. In der bereits eingetretenen Dunkelheit war es dann nicht leicht, einen geeigneten Landungsplatz zu finden, aufserdem machen die vielen Baumstämme im Strome eine Canoereise bei der Dunkelheit sehr gefährlich. Als wir eben das Zelt aufstellen wollten, fing es plötzlich an in Strömen zu regnen, so dafs noch alle Lasten nafs wurden, ehe wir sie bergen konnten. Auch mein bereits draufsen aufgestelltes Feldbett wurde derartig durchnäfst, dafs ich an Schlaf nicht denken konnte, da mir keine trockenen Decken zur Verfügung standen. Nachdem ich mich daher selbst trocken umgezogen hatte, liefs ich ein Feuer im Zelte unterhalten, un mich zu erwärmen und die in Scharen erscheinenden Moskitos durch den Rauch fortzujagen.

Am nächsten Morgen liefs ich bereits um $5^{1 / 2}$ Uhr weiterfahren. Nach dem Regen hatte sich die Temperatur gehörig abgekühlt, auch lag ein feiner Nebel auf dem Flusse, der sich erst mit Aufgang der Sonne hob. Es war ein herrlicher Morgen. Nach einer Stunde erreichten wir das Nachtlager eines Inspektors der Telegraphenlinie, welche längs des rechten Ufers vom Stanley-Pool nach Coquilhatville im Bau begriffen war. Der Herr war am Tage vor mir von Coquilhatville abgefahren und wollte auch nach Irebu zurïckkehren. Da sein Canoe schneller lief als das meinige, lud er mich ein, mit ihm zu fahren und mein Canoe nachkommen zu lassen. Wir machten unterweg's einige Fahrtunterbrechungen, er, um die Linie zu inspizieren, ich, un mir die Zusammensetzung des Waldes anzusehen. Als wir gegen $12^{1 / 2}$ Uhr in Irebu anlangten, war von meinem Canoe noch nichts zu sehen, dasselbe traf erst gegen 2 Uhr ein; natürlich hatten sich die Leute, da ich nicht dabei war, auch nicht übermälsig angestrengt. Da in Irebu zur Zeit kein gröiseres Canoe zu finden war, wurde ich leider gezwungen, daselbst einige Tage Rast zu machen, bis ein solches eintraf. Kommandant Jouniaux versuchte, mir den Aufenthalt so angenehm als möglich zu machen; er führte mich anf der Station umher und gab mir Aufklärung über die verschiedenster Dinge, welche mich interessierten. Auf einigen kleinen Exkursionen, welche ich in der Umgegend unternahm, hatte ich Gelegenheit, den Charakter der Wälder in der Umgegend kennen 
zu lernen. Da es ziemlich ausgedehnte Grassteppen in Fülle hier gab, in denen diese Wälder, selten gröfsere Komplexe bildend, zerstreut umherlagen, so war natürlich auch die Vegetation dieser Buschwälder eine ganz andere, als ich sie im Congo vorher kennen gelernt hatte. Landolphien waren hier und da vereinzelt anzutreffen, aber nur in dünnstämmigen Exemplaren, welche von den Eingeborenen noch nicht angeschnitten wurden. Landolphia florida war längs der Flufsufer sehr verbreitet. Die orangegelben Früchte werden von den Affen gern gefressen, da die Samen ron einer süfsen Pulpa umgeben sind. Costus- (Bossassanga-) Arten waren allenthalben am Rande der Wälder und Gebäsche reichlich vorhanden. Da wo frisch Urwald geschlagen wird, stellen sich die Pflanzen gewöhnlich sehr bald ein. Ein nicht unerheblicher Teil der Grassavannen war mit Borassuspalmen bedeckt, was der ganzen Landschaft einen recht imposanten Anblick verlieh. Die Früchte der Borassuspalme werden nur selten von den Eingeborenen gesammelt, da sie von einem süfslichen Fruchtfleische umgeben sind, doch wird in vielen Gegenden der Stamm direkt unterhalb der Krone angebohrt zur Gewinnung von Palmenwein. Nicht selten sieht man Strecken, in denen die Borassuspalmen durch dieses Anbohren getötet sind.

Endlich, am 17. Juli, traf das langersehnte Canoe ein, so dufs ich am 18. Juli abreisen konnte. Das Canoe war sehr dick gebaut und hatte vorn und hinten eine kleine Plattform, auf welcher noch einige Ruderer stehen konnten; es ist dieses eine Eigentümlichkeit der Ubangi-Canoes, von denen die grölseren sogar Plattformen für sechs bis sieben Ruderer vorn und hinten besitzen sollen. Infolge langjährigen Gebranches war das Fahrzeug an den Seiten etwas defekt geworden, so dafs ich zweifelte, meine sämtlichen Lasten unterbringen zu können. Als wir dann am Nachmittage abfuhren, ragte, nachdem sich noch meine zehn Ruderer (Congostaat-Soldaten und ein Sergeant) hineingesetzt hatten, eben nur noch der oberste Rand an den Seiten empor, so dafs ich sehr bezweifelte, richtig in Lukulela anzukommen. Noch länger in Irebu warten wollte ich auch nicht, da das nächste gröfsere Canoe, welches man mir zur Verfügung hätte stellen können, erst nach einer weiteren Woche erwartet wurde. Das Wetter war für die Reise in dem defekten Canoe nicht gerade das beste, denn es wehte eine ziemlich steife Brise auf dem Strome. Von Insel zu Insel weiter zur Mitte des Flusses fahrend, machten wir allmählich schnelleren Fortschritt, je mehr wir in den Strom hineingelangten. Wir waren kaum eine Stunde von lrebu fortgefahren, als sich plötzlich ein riesiges Nilpferd etwa zehn Schritte vor dem Canoe aus dem Wasser hob und brüllte. Da wir inmitten des Flusses waren, war die Lage nicht 
sehr angenehm, um so mehr, als ein Stols des Tieres genügt bätte, uns mit sämtlichen Lasten umzuwerfen. Ich liefs den Kurs etwas ändern und hielt mein Gewehr in Bereitschaft. Das Tier tauchte sogleich wieder unter und erschien kurz darauf wieder hinter dem Canoe. Nun glaubte ich feuern zu müssen, denn das wïtende Tier hatte offenbar die Absicht, uns anzugreifen. Ein Schufs ertönte, und mit furchtbarem Geheul tauchte der Riese wieder unter, ohne sich zu einer zweiten Salve sehen zu lassen, denn nun hatte ich den Soldaten befohlen, auch ihre Gewehre in Bereitschaft zu halten. Die Leute meinten zwar, dal's ich das Tier tödlich verletzt habe und dafs es nach etwa einer Stunde wieder oben an der Wasserfläche erscheiven würde, doch war ich nicht meines Schusses sicher genng, um deshalb Zeit zu verlieren, zumal, da es dann sehr fraglich gewesen wäre, ob wir noch einen Lagerplatz für die Nacht gefunden hätten, und in meinem Canoe mir die Fahrt die Nacht hindurch zu gefahrvoll vorkam. Von Insel zu Insel weiter vordringend, kamen wir gegen Abend in Sicht des französischen Congo-Ufers, auf dem mir meine Lente bald die Missionsstation Lironga zeigten. Da es bereits zu dunkeln anfing, liefs ich auf die Station zusteuern und traf auch gegen $6 \frac{1}{2}$ Uhr wohlbehalten daselbst ein. Die französischen Missionare luden mich ein, bei ihnen über Nacht zu bleiben.

Bevor ich nächsten Morgen weiterfulır, machte ich einen kleinen Rundgang auf der Station. Alles war vorzüglich in Ordnung gehalten, besonders die verschiedenen Anpflanzungen. Hier sah ich auch seit längerer Zeit einmal wieder ein Batatenfeld. Die Negerjungen, welche hier erzogen werden, werden sehr streng gehalten und sollen vor allen Dingen zu guten Arbeitern herangebildet werden. Nach allem, was ich hier sah, schien es, als ob man den Knaben auch schon etwas Tüchtiges beigebracht habe. Bei Frühstück erzählten mir die Herren einige ihrer Jagderlebnisse mit Elefanten, von denen diese Gegend noch voll ist. Da die Tiere die, Anpflanzungen nicht selten zerstören sollen, ist es natürlich eine grolse Freude für die Station, wenn eins derselben erlegt wird, ganz abgesehen davon, dafs dadurch riesige Mengen von'Fleisch gewonnen werden, welches dann unter die Eingeborenen verteilt wird, denn dasselbe wird selı geschätzt. Als ich gegen 7 Uhr aufbrach, war das Wasser des Stromes derartig bewegt, dafs mir die Missionare rieten, noch länger zu bleiben, ich mulste es aber ausschlagen, denn ich wollte nicht $\mathrm{zu}$ viel Zeit verlieren.

Die Fahrt über den Congo an jenem 'Tage werde ich nicht vergessen. Anfangs ging alles gut, das Canoe wurde zwar immer hin und her geschleudert, doch schlugen die Wellen selten über den Rand; je mehr wir aber nach der Mitte des Stromes kamen, desto 
furchtbarer wurde die Fahrt. Die Leute wufsten vor Furcht kaum mehr meinen Befehlen zu gehorchen, denn das Getöse war betäubend, ebenso schlugen die Wellen beständig in das Canoe hinein, so dals zwei Leute nur immer das eindringende Wasser ausschöpfen mufsten; ich selbst glaubte nicht mehr daran, clafs wir das andere Ufer erreichen würden, denn mehr als eininal sah ich Wellen kommen, von denen ich sicher glaubte, umgeworfen zu werden, und nur durch plötzliche Wendungen des Canoes wurde dieses vermieden. Ich selbst ruderte mit allen Kräften und arbeitete mich dabei trotz des starken, kalten Windes, welcher wehte, tüchtig in Schweils, dabei hatte ich noch auf alles aufzupassen, denn die Leute selbst waren ganz kopflos geworden. Es waren einige aufregende Stunden. Endlich gegen 10 Uhr gelang es uns, eine Sandbank zu erreichen, wo ich anlaufen liefs, um mich nicht noch einmal der Gefahr auszusetzen, mit Mann und Maus zu ertrinken oder den Krokodilen zum Opfer zu fallen. Kaum hatten wir das Canoe auf den Sand gezogen, als sich ein furchtbarer Tornado mit einem echten Tropenregen erhob, der uns in Kürze alle bis auf die Haut durchnälste. Wären wir noch eine halbe Stunde länger auf dem Wasser gewesen, so wäre das Canoe sicher untergegangell. Wie ich richtig vermutet hatte, legte sich nach dem Regen der Sturm auch bald, und das Wasser wurde allmählich ruhiger, so dafs wir um $12 \mathrm{Uhr}$ unsere Fahrt wieder aufnehmen konnten. Die Leute fanden denn auch bald ihre Courage wieder, besonders da ich auf der Sandbank drei Enten geschossen hatte, welche ich ihnen schenkte, denn wenn der Neger seinen Magen gefüllt hat, so ist er noch einmal so gut zu gebrauchen. Als kurz darauf die Sonne wieder erschien, zeigten sich bald die verschiedensten Wasservögel und Affen wieder. Es gelang mir auch noch, einige derselben zu erlegen, worüber meine Leute derartig in Freude gerieten, dafs sie sogleich einen Gesang auf den „Mundele na niama mingi“ (weifsen Herrn, der viel Fleisch giebt) anstimmten. Da die Leute wufsten, dafs sie am Abend das Fleisch der erlegten Tiere bekommen würden, ruderten sie mit doppeltem Eifer, so dafs wir im Laufe des Nachmittags eine grofse Strecke zurücklegen konnten. Die Vegetation am Flufsrande blieb dieselbe, wie ich sie bereits früher beobachtet hatte. Nilpferde wurden immer häufiger, hin und wieder zeigte sich aucb ein Krokodil auf den Sandbänken oder träge im Wasser schwimmend. Eine Kugel, welche ich immer für diese Tiere in Bereitschaft hielt, trieb dieselben bald aus ihrer Ruhe. Als ich am Abend einen geeigneten Lagerplatz gefunden und mein Zelt aufgestellt war, ging ich sogleich, ohne erst ein Abendesssen einzunehmen, zur Ruhe und verfiel sofort in einen tiefen Schlaf, so war ich von der Aufregung des heutigen Tages erschöpft; selbst die vielen Moskitos, welche mich umschwärmten, konnten mich nicht aufwecken. 
Wieder vollständig erfrischt, liefs ich am folgenden Tage, nachdem das Zelt schnell eingepackt war, gegen $6 \mathrm{Uhr}$ weiterfahren. Wir trafen heute mehr Nilpferde, als ich je vorher gesehen; häufig schien es fast, als ob sie uns entgegenkormen wollten, um uns anzugreifen. In solchem Falle wurde unter grofsem Lärm tüchtig fortgerudert, ich stellte mich bereit, um etwa zu nahe herankommende Tiere mit einer Kugel zu empfangen. Es ist mir merkwürdigerweise nie passiert, dafs mein Canoe von Nilpferden umgeworfen wurde, obgleich das auf Reisen im Congo nicht selten vorkommt, und einige Herren daselbst nur zu häufig das Unglück zu haben scheinen. - In den Gegenden, wo die Europäer noch nicht häufig vorgedrungen sind und den Nilpferden daher noch nicht derartig nachgestellt worden ist, sind dieselben natürlich lange nicht so bösartig als im riel befahrenen Congo. Es ist sicher, dafs der Jahre des Vorhandenseins von Nilpferden in den afrikanischen Flüssen nicht mehr sehr viele kommen werden, wenn man fortfährt, diese Tiere in derselben Weise zu vernichten, wie es jetzt geschieht. Die Jagd auf Nilpferde ist leicht und kaum sehr gefahrvoll. denn die Tiere sind sehr dumm, es gehört also gar kein besonderer Heldenmut dazu, eins zu töten. Am Vormittage fuhren wir zum grofsen Teile am Rande grofser, häufig sumpfiger Savannen entlang, in denen offenbar viele Büffel vorhanden waren, wie die zahlreichen Spuren am Flufsrande bewiesen.

Als wir uns gegen 12 Uhr eben an Land begeben wollten, ging eine Büffelherde trabend davon, die ganze Gegend war offenbar äufserst wildreich. Ich schols mir noch zum Frühstück eine prachtvolle grofse Ente. Wir lagerten in einem herrlichen Wäldchen, dessen Bäume von den Blüten einer wundervollen rosenroten Milletia bedeckt waren. Einige in der Nähe unseres Lagerplatzes stehende Ficusarten untersuchte ich, doch, wie ich erwartet, ohne ein günstiges Resultat zu erzielen. Als wir uns eben wieder auf der Fahrt befanden, brach plötzlich ein Tornado aus, der von einem starken Regen begleitet wurde und mich also zwang, wieder an Iand anlaufen zu lassen und das Canoe mit dem ausgebreiteten Zelte zu überdecken. Wir wurden alle arg durchnälst, doch das hielt uns nicht ab, sogleich nachdem sich der Tornado gelegt hatte, weiter zu fahren. Am Abend fanden wir einen wundervollen Lagerplatz, der aber von Büffeln und Nilpferden vollständig zertreten war. Im Wasser vor uns schwammen etwa 10 Nilpferde umher, welche uns eifrig beohachteten, hier und da erhob sich eins derselben brüllend, um dann wieder für einige Zeit zu verschwinden. Ich streifte nit einem meiner Leute noch umher, um mir einen Abendbraten zu schiefsen, und hatte auch das Glück, mich mehrmals an einen Schwarm Enten heranschleichen zu können, von denen ich fünf erlegen konnte. Das 
gab wieder ein Fest für die Leute. In der Nacht wurden wir derartig durch die sich immer näher an uns heranwagenden Nilpferde, welcbe durch ihr Gebrüll uns im Schlafe störten, belästigt, dafs ich beschlofs, den Tieren ein Audenken zu geben. Ich schol's auf das uns im Wasser am nächsten schwimmende Tier, das übrigens kaum 20 Meter entfernt war, und traf es so günstig, dafs es mit einem furchtharen Geheul unterging. Ich liatte keinen Zweifel, dafs ich das Tier tödlich verwundet hatte, wodurch seine Genossen sich denn auch wohlweislich in besserer Entfernung hielten. Meine Leute mufsten dann während der Nacht noch wiederbolt auf einige allzu freche Exemplare schiefsen, um dieselben wieder zu verscheuchen.

Am nächsten Morgen befürchtete ich zwar einen Angriff seitens der Hippopotamen auf mein Canoe, dieselben liefsen uns aber rubig abziehen, offenbar froh darüber, nun anch auf die Weide gehen zu können.

Das Wasser war wieder sehr bewegt, aufserdem hatten wir eine sehr starke Brise gegen uns, so dafs wir nur langsam fortkamen. Das Flufsbett war zum Überflusse reichlich mit Felsen besät, so dafs wir nicht selten in Gefahr kamen, unser Canoe zu zerschellen, und häufig genug konnten wir hören, wie wir eben an die Spitzen eines solchen scharfen Felsens anstreiften. Gegen 9 Uhr kam der Posten Lukulela in Sicht, nach einer weiteren Stunde trafen wir daselbst ein. Die "Hainaut". welche hei dem Tornado am vorhergehenden Tage etwas Havarie erlitten, lag hier vor Anker und wurde für die Fahrt nach dem Stanley-Pool etwas repariert. Leutnant Serulea, der Kommandant des Postens, empfing mich sehr liebenswürdig und wies mir eine recht angenehme Wohnung an.

Nachdem die "Hainant" gegen Mittag abgefahren war, machte ich mit Herrn Jacquier de Longprès, dem Stationsassistenten, einen Rundgang auf der Station. Der Kakao stand hier besser als in Coquilhatville, was ich dem offenbar besseren Boden zuschreibe; der Kaffee war auch gut gehalten; die ganze Station machte überhaupt einen recht netten Eindruck, eine Thatsache, die um so anerkennenswerter ist, als man hier nur eine geringere Zahl von Arbeiteru beschäftigte. Kautschuksamen waren erst ausgelegt worden, daher also war noch nichts vou den Pflanzen zu sehen. Einige alte Kautschuklianen hatte man beim Umlegen des Waldes geschont, dieselben waren ziemlich alt und gaben guten Kautschuk. Wenn die Eingeborenen im Walde eine solche Liane finden, so machen sie zunächst den Baun oben von den $Z$ weigen möglichst frei, bis sie die ganze Liane herunterziehen können, dieselbe wird darauf längs des Bodens möglichst ausgebreitet und durch Astgabeln oder Unterlagen von Holzklötzen und Steinen etwa einen Fufs über den Boden erhoben, dann 
erst werden in Abständen von etwa einem Fufs Einschnitte gemacht, aus denen dam die Latex in die zu diesem Zweeke untergesetzten Gefälse (meist Lehm- oder Thontöpfe) hineinläuft. Natürlich werden die Lianen von den Eingeborenen gewöhnlich so tief angeschnitten, dafs sie bereits nach einmaligem Anzapfen zu Grunde gehen. Trotz der rerschiedenen Behauptungen und Veröffentlichungen diesbezüglich, habe ich mich wäbrend meiner Reise überzeugen können, dafs man im Congo den Kautschukplanzen auch nicht nehr Schonung augedeihen läfst als in den anderen Ländern Afrikas. Die Regierung versucht zwar, durch Erlasse aller Art gegen den Raubbau zu arbeiten, doch sind es zum Teil die Ausführenden selbst, welche den Raubbau ermutigen, da sie dadurch einen grofsen momentanen Gewinn erzielen, der sonst ihren Nachfolgern in die Hände fallen würde. Leider waren an den Kautschuklianen hier in Lukulela weder Blïten noch Früchte zu finden, so dafs ich nicht die Art feststellen konnte.

Am Nachmittage des nächsten Tages lud mich der Kommandant zu einer Jagd auf Büffel und Elefanten ein. Wissend, dafs ich somit tiefer in die Wälder hineinkommen würde und daselbst vieles mir Neue zu seben bekommen würde, sagte ich sehr gern zu. Wir fubren daher noch am Nachmittage über den Congo hinüber und landeten zunächst an einer mit hohem Grase bedeckten Ebene, wo wir Büffelspuren in Menge fanden. Nachdem die nötigsten Vorbereitungen zur Errichtung des Lagers für die Nacht getroffen waren, brachen wir sogleich zur Jagd auf. Trotz der ganz frischen Spuren gelang es uns jedoch dennoch nicht, innerhalb der ersten zwei Stunden eines der Tiere zu sehen. Als dann ein plötzlich aufgejagter Leguan noch geschossen wurde, gaben wir die Jagd auf die Büffel auf, da die durch den Schufs gewarnte Herde sich nunmehr sicher doppelt vorsichtig bewegen würde, wenn sie nicht überhaupt entflohen war. Nachdem wir einen Sumpf überschritten hatten, drangen wir in einen daran angrenzenden dichten Wald ein. Nach verschiedenen Streifzügen, auf welchen wir sehr viele frische Elefanten- und Büflelspuren antrafen, 'wurden wir von unserem eingeborenen Fährtenfinder plötzlich gewarnt und stiefsen auch wirklich auf eine Herde von Wildschweinen. Im näehsten Augenblicke krachten schon unsere Schüsse auf die Tiere nieder. Die rneisten wurden verwundet, drei gelang es zu töten. Unterdessen war es nun auch Zeit geworden, an den Rückweg zu denken, damit wir noch die Flufsufer vor Anbruch der Dunkelheit erreichen könnten. Erst spät am Abend kamen auch unsere Leute mit den erlegten Wildschweinen an, von denen wir uns dann noch zum Abendessen einige saftige Stücke braten liefsen. Der Mond war bereits in seiner vollen Pracht aufgegangen, als wir uns zum Abend- 
essen niedersetzten, um sofort durch unsere Leute auf einige auf dem Flusse dahinschiefsende Canoes aufmerksam gemacht zu werden. Da uns diese fluchtähnliche Fahrt der Canoes verdächtig vorkam, riefen wir die Insassen der Canoes an. Dieselben ruderten daraufhin jedoch noch schneller. Leutnant Serulea, welcher bereits einige Zeit in der Gegend war, vermutete daher sehr richtig, dafs die Insassen des Canoes desertierte Soldaten aus Irebu seien, welche nach dem französischen Posten Lukulela (français) entweichen wollten, und sandte ihnen daher einige Kugeln nach. Auch wurde sofort unser Canoe zum Einfangen der Leute nachgeschickt. Diesen gelang es jedoch, sich im Schatten einer Insel zu verbergen, wo sie dann nicht mehr zu finden waren. Erfolglos kehrten daher unsere Leute zurück.

Schon um 4 Uhr setzten wir am nächsten Morgen unsere Jagd weiter fort. Da wir vermuteten, dafs das durch unsere Schüsse gewarnte Wild sich nuu weiter fort legeben habe, fuhren wir den Strom etwa eine Stunde weiter hinauf. Am Rande eines Sumpfes wurde dann ein Lager anfgeschlagen. Das Überschreiten dieses Sumpfes, welcher uns von dem Walde trennte, war mit einigen schwierigkeiten rerknüpt, schon bei den ersten Schritten sank man bis über die Kniee ein. Nachdem wir endlich in dem etwas trockneren Walde angelangt waren, gingen wir sehr vorsichtig vor, da wir frische Elefantenspuren in Menge bemerkten und daher die Tiere in unmittelbarer Nähe vermuteten. Nach etwa $1^{1 / 2}$ Stunden gab unser führender eingeborener Elefantenjüger, welcher weniger ein guter Schütze als ein vorzïglicher Fährtenfinder war, ein Zeichen, woraufhin wir unseren Leuten zurückzubleiben befahlen und nun init doppelter Vorsicht vorschlichen. Bald sahen wir zwei fressende Elefinten vor uns, welche uns noch nicht bemerkt hatten. Bis auf $40 \mathrm{~m}$ gelang es uns unbemerkt heranzukommen, als das Männchen sich plötzlich wendete und uns bemerkte. Ehen sehien sich das Tier mit weitabstehenden Ohren auf uns werfen zu wollen, als auch schon unsere Schïsse erklangen und der Riese lautlos zusammenbrach, die Zähne in den Boden stofsend. Es war ein Anblick, den niemand vergessen wird, der je etwas ähnliches gesehen. Das Weibchen gab nun sofort Fersengeld. Einige ihm nachgesandte Schüsse verwundeten es zwar, konnten ihm aber keinen besonderen Schaden zufügen, da wir nur den hinteren T'eil des Tieres zum Ziel nehmen konnten. Dem gestïrzten Elefanten jagten wir nun nochmals drei Kugeln in den Kopf, um ihm vollends den Garaus zu machen. Unsere unterdessen herbeigekommenen Leute benahmen sich wie toll vor Freude auf die Aussicht, nun einmal wieder tïchtig Elefantenfleisch zu essen zu bekommen, und führten einen wahren Freudentanz um den gefällten Riesen herum auf. Nachdem 
wir darauf den Befehl gegeben, das Tier zu zerlegen und die Teile in unser Lager zu bringen, brachen wir aut', um nach weiterer Beute zu suchen. Bald traten wir in einen wundervollen Wald hinein, welcher von Elefantenpfaden nach allen Richtungen hin durchkreuzt war. An einigen sumpfigen Stellen sah man, dafs sich noch kurz ror uns die Tiere darin herumgewälzt hatten, genug, wir sahen hier, dafs wir uns inmitten eines von Elefanten dicht belebten Striches befanden. Unser Jagdeifer wuchs natürlich nun nach dem erfolgreichen Morgen sehr bedeutend. An einem Baum, dessen sehr saftreiche Rinde die Elefanten sehr gern zu fressen schienen, sahen wir sowohl an der ganz frisch abgeschälten Rinde wie an den noch rauchenden Exkrementen, dals wir den Tieren sehr nahe sein mufsten. Eine über uns in den Bäumen sich aufhaltende Affenherde verdarb uns aber das Vergnügen durch das wüste Geschrei, welches die Gesellschaft, die offenbar nie rorher einen weifsen Menschen zu Gesicht bekommen, ausstiels, als sie uns bemerkte. Wir wurden so ärgerlich über die uns nun von Baum zu Baum verfolgende Herde, dafs wir schliefslich beschlossen, die Tiere zu verjagen, da sonst weitere Erfolge unmöglich waren. Es blieb uns daher nichts anderes übrig, als einige der Tiere herunterzuknallen. Ruhig blieben dieselben sitzen, als unsere Kugeln um sie herumpfiffen. Als sie aber, nachdem einige heruntergefallen, doch einsahen, dafs unsere Gewehre nicht ganz harmlose Dinge waren, entflohen sie unter entsetzlichem Geheul. Nun erst konnten wir weiter den Spuren der Elefanten folgen. Gegen Mittag gelang es uns deun auch wieder, an einige Tiere heranzukommen, welche wir allerdings wegen des sehr dichten Unterholzes nur zum Teil sehen konnten. Wir verwundeten das eine offenbar sehr schwer, denn der Blutverlust des Tieres mufste nach den Spuren, welchen wir nachher folgten, sehr bedeutend sein, und an verschiedenen Stellen schien es, als sei das Tier zusammengebrochen, aber es gelang uns dennoch nicht, die Spuren weiter zu verfolgen, da sie sich allmählich in der alten Spur wiederfanden und uns so immer wieder irre leiteten. Nach einigen Stunden vergeblichen Suchens nach dem verwundeten Elefanten, von dem wir berechtigt waren zu glauben, dals er unterdessen bereits vollständig zusammengebrochen sei, war es denn auch Zeit, an die Rückkehr zu denken, besonders da sich in unseren Magen bald eine bedeutende Leere bemerkbar machte. Nach einem Kompas durch Dick und Dünn marschierend, gelangten wir, nachdem wir einige Sümpfe überschritten hatten, in welche wir bis über die Hüften einsanken, endlich etwa eine Meile unterhalb unseres Lagers an die Flufsufer.

Wir arbeiteten uns nun bis auf Hörweite auf unser Lager zu durch und wurden schliefslich im Canoe abgebolt. Unser Koch hatte während unserer Abwesenheit das Essen, bestehend aus Wild- 
schweinbraten, für uns zurechtgemacht, so dafs wir sogleich unseren Hunger stillen konnten. Erst um $5 \mathrm{Uhr}$ hatten unsere Leute den zerlegten Elefanten vollständig bis zum Flusse geschafft und in das Canoe eingeladen. Natürlich stellte sich bald heraus, dafs die nichtswürdigen Kerle wieder grofse Mengen Fleisch im Busch versteckt hatten, um es danu über Nacht oder am nächsten Tage abzuholen. Einige Leute, welche wir dabei ertappen kounten, wurden bestraft, das versteckte Fleisch, welches wir nach einigem Suchen doch bald fanden, ihnen natürlich auch wieder abgenommen. Auf der Rückfahrt hatteu wir noch das Glück, einige Nilpferde auf einer Sandbank, vollständig aufserhalb des Wassers, beobachten zu können. Ziemlich ermüdet kamen wir ain Abend in Lukulela (bèlge) wieder an. Natürlich war der folgende Tag, an welchem das Fleisch verteilt wurde, ein Festtag für die Lente der Station. Ein jeder bekam da seinen Teil und hatte auch Grund, zufrieden zu sein, denn an einem ausgewachsenen Elefanten sitzt eine enorme Masse von Fleisch; dazu hatten wir dann ja auch noch die drei erlegten ziemlich grolsen Wildschweine, von denen wir drei Europäer doch nur sehr wenig hatten verzehren kömnen.

Da ich in Lukulela hörte, dafs sich vielleicht bald eine Gelegenheit linden werde, den Sanga von Bonga aus zu befahren, so lag mir natürlich daran, möglichst bald nach Bonga zu kommen. Leutnant Serulea wollte mich bis Bonga hinübergeleiten, da er dort den Herren einen Besuch versprochen hatte. Wir hatten unsere Abreise von Lukulela auf den 25. Juli angesetzt, konnten aber erst am Nachmittage fortfahren, da das Wasser im Congo am Vormittage so hohe Wellen schlug, dafs gar nicht daran zu denken war, das andere Ufer zu erreichen. Trotz des noch immer gefährlichen Wellenganges erreichten wir bald das französische Ufer und sprachen dort auf dem französischen Lukulela-Posten vor. Nach kurzem Aufenthalte fuhren wir bald in den Likensi-Arnı des Congo, welcher zum Sanga hinüberführt, ein, mufsten aber für die Nacht unser Lager aufschlagen, ohne Bonga erreichen zu können, da wir von der Dunkelheit überrascht wurden und das Fahren in dem engen, von Nilpferden wimmelnden Kanale nicht ohne Gefahr war. In dieser Nacht bekamen wir dann auch schon einen Vorgeschmack von den Bonga-Moskitos, so dafs wir nicht an schlafen denken konnten. Mit Tagesgrauen brachen wir am 26. Juli wieder auf. Nach etwa einstündigem Rudern erreichten wir den Sanga. Um 7 Uhr kam Bonga in Sicht. Ich fand bei dem Vertreter der Société Anonyme Bèlge Aufnahme für die Zeit meines Aufenthaltes bis zur Abreise nach dem Ngoko. Bis dahin sollte allerdings noch eine geraume Zeit vergehen. 


\section{Kapitel.}

\section{Sanga-Ngoko-Reise und Riickreise nach Kamerum.}

In Bonga hatte ich nun einen Ort erreicht, in dem ich die ersten Nachrichten aus der Südostecke unseres Kamerun-Gebietes einziehen konnte. Ein Angestellter der Société Anonyme Belge war gerade vom Ngoko heruntergekommen und konnte mir die Verhältnisse daselbst schildern. Wie sich später herausstellte, hatte er allerdings Vieles übertrieben, doch waren einige seiner Erzählungen für mich von Nutzen. Von Herrn Oberleutnant Dr. R. Plebn hatte ich einen Brief in Bonga vorgefunden, in dem er mich auf seinen Mangel an Leuten und die Unmöglichkeit aufmerksam machte, am Ngoko Träger zu engagieren. Er riet mir, Leute vom Congo mitzubringen. Das war nun leider nicht mehr ausführbar, da im Congostaate erst vor kurzem ein Erlals des Gouverneurs erschienen war, wonach die Ausfuhr von Arbeitern aus dem Gebiete des Staates verboten war. Hätte ich nicht in Kamerun den Schilderungen des Herrn Oberleutnants v. Carnap entnehmen müssen, dafs die Trägerfrage im Ngoko-Gebiete leicht zu lösen sei, so hätte ich vom Congostaate mir die Erlaubnis erbeten, Träger nach dem Ngoko hinaufnehmen zu dürfen; nun war das hier im Innern nicht mehr möglich, denn eine solche Erlaubnis konnte mir nur der Gouverneur in Boma geben. Die Verhältnisse lagen also für einen guten Fortgang der Expedition denkbar ungünstig. Dazu kam noch, dafs die Aussicht auf eine Gelegenheit, den Sanga hinaufzukommen, immer bedenklicher wurde, um so mehr, da das Wasser gauz bedeutend gefallen war.

Am 29. Juli traf der „Frédéric", ein Dampfer der „Nieuwe Afrikaansche Handels-Vernootschap" mit Elfenbein von oberen Ubangi ein. Der Kapitän dieses Dampfers führte ein grofses Canoe bei sich, welches er am Stanley-Pool zu verkaufen gedachte. Da ich schon seit längerer Zeit nach einem solchen gesucht hatte, so nahın ich denn anch die Gelegenheit wahr und erwarb mir dasselbe für 250 Fres. Nun versuchte ich alles mögliche, um Ruderer für das Canoe anzuwerben, damit ich dann die Fahrt nach dem Ngoko im Canoe unternehmen könnte. Da der französische Beamte, welcher 
in Bonga stationiert war, unter den Eingeborenen sehr wenig Einflufs besafs, so verzögerte sich die Sache immer mehr, so dafs ich mich schlieficlich an das holländische Haus wendete, um von deren Leuten eventuell einige für kurze Zeit zu erhalten. Schliefslich war denn auch alles so weit vorbereitet, dafs ich schon einen bestimmten Tag zur Abreise in Aussicht nahm, als am 2. August ein Boot aus Wesso am Sanga eintraf, mit der Nachricht, dafs der von der „Südkamerun-Gesellschaft ${ }^{\star}$ gemietete Dampfer bereits in zwei bis drei Tagen eintreffen würde. Schon am nächsten Tage erschien derselbe mit dem Direktor der Gesellschaft, Herrn Langheld, und dem Hauptagenten der "Société Anonyme Belge" am Sanga, Herrn van Beers, an Bord. Herr Langheld war direkt rom Ngoko gekommen und wollte nun versuchen, im Congo Leute für die Gesellschaft anzuwerben. Da er noch nicht von dem neuen Erlasse des Gouverneurs des Congostaates gehört hatte, machte ich ihn darauf aufmerksam, dafs er dort wenig Erfolg haben werde; doch glaubte er, in den Gegenden, in denen er früher als Agent einer belgischen Handelsgesellschaft thätig gewesen war, sehr leicht wenigstens genügend Leute zur Equipierung seines Dampfers zu finden. Er gedachte, in wenigen Tagen wieder zurückzukehren, um dann wieder nach dem Ngoko hinaufzufahren. Natürlich zog ich vor, in diesem Falle auf die Canvereise zu verzichten und bis zur Rückkehr des Dampfers zu warten. Meine Zeit füllte ich, soweit es hier in Bonga möglich war, durch Exkursionen und Nachholen laufender Arbeiten aus.

Ich hatte in einem kleinen Buschwalde in der Nähe meines Hauses ein Exemplar der Landolphia Klainei entdeckt, welche einen sehr guten Kautschuk liefert. Leider sind die Stämme dieser Art verhältnismälsig dünn, so dafs es immer eine geraume Zeit dauerte, ehe ich genügend Saft zum Experimentieren einsammelte. Diesen koagulierte ich in der verschiedensten Weise. Durch Zusatz von Bossassangasaft erzielte ich eine sofortige Koagulation zu einer flockigen Masse, welche dann zusammengeprefst einen Kautschuk ergab, welcher ähnlich wie der "Kassai-rouge"-Kautschuk fast durchsichtig war. Da Landolphia florida in der Nähe vorhanden war, sammelte ich auch von dieser Latex ein und versuchte, auf alle mögliche Arten einen brauchbaren Kautschuk daraus zu gewinnen, mufste die Hofinung darauf aber bald aufgeben. Es gelang mir nur nach Vermischung mit dem Safte der Landolphia Klainei ein Produkt zu erzielen, welches bedeutend schlechter war als das von der reinen Milch der L. Klainei gewonnene, sich aber doch verwerten lassen würde. Es ist übrigens auffallend, dafs die Milch der L. florida sofort gerinnt, sobald sie mit der Luft in Berührung kommt; um sie 
mit der der Landolphia Klainei zusammen koagulieren zu können, hatte ich sie vorher mit Wasser zu rerdünnen, damit auf diese Weise eine bessere Verbindung der beiden Milcharten hergestellt werden konnte. Es wäre sehr wünschenswert, dafs derartige Versuche, Milch einer kautschukliefernden Pflanze mit der verwandter Arten, welche keinen Kautschuk geben, zu koagulieren, weiter fortgesetzt würden. Ich konnte diese Experimente leider damals nicht fortführén, da ich bald die vorhandenen Pflanzen der Landolphia Klainei derartig angezapft hatte, dafs ich nicht mehr genügend Latex erhielt.

Die in der Umgebung von Bonga vorhandenen Ficusarten prüfte ich auch alle auf ihren Kautschukgehalt, konnte aber unter den sämtlichen Arten keine ausfindig machen, welche sich hätte verwenden lassen; stets war das Endresultat ein gleiches, man erhielt selbst bei Anwendung der schärfsten Säuren eine äufserst harzreiche, vogelleimähnliche Masse. Bei den grofsblättrigen Arten aus der Verwandtschaft der Ficus Vogelii und Ficus Preussii war diese meist dicker und weniger von Harzen durchsetzt als bei den Arten aus der Verwandtschaft der Ficus salicifolia, während alle ranhblättrigen Arten überhaupt nicht in Betracht kommen konnten, da sie derartig harzreich waren, dafs man nur mit Mühe die Masse von den Händen freimachen konnte. Bossassangasaft hatte bei der Ficusmilch entweder gar keinen oder nur sehr geringen Einflufs. Die Bossassangapflanze, welche ich nun allenthalben antreffen konnte, heifst in ihren sämtlichen Arten bei den Bangalas ūnd Wangatas übrigens auch Makabo, ja sogar in einigen Gegenden im Mittelcongo-Gebiet ist sie unter letzterem Namen bekannter.

Tag für Tag verging unterdessen, und doch war noch nichts von Herrn Langheld mit dem "Major Cambier" oder von anderen Dampfern, welche den Sanga hinauffuhren, zu sehen. Nach dem Ubangi schien die Verbindung bedeutend güustiger zu sein, denn es trafen nicht weniger als drei Dampfer auf dem Wege dorthin in Bonga ein. Diese Dampfer kommen in Bonga meist ganz unerwartet an und gehen schon nach ein- bis dreistündigem Aufenthalte häufig weiter flufsaufwärts. So ist man denn gezwungen, sich stets fertig zu halten, damit man beim Eintreffen eines Dampfers die Chancen nicht verliert, mit demselben mitfahren zu können. An längere Exkursionen ist bei diesen Zuständen dann natürlich auch nicht zu denken. Die Umgebung von Bonga speziell war auch nicht besonders interessant, da das Land mehr oder minder kultiviert war oder aus Steppen mit vielen Sümpfen bestand. Ich bereute natürlich sehr, nicht länger in Lukulela geblieben zu sein, denn dort wäre ich persönlich viel besser aufgehoben gewesen, und hätte auch mehr zur Erreichung der Ziele der Expedition thun können. In 


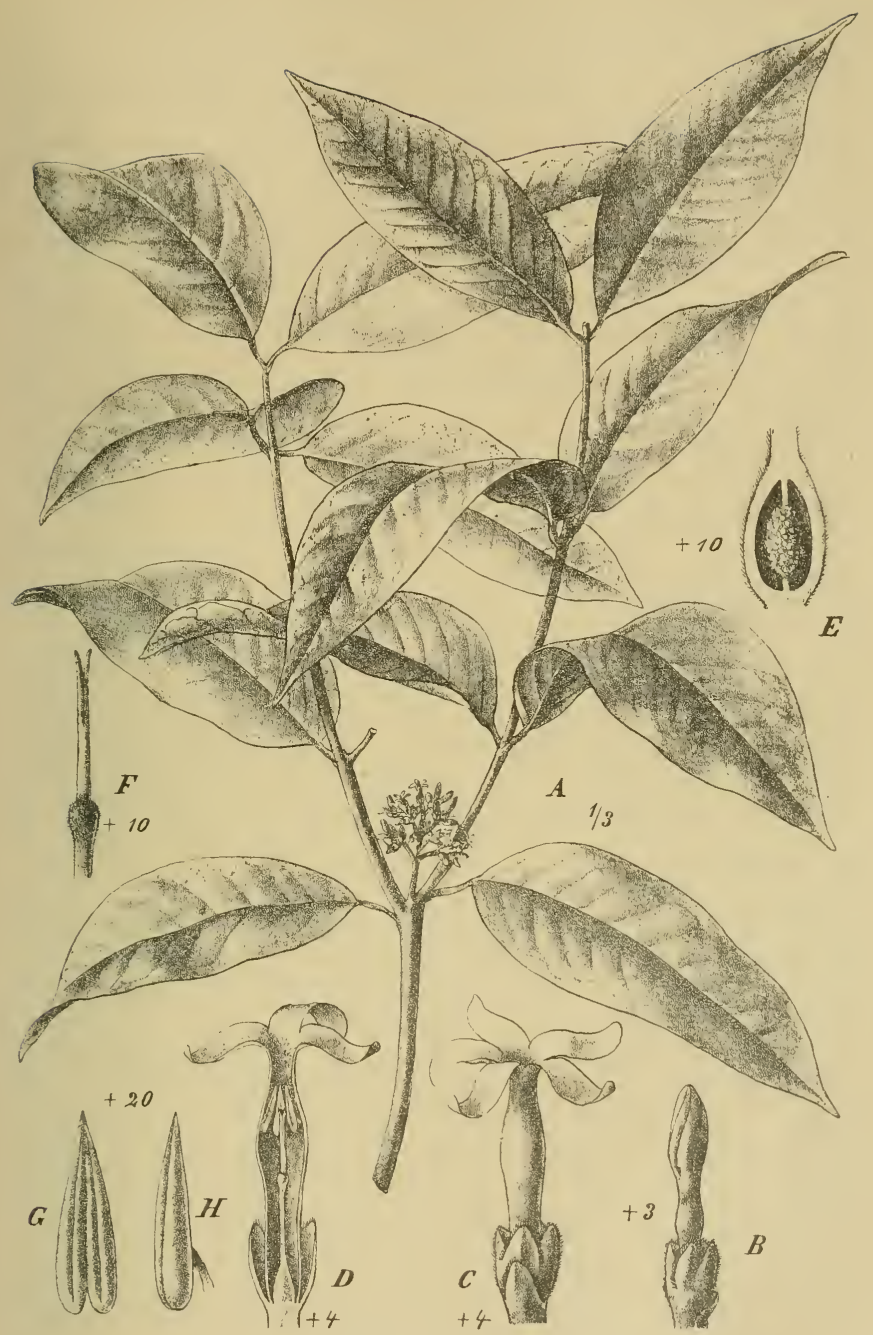

Landolphia Klainei Pierre.

A Zweig, B Knospe, C Blüte, D Längsschnitt durch die Blüte, E Durchschnitt durch den Fruchtknoten, F Fruchtknoten und Griffel, G Anthere von vorn, H dieselbe von der Seite. 
Bonga waren die Lebensmittel auch noch sehr spärlich, so dafs wir sogar Adler und Papageien mit Genufs zum Abendessen verzehrten. Ich teilte von den von mir mitgenommenen Lebensmitteln, soweit dies möglich, mit den Agenten der Handelsgesellschaft, kaufte auch noch rerschiedenes von dem holländischen Hause, mulste aber auch etwas für die Sanga-Reise mitnehmen, da ich dort erst gar nichts zu erwarten hatte. In Ngoko hatte ich wieder genügend, da ich vorsichtigerweise vier Trägerlasten dorthin hatte voraussenden lassen. Auch an Aufhetzungen liefs man es in Bonga nicht fehlen; so wollte ich mich z. B. eines Tages bei einem Unteragenten des holländischen Hauses; welcher den gerade abwesenden Herrn van $\mathrm{Z}$ oysten vertrat, erkundigen, ob denn nicht bald einer ihrer Dampfer den Sanga hinauffahre, als ich zu meinem nicht geringen Erstaunen hören mufste, er könne mir nicht die Erlaubnis geben, da ihm ron einem der Angestellten der Société Anonyme Bèlge mitgeteilt sei, ich reise unter falschen Angaben, sei in Wirklichkeit aber nur ein Agent der Südkamerun-Gesellschaft, und könne somit als ein Angestellter einer Konkurrenzfirma natürlich nicht die Erlaubnis bekommen, die Dampfer des holländischen Handelshauses zu benutzen. Selbst wenn man also zu einem gemeinnützigen Zwecke in eine Gegend entsendet wird, in der das Reisen äufserst strapaziös und aufreibend, ja sogar nicht ungefährlich ist, mufs man sich diesen gehässigen Neidern und Reden aussetzen. Es ist dieses nicht das einzige derartige Beispiel, welches ich anführen könnte, ich habe deren in Menge; ja selbst nach meiner Rückkehr nach Europa hatte ich noch einmal ein solches kennen zu lernen.

Glücklicherweise traf der „Major Cambier“ am 20. August in Bonga ein. Herr Langheld hatte auf seiner Reise keinen Erfolg gehabt und kam nun mit derselben sehr schwachen Besatzung zurück. Da er erst noch den Dampfer laden lassen mufste, so wurde unsere Abreise auf den 23. August festgesetzt. Die beiden noch übrigen Tage benutzte ich nun noch dazu, meine sämtlichen Lasten gründlich durchtrocknen zu lassen und dann alles fertig zu verpacken. Von der belgischen Gesellschaft kaufte ich noch einige Handelsartikel, welche im Ngoko-Gebiete am meisten Absatz finden sollten. Herr Langheld war auch so freundlich, mir zu versprechen, etwaige noch fehlende Sachen mir später abzulassen.

Am frühen Morgen des 23. August war die Fracht auf dem "Major Cambier" fertig gestaut, und somit stand unserer Abfahrt nichts mehr im Wege. An der einen Seite führten wir einen grofsen Leichter mit, an der anderen mein grofses Canoe, welche beiden Fahrzeuge dazu dienen mufsten, das zur Heizung der Maschine nötige $\mathrm{Holz}$ aufzunehmen; aufserdem hatten die eingeborenen 
Passagiere und die Holzschläger, sofern sie nicht direkt auf dem Dampfer gebraucht wurden, sich dort aufzuhalten. Ein am Abend vorher ansgebrochener Tornado hatte die Luft bedeutend abgekühlt, so dafs der Morgen mit der eben anfgehenden Sonne eine wirkliche Erholung nach den heilsen Nächten und Tagen war. Bald waren wir um eine vorspringende Landzunge in den wirklichen Sanga eingebogen, und Bonga entschwand unseren Blicken. Nach kurzer Zeit passierten wir die Ausmündung des Likensi-Kanals, dessen ganze Umgelung aus sumpfigen Grassavannen besteht, welche aber immer mehr verschwanden, je weiter wir flufsaufwärts fuhren. Der Wald wurde bald immer vorwiegender, ja das für uns jetzt linke Ufer war schon ohne Unterbrechung dicht bewaldet. Am Rande der Inseln und der sumpfigen Flufsufer bildete eine Euphorbiacee, welche von den Eingeborenen Bubandja genannt wird, häufig dichte Gebüsche, in deren Schatten die Webervögel gern ibre Nester banen, denn da wo diese Bubandjapflanze am Flufsrande auftritt, ist das Wasser stets tief und die Nester sind daher weniger Verfolgungen ausgesetzt. Auf Flufskarten bilden derartige Bubandjagestrüppe nicht selten gute Kennzeichen. Bald wurde es bedeutend heifser, hin und wieder zeigte sich der Kopf eines trägen Nilpferdes oder eines auf dem Sande sich sonnenden Krokodils. Wie Herr Langheld mir mitteilte, stieg das Wasser des Flusses sehr bedeutend, es mufsten also im Quellgebiete des Sanga oder eines seiner bedeutenderen Nebenflüsse starke Regen gefallen sein. Wir passierten einige Inseln, welche alle dicht mit Gebüschen oder Wald bedeckt waren. Gegen $1 \mathrm{Uhr}$ mittags liefen wir an, da wir sonst zu befürchten hatten, dafs unser Holz vollständig verbraucht werden würde. Fast die ganze Besatzung des Dampfer's wurde nun mit Beilen ansgerüstet und mufste znm Holzschlagen in den Wald hinein. Ein jeder der Leute hatte eine bestimmte Menge Holz zu schlagen; sobald er damit fertig war, war er frei. Hatte irgend jemand eine härtere Strafe verdient, so wurde er einfach zum Schlagen einer doppelten Menge von Holz verurteilt, das half gewöhnlich. Der Wald, an welchem wir angelegt hatten, war sehr arm an Unterholz, aber dicht mit Phrynium und Comelinaceen bedeckt, was der ganzen Landschaft einen eigentümlichen, tropischen Anstrich gab, besonders wenn sich hier und dort Calamusarten zeigten. Auffallend war der Reichtum von Elefantenspuren, welche wie ein dichtes Netzwerk den Wald nach allen Richtungen durchquerten. Offenbar hatte kein Dampfer vor uns hier angelegt, denn die Holzverhältnisse waren hier so günstig, dafs einige unserer Leute schon vor Eintritt der Dunkelheit die ihnen vorgeschriebene Menge zusammengebracht hatten. Diejenigen, welche noch während der Dunkelheit zu arbeiten 
hatten, brachten nun Kopalstücke hervor, welche sie als Fackeln rerbrauchten. Dieselben geben ein gutes Licht und rerbrennen so langsam, dafs ein etwa faustgrofses Stück für die ganze Nacht ausreicht. Allenthalben sah man diese Kopalfeuer im Walde noch bis tief in die Nacht hinein. Schon früh am nächsten Morgen ging es weiter. Bereits un 4 Uhr mufste alles an Deck aufstehen, um das am Nachmittage und Abend geschlagene und gespaltene Holz zum Gebrauch zu verstauen. Moskitos summten während dieser Zeit noch in Mengen um uns herum und benutzten jede Gelegenheit, uns zu peinigen. Nach etwa einstündiger Fahrt passierten wir eineu Ausfluls des „Likuala aux herbes", welcher hier in den Sanga mündet, während aufserdem ein anderer Arm in den Ubangi einlaufen soll. Es ist interessant und recht bezeichnend für das Konzessionensystem der Franzosen, dafs man hier zwischen dem "Likuala aux herbes", welcher, ron Norden kommend, mit dem Sanga parallel läuft, und dem Sanga eine Landkonzession ausgegeben hat, welche fast nur aus grofsen Sumpfflächen, die mit Wassergras bedeckt sind, besteht. Bedenkt man nun, dafs der Hauptanziehungspunkt zum Ankauf dieser Konzessionen der vermutliche Kautschukreichtum der Gegenden ist, so wird man wohl begreifen können, dafs die durch Ankauf rou nutzlosen Sümpfen enttäuschten Konzessionäre sobald als möglich rersuchen werden, ihre Konzessionen, auf denen sie kaum genug trockenen Boden haben, um ein Haus zu bauen, zu verkaufen.

Die beiden Ufer des Sanga sind in etwa ein Dutzend Konzessionen geteilt worden, zu welchen kleinere oder gröfsere Gebiete gehören, welche sich rom Flufsufer weg ins Land hinein ausdehnen. Ton dem Sanga, unterhailb der Einmündung des Ngoko, ist bis jetzt jährlich kaum mehr als eine Tonne Elfenbein heruntergekommen; auch andere Erzeuguisse sind bisher noch nicht in Betracht zu ziehen, denn die Fabrikation des Kautschuks ist den Eingeborenen bis heute noch nicht bekannt. Das ganze Gebiet steht mit Ausnahme einiger weniger Erhebungen, welche die Eingeborenen bereits zur Errichtung ihrer Iörfer beschlagnahmt haben, für mindestens einige Monate im Jahre unter Wasser, ist also dann nicht benutzbar. In der trockenen Jahreszeit, selbst beim niedrigsten Wasserstande, durchziehen tiefe Sümpfe wie ein Netzwerk die Wälder und hemmen so das tiefere Eindringen ins Innere. Wesso, die Haupthandelsniederlassung am Sanga, unterhalb der Ngoko-Mündung (etwa eine halbe Stunde unterhalb derselben), dürfte fast der einzige Ort sein, ron wo aus ein Vordringen nach der Küste zu für Handelszwecke möglich und rentabel ist. Den gröfsten Teil seiner Produkte hat Wesso stets rom oberen Sanga und aus den Ngoko-Faktoreien bezogen. Ich halte es somit für mindestens sehr fraglich, ob eine 
einzige Konzessionsgesellschaft an dem unteren Sanga grofse Gewinne erzielen würde, und dort sitzen nunmehr etwa sechs verschiedene Gesellschaften. Bonga, das seinen Handel hauptsächlich mit den Lenten rom Likuala, Likuba und eventuell vom Alima (indirekt) treibt, schliefse ich aus. Dieses würde übrigens auch in Zukunft das ganze Elfenbein, welches die Bonga-Händler vom Sanga und Ngoko herunterbrachten, einbülsen. Ich will hier nicht unerwähnt lassen, dafs bis jetzt über den Sanga noch recht wenig bekannt ist, und dafs die Gebiete zwischen ihm und dem Ubangi für den Europäer noch vollständig „terra iucognita“ sind; doch ist nach allem, was die Eingeborenen erzählen, nicht viel ron dorther zu erwarten. Über die vielen Konzessionen am oberen Sanga kann ich kein Urteil fällen, da ich diese Gebiete nicht aus eigener Anschaunng kenne. Wie gut unterrichtete Herren mir sagten, welche dort gewesen sind, liegen auch da die Verhältnisse nicht sehr viel anders. Die Landesprodukte sind dort wohl reicher rorhanden und das Bereisen des Landes bedeutend einfacher, doch sollen die einzelnen Konzessionsgebiete so klein sein, dafs ein wirklich rentables Ausbeuten der Produkte nur in wenigen möglich ist. In der näheren Zukunft wird man sich wohl anf Kautschuk und Elfenbein als alleinige Exportartikel beschränken müssen, da die bedeutenden Transportunkosten die Ausfuhr anderer Produkte unmöglich machen. In Bonga spielt der Tauschhandel mit Tabak und Palmenöl rom Likuala und Likuba augenblicklich die Hauptrolle, beides Artikel, welche z. B. am Ngoko zu den besten Tauschwaren zählen, so dafs sich die Handelsniederlassungen in Bonga ganz gut gewissermafsen als Zwischenhändler-Stationen rentieren. So werden z. B. die Tabakrollen mit 2 Mitakus (=10 Ctms.) anfgekauft, um dann etwa für 1 Fre. wieder losgeschlagen zu werden; dabei ist nicht zu vergessen, dafs der den Tabak verkaufende Likuba- oder Likuala-Mann selten mit den erhaltenen Mitakus fortgeht, sondern diese wieder bei dem Kaufmann gegen Stoffe oder andere europäische Artikel eintauscht, ebenso lälst sich der Europäer am Ngoko für seine Tabakrolle nicht einfach Geld gebeu, sondern Landesprodukte, welche er zu einem ron ihm bestimmten Satze annimmt.

Schon bevor wir den "Likuala aux herbes"-Ausflufs bemerken knnnten, wurde uns seine Nähe durch grolse Mengen treibender Tassergräser und fortgerissener Gesträuche bereits angezeigt. Es war fast gefährlich, zwischen den treibenden Massen den Dampfer hindurchzusteuern, denn einige hatten eine ziemliche Ausdehnung und Stärke. Die Mündung des Flusses ist ein Eldorado für Nilpferdjäger. Stets sind die Tiere in dem für sie so nahrungsreichen Gebiete in Menge anzutreffen, selbst in den Jahreszeiten, in denen 
man ihrer selten ansichtig wird, zur Zeit der hoheu Flut. Auch wir sahen einige Trupps im Wasser spielend, konnten aber leider nicht zu Schufs kommen. Dafs die Eingeborenen die Tiere nicht allein durch Harpunieren und Schiefsen erlegen, bewiesen einige grofse Fallen, welche wir hier sahen. Dieselben waren ähnlich wie ein Schaffot hergestellt mit einem von oben herabhängenden Speere. In welcher Weise die Tiere angezogen wurden und wie die Falle sonst zusammengesetzt war, konnte ich vom Dampfer aus nicht genau sehen. Krokodile wurden immer häufiger, je weiter wir flufsaufwärts kamen. Da Sandbänke jetzt selten waren, lagen die Tiere meist auf umgefallenen oder überhängenden Baumstämmen in der Sonne. Herrn Langheld gelang es, mehrere zu schiefsen, da dieselben in ihren Todeszuckungen aber stets in das Wasser zurückfielen, so konnten wir keines derselben bekommen, so gern wir auch das Fleisch für unsere Leute gehabt hätten, deun sämtliche Stäıme am Congo verzehren Krokodilfleisch mit dem grölsten Behagen. Ebenso wie das Fleisch der Elefanten und Nilpferde wird das Krokodilfleisch langsam über Feuer getrocknet, um es haltbarer zu machen. $\mathrm{Zu}$ diesem Zwecke werden kleine, etwa $1^{1 / 2}$ bis ¿ Fuls hohe Stellagen erbaut, welche oben mit dünnen Zweigen überdeckt sind; nachdem unter der Stellage ein Fener gemacht ist, wird das in 1 bis 2 Pfund schwere Stücke geschnittene Fleisch mit den Knochen auf die Stellage gelegt. Nach etwa einem halben Tage ist das ganze Fleisch dann infolge des stets unterhaltenen Feuers von einer vollständig ausgedörrten Kruste umgeben, welche es ror Fäulnis bewahrt. Selbst wenn das Fleisch zu faulen begiunt, ver achtet es der Congo-Neger nicht, obgleich ich mich nicht elinnern kann, je einen Congo-Neger rohes Fleisch essend gesehen zu haben. Das Verzehren verfaulten Fleisches und anderer in Fäulnis begriffener Nahrungsmittel hat bei der Leuten sehr häufig höchst widerliche Hautkrankheiten zur Folge, welche von Europäern nicht selten für Syphilis angesehen werden, obgleich sie nicht das geringste damit zu thun haben. Auch auf dem Dampfer hatten wir stets eine Anzahl von Leuten, die an merkwürdigen Hautkrankheiten litten. Dieselben, wie überhaupt alle Kranken, mulsten gewöhnlich um 8 Uhr bei Herrn Langheld antreten, um sich dann untersuchen zu lassen. Hautkrankheiten wurden im Falle offener Wunden mit Jodoform meist erfolgreich behandelt. Es gab so auf dem Schiffe für Herrn Langheld, welcher dasselbe in Ermangelung eines Kapitäns selbst führte, stets viel zu thun; ich versuchte mich dabei so nützlich wie möglich zu machen. Da wir genügend mit $\mathrm{Holz}$ versehen waren, konnten wir am zweiten Tage unserer Reise etwas länger fahren und machten daher erst 
um 2 Uhr Halt. Der Wald, an welchem wir damals anlegten, war äufserst charakteristisch für die Region. Die Mehrzahl der gröfseren Bäume stand, wie es die Pandanusarten zu thun pflegen, auf hohen Stelzwurzeln. Das liefs sich auch alles sehr leicht erklären, denn schon jetzt bei dem noch niedrigen Wasserstande kounte man kaum in irgend welcher Richtung den Wald durchstreifen, überall stiefs man auf Wasser. Da Affen sehr bäufig waren, nahm ich mein Gewehr mit und schofs einen derselben, um für die Leute etwas Fleisch zu besorgen; da mein Junge, Maketu, und Herrn Langhelds Junge auch je noch einen schossen, so konnten die Leute am Abend einen grofsen Schmans abhalten, d. h. erst nachdem sie mit dem Schlagen des Holzes fertig waren. Doch wenn etwas derartiges in Aussicht steht, geht bei dem afrikanischen Neger die Arbeit häufig merkwürdig schnell vor sich. Vou Landolphien oder sonstigen Kautschukpflanzen war in dem Walde nichts zu sehen, wohl aber gab es riesige Rotholzbäume, deren $\mathrm{Holz}$ bei den Eingeborenen sowohl wegen seiner Härte als auch zum Rotfärben des Körpers geschätzt wird. Auf einer Streiferei im Walde stiefs ich plötzlich auf einen eigenartigen breiten Weg, welcher vom Flufsufer direkt ins Innere führte und mit quergelegten glatten Baumästen in Abständen bedeckt war. Diesen Weg verfolgend, trat ich bald in eine Lichtung, wo einige bereits halbfertige, aus Rotholz gearbeitete Canoes lagen. Leere Plätze bewiesen, dafs die Eingeborenen an dieser Stelle bereits mehrere Canoes hergestellt hatten, und zwar, wie die beiden noch rorhandenen, von ziemlichen Dimensionen. Auf dem mit Baumästen belegten Wege wurden dieselben zum Wasser geschleift. Von der Bevölkerung selbst war keine Spur zu entdeckeu, weder am vorhergehenden Tage, noch heute hatten wir ein Dorf zu Gesicht bekommen. Es giebt deren wohl sicher einige, welche versteckt in der Nähe der Flufsufer liegen, sicher aber ist das untere Sanga-Gebiet äufserst dünn bevölkert. Die Wälder sind alle von Elefanten- und Büffelspuren durchzogen, selbst Spuren von Nilpferden konnte man bis tief in den Wald hinein beobachten, besonders an Stellen, wo infolge des Zusammenbrechens eines grofsen Urwaldbaumes eine Lichtung entstanden war, in der junges Gras und kleine Kräuter (wie Justicia, Impatiens und Comelinaceen) aufschossen, welche diese Tiere gern abweiden. In der Nacht gab es wieder so viele Moskitos, dafs man nicht eine Minute lang schlafen konnte. Besonders eine hier verbreitete sehr kleine Art, welche durch weitmaschigere Netze bequem hindurchschlüpfen kann, ist es, welche den Menschen hier in den Nächten das Leben verbittert, während man am Tage von hunderten von Elefantenfliegen umschwärmt wird. 
Schon vor 3 Uhr morgens wurde es auf dem Schiffe lebendig. Herr Langheld hatte sich durch den Mond täuschen lassen, und glaubend, es sei bereits Tagesanbruch, hatte er die Leute geweckt. Da Nebel auf dem Flusse lag und infolgedessen die auf der prorisorischen Flufskarte angegebenen Landmale nicht zu erkennen waren, mufsten wir noch bis 5 Uhr warten, ehe wir abfahren konnten. Schon gegen 11 Uhr zwang uns ein starker Regen, eine Zeitlang am Lande anzulegen und die Zeit durch "Holzmachen" auszufüllen. Ich machte eine kleine Exkursion, auf der ich auf einige Exemplare ron Landolphia Klainei stiefs. Für den Botaniker giebt es in diesen so häufig überschwemmteu Wäldern nur eine sehr spärliche Ausbente. Unterholz oder Kräuter sind weniger rorhanden, dagegen sind die Blüten der Urwaldbäume und die auf letzteren wachsenden Epiphyten vur da zu erlangen, wo Wald geschlagen wird oder einer der Riesen gefallen ist. Nach etwa zweistündigem Aufenthalte dampften wir weiter, um nach kurzer Zeit für den Rest des Tages wieder zum "Holzmachen" anzulegen.

Am 28. August konnten wir infolge des Nebels auch nicht so früh abfahren, als wir es gewünscht hätten, denn an vielen Stellen ist das Fahren infolge der Sandbänke sehr gefährlich. Der Flufs, welcher während der letzten Tage auffallend eng gewesen war, verbreiterte sich hier ganz auffallend und besafs häufiger Inseln als zuvor. Damals konnte ich mir die Ursache dieser scheinbaren Terengung des Flusses nicht erklären; auf der einige Monate später erfolgten Fahrt stromabwärts löste sich dieses Rätsel. Ich werde später darauf zurückkommen. Die dicht bewaldeten Ufer waren anfangs noch immer sehr niedrig, bis wir gegeu $10 \mathrm{Uhr}$ das erste Dorf, N'Kunda, erreichten, welches auf einem etwa 100 Fufs über dem damaligen $W$ asserspiegel sich hinziehenden Hügelrücken liegt. Vorher passierten wir noch einige kleinere verlassene und im Terfall begriffene Dörfer, deren Insassen wohl alle durch die Raubzüge des alten Häuptlings Wesso, welcher ein Jahr vor der Besitzergreifung dieser Gebiete durch die Franzosen gestorben ist, rertrieben waren. Die Bewohner von N'Kunda schienen wenig Lust zu haben, uns Nahrungsmittel zu verkaufen: als wir anliefen, lielsen sich nur einige neugierige Weiber und eine Schar nackter Kinder sehen, die natïrlich sofort wegliefen, als wir Europäer Miene machten, an Land zú kommen. Das I)orf besitzt wie die meisten Dörfer dieser Gebiete nur eine Strafse, zu deren Seite sich je eine Häuserreihe hinzieht. An beiden Enden der Strafse standen je eine gröfsere Ilütte, in der die Männer zu Beratungen oder zu allgemeinen Gelagen zusammenzukommen pflegen. Die Bevölkerung ist mit den Bonga-Leuten nahe verwandt und setzt sich zum grofsen Teile sogar 
aus direkten Abkömmlingen derselben zusammen. Die Lebensmittel, welche wir hier erstehen konnten, waren durchans nicht billig und nur spärlich aufzutreiben, da die Eingeborenen ihre Hühner oder die wenigen Ziegen, welche sie besitzen, nicht gern verkaufen. Tabak, Salz und europäische Stoffe sind hier die begehrtesten Artikel. Perlen und Öl scheinen weniger gut zu gehen, doch hängt das alles ron dem unberechenbareu Einfäll des Negers ab. Das Fallen des Wertes einiger sonst wertvoller Artikel wie Feuersteine und Cutlas ist eventuell zu erklären; darauf werde ich später bei der Schilderung meiner N'goko-Reise zurückzukommen haben.

Nach etwa dreistündigem Aufenthalte verliefsen wir das Dorf N'Kunda und dampften nun den Flufs noch eine Strecke weiter hinauf, bis wir an einer Stelle anlegen konnten, wo wir genügend $\mathrm{Holz}$ vermuteten. Ich machte am Nachmittage wieder einige Streifzüge durch die Wälder, sah aber nur Landolphieu, von Kickxia dagegen keine Spur, ein Regengufs zwang mich schliefslich, bald wieder zurückzukehren. Je weiter wir flufsaufwärts gekommen waren, desto weniger wurden wir von Moskitos belästigt, ein Umstand, der sich wohl hauptsächlich durch das Fehlen der nach der Sanga-Mündung zu häufigen Grassteppen und Wassergrassümpfe erklären liefse.

Um am 29. August möglichst weit fahren zu können, wurde gegen Mitte des Tages eine kurze Zeit hindurch angelegt, um etwas mehr Holz schlagen zu lașsen. An dem weniger wichtigen Dorfe Bussundi fuhren wir vorüber, ohne auf das Geschrei der am Ufer stehenden Eingeborenen, welche uns wohl zum Anlegen bewegen wollten, Rücksicht zu nehmen. In der Nähe der Stelle, wo wir am Nachmittage für den Rest des Tages anlegten, gab es nicht unbedeutende Quantitäten einer guten Kautschuk liefernden Landolphiaart, ebenso wuchs am Flufsrande eine Coffeaart, deren Frïchte leider noch nicht zum Gebrauche reif genug waren. Auch fehlten an den Exemplareu Blüten, um die Art feststellen zu könuev, ich fand dieselbe längs des Sanga und auch später im Ngoko-Gebiete häufiger.

Der nächste 'Tag brachte uns am Vormittage nach dem Dorfe Pembe, welches ähnlich wie N'Kunda auf einem Hügelrïicken erbaut ist und auch nur aus zwei langgestreckten Häuserreiheu besteht. Hier waren wir beim Einkaufen von Lebensmitteln bedeutend erfolgreicher als in N'Kunda, besonders Haumesser (Cutlas) fanden guten Absatz. Das ganze Auftreten der Lente zeigte, dafs sie nicht so verwöhnt waren als die N'Kunda-Leute. Wundervolle Schmetterlinge (Papilioniden und Euploeen) gab es hier in Mengen. Die Tiere, welche am Flufsrande gierig die Feuchtigkeit aufsogen, liefsen sich mit Leichtigkeit mit der Hand fangen, ohne dafs man 
sie dadurch lädierte. Ich versuchte, eine Exkursion in die nahe gelegenen Buschwälder zu machen, wurde aber allenthalben durch Sümpfe, welche zu dieser Zeit den Hügel zu umgeben scheinen, daran verhindert.

Als wir kurz nach 1 Uhr von Pembe abfuhren, sahen wir vor uns in der Ferne den französischen Regierungsdampfer "Tirier*, wohl einen der elendesten Dampfer, welcher den Congo befährt, ron dem Dorfe Likilemba abfahren. Schon nach kurzer Fahrt hatten wir denselben überholt. Dieser Dampfer ist der einzige, welchen damals die französische Regierung für den Congo besals, obgleich sie doch eine ganze Flottille für den Sanga sowohl wie für den Ubangi nötig gehabt hätte. Man mietete stets für schwere Preise die Dampfer des auch in Brazzaville vertretenen holländischen Handelshauses.

Für den Nachmittay legten wir gegen 2 Uhr an einer Land. zunge an, welche sich zu unserer Freude als sehr reich an Brennholz erwies. Der morastige Boden des Waldes daselbst war mit grolsen Mengen einer kleinen, calamusähnlichen, stacheligen Palme bedeckt, welche bei meinen Streifereien für mich sehr lästig waren. Landolphia Klainei gab es am Flufsrande reichlich, doch fehlte dieselbe, sobald man weiter in den Wald eindrang. Zum ersten Male sah ich hier ein verlassenes Lager von Elefantenjägern, wie sie in der Ngoko-Region besonders häufig zu finden sind. Die sehr primitiv aufgebauten Hütten bestanden aus zusammengesteckten Zweigen und Stöcken, welche etwa eine hingestreckte Viertelwalze bildeten, die mit Phryniumblättern gedeckt war. Im Innern einer jeden Hütte befand sich ein niedriges, schmales Bett, das, kaum einen Fuls über dem Erdboden erhoben, aus zusammengebundenen Stangen bestand. Feuerstellen waren sowohl in den Hütten als auch aufserhalb derselben vorhanden.

Trotz des Nebels fuhren wir am 31. August schon früh ab. Im Laufe des Vormittags hatten wir einige Untiefen zu passieren, bevor wir das Dorf Boka erreichten. Diese allerdings ziemlich unbedeutende Ortschaft war bereits zur Hälfte überschwemmt, als wir daran vorbeifubren. Auffallend war eine verhältnismälsig grofse Zahl von Ziegen, welche die Bewohner zu besitzen schienen. Von dem Dorfe Boka an heben sich die Ufer des Flusses allmählich, ja der Ortschaft gegenüber zieht sich ein langer Hügelrücken hin, wie ich ibn sonst am Sanga unterhalb der Ngoko-Mündung gar nicht kenne; auf diesem haben die Einwohner Bokas ihre Bananenpflanzungen angelegt und besitzen daselbst wahrscheinlich auch ihre Hütten während der Hochwasserperiode. Gegen Mittag bereits ging unser Holz derartig auf die Neige, dafs wir anlegen mufsten. 
Nach kurzer Zeit fuhren wir darauf weiter, um gegen 3 Uhr noch einmal zum Holzfällen anzulegen, denn uns lag viel daran, endlich das nicht mehr ferne Wesso zu erreichen. Der Holzvorrat, welchen wir nun einnabmen, reichte gerade aus, um uns gegen $5^{1 / 2}$ Uhr am $\Lambda$ bend nach Wesso zu bringen, wo kurz vor uns der "Tirier" eingelaufen war.

Da wir noch während des Vormittages am nächsten Tage in Wesso zu bleiben gedachten, verschob ich eine Besichtigung des Ortes auf den nächsten Vormittag; aulserdem brach nun die Dunkelheit ein, und einige Zollformalitäten mufsten noch bei dem hier stationierten französischen Beamten erledigt werden.

Am Abend waren wir alle in Wesso anwesenden fünf Europäer (aufser dem Gastgeber bestehend aus dem Agenten des holländischen Hauses, dem französischen Chef de Poste, Herrn Langheld und mir) zusammen bei dem Agenten der Société Anonyme Bèlge zu gemeinsamem Abendessen versammelt.

Nachdem ich am nächsten Morgen das Dorf Wesso, welches schon ganz den Charakter der Fan-Dörfer trug, besucht hatte, dehnte ich meine Exkursion noch weiter ins Innere aus. Etwa $1^{1} / 2$ Stunden war ich mit meinem Jungen marschiert, und doch kam ich nicht aus den kultivierten Gebieten heraus. Die früher unter Kultur gewesenen Strecken, welche man nun nach Art der Negerkultur wieder verwildern liefs, waren mit dichtem Busch bestanden, in dem aufser Costusarten keine Pflanzen zu finden waren, welche mich interessierten. Besonders Trema scheint in solchen Lokalitäten neben Zingiberaceen häufig sich einzustellen. Ich wäre gern weiter marschiert, mufste es aber aufgeben, da ich zur Zeit am Dampfer zurück sein wollte, um dessen Abfahrt nicht zu verzögern. lch rermute nach allem, was ich auf jener Tour gesehen, dafs Kickxia in den noch nicht kultivierten trockneren Teilen westlich vom Wesso vorhanden sein dürfte. Kurz nach dem Mittagsmahle fuhren wir wieder von Wesso ab, um nun bald aus dem Sanga in den Ngoko einzubiegen, welcher sich etwa eine halbe Stunde oberbalb Wesso in den Sanga ergiefst. Nördlich von Wesso senkt sich das Land wieder sehr bedeutend, so dafs die Ufer jetzt schon kaum über dem Wasserspiegel hervorragten. An einer kleinen, flachen Insel vorbeifahrend, welche direkt am Zusammenflusse der beiden Flüsse liegt, während des hohen Wasserstandes aber völlig überschwemnt ist, bogen wir in den Ngoko ein. Man batte mir diesen Flufs mit den schwärzesten Farben geschildert und behauptet, dafs nicht einmal ein Vogel dort zu finden sei, doch das war natürlich arg übertrieben. Im wesentlichen bot er denselben Anblick dar wie der Sanga, nur war er bedeutend enger und die Strömung wohl 
etwas reifsender. Gegen $t^{1 / 2}$ Uhr, nachdem wir etwa zwei Stunden deu Ngoko hinaufgefahren waren, ging unser Feuerungsmaterial zur Neige, so dafs wir gezwungen wurden, für den Rest des Tages und die Nacht hindurch an Land anzulegen, um Holz schlagen zu lassen. Selten hatte ich einen Wald gesehen, der derartig von Elefanten zertreten war wie der, an welchem wir hier lagen. Landolphia war schon ziemlich reichlich vertreten, ebenso Kaffee, doch war für Kickxia der Boden offenbar zu feucht, denn auch hier war der Wald schon teilweise überschwemmt. Es war zu verwundern, dafs wir auch hier trotz der Waldsümpfe fast gar nicht während der Nacht von Moskitos zu leiden hatten. Bald passierten wir zwei unbedeutendere Dörfer der Misanga, wie man hier die Eingeborenen nennt, und kurz darauf gingen wir bei dem Dorfe Muntunda vor Anker. Die Bauart des Dorfes war auch die für die Fau typische, wie ich sie bereits bei Wesso beobachtet hatte. Die dicht aneinander stehenden Hütten waren zu beiden Seiten einer einzigen breiten Stralse aufgebaut, welche durch je ein befestigtes Haus, in dem alle Versammlungen abgehalten werden, an beiden Enden abgeschlossen wird. Diese Häuser, welche allgemein bei den Europäern als Palaver-Häuser bezeichnet werden, haben statt der bei den gewöhnlichen Hütten aus Rinde hergestellten Brüstungen eine dicke Untermauer, welche aus verschiedenen Schichten von aufrechten Baumstämmen gebildet wird. Hier am unteren Ngoko waren diese Häuser nie so verstärkt wie ich sie später am Dja gresehen, denn während die Mauern bier aus zwei bis drei Schichten von Baumstämmen bestauden, wurden sie zum Beispiel in dem Dorfe des Häuptlings Lobilo aus zehn und mehr Schichten gebildet. Zum ersten Male sah ich auch hier bemalte Thürpfosten und Schwellen, ja einige Leute hatten sich sogar zu vollständig bemalten Hütten aufgeschwungen. Rot und Weils waren die verwendeten Farben. Auch hier sah ich, dafs mir die Kaufleute in Bonga die Verhältnisse zu schwarz geschildert hatten; glänzend waren sie ja freilich nicht; wohl aber gelang es uns, vou den Leuten einige Hühner und Bananen zu kaufen. Herr Langheld behauptete allerdings, dafs es das erste Mal sei, dafs er hier einige Efswaren erstanden hätte. Faul sind diese Fan-Völker im Ngoko ohne Zweifel, und es mag lange dauern, ehe man sie zur Arbeit wird erziehen können, und viel wird auch ron der Tüchtigkeit der deutschen Stationsleiter in jenem Bezirke abhängen, wie weit und wann das gelingt. Nach sehr kurzem Aufenthalte in Muntunda dampften wir gegen 10 Uhr wieder weiter. Bald sahen wir die ersten etwa 300 Fufs hohen Hügel, zwischen welchen hindurch der Ngoko sich Bahn gebrochen hat, vor uns auftauchen. Da wir nur sehr knapp mit Holz 
versehen waren, liefs Herr Langheld am Fufse der ersten Hügel wieder etwas Holz schlagen. Von diesen Hügeln aus, welche wir gegen Mittag verliefsen, hatten wir noch etwa vier Stunden bis zur zweiten Ngoko-Insel zu fahren, welcher gegenüber die Station auf dem Hügel liegt. Es wechselten während dieser Fahrt Hügel und Niederungen beständig ab. Da unsere deutsche Station in der Nähe einer Kette von Flufsschnellen liegt, welche nur eine schmale Passage an der Seite der Insel freilärst, legten wir uns an der Insel vor Anker und gaben ein Signal mit der Dampfpfeife, um unsere Ankunft auf der Station, welche man rom Flusse aus nicht erblicken konnte, anzuzeigen. Bald erschien auch ein Canoe, in welchem der Lazarethgehülfe Herr Peter safs, welcher mich nun im Auftrage des Herrn Oberleutnants Dr. Plehn willkommen hiefs. I) a noch eine ganze Anzahl von Lasten für mich und für die Station mitzunehmen waren, und Herr Langheld anch noch vor Anbruch der Dunkelheit seine etwa zehn Minuten weiter stromauf gelegene Faktorei erreichen wollte, so fuhr ich mit Herrn Peter erst noch bis zur Faktorei hinüber, um dann der Einladung des Herrn Dr. Plehn, bei ihm zu wohnen, Folge zu leisten. Nachdem ein Teil meiner Lasten in mein grofses Canoe hinüber gepackt war, fuhren wir über die Scbnellen hinweg zur Station zurück. Ein etwa 20 Minuten langer Anstieg brachte mich zur Station, wo mich Dr. Plehn äufserst liebenswürdig aufnahm. Da es bereits zu dunkeln anfing, setzten wir uns kurz darauf zum Abendessen nieder, bei welchem wir, Dr. Plehn, Herr v. Lüdinghausen, als stell. vertretender Stationsleiter, und ich bis tief in die Nacht hinein Neuigkeiten austauschten. Dr. Plehn hatte seit vielen Monaten keine Nachrichten aus Kamerun erhalten und war daher ein dankbarer Zuhörer bei allem, was ich von dort zu berichten hatte.

Als ich mir am nächsten Tage die kaum drei Monate alte Station auf einem kleinen Rundgange betrachtete, war ich erstaunt, zu sehen, was alles geleistet worden. Wie anders sah es hier aus als auf den französischen Stationen, welche ich in der letzten Zeit gesehen. Um auch von den Eingeborenen unabhängiger zu sein, hatte man Anpflanzungen von Mais und Bananen begonnen, sowie ein Feld Bergreis ausgesäet, das vorzüglich stand. Alles zeigte die wunderbare Umsicht, mit welcher Dr. Plehn bei Anlage der Station vorgegangen war. Es gab allerdings auch einen Übelstand, den zu erwähnen ich nicht unterlassen darf, nämlich die Entfernung des Wassers, welches die Leute immer vom Flusse her heraufzuholen hatten. Dr. Plehn sprach mit mir verschiedentlich darüber und war selbst ans diesem Grunde nicht ganz zufrieden mit der Anlage seiner Station; doch war da nichts zu ändern mög- 
lich, wenn er nicht die sicher gesundere und kühlere Lage auf dem Hïgel aufgeben wollte. Gesundheitlich war die Station trotz ihrer guten Lage etwas rom Unglück rerfolgt worden. Es waren mehrere Leute besonder's unter den Arbeitern (Weiboys aus Liberia) bereits gestorben, doch meist an Krankheiten, welche sie noch von der Küste mitgebracht hatten, aufserdem war eiue bedenklich grofse Zahl von Dysenteriefällen vorgekơmmen, auch einige Schwarzwasserfieber, von welchem auch Herr v. Lüdinghausen und der Unteroffizier Kruschka, welcher die Soldaten zu drillen hatte, befallen worden waren. Diese grofse Zahl von Krankheitsfällen ist leicht zu erklären, wenn man bedenkt, welche Mühen die Sanga-Ngoko-Expedition auszuhalten hatte, ehe sie zum Bau der Station schreiten konnte, und darauf die schweren Arbeiten bei zum Teil sehr dürftiger Ernährung, denn infolge der schlechten Terbindungen war der europäische Proviant lange Zeit am Congo liegen geblieben. Je mehr man die Geschichte dieser Station kennt, desto mehr ist man gezwungen, die Energie der vier Europäer, unter deren Leitung diese Station entstand, zu bewundern, und ganz besonders die des Führers, Dr. R. Plehn. Mit Dr. Plehn und Her'rn Langheld, welcher zu Mittag zur Station gekommen war, besprach ich dann am Nachmittage die Möglichkeiten meiner Exkursionen. Dr. Plehn war so liebenswürdig, mir für die Zeit meines Aufenthaltes Soldaten und Leute zur Verfügung zu stellen.

Einige Exkursionen, welche ich am nächsten Tage zuerst eirmal in die nähere Umgebung der Station machte, zeigten mir, dafs die Bossassangapflanze in ziemlichen Mengen vorbanden sei. Ebenso fand ich Landolphien in jüngeren Exemplaren in der Nähe der Station, am Flusse aber mit langen, dicken Ästen. Landolphia florida war längs der Ufer auch reichlich vorhanden und durch die gelben, über apfelgrofsen Früchte schon von weitem zu erkennen.

Am 5. September ging ich zusammen mit Leutnant Plehn läng's des Flul'sıandes zur Faktorei der Südkamerun-Gesellschaft hinüber, um einige dort in der Nähe bekannte Kautschukbäume zů untersuchen. Etwa zehn Minuten von der Faktorei entfernt, brachte mich ein Marsch durch den Wald zu den betreffenden Bäumen, in welchen ich zu meiner Freude Kickxia elastica feststellen kounte. Auf einigen Exkursionen, welche ich nun während der nächsten Tage unternahm, gelang es mir, die Kickxia in ziemlicher Zahl rings um die Station herum, sowohl auf den Thälern wie auf den. Hügeln feststellen zu können. Ich schickte einige Leute speziell aus zu dem Zwecke, eine gröfsere Quantität Milch einzusammeln, mit der ich experimentieren konnte. Anfangs, während der warmen 
Tage, kamen die Leute mit weniger Milch zurück, als ich eigentlich erwartet hatte. Als Grund dafür führten sie an, dals bei der grofsen Hitze die Milch kurz nach Austritt an die Luft sehr bald koaguliere. Als ich dieselben Leute bei kühlerem Wetter aussandte, wurden ihre Aussagen durch die grofsen Quantitäten Milch, welche sie heimbrachten, bestätigt; auf späteren Exkursionen sah ich auch die zuerst angeschnittenen Bäume mit dem an der Luft koagulierten Kautschuk. Ich erwähne diese Umstände besonders, da sie zeigen, dafs die Kickxien vielleicht vorteilhafter bei kaltem als bei warmem Wetter angezapft werden, was für den plantagenmälsigen Anbau von Nutzen sein kann. Auch ist es nicht unwahrscheinlich, dafs die Kickxia bei feuchtem oder kaltem Wetter einen gröfseren Ertrag an Latex liefert als bei trockenem und heifsem Wetter. Inwieweit der Prozentsatz des Kautschuks zu der gewonnenen Quantität von Milch unter diesen verschiedenen Witterungsverhältnissen variiert, ist noch eine offene Frage, welche erst durch jahrelange Versuche endgültig entschieden werden kann. Während meines verhältnismälsig kurzen Aufenthaltes im Ngoko-Gebiete konnte ich nichts sicheres in dieser Hinsicht feststellen. Über die verschiedenen Methoden, welche ich bei der Koagulation der Kickxiamilch angewendet habe, habe ich schon früher einmal berichtet. Die erste Methode, welche ich anwendete, das Einkochen der Milch, scheint mir die empfehlenswerteste. Durch Zusatz von Bossassanga wird, wie die ron mir mitgebrachten Proben bewiesen haken, der Kautschuk nicht verbessert.

Die Para-Rüuchermethode ebenso wie die Centrifugivmethode sind, da beide zu viel Arbeitskräfte bedingen, für Afrika und ganz besonders für diesen Teil Afrikas nicht zu empfeblen.

Auch ein trichterförmiges Gefäls zum Austrocknen der Milch hatte ich mitgenommen und konnte es nun zum ersten Male gebranchen. Ich gofs die Milch in dieses Gefäfs hinein und liefs sie mehrere Tage hindurch stehen, bis sich die Kautschukkügelchen nach oben abgesetzt hatten. Die oberste, sehr harzreiche Schicht wurde abgenommen, nachdem die Milch genügend in Wasser und Kautschukkügelchen gesondert war, und das Wasser allmählich durch einen am Grunde des Gefäfses angebrachten Hahn abgelassen. Die zurückbleibende flockige Masse blieb zum besseren Austrocknen erst noch einige Tage stehen, um dann durch einfaches Pressen mit der Hand endgültig in Kautschuk verwandelt zu werden. Der auf diese Weise gewonnene Kautschuk erfordert wenig Arbeit und ist nicht der Gefahr ausgesetzt, anzubrennen, wie es beim Kochen der Fall ist. Es ist daher nicht unwahrscheinlich, dafs auch diese Methode des Austrocknens sich bei Gewinnung des Kautschuks in 
den Plantagen bewähren wird. Da ich später noch einmal auf die verschiedenen Methoden der Koagulation einzugehen haben werde. so will ich darüber hier nicht mehr sagen, sondern nun auf die Anzapfungsmethoden der Kickxien übergehen. Die von mir mitgenommenen Instrumente bewährten sich nur halb, da man mit ihnen nur langsam arbeiten konnte. Der Pikierapparat war im Verbältnis zur Zähigkeit der Kickxiarinde leider zu schwach gebaut, so dafs sich die Zähne beim Einschlagen teils umbogen, teils abbrachen. Ich möchte fast glauben, dafs besonders bei warmem Wetter diese Pikiermethode etwas für sich haben dürfte, besonders wenn man durch einen am Fufse des Stammes herumgelegten Ring den etwa herunterlaufenden Saft auffangen könnte, so dals auf diese Weise nichts verloren geht. Diese Methode hat vor allen anderen den Vorzug, dals der Baum dadurch nicht so leicht verletzt wird, und das ganze Jahr hindurch in kurzen Abständen angezapft werden kann. Der Kautschuk, welcher dann natürlich auch in der Form der Ceara-Kautschukthränen exportiert werden müfste, würde sicher durch seine Reinheit und Trockenheit einen guten Preis erzielen.

Für die verbreitetste und bei einmaligem Anzapfen rentabelste Methode des Grätenschnittes mülste man noch passende Instrumente erfinden, mit denen man schnell und ohne die Cambiumschichten unter der Rinde zu verletzen, arbeiten könnte.

Bei den Fantis ist zum Besteigen der geraden Kickxiastämme ein Steiggürtel gebräuchlich, welcher wirklich verdiente, allenthalben eingeführt $z u$ werden. Mit Hülfe dieser Gürtel sind die Leute in der Lage, jeden geraden Stamm ohne Mühe zu besteigen, so lange sie ihn umspannen könneu. Bei Anwendung des Grätenschnittes mufs natürlich darauf gesehen werden, dafs die Schnitte nicht zu tief eindringen, denn der Schaden, welcher dadurch hervorgerufen wird, steht in keinem Verhältnis zu der geringen Menge Kautschuks, welche man dadurch mehr erhält. Aufserdem wäre es wünschenswert, dafs auch hier etwa da, wo das Gefäls zum Auffangen des Saftes angebracht wird, ein erhabener rinnenartiger Ring um deu Stamm gelegt wird, durch welchen etwa an der Rinde herunterlaufende Säfte aufgefangen werden können. Zum Anschneiden der Stämme dürfte sich ein Instrument empfehlen, das ähnlich wie die in unserer Forstivirtschaft allgemein verwendeten "Baumreifser" gebaut ist, aber nit einer verstellbaren zweischenkeligen Schneide versehen ist, deren beide Schenkel sich an der scharfen Kante vereinigen und so zwischen sich einen Hoblraum lassen, durch welchen das ausgeschälte Rindenstück nach oben entweichen kann. Ich werde an anderer Stelle auf dieses Instrument zurückkommen. 


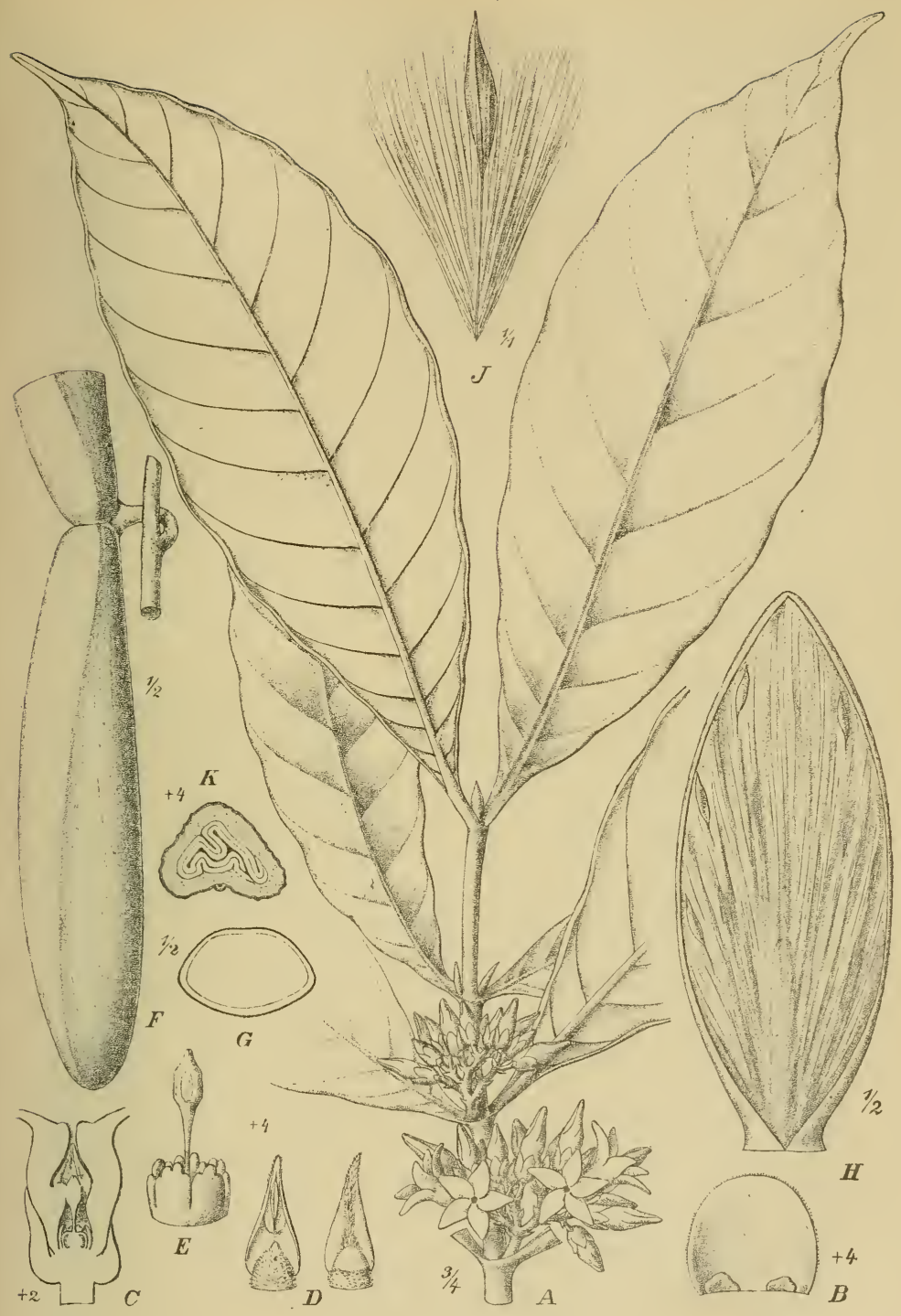

Kickxia elastica Preuss.

A Blühender Zweig, B Kelchblatt von innen, C Längsschnitt durch die Blüte, D Antheren, E Fruchtknoten mit Griffel, F Frucht, G dieselbe im Querschnitt, H dieselbe aufgesprungen, J Samen, K Samenquerschnitt. 
Betonen möchte ich noch, dafs dieser Baumreifser nur für glatte, aufrechte Stämme, insbesondere Kickxia- und eventuell Ceara- und Para-Bäume konstruiert sein soll. Bei Landolphien verhindert schon die sehr unebene Rinde sowie sehr variable Dicke derselben seine Anwendung.

Herr Dr. Plehn liels am 13. September seine sämtlichen Arbeiter zusammentreten, um vor ihren Augen die Bereitung eines reinen Kautschuks demonstrieren zu lassen. Ich zeigte den Leuten damals die für sie am leichtesten begreifliche Methode der Gewinnung des Kautschuks durch Kochen. Um sie auf die Unterschiede der Güte des von ihnen und von mir hergestellten Kautschuks aufmerksam zu machen, wurde ein von den Soldaten hergestellter Kautschukball zugleich mit den von mir angefertigten Stücken herumgegeben und die Leute zu gleicher Zeit darauf aufmerksam gemacht, dafs nur der Kautschuk in den Faktoreien der Südkamerun-Gesellschaft zu verkaufen sei, welcher in der von mir demonstrierten Art hergestellt ist. Ich bin sicher, daf's es Herrn Dr. Plehn in nicht zu langer Zeit gelungen wäre, die Kautschukgewinnung in seinem Bezirk einzuführen, bätte ihn nicht kurz darauf ein so trauriges Schicksal unseren Kolonien für immer entrissen.

Da bereits an den Kickxiabäumen einige reife Früchte sich zeigten, so machte ich mit einigen Leuten am 20. September einen Ausflug ins Innere nach der Richtung von Djimu zu, um Samen zu sammeln. Nach etwa 20 Minuten erreichten wir eines der bedeutenderen Dörfer der Umgegend, Kataku, von wo aus ich von dem gewöhnlichen Djimu-Wege, den vor mir Dr. Plehn als erster Europäer betreten hatte, abbiegend, auf ein nördlich von Kataku liegendes kleines Dorf zu marschierte. Auf dem Wege dorthin stiefs ich auf eine Quelle mit prachtvollem Wasser (wohl das beste in der ganzen Umgebung), von welchem bis dahin nur die Eingeborenen und die Soldaten der Station, welche von den Dörfern der Eingeborenen ihren Proviant holten, Kenntnis hatten. In dem Dorfe, welches wir nun erreichten, soll, nach Angaben der dortigen Eingeborenen, kein Weifser vorher gewesen sein. Man sieht also, wie sehr unbekannt diese Region unseres Schutzgebietes geblieben ist. Dieses neue Dorf, dessen Namen ich leider nie erfahreu habe, machten wir nun zum Operationscentrum. Von hier aus drang ich in die äufserst kickxiareichen Wälder ein und konnte so eine grofse Jenge von Früchten zusammenbringen. Die Eingeborenen waren mir gegenüber zwar äufserst furchtsam und mifstrauisch; doch schienen sie zu den Soldaten, dank dem klugen Vorgehen des Dr. Plehn, in sehr gutem Verhältnis zu stehen. Auch einige Leute 
vou der Station trafen am Nachmittage ein, teils vou einem nordöstlich gelegenen Dorfe mit Proviant reich beladen zurückkehrend, teils von Kataku kommend, um auch hier noch Proviant zu kaufen. Am Abend traf ich daun wieder von dieser äufserst interessanten Exkursion mit vielen Kickxiafrüchten (vier vollen Lasten) auf der Station ein.

Da sich am 22. September eine günstige Gelegenheit bot, nach dem oberen Dja hinaufzufahren, so benutzte ich mit Freude eine Einladung des Herın Bunge, welcher mit der "Holland" nach dem Ngoko gekommen war, um die Faktoreien des holländischen Hauses der Südkamerun-Gesellschaft zu übergeben, daran teilzunehmen.

Wir verliefsen auf dem Dampfer "Holland" am frühen Morgen die Faktorei "Wilhelmina“, welche auf dem französischen Ufer gegenüber der deutschen Station liegt, und fuhren den Ngoko hinauf. Ich hatte einige Soldaten von Dr. Plehn zur Begleitung und, um nachher noch eine Canoereise machen zu können, mein grofses Canoe mitgenommen. Nach etwa einstündiger Fahrt erreichten wir einen grolsen, alleinstehenden Felsen, welchen ich bereits von einer früheren Reise her kannte. Von seiten Herrn Langhelds war auf seiner Flufskarte dieser Felsen mit dem Namen "Plehn-Felsen" belegt worden, ein Name, welcher hoffentlich, in Anbetracht der Verdienste Dr. Plehns um diesen Bezirk, bestehen bleiben wird. Da ich noch häufig Gelegenheit haben werde, dieses eigentümlichen, isolierten Felsens Erwähnung zu thun, so will ich hier gleich bemerken, dafs auch ich denselben einfach als Plehn-Felseu bezeichnen werde. Bis zur vierten Ngoko-Insel war ich schon vorher den Flufs hinanfgefahren, heute kamen wir noch weiter hinauf, mufsten aber gegen $2^{1 / 2}$ Uhr anlegen, um für den nächsten Tag Holz schlagen zu lassen. Mit einigen Soldaten versuchte ich tiefer in den Wald einzudringen, wurde aber auf allen Seiten durch Sümpfe daran verhindert. Auf dieser Streiferei gelang es mir, nicht weniger als fünf mir neue Orchideen von einem einzigen Baume herunterzuholen. Von Kautschuklianen oder Kickxien war an dieser Stelle nichts zu sehen, wohl aber einige Coffeasträucher. Landolphia florida war längs des ganzen Flufsufers reichlich vertreten, allenthalben durch die orangenähnlichen Früchte leicht kenntlich. Wir waren nun nicht mehr weit ron dem Zusammenflusse des Bumbe und des Dja entfernt, wo wir am nächsten Tage die Faktorei der „Südkamerun-Gesellschaft" zu erreichen gedachten. Bevor wir dorthin kamen, passierten wir noch die Mündung des Como-Flusses, in welchen bis dahin noch kein Europäer eingedrungen war. Gegen Mittag: trafen wir auf der Bumbe-Faktorei ein. Dieselbe war erst vor kurzer Zeit angelegt worden, so dals man erst ein Haus hatte fertigstellen 
können; die Vorräte an Waren und Proviant befanden sich noch in den zu ihrer Bergung aufgestellten Zelten. Ein Europäer, Herr Kalmar, war zur Leitung der Faktorei hier zurückgelassen worden. Bei unserer Ankunft beklagte sich derselbe, dafs die Eingeborenen des an der Faktorei angrenzenden Dorfes sich geweigert, das durch Herrn Langheld von ihnen käuflich erworbene Land abzutreten. Herr Langheld hatte infolgedessen mit dem Häuptling des Dorfes ein längeres Palaver abzuhalten, um ihm zu erklären, dafs der Kauf des Landes die Gesellschaft zum Besitzer desselben gemacht; es dauerte eine geraume Zeit, ehe die Eingeborenen das einsehen konnten. Ein sehr starker Regen zwang uns leider, am Nachmittage auf dem Dampfer zu verweilen, obgleich ich gern ein kleines noch vollständig unbekanntes Flüfschen, den „Bumbesse“, welches neben dem Bumbe in den Ngoko einmündet, befahren hätte, um so tiefer in das Land eindringen zu können, da man sonst allenthalben durch Sümpfe daran verhindert wurde.

Da sich das Wetter am 24. September (am folgenden Tage) besserte, so konnte ich die Fahrt den Bumbesse hinauf antreten. Torher wurden noch zwei Herren den Bumbe hinaufgeschickt, um die Faktorei des holländischen Hauses zu übernehmen, welche bei den Bumbe-Schnellen, von den Eingeborenen in der Bangala-Sprache als "Mei makessi" (scharfes Wasser) bezeichnet, gelegen ist. Zu der Fahrt den Bumbesse hinauf hatte ich vier Soldaten mitgenommen, welche alle mit einem Haumesser ausgerüstet waren, denn schon an der Mündung war es ersichtlich, dafs man sich durch viel überhängendes Gestrüpp hindurchzuarbeiten habe. Da ich auch einigermalsen die Richtung des Flüfschens festlegen wollte, hatte ich mit dem Kompals in der Hand tüchtig aufzupassen, dafs wir nicht irgendwo festfuhren. Unter ziemlichen Schwierigkeiten batten wir oft unser Canoe zwischen den durchgeschlagenen Lianen hindurchzuzwängen, um wieder in offenes Wasser zu gelangen. Gegen $10 \mathrm{Uhr}$ kamen wir an eine Brücke, welche bewies, dafs Eingeborene hier in der Nähe hausen müssen; dieselbe war sehr primitir, durch zwei auf Gabeln ruhende Stangen hergestellt, welche an der Seite durch ein Zaunwerk gegen die Gewalt des Wassers geschützt waren. Etwa zwei Meter oberhalb der Stangen war parallel mit diesen eine Liane gespannt, welche dem die Brücke Passierenden offenbar zur Stütze dieneu sollte. Wir kamen an diesem Hindernisse auch rorbei, indem wir das Canoe allmählich darüber schleiften. Um $11 \mathrm{Uhr}$ wurde endlich durch Fallen unserm weiteren Vordringen ein Ziel gesteckt. Die Ufer des Flüfschens, welche hier bedeutend näher zusammentraten, waren durch ein Zaunwerk verbunden, dafs sebr geschickt lureh Lianen verknotet war und nur zwei Öffnungen liefs, durch 
welche die Tiere passieren konnten. Oberhalb dieser Öffnungen sah man Schlingen, welche offenbar zum Anbringen von Speeren angelegt waren. Da von dieseu Fallen ein Pfad in den Wald hinein führte, der offenbar unlängst von Menschen betreten war, so liefs ich einen Soldaten bei dem Canoe zurück und drang nun mit den drei anderen Soldaten auf dem Pfade vor. Zu meiner nicht geringen Freude konnte ich hier im Walde Kickxia sowohl wie Landolphia feststellen, erstere sogar in ziemlicher Menge. Da meine Zeit beschränkt war und noch keine weiteren Anzeichen von Menschen zu entdecken waren, liefs ich nach etwa halbstündigem Marsche im Walde wieder zum Canoe zurückkehren, hatte doch diese Exkursion wenigstens zur Entdeckung der Kickxia hier am Bumbesse geführt. Dieser Standort der Kickxia war für mich um so interessanter, als der Wald deutliche Anzeichen einer zeitweisen Überschwemmung trug, somit also der Baum auch in Regionen mit bedeutender Bodenfeuchtigkeit zu gedeihen scheint. Auf der Rückfahrt liefs ich an den Stellen, wo der Wald nicht überschwemmt war, landen, um anch dort nach Kickxia zu fahnden, kounte aber hier nur das Vorkommen von Landolphia konstatieren. Am Nachmittage machte ich nun noch einige Exkursionen längs des NgokoUfers, wo ich auch wieder Landolphia feststellen konnte. Auch hier entdeckte ich wieder einige interessante Orchidaceen.

Am Morgen des 25. September dampften wir weiter, jetzt den Dja hinauf, durch dessen Zusammenflufs mit dem Bumbe der Ngoko gebildet wird. Die Ufer waren auch hier teilweise recht niedrig, teilweise erhoben sich etwa bis 100 Meter hohe Hügel längs derselben. Der Strom war hier noch bedeutend stärker als auf dem Ngoko. Die Vegetation scheint üppiger zu sein, als ich sie am Ngoko beobachtet habe. Nach etwa zweistündiger Fahrt passierten wir das Dorf Djama auf der Insel gleichen Namens nebst einer Abzweigung desselben auf einer daneben liegenden Insel. Die Ufer erschienen auf unserer linken Seite nun stets mehr oder minder erhöht. Kurz hinter Djama hatten wir einige Stromschnellen zu passieren, welche glücklicherweise an einer Seite einen Kanal zur Durchfahrt frei liefsen. Gegen $4^{1} / 2$ Uhr erreichten wir dann das Ziel nuserer Reise, die Faktorei Bomudali. Dieselbe liegt gegenüber der Insel Bomudali mit dem darauf befindlichen gleichnamigen Dorfe von für dortige Verhältnisse ziemlicher Ausdehnung. Diese Faktorei wurde durch einen Eingeborenen geleitet. Ein recht nettes, aus hiesigem Bambus (Raphiapalmen-Rippen) gebautes luftiges Häuschen mit einer breiten Veranda hatte man hier aufgebaut, in dem sich ein Europäer recht gut hätte aurhalten kömnen. Ich unternahm sogleich eine Exkursion in den Wald, der leider auch zum grofsen 
Teile überschwemmt war, so dals ich total durchnässt gegen Abend zum Schiffe zurückkehrte.

Da mir nicht viel daran lag, dieselben Gegenden noch einmal vom Dampfer aus zu betrachten, so hatte ich beschlossen, die Rückreise im Canoe zu machen. Da der Dampfer von hier aus umkehren sollte, so fuhr ich bereits um $5^{1 / 2}$ Uhr am Morgen des 26. September von Bomudali ab. Da noch Nebel auf dem Flusse lag, konnten wir anfangs nur wenig von der Urwaldvegetation erkennen. Erst als gegen 8 Uhr die Sonne durchdrang, wurde das Bild interessanter und lebendiger. Die Papageien in den Zweigen fingen ihr Geschrei an, oben sah man die Nashornvögel über die höchsten Gipfel der Bäume dahinschweben. während die buntbefiederten Königstischer auf den Büschen am Wasser auf Beute warteten. Nun am Ufer entlang fahrend, sah ich häufig riesige Kautschuklianen von den Zweigen hängen, deren riesige, etwa kinderkopfgrolse Früchte durch ihr Gewicht die Zweige berunterzogen. Leider hingen diese Früchte meist zu hoch, um sie zu erlangen, selbst einige Schüsse auf dieselben hatten keine Wirkung. Doch gelang es mir nach einigen vergeblichen Versuchen, endlich dreier derselben habhaft zu werden, um sie nach der Station mitzunehmen. Von Kickxia konnte ich nur hin und wieder einige Exemplare an dem höheren Ufer entdecken; doch liefs ein grofser Sumpf, welcher die Hügel von dem Flusse trennte, eine genauere Untersuchung derselben nicht zu. Gegen Mittag erreichten wir Djama, nachdem wir noch kurz vorher durch einen tüchtigen Regenschauer vollständig durchnälst worden waren. Meine Leute hatten zwar in dem Dorfe Bomudali tüchtig Essen kaufen können, so dafs sie noch reichlich versehen waren, doch hielt ich es trotzdem für geraten, mich hier noch einmal tüchtig zu verproviantieren, da ich nicht wufste, wie lange ich noch bis zu meiner Ankunft auf der Station unterwegs bleiben würde, zumal ich beabsichtigte, den N'komo zu befahren, um auch dort soweit als möglich in die Wälder einzudringen. Ich besuchte daher die beiden Djama-Inseln und kaufte dort an Lebensmitteln für meine wenigen Leute nicht unbedeutende Quantitäten ein, und zwar zu äufserst billigen Preisen. Ich will zwar nicht verleuguen, dafs die Anwesenheit der Soldaten wahrseheinlich nicht wenig dazu beitrug, doch sah ich darauf, àals den Leuten nichts mit Gewalt abgenommen wurde. Wer nicht verkaufen wollte, wurde in keiner Weise dazu gezwungen. Ich konnte hier Hühner und Eier für Öl und Salz einkaufen. Etwa ein halber, ziemlich kleiner Tassenkopf mit Öl genügte, um ein Huhn zu erstehen. Für meine Leute gab es Büffelund Elefantenfleisch und sehr viel Planten. So konnten wir also, reichlich versehen, am Nachuittage unsere Weiterreise antreten. 
Nach kurzer Zeit liefs ich an Land anfahren, mu Mittag kochen zu lassen. Wir waren kaum damit fertig, als die "Holland“ unsere Lagerstelle passierte, auf der Rückreise nach Bumbe, welches übrigens schon ron unserem Lager aus in Sicht war. Ich unternahm nun noch eine Exkursion, auf welcher ich wieder das Vorhandensein der Kickxia, wenn auch nur in vereinzelten Exemplaren, konstatieren konnte; dann liefs ich den Dja bis zum Bumbe hinunter weiterfahren, wo ich gegen 6 Uhr abends bei dem Dampfer anlangte. Am Ahend versammelten wir hier anwesende fünf Europäer uns auf dem Dampfer, wo uns Herr Kalmar nach dem Abendessen durch ein Konzert auf der Violine unterhielt. Da ich am nächsten Morgen früh aufbrechen wollte, ging ich um 10 Uhr schlafen.

Der nächste war wieder einer jener prächtigen Morgen, wie ich sie besonders nach einem Regentage schon häufig im Ngoko erlebt hatte; lantlos glitt unser Canoe am Ufer des Flusses entlang, jedes Geräusch wurde noch durch den dichten Nebel, welcher auf dem Flusse lag, gedämpft. Als sich gegen 9 Uhr der Nebel gehoben, liefs ich auf einer sandigen Stelle am Ufer das Canoe aufziehen, um den Soldaten Zeit zum Frühstück zu geben, während ich mit meinem Jungen im Walde umherstreifte, soweit es die uns umgebenden Sümpfe gestatteten. Auch hier gab es viele Landolphien, besonders L. florida, deren Früchte eine Schar Affen angelockt hatten, von welchen ich für meine Leute zwei erlegen konnte. Während ich im Walde umhergestreift, hatte der Koch das Frühstïck fertig gemacht, so dafs wir kurz darauf, obne grofsen Zeitverlust, weiterfahren konnten. Gegen $11 \mathrm{Uhr}$ erreichten wir die Mündung des N'komo-Flusses, in welchen wir nun eindrangen. Die Strömung war hier auffallend stark, besonders da, wo Bäume in das Wasser hineingefallen waren. An einigen Stellen mufsten wir uns längs der Ufer an dem Gesträuch entlang hinziehen, um gegen die starke Strömung ankommen zu können. Ein riesiges Krokodil, welches auf einem Baumstumpfe lag, schofs ich auf dieser Fahrt, doch entging uns das Tier leider, weil es in seinem Todeskampfe rom Stamme herunter in das Wasser fiel. Gegen 12 Uhr liefs ich an einer offenen Stelle an Land fahren, um den Leuten, welche sich sehr stark hatten anstrengen inüssen, Rast zum Mittagessen zu geben. Elefanten-, Büffel- und Nilpferdspuren gab es in Menge, ron den Tieren selbst war leider nichts zu sehen. Die \B̈ume hingen am Ufer voll von Orchideen, unter denen besonders Angraecum pellucidum Ldl. mit seinen langen herunterhängenden Blütentrauben auffiel. Hier und dort waren Kautschuklianen (Landolphia! zu sehen, doch bis jetzt selten in gröfseren Mengen. Ich drang mit einem Soldaten tiefer in den Wald ein, um nach Kickxia zu suchen, 
kounte daron hier aber nichts entdecken. Als wir uns am Nachmittage kaum wieder anf der Weiterfahrt befanden, überraschte uns wieder ein starker Regen, der uns aber nicht hinderte, weiter zu rudern. Bald schien es, als sei unserm weiteren Vordringen eine Schranke gesetzt, denn vor uns lagen zwei grolse Bäume im Wasser. Als wir näher kamen, erkannten wir in denselben eine Brïcke der Eingeborenen. Die beiden Bäume waren von denselben grefällt

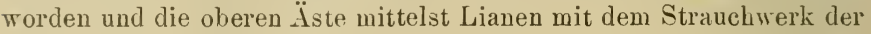
anderen Seite verbunden, so dals man, von Ast zu Ast kletternd, den Flufs überschreiten konnte. Zur Sicherung des Überganges waren einige Lianen darüber gespannt worden, an deneu man sich halten konnte. Von menschlichen Wesen selust war keine Spur zu entdecken. Ich glaube sicher, clas diese Brücke von den Zwergvölkern dieser Urwälder gelegt worden ist, denn nur diese allein bewohmen jene Wildnis. Mit unseren Haumessern gelang es uns, eine Öftnung durch die im Wasser liegenden Kronen der Baume zu schlagen, durch welche wir unser Canoe hindurchschieben konnten. Tir wurden alle dabei von einer Schar Ameisen, welche eluen den Flufs auf dem Baume zu überschreiten schienen, arg zugerichtet. Als sich gegen Abend der Himmel aufgeklärt hatte, begannen sich die verschiedensten Tiere hören zu lassen, besonders Elefanten hörte man häufig. Ein Schưs, welchen ich auf eine Schar Enten abfeuerte, rief dann plötzlich für kurze Zeit eine allgemeine Stille herro. Gegen $5 \frac{1}{2}$ Uhr liefs ich anhalten und für mein Zelt unter einem grolsen Baume den Platz reinigen. Bei der dichten Bewaldung lrach die Dunkelheit überraschend schnell herein. Es war eine wundervolle Nacht, welche nun folgte, als der Mond sein friedliches Licht über den Urwald ergols. Noch lange sals ich an dem Abend ror meinem Zelt und genofs die kühle Luft. Die Stille des Waldes wurde nur hin und wieder durch das Trompeten eines Elefanten unterbrochen.

Kurz nach 6 Uhr waren wir am nächsten Morgen auf der Fahrt. Mit jeder Minute wuchs die Stärke der Strömung, so dafs ich schon mit einigem Grauen an die Rückfahrt dachte, da dann bei den vielen Windungen des Flusses und den vielen, in demselben liegenden, Baumstämmen mser Canoe nur zu leicht hätte umgerissen werden könuen. Gegen $7^{1} / 2$ Uhr wurde nun leider unserem weiteren Tordringeн durch einen neuen Baumstamm eine Schranke gesetzt. Auch dieser war wieder ron Menschenhand gefällt worden und lag unglücklicherweise so im Wasser, dafs für unser Canoe keine Passage bliel,. Unter Schwierigkeiten wäre es uns vielleicht gelungen, das Canoe darïlser hinweg zu ziehen oder über Land wieler in fahrbares Gewässer zu bringen, doch glaubte ich, etwa so weit vor- 
gedrungen zu sein, als der N'komo deutsch war. Da der Zweck meiner Mission auch nicht in geographischen Forschungen bestand, so glaubte ich auch, hier uukehren zu müssen, hatte ich doch wenigstens Kautschuklianen hier in ziemlichen Mengen feststellen können. Bevor ich unkehrte, unternahm ich noch eine kleine Exploration der Wälder, in welche ich tiefer eindrang. Dieselben enthielten Kautschuklianen in Quantitäten, welche einen regelmäfsigen Abbau wohl lohnen würden. Ehe es jedoch zn einem solchen in diesen doch immerhin recht entfernten Regionen kommen wird, dürften noch viele Jahre hingehen. Eine der ersten Aufgaben des Stationsvorstehers sowohl, wie ror allen Dingen der Kaufleute im Ngoko-Distrikte, dürfte es vor allen Dingen sein, den Eingeborenen den Wert des Kantschuks und die Gewinnung desselben klar zu legen, und, wenn möglich, in einer solchen Weise, dafs der Raubbau sich nicht auch hier einbürgert. Ich selbst befürchte zwar, dafs sich dieser selbst bei strengen Mafsregeln nicht wird fernhalten lassen. Doch dessenungeachtet wäre es entschieden wünschenswert, dafs im Ngoko-Gebiete ein unnötiges Umschlagen der Kickxiabäume strengstens bestraft würde, sobald sich ein solches nachweisen läst. Ich werde noch einmal darauf zurückzukommen haben, da ich selbst einmal Zeuge eines solchen Umschlagens von Kickxiastämmen gewesen bin; doch davon später.

Noch im Laufe des Vormittags traten wir unsere Rückfahrt an, die infolge der vielen Krümmungen des Flusses sowie der vielen darin liegenden Baumstämme sehr gefährlich war. Bei der reifsenden Strömung sauste das Canoe dahin, wie ich es nie geglaubt hätte. Ich selbst hatte ein Ruder genommen, um im Falle der Not auch beim Steuern zur Hand zu sein. Besonders fürchtete ich die untere Baumbrücke, welche uns sehr leicht hätte umreifsen können. Genau nach der Karte, welche ich von dem Flusse bei der Fahrt hinauf angefertigt hatte, unsere Route verfolgend, machte ich schon vorher die Soldaten auf die kommenden scharfen Kanten und schnellen Strömungen aufmerksam und liefs, als wir uns der Brücke näherten, rückwärts rudern, so dafs wir dem Strome entgegenarbeiteten und dann schliefslich langsam gegen die Brücke angetrieben wurden. Nachdem wir das Canoe dann auch glücklich durch die von uns geschlagene Öffnung hindurchgezogen hatten, ging es mit derselben Schnelligkeit wie vorher weiter nach dem Ngoko zu. Noch eine Stelle gab es, die für uns gefährlich werden konnte. Dort hätte auch beinahe die Fahrt ein Ende gefunden, wenn wir nicht plötzlich von der Strömung fortgerissen und in ein Strauchwerk hineingeschleudert worden wären, wo ich glücklicherweise noch zur rechten Zeit einige Äste ergriff, mit Hülfe derer ich 
das Canoe zurückhalten konnte. Nachdem wir diese Stelle dann auch glücklich passiert hatten, hatten wir offeues, wenn auch noch reifsendes Fahrwasser. Man wird sich einen Begriff von der Macht dieser Strömung machen können, wenn man bedenkt, dafs wir aie Fahrt flufsabwärts in etwa einem Viertel der Zeit machten, als die Fahrt flufsaufwärts. Ich mufs offen bekennen, dafs ich froh war, als wir wohlbehalten wieder im Ngoko angelangt waren. Wir fuhren nun den Ngoko weiter hinunter, bis wir einen rerlassenen Weiler am Flufsufer erreichten, wo ich zum Zwecke des Abkochens Rast machen liefs.

Das Feuer war kaum angezündet, als einer der Soldaten mit der Nachricht kam, dals in einer Hütte ein halbverhungertes Weib liege, das kaum mehr sprechen könne. Ich liefs die Frau nun heranbringen und ihr etwas zu essen geben. Allmählich konnten wir denn ihren Reden entnehmen, dafs sie von ihren Stammesgenossen hier vor einigen Wochen ausgesetzt sei. Ihren richtigen Heimatsort konnten wir nicht erfahren, wie überhaupt ihre Aussagen häufig verwirrt waren und sich nicht selten widersprachen. Offenbar war das Weib irrsinnig. Sei es nun, dafs sie erst durch den Hunger in diesen Zustand verfallen war, denn sie hatte sich während der ganzen Zeit von den ölhaltigen Samen einer Leguminose ernährt, sei es, dafs sie infolge ihres Irrsinnes von ihren Stammesgenossen ausgesetzt war, ich konnte sie hier natürlich nicht zurücklassen, denn sie wäre sicher in wenigen Tagen verhungert, da sie schon jetzt kaum mehr Kräfte genug besafs, sich aufrecht $\mathrm{zu}$ halten. Als wir dann diesen von Flöhen wimmelnden Platz verliefsen, wurde die Frau mit in das Canoe gesetzt, nachdem die Soldaten vorher vergeblich versucht hatten, sie $\mathrm{zu}$ waschen. Das Wetter sah schon recht drohend aus, als wir unseren Lagerplatz verliefsen, so dafs wir wenig überrascht waren, als plötzlich ein wolkenbruchartiger Regen mit starkem Sturm zn wüten begann. Wenn selbst wir auch alle bis auf die Haut durchnäst wurden und die Situation nichts weniger als angenehm war, so freuten wir uns dennoch alle, dafs wenigstens auf diese Weise die würdige Matrone in unserem Canoe einmal tüchtig gewaschen wurde, denn der Schmutz und Aschenstaub, welcher an ihrem Körper haftete, spottete jeder Beschreibung. Da der Sturm für unsere Weiterreise zu gefährlich zu werden schien, lieís ich an einer sandigen Stelle unter einer alleinstehenden Sterculia an Land fahren, um dort für die Nacht das Zelt aufschlagen zu lassen. Leider war aber der Boden an dieser Stelle so locker, dafs die Zeltpflöcke ron dem Sturme immer wieder herausgerissen wurden, so dafs wir nach vielen vergeblichen Versuchen doch schliefslich die Hoffnung aufgaben, das Zelt hier 
aufschlagen zu können. Trotz des Regens und Sturmes mufsten die Soldaten sowie die auderen Insassen des Bootes wieder zu deu Rudern greifen, um uns nach einem günstigeren Lagerplatz zu bringen, den wir denn auch bald erreichten. Unter strömendem Regen wurde ein Platz für das Lager im Walde freigelegt und die Zelte für mich und meine Begleitung aufgeschlagen. Dieser furchtbare Regen hielt mit dem Sturme fast die ganze Nacht hindurch an, so dals mau bei dem Getöse, welches durch den Regen, den Sturm und die herunterbrechenden trockenen Zweige und Äste verursacht wurde, kaum an Schlafen denken konnte.

$\mathrm{Zu}$ unserer Freude klärte sich der Himmel am nächsten Morgen auf, so dafs wir bereits früh weiterfahren konnten. Es lag mir daran, noch an demselben Tage die Station zu erreichen. Meine Leute hatten daher tüchtig zu rudern, selbst das vom Hungertode befreite Weib, welches sich merkwürdig schnell wieder erholt hatte, mufste ein Ruder zur Hand nehmen und helfen. Im raschen 'Tempo ging es nun flufsabwärts an den wenigen Inseln vorbei, welche hier im Ngoko liegen. Dieselben waren zumeist schon durch das jetzt schnell steigende $W_{\text {asser }}$ überschwemmt worden. Als wir gegen Mittag in die Nähe des Plehn-Felsens kamen, welcher auch nur noch um einige Fufs aus dem Wasser hervorragte, liefs ich zum Abkochen kurze Rast machen. Ich durchstreifte während der Zeit wieder die Wälder, ohne aber auf Kickxien zu stofsen, wie ich gehofft hatte. Einige Ficusbäume aus der Verwandtschaft der Ficus Vogelii, welche hier wuchsen, zapfte ich an und kochte dann die Milch, teils nach Zusatz von Salz, teils mit Essigsäure vermischt, erhielt aber nur eine klebrige, zähe Masse, die keinen Wert hatte. Während des Nachmittag's ging es danu ununterbrochen bis zur Faktorei der Südkamerun - Gesellschaft weiter, welche wir mit eintretender Dunkelheit erreichten. Von Herrn Langfeldt erfuhr ich hier, dals Dr. Briart mit einem neuen Dampfer der Société Anonyme Belge, dem "Président Urban", in der Zwischenzeit dagewesen sei. So hatte ich leider diese Gelegenheit verpafst, nach dem Congo zurückzukehren. Nach kurzer Fahrt erreichten wir dann gegen $8^{1 / 2}$ Uhr die Ngoko-Station wieder.

Da der „Président Urban" für Dr. Plehn die sämtlichen von ihm bestellten Ausrüstungsgegenstände für eine geplante längere Expedition ins Innere mitgebracht hatte, so setzte Dr. Plehn den Aufbruch zu dieser Expedition auf den 10. Oktober fest. Da nach dieser Zeit zu wenig Leute auf der Station sein würden, um mich bei meinen Exkursionen zu begleiten, so beschlofs ich, die Zeit noch tüchtig zum Sammeln von Kickxiafrüchten zu verwenden. Noch verschiedene Male machte ich Ausflüge immer wieder in mir noch 
unbekannte Gegenden um die Station herum. Überall konnte ich die Kickxia in Mengen feststellen und jedesmal den Vorrat der Samen bedeutend vergröfsern, so dafs ich schliefslich gegen 400000 Samen haben mulste.

Meine verschiedenen Experimente mit Kickxia- und Landolphiamilch setzte ich zu derselben Zeit fort. Besonders die Methode der Gewinnung des Kautschuks dnrch allmähliches Austrocknen der Milch und durch Centrifugieren.

Zusammen mit Dr. Plehn unternahm ich am 4. Oktober einen Ausflug auf die Hügel der anderen Ngoko-Seite. Von der Faktorei „Wilhelmina“, welche nun verlassen war, ging zur Zeit der einzig mögliche Weg erst in den Wald hinein, um sich dann langsam gegen die Hügel vorzuschlängeln. Wiederholt mufsten wir uns von unseren Leuten durch Morast und Wasser tragen lassen, denn bei dem jetzt schon recht hohen Wasserstande war bereits ein grofser Teil des zeitweise trockenen Waldes vollständig überschwemmt. Nachdem wir dann glücklich deu Fufs des Hügels erreicht hatten, drangen wir auf einem schmalen Eingeborenenpfade bis zur Spitze vor, wo sich einige Leute des Kataku-Dorfes, offenbar um der zu grofsen Nähe der Weifsen zu entgehen, seit kurzem angesiedelt hatten. Die Leute hatten Bananenpflanzungen angelegt, beklagten sich aber bei uns, dafs die Elefanten ihnen viel Schaden zufügten. Da Dr. Plehn möglichst bald zur Station zurückkehren wollte, blieb ich mit meinem Jungen und einem Soldaten allein zurück, um zu versuchen, auch hier das Vorkommen ron Kickxia zu konstatieren. Als ich nach einigem Suchen diesen Zweck erreicht hatte, kehrte auch ich wieder auf das andere Ufer zurück, wo ich auf der Station mit dem Trocknen der Kickxiasamen und dem Einpacken der Kautschukproben jetzt viel zu thun hatte.

Da ich es für sehr wahrscheinlich hielt, dafs zur weiteren Feststellung des Verbreitungsgebietes der Kickxia eine Reise nach dem oberen Dja von Nutzen sein würde, so entschlofs ich mich, einer Einladung des Herrn Langheld, ihn dorthin zu begleiten, nachdem er die Plehnsche Expedition nach dem Bumbe gebracht hätte, Folge zu leisten, besonders da ich wuiste, dafs ich vor Ende des Monats Oktober nun keine Gelegenheit haben würde, die Rückreise nach dem Congo anzutreten. Gern wäre ich mit Dr. Plehn zusammen gegangen, um dann nach der Küste zu durchzumarschieren, doch das war nun leider infolge des Trägermangels unmöglich. Selbst Dr. Plehn mufste sein Gepäck schon auf das Allernotwendigste beschränken, um genügend Leute zum 'Transporte seiner Sachen zu haben. Es war für mich damals nicht leicht, auf diese Expedition zu verzichten, von der wir uns so viel Interessantes versprachen. 
Nachdem die Hauptinenge der Lasten der Plehnschen Expedition schon am 10. Oktober nach dem "Major Cambier" zu Herrn Langhelds Faktorei hinübergeschafft worden waren, rerliefsen wir, Dr. Plehn, Herr Peter, welcher an der Expedition teilnehmen sollte, und ich, am frühen Morgen mit den Soldaten und Trägeru die Ngoko-Station, um damn zum "Najor Cambier" mit dem letzten Reste der Expeditionsgüter nachzufolgen. Ich werde diesen Morgen nie vergessen, an dem ich damals zum letzten Male mit Plehu zusammen den Ngoko-Hügel hinunterstieg und mit ihm ïber den eventuellen Ausgang der Expedition sprach, der nach unseren damaligen Ansichten nur ein glücklicher und für die Erforschung unseres Schutzgebietes sehr günstiger sein konnte. Leider hatte das Schicksal es anders beschlossen.

Nachdem gegen 9 Uhr endlich alles auf dem Dampfer untergebracht war, konnten wir abfahren. Die Scenerie war mir, der ich diese Fahrt nun bereits wiederholt gemacht hatte, ja bekannt genug. Von dem Plehn-Felsen war kaum noch die Spitze zu sehen; so war das Wasser in den wenigen Tagen gestiegen. Am Nachmittage wurde eine Stunde lang Halt gemacht, um neuen Holzvorrat zu schaffen. Dann fuhren wir bis zum späten Nachmittag weiter und legten, bevor wir die N'komo-Mündung erreicht hatten, uns vor Anker. Das Aufschlagen des Lagers dauerte heute eine ziemliche Zeit, da Dr. Plehus Soldaten mit dem Aufstellen seines grofsen Zeltes noch nicht recht Bescheid wufsten. Bis zum späten Abend safsen wir Europäer noch bei der wundervollen Beleuchtung, welche der Mond über die Landschaft warf, zusammen. Am nächsten Morgen dampften wir damn zeitig ab, um noch vor Mittag bei der Bumbe-Faktorei einzutreffen. Es war einer der heifsesten Tage, welche ich erlebt hatte; alles schien niedergedrückt zu sein, nur der unermïdliche Herr Langheld lief, ohne sich irgendwie zu schonen, in der Sonne umher, bis alles in Ordnung war. Wir salsen alle gerade beim Essen, als ein Soldat mit der Nachricht kam, dafs auf der anderen Seite des Bumbe ein riesiges Krokodil im Wasser schwämme. Dr. Plehn war sofort mit seiner Büchse zur Hand, und in der nächsten Minute hatte das Tier einen Schufs im Kopfe, der es auf der Stelle getötet haben mufste, denn das Tier blieb obeu. Der Sicherheit halber schofs Dr. Plehn noch einmal und zwar noch einen solchen Meisterschufs. Die Soldaten, welche schon die sicherheit ihres Herrn beim Schiefsen kannten, hatten auch sofort das Canoe, welches Dr. Plehn von mir übernommen, in den Flufs gezogen und ruderten nun mit allen Kräften zur Stelle, um die Jagdbeute einzuholen, die dann zur grofsen Freude der Leute verteilt wurde. Das Krokodil war eines der grölsten, welche ich je gesehen. 
Da Dr. Plehn mit dem Packen seiner ganzen Expeditionsgüter noch nicht vollständig fertig war, so beschlofs er, erst am 14 . Oktober ron Bumbe aufzubrechen; ich hatte also bier noch einen freieu Tag. Ich benutzte daher die Gelegenheit, mit Herrn Kalmar und Herrn Schultz, welcher mit uns nach Bomudali fuhr, um die Faktorei daselbst zu überuehmen, eine Canoefahrt den Bumbe hinauf zu machen, wo zum Bau der Häuser der Bumbe-Faktorei Baumstämme gefällt werden sollten. Die Freude, welche ich hier bei dem Anblicke der bäufig vorhandenen Kickxien empfand, wurde mir bald genommen, als ich sah, dafs Herr Kalmar eine nach der anderen fällen liefs, da er behauptete, dafs sonst keine andereu geraden Stämme zum Häuserbau vorbanden seien als die Kickxien. Es ist doch schade, dafs selbst die Europäer hier nicht mehr darauf achten, die Schätze, welche das Land bietet, möglichst zu wahren; gerade deshalb wäre es auch sehr wünschenswert, dafs von der Regierung Mafsregeln getroffen würden, ein solches Treiben zu verhindern. Wie ich mich später überzeugen konnte, sind die Befestigungen der Palaverhäuser der Fan-Stämme im Ngoko auch vorzugsweise aus Kickxiastämmen hergestellt. Bedenkt man nun, dals diese Dörfer bei der geringsten Gelegenheit verlassen werden und an einer anderen Stelle ein neues errichtet wird, zu dem wieder viele Kickxiastämıne nötig sind, so kann man sich leicht vorstellen, welcher Schaden mit der Zeit unter deu Kickxiabeständeu angerichtet wird, der leicht vermieden werden könnte. Der Eingeborene fällt natürlich lieber die weichen Kickxiastärume, als die zähen und harten Bäume, welche seinen schlechten Instrumenten so viel Widerstand entgegensetzten, um so mehr, als ja bei seiner Gewohnheit, die Dörfer immer wieder zu verlegen, das Holz gar nicht besonders dauerhaft zu sein braucht.

Am Morgen des 14. Oktober stand Dr. Plehn mit seiner Expedition schon zeitig fertig da. Es war arrangiert worden, dafs der "Major Cambier" die Expedition noch eine kurze Strecke den Bumbe hinauf bis kurz vor Kodjo bringen sollte. Die erste Hälfte, welche Herr Peter fübrte, ging gegen 7 Uhr ab. Da ich auch gern einen Teil des Bumbe sehen wollte, fuhr ich auch mit, um dann mit dem Dampfer wieder umzukehren. Dr. Plehn führte dann den Rest auch sogleich nach. Wir beide nahmen noch einmal Abschied voneinander und wünschten uns gegenseitig viel Erfolg und Gesundheit auf unseren Reisen und trennten uns daun in dem Glauben, dafs wir uns beide in Europa wiedersehen würden. "Grülsen Sie noch alle meine Freunde und Bekannten an der Küste," das waren seine letzten Worte, welche er mir noch vom Dampfer aus zurief; dann war der Dampfer um eine Landzunge gebogen, die ihn uns verbarg. 
Kurz nachdem der „Major Cambier" zurückgekehrt war, wurde alles zur Weiterfahrt den Dja hinauf fertig gemacht. Um $1 \mathrm{Uhr}$ schon fuhren wir ab. Bei den Djama-Inseln machten wir einen kurzen Halt, um Lebensmittel zu kaufen, da das kleine Dorf neben der Bumbe-Faktorei für die vielen Leute, welche während der letzten Tage dort gewesen waren, nicht genug hatte liefern können. Gegen Abend legten wir dann an einer etwas trockeneren Uferstelle an, wo ich Kickxia sowohl wie Landolphien in ziemlichen Quantitäten fand. Herru Langheld sowohl wie Herrn Schultz machte ich nun auf die Lnterschiede aufmerksam, welehe die Kickxia unter den anderen Bäumen leicht kenntlich macht. Moskitos gab es übrigens hier wieder reichlich. Am frühen Morgen erreichten wir am 15. Oktober die Bomudali-Faktorei, wo wir für den Rest des Tages zu bleiben hatten, da es hier für Herrn Langheld viel zu thun gah, denn es mufsten vor allen Dingen viele Waren hier gelandet und gestaut werden, welche Herr Schultz, der die Faktorei leiten sollte, beim Einkaufen des bis dahin einzig in Betracht kommenden Produktes, des Elfenbeins, nötig hatte. Da ich bei meinem ersten Aufenthalte in Bomudali in den Wäldern hinter der Faktorei vergeblich nach Kickxia gesucht hatte, so schlug ich auf meinen Streifereien diesmal eine andere Richtung ein und hatte auch hier wieder die Freude, Kickxia zwischen der BomudaliFaktorei und dem Dorfe Lobilos in Mengen zu sehen. Je mehr ich von der Gegend sah, desto mehr gewann ich die Überzeugung, dafs hier dereinst sich ein enormer Kautschukhandel entwickeln müsse, vorausgesetzt, dafs heizeiten gegen Mifsbrauch dieser Goldgruben unserer Kolonie Kamerun Schritte gethan werden.

Die Eingeborenen dieses Teiles des Dja unterscheiden sich schon ganz bedeutend von den weiter unten wohnenden Misangas. Besonders auffallend ist die Haartracht der Weiber. Neben einer grolsen Raupe von Haaren, welche über den Scheitel bis zum Hinterkopf hinunterläuft, sind die Haare zu beiden Seiten oberhalb der Schläfen in raupenförmige Ringe frisiert. Um diese Frisur, welche eine sehr lange Zeit in Anspruch nehmen mufs, zu schützen, ist sowohl je oberhalb der Ohren wie an der Haarwurzel über der Stirn eine grofse, muschelförmige, aus Bast hergestellte Klappe in das Haar eingeflochten. Während des Schlafes oder sonst bei Gelegenheiten, bei welchen diese Haarfrisur in Gefahr kommt, zerstört zu werden, werden diese Klappen durch ein Tuch gegen den Kopf angezogen und bedeckt und dienen so zum Schutze des Ganzen. Die Gesichtszüge der Eingeborenen sind hier entschieden intelligenter und ansprechender als die der Misangas. Während unseres Aufenthaltes in Bomudali kamen auch einige Bomabassa-Leute, welche, aus R. Schlechter, Westafrikanische Kautschuk-Expedition. 
ziemlicher Entfernung kommend, mit den Bomudali-Leutes in Handelsbeziehungen stehen. Dieselben zeichneten sich durch eigentümlich blaue Tättowierung auf der Stirn und der Oberlippe aus. Im grofsen und ganzen schien die Bevölkerung den Weifsen gegenüber sehr scheu und furchtsam zu sein.

Ein merkwürdiges Stück, welches ich hier erstand, aber später auf meinen Reisen zerbrach, möchte ich hier erwähnen, da es ethnologisch von Interesse sein mag, nämlich eine Flöte, die einzige, welche ich je in diesen Gegenden gesehen. Das Instrument war aus einem mir unbekannten hohlen Pflanzenstengel hergestellt und hatte ungefähr die Form der in Deutschland allgemein verbreiteten Blechflöten.

Da Herr Langheld mit den Einrichtungen in seiner Faktorei so weit fertig war, konnten wir am Morgen des nächsten Tages unsere Reise den Dja weiter himauf fortsetzen. Gegen S Uhr verliefsen wir am Morgen des 16. Oktober Bomudali und dampften auf das Dorf des im Dja von seinen sämtlichen Nachbarn gefürchteten Häuptlings Lobilo zu. Die Scenerie war fast dieselbe wie am Dja unterhalb Bomudali, die Vegetation wohl etwas üppiger und die Ufer, besonders in der Nähe des Dorfes Lobilos, etwas höher. Schon rom Dampfer aus konnte man die vereinzelt stehenden Kickxien sehen, besonders als wir uns dem Dorfe Lobilos näberten. Lobilo hatte schon von unserem beabsichtigten Besuche Kunde erhalten, so dafs uns, als wir sein Dorf erreichten, eine grofse neugierige Menschenmenge empfing. Unterweg's hatten wir verschiedene Iörfer passiert, welche infolge der Erpressungen dieses Negerhäuptlings verlassen waren, und was war nun schliefslich seine Macht? Etwas anderes als Hinterlist konnte es nicht sein. Als wir in sein Dorf kamen, safs er versteckt in einem der Palaverhäuser und zitterte am ganzen Körper, als wir ihm zur Begrüfsung die Hand gaben; wahrscheinlich hatte er wieder ein böses Gewissen. Man sah dem Kerl in diesem Augenblicke übrigens so recht den feigen Schurken an. Für jeden, der ihm gegenüber etwas imponierend auftreten kamu, ist dieser Feigling meiner Meinung nach wenig gefährlich. Viel mehr als Lobilo interessierte mich das Dorf, denn für ein Fan-Dorf in der Ngoko-Region ist dieses ganz abnorm gebaut und dürfte wohl einzig im ganzen Bezirke dastehen. Zunächst ist das ganze Dorf von einem hohen Lattenzaune umgeben, welcher etwa ein Quadrat bildet; der Zugang in das Dorf hinein ist nur durch die vollständig dunklen Palaverhäuser möglich, deren Eingang so schmal ist, dafs man nur mit Mühe sich hineinzwängen kann. Beide Palaverhäuser waren durch viele Schichten von Baumstämmen befestigt. Die Hütten, welche zwar nach Art der 
Fans sich an einer einzigen Strafse entlang hinzogen, waren auch stärker gebaut, als man sie gewöhnlich im Ngoko siebt; aufserdem standen hinter denselben noch kleinere Hütten und Vorratshäuser, welche ich sonst auch nirgend beobachtet hatte. Die unten beschriebene Haartracht war bei den Weibern die allgemeine, die Männer batten vorn und hinten das sonst nicht weiter frisierte Haar in eineu oder zwei steife, abstehende Zöpfe geflochten. Aufser Perlen und einigen Arm- und Fufsringen sah man von Schmuck selten etwas. Die Bekleidung bestand bei den Männern in einem kurzen, weiten Basttuche, bei den Weibern in einer Schürze aus demselben Stoff, der übrigens vor seinem Gebrauche mit zerpulvertem Rotholz und Fett beschmiert wird.

Ich machte eine kurze Exkursion, un die Natur des Waldes hier kennen zu lernen, und hörte von Herrn Langheld, als ich zurückkehrte, dafs einige Pygmäen, hier Badjiris genannt, sich im Dorfe Lobilos befänden. Da mir Dr. Plehn viel von diesem Zwergvolke, das sich nach Angaben der Eingeborenen Bakolos nennt; erzählt hatte und ich bereits häufig verlassene Hütten herumziehender Trupps im Urwalde angetroffen hatte, so war ich natürlich begierig, dieses interessante Völkchen selbst näher kennen zu lernen. Auf meinen Wunsch liefs Lobilo die Leute heranholen. Lis waren drei Männer, welche ich hier sah. Dieselben waren durchaus nicht übermälsig klein, wenn aush unter mittelgrofs, aber merkwürdig robust gebaut. Ihr Blick war äufserst scheu und listig, doch lag dessenungeachtet keine Falschheit darin. Merkwürdig für einen Neger war der Bart, welchen ein jeder dieser Männer hatte, da er bis anf die Brust reichte. Wie mir Dr. Plehn erzählte, waren sämtliche Bakolos, welche er auf seiner Reise nach Djimu näher zu beobachten Gelegenheit gehabt hatte, bartlos; ich erwähne dies, da auch die Mehrzahl der Männer, welche ich später sah, sich durch einen für einen Neger merkwürdig üppigen Bartwuchs auszeichnete. Dr. Plehn gebührt die Ehre, die ersten sicheren Nachrichten über das Vorhandensein dieses Zwergvolkes in seinem Bezirke gegeben zu haben. Unter seinen ethnologischen Aufzeichnungen zeigte er mir sehr viel Notizen über àiese Leute, auch eine kleine Sammlung von Wörtern ihrer Sprache. Er hatte auch bis zu dem Augenblicke, als wir uns am 14. Oktober am Bumbe trennten, nur Männer der Badjiris gesehen; die Weiber waren stets zur Zeit entflohen. Lobilo hatte diese Männer für sich gewonnen, um durch sie Elefanten jagen zu lassen, denn das ist ihre Hauptbeschäftigung; auch sollen sie dabei eine solche Gewandtheit haben, dafs es ihnen mit ihreu Lanzen immer gelingt, so viel Elefanten zu erlegen, dals es ihnen nie an Fleisch mangelt. Wie mir Plehn mitteilte, 
schreiben die Fan-Stämme dem letzteren Úmstande es zu, dafs die Bakolos Menschenfleisch verschmähen.

Nachdem Herr Langheld mit Lobilo noch die Geschenke ausgetauscht hatte, dampften wir kurz nach Mittag weiter. Nach etwa zweistündiger, ziemlich eintöniger Fahrt erreichten wir die Mündung des auch noch rollständig unerforschten Kudu-Flusses und das dicht dahinter am Dja liegende Dorf N'goala, welches das Endziel der jetzigen Flufsfahrt sein sollte. Nach Dr. Plehns Angaben dürften die grofsen Schnellen, für welche er den Namen Carnap-Schnellen, zu Ehren des Herrn Oberleutnants v. Carnap-Quernheimb, welcher zuerst bis in die Südostecke Kameruns vordrang, gewählt hatte, noch drei bis vier Stunden Dampferfahrt oberhalb des Dorfes N'goalit gelegen sein. Da wir einige Zeit hier vor N'goala liegen bleiben wollten, so benutzte ich die Gelegenheit, ein auf der anderen Seite des Kudu eine halbe Stunde Weges im Innern gelegenes Dorf zu besuchen. Zusammen mit dem Kapitän des Dampfers, einem Skandinavier, machte ich mich in Begleitung eines Führers aus dem Dorfe N'goala und einiger Eingeborenen vom Dampfer aus auf den Marsch. In einigen kleinen Canoes setzten wir über den Kudu und traten dann in den Wald ein, der trotz seines feuchten Bodens doch zahlreiche Kickxien enthielt. Unterwegs erzählte mir der Führer von N'goala, dafs ein Lager der Bakolos in der Nähe sei. Eine solche Gelegenheit liels ich mir nicht entgehen; meinen Leuten möglichst leises Gehen gebietend, marschierte ich mit dem Führer voraus und bog mit ihm von dem Wege ab in den Wald ein. Es gelang uns auch wirklich, unbeachtet an das Lager heranzuschleichen, welches auf einer kleinen Erhöhung lag. Ich stürmte dann plötzlich vor und stand nun zum grofsen Schrecken der Bakolos unter ihnen. In heilloser Furcht ergriff alles die Flucht, denn einen Weilsen hatte wohl noch keiner von ihnen gesehen. Es gelang uns aber doch, einige Männer und zwei Weiber zu halten und schliefslich so weit zu beruhigen, dafs sie mir sogar eine ibrer Elefantenlanzen verkauften. Die Weiber waren noch kleiner als die Männer und hatten recht häfsliche Gesichtszüge. Die Hütten hatten die Form einer hingestreckten Viertelkugel und standen im Kreise herum; sie waren nur grofs genug, dals etwa zwei Personen Platz darin hatten. Als nun auch die übrigen Leute herangekommen waren, setzten wir den Marsch nach dem Dorfe im Innern fort. Unser Führer schien ein recht verständiger Bursche zu sein; als wir uns dem Dorfe näherten, gebot er den Leuten, sich möglichst leise heranzuschleichen, da sonst die Eingeborenen fliehen würden, denn einen Weifsen hätten auch diese wohl kaum gesehen. Auch hier gelang es uns, bis zum Dorfe vorzuschleichen, ehe wir bemerkt wurden. Dann 
erhob sich plötzlich das Geheul der Weiber, als sie uns erblickten. Ich rief den Leuten zu, sie sollten nur beruhigt sein, denn ich sei nur gekommen, um ihr Dorf zu sehen und Hühner von ihnen zu kaufen. Die Weiber, welche entflohen waren, kamen auch wieder, als sie sahen, dafs wir uns mit den Männern ganz friedlich unterhielten; schliefslich wurden sie sogar ganz dreist. Ich hatte nur wenige Tauschartikel mitgenommen, da ich glaubte, dafs hier nicht viel zu kaufen sei; die Leute boten aber so riel an, dafs ich ihnen den Torschlag machte, bis zum Dja mitzukommen, wo sie am Dampfer einen besseren Markt finden würden. Mit einer ganzen Kolonne zogen wir dann zum Dampfer zurück, wo die Leute noch manches rerkaufen konnten. Herr Langheld wollte durchaus noch wieder ror Aubruch des Abends bis Bomudali zurück; ich hätte mich gern hier noch unter dem Völkchen etwas länger aufgehalten, das einen viel intelligenteren und freundlicheren Eindruck machte als die Misangas am Ngoko. Kurz nach 4 Uhr traten wir nun die Rück- fahrt an, welche bei der schnellen Strömung des Flusses nur die Hälfte der Zeit in Anspruch nahm als die Fahrt flufsanfwärts. Tor Lobilos Dorf wurde nicht einmal angehalten. Schon bei eintretender Dämmerung warfen wir an der Bomudali-Faktorei Anker. Ich habe übrigens hier noch nachzuholen, zu erwähnen, dafs Kopalbäume am Dja so weit in Menge am Flufsufer vorhanden waren, als wir gekommen wareu. Dr. Plehn erzählte mir auch einmal, dafs er bei den CarnapSchnellen beobachtet hätte, dafs seine soldaten auch dort ein Harz während der Nacht gebrannt, welches er für Kopal hielt. Es ist also wahrscheinlich, dals dieser Kopalbaum längs des Flusses noch weit hinaufsteigt. Interessant ist, dafs man ihn sehr selten in weiterer Entfernung rom Flufsrande findet.

Am Vormittage des nächsten Tages wurde die ganze Besatzung des Dampfers ausgeschickt, um Holz zu schlagen, denn Herrn Langheld hielt es nicht länger hier; er wollte durchaus zu seiner Faktorei zurück. Gegen Mittag nahmen wir Abschied von Herrn Schulz, welcher nun hier allein zurückbleiben soll. Mit dem gröfstmöglichen Dampfdruck wurde der "Major Cambier" den Dja hinuntergejagt, wobei uns die starke Strömung noch Beistand leistete. Schon um 3 Uhr trafen wir an der Bumbe-Faktorei ein. Nach nur halbstündigem Aufenthalte dampften wir weiter den Ngoko hinunter. Diese Fahrt, welche wir nun wachten, dürfte wohl für lange Zeit die schnellste bleiben, welche je auf dem Ngoko geleistet wurde, denn schon gegen 7 Uhr trafen wir in der Faktorei ein. Unterwegs sahen wir noch eine Herde Büffel am Flufsrande, welche aber schnell im Busche verschwanden, als sie unserer ansichtig wurden. Da es zu spät war, um jetzt noch die ermüdeten Leute 
zur Canoefahrt anzutreiben, schlief ich am Abend noch auf dem Dampfer und kehrte erst an nächsten Morgen zur Ngoko-Station zurück, wo ich bei strömendem Regen eintraf. Die Regenzeit schien jetzt überhaupt hier einzusetzen, denn während der letzten Zeit hatten wir auffallend starke und häufige Niederschläge gehabt. Herr Gruschka, welchen wir am Schwarzwasserfieber niederliegend verlassen hatten, war wieder einigermafsen hergestellt, doch noch immer so schwacb, dafs er nicht arbeiten konnte. Herrn v. Lü dinghausen fielen daher nun die sämtlichen Arbeiten allein zu

Die Zeit, welche ich noch auf der Station rerweilte, hatte ich mit dem Einpacken meiner Sachen und Trocknen der Kickxiasamen sowie anderen laufenden Arbeiten auszufüllen. Dasselbe herzliche und liebenswürdige Entgegenkommen, welches ich bei Dr. Plehn gefunden, wurde mir nun auch von Seiten des Herrn จ. Lüdinghausen zu teil. In Zukunft konnte ich nur einige kleine Exkursionen machen, da ich kein Personal aufzutreiben vermochte, welches mich begleiten konnte. Herr v. Lüdinghausen war zwar so freundlich, mir von den wenigen Leuten, welche ihm gelassen waren, einige zur Verfügung zu stellen, doch machte ich keinen Gebrauch davon, weil ich wufste, wie nötig er sie selbst brauchte. Einmal noch wollte ich versuchen, auf die Hügel auf der anderen Seite des Ngoko zu kommen, mu?ste es aber aufgeben, da der ganze Wald am Fufse derselben überschwemmt war.

Am Nachmittage brach während dieser Zeit mit merkwürdiger Regelmälsigkeit ein Tornado mit Regen aus, welcher häufig so stark war, dafs die Häuser auf der Station Gefahr liefen, umgeblasen zu werden. Herr v. Lüdinghausen lief́s zwar gerade ein neues Steinhaus bauen, doch wäre es uns dennoch sehr unangenehm gewesen, wenn uns in den provisorisch aufgebauten (Raphia-) Bambushäusern das Dach entführt worden wäre. Es ist nicht unwahrscheinlich, daf's wir es der äufserst luftigen Konstruktion dieser Häuser, welche den Wind von allen Seiten hindurchfegen liefsen, zu verdanken haben, dafs wir einem derartigen Zufalle entgingen.

Herr Kruschka, welchen Herr v. Lüdinghausen zur Erholung auf eine kleine Reise nach Djimu, die Herr Langheld mit dem "Hajor Cambier" kurz nach unserer Rüekkehr vom Dja angetreten, mitgeschickt hatte, traf am 29. Oktober plötzlich mit der Nachricht wieder auf der Station ein, dafs am 1. November die "Holland" von Wesso nach dem Stanley-Pool abfahren wolle. Glücklicherweise hatte ich mich so weit bereit gehalten, dafs ich denn auch dank der liebenswürdigen Unterstützung von seiten des Herrn v. Lüdinghausen, welcher mit einigen Lenten aushalf, bereits am nächsten Tage unterwegs war. Es wurde 
mir ordentlich schwer, hier von der Ngoko-Station Abschied zu nehmen, wo ich erst mit Dr. Plehn und dann mit Herrn v. Lüdinghausen so angenehme Stunden verlebt hatte. Das ziemlich grofse Canoe war kaum im stande, meine vielen Lasten zu tragen; doch hier galt kein Zögern, wenn ich nicht viel Zeit verlieren wollte. Sehr hatte ich mich woch am letzten Tage gefreut, dafs Herr r. Lüdinghansen durch sein forsches Auftreten es so weit brachte, dafs vier Misangas einwilligten, zusammen mit einigen Leuten ron fler Station mich nach Wesso zu bringen. Es war dieses das erste Mal, dafs die Misangas zu einer derartigen Arbeitsleistung gebracht worden waren.

Da ich zu gleicher Zeit die Post der Station mitnehmen sollte, hatte ich bis gegen 3 Uhr nachuittags zu warten, ehe ich am 30. Oktober aufbrechen konnte. Wir kamen daher denu auch nicht sehr weit, besonders da ich am Dorfe des Häuptlings Angojo anlegen liefs; um einige Lebensmittel zu kaufen. Ehe wir von dort aus das Dorf N'gali erreichten, war es stockfinster geworden, aufserdem hatte wieder ein Tornado eingesetzt, so dafs die Situation nicht ganz gefahrlos war. Erst gegen $7^{1 / 2}$ Uhr trafen wir in N'gali ein. Ich wollte nicht erst mein Zelt und das Feldbett unter den übrigen Lasten hervorsuchen lassen, und setzte mich deshalb zum Schlaf in einen langen Stuhl. Doch, o weh! Es gab hier Millionen von Moskitos, welche mich während der ganzen Nacht nicht schlafen liefsen. Noch müder als am Abend vorher, setzten wir am nächsten Morgen gegen 6 Uhr unsere Reise fort. Nach einer Stunde liefs ich einige Minuten an einem kleinen Dorfe Halt machen, wo uns die Eingeborenen Elefantenfleisch zum Kaufe anboten. Von dort aus ging es bis 1 Uhr ohne Unterlafs weiter, bis wir den Sanga erreichten. In Sicht von Wesso liefs ich nun noch anhalten, um den Leuten Zeit zum Essen zu gewähren. Kurz darauf trafen wir auch wohlbehalten in Wesso ein, wo man mich bereits aufgegeben hatte, da man dachte, dafs ich schon am Abend vorher oder gar nicht eintreffen würde. Der Dampfer war glücklicherweise noch nicht alggefahren. Im Laufe des Nachmittags liefs ich meine Lasten an Bord des Dampfer's unterbringen und schickte dann das Canoe mit der Bemannung zur Ngoko-Station zurück.

Da am 1. November der Nebel, welcher den ganzen Flufs bedeckte, uns verhinderte, zu der festgesetzten Stunde zeitig abzufabren, so wurde es ziemlich spät, ehe wir die Reise antreten konnten. Aufser mir war noch ein französischer Beamter rom oberen Sanga Passagier auf dem Dampfer; auch er wollte zum Stanley-Pool hinunter. Da der Dampfer nur sehr langsam fuhr und sich fast nur treiben lassen mufste, denn er hatte sich noch während der letzten 
Ngoko-Reise einige arge Schäden zugezogeu, so kamen wir trotz der starken Strömung doch recht langsam vorwärts. Holz wurde nur halb soriel verbraucht als auf dem „Major Cambier.". Es war eine elende Fahrt auf einem der schlechtesten Dampfer, welche den Congo befahren. Hätte ich Leute genug gehabt, w ürde ich sicher eine Canoereise dieser I)ampferfaht vorgezogen haben, denn dann hätte man doch wenigstens noch die Ufer besser kennen gelernt. I)a wir, nach Angabe des Kapitäns, Holz für drei volle Tage besalseu, so fuhren wir bis 5 Uhr am Nachmittage ohne Unterbrechung. Gegen $1^{1 / 2}$ Uhr sahen wir Likilembe und bald darauf Pembe allmählich hinter uns verschwinden. Bei einem Dorfe, Butinda, welches wir bei der Auffahrt nicht gesehen hatten, legten wir uns am Abend vor Anker. Auch während der Fahrt am nächsten Vormittag'e sahen wir ein Dorf, welches mir auch früher entgangen war, es wurde N'gunga genannt. Gegen Mittag erreichten wir N'kunda, wo, seit der Zeit meiner Reise den Fluls hinauf, eine Faktorei einer französischen Gesellschaft, in deren Konzessionsgebiet der Ort grehörte, entstanden war. Hier befanden sich zwei Europäer, welche sich beide sowohl darüber beklagten, dafs die Eingeborenen ihnen keine Lebensmittel verkaufen wollten, so dafs sie gezwungen seien, allein von Konserven zu leben, als auch, dals es überhaupt keinen Handel gebe, denn bis zur Zeit (sie waren bereits zwei Monate in N'kunda) hätten sie noch keinen Zahn Elfenbein kaufen können. Diese Aussagen bestätigten genau meine Ansichten über die französischeu Konzessionen am Sanga, wie ich sie übrigens weiter oben und bereits auch an anderen Orten wiederholt ausgedrückt habe. Die armen Leute wulsten vor Langeweile nicht, was sie anfangen sollten. Mit grolsen Eifer hatten sie einen weiten Platz freigeschlageu, um nun daselbst ein grolses Haus aufzuführen, denn bis zu unserer Ankunft hatten sie in Zelten gewohnt.

Als wir am Nachmittage N'kunda verlielsen, erhob sich ein solcher Sturm, dals wir mit dem Dampfer vergeblich versuchten, umzudrehen; erst als wir im Schutze einer Insel waren, konnten wir wieder richtig manövrieren. Wir wurden dann bald von der Strömung ergriffen, welche uns, selbst wenn wir keinen Dampf gehabt hätten, unserem Ziele schnell zuführte. Gegen Abend liefen wir bei einem verlassenen Dorfe an Land. Da wir das Holz der alten Hütten gut als Feuerungsmaterial verwenden kounten, so liefs unser Kapitän die ganze Besatzung daran gehen, die gesamteu Holzvorräte auf dew Dampfer zu bergen. Ich sah hier übrigens einige Mittelpfähle an den Häusern, wie ich sie früher noch nicht beobachtet hatte. Dieselbeu waren am oberen Ende in drei bis fünf verkehrte, ïbereinander stehende Kegel ausgeschnitzt worden und 
endeten mit zwei kurzen Spitzen. Der das Dach tragende Querbalken war zwischen diese zwei Spitzen aufgelegt. Unterhalb dieser kegelartigen Verzierung an der Spitze der Pfähle war ein viereckiges Loch angebracht worden, über dessen Bedeutung ich nie recht klar geworden bin, es sei denn, dafs man dort Pulverhörner oder sonstige Gegenstände aufhängte.

Dals wir uns nun der schlimmsten Moskito-Region des Congo näherten, wurde uns nur zu bald klar an den vielen Stichen, mit denen wir Europäer bedeckt waren. In der Nacht konnten wir kaum schlafen. Auch die Eingeborenen haben unter dieser Plage sehr zu leiden, da sie fast alle mit vollständig entblölstem Körper sich zur Ruhe legen.

Wieder verhinderten uns starke Nebel am 3. November, vor $9 \mathrm{Uhr}$ aufzubrechen. Wir verfolgten einen Kurs, welcher von dem, welchen wir mit dem "Major Cambier" bei der Fahrt flufsanfwärts eingeschlagen, etwas abwich. So kam es, dafs wir auch hente gegen Mittag wieder ein Dorf erreichten, von dem ich vorher auch nichts g'ehört hatte. Unserem Kapitän war es wohlbekannt, da er dort bereits häufiger $\mathrm{Holz}$ gekauft hatte. Auch diesmal versuchten wir wieder, einiges zu erhalten. Nach langem Feilschen willigten die Dorfbewohner schliefslich ein, uns etwas von ihrem Vorrate abzulassen. Das Dorf lag an einem kleinen, dicht mit Wassergras, Pistia, Azolla und Utricularia bedeckten Creek, welcher, wie mir die Eingeborenen erzählten, weit aus dem Innern kommt, wo viele Nilpferde (Ngubos) seien; nur bei sehr hohem Wasserstande sei es möglich, dort hinzukommen. Die Leute waren äufserst mifstrauisch. Gegen Abend setzten wir unsere Fahrt dann fort. In der Nähe des Platzes, welchen wir zum Nachtlager erkoren hatten, fand ich viel Landolphien, welche guten Kautschuk gaben. Auch hier wurden wir von den Moskitos arg zugerichtet. Da der Flufs uur wenig Abwechselung bot und der Dampfer nur langsam vorwärts kam, fing die Fahrt an, uns beiden Passagieren äufserst langweilig zu werden. Nicht einmal ein Nilpferd oder ein Krokodil liefs sich sehen; aufserdem regnete es sehr häufig, so dals wir uns nicht selten recht ungemütlich befanden. Weifse Edelreiher waren die einzigen Tiere hier, welche einen Schufs Pulver wert gewesen wären; doch diese verschwanden immer wieder, bevor wir uns auf Schufsweite nähern konnten, denn die Maschine unseres Dampfers verursachte einen solchen Lärm, dafs alle Tiere verscheucht werden mufsten. Gegen Mittag langten wir an einem Dorfe an, welches an einem breiten Arm des Sauga gelegen war, der dem Kapitän und mir bis dahin unbekannt war. Da das Fahrwasser günstig schien und wir vermuteten, sehr bald wieder in den alten Kurs zurückzukommen, liefss 
sich der Kapitän bewegen, in diesen Arm des Flusses einzufahren. Obgleich wir bis gegen Anbruch der Dunkelheit fuhren, war doch noch keine Gelegenheit gewesen, in den Hauptstrom zurückzukehren. Wir wären erentuell wieder umgekehrt, wenn wir nicht aus der stark ablauferden Strömung ersehen hätten, dafs wir uns immer noch im Sanga befanden. Yon einer so grofsen lnsel. wie wir sie hier offenbar an unserer seite hatten, war im Sanga gar nichts bekannt. Sehr neugierig wurden wir schliefslich, doch zu wissen, wo wir endlich wieder in uns bekannte Gegenden kommen würden; der nächste Tag mufste ja diese Frage lösen. Natürlich war auch die Gefahr rorhanden, dafs wir infolge schlechter Wasserverhältnisse umkehren miülsten, wir bätten dınn zwei Tage Zeit rerloren. Am nächsten Tage dampften wir schon zeitig ab, da wir doch alle gespannt der Dinge harrten, welche nun kommen würden. Das Fahrwasser war gut. Jede neue Biegung zeigte uns dasselbe Bild, zu beiden Seiten hoher Urwald, durch den diese prachtvolle Wasserstrafse führte. So fuhren wir in diesem Kanal des Sanga hin, bis wir endlich zu unserer Freude gegen Mittag den Hauptstrom wieder vor uns sahen. Wie sich herausstellte, hatten wir durch diese Fahrt eine bedeutende Verkürzung der Route erreicht, denn die Ausmündung des Kanales lag in nicht grofser Entfernung der Mündung des "Likuala aux herbes" und war bisher stets als eine Mündung eines Nebenflusses des Sanga betrachtet worden. Gegen 4 Uhr erreichten wir die Mündung des „Likuala aux herbes" und machten dann nach etwa noch einstündiger Fahrt Halt, um den Leuten Zeit zu geben, für den Dampfer genügend Holz zu schlagen. Im Walde waren hier nur wenige Kautschuklianen zu sehen. Erst gegen 9 Uhr konnten wir am nächsten Tage fort, da wir nicht genügend Holz hatten, denn, da keine richtige Aufsicht über die Leute existierte, so benutzten dieselben natürlich auch jede Gelegenheit, um möglichst zu fanlenzen. Die Savannen waren schon seit gestern immer häufiger geworden und waren heute sogar an der Likuala-Seite vorherrschend. Gegen Mittag erreichten wir die Mündung des Likensi-Kanales. Hier hatten wir noch das Glück, zu sehen, wie vier Eingeborene in zwei kleinen Canoes ein Nilpferd, welches sie offenbar bereits vorher verletzt hatten, harpunierten. Es war erstaunlich, dafs das geängstigte Tier nicht die Canoes umwarf. Kurz nach 1 Uhr trafen wir dann glücklich wieder in Bonga ein.

Wir hatten gehofft, in Bonga einen Holzvorrat zu finden, der es uns ermöglichen würde, am nächsten Morgen gleich weiterzufahren, hatten uns hierin aber getauscht. Während des folgenden Tages mulste daher die ganze Schiffsbesatzung für einen neuen Holzvorrat sorgen, da wir im Congo voraussichtlich Schwierigkeiten 
Labeu würden, die nötigen Holzmengen ohne grofsen Zeitverlust zu beschaffen. Ich hatte in Bonga noch einiges zu ordnen und benutzte dann den Rest der Zeit dazu, eine Exkursion zu machen, bei der ich aber nichts Neues entdecken konnte.

Kurz nachdem wir am 8. November morgens Bonga verlassen hatten, um nun nach dem Congo zu fahren, trafen wir den "M'Fumuntango", einen gröfseren Dampfer des holländischen Hauses. Unser Kapitän, welcher gern derartige Gelegenheiten benutzte, sich eine kleine Abwechselung zu gestatten, liefs an Land anlaufen und ging dann an Bord des ,M'Fumuntango“, um sich nach Neuigkeiten zu erkundigen. Auf dem Dampfer hefand sich der Gouverneur des Congo français, welcher mit seinem ganzen Stabe auf einer Reise nach dem Ubangi begriffen war. Unser Kapitän, welcher wohl hier eine Gelegenheit gefunden zu halben glaubte, sich besonders auszeichnen zu können, heuutate einen Fieheranfall seines Kollegen zum Vorwande, um unseren Dampfer, welcher hier nur leicht an einer Grasbank durch einen Auker befestigt war, im Stiche zu lassen, und nun den "I'Fumuntango" nach Bonga zu führen, obgleich sich auf demselben noch ein zweiter Kapitän für etwaige Notfälle befand. Da wir noch in Sicht ron Bonga wiren, meiner Ansicht nach ein ebenso überflüssiger wie gewagter Schritt, denn es war deutlick zu sehen, dals wir innerhalb der nächsten Stunde einen starken Tornado zu erwarten haben würden. So geschah es nun auch, dafs der äufserst lose befestigte Dampfer ohne Führung diesem Sturme preisgegeben wurde. Weun wir losgerissen worden wären, so wäre der Dampfer rettungslos verloren gegangen, deun seine Steuermaschine fungierte sogar in der gewöhulichen Strömung kaum und wäre beim Tornado vollends nutzlos gewesen. Als der Sturm ausbrach, liefs ich einen zweiten Anker, welcher glücklicherweise an Bord war, vom hinteren 'T'eile des Danpfers nach dem Ufer hinüberlegen und dann den Dampfer soweit als möglich an die Grashank heranziehen, so dafs er etwas sicherer lag und vom Sturme weniger zu leiden hatte. Als der Tornado vorüber war, wäre es Zeit gewesen, dafs der Kapitän hätte wieder zurückkommen können, doch schien es diesem in Bonga so gut zu gefallen, dal's er auch am Abend noch nicht zurïckkehrte. Gegen 11 Uhr am nächsten Tage erschien ein Canoe von Bonga, welches von dem Chef de Poste daselbst geschickt war, um drei von einer französischen Firma entlaufene Bangalas; welche der Kapitän engagiert hatte, zurückzuholen. Von ihm selbst war noch uichts zu sehen. Erst um 2 Uhr erschien er, sehr verguügt über die Unterbrechung, welche ihm die Rückreise nach Bonga gestattet hatte. Nun hatte er natürlich Eile, fortzukommen, um das Versäumte nachzuholen. Da ich den 
Maschinisten aufgefordert hatte, einen gewissen Dampfdruck zu halten, damit wir sogleich nach Ankunft des Kapitäns abfahren könten, waren wir sehon kurz nach 2 Uhr in der Lage, abdampfen zu können. Zwischen den Inseln und dem Festlande fuhren wir stromab. Man wulste nie recht, ob man sich hier noch im Sanga oder im Congo befände, da die davor gelagerten Inseln gewissermafsen die Scheide zwischen Congo und Sanga bilden, während andererseits durch den Kanal von Likensi das herunterkommende Wasser des Congo bei Bonga rorbeiflielst. Die Mründung des Likuala, welcher mit dem "Likuala aux herbes" nichts zu thun hat, passierten wir gegen $3 \mathrm{Uhr}$ und gelangten dann kurz darauf in den wahren Congo, welcher dort gerade ein recht typisches Bild darbot mit seiner breiten Wasserfläche und den unzähligen Inseln. Als die Sonne sank, gelang es uns, in dem Gewirr von Inseln noch eben éinen Platz zum Anlegen für die Nacht zu erreichen; Holz gab es hier allerdings nicht, so dafs sich wohl bald wieder Mangel bei uns einstellen mufste. Erst gegen $10 \mathrm{Uhr}$ liefs der Kapitän am nächsten Tage abfahren. Da ich in Eile war, nach der Küste zur rechtzeitigen Abfahrt eines Dampfers zu kommen, um möglichst wenig Zeit zu verlieren, war wir dieses doppelt unangenehm. Da wir zwischen den vielen Inseln auch nicht einen direkten Kurs einhalten konnten, so war unser Fortschritt nur ein sehr langsamer. Ein Tornado, welcher am Nachmittage heraufzog, zwang uus, an einer Sandbank Schutz zu suchen. Dat das Wetter noch lange Zeit sehr drohend aussah, konnten wir auch im Laufe des Nachmittags nicht weiterfahren. Nilpferde gab es nur sehr spärlich, aber desto mehr Schlangenhalsvögel und weifse Reiher. Ich unternahm noch am Nachmittage eine Canoefahrt zwischen den Inseln hindureh, um zu versuchen, ob ich nicht irgendwo in den Wald eindringen könnte, mufste diesen Versuch aber bald aufgeben, da die sämtlichen Wälder überschwemmt waren. Am nächsten Tage fuhren wir kurz nach 6 Uhr ab. Gegen 8 Uhr trafen wir bei der belgischen Station Bolobo ein, wo wir uns wieder tüchtig mit Hühnern rersehen konnten. Ich wollte mir die Station näher ansehen und erkundigte mich nach dem Kommandanten. „Er sei mit 50 Solcaten ins Innere gezogen, um die Eingeborenen zu lehren, wie Kautschuk gemacht werde", erbielt ich zur Autwort. Auf einer kleinen Streiferei sah ich auch hier ein Exemplar der Kickxia latifolia. Nachdem wir unsere Einkäufe beendet (wir hatten etwa 50 Hübner gekauft), dampften wir weiter. Bei einem kleinen Holzposten unterhalb der Station liefen wir an, da der Kapitän glaubte, von dem den Posten verwaltenden Eingeborenen Holz kaufen zu können. J)erselbe gehorchte aber seineu Instruktionen genau und gab kein 
Holz ab. Wir hielten uns nun gar nicht weiter auf, sondern suchten sogleich nach einem Platze, wo wir genügend Holz finden würden, dals es sich verlohnte, daselbst schlagen zu lassen. Nach etwa halbstündiger Fahrt legten wir für einige Zeit an, bis wir uns überzeugt hatten, dafs es sich nicht verlohne; hier weiter Holz schlagen zu lassen. An dem Abend desselben Tages erreichten wir gegen 6 Uhr die englische Missionsstation Chumbiri, welche wir

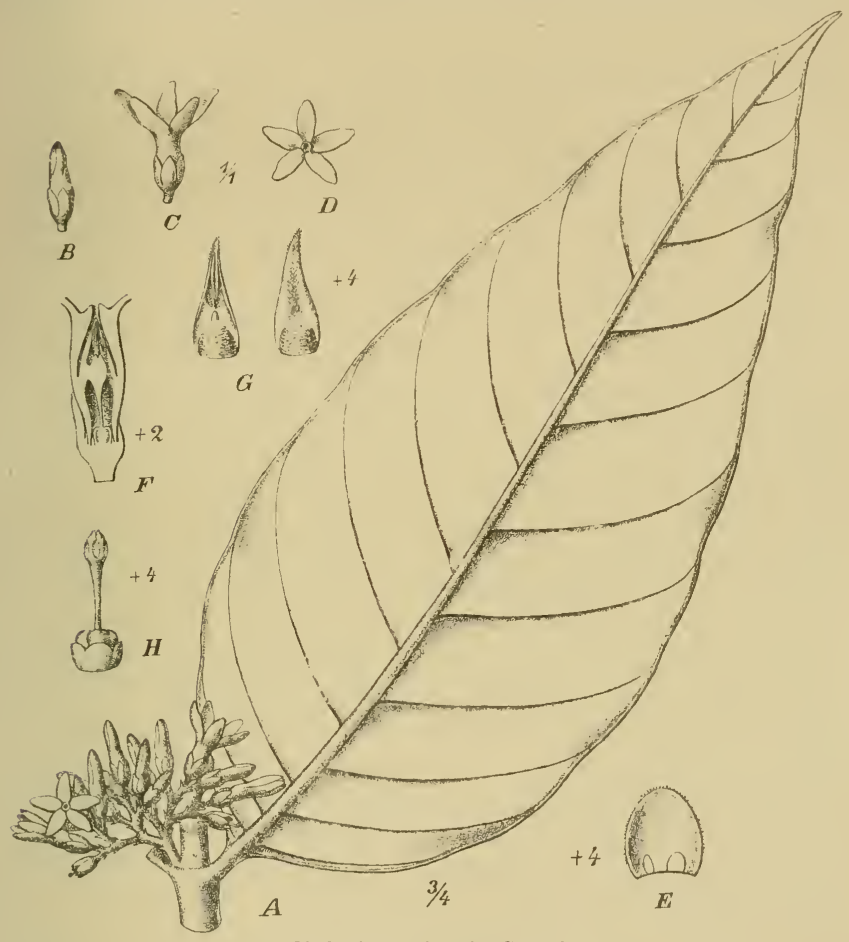

Kickxia latifolia Stapf.

A Zweigstück, B Knospe, C Blüte, D dieselbe von oben, E Kelchblatt von innen, F Längsschnitt durch die Blüte, G Antheren, H Fruchtknoten mit Griffel.

aber von Europäern verlassen fanden. Kurz nach uns traf der Missionsdampfer "Peace“ ein, welcher von Herrn Grenfell, dem bekannten Congo-Forscher und Entdecker der Ubangi-Mündung, geführt wurde. Sehr interessante Neuigkeiten sowie verschiedenes über seine letzte Reise gab dieser noch immer äufserst rüstige alte Missionar und Forscher an jenem Abend zum besten. Am 12. No- 
rember kamen wir nun endlich einmal wieder schon um. 6 Lhr fort, allerdings auch nur, um wieder eine kurze Fahrt zu machen, denn schon um $9 \mathrm{Uhr}$ wurde abermals angehalten, da unser Holzvorrat nun völlig erschöpft war. Jch bestieg, während $\mathrm{Holz}$ geschlagen wurde, einen der bewaldeten Hügel in der Nähe, fand aber keine Landolphien dort, wie ich eigentlich erwartet hatte. Ton dieser dnlegestelle bis zur Mündung des Kassai hatten wir nur eine sebr kurze Fahrt. Gegenüber der Kassai-Mündung hatte das holländische Haus auch eine Faktorei bei dem Dorfe Bokabo, wohin wir nun zunächst unsern Kurs richteten. Kurz nach dem Essen langten wir ror der Faktorei an. Ein sehr netter, junger Holländer, wélcher der Faktorei vorsteht, führte mich an Nachmittage in der Umgebung umher, wo er einiges Interessante für mich zu finden glaubte. Savannen wechselten hier mit Urwald ab, erstere häufig durch Sümpfe unterbrochen. An sandigen, sonnigen Stellen im kurzen Grase sah ich bier den Wurzelkautschuk wachsen, von dem die Bateke auch schon anfaugen sollen, Kautschuk zu bereiten. Da es unser Kapitän mit der Zeit offenbar nicht sehr eilig hatte und am nächsten Tage in Bokabo liegen blieb, so benutzte ich diesen grezwungenen Aufenthalt dazu, die Ungebung näher zu untersuchen. Wurzelkautschuk war ziemlich reichlich vertreten, verschwand aber sofort, weun das Terrain weniger sandig und feuchter wurde. Auf den Bäumen in den Wäldern wie auch auf einzeln stehenden Bäumen, häufig der prallen Sonne ausgesetzt, wuchs hier eine Orchidee, welche allerdings nicht in Blüte war, doch noch an vertrockneten Blüten, welche sich in den Blattachseln fanden, leicht erkennen liefs, dafs man es mit dem offenbar seltenen Angraecum ichnenmoneum zu thun hatte. Auch eine Bossassanga-Art sah ich hier zum ersten Male, welche wohl für die Wissenschaft neu sein dürfte.

Bis zu dieser Faktorei bei Bokabo kommen die Bateke ans dem Innern des Congo frauçais, um ihren Kautschuk zu rerkaufen. Am Nachmittage erschienen auch wieder einige, welche wenige Zähne Elfenbein und einige Taschen voll Kautschuk brachten. Der Kautschuk war in grolse Kugeln geformt, welche einen ziemlich reinen Schnitt zeigten, aber doch viele Hohlräume besalsen. Nach Angaben der Leute stammte er von Landolphien her. Diese Bateke liatten eine interessante Haarfrisur. Die nach dem Scheitel zusammengekämmten Haare waren zu einem langen, stumpfen Kamme zusammengeflochten, welcher sich von der Stirn zum Hinterkopfe zog.

Da von seiten dieser Faktorei oberhalb des Dorfes Bokabo Holz für passierende Dampfer des holländischen Hauses geschlagen wird, so beschlofs unser Kapitän, dorthin zu fahren, um sich mit 
Holz zu versehen. Am Morgen des 14. November dampften wir ab, nun wieder stromauf. Um die Strecke bis zu dem Holzposten zurückzulegen, wozu ein Canoe gewöhnlich 1 bis $1 \frac{1}{2}$ Stunclen gelraucht, waren wir drei Stunden anf der Fahrt. Erst gegen $1 \mathrm{Uhr}$ war danu das Holz auf dem Dampfer verstaut, so dafs wir an die Weiterreise denken konnten. Auf der Rückfahrt hielten wir noch bei der Bokabo-Faktorei an, um Post wach Brazzaville mitzunehmen, dann setzten wir ohne Unterbrechung die Fahrt bis 4 Uhr nachmittags fort. Die „Marie“, ein kleiner Dampfer eines französischen Hauses, kam vor uns den Strom hinauf. Das gab nuu natürlich dem Kapitän unseres Dampfers wieder Grund, anzuhalten, um zu gleicher Zeit mit dem Kapitän der „Marie“ für den Rest des Tages sich festzulegen. Unsere Fahrt nach dem Stanley-Pool, die ja schon allerdings eine sehr langsame war, wurde auf diese Weise immer mehr verlängert. Am 18. November ereilte uns nun gar erst das Unglück. Wir hatten den Dampfer "Brazzaville* getroffen und natürlich wieder für einige Zeit die Fahrt unterbrochen. Der Kapitän kam schliefslich in ziemlich benebeltem Zustande wieder zurück und liels die Fahrt fortsetzen. Ich machte ihn damals schon auf einen heraufziehenden Tornado aufmerksam, welcher in Kürze ausbrechen mulste. Er lachte nur und behauptete, dagegen mit der "Holland" anfahren zu können. Der Tornado brach bald darauf aus und trieb den Dampfer, welchen er wie eine Feder erfalste, gegen Felsen und Baumstämme, so dals wir ein grofses Leck erhielten und sich die ganzen unteren Räume in Vorderteile des Schiffes bald mit Wasser füllten. Zu unserem Glücke wurden wir dann gegen eine Sandbank aufgetrieben, so dafs wir gerettet waren.

Den Nachmittag sowohl des 15. Norember wie den ganzen Vormittag des nächsten Tages dauerten nun die Reparaturen, welche glücklicherweise an Ort und Stelle ausgeführt werden konnten. Unsere Fracht, welche nicht leicht verderben kounte, deun sie bestand fast nur aus Elfenbein, mulste ausgeladen und an Land gebracht werden. Ich benutzte wieder diesen Zwischenfall zu Streifereien in den Wäldern, um nach Kantschuk zu fahnden. Landolphia owarilusis war ziemlich verbreitet, aulserdem noch eine windende Carpodinusart, welche keinen Kautschuk gab. Von einer kleinblütigen Landolphie fand ich im Walde noch auf dem Boden Blüten, konnte der Pflanze selbst aber nicht habhaft werden, obgleich ich lange danach suchte.

Endlich nach 2 Uhr konnten wir die Falnt fortsetzen. Die bügeligen, zum grofsen Teile bewaldeten Ufer boten einen recht pittoresken Aublick dar mit ihren häufig steil abfallenden Wänden. Am Ufer des Stromes dehnten sich mächtige Sümpfe aus, welche 


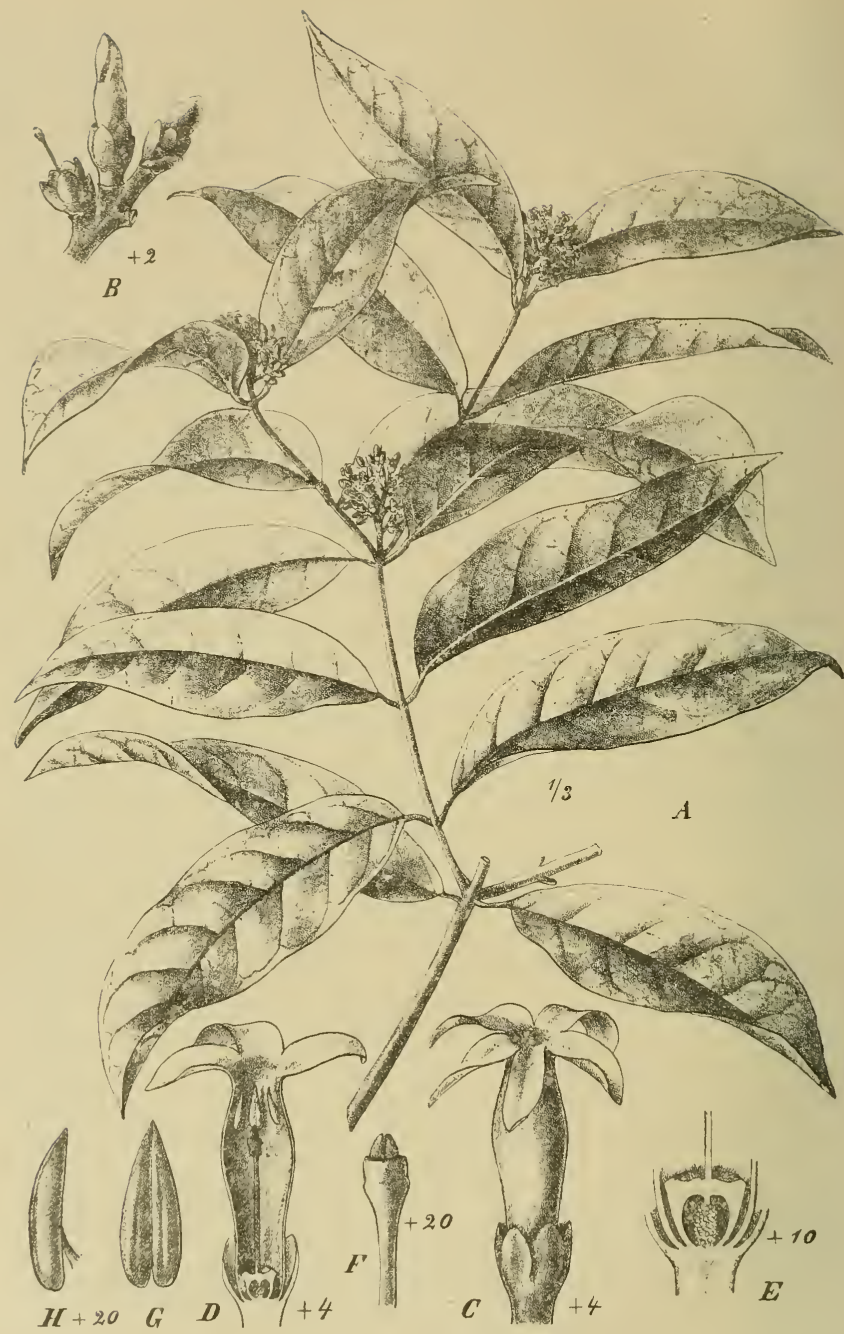

Landolphia owariensis P. Beanv.

A Blühender Zweig, B Knospen, C Blüte, D Längsschnitt durch dieselbe, E Längsschnitt durch den Fruchtknoten, F Griffel, G Anthere von vorn, H dieselbe von der Seite. 
grolsen Scharen von Vögeln Schutz boten. Gegen Abend legten wir uns mit einbrechender Dämmerung wieder am Ufer fest. Der 17. November endlich brachte die Erlösung von dieser furchtbaren Reise. Da wir früh aufgebrochen, fuhren wir schon gegen 9 Uhr im Stanley-Pool ein und kamen endlich gegen Mittag in Brazzaville bei h̉er Hauptfaktorei des holländischen Hauses an. Noch an demselben Nachmittage fubr ich nach Kinchassa hinïber. Dort besuchte ich noch Herrn Dr. Briart und Herrn Vaalbroek, um mich ron diesen Herren zu verabschieden. Hier entlief mir auch mein Bangala-Diener, welcher wohl glaubte, dafs ich ihn zu weit ron seiner Heimat wegführe.

Am 19. Norember siedelte ich darauf zur Station Dolo über, welche nunmehr nach der sandigen Ebene hinter der ehemaligen alten Station verlegt worden war. Ich hatte so Gelegenheit, noch einmal die Wurzelkautschuk-Pflanze zu sehen, und liel's einige hundert Früchte derselben sammeln, um sie zunächst einmal nach Kamerun überzuführen.

Meine Kickxiasamen, welche ich in der letzten Zeit häufig durchgetrocknet hatte, waren hier noch in gutem Zustande. In der Nacht gab es wieder Scharen von Moskitos.

Am 20. November brachte mich die Eisenbahn, nach einer ziemlich interessanten Fahrt, über die nun in vollem Blütenflor stehenden Savannen nach Tumba, wo wir Passagiere des Zuges wieder für die Nacht Quartier suchen mufsten. Am 21. November traf ich dann gegen Abend in Matadi ein. Da ich schon gehort hatte, dafs Kapitän Jensen, welcher mich im Februar nach Lagos gebracht hatte, hier mit der "Leopoldville“ liege, um über Lagos und Sierra Leone nach Antwerpen zu fahren, so ging ich zu ihm an Bord. Da der Tampfer eigentlich keine Passagiere vor seiner Abfahrt annahm, so lud mich Kapitän Jensen ein, bis zur Zeit der Abfahrt sein Gast zu sein.

Am 24. November verliefs die "Philippeville" Natadi und fuhr, ohne sonstwo anzulaufen, bis Boma, wo wir nach dreistündiger Fahrt eintrafen. Da keine wichtigeren Telegramme in Lagos aufzugeben waren, konnte die "Philippeville" dort nun doch nicht anlanfen, denn sie würde sonst zu spät in Antwerpen eingetroffen sein. Ich beschlols daher, in Banana auf den englischen Dampfer zu warten, welcher bereits seit einiger Zeit erwartet wurde. Mit diesem konnte ich allerdings nicht anders nach Kamerun kommen, als dafs ich die ganze Reise bis Angola hinunter machte. Für meine Kickxiasamen war das sehr ungünstig, denn wenn ich mit der „Philippeville“ nach Lagos hätte fahren können, so wäre ich einen ganzen Monat früher in Kamerun eingetroflen. 
In Boma machte ich noch Abschiedsbesuch bei Herrn Gouverneur Vanghermé, um mich daselbst auch für die Unterstützung zu bedanken, welche ich auf meinen Reisen seitens des Congostaates erhalten batte.

Am 25. November verliefs der Dampfer Boma, um nach vier Stunden in Banana einzutreffen. Hier entdeckte ich beim Ausschiffen meiner Lasten, dafs ein Kolli mit getrockneten Pflanzen abhanden gekommen sei. Alles Suchen half nichts. Offenbar war das Paket auf der Eisenbahn verloren worden; ich stellte natürlich sofort die nötigen Nachforschungen an.

In Banana quartierte ich mich in dem „Hôtel des Magasins Généraux" ein, einem an Meere gelegenen Gebäude, welches infolge der angenehmen Brise, welche mehr oder minder beständig hier weht, für Rekonvaleszenten als Aufenthaltsort sehr zu empfehlen ist. Die ganze Einrichtung war allerdings nicht vom allerbesten, doch gab sich der Verwalter die grölste Mühe, seinen Gästen den Aufenthalt so angenehm wie möglich zu machen. Der Aufenthalt in Banana wäre furchtbar langweilig gewesen, da man keine Exkursionen machen konnte, weil der Dampfer stündlich erwartet wurde, wenn nicht noch Herr Dr. Sucaro aus Leopoldville und der englische Missionar Mr. Forfeit mit seiner Gemahlin anwesend gewesen wären. In dieser angenehmen Gesellschaft verging uns die Zeit schnell genug. Ich hatte aufserdem mit dem Lüften meiner Samenkisten und dem Durchtrocknen meiner Lasten immer mehr oder minder zu thun.

Erst am 7. Dezember erschien endlich der langersehnte Dampfer „Niger“, welcher mich hier erlösen sollte. Um besser Erkundigungen betreffs meines verlorenen Pflanzenpakets anstellen zu können, machte ich die Reise nach Matadi noch einmal. Der Directeur d'Exploitation der Eisenbahn, Herr Levi, gab sich die gröfste Mühe, dasselbe für mich zurückerlangen zu können. Solange wir in Matadi waren, allerdings ohne Erfolg; doch erhielt ich dann später in Kamerun die Nachricht, dafs das Paket gefunden worden sei. Bis zum 12. Dezember dauerte unser Aufenthalt in Matadi. Am Nachmittage des folgenden Tages verliefsen wir die CongoMündung bei Banana und nahmen dann einen südlicheren Kurs an der Küste von Augola entlang.

Am frühen Morgen des 14. Dezember fuhr der „Niger“ vor Mussera an, einem kleinen Orte, der auf einem nach dem Meere zu steil abfallenden Hügel liegt. Die Brandung an der ganzeu Angola-Küste bis sao Paulo de Loanda hinunter ist sehr stark und deshalb das Landen der Waren mit ziemlichen Schwierigkeiten verknüpft. Bis zum späten Nachmittage hatten wir zu thun, bis 
wir den für diese Niederlassung bestimmten Cargo gelandet hatten. Von Mussera bis Kissembo dauerte die Fahrt nur zwei Stunden. Die Ortschaft Kissembo ist ganz ähnlich wie Mussera angelegt und fast ebenso grofs. Nachdem wir am Morgen des 15. Dezember auch die Ladung für Kissembo gelöscht und die wenigen Exportwaren, bestehend aus Kaffee und sehr wenig Kautschuk, geladen hatten, dampften wir nach Süden weiter und erreichten gegen 10 Uhr die Handelsniederlassung Ambriz. Hier hatte der Dampfer bis zum Abend zu thun, da wir auch einen nicht unbedeutenden Teil neuer Fracht für Europa mitnehmen mufsten. Schon bevor die Sonne an 16. Dezember aufging, fuhren wir in den Hafen von Sao Paul de Loanda ein. Sogleich nach dem Frühstück fuhr ich zur Stadt, um unserem deutschen Konsul daselbst, Herrn Dr. Gleim, einen Besuch abzustatten. Gern wäre ich einer Einladung desselben gefolgt und hätte mich länger hier aufgehalten; doch das war nicht möglich, da ich schon sehr viel Zeit im Congo verloren hatte. Auf den Hügeln am Rande der Stadt wuchs Euphorbia rhipsaloides Welw. in grofsen Quantitäten. Ich konnte mich hier daron überzeugen, dals der Milchsaft dieser Pflanze derartig mit anderen Substanzen vermischt ist, dafs das aus ihm durch Koagulation gewonnene Produkt nicht als Kautschuk verwendet werden kann. Ich nahm einige Zweige der Pflanze mit, um sie nach dem botanischen Garten in Victoria (Kamerun) überzuführen. Schon am Nachmittage dampfte der "Niger" wieder nordwärts. Ich war grerade noch zur rechten Zeit an Bord angekommen. Aufser Kaffee und Kautschuk, letzteren in ziemlich unbedeutenden Quantitäten, hatten wir hier auch eine Anzahl grofser Ballen geschlagener Blätter von Sanseviera teretifolia als Ladung erhalten.

Beror wir auf der Rückreise die Congo-Mündung wieder passierten, liefen wir an 17. Dezember noch zwei Kïstenplätze an, erst Ambrizette und darauf Mussera. In Ambrizette hatten wir fast den ganzen Tag zu thun, so dafs ich es vorzog, an Land zu fahren. Die ganze Küste Angolas litt damals unter einer längeren Dürre, so dafs die Vegetation mehr oder minder vertrocknet war. Es gab infolgedessen nichts Interessantes hier für mich zu sehen. Als wir in der Nacht vom 1S. zum 19. Dezember etwa der Congo-Mündung gegenüber waren, hatten wir den seltenen Anblick eines wahrhaft wundervollen Meereslenchtens. Auch einige Scharen phosphoreszierender Fische zogen in der Nähe des Dampfers vorüber. Am nächsten Morgen erreichten wir Kabinda. Von nun an hatten wir an allen Küstenplätzen bis Kamerun hinauf Palmenkerne als Hauptfracht einzunehmen. Palmenöl und kleinere Quantitäten von Kautschuk kamen auch noch von den meisten Niederlassungen 
hinzu. Ton Kahinda fuhren wir zunächst nach Landana und C'hiloango, wo wir eiue Fracht von 6000 Säcken Palmenkerue und 250 Tonuen Öl erhielten, so dal's wir drei volle Tage daselbst zu thun hatten. Am 23. Dezember liefen wir noch Nyanga und bald darauf Settekama an, erhielten aber keine Ladung. Nun ging es direkt auf Cape Lopez zu, wo wir am Nachmittag des 24. Dezember eintrafen. Ich benutzte unseren kurzen Aufenthalt daselbst zu einer Exkursion in die Sümpfe hinter der Niederlassung. Während des heiligen Abends waren wir auf der Fahrt nach Gabun. Am frühen Morgen des Weihnachtstages erreichten wir Libreville, die Hauptstadt des französischen Congo-Gebietes (Gabun). Da wir nicht die Erlaubnis bekameu, während der Feiertage Cargo einzunehmen, so wareu wir gezwungen, $2^{1} / 2$ Tage hier zu bleiben. Gleich am ersten Tage machte ich unserem deutschen Konsul Herrn Gebauer meine Visite. Einer Einladung, während der Zeit meines Aufenthaltes in Libreville sein Gast zu sein, leistete ich gern Folge, da ich daun nicbt immer des Abends zum Dampfer zurückzukehren brauchte und so mehr Zeit hatte, die Umgebung und den botanischen Garteu kennen zu leruen. Herr Gebauer führte mich auch sogleich zu Herrn Chalot, dem Direktor des botanischen Gartens, unter dessen kundiger Führung ich die Sehenswürdigkeiteu dieses nach dem Victoria-Garten wohl besten botanischen Gartens von Afrika besichtigen konnte. Unter anderen interessanten Sachen erhielt ich hier Stecklinge einer mit Landolphia sehr nahe verwandten Kautschukliane, der Ancylobotrys pyriformis Pierre, sowie gute Samen von Coffea Chalotii, einer neueu Kaffeeart aus der Ubangi-Region.

Für den 26. Dezember hatten wir eine Besichtigung der etwa zwei Stunden von Libreville entfernt liegenden Woermannschen Sibange-Plantage in Aussicht genommen. Schon früh aul Morgen fuhren wir durch die Stadt, soweit die Wege dazu geeignet waren. Als dieselben dann aber schmäler wurden, schickten wir den Wagen zurück und setzten nun zu Fufs die Reise weiter fort. Bald hatten wir die Zone des ron den Eingeborenen teils einst kultivierten, teils noeh unter Kultur stehenden Landes um Libreville durchschritten und traten num in einen prachtvollen Urwald ein, welcher an Üppigkeit mit den Wäldern am Fufse des Kamerun-Gebirges wohl rivalisieren kaun. Da wir die Sibange-Plantage noch erreichen wollten, bevor es zu heifs werden würde, denn der Tag versprach ein wundervoller zu werden, so hielten wir uns hier nicht erst auf, sondern schritten rüstig weiter, bis wir gegen $10 \mathrm{Uhr}$ auf der Plantage anlangten.

Bis zu der Zeit hatte man nur Kaffee angepflanzt und dann die ganze Plantage, welche doch schliefslich vichts einbrachte, mehr 
oder minder vernachlässigt. Ein Grasbrand, welcher sich über die Plantage ausgebreitet hatte, hatte einen grofsen Teil der Kaffeestämme teils vollständig getötet, teils arg beschädigt. Seitdem Herrn Gebauer die Vertretung der Firma Woermann in Gabun übergeben worden war, hatte er sich dieser Plantage wieder etwas angenommen und einen Europäer dorthin geschickt, der dafür sorgen mufste, dafs die rorhandenen Bestände einigermafsen rein gehalten wurden. $\mathrm{na}$ infolge eines Alkommens, welches Herr Gebauer mit der französischen Regierung in Gabun getroffen, sich nun für den Kaffee ein bedeutender Preis erzielen liefs, so gewann natürlich das Torhandensein der schon Früchte tragenden Kaffeestämme eine ganz andere Bedentung für die Plantage. Herr Gebauer behauptete, dafs er in der letzten Zeit schon einen kleinen Verdieust aus der Anlage gezogen hätte. I) er nach seiner Aussage aber bedentend gröfsere Quantitäten absetzen könnte, so würde von der Plantage in Zukunft wohl Gewinn zu erwarten sein; natürlich vorausgesetzt, dafs der ausnahmsweise gute Absatz des Kaffees anhält. Mit Kakao hatte Herr Gebauer auch einige Versuche machen lassen. Die vorhandenen Pflanzen sahen sehr gesund uud kräftig aus, so dafs ich es also nicht für ausgeschlossen halte, dafs der Kakao hier gedeihen wird. Der Feuchtigkeitsgehalt der Luft ist hier allerdings ein bedeutend geringerer als in den Plantagengebieten Kameruns, und deshalb dürfte es hier sehr geraten erscheinen, mehr Schattenlüume stehen-zu lassen. Für Kickxia-Anpflanzungen würde sich der Boden sehr gut eignen. Gegen Abend kehrten wir nach Lilıreville zurück. Nun hatte ich unterwegs mehr Zeit, auf die Vegetation zu achten, fand auch bald einige Landolphien, aber nur in sehr schwachen Exemplaren. I)ie sämtlichen stärkeren Lianen werden von den in der Umgebung der Stadt wohnenden Gabunesen sofort zur Kautschukgewinnung abgebaut, sobald sie anzapfbar sind.

Ton Gabun längs der Küste weiter nach Norden fahrend, erreichte der „Niger" am früben Morgen des 28. Dezember die Corisco-Bucht. In der Nähe der Elobi-Inseln an der.Mündung des Muni-Flusses an einer englischen Faktorei, "Ukaka-Beach" genannt, gingen wir vor Anker. Nachdem der kleine Vorrat an Palmenkernen, Öl und Kautschuk im. Dampfer rerstaut war, fuhren wir den Muni-Flufs hinauf, um daselbst an rerschiedenen Orten grofse Mahagoniholz-Stämme einzuladen. Ich entdeckte während einiger Exkursionen, die ich in den Wäldern unternahm, Ancylobotrys pyriformis in Menge und schaffte einige Exemplare an Bord, um sie nach Victoria überzuführen. Botanisch war diese Gegend äufserst interessant. Die Eingeborenen, welche zu der grofsen Familie der Fan-Völker gehören, zeichneten sich durch sehr reichen Perlenschmuck aus. Sie 
sollen sehr hinterlistig sein und keinen Europäer hier weit ins Innere hineinlassen. Bis jetzt ist es offenbar auch noch keinem gelungen, trotz der Wasserstrafsen, welche rorhanden sind, weiter als zwei Tagereisen ins Innere vorzudringen.

Am 29. Dezember rerliefsen wir den Muni-Flufs wieder und dampften nun längs der Küste nach Norden bis in die Nähe des Benito-Flusses, wo wị auch wieder eine grofse Zahl Mahagoniblöcke empfingen. Wir hatten etwa eine englische Meile von der Küste entfernt Anker geworfen. Neun oder zehn dieser Mahagoniblöcke wurden an der Küste immer zu einem Flofs verbunden und dann durch die Dampfpinasse des „Niger“ zum Dampfer hinübergezogen. Am Abend des 31. Dezember erreichten wir Batta. Nachdem wir uns noch am Neujahrstage in Grofs-Batanga kurze Zeit aufgehalten hatten, fuhren wir am 2. Januar 1900 in den Kamerun-Flufs ein und warfen um 8 Uhr der Stadt gegenüber Anker. 


\section{Kapitel.}

\section{Kamerul- und Bakossi-Expedition.}

In Kamerun angekommen, machte ich zunächst dem dortigen Richter, Herrn Grafen v. Oberndorf, welcher dort den Herrn Gouverneur vertrat, meine Visite, um mich als zurückgekommen bei ihm zu melden. Von ihm erfuhr ich nun Genaueres über die Zustände im Innern, von denen ich schon Gerüchte in Batanga vernommen. Leutnant v. Que is und Conrau waren in der Zwischenzeit ermordet worden. In Kamerun wurde eben die Strafexpedition, welche Hauptmann v. Besser führen sollte, ausgerüstet; man wartete mit der Entsendung derselben nur noch auf einige Ausrüstumgen, welche der nächste Dampfer bringen sollte. Unter diesen Umständen schien die Ausführung einer Expedition in die Gebiete der Bakossi, welche so wie so bereits den Ruf eines leicht erregbaren Volkes genossen, sehr in Frage zu kommen. Da ich an der Südküste infolge der Buli-Aufstände auch nicht weiter ins Innere vordringen konnte, hatte ich jene Bakossi-Expedition geplant, denn ich vermutete in jenen Gegenden das Vorhandensein der Kickxia elastica.

Da ich vorher keine andere Gelegenheit fand, nach Victoria zu fahren, wartete ich bis zur Abfahrt des „Niger“, um dorthin zu gelangen. Am 5. Januar fuhren wir aus dem Kamerun-Flusse hinaus und erreichten gegen Mittag die Ambas-Bay, welche in der Mittagssonne sich in ihrer ganzen Pracht zeigte. Während meiner sämtlichen Reisen hatte ich doch keinen Platz in Afrika gesehen, welcher dieser A mbas-Bay an Üppigkeit der Vegetation und Schönheit der Lage gleichkommt. Capetown in Südafrika ist entschieden auch schön gelegen und würde wohl die Ambas-Bay an Schönheit übertreffen, wenn nicht dort die Vegetation trotz ihrer immensen Reichhaltigkeit einen so äufserst dürftigen Charakter tragen würde. Am Nachmittage liefs ich meine sämtlichen Sachen an Land schaffen und quartierte mich wieder im Hotel der Ambas Bay Trading Company ein, das unterdessen bedeutend verbessert worden war, so dafs man sich, dank den Bemühungen des Herrn Lange, hier stets sehr wohl fühlte. Zu meiner grofsen Freude vernahm ich, dafs Herr Geheimrat Wohltmann auch am Tage vorher angekommen sei. Am Nach- 
mittage ging ich dann noch sofort zum botanischen Garten, um dem Gärtner daselbst die von mir mitgebrachten Pflanzen und Samen zu überweisen. Die Kickxiasamen sahen schon recht bedenklich aus, so dafs ich befürchtete, sie hätten trotz der Sorgfalt, mit der ich sie behandelt hatte, ihre Keimfähigkeit verloren. Leider war dieses auch wirklich der Fall, wie sich bald herausstellte.

Am Abend kam Herr Bergassessor Hupfeld, der Generalbevollmächtigte des Herrn Sholto Douglas, und bat mich, doch noch am selbigen Tage Herrn Geheimrat Wohltmann aufzusuchen, bei dem ich am Nachmittag vergeblich vorgesprochen hatte. da sie am nächsten Morgen nach Buëa aufbrechen wollten. Mit Herrn Geheimrat Wobltmann verabredete. ich nun, dals ich zusammen mit Herrn Stammler, dem Leiter der Moliwe-Pflanzung, nach Buëa nachkommen wolle, um mich dann an einer Rundreise in den Plantagengebieten des Kamerun-Gebirges zu beteiligen; ich wäre lieber sofort mit nach Buëa gegangen, um dem Herrn Gouverneur v. Puttkamer Bericht über die Sanga-Ngoko-Reise zu erstatten, wollte aber doch erst die Terteilung der Kickxiasamen erledigen, soweit dieses möglich war.

Am Sonntag, den 7. Januar, ging ich nach Kriegsschiffhafen zu Herrn Friederici, um dort das Resultat der von mir gemachten Torschläge betreffs Anpflanzung der Kickxien zu sehen. Zu meiner grofsen Freude standen die Pflanzen sehr gut, und, soweit bis dahin beurteilt werden konnte, bewährten sich die Vorschläge. Es waren beim Umpflanzen aus den Samenbeeten in den gelichteten Wald eine Anzahl ron Pflanzen zu Grunde gegangen, besonders da, wo sich am Waldrande zwei scheufsliche Unkräuter, eine Convolvulacee und eine Momordica, zeigten, welche mit grolser Geschwindigkeit alles überwucherten und die kleinen Pflanzen erstickten. Bis dieselben angewachsen sind, wird es natïrlich nötig sein, dals sie einigermafsen rein von Unkraut gehalten werden, damit letzteres nicht mehr die Oberband über sie gewinnen kann. Herr Friederici war mit dem Gedeihen der Pflänzchen durchaus zufrieden. Die im Samenbeete zurückgelassenen Kickxien hatten sich natürlich viel besser entwickelt, da sie nicht durch das Umplanzen in ihrem Wachstum gestört worden waren; einige derselben hatten eine Höhe von zwei Fuls erreicht. Eine Rundfahrt in der Kakaoplantage bewies, dafs auch hier die schon günstigen Zustände sich immer mehr vervollkommneten. Die verschiedensten neuen Anlagen sind geschaffen worden. Besonders das Torwerk „Wasserfall" hatte seinen Anblick sehr verändert, da die Kakaopflanzen, welche ich damals dort gesehen, nun zu stattlichen Bäunchen herangewachsen waren, obgleich die spärlichen Regen, welche während meiner Abwesenheit 


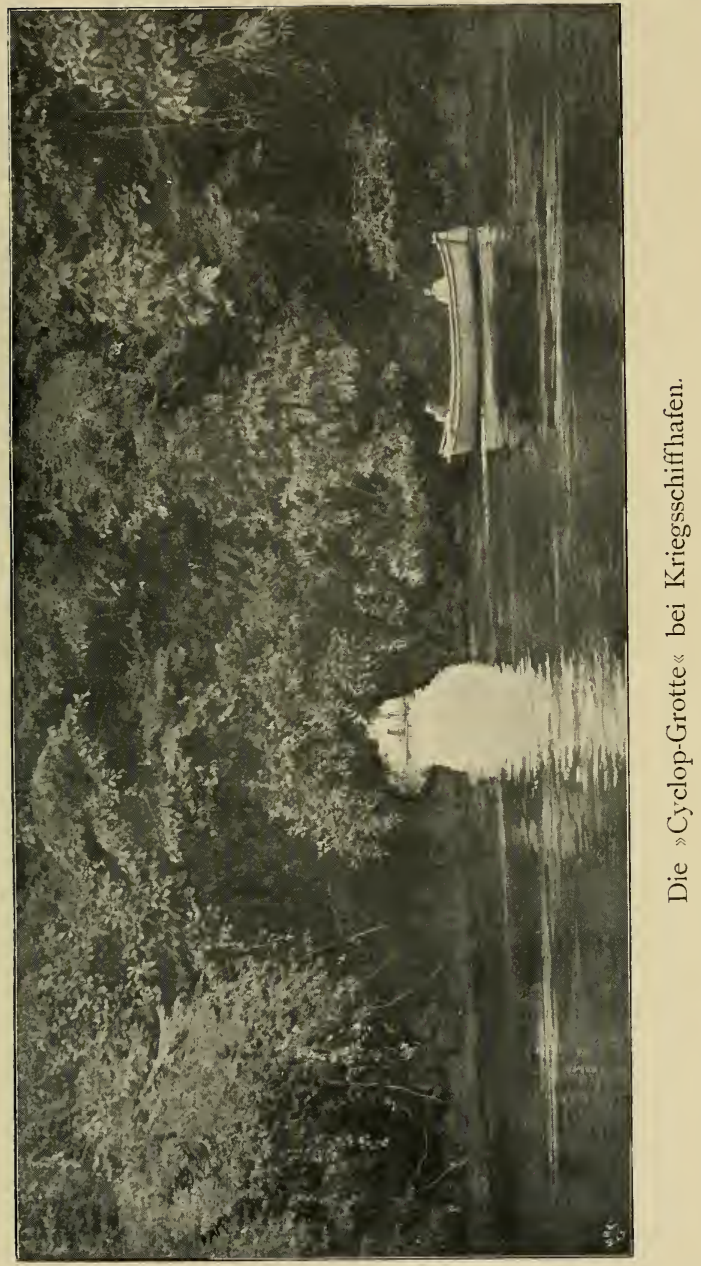



gefallen, für die Entwickelung der Anlagen äufserst ungünstig gewesen waren. Am Abend noch kehrte ich wieder nach Victoria zurïck, da ich am 8. Januar früh zur Moliwe-Pflanzung aufbrechen wollte.

Mit drei Trägern und meinen beiden Jungen, ron denen der eine recht gut Deutsch verstand, brach ich am 8. Januar früh am Morgen auf. Ich fühlte mich ganz wohl und marschirte daher mit den Leuten ziemlich schnell bis zum Limbe-Vorwerk der "Victoria“Pflanzungsgesellschaft. Hier hefiel mich plötzlich ein starkes Unwohlsein, so dafs ich gezwungen wurde, mich daselbst einige Zeit niederzulegen. Das starke Erbrechen schien fast ein Zeichen zu sein, dafs ich mir ein heftiges Fieber zugezogen hatte. Doch gegen 2 Uhr an Nachmittag fühlte ich mich wieder wohl genug, uın den Marsch fortsetzen zu können. Wir stiegen auf einem breiten, noch nicht ganz vollendeten Wege bis Boniadikombe am Fufse des Gebirges empor und marschirten dann von dort auf einem Waldwege bis zur Moliwe-Pflanzung, welche wir gegen 4 Uhr erreichten. Herr Stammler, welcher bereits von meiner beabsichtigten Ankunft benachrichtigt war, hatte schon alles so weit vorbereitet, damit wir zeitig von Moliwe nach Buëa am nächsten Tage aufbrechen könnten. Ich fühlte mich infolge des Marsches nach meinem kleinen Fieberanfall noch nicht recht wohl und ging daher zeitig schlafen, um am nächsten Tage für den anstrengenden Marsch nach Buëa frisch genug zu sein.

Da es am nächsten Morgen zu regnen begann, verschoben wir unseren Aufbruch bis um 10 Uhr. Um aber die Zeit bis dahin nicht zn verlieren, besichtigte ich die Plantage und vor allen Dingeu die mit Kickxia bepflanzten Teile. Herr Stammler war ganz entzückt von den Resultaten, welche er erzielt hatte. Einige der ausgepflanzten Bäumchen hatten auch bereits eine Höhe von zwei Fufs erreicht. Fast möchte ich sagen, die Pflanzen standen hier noch besser als auf der Kriegsschiffhafen-Plantage. Unkraut kam hier weniger anf, da die Plantage nicht am Waldrande begann und daher weniger Sonne für die Unkräuter vorhanden war.

Als der Regen etwas nachgelassen hatte, brachen wir zusammen mit acht Trägern und unseren Jungen nach Boniadikombe auf. Von dort aus schlugen wir einen schmalen Pfad ein, welcher uns durch teilweise kultiviertes Gebiet und durch einige Dörfer hindurch, allmählich am Abhange des Gebirges ansteigend, oberbalb Bomana in den breiten Victoria-Buëa-Weg brachte. Gegen 1 Uhr erreichten wir ein Hotel, welches von einem unternehmenden Sachsen an der Buëa-Strafse aufgebaut ist, um den ermüdeten Wanderern etwas Rast und Erfrischung zu bieten. Da Herr Stammler mit dem Besitzer 
dieses Hotels so wie so verschiedenes Geschäftliche abzumacben hatte (der Grund, auf welchem es aufyebant ist, gehörte noch zur Moliwe-Pflanzung), so gaben wir unseren Leuten eine Stunde Ruhe, während welcher wir ms zum Mittagessen niedersetzten. Ton dem Hotel „Sachsenhof" bis zum Rande des Buëa-Plateaus hatten wir noch etwas über eine Stunde zu marschieren. Selten war mir ein Marsch so schwer geworden als dieser; offenbar batte ich meinem nicht wieder ganz hergestellten Körper zu viel zugemutet, deun auch für einen gesunden Menschen ist dieser. Marsch bis Buëa hinauf nicht gerade ein leichter Spaziergang. Sobald wir auf dem Plateau waren, fühlte ich frischen Mut. Schon nach kurzer Zeit sahen wir Buëa vor uns liegen und kamen endlich um 5 Uhr auf der Station selbst an. Hier bekamen wir von Herrn Leuschner unsere Zimmer wieder im Rekonvaleszentenhause angewiesen, wo wir uns denn gleich tüchtig reinigten und umzogen, denn von dem Marsche auf der staubigen Strafse (es hatte zwischen Bomana und Buëa an Morgen nicht geregnet) waren wir von oben bis unten beschnutzt. Zum Abend waren wir von Herrn Gouverneur v. Puttkamer zum Essen eingeladen. Bei dieser Gelegenheit äufserte sich Herr Gouverneur Köbler von Togo, welcher nach Kamerun berufen war, um den bald zur Erholung nach Europa zurückkehrenden Herrn Gouverneur v. Puttkamer zu vertreten, dafs er mich auch in Togo in jeder Weise unterstützen würde, falls ich, den vou Herrn Geheimrat Wohltmann und Herrn Bergassessor Hupfeld gemachten Torschlägen folgend, auch eine kurze Bereisung des MisahöheBezirkes unternehmen würde. Damals kounte ich mich noch nicht sicher für die Sache entscheiden, doch war schliefslich das Versprechen des Herrn Gouverneurs Köhler der Hauptgrund, welcher wich veranlafste, wirklich später zuzusagen.

Herr Geheimrat Wohltmann, Herr Bergassessor Hupfeld und Herr Stammler brachen bereits am nächsten Morgen auf, um nach der Lisoka-Plantage zu gehen, wo ich mit den Herren am folgenden 'Tage zusammenzutreffen versprach, da ich Herrn Gouverneur v. Puttkamer noch Bericht über die Sanga-Ngoko-Reise erstatten wollte.

Den Verabredungen gemäfs brach ich am 11. Januar ron Buëa auf, nin Herrn Geheimiat Wohltmann nach Lisoka zu folgen. Auf einer breiten, schönen Strafse, wie sie Herr Leuschner nach allen Richtungen von Buëa aus innerhalb seines Bezirkes bat anlegen lassen, stieg ich langsam von dem Buëa-Plateau herab und erreichte nach etwa $1 \frac{1}{2}$ Stunden das wundervolle Lisoka-Plateau, welches etwa $100 \mathrm{~m}$ unterhalb des Buëa-Plateaus liegt, also in einer Höhe, welche noch für Kakaobau geeignet ist. Das Plateau ist hauptsäch- 
lich mit Elefantengras bedeckt, in welchem sich kleinere Komplexe von Wald und vor allen Dingen viele einzeln stehende Bäume befinden, welche dann bei den Kakaokulturen gerade genügend Schatten für die Anlagen spenden. Bei dem Dorfe Moliko zweigte sich der Weg zur Plantage von dem Wege ab, welcher über Malende nach Mundame führt. In der Umgebung des Dorfes Moliko sah ich, kurz bevor ich die Lisoka-Plantage erreichte, an den gröfseren Baumstämmen Kautschuklianen, deren Früchte von den Eingeborenen als "Maniongo" gegessen werden. Die Exemplare waren aber alle derartig von den Messern der Eingeborenen (Baquiris) bearbeitet, dafs die herausträufelnde Milch eben nock für mich genügte, festzustellen, dafs diese Art einen brauchbaren Kantschuk liefere. Offenbar ist dies dieselbe Pflanze, welche durch Dr. Preufs bereits als kautschukliefernd bezeichnet wurde. Als ich um $12 \mathrm{Uhr}$ auf der Plantage eintraf, war kein Europäer anwesend. Ilie Eingeborenen, welche ich beim Hause fand, gaben an, dafs die Europäer in einiger Entfernung augenblicklich dabei seien, eine nene Anlage zu schaffen, und liefen sogleich, um jemand herbeizurufeu. Um 1 Uhr erschienen auch die zwei Herren, welche sich als Angestellte der LisokaPlantage rorstellten und mir mitteilten, dafs Geheimrat Wohltmann und die übrigen Herren, welche unter Führung des Leiters der Plantage, Herrn Hilfert, die weiter gelegenen Gelände der Plantage zu besichtigen gegangen seien, gegen Aluend zurückzukommen versprochen hätten.

Am Nachmittage streifte ich nun auf dem Gebiete der Plantage umber und hatte die Freude, zu sehen, dafs hier viel Landolphien vorhanden seien. Herr Hilfert hatte Samen dieser Art ausgesät und ging mit der Absicht um, später die jungen Pfänzchen am Fufse der Schattenbäume auszusetzen. Der Kautschuk, welchen diese Art liefert, ist vorzüglich. Die Milch koaguliert sehr leicht und schnell sowohl durch einfache Erwärmung als auch durch Einflufs der Luft. Ich sammelte einige Früchte, um dieselben mit nach Victoria hinunterzunehmen, wo die Samen im botanischen Garten ausgesät werden sollten.

Gegen Abend trafen auch die abwesenden Herren ein. Es wurde nun beschlossen, am vächsten Tage früh von Lisoka anfzubrechen, um über Boanda und Buenga nach der Moliwe-Pflanzung den Berg hinabzusteigen.

Um 6 Uhr wurden die Anstalten zum Aufbruch begonnen; doch kamen wir nicht vor $8 \frac{1}{2}$ Uhr fort, da noch vieles zu regeln war und viele Lasten wieder gepackt werden mufsten, aufserdem die Leute mit dem Abbrechen des grofsen Zeltes, welches Herr Geheimrat Wohltmann von Buëa mitgenommen, noch nicht Bescheid 
wufsten. Unsere Kavalkade bestand aus fünf Europäern (Herrn Geheimrat Wohltmann, Bergassessor Hupfeld, Herrn S tammler, Herrn Hilfert und meiner Person) und gegen 20 Eingeborenen. Her Geheimrat Wohltmann und Herr Hilfert waren beritten. Das Dorf Moliko lielsen wir rechts liegen und marschierten quer durch das Plantagengebiet, bis wir die Moliko--Muëa-Strafse erreichten. Der Weg ron Moliko bis zum Muëa-Marktplatze war vollständig eben und führte durch dieselbe Parkland-Formation, wie sie bei Lisoka so verbreitet ist. Tom Mnëa-Marktplatze, auf welchem übrigens, noch rom letzten Markte herrührend, grofse Mengen von Schalen der Landolphia- (Manyongo-) Früchte umherlagen, führte der Weg mehr wach der Seeküste zu. Langsam stiegen wir tiefer hinab. Hier und dort zeigte sich zunächst häufiger Buschwald. aber doch noch recht viel Elefantengras. Das Terrain, über welches wir marschierten, bestand ausschliefslich aus verwittertem Basalt, war also sehr fruchtbar. Hin und wieder traten steinigere Stellen ein, besonders an abschüssigem Terrain, wo der Regen die Humusschichten herabgespült hatte. Besonders häıfig wurden diese steinigen Stellen, nachdem wir den Minya-Bach passiert hatten. Herr Stam mler, welcher eine Stunde vor uns von Lisoka abmarschiert war, um die rechten Wege zu erkunden, wartete bereits einige Zeit auf uns, als wir gegen 10 Uhr im Dorfe Bomaka eintrafen. Von Bomaka bis Boanda, einem gröfseren Dorfe, hatten wir blofs einen Marsch von einer halben Stunde über ein zum Teil fruchtbares, wenig abfallendes Terrain. In Boanda, für welches wir eine Höhe von etwa $450 \mathrm{~m}$ über dem Meeresspiegel konstatierten, machten wir eine längere Ruhepause, um Mittag zu essen. Hier sahen wir übrigens einige Kokospalmen, die hier wohl die Grenze der Höhe erreicht haben dürften, in der sie noch gedeihen.

Um 12 Uhr brachen wir wieder auf. Der Weg ron Boanda ïber Bokoba bis Dibanda war nicht schlecht und das Terrain teilweise noch gut; doch dann fiel der Berg ziemlich steil bis Buenga ab. Jas Maultier, welches IIerr Geheimrat Wohltmann geritten, konnte nur mit gröfster Mühe und Vorsicht hinabgeführt werden. Herr Hilfert kehrie von hier nach Lisoka zurück, um nicht seinem I'ferde den Abstieg auf dem steilen Wege zuzumuten; aufserdem war es schon 3 Uhr am Nachmittage, und er hatte einen weiten Weg ror sich, wenn er noch vor Nacht in Lisoka eintreffen wollte. In dem Walde, welcher nun das ganze Terrain bedeckte, fand ich auch wieder Landolphien, doch von Kickxia war nichts zu sehen. Es wäre mir besonders lieb gewesen, wenn ich die Kickxia auch in Basaltboden hätte nachweiseu können. Da wir in Dibanda keinen Führer bekommen konnten, welcher uns bis Fuë führen sollte, so 
meldeten sich schliefslich drei Weiber dazu, welche für sich ein kleines Geschenk beanspruchten. Allein fürchtete sich eine jede mit uns zu gehen. Der Abstieg von Dibanda bis Fuë, welchen wir in etwa $1^{1 /} / 4$ Stunden zurücklegten, betrug etwa $200 \mathrm{~m}$. Von Fuë bis Buenga-Dorf, zum Unterschiede von Buenga-Markt, welches an der Küste an den Creeks liegt, die von N'Bamba zum Mungo führen, nahm der Marsch nur eine halve Stunde in Anspruch. Unser Barometer gab für Buenga $190 \mathrm{~m}$ Höhe an. Da es zu spät war, um noch bis Moliwe weiter zu marschieren, so wurde beschlossen, in Buenga Nachtquartier zu machen. Für Herrn Geheimrat Wohltmann wurde das Zelt aufgestellt. Wir übrigen Europäer liefsen unsere Feldbetten in einem geräumigen Hause der Eingeborenen aufstellen. Da wir heute einen langen Marsch hinter uns hatten und auch am nächsten Tage sehr zeitig weitermarschieren wollten, so begaben wir uns bald zur Ruhe, trotz des herrlichen, mondhellen Abends. Die Togo-Lente, welche Herr Stammler als Träger mitgenommen, führten noch bis tief in die Nacht hinein unter grolsem Lärm Tänze auf, welche uns doch nicht abhalten konnten, sehr bald fest zu schlafen.

Gegen $7 \frac{1}{2}$ Uhr setzte sich unsere Karawane wieder in Bewegung. Der Weg war so steinig, dals wir mit unseren schwerbepackten Trägern langsamer marschieren mufsten. Viele Strecken dieses Terrains dürften infolge des mit Basaltgeröll zu stark durchmischten Bodens für Kakaopflanzungen ungeeignet sein. Unsere Reiseronte ging vou Buenga in ziemlich direkter Richtung auf das Haus der Moliwe-Pflanzung zu, auf deren Gebiete wir uns bereits hefanden. Da wir in rechtem Winkel zur Richtung der Wasserläufe vorgingen, welche vom Gebirge kamen, so hatten wir eine ziemliche Zahl von Bächen zu durchschreiten, welche sich übrigens alle durch sehr felsige Iıäufe und kristallklares, sehr kaltes W asser auszeichneten. Der Ombe war der bedentendste derselben. Wir passierten ihn dicht hinter dem Dorfe Bonjo, einem kleinen, unbedeutenden Weiler, welcher von Baquiris bewohnt wird. Vom Ombe-Flusse ab änderte sich die Gestaltung der Bodenverhältnisse allmählich wieder. Das Geröll verschwand mehr und mehr und hörte endlich wieder ganz auf, als wir den Moliwe-Bach überschritten hatten, um nunmehr in ein berrliches, fruchtbares Thal überzugehen, in welchem Herr Stammler sich angebaut hatte. Herr Geheimrat Wohltmann und Herr Hupfeld waren beide sehr angenehm überrascht, als wir uns plötzlich in der Plantage befanden, deren Lage und Stand der Kulturen bei weitem die Erwartungen überstieg, welche beide Herren gehegt hatten. 
Für den Rest des Tages blieben wir zusammen in Moliwe. Am Nachmittag besichtigte ich noch einmal gemeinsam mit Herru Hupfeld die Kickxia-Anlage und die Arbeiterhäuser, welche hier auch recht nett eingerichtet waren. Herr Stammler hatte, da seine Arbeiter zur Hälfte aus Togo-Leuten, zur anderen aus Balundus rom Elefantensee sich zusammensetzten, zwei grofse Arbeiterhäuser gebaut, $u m$ die sich schlecht vertragenden beiden Tölker getreunt zu halten. 'Togo- und Balundu-Leute durften auch nicht zusammen arbeiten, da sonst zu leicht Streitigkeiten ausbrachen. Es war hier entschieden in der kurzen Zeit seit der Einrichtung der Plantage sehr viel geleistet worden, besonders wenn man in Betracht zieht, dafs Herr Stammler zuerst weiter unten, am Fufse des Gebirges, eine Anpflanzung begonnen hatte, wo ich ihn im April 1899 besucht hatte. Infolge vieler Schwierigkeiten, welche sich ihm damals dort unten entgegenstellten, hatte er seine Hauptpflanzungen dann an die Stelle hinauf verlegt, wo er zur Zeit seinen Wohnsitz aufgeschlagen. Da Herr Geheimrat Wohltmann und Herr Hupfeld noch am Abend des 17. Januar in Victoria eintreffen wollten, so reisten beide Herren bereits am nächsten Tage gegeu Mittag ab. Ich selbst blieb noch bis zum anderu Tage in Moliwe, wo ich am Nachmittage mit Herrn Stammler die Berechnung einer Kickxiaplantage aufstellte und einige Rundgänge in der Plantage machte, bei denen wir einige für neue Kakao- und Kickxia-Anpflanzungen in Aussicht genommene Lokalitäten besuchten. Ein Umstand, welcher übrigens das jetzige Centrum der Anlagen auf der Moliwe-Pflanzung besonders wertvoll macht, sind die äulserst günstigen $W$ asserverhältnisse, welche daselbst vorhanden sind. Der Moliwe-Bach, aus welchem sich eine sehr bedeutende Wasserkraft gewinnen liefse, windet sich in verschiedenen Bogen am Fufse des Hügels entlang, welchen Herr Stammler mit grofser Umsicht für die Erbanung der für die Europäer bestimmten Häuser gewählt hat.

Am Morgen des 15). Januar folgte ich nun Herrn Geheimrat Wohltmann nach Victoria, um von dort aus mit ihm zusammen am 18. Januar einen nochmaligen Besuch auf der KriegsschiffhafenJ'lantage zu machen. Die Zwischenzeit von drei Tagen benutzte ich dazu, Vorbereitungen für die Bakossi-Expedition zu treffen, welche ich nun doch auszuführen beschlossen hatte, und im botanischen Garteu noch einmal mit Ficus elastica Koagulationsversuche zu machen. Der Bezirksamtmann von Victoria war so freundlich, mir bis nach Buëa Leute des Bezirksamtes als Träger zur Verfügung zu stellen, was mir um so angenehmer war, als gar keine Träger sonst aufzutreiben waren, denn die Baquiris in Victoria 
zeichnen sich vor allen anderen durch Unmut zur Arbeit ganz besonders aus.

Am 18. Januar machte ich damn zusammen mit Herrn Geheimrat Wohltmann den verabredeten Besuch in Kriegsschiffhafen, wo auch Herr Hupfeld, welcher nach Kamerun gefahren war, über N'Bamba gegen Mittag eintraf. In den Saatbeeten, auf denen die nun acht Monate alten Kickxien standen, hatte sich auf diesen eine kleine Raupe ausgebreitet, welche, wie ich nachweisen konnte, von einem benachbarten Gemüsebeete hinübergewandert war und an den Kickxiablättern eine sehr bekömmliche neue Nahrung gefunden zu haben schien. Hoffentlich wird bei etwaigem Verpflanzen ron Kickxien, welche von dieser Raupe befallen sind, darauf geachtet werden, dafs die Tiere vorher abgenommen werden, damit sie nicht in die Kickxiabestände mit hinüber geführt und verbreitet werden. Obgleich ich nicht glaube, dafs die Raupen, welche sonst nur auf niedrigen Kräutern auftreten, in den Beständen argen Schaden anrichten würden, so ist es doch immerhin wünschenswert, dafs die Anlagen von Anfang an möglichst ungezieferfrei gehalten werden und darauf geachtet wird, dafs nur wirklich gesunde Pflanzen dorthin verpflanzt werden.

Während Herr Geheimrat Wohltmann und Herr Hupfeld am 19. Januar eine Besichtigung des N'Bamba-Vorwerkes unternahmen, kehrte ich am Vormittage nach Victoria zurück, um noch die letzten Vorbereitungen für den am 20. Januar in Aussicht g'enommenen Aufbruch nach den Bakossi-Bergen zu rollenden.

Vom Bezirksamte war mir bis Buëa ein Pferd zur Verfügung: gestellt worden, so dafs ich den Marsch bergan mir ersparen konnte. Mit zwölf Trägeru und meinen zwei Jungen war ich am Morgen des 20. Januar anch bereits um 6 Uhr unterwegs. Da einer der Träger, welcher schon vor Boana nicht mehr weiterkonnte, zurückgeschickt und seine Last auf die schon an sich schweren Lasten der übrigen verteilt werden mufste, machten wir nur langsame Fortschritte. Als wir dann gegen Mittag zum "Sachsenhof “ kamen, liefs ich Halt machen und erbat mir von den Wegebauern, welche daselbst ihr Lager aufgebaut hatten, einen Mann als Träger für den Nachmittag. Der Vorsteher des Lagers war so freundlich, mir sofort einen starken Mann abzugeben. Nachdem nun die Last des Trägers, welchen ich krankheitshalber am Vormittage zurückgeschickt hatte, wieder zusammengestellt war und ich meine Mahlzeit im "Sachsenhof beendet hatte, brachen wir wieder auf. Ein Missionar, welcher auf dem Wege nach Buëa war, gesellte sich nun auf' dem Weiterritte zu mir. Da schliefslich die Träger doch zu langsam marschierten, ritten wir voraus und erreichten gegen 
$3 \mathrm{Chr}$ das Buëa-Plateau. Auf einem mir bis dahin noch unbekannten Wege über Klein-Soppo kamen wir gegen $4^{1 / 2}$ Uhr auf der Station Buëa an. In dem Rekonvaleszentenhause bei der Familie Leuschner fand ich wieder Unterkunft. Meine Leute trafen dann kurz darauf mit meinen Sachen auch ein. Da ich die Träger von hier aus zurückschicken mufste, so sprach ich gleich mit Herrn Leuschner über die Möglichkeit, von hier bis Mundame neue Träger zu engagieren. Herr Leuschner war so liebenswürdig, zu den benachbarten Dörfern zu schicken, un Träger auftreiben zu lassen. Die ausgesandten Leute kamen gegen Mittag des nächsten Tages, eines Sonntages, zurück mit der Nachricht, dafs zeitig am nächsten Montag die verlangte Anzahl von Trägern auf der Station erscheinen würde. Die prompte Regelung der Trägerfrage bei einem Tolke wie die Baquiris war ein recht guter Beweis der Thatsache, dals Herr Leuschner es sehr gut verstanden hat, den Eingeborenen den nötigen Respekt vor dem Weifsen beizubringen und ïberhaupt die Leute riehtig zu behandeln. Es geht zugleich daraus hervor, dals bei einer solchen Behandlung selbst der Baquiri zu Arbeitsleistungen herangezogen werden kamn, wie es allenthalben mit den geistig allerdings höher stehenden Völkern in Togo der Fall ist.

Ich benutzte den Sonntag zu einer Exkursion nach dem oberen Waldrande des Kamerun-Pieks, wo ich einige interessante Gewächse sammelte. Da die Träger erst gegen $7^{1 / 2}$ Uhr am 22. Januar eintrafen, so kamen wir erst gegen $8 \mathrm{Uhr}$ fort. Um möglichst bald aufbrechen zu können, hatte ich die Lasten schon alle fertig auslegen lassen, so dafs wir ohne weiteren Aufenthalt unseren Marseh antreten konnten. Auf dem schon früher beschriebenen Wege erreichten wir gegen 10 Uhr das Dorf Moliko, wo ich nur eine Rast von 10 Minuten machen liefs. Durch zum Teil unter Kultur stehendes Terrain marschierten wir dann, nachdem wir auch das Muëa-Dorf passiert hatten, bis nach Mamu. Zwischen Muëa und Mamu begann der Wald, welchen wir nun für lange Zeit zu durchziehen hatten. Äulserst interessant, und für einen etwa später in diesen Gegenden reisenden Botaniker eines längeren Aufenthaltes wcrt, ist eine breite Wiese, welche durch einen, sie in vielen Armen durchrieselnden Bach stellenweise etwa fulstief unter Wasser gesetzt ist. Vanilla africana wuchs in den Gebüschen am Rande dieser Wiesen allenthalben, leider ohue Blüten; häufig leisteten andere Orchidaceen, welche hier bis auf die Äste der kaum mannshohen Sträucher heruntersteigen, ihr Gesellschaft. Landolphien gab es im Walde auch hin und wieder, doch seltener mit dickeren Stämmen. Offenbar ist diese Gegend noch zu häufig 
von den Kautschuksammlern besucht, die alles anschneiden oder gar abschlagen, was sie an einigermafsen anzapf baren Lianen sehen. Erst wenn eine solche Gegend dann derartig abgeerntet ist, dafs sich das Kautschuksammeln kaum mehr rentiert, wird den Landolphien Zeit gelassen, wieder nachzuwachsen. Über die Art und Weise der Gewinnung der Latex, wenigstens die häufigste derselben, werde ich weiter unten noch Näheres zu berichten haben. Als wir das Dorf Mamu erreichten, wo die Eingeborenen eben dabei waren, ein grölseres Stück Wald abzuschlagen und abzubrennen, gab ich den Trägern eine zweistündige Rast zum Essen. Während wir noch in Mamu waren, kamen einige Träger zu mir, um meine Erlaubnis zu erfragen, ob sie von dem nächsten Dorfe, Ekona, nach Buëa zurückkehren könnten. Natürlich gewährte ich den Leuten das nicht, sondern liefs die ganze Gesellschaft zusammentreten und notierte ihre Namen, um sofort zu wissen, wenn jemand etwa desertieren sollte, wer der Übelthäter sei; um aber das Desertieren zu verhüten oder wenigstens zu erschweren, ernannte ich einen Mann, welcher mir am meisten Achtung zu geniefsen schien und auch einen ganz intelligenten Eindruck machte, zum „Headman“ und erklärte ihm nun, dafs ich ihm das Doppelte bezahlen werde, als vereinbart sei, er aber hafte mir dafür, dafs niemand desertiere. Das machte offenbar einen Eindruck auf die Gesellschaft, denu, ohne noch einmal sich murrig zu zeigen, zog ein jeder mit seiner Last weiter, als ich das Zeichen zum Aufbruch gab. Da ich nicht gern sah, dals der "Headman" auch eine Last zu tragen hatte, gab ich ihm die Erlaubnis, zu versuchen, für seine Last einen Träger zu engagieren. Auf diese Weise wurde es nun den Leuten klar, dafs ich den Mann wirklich zum "Headman" gemacht; ich möchte vorausschicken, dafs ich meine Wahl sehr gut getroffen, denn der Mann bewährte sich vorzüglich und verstand es auch sehr gut, sich bei seinen Stanmesgenossen in Respekt zu halten. Einen neuen Träger zu engagieren, gelang uns schon in Mamu. Auf.dem Marsche hier hielt ich dieselbe Marschordnung ein wie schon auf der Yoruba-Expedition. Die sämtlichen Träger hatten vorzumarschieren, dann kam der „Headman“ direkt vor mir, welcher meine Büchsflinte zu tragen hatte, und hinter mir die Jungen mit einigen Kleinigkeiten, wie Regenmantel, Mütze, Feldflasche und Aneroid. Von Mamu bis Ekona fübrte uns ein kurzer Marsch. Da in Ekona die Kenntuis des Landes bei den Leuten aufhörte, so liefs ich den Häuptling rufen und veranlafste ihn, mir bis zum nächsten Dorfe einen Führer gegen Bezahlung zu stellen; natürlich wurde die Bezablung erst dann geleistet, wenn ich den Führer zurückschickte. Der gute Weg hörte in Ekona auf. Auf einem Wald- 
wege über hügeliges und zum Teil recht felsiges Terrain marschierten wir weiter. Je mehr wir uns von Buëa entfernten, desto häufiger trafen wir Kautschuklianen im Walde, welcher übrigens hier lange nicht mehr den so üppigen Charakter trug wie an der Seeseite des Gebirges. Man konnte hier sehr leicht erkennen, dafs die Niederschläge wesentlich geringere waren. Bis zum Dorfe Meandja hatten wir einen langen Marsch vor uns. Kurz bevor wir dasselbe erreichten, gelangten wir an den Meandja-Bach, an welchem die Üppigkeit der Vegetation wieder ihren Höhepunkt erreicht. Der nicht sehr tiefe Bach flofs sehr schnell dahin und gewährte, wenn man an seinem Ufer stand, bei der Übergangsstelle einen der schönsten Anblicke, welche ich je ron derartigen Scenerien genossen. Zuw ersten Male sah ich hier, von den Bäumen am Wasserrande herunterhängend, die langen Zweige von Vanilla africana im schönsten Blütenflor. In Meandja liefs ich das Zelt aufschlagen, um für die Nacht daselbst zu bleiben, denn wir hatten für den ersten Tag einen schönen Marsch hinter uns. Bald hatten wir alles für die Nachtruhe hergerichtet, und die Leute safsen vergnügt am Feuer, sich ihres Lebens freuend; hatten sie doch tüchtig zu essen, das war ihnen die Hauptsache. Nachdem ich noch in dem krystallhellen, kühlen Wasser des Meandja-Baches ein Bad genommen, beschlofs ich mein Tagewerk mit Erledigung der laufenden Arbeiten, wie Tagebuch schreiben und Pflanzen einlegen.

Schon zeitig hatte ich am nächsten Tage die Leute zusammenkommen lassen, um alles zum weiteren Marsche fertig zu machen. Das Zelt war schnell abgebrochen und die Lasten wieder fertig geschnürt. Schon kurz nach $6 \mathrm{Uhr}$ konnten wir Meandja verlassen. Der Führer aus Ekona willigte ein, uns noch eine kleine Strecke weiter zu begleiten, da er in Mujuka Verwandte habe, welche er bei dieser Gelegenheit aufsuchen könne. Kurz hinter Meandja kamen wir wieder an einen Bach, welcher dem Meandja-Bach an Schönheit gleichkam; der Führer nannte ihn „Mupaba“. Langsam senkte sich das Terrain hier, meist in kleinen Terrassen, von denen eine der anderen folgte. In dem Walde, welcher dem bei Mamu glich, machte mich der F'ührer wiederholt auf Kautschuklianen aufmerksam; von Kickxia aber war noch nichts zu sehen, obgleich ich sehr eifrig danach ausschaute. Der Führer erzählte, dafs ihm von einem Baume, welcher Kautschuk gebe, nichts bekannt sei; er kenne viele, die die weifse Milch geben, aber "Maniango" sei das nicbt. Kurz nachdem wir wieder einen Bach, den Sope, überschritten batten, dessen Wasserfläche mit den weifsen Blüten des schönen, hier in allen Gebirgsbächen häufigen Crinum natans dicht bedeckt war, erreichten wir das Dorf Mujuka. Durch Ver- 
mittelung unseres Ekona-Führers gelang es uns bald, in Mujuka einen neueu Führer zu bekommen, so dafs wir ohne grofsen Zeitverlust weitermarschieren konnten. Es war sehr gut gewesen, dafs ich so vorsichtig war, einen Führer zu nehmen, denn gleich hinter Mujuka begann ein dichter Wald, in dem sich so viele Wege kreuzten, dals wir sicher nicht zurechtgefunden hätten. Schon von Meandja an hatten wir viele Elefantenspuren gesehen; hier im Mujuka-Walde gab es deren noch viel mehr, wir stiefsen wiederholt auf Spuren, wo die Leute behaupteten, dafs Elefanten eben vor unserer Ankunft geflüchtet sein müfsten. Nach etwa $1 \frac{1}{2} 2$ stündiger Wanderung hörten wir schon aus der Ferne das Getöse des NjokeBaches, der dicht bei dem Dorfe Njoke einen nicht unbedeutenden Wasserfall besitzt. Als wir schliefslich dicht unterhalb des Falles an den Bach kamen, stellte sich heraus, dafs derselbe nur in Canoes passierbar sei. Da auf dem anderen Ufer sich einige Leute mit Canoes befanden, so liefs ich dieselben anrufen und auffordern, die Expedition über den Bach zu bringen, was denn auch sofort geschah, wenngleich mit einigem Zeitaufwande, denn wir konnten in die kleinen Canoes nur immer drei Mann mit ihren Lasten unterbringen. Vermittelst langer Raphiablattrippen wurden die Canoes über den Bach gebracht. Da es viele Felsen gab, war es bei der starken Strömung erforderlich, dafs stets einer der Eingeborenen dabei war, welcher das Wasser kannte. Nachdem wir aus dem ziemlich tiefen Thale des Baches herausgetreten waren, erreichten wir dann das Dorf Njoke, welches unter allen Dörfern, die ich auf der Reise bis dahin gesehen, das bedeutendste war. Zum ersten Male trafen wir hier auch Dualla-Händler an. Bei den Bewohnern von Njoke gewahrte ich eine allgemeine Furcht, auch sah man in dem grofsen Dorfe auffallend wenig Leute. Mich nach der Ursache erkundigend, erfuhr ich von den Duallas, dafs die meisten Einwohner bei meiner Annäherung in den Busch geflohen seien; man hatte gehört, dafs die Strafexpedition (unter Hauptmann v. Besser) bald erscheinen würde, und hielt allgemein die meinige dafür. Natürlich hatten die Gerüchte die Stärke meiner Expedition ungeheuer übertrieben und aus einigen Trägern mit roten Mützen sogleich eine Schar Soldaten gemacht. In Njoke liefs ich nur einen kurzen Aufenthalt machen, da ich mir vorgenommen, erst in Malende den Trägern Zeit zum Essen zu geben. Der Weg von Njoke bis Malende führte durch einen sehr interessanten, jedoch ziemlich trockenen Urwald, in dem es sehr viele Elefanten geben soll. Von Dr. Preufs war hier in diesem Walde die Kickxia elastica zuerst nachgewiesen worden. Da mir nicht besonders daran liegen konnte, die Kickxia 
an einem bereits bekannten Standorte nochmals aufzusuchen, so liefs ich, ohne mich weiter aufzuhalten, durchmarschieren. Landolphien gab es auch, doch schien denselben sehr nachgestellt zu werden; nicht selten sah man von den Bäumen Stammstücke derselben herunterhängen, deren unteres Ende, soweit die Leute mit ihren Haumessern hinaufreichen konnten, abgeschlagen war. Gegen 1 Uhr trafen wir bei der von der Soppo-Plantage anfgestellten Hütte ein und kurz darauf im Dorfe Malende selbst, wo wir uns unter einem Mangobaume lagerteu.

Die in der Nähe von Malende von Dr. Preufs nachgewiesenen Kickxiastämme waren ron Herrn Günther von der SoppoPlantage, wie behauptet wurde, pachtlich erworben und zu ihrer Bewachung ein Eingeborener nach einer kleinen Faktorei in Malende geschickt worden. Um die Stämme kenntlich zu machen, soll ein jeder damals mit einer kleinen Blechmarke versehen worden sein. Eine plötzliche Abberufung des Herrn Günther hatte eine vollständige Vernachlässigung des Malende-Unternehmens zur Folge gehabt, welches, wenn auch nicht in der vou Herrn Günther ausgeführten Art, doch zu einem sehr guten Resultat geführt haben könnte. Es ist sehr zu hoffen, dafs dieser Sache bald wieder mehr Interesse entgegeugebracht wird, bevor die Eingeborenen die bei Malende vorhandeneu Stämme sämtlich umgeschlagen haben.

In dem Dorfe, aus dem übrigens auch die gröfsere Menge der Einwohner entflohen war, liefs ich nun eine zweistündige Mittagsrast machen. Glücklicherweise hatte ich zum Tauschhandel hauptsächlich Tabak mitgenommen, welcher hier einen reifsenden Absatz fand. Für ein jedes Blatt konnte ich ein Ei kaufen, für ein „head“ ein Huhn. Die Duallas, deren Einflufs übrigens hier sehr bedeutend zu sein scheint, kamen alle sogleich nach meinem Lagerplatz und boten ihre unterthänigsten Dienste an; ein jeder glaubte, schon dafüir einige Blätter Tabak geschenkt zu bekommen. Als die Herren aber sahen, dafs sie sich in der Hinsicht in meiner Person geirrt hatten, zogen sie sich allmählich wieder zurück, mit Ausnahme einiger weniger Unverschämter, welche mir wie die Hunde auf Schritt und Tritt folgten. Als schliefslich von diesen auch der furchtsame Häuptling des Dorfes herangeschleppt wurde, forderte ich letzteren auf, mir bis Bakundu einen Führer zu stellen. Er kam zwar anfangs mit einigen Ausflüchten, welche ich nicht anerkennen wollte, bis ich ihm ein Blatt Tabak schenkte, welches nun plötzlich Freundschaft zwischen uns schuf. Nicht nur ging er, einen jungen Mann, welchen er seinen Sohn nannte, als Führer herbeizuschleppen, sondern schickte mir sogar einige Hühner als 
"Dash"; der Landessitte gemäls schickte ich ihm auch einen „Dash“ bestehend aus 4 "head" Tabak, worüber er sich so freute, dafs er mir noch einen schönen Ebenholzstock brachte, für den er dann noch ein „head" Tabak erhielt. Ich glaube, dieses "Dash“Austauschen bätte sich noch weiter fortgesetzt, wewn ich ihm nicht hätte sagen lassen, dafs er keinen "Dash" mehr bringen solle, ich sei schon genügend von seiner freundschaftlichen Gesinnung überzeugt. Diese Dörfer Malende und Njoke, welche beide etwa gleich grofs sind, sind sonst bei Besuchen der Europäer gewöhnlich nicht sehr zuvorkommend, doch hatte die Aussicht auf die herannahende Strafexpedition die Leute ganz aus dem Häuschen gebracht; es dauerte lange, ehe ich die Leute davon überzeugen konnte, dafs sie vou derselben garnichts zu befürchten hätten, da sie ja stets den durchziehenden Europäern gegenüber freundlich gesinnt gewesen seien. Unser Mujuka-Führer kehrte hier um.

Gegen 2 Uhr am Nachmittage brachen wir wieder von Malende auf. Der Wald war genau so beschaffen wie zwischen Njoke und Malende. Der Weg, welcher über ziemlich ebenes Terrain führte, war nicht schlecht. Nach etwa einer halben Stunde Wanderns sahen wir an Wege die ersten Kickxien. Es waren noch junge Pflanzen, welche etwa $8 \mathrm{Fufs}$ hoch waren; von älteren Bäumen sah ich noch nichts. Wiederholt hatten wir kleine Bäche zu überschreiten, von denen aber keiner tief genug war, um uns irgend welche Schwierigkeiten entgegenzustellen. Schon um $4^{1} / 2 \mathrm{Uhr}$ gelangten wir zum Dorfe Bakundu, das vollständig leer war. Die gesamte Einwohnerschaft war in die Wälder geflohen. Inmitten der breiten Dorfstrafse liefs ich mein Zelt aufstellen. Die Häuser waren hier ganz anders gebaut als bei den Stämmen, durch deren Gehiete wir bis dahin gezogen waren. Sie waren sehr hoch und geräumig. Der ganze Unterbau bestand aus Lehmwänden, die Dächer waren aus Elaisblättern hergestellt. In die Häuser hinein führten hohe, hölzerne Türme, an welche übrigens mit Kreide, wahrscheinlich von einem schriftkundigen Dualla, angeschrieben war, dafs die Insassen vor dem Europäer in den Busch entflohen seien. Meine Jungen, welche diese Schrift lesen konnten und die Sachen übersetzten, freuten sich ungeheuer über diesen Einfall. In den Wald liefs ich nun wieder hineinrufen, dafs ich in friedlicher Absicht gekommen sei, und die Bewohner auffordern, in ihre Hütten zurückzukehren; meinen Leuten verbat ich strengstens, sich irgend welchen Eigentums der Dorfbewohner zu bemächtigen. Die vom umberliegenden Walde aus ihren Terstecken uns beobachtenden Eingeborenen mufsten sich wohl allmählich ïberzeugt haben, dafs ich wirklich keine Feindseligkeiten im Schilde führte, und kamen 
einzeln, langsam und sehr scheu zurück. Als sich nun auch der Häuptling meldete. schenkte ich ihm, um mir das Vertrauen der Leute zu erwerben, einige Blätter Tabak, welche den erwünschten Erfolg auch erzielten. Bald wurden die Leutchen zutraulicher und kamen mit ihren Geschenken an, d. h. um auch von mir dafür ein Äquivalent in Empfang zu nehmen. Auch für meine Leute konnte ich genügend Planten (Kochbananen) erstehen, so dafs ich hier nicht gezwungen war, mir selbst zu helfen. Hühner und Eier waren zu billigen Preisen in Mengen zu haben. Da diese mit Reis während meiner Expeditionen meine Hauptnahrung zu sein pflegten, machte ich natürlich ausgiebigen Gebrauch von dieser Gelegenheit, mich wieder zu verproviantieren. Die Weiber des Dorfes erschienen erst spät am Abend, da sie wohl noch immer gehofft hatten, dafs ich abziehen würde. Allmählich hatte sich die ganze Bevölkerung bei meinem Zelte zusammengefunden. Fast wäre diese Harmonie durch einen kleinen Zwischenfall gestört worden. Einer der Leute des Dorfes wurde ertappt, als er eben eines unserer Beile stehlen wollte. Natürlich ergriffen ihn meine Leute sofort und wollten ihn tüchtig durchprügeln. Da ich befürchtete, dals es dadurch zu einer ernsteren Erregung bei den Eingeborenen kommen möchte, trat ich dazwischen und liefs den Übelthäter zu mir vors Zelt bringen. Bestraft mufste der Mann werden, das war unumgänglich notwendig, um neueu Diebstählen vorzubeugen. Vor dem versammelten Volke liefs ich dem Häuptling sagen, dafs es mir leid thue, dafs gerade hier bei ihm der Versuch gemacht worden sei, mich zu besteblen. Ich stellte es ihm trotzdem frei, um ihm $\mathrm{zu}$ zeigen, dafs ich Frieden wolle, den Mann selbst nach Landessitte zu bestrafen oder mir seine Bestraîung zu überlassen. Da der Häuptling mich bat, den Mann selbst zu bestrafen und sich auch die Eingeborenen damit einverstanden erklärten, liefs ich dem Missethäter zur grofsen Belustigung der versammelten Corona durch meinen "Headman" eine tüchtige Tracht Prügel geben, welche auf ihn wohl nicht so demoralisierend gewirkt haben mag als die Verspottungen, denen er dann seitens seiner Stammesgenossen ausgesetzt war. Am Abend führten die Bakundu-Leute mir zu Ehren noch einen grofsen Tanz auf, der bis tief in die Nacht hinein dauerte, obgleich ich mich bereits lange vorher zur Ruhe begeben hatte.

Im besten Einvernehmen mit den Eingeborenen schieden wir am frühen Morgen des folgenden Tages von Bakundu. Der Häuptling hatte mir zwei seiner Leute als Führer mitgegeben, welche mich bis nach Mokonye bringen sollten. Nachdem wir kurz hinter Bakundı noch kleine Strecken kultivierten Landes durchquert 
hatten, traten wir bald in einen Urwald ein, welcher sich durch Reichtum an Kautschuklianen auszeichnete. Häufig sah man am Wege liegend die kleinen Häuflein von Landolphiazweigen, welche in etwa 2 Fufs lange Stücke geschnitten waren, um daun im Dorfe durch weiteres Zerschneiden und Auffangen der aus ihnen erhaltenen Milch zur Kautschukfabrikation gebraucht zu werden. Ich habe schon früher einmal dieses Frischbleiben der Milch dadurch zu erklären versucht, dafs sich nach dem Anschneiden bald die geöffneten Milchkanäle durch die an der Luft bald koagulierende Milch verschliefsen und so eine Koagulation der im Innern der Zweige enthaltenen Milch verhüten. Auch Kickxia elastica war hin und wieder zu sehen, meist allerdings in kleineren Exemplaren. Die ersten umgeschlagenen Bäume sahen wir auch auf jenem Marsche. Dieselben waren in Abständen von etwa einem Fufse mit eingeschnittenen Ringen versehen, unter denen kleine Gefälse zum Auffangen der Milch aufgestellt worden waren. Das Terrain war nicht selten von tiefen Thälern durchschnitten, in denen während der Regenzeit Wasserläufe von nicht unbedentender Stärke vom Gebirge herunterkommen sollen. Nach etwa einstïndiger Wanderung gelangten wir nach dem Dorfe Bakumi, aus dem bei unserer Annäherung die sämtlichen Einwohner entflohen waren. Wir zogen hier nur hindurch, ohne uns überhaupt aufzuhalten. Der Urwald hinter Bakumi war dem zwischen Bakundu und Bakumi in jeder Beziehung gleich. Auch dort sahen wir wieder viele Landolphien und hin und wieder eine Kickxia. Die Leute, besonders der "Headman", denen ich die Kickxia gezeigt hatte, bekamen bald einen scharfen Blick für dieselbe und machten mich immer auf die Bäume aufmerksam, wenn wir in ihre Nähe gelangten. Gegen 11 Uhr marschierten wir in einem Dorfe ein, welches unser Führer Batanga nannte. Ebenso wie in Bakumi waren die Hütten wieder denen der Baquiri ähnlich. Auch hier fanden wir kein lebendes Wesen im Dorfe, obgleich die noch rauchenden Feuer bewiesen, dafs bis vor kurzem die Einwohner in ihren.Hütten waren. Ich liefs die Leute, welche wahrscheinlich sich wieder im Walde in der Nähe versteckt hielten, durch Rufen auffordern, zurückzukehren, da ich. Lebensmittel für meine Träger von ihnen kaufen wollte, anderenfalls sei ich gezwungen, meinen Leuten die Erlaubnis zu geben, sich selbst Planten abzuschlagen. Da schliefslich niemand erschien, gab ich dem "Headman" Erlaubnis, drei Büschel Planten abzuschlagen und unter den Trägern zu verteilen. Auch einige reife Kokosnüsse, deren es hier viele gab, liefs ich herunterholen, um die erfrischende Milch derselben zu trinken. Die schönen Bananenbestände bewiesen hier, dafs die Umgebung sehr fruchtbar sei. 
Trotz des Exempels, welches ich am vorhergehenden Abend batte statuieren lassen, konnte einer der Träger doch nicht der Versuchung widerstehen, in einer Hütte eine Decke zu stehlen. Mein "Headman", dem ich gedroht batte, ihn zu bestrafen statt des Übelthäters. falls er mir derartige Vorkommnisse nicht sofort melde, zeigte mir prompt an, dals der Manu auf frischer That ertappt sei. Da gerade aus derartigen Kleinigkeiten, wie das Entwenden der Decke schliefslich eine war, in einem Lande wie hier, wo die Eingeborenen immerhin in Erwartung der herannahenden Strafexpedition, deren wirkliche Ziele ihnen unbekannt oder unverständlich waren, ziemlich aufgebracht schienen, die unangenehmsten Feindseligkeiten entstehen können, liefs ich den Mann mit seiner gestohlenen Decke zu mir bringen, ihm erst die Decke abnehmen und schliefslich eine tüchtige Tracht Prügel verabreichen. Als wir gegen 2 Uhr nachmittags, nachdem sich die Träger ordentlich satt gegessen hatten (denn die drei Büschel Planten waren für die Anzahl der Leute so reichlich bemessen gewesen, dafs sie einen grofsen Teil der gekochten Nahrung in den Töpfen zurückliefsen), wieder zum Aufbruch fertig waren, hatte sich kein einziger der Einwohner des Dorfes sehen lassen. Fast befürchtete ich, dafs die Leute etwas Schlimmes im Schilde führten, so merkwürdig ruhig war alles umher. Doch ohne irgend welchen Zwischenfall konnten wir unseren Marsch wieder fortsetzen. Kickxia war nun schon häufiger zu sehen, obgleich ein nicht geübtes Auge die häufig versteckten Bäume leicht ïbersehen mag. Der Wald zeigte eine recht üppige Vegetation, wie ich sie, seitdem wir aus der Basaltregion bei Nyoke herausgetreten waren, nicht wieder beobachtet hatte. Gegen $3^{1} / 2$ Uhr erreichten wir das kleine Dorf Ediki, in welchem auch von Einwohnern nichts zu sehen war. Kurz vor dem Dorfe hatten wir auf einem Baumstamme den Ediki-Bach zu überschreiten. Ein langer Schwarm grof'ser, dunkelbrauner Ameisen benutzte zu derselben Zeit den Baumstamm als Brücke. Meine Leute mit ihren nackten Füfsen wurden von den gereizten Tiereu furchtbar gebissen, so dafs einige vor Schmerz entsetzlich heulten, besonders diejenigen, welche zuletzt den Stamm zu passieren hatten, nachdem der Schwarm immer mehr in Aufregung gebracht worden war. Selbst ich fühlte viele Bisse an den Beinen, obgleich meinc Schuhe noch durch dicke Ledergamaschen geschützt waren; allenthalben, wo es nur eine Öffnung gab, schlüpften die Tiere hindurch, um ihre Wut an dem blolsen Fleische auszulassen.

In Ediki wollten die Führer für die Nacht bleiben, da Mokonye nach ihrer Angahe zu weit entfernt sei, um den Marsch dorthin noch an demselbigen Tage machen zu können. Da ich diesen An- 
gaben nicht trante, zwang ich die Leute, weiter zu marschieren. Der Weg bis nach Mokonye war nun allerdings der schlimmste Teil des Weges, den wir bisher gewandert. Abgesehen davon, dafs es einen Hügel nach dem anderen hinauf- und hinunterging, hatten wir für eine geraume Zeit in einem Bache zwischen Felsen hindurchzuwaten, und zwar häufig über so schlüpfriges Terrain, dafs sich verschiedene Träger mit ihren Lasten plötzlich ins Wasser setzten. Nicht selten war anch der Weg in jener Schlucht durch umgestürzte Baumstämme derartig verbarrikadiert, dafs wir gezwungen waren, uns mit unseren Haumessern einen Weg zu bahnen. Jetzt konnte ich natürlich auch die Abneigung der beiden Führer gegen dieses Stück Weges verstehen. Allem Anscheine nach wird dieser Weg von Ediki nach Mokonye selten benutzt. Wie ich auch später in Erfahrung bringen konnte, geht von Ediki ein Weg zum Mungo hinunter, von wo aus der Verkehr bis Mundame nur in Canoes vor sich geht. Nach etwa dreistündiger Wanderung erreichten wir wirklich, gehörig durch diese Klettereien ermüdet, mit eintretender Dunkelheit Mokonye, wo die an den Anblick des Europäers bereits sehr wohl gewöhnten Eingeborenen uns mit grofsem Geschrei empfingen. Die Preise für einige Lebensmittel, welche ich hier in Mokonye für mich und meine Leute erstand, zeigten uns, dafs wir nun nicht mehr weit von den europäischen Niederlassungen bei Mundame waren, wo die Mokonye-Leute bei den dortigen Weifsen einen guten Absatz für ihre Erzeugnisse finden. Noch in der Dunkelheit mufsten meine Träger das Zelt aufstellen und die Lasten darin unterbringen, da ich den als Spitzbuben bekannten Mokonye-Leuten nicht Gelegenheit geben wollte, sich an meinen Sachen zu vergreifen.

Am frühen Morgen des 25. Januar waren wir bereits wieder auf dem Marsche nach Mundame zu, wo ich die Absicht hatte, die Jantzen-Thornählensche Plantage aufzusuchen. Nach Angaben der Eingeborenen sollte Mundame noch einen kleinen Marsch entfernt liegen. Dicht hinter Mokonye gelangten wir auf einen schönen breiten Weg, welcher Mundame mit Johann-Albrechts-Höhe, der Station am Elefantensee, verbindet. In den Wäldern sah ich zu meiner Frende, dafs die echte und die falsche Kickxia, beide, vorhanden waren, und zwar, wie mir schien, auf Basaltboden wachsend. Etwa eine knappe halbe Stunde hinter Mokonye erreichten wir das sogenannte "Mokonye-Niggerdorf", welches nur aus wenigen Hütten bestand. Ohne Aufenthalt marschierten wir weiter. Nach kurzer Zeit lichtete sich der Wald vor uns, und wir betraten bald eine recht sauher gehaltene Kakaoplantage, in der ich, da keine zweite derartige Anlage in der Gegend vorhanden ist, die 
Jantzen-Thormählensche Besitzung vermutete. Ich hatte mich auch nicht getäuscht, denn bald darauf kamen die Arbeitshäuser und dicht dahinter die Wohnung eines Europäers zum Vorschein, in der ich dann auch Herrn Schubert, unter dessen Leitung die Plantage damals stand, begrüfsen konnte. Mit seiner Genehmigung liefs ich nun sogleich mein Zelt aufschlagen und richtete mich zu einem eintägigen Aufenthalte ein, da mir nicht daran lag, in Mundame selbst bis zu meiner Weiterreise zu verbleiben, denn hier konnte ich in den Wäldern entschieden mehr für die Ausführung meiner Aufgaben thun, als in Mundame. Meine Träger, deren Kontrakt nun gewissermafsen abgelaufen war, löhnte ich noch am Vormittage ab und schickte dieselben dann sogleich nach Buëa zurück. Da es unter den damals bei Mundame herrschenden Verhältuissen ınmöglich war, Arbeiter irgend welcher Art anzuwerben, kam es mir sehr gelegen, dals Herr Schubert sich bereit erklärte, mir für die Weiterreise ins Bakossi-Gebiet von seinen BakunduArbeitern die nötige Anzahl als Träger zur Verfügung zu stellen.

Zu meiner gröfsten Freude sah ich hier, dafs Herr Schubert mit grolsem Geschicke die Plantage leitete, trotz der vielen entgegengesetzten Gerüchte, welche damals in Kamerun kursierten. Auch Kickxien gab es hier in ziemlicher Anzahl. Herr Schubert hatte sehr verständigerweise diese Bäume stehen lassen und auch Saatbeete zu neuen Pflanzungen angelegt, in denen die kleinen Pflänzchen prächtig standen. Die ursprünglich von Herrn Conrau angelegten Kakaopflanzungen waren zwar sehr unregelmäfsig und gänzlich aufser Reihen gepflanzt, doch hatte Herr Schubert da, wo die Bäumchen zu eng standen, die Bestände gelichtet und gereinigt, so dafs auch jener Teil der Anpflanzungen nun einen günstigeren Eindruck machte. Die von Herrn Schubert angelegten Pflanzungen standen vorzüglich. Um meiner Sache ganz sicher zu sein, d. h. wirklich feststellen lassen zu können, dafs Kickxia elastica hier in verwittertem Basalt wachse, entnahm ich an den Stellen, wo die Kickxia standen, einige Bodenproben, welche auch später von Herrn Geheimrat Wohltmann, dem ich dieselben vorlegte, als „schwerer verwitterter Basalt" bezeichnet wurden. Das Vorkommen der Kickxia in diesen Gebieten ist deshalb von Wichtigkeit, da es beweist, dals der Baum auch auf Basaltboden gedeiht und guten Kautschuk giebt, denn einige kleine Proben, welche ich anfertigte, standen an Güte den Proben, welche ich im Ngoko-Gebiete hergestellt hatte, in keiner Weise nach. Die vorhandenen Stämme waren alle noch klein und schienen kaum älter als sieben Jahre zu sein, was dadurch erklärlich erscheint, dafs auch jetzt noch in der Umgebung die Eingeborenen alle 
älteren Stämme, welche sie ausfindig machen können, zur Kautschukbereitung umschlagen. Kolabäume zeigte mir Herr Schubert auch in einigen Exemplaren. Die Eingeborenen sollen nach seiner Angabe auch dort die Samen dieser Bäume viel essen.

Am Nachmittage ging ich zusammen mit Herrn Schubert nach Mundame, um auch diesen Platz kennen zu lernen und in der Jantzen-Thormählenschen Faktorei daselbst für die Weiterreise Tabak zu kaufen, denn da ich nun durch die glïckliche Lösung der Trägerfrage in Stand gesetzt worden war, sofort die Expedition weiterzuführen, wollte ich Gebrauch davon machen und sogleich am Morgen des nächsten Tages wieder aufbrechen. Da ich gesehen hatte, wie vorzüglich sich der Blatttabak als Tauschartikel bei den Eingeborenen bewährte, kaufte ich in Mundame alles auf, was ich davon erstehen konnte. Mundame ist eine kleine Handelsniederlassung der Europäer, welche aus wenigen Faktoreien besteht, die in der Nähe des alten, ziemlich elenden Dorfes Mundame angelegt sind. Da der Mungo bis hier hinauf während des ganzen Jahres für Canoes und während der meisten Monate auch für kleine Flufspinassen schiffbar ist, so dafs die meisten Lasten und Waren auf dem Flufswege bis Mundame geschafft werden kömnen, geht ein grofser Teil der Produkte, welche aus dem Innern kommen, von hier aus auf dem Flufswege nach Kamerun hinunter. Fast alle kaufmännischen Unternehmungen gehen auch von hier aus ins Innere, so dafs in dem sonst unbedeutenden Plätzchen stets ein ziemlich reges Leben herrscht. Auch zur Zeit meiner Anwesenheit in Mundame gab es nicht weniger als fünf Europäer dort, für einen kleinen Platz in ziemlicher Entfernung von der Küste in diesen Gegenden des Schutzgebietes eine erhebliche Anzahl. Am Abend kehrten wir noch zur Plantage zurück, wo ich durch meine Jungen schon einen Teil der Lasten für den bevorstehenden Aufbruch herstellen liefs.

Obgleich die Balundu-Träger, welche mir Herr Schubert freundlichst abgetreten hatte, schon zur frühen Zeit am nächsten Tage erschienen waren, ging doch das Packen der noch übrigen Lasten und das Abbrechen des Zeltes nur langsam von statten, da die Leute noch völlig ungeschult waren. So kam es, dafs wir erst um 7 Uhr aufbrechen konnten. Auf dem mir bereits bekannten Wege marschierten wir bis Mokonye zurück, um dann die weiter nördlich verlaufende Strafse nach Johann Albrechts-Höhe noch weiter zu verfolgen. In Mokonye nahm Herr Schubert, welcher mich bis dorthin begleitet hatte, Abschied von mir. Kurz nachdem wir das Hauptdorf Mokonye hinter uns hatten, durchzogen wir noch ein zweites Niggerdorf gleichen Namens, in welchem ich einen 
kurzen Halt machen liefs, da viele meiner Leute hier von Verwandten und Bekannten Geschenke an Elswaren für den Weg mitbekamen. Den kurzen Aufenthalt benutzte ich dazu, die Einwohner zusammentrommeln zu lassen und ihnen eine Belohnung zu versprechen, falls sie während meiner Abresenheit im Bakossi-Gebirge Kickxiafrüchte für mich sammeln würden. Zur Antwort erhielt ich hier, dafs in der Nähe ihres Dorfes Kickxia nicht mehr vorhanden sei, da sie bereits alles zur Kautschukgewinnung ausgeschlagen hätten. Hier war also von den Lenten nichts zu erwarten. Bei den Eingeborenen heilst die Kickxia elastica „Fischunge“. Bald passierten wir noch zwei dicht bei einander liegende kleine Dörfchen und bogen dann hinter dem Fischemme-Bach ron der Hauptstrafse ab. Das Dorf Fikolomei, welches wir bald darauf erreichten, war beiderseits von kultiviertem Terrain umgeben, auf dem die Leute Erdnüsse, Bohnen und Bananen (Planten) anbauten. Auch Manihot utilissima war hin und wieder gebaut, schien aber nicht eine so begehrte Nahrung zu sein als die Bohnen und Planten. Auf den Feldern sahen wir hier häufig kleine Fetischbäuschen, welche kaum zwei Fufs hoch waren; sie sind aufgestellt, um die Felddiebe fernzuhalten. Dicht hinter dem unter Kultur stehenden Gelände bei Fikolomei betraten wir einen dichten Wald von grofser Ausdehnung, durch welchen wir eine gute Stunde zu marschieren hatten. Der Weg war in demselben sehr schlecht und allenthalben von darüber hinkriechenden Baunwurzeln bedeckt, so dafs es nicht leicht war, auf die Umgebung zu achten, ohne über die Wurzeln häufig zu stolpern. Landolphieu gab es hier sehr viele. Einige Häufchen frisch aufgestapelter $Z_{\text {weigstiicke bewiesen, dafs auch hier }}$ die Eingeborenen dieselbe Methode der Kautschukgewinnung baben wie die weiter südlich wohnenden Stämme. Den gröfsten Kickxiastamm, welchen ich je gesehen, fand ich auch hier in dem Walde. Derselbe mufste bereits seit einiger Zeit gefällt worden sein, denn seine Rinde fing stellenweise bereits an zu verfaulen. Die herumgezogenen Ringe liefsen dennoch deutlich erkennen, dafs wir es mit einer Kickxia zu thun hatten. Nach meinen Schätzungen war der Stamm etwa $15 \mathrm{~m}$ lang und hatte da, wo er gefällt war, einen Durchmesser von drei Fufs. Gegen $10 \mathrm{Uhr}$ gelangten wir an einen Bach nit felsigem Bett, welchen meine Träger Ngomolenge nannten, und kurz darauf erreichten wir eine kleine Ortschaft, welche den gleichen Namen fübrte. Dieselbe bestand nur aus drei Hütten; in einer derselben fanden wir ganz versteckt in einer Ecke ein altes Weib sitzend, von der wir schliefslich erfulren, dafs die übrigen Bewohner ausgerückt seien, als wir erschienen. Da ich die Ab. sicht hatte, hier mehr über das Vorhandensein der Kickxia in diesen 
Gegenden auszukundschaften, und zu diesem Zwecke die Leute sehen wollte, bestach ich die Alte mit einigen Tabaksblättern und forderte sie dann auf, die anderen Leute herbeizurufen. Es dauerte auch gar nicht lange, so war die ganze Gesellschaft friedlichst um uns herum versammelt, ıт uns alles mögliche für Tabak zu verkaufen, sogar Kautschuk brachten sie an. Als ich dann durch meine Leute fragen liels, ob die Fischungepflanze denn in der Gegend viel vorhanden sei, und eine bejahende Antwort erhielt. forderte ich einen Mann auf, mich zu einigen hinzuführen, und siehe da, dicht bei den Hütten standen einige Exemplare. Ich erfuhr dann auch, dafs hier die Bäume umgeschlagen würden, wenn sie stark genug seien, um genügend Kautschuk zu liefern. Als ich die Leute dann auffordern liefs, Früchte des Baumes für mich zu sammeln, versprachen sie, es zu thun. Bis um 12 Uhr verblieben wir in dem Dorfe, un dann trotz der drückenden Hitze den Marsch wieder aufzunehmen, denn ich wufste, dafs wir durch einen dichten Urwald zu marschieren haben würden, in dem wir von der Sonne wenig merken komnten. Gleich hinter dem Dorfe begann der Wald. Kickxia sah ich auf diesem Marsche mehr als früher an irgend einem Platze, seitdem ich auf dieser Expedition war. Ich hatte meinen Trägern eingeschärft, möglichst auf grofse Stämme zu achten, so dafs ich alle Augenblicke wieder auf solche aufmerksam gemacht wurde. Wiederholt schnitt ich die Bäume an und konnte stets guten Kautschuk aus der Milch gewinnen. Der Weg, auf dem wir marschierten, war in einem sehr schlechten Zustande, was noch um so unangenehmer wurde, da er fast gänzlich mit Achyranthes zugewachsen war, deren spitze Früchte uns bei jedem Schritt ins Gesicht schlugen; so dafs ich häufig, meine beiden Arme vor das Gesicht legend, marschieren mufste, um mich einigermafsen zu schützen. Für die Träger mit ihren entblölsten Oberkörpern mufs dieser Marsch entsetzlich gewesen sein. Hänfig machte die Vegetation über weite Strecken hin den Eindruck, als sei das Land vor Jahren kultiviert gewesen. Costus und Achyranthes, zwei Zeichen ehemaliger Kultur, waren in riesigen Mengen vorhanden. Hochwald, in dem wir ohne grofse Schwierigkeiten marschieren kounter, war nur strichweise anzutreffeu. Die ganze Landschaft machte einen äufserst uninteressanten Eindruck, der für mich nur durch das Vorhandensein der Kickxia erträglich wurde. Nach dreistündiger, unuuterbrochener Wanderung erreichten wir endlich zur grofsen Genugthuung der Leute unser nächstes Ziel, das Dorf Otam, das wohl nicht vorher von einem Europäer betreten worden war, wie überhaupt die Route, welche ich nach den Bakossi-Bergen eingeschlagen, bis dahin den Europäern unbekannt geblieben war. Hin und wieder hatten wir auch während des Nachmittags die von 
den Eingeborenen geschnittenen Landolphiazweige am Wege liegen sehen, welche uns bewiesen, dafs auch hier die Eingeborenen viel Kautschuk bereiten. Da ich in Otam erfuhr, dafs das nächste Dorf in sehr grofser Entfernung liege, gab ich den Leuten die Erlaubnis, für die Nacht sich Lagerplätze zu suchen, nachdem sie mein Zelt aufgestellt hatten. Ich selbst machte einige Exkursionen, welche für mich äufserst interessant waren, da ich auch Exemplare der falschen Kickxia (K. africana Bth.) dabei fand. Den Eingeborenen waren beide Arten sehr wohl bekannt, dieselben hatten sogar verschiedene Namen; während, wie ich schon vorhin erwähnt, Kickxia elastica bei den Leuten „Fischunge" hiefs, führte Kickxia africana den Namen „Mukama“; die Leute waren sogar im stande, schon am Wuchs beide Pflanzen zu unterscheiden. Mir fiel hier übrigens auf, dafs die Samen der Kickxia africana heller gefärbt sind als die der K. elastica.

Dicht bei dem Dorfe befand sich einer der in jenen Gegenden so überaus häufigen Fetischplätze. Dieselben bestehen aus einem runden freien Platze, welcher dicht mit Dracaenastämmen umpflanzt ist. Innerhalb des Platzes steht ein einzelner Fetischbaum, welcher den verschiedensten Pflanzenfamilien angehören kann, denn ich sah die verschiedensten derartigen Bäume auf solchen Plätzen. Nicht uninteressant war mir auch ein Grabmal, welches sich in der Nähe befand. Es waren die sämtlichen Töpfe, Taschen und sonstigen Utensilien des Verstorbenen, auf einen Haufen geworfen, ebenso eine grofse Anzahl von Makaboknollen (Xanthosoma esculentum), darüber hing, zwischen zwei Stöcken ausgespannt, die Kleidung des Verstorbenen. Ob der Leichnam darunter begraben war, oder in der Hütte eingescharrt wird, darüber konnte ich nichts erfahren. Die Eingeborenen befürchteten offenbar eine Zauberei, wenn sie mir dieses verraten würden.

An jenem Abend hatten wir viel von Moskitos und Sandfliegen zu leiden, besonders aber die letzteren waren es, welche in diesen Gegenden als furchtbare Landplage auftraten. Diese winzigen, kaum sichtbaren kleinen Dipteren hinterlassen Spuren ihrer Thätigkeit, gegen welche ein Moskitostich oft unbedeutend erscheint. Die Eingeborenen hier im Dorfe waren am Abend so merkwürdig stille und belästigten uns so wenig mit ihrer Anwesenheit, dafs es mir sehr auffiel. Es schien überhaupt auch hier der gröfsere Teil der Bevölkerung sich langsam aus der Nähe des „weifsen Zauberers" hinweggeschlichen zu haben. Von den wenigen zurückgebliebenen Leuten erhielt ich fünf Hühner und so viel Planten zum Geschenk, dafs meine Leute wieder einmal nicht wufsten, wie sie die Vorräte verschlingen sollten. Auch Eier konnte ich hier 
kaufen; für ein Blatt Tabak erhielt ich durch geschicktes Manövrieren meiner Jungen drei Stück. Tabak schien für die Leute der grölste Genufs geworden zu sein, und dennoch mufs es doch auffallen und ist recht charakteristisch für den Neger dieser Waldgebiete, dals die Leute trotz des fruchtbaren Bodens, welchen sie besalsen, nirgendwo selbst Tabak bauten, obgleich es ihwen eine Leichtigkeit gewesen wäre, Samen davon vou einigen Bakossi-Dörfern zu erhalten.

Nach der Bauart der Hütten zu urteilen, gehören die Leute in Otam noch zu den Balundu, obgleich sie sich von diesen ziemlich fern zu balten scheinen und ihre hauptsächlichsten Verkehrswege nach Westen zu den Bakundu-Dörfern hinüberführen. Die Bakundu bauen jedoch ganz andere Hütten, wie ich bereits oben bei Gelegenheit der Beschreibung meines Eintreffens in dem Bakundu-Dorfe erwähnt habe. Unsere nähere Kenntnis der Stämme südlich vom Elefantensee bis zum Mungo nach Malende hinunter scheint überhaupt noch sehr im Argen zu liegen und wäre wohl wert, einem Forscher zum Spezialstudium zu dienen. Es sitzen in diesen Gegenden an verschiedenen Stellen, eingesprengt inmitten anderer Stämme, kleine Gruppen von Dörfern, welche sich wohl noch von früheren $W$ anderungen her an den betreffenden Orten haben halten können, während die Hauptmasse des Stammes andere Wohnsitze aufgesucht hat oder dazu gezwungen wurde. So ist z. B. die äufserst merkwürdige Verbreitung der Bakundu-Dörfer für jeden, welcher in diesen Gegenden umherreist, auffallend. Um wirklich Positives über einige dieser Fragen bringen zu können, wäre ein längerer Aufenthalt unter diesen doch recht wenig bekannten Völkern des Waldgebietes notwendig, als ich ihn mir gönnen konnte. Conrau, welcher uns mit höchst interessanten und wichtigen Aufsätzen über die nördlich und nordöstlich vom Elefantensee wohnenden Stämme beschenkt hat, scheint sich weniger für die Gebiete südlich des Sees interessiert zu haben.

Am 27. Januar brachen wir sehr zeitig von Otam auf, denu nach Aussage der Otam-Lente lag das nächste Dorf sehr weit entfernt. Durch einen dichten Wald führte der schmale Pfad, welcher in recht schlechtem Zustande war und zeigte, dafs er nur selten betreten werde. Das Gebiet war sehr gut bewässert, aber stellenweise etwas steinig. Je weiter wir nach dem Mungo zu vordrangen, desto üppiger wurde der Wald und desto häufiger hatten wir teils stark flieísende, teils jetzt zur Trockenzeit dürre Bachthäler zu überschreiten, welche allerdings sich nur so weit eingebettet hatten, dafs das Land seinen ebenen Charakter nicht verlor. Landolphia sah man recht häufig, ebenso Kickxia, doch 
schien aie Kickxia africana hier von beiden Arten die vorherrschende zu sein. Als wir eben in eines der Bachthäler hinabstiegen, trabte ein Trupp von acht Elefanten, welche wir wohl in ihrem Morgenbade gestört hatten, den jenseitigen Abhang hinauf. Es war ein grofsartiger Anblick, zu sehen, wie die Tiere allmählich durch das Dickicht hindurchbrachen, wo sie unseren Augen bald entschwanden. Elefantenspuren gab es hier in grofsen Mengen, auch machten mich die Leute häutig auf Spuren von Wildschweinen aufmerksam, doch bekamen wir keines derselben zu sehen. Als wir nach etwa dreistündigem DLarsche den Mungo erreichten, welcher übrigens hier Manya genannt wird, hatten wir bereits durch fünf nicht unbedeutende Bäche waten müssen. Der Manya hatte zur Zeit, als wir ihn passierten, eine Wasserfläche von etwa $30 \mathrm{~m}$ Breite und war an der Furt bis zu $1 \frac{1}{2} \mathrm{~m}$ tief. Das ausgetrocknete Flufsbett bewies, dals er bei höherem Wasserstande bis $100 \mathrm{~m}$ breit sei, wenigstens an der Stelle, wo wir ihn überschritten. Inmitten des Fluisbettes befand sich eine Insel, auf der nur Gras zu wachsen schien, welches für die Elefanten der Gegend eine gute Lockspeise abgeben muls, denn von vielen Richtungen sah man die Spuren der Tiere nach dieser Insel führen. An der südlichsten Spitze der Insel machte ich eine merkwürdige Entdeckung, welche sicher mit der vulkanischen Beschaffenheit des Bodens zusammenhängt. In dem Flufssande hatten sich am Rande des Wasserspiegels eine gröfsere Zahl trichterförmiger Miniaturkrater gebildet, aus welchen eine ölige oder fettige Substanz zum Tageslichte befördert wurde. Die Krater hatten einen Durchmesser von etwa einem Fufse und schienen je nach der Höhe des Wasserspiegels verschoben zu werden. Der Inhalt machte etwa den Eindruck, als bestehe er aus Petroleum, das mit Wasser vermiseht war. Ich will damit nicht etwa sagen, dafs ich die Meinung gewonnen habe, dals es sich hier um Petroleumquellen handele, denn bei der starken Vermischung des ausgestofseneu Produktes mit Wasser wäre es nur mit Hülfe einer genauen chemischen Analyse möglich, festzustellen, welche Öle in der Flüssigkeit enthalten sind.

Sobald wir den Manya überschritten hatten, stiegen wir langsam auf einen Hügelrücken hinauf. Mit jedem Schritt wurde der Weg schlechter, so dafs wir endlich nichts weiter vor uns hatten als einen kleinen Gielsbach, in dessen felsigem Bette wir nun für eine gute halbe Stunde zu marschieren hatten, dabei immer von Felsen zu Felsen weiter hinaufkletternd. Entsetzlich müde gelangten wir dann endlich bis über den Hügelrücken, wo ich, um den Leuten wieder frischen Mut zu geben, eine kleine Pause machen liefs. Der Wald wurde nun immer interessanter, je weiter 
wir vordrangen, besonders da, wo die reifsenden Bäche gröfsere Thäler ausgewaschen hatten. Wir mufsten noch mehrere derartige Bäche überschreiten, bis wir endlich bei Banga aus dem Walde heraustraten. Das Gebiet, welches wir nun vor uns hatten, gehörte zu den fruchtbarsten Geländen, welche ich geseben. Der niedergeschlagene Wald bewies, dafs die Bakossi, in deren Gebiet wir uns nun befanden, die Ebenen hier früher unter ausgedehnter Kultur gehabt hatten; auch einige verfallene Hütten zeigten sich bald, die uns den gleichen Beweis liefern konnten. Zu unserem nicht geringen Erstaunen setzte sich der schmale Weg plötzlich in einer breiten, reingehaltenen Stralse weiter fort, und etwa eine halbe Stunde später zogen wir in Mafura, dem ersten Bakossi-Dorfe, ein. Die Eingeborenen hatten von unserem Kommen nicht eher etwas bemerkt, als bis wir bereits im Dorfe waren. So kam es, dafs wir fast die ganze Gesellschaft beim Mittagsschlafe antrafen. Ich forderte die Leute nun auf, mir ihren Häuptling zu zeigen, erhielt aber als Antwort, dafs derselbe in Eko-Keyoke, dem nächsten Dorfe, sei. Als ich dann noch einige Kleinigkeiten mit Tabak eingetauscht und mir so die Leute gewonnen hatten, gab ich zum grofsen Entsetzen meiner ermüdeten Lente den Befehl zum Aufbruch. Doch da half nun einmal nichts, erst in EkoKeyoke wollte ich Mittagsrast machen, und dabei blieb es.

Die Hütten, welche ich hier im ersten Bakossi-Dorfe sah, setzten mich nicht wenig in Erstaunen, denn dieselben waren nicht wie die der übrigen Waldland-Bewohner am Kamerun-Gebirge viereckig, sondern vollständig rund mit einem Spitzdach. Das Vorhandensein dieser runden Bakossi-Hütten mufs um so mehr auffallen, als die sämtlichen umwohnenden Stämme die gewöhnlichen Hütten der Waldland-Völker haben. Sollten diese Bakossi etwa erst in späterer Zeit hierher gewandert sein und diese Form der Hütten dann noch aus ihrer früheren Heimat herstammen?

Als wir das Dorf Mafura verliefsen, folgte uns ein ganzer Schwarm von Leuten nach, die sich offenbar lebhaft über den nenen Weifsen wunderten, welcher nun wieder von einer nie geahnten Richtung in ibr Land gekommen war, denn Conrau, welcher anch in Mafura gewesen ist, kam von der entgegengesetzten Seite. Bis Eko-Keyoke hatten sich von den vielen Leuten, welche auf den Feldern arbeiteten, soweit sie, wie z. B. die meisten Weiber, nicht sofort davongelaufen waren, noch viele Bakossi uns angeschlossen, so dafs der ganze Zug sich nun bedeutend verlängerte, und mein "Headman" gehörig aufpassen mulste, dafs die Träger, wie es immer mein Wunsch war, möglichst geschlossen marschierten. Die Felder, welche man hier sah, zeugten von der riesigen Frucht- 
barkeit des Bodens. Aufser Bananen, Manihot und Xanthosona wurde hier eine Bohne (eine Vigna-Art) mit grofsen violetten Blüten in riesigen Quantitäten gezogen. Wie ich mich später überzeugen konnte, hatte diese Bohne einen vorzüglichen Geschmack und dürfte sich auch, da sie reichlich Früchte trägt, zur Kultur in anderen Distrikten Kameruns sehr empfehlen. Die Bakundu-Lente afsen dieselben mit einer wahren Leidenschaft und kauften sich häufig selbst für den sonst so hochgeschätzten Tabak davon. Auch in Eko-Keyoke fand ich durchaus freundliche Aufnahme. Die Leute räumten sofort ein Haus für mich, damit ich nicht draufsen sitzen brauchte, wo man von den vielen Elefantenfliegen, welche gierig an jeder nackten Körperstelle den Schweifs aufsaugten, sehr stark belästigt wurde. Für einige Blätter Tabak brachten mir die Leute einige riesige Plantenbüschel, an welchen sich meine Leute wieder ergötzen konnten. Sowie sie sich den Magen denn auch wieder gefüllt, waren alle Strapazen des langen Vormittagsmarsches vergessen, so dafs ich beschlofs, noch am Nachmittage bis nach Nyassosso oder wenigstens bis unter den Kupee-Berg zu marschieren.

Das ganze Gebiet um Mafura und Eko-Keyoke herum gehört zu den prächtigsten Geländen, welche ich in Kamerun gesehen. Der Regenfall ist allerdings nicht so reichlich wie zwischen Victoria und Bibundi, doch ist das Land sonst so vorzüglich bewässert und auch die Luftfenchtigkeit eine derartige, dafs meiner Ansicht nach die sämtlichen Kulturen, welche sich bisher unten in den Küstengebieten bewährt haben, auch hier zu guten Resultaten führen werden. Dazu kommt noch, dafs das ganze Land äufserst fruchtbar ist und grofse Ebenen aufweist, welche viel leichter unter Kultur gesetzt werden könnten als die hügeligen Plantagengebiete am Fufse des Kamerun-Gebirges. Diesen günstigen Umständen mufs man nun allerdings auch wieder die Transportschwierigkeiten entgegenhalten, welche zuerst vorbanden sein werden; doch auch diese würden sich leicht beseitigen lassen, denn wenn erst einigermafsen gute und direkte Wege von diesen Gebieten nach Mundame angelegt sein werden, so würde sich der Weg bis Mundame doch bequem in $1^{1 / 2}$ Tagen zurücklegen lassen, die Unkosten also nicht sehr bedeutend sein.

Kurz bevor wir Eko-Keyoke erreichten, hatten wir einen der romantischsten Plätze passiert, welchen ich seit langer Zeit gesehev. Der Ngire-Bach wälzte sich unter furchtbarem Getöse in einer tiefen Felsschlucht mit vollständig steilen Wänden unter uns hin; inber die Schlucht hatten die Eingeborenen eine sehr bequeme, feste 
Brücke mit hohen Geländern gebaut, von welcher aus man in Ruhe dieses imposante Bild betrachten konnte.

Nachdem wir unser Mittagessen beendet hatten, zogen wir weiter des Weges, unserem Ziele, dem Kupee-Berge, entgegen. Meine Leute batten sich mit den Bakossi merkwürdig rasch befreundet, und zwei hatten sogar Ersatz zum Tragen ihrer Lasten gefunden. Da ich sah, dals sie dennoch in Sicht ihrer Lasten verblieben und es den Bakossi Freude zu machen schien, an dem Zuge teilzunehmen, liefs ich das ruhig hingehen. Der Zug, welcher nun in rascher Reihenfolge durch verschiedene Dörfer ging, vermehrte sich immer mehr. Mir wurde mit jedem Augenblicke unverständlicher, wie diese lebenslustigen Bakossi an der Küste einen so schlechten Ruf erhalten haben konnten. Dibandjó, das nächste Dorf hinter EkoKeyoke, war viel freier gelegen als letzteres, bot aber sonst nichts Besonderes dar. Ohne Aufenthalt zogen wir im schnellen Schritt weiter. Das Beispiel, welches die beiden Bakossi aus Eko-Keyoke gegeben, wirkte sehr bald; schon als wir durch Etó kamen, sab ich den gröfseren Teil meiner Lasten auf den Köpfen junger Bakossi, die sich freiwillig meinen Leuten anboten. Kurz darauf sah ich den hohen Gipfel des Kupee-Berges vor uns, dessen verschleierte Spitze bis dahin von Wolken verdeckt war. In Ngusi liefen die Leute mit allen möglichen Geschenken auf uns zu. Da ich aber den Tabak in den Lasten verpackt hatte, so konnte ich das alles nicht annehmen, da ich ja das landesübliche Gegengeschenk nicht machen konnte. Meine Träger liefen nun alle frei umber, da sie schliefslich alle jemanden gefunden hatten, der ihnen die Last tragen wollte. Dals die Bakossi natürlich auf ein Geschenk meinerseits rechueten, war mir vollständig klar, doch drückte ich gern heute ein Auge zu, waren doch meine Leute seit $5^{1 / 2}$ Uhr morgens auf schlechten Wegen ununterbrochen mit ihren schweren Lasten über die Felsen und gefallenen Bäume weggeklettert, bis wir schliefslich bei Mafura in deu guten Weg gelangten. Die Hitze war auch bedeutend gewesen, so dals den Leuten ihre Märsche noch beschwerlicher erscheinen mufsten. Als wir eben durch Ngusi, ein grofses, sich lang hinstreckendes Dorf, hindurchgezogen waren, kam der Häuptling mir nachgelaufen, um mich zu bitten, doch eine Zeit bei ihm zu verweilen. Ich bedauerte, dafs das nicht möglich sei, da meine Leute schon vorausmarschiert seien. Er versprach mir darauf, mich in Nyassosso zu besuchen, wohin er mir auch Eier und Hühner als Geschenk senden wollte. Schon hinter Ngusi begannen sich steilere Steigungen im Wege zu zeigen, bis wir hinter dem Dorfe Endumenui plötzlich unter einem grofsen Hügel standen. Bis dorthin war so schnell 
marschiert worden, seitdem wir Eko-Keyoke verlassen hatten, dals ich damals in mein Tagebuch einschrieb: „Unser Nachmittagsmarsch von Eko-Keyoke bis hinter Endumenui artete zu einer wahren Treibjagd aus." Es war wirklich ein gut Stück zu stark getrieben worden, so dafs ich nuu den Leuten, die schon anfingen, übermütig zu werden, gebot, in dem gewöhnlichen Tempo zu marschieren.

Von Dibandjo bis Endumenui waren die sanft aufsteigenden Gelände hauptsächlich mit Elefantengras bedeckt, aus dem sich teils einzeln oder in Gruppen und kleinen Wäldchen Bäume erhoben. Zu unserem Glücke war der Berg; welchen wir hinter Endumenui zu erklettern hatten, dicht bewaldet, so dals die Sonne die mit ihrem schweren Gepäck langsam emporkletternden Träger nicht erreichen konnte. Dieser Aufstieg dürfte für meine Träger für denselben Tag zu viel geworden sein, hätten wir nicht das Glück gehabt, in den Bakossi diese Hülfe zu findeu. Nach etwa einstündigem Emporsteigen gelangten wir auf die Ebene am Fufse des höchsten Kegels des Kupee-Berges, und bald darauf zogen wir in Nyassosso ein. Ich liefs sofort bis in die Nähe der Baseler Missionsstation marschieren und daselbst mein Lager anfschlagen. Herr Walker, der deutsche Missionar, welchen ich bereits von meiner Schiffsreise von Lagos nach Victoria her kannte, begrüfste mich auf das herzlichste. Ihm sowohl wie seiner Fran Gemahlin bin ich zu grofsem Danke verpflichtet für die Art, in der sie mir den kurzen Aufenthalt in Nyassosso so angenehm gemacht haben.

Von meinem Lager aus konnte ich den Kupee-Berg am Abend in seiner ganzen Pracht bewundern. als die Sonne unterging und ihren rötlichen Schinmer über das ganze Panorama warf. Der Berg ist bis zu seinem Gipfel dicht bewaldet und ähnlich wie der Kamerunberg kegelförmig aufgebaut. In den Wäldern giebt es noch viele Kantschuklianen, doch scheint Kickxia nicht über $500 \mathrm{~m}$ Höhe hinaufzusteigen. Meine Befunde über die Höhe von Nyassosso stimmten nach Aussagen der Missionare mit denen des Geologen Herrn Dr. Esch, welcher etwa zwei Jahre vor mir die BakossiGebirge besuchte und auch den Gipfel des Kupee-Berges erstieg, ziemlich überein. Ich selbst hätte gern eine Besteigung des Berges unternommen, glaubte mich aber nicht in Nyassosso lange aufhalten zu dürfen, da ich noch vor Ende des Monats Februar von einer beabsichtigten Reise nach der Südküste des Kamerun-Gebietes zurückkehren mufste, un mit deḿ Dampfer am 4. März nach Togo zu reisen. Es wurde mir damals ordentlich schwer, von Nyassosso wieder abzuziehen, ohne die Bergbesteigung und eine kleine Expedition bis zur Grenze der Grasregion im Norden, welche nach Herrn Walkers Aussagen nur zwei 'Tagemärsche von Nyassosso 


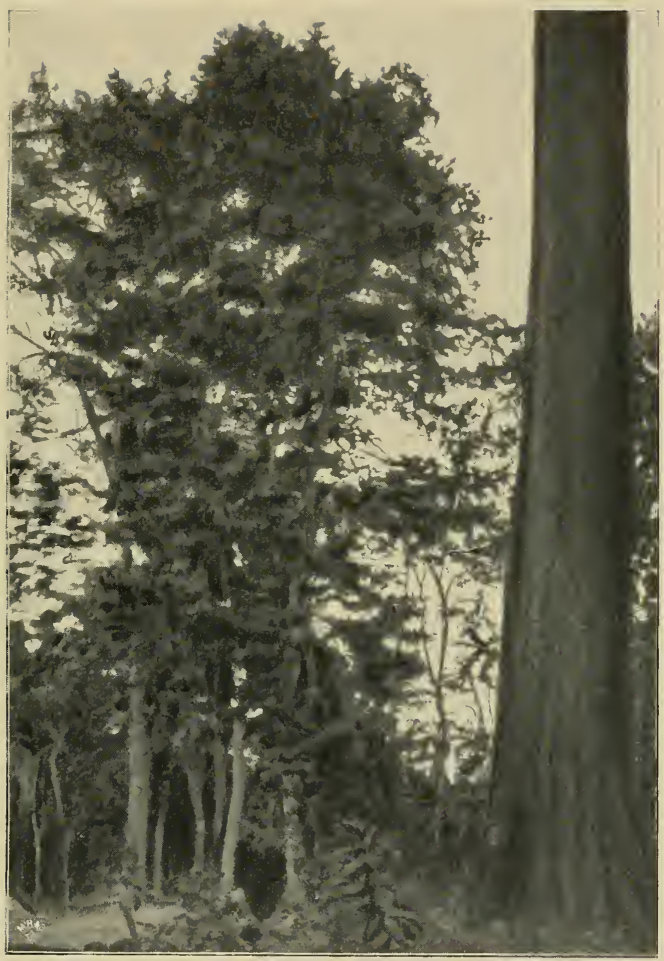

Kickxia-Bäume in Mundame. 

beginnen soll, gemacht zu haben. Froh zog ich wiederum von Nyassosso weg, da ich mir sagen konnte, dafs die Aufgabe, welche ich mir für die Bakossi-Expedition gestellt hatte, vollständig gelöst war. Ich hatte Kickxia bis in die Bakossi-Gebirge binein nachweisen können und hatte auch Landolphien in mehr oder minder grofsen Quantitäten längs der ganzen Route gefunden. Daf́s die Gebiete am Fufse des Gebirges bei Mafura und Eko-Keyoke so günstige Bedingungen zur Anlage von Plantagen lieferten, war auch bis dahin nicht zu erwarten gewesen, wie ja überhaupt über jene Gebiete gar nichts bekannt war, da alle anderen Reisenden vom Wuri oder den Mungo-Fällen her auf einer ganz anderen Route in das Bakossi-Gebiet gelangt waren. Auch Herrn Walker, welcher bereits seit längerer Zeit in Nyassosso lebte, war die von mir eingeschlagene Route nicht bekannt. Gern hätte ich zu dem Rückmarsche einen vou Conrau auf seiner Karte jener Gegenden aufgezeichneten und von ihm benutzten Weg längs des Mungo gewählt, mufste aber diesen Plan aufgeben, da ich keinen Eingeborenen finden konnte, der den Weg kannte.

Am 28. Januar unternahm ich unter Führung des Herrn Missionar Walker noch eimen kleiuen Spaziergang, um die etwas unterhalb von Nyassosso liegenden Sägewerke der Station zu besichtigen, in denen das sämtliche Bauholz für die Bakossi-Mission geschnitten wird. Zur Herstellung von Brettern und Balken wurde hauptsächlich eine Terminalia-Art verwendet, welche sich durch besondere Härte ihres Holzes auszeichnen soll. Das Terrain auf dem Plateau, in welches wir hinabstiegen, war auch vorzugsweise mit Elefantengras bedeckt, aus dem sich verschiedene Bäume, einzeln oder in Gruppen, erhoben. Hier und dort sah man ausgedehntere Gebüsche, besonders in der Nähe der Waldungen. Auch hier im BakossiGebiete haben die Eingeborenen die schlechte Gewohnheit, das Gras niederzubrennen, wenn sie ihre Pflanzungen anlegen wollen, ohne dabei die nötigen Vorsichtsmafsregeln zu treffen, so dals nicht selten Waldbrände vorgekommen sind, welche natürlich einen grofsen Schaden anrichteten, denn an Stelle der Wälder tritt an den abgebrannten Orten gewöhnlich das Elefantengras auf, das zu nichts nütze ist und nur das Ungeziefer der Umgegend anzieht.

Da ich keine Zeit zu verlieren hatte, brach ich schon früh von Nyassosso am 29. Januar auf, um auf demselben Wege, auf dem wir gekommen waren, wieder nach Mundame zurückzumarschieren. Meine Träger äufserten die Absicht, mit mir noch weiter zu zieheu, doch das ging nun einmal nicht, ich mulste umkehren. Hätte ich allerdings damals gewufst, wie lange ich noch an der Küste warten sollte, ehe ich nach dem Süden reisen konnte, so hätte ich sicher 
rersucht, über Land nach dem Sanaga zu gelangen, um dann über Klein-Batanga längss der Küste nach dem Süden zu gehen.

Um 6 Uhr liefs ich schon von Nyassosso abmarschieren. Über Endumenui, Ngusi, Etó und Dibaudjó marschierten wir, ohne uns irgendwo in diesen Dörfern aufzuhalten, direkt bis Eko-Keyoke. Tor Eko-Keyoke hatten wir den Ebury-Bach, welcher sich in einem grofsen Bogen dort dem Dorfe nähert, zu überschreiten. Derselbe erinnerte mich sehr lebhaft an den Meandja-Bach am KamerunGebirge. In Eko-Keyoke liefs ich nur wenige Minuten rasten, da ich mit dem Häuptling noch über einige Dinge sprechen wollte. Durch das nur aus drei Hütten bestehende Dörfchen Dibara gelangten wir gegen $10^{1} / 2$ Uhr wieder nach Mafura. Hier liefs ich nun eine Rast vou drei Stunden machen, um die Leute für den langen Nachmittagsmarsch, welcher uns bevorstand, möglichst frisch zu erhalten. Es gab hier in Mafura übrigens derartige Mengen von Elefantenfliegen, dafs ich nicht einmal mit Ruhe essen konnte, obgleich ich rings um meinen Tisch herum kleine Feuer hatte machen lassen, um durch den Rauch die Tiere möglichst zu verscheuchen. Leider half dieses Mittel aber nicht, so dafs ich meine Arbeiten, mit denen ich die Lagerzeiten zu vertreiben pflegte. bis auf den Abend verschieben mufste. Auf dem Marsche durch die hinter uns liegenden Bakossi-Dörfer war mir übrigens damals aufgefallen, dals an jeder Palaverhütte zwei Elefauten-Unterkiefer lagen. Ich erkundigte mich in Mafura nach der Ursache dieser Sitte, konnte aber nichts über deren Bedeutung erfahren; offenbar haben dieselben etw as mit dem Fetischglauben der Leute zu thun. Am Nachmittage traten wir den Marsch durch den Urwald nach Otam an, dessen Länge uns ja bereits bekannt war. Bis zum Etinge-Bach befanden wir uns noch auf der wundervollen, fruchtbaren Ebene und gutem Wege, vou da ab ging es stets über Hügel und die Thäler der kleinen Bäche. Der Abstieg zum Manya-Flusse machte uus besonders viel zu schaffen, da die Träger auf den mit Algen bedeckten Felsen leicht ausglitten und dann mit ihrer Last fielen. Etwa $1 \frac{1}{2}$ Stunde vor Otam passierten wir die verlassenen und in Zerfall begriffenen Hütten des ehemaligen Ortes Etamarca, dessen Einwohner nach Mafura gezogen sein sollen. Gegen Abend trafen wir in Otam ein. Ich liefs sofort mein Zelt aufstellen und begann dann mit einigen schriftlichen Arbeiten, welche bis tief in die Nacht hinein damerten. Zu meinem Erstaunen wurden wir in der Nacht von Moskitos arg gepeinigt.

Am Morgen des 30. Januar brachen wir sehr zeitig von Otam auf, um durch den infolge der vielen Achyranthes-Büsche am Wege recht unangenehm zu passierenden Buschwald nach Ngomolenge zu gelangen. J)ie Namen der Bäche, welche wir passierten, sind 
nach Angaben der Eingeborenen Take und N'kobe. Die Leute von Ngomolenge, welche versprochen hatten, für mich Kickxiafrüchte zu sammeln, hatten blofs sechs derselben gefunden, statt dessen aher einige Kilo Kautschuk in der Zeit hergestellt, welche sie mir nuu für Tabak zum Kaufe anboten. Natürlich waren sie sehr entrüstet darüber, dals ich den Kautschuk nicht nahm. Nach kurzem Aufenthalte zogen wir direkt bis Mokonye-Niggerdorf fort und erreichten die Mundame-Plantage am Nachmittage. Nachdem ich daselbst mein Lager wieder aufgeschlagen hatte, ging ich zusammen mit Herrn Schubert noch nach Mundame, um mich nach einer Gelegenheit zu erkundigen, ein Canoe zu besorgen, das grofs genug sein mufste, meine sämtlichen Lasten zu befördern, da ich mich entschlossen hatte, auf dem Mungo die Rückreise nach Victoria anzutreten. Ohne etwas ausgerichtet zu haben, kehrten wir am Abend nach der Plantage zurück, um am nächsten Tage unsere Bemühungen zu erneuern.

Herr Schubert hatte, seinem Versprechen gemäls, während meiner Abwesenheit auf der Bakossi-Expedition in der Umgebung der Plantage Kickxiafrüchte für mich sammeln lassen, welche ich nun zur Küste mitzuuehmen gedachte. Einschliefslich der Samen, welche ich unterwegs gesammelt hatte, und der, welche mir die Eingeborenen von Ngomolenge besorgt hatten, konnte ich etwa 10000 Samen zur Küste mitnehmen.

Unseren eifrigen Bemühungen gelang es doch, am 31. Januar ein, wenn auch defektes, Canoe zu bekommen, mit dem ich es wagen wollte, die Rückreise anzutreten. Demgemäls brach ich am 1. Februar von der Plantage auf. Von Mundame konnte ich erst um $10 \mathrm{Uhr}$ abfahren, da das defekte Canoe sich noch im letzten Augenblicke gegen ein besseres umtauschen liess. Ich hatte in dem Canoe nur sechs Ruderer, da man nur mit Not in Mundame vier Leute anftreiben konnte, welche einwilligten, mich bis N'Bamba zu bringen. Meine beiden Jungen mufsten deshalb natürlich auch tüchtig helfen. Da der Mungo einen recht niedrigen Wasserstand hatte und deshalb die Strömung nur eine langsame war, wir aufserdem noch wiederholt auf Sandbänke gerieten, danerte die Fahrt länger, als ich gedacht. Erst gegen $2^{1 / 2}$ Uhr am Nachmittage trafen wir bei der Baseler Missionsstation Bakundu ein, welche nicht mit dem Bakundu zu verwechseln ist, das ich früher besucht hatte. Ich liefs den Leuten nun etwas Zeit zum Essen, während ich zur Station hinaufging, um den Missionaren Grülse aus Nyassosso zu überbringen. Von Bakundu bis MalendeStrand war die Fahrt erst recht unangenehm, da es hier noch viel mehr Sandbänke gab, als zuvor, auf die natürlich meine Leute, 
welche alle ungeübte Ruderer waren, mit tödlicher Sicherheit auffuhren, so dafs ich sie immer wieder ins Wasser schicken mulste, um das Canoe wieder flott zu machen. Da die Früchte des Wollbaumes (Ceiba pentandra) gerade reif waren und die flockigen Samen zu Millionen vom Winde herungetragen wurden, war stellenweise die ganze Wasserfläche von den Samen derartig bedeckt, dafs man glauben mochte, man befinde sich vor einem Schneefelde. Die Eingeborenen sammelten, in kleinen Canoes umberfahrend, grofse Mengen dieser Flocken ein. Wie ich noch am Abend Gelegenheit hatte, zu sehen, fertigten sie aus denselben Kissen an, welche sich allerdings sehr gut gebrauchen liefsen. Ob die Leute noch eine besondere Verwendung für die Samen haben, konnte ich während dieser sebr beschleunigten Flufsreise nicht feststellen; da dieselben sehr ölhaltig sind, ließsen sie sich eventuell zur Ölbereitung relwenden, besonders dort, wo sie, wie am Mungo, in riesigen Mengen mit Leichtigkeit aufgesammelt werden können. Erst mit eintretender Dunkelheit trafen wir in Malende-Strand ein. Da hier nur ein Haus mit drei Abteilungen stand, so war ich gezwungen, mit meinen Leuten eine derselben einzunehmen, denn ich wollte, um die damit verbundenen nicht unbedeutenden Umstände zu rermeiden, nicht erst mein Zelt aufschlagen lassen. Die in dem Hause wohnenden Eingeborenen inufsten sich dann die beiden anderen Abteilungen teilen. Während der Fahrt von Mundame bis Malende-strand hatte ich da, wo die Ufer etwas hügelig waren, einige Kickxien beobachtet und von einer auch einige Frïchte herunterholen lassen. Auch Lianen, welche Kautschuk lieferten, kamen mir hin und wieder zu Gesicht, doch war die nicht brauchbare Landolphia florida vorherrschend.

An die Nacht, welche ich in Malende-Strand nach jenem Tage durchzumachen hatte, werde ich noch lange denken. Ein Kind der das Haus bewohnenden Eingeborenen war krank, und man glaubte allgemein, dals es in der Nacht sterben würde; die Mutter desselben war halb wahnsinnig vor Verzweiflung geworden. Nachdem ich dem Jungen, welcher einfach an einer sehr starken Verstopfung zu leiden schien und daher immer über starke Schmerzen im Magen klagte, etwas Calomel gegeben und den Leuten versichert hatte, dafs die Sache ganz ungefährlich sei, beruhigten sie sich einigermafsen. Froh über diesen Erfolg, legte ich mich nieder, wurde aher derartig von Moskitos gepeinigt, dafs ich trotz einer ziemlichen Ermüdung nicht an Schlaf denken konnte. Um mich nun erst vollends wachzuhalten, fing der Kranke wieder an zu stöhnen, und sofort begann die ganze Gesellschaft mit einem wrüsten Geheul, dafs der Junge jetzt sicher sterbe. Da die Mutter 
glaubte, dafs die Medizin des Weifsen nicht helfe, nahı sie natürlich zu ihren eigenen Mitteln Zuflucht. Wie eine Wahnsinnige schlug sie bei dem Lager des Kranken in die Luft hinein und bewegte sich so schlagend zum Ausgange hin, als ob sie etwas vor sich hertreibe, dabei stiefs das Weib die merkwürdigsten unartikulierten Lante aus, welche wohl Beschwörnngen sein sollten; vor der Thür erreichte diese Scene ihren Höhepunkt. Nach etwa fünf Minuten langem Kreischen und Schimpfen, als ob sie jemand fortjagen wolle, was in diesem Falle wohl ein böser Geist war, kehrte sie rückwärts gehend und immer noch wie wahnsinnig vor sich herschlagend, ins Haus zurück, wo sie erschöpft am Lager des Kranken zusammenbrach. Nach einiger Zeit kamen noch mehrere Eingeborene, welche wohl Verwandte des kranken Kindes sein mulsten. Die Weiber klagten die ganze Nacht hindureh. Dals man mir damals nicht vorwarf, dals meine Medizinen den Zustand des Patienten verschlimmert haben, wunderte mich zur Zeit sehr. Da doch nicht an Schlaf zu denken war, liefs ich schon um 4 Uhr das Canoe zur Abfahrt bereit machen und die Lasten, welche wir im Hause gebraucht hatten, hineinschaffen. Als ich meinen Thee trank, kam mir der Gedanke, dafs ich dem krankeu Kinde davon eingeben könne, doch die Leute hatten kein Vertrauen mehr zu den Medizineu des Weifsen und nahmen den Thee nicht an, bis zu aller Erstaunen plötzlich der vermeintlich Halbtote aufstand und mich noch um etwas Medizin bat, die ich ihm dann auch in Form von einer neuen Dosis Calomel eingab. Unter grofsen Dankesbezeugungen der Mutter, welche nun vor Freude ïber die Wiedergenesung ihres Sohnes fast noch toller wurde als vor Verzweiflung über seine Krankkeit, liels ich um 5 Uhr abfahren, um so möglichst schnell zu entkommen.

Wir machten ziemlich schnelle Fortschritte, solange es kühl war, doch sobald die Sonne etwas höher stieg, erschlafften die Leute sehr merklich, so dafs ich sie beständig anzufeneru hatte. Erst als ich gegen Mittag einige Enten und Reiher geschossen, und drohte, dafs ich das für mich überflüssige Fleisch an die Eingeborenen des uächsten Dorfes verschenken würde, wenn sie sich nicht mehr beeilten, ruderten sie wieder kräftiger, bis ich bei einem Dorfe, welches die Leute Mangono nannten, zum Kochen Halt machen lassen wollte. Trotz langer, vergeblicher Bemühungen war hier aufser einem einzigen Plantenbüschel bei den Einwohnern nichts Elsbares für meine Leute aufzutreiben, so dafs ich es vorzog, noch bis $1 \mathrm{Uhr}$ weiterfahren zu lassen. In dem Dorfe, welches wir darauf erreichten, hatten wir mehr Glück nnd komnten uns nun Zeit nehmen, etwas zu geniefsen. Als wir dann am Nachmittage weiterfuhren, machte sich bald die Nähe des Meeres durch eine an- 
genehme, starke Brise bemerkbar, welche für uns sehr wohlthuend war. Wir passierten eine ganze Reihe von Dörfern, in denen das Dualla-Element sofort als das herrschende zu erkennen war. Längs der Ufer batten die Eingeborenen schmale Streifen des niedriger gelegenen Landes mit Koko (Xanthosoma), Manihot und Mais be-pflanzt; man erkannte sehr schnell, dafs man es hier nicht mehr mit einem der Buschvölker zu thun hatte. An seichteren Stellen waren Reusen zum Fangen von Fischen aufgestellt, und häufig sah man Kinder und Weiber in kleinen Canoes dabei beschäftigt, Fische zu fangen. Gegen Abend sahen wir die ersten Mangroren und erreichten gleich danach die Mungo-Dörfer, in deren gröfstem ich für die Nacht zu kampieren gedachte. Die Eingeborenen (Duallas), welche uns sogleich am Strande umringten, zeichneten sich durch Unverschämtheit und Frechheit aus. Als ich den sogenannten König zu sprechen verlangte, hiefs es, dafs derselbe abwesend sei, aber bald zurückerwartet werde. Ich versuchte nun, einen Führer zu engagieren, welcher uns durch die unzähligen Mangroven-Creeks bis N'Bamba bringen sollte, doch stellten die Leute derartig hohe Becling'ungen, dafs ich alle weiteren Verhandlungen abbrach und energisch forderte, dafs man den "König" sofort rufe. Als die unverschämte Gesellschaft nun einsah, dafs sie sich ihre Chancen verscherzt hatte, berieten sie sich eine Zeit lang und schickten dann ein Canoe ab, welches, wie sie sagten, den König von meiner Anwesenheit in Kenntuis setzen sollte. Am Abend kam derselbe endlich an, als ich bei meinem Abendessen safs. Um ihm zu zeigen, dafs er mit mir nicht so umspringen könne; wie seine Leute zu glauben schienen, liefs ich ihn erst eine geraume Zeit warten, bis ich mit Essen fertig war, dann beschwerte ich mich über das freche Benehmen seiner Leute und riet ihm, ihnen zu sagen, dafs sie sich besser vorsehen müfsten, sonst könnten sie eventuell den Kürzeren ziehen. Als Führer verlangte ich dann von ihm einen jungen Mann für eine ron mir festgesetzte Bezahlung. Nach einem furchtbar langweiligen Palaver, das bis in die Nacht hinein währte, einigten wir uns schliefslich darauf, dafs er seinen Solın, welcher die Creeks gut kannte, als Führer mitgeben solle, wofür ich 4 Mk. zu zahlen hatte. Ein Geschenk, das mir der Kerl noch am Abend sandte, schickte ich wieder zurück, indem ich ihm sagen liefs, dafs ich mit dem unverschämten Benehmen seiner Leute nicht zufrieden gewesen, und da er als „König“ dafür verantwortlich sei, wolle ich auch mit ilım keine Geschenke tauschen. Meine Leute hatten das Canoe an einer steilen Bank an beiden Seiten festgelegt, damit durch den Wechsel von Elbbe und Flut nicht Unheil entstände. Ich hatte mich in das Canoe auf die Lasten während der Nacht zum Schlafen vieder- 
gestreckt, erwachte aber plötzlich durch einen eigentïmlichen Ruck und sah nun zu meinem Schrecken, dafs die Leute das Fahrzeng zu kurz angebunden hatten, so dafs dasselbe, da die Ebbe eingetreten war, in freier Luft umherhing und, für mich um so unangenehmer, vollständig schief, denn die eine Seite war auf einer vorspringenden Baumwurzel hängen geblieben. Ich durfte mich nun nicht eher rühren, als bis es mir gelungen, einige meiner Leute heranzurufen, mit deren Hülfe ich das Canoe ins Wasser herablassen konnte und so aus der unangenehmen Lage befreit wurde.

Mit Sonnenaufgang liels ich am nächsten Tage abfahren, froh, von dieser Gesellschaft von Duallas Abschied nehmen zu können. Die Vegetation, welche wir anfangs vor uns hatten, bestand aus einer Übergangsvegetation, ehe wir in die Gebiete kamen, in denen wir nur die typische Mangroven-Formation vor uns hatten. Wiederholt sahen wir Krokodile, welche bei unserer Annäherung schleunigst sich unsichtbar machten. Hätten wir den Führer nicht bei uns g'ehabt, so hätten wir uns sicher in diesen Creeks verirrt, ein solches Labyrinth von Wasserläufen hatten wir zu durchfahren. Wiederholt schien es, als sei ein Tornado im Anzuge, der für uns sehr unangenehm werden konnte, da wir nirgends anlegen konnten. Als wir über den grofsen Möven-See fuhren, brach auch wirklich ein kleiner Sturm aus, der uns zwang, eine Zeit lang das Canoe zwischen die Mangroven zu bringen, da wir sonst unfehlbar umgeworfen worden wären. Bald erschien jedoch die Sonne wieder, so dafs wir ohne grofsen Zeitverlust unsere Reise fortsetzen konnten. Eine solche Fahrt von einigen Stunden zwischen Mangrovengebüschen hindurch gehört zu den langweiligsten Toureu, welche man je unternehmen kann. Nichts als stets dieselben Rhizophoraceen und Avicennien, selten aufser Krokodilen ein lebendes Tier, höchstens bier und dort einige behend entfliehende Meerkatzen zu sehen, dazu die schwere, drückende Luft des Morastes und meist eine furchtbare Hitze, das sind die Erinnerungeu, welche ich von allen derartigen Touren mit heimgenommen habe. Doch auch diese Fahrt erreichte ibr Ende. Gegen Mittag kamen wir vor der Nikol-Insel in der Nähe des Dorfes Dikulu in die offene See. Da meine Leute recht ungeübte Ruderer waren, war die Fahrt nicht ungefährlich, denn auf dem Wasser stand eine steife Brise, welche ziemlich hohe Wellen erzeugte; wir konnten uns auch nicht der Küste zu sehr nähern, da längs derselben grofse Mengen von Felsen zerstreut waren. Vor der Dikulu-Bucht liefs ich einmal zwischen den Felsen hindurch an das Land heranfahren, um kurze Zeit daselbst zu verweilen, denn wir hatten noch nichts genossen, und ich wollte schnell etwas Essen für die Leute kochen lassen. Nizch etwa einstündigem 
Aufenthalte fuhren wir ïber die Dikulu-Bucht hinüber und bogen dann um die nächste Spitze in die schöne Bimbia-Bucht ein, in der wir gegen $4 \mathrm{Uhr}$ bei N'Bamba landeten. Herr Rehbein, der Tertreter des Herrn Friederici, war zufällig in dem Hause, so dafs ich sogleich mit ihm die nötigen Arrangements betreffs Beförderung meiner Lasten nach Victoria treffen konnte. Er war so freundlich, die Sachen zu ïbernehmeu und am nächsten Tage, einem somutage, die Lasten durch einige Yaunde-Arbeiter unter Führung eines meiner Jungen, den ich zu dem Zwecke in N'Bamba zurückliefs, nachzuschicken. Die vier in Mundame gemieteten Leute und der Führer aus den Mungo-Dörfern sollten am nächsten Tage das Canoe nach Kamerun bringen, um es daselbst bei der Faktorei von Jantzen \& Thormählen abzugeben. Ich selbst ging mit einem Jungen und mit einem Träger noch am Nachmittag nach Victoria weiter über Land. In Victoria traf ich dann am Abend ein, froh, dafs alles so glücklich abgelaufen war. Leider wurde ich daselbst gleich mit einer Nachricht empfangen, welche mich tief erschütterte, Plehn sei auf seiner Expedition nach den Gegenden des Yong durch einen vergifteten Pfeil getötet worden. Fast wollte ich meinen Uhren nicht trauen, als ich das hörte. Welch ein Schicksalsschlag war das wieder für die Kolonie, wieder war einer der tüchtigsten Beamten verloren, der nicht so leicht zu ersetzen sein wird, denn Ir. l'lehn hatte unter den so schwierigen Verhältnissen die SangaNgoko-Expedition in einer Weise geführt, dals selbst seine Neider ihm ihre Bewunderung nicht versagen kounten.

Füı die nächste Zeit war ich nun leider an Victoria gebunden, da sich keine Gelegenheit bot, nach dem Siiden zu gelangen. Es war höchst unangenehm für mich, immer mehr von meiner kostbaren Zeit durch unnützes Warten in dieser Weise zu verlieren. Ich benutzte daher die Zeit mit Einpacken eines grofsen Teiles meiner Lasten für Togo sowohl, als auch aller nun überflüssigen für Europa. Am 8. Februar kam endlich die "Nachtigal" ron Kamerun mit der Strafexpedition des Herru Hauptmann v. Besser, welche, von Victoria aus ins Innere marschierend, erst die Bangwa, die Mörder des Herrn Conrau, bestrafen und dann nach den CrossSchnellen vorgehen sollte, wo die Eingeborenen den Leutnant v. Queil's niedergemacht hatten. Am 10. Februar benutzte ich die Gelegenheit, mit der "Nachtigal“ nach Kamerun zu fahren, vou wo aus ich eber Gelegenheit, nach dem Süden zu kommen, erhoffen konnte. Bei dem Vertreter der Firma Jantzen \& Thormählen, welche mich in jeder Weise während meines Aufenthaltes in Kamerun unterstützt hatte, fand ich Aufnahme für die Zeit meiner gezwungenen Ruhe in Kamerun. Herrn Gouverneur Köhler, welcher den in- 
zwischen nach Europa abgereisten Herrn Gouverneur v. Puttkamer vertrat, stattete ich kurzen Bericht über meine Bakossi-Reise ab und besprach mit ihm die Möglichkeit meiner Togo-Reise, auf der er mich in jeder Weise zu unterstïtzen versprach.

In Kamerun hatte ich während meines damaligen Aufenthaltes Gelegenheit, die äufserst ungünstigen Handelsverhältnisse des Platzes kennen zu lernen, welche durch die malslose Konkurrenz der vielen dort ansässigen Firmen hervorgerufen worden waren. Die Kaufleute hatten zwar unter sich ein Syndikat gebildet, welches den Zweck hatte, die Preise möglichst zu halten, doch konnte sich anch das nicht bewähren.

Der Kautschuk, den ich hier von den Duallas zum Verkauf angeboten sah, bestand aus kleinen Stücken von der Gröfse eines Pfennigs, so dafs man glauben sollte, ein Betrug wäre in solchem Falle nicht möglich. Doch auch hier hatte der schlaue Negerkopf ein Mittel ausfindig gemacht, nit dessen Hülfe er den Europäer betrïgen konnte. Der nasse Kantschuk wurde einfach mit Sand vermischt und dann dem Weifsen erst verkauft. Wenngleich man auch sofort sehen konnte, dafs der Neger dieses Mittel angewendet hatte, um mehr Gewicht in seiner Ware zu erzielen, so wulste man doch nicht zu schätzen, wie viel Sand in der Menge vorhanden war. Deu Kautschuk zurückzuweisen, wäre auch nicht angebracht gewesen, da der Betrüger seine Ware sicher bei einem Konkurrenten abgesetzt hätte. Dals unter solchen Verhältnissen ein Handel in dem Orte Kamerun sich nicht heben kann, muls jedem denkenden Menschen einleuchten. So ist es auch zu erklären, dals die Kaufleute am Kamerun-Flusse klagen, dal's sie nichts verdienen, während ihre Kollegen an der Südküste bedeutenden Gewinn, besonders aus dem Kautschukhandel, erzielen sollen.

Nachdem ich eine volle Woche umsonst in Kamerun gewartet hatte, bot sich mir endlich am 16. Februar eine Gelegenheit, die Reise nach der Südküste zu machen. Wie bedauerte ich damals, dals ich mich nicht länger im Bakossi-Gebiete oder in der Umgegend aufgehalten hatte, statt hier in Kamerun so lange fast zwecklos umhersitzen zu müssen. Doch ich war zur Küste gekommen, da ich unter dem Eindrucke war, dafs mich die "Nachtigal" nach dem Südeu bringen sollte.

Es sollte offenbar alles wicht recht gehen, denn erstens kam der englische Dampfer, welcher für die Fahrt nach dem Süden bestimmt war, nicht vor dem 17. Februar fort, zweitens aber sollte er, was sonst fast nie vorkam, die sämtlichen kleinen Plätze vor Grols-Batanga besuchen, um dort Fracht zu löschen; ich konnte also nicht erwarten, vor dem 20. Februar in Grols-Batanga einzu- 
treffen, während ich unter den gewöhnlichen Umständen dort bereits einige Stunden nach der Abfahrt von Kamerun angelangt wäre. Was half es, ich hatte mich zu fügen. Ob ich bis nach Campo kommen würde, wie ich ursprünglich beabsichtigte, war eine Frage der Umstände, die sich erst später ergeben mufste; ich hatte allerdings sehr geringe Hoffnung, das alles noch bis Ende des Monats ausführen zu können.

Am 17. Februar lichtete die "Lagos" die Anker und begann die Reise flufsabwärts nach der Mündung des Kamerun-Flusses. Um Kap Swellaba herum dampften wir in die offene See hinaus, um uns dann bald wieder der Kü̈ste zu nähern. Bei Klein-Batanga waren wir so nahe derselben, dafs wir ohne Fernglas mit Leichtigkeit die Hänser zählen konnten. Nur langsam kamen wir fort, da es auf der See etwas neblig wurde, bis wir gegen 4 Uhr vor Longji zu Anker gingen. Da wir in ziemlicher Entfernung von der Küste lagen, war gar nicht daran zu denken, noch an demselben Tage den Cargo für diesen Küstenplatz zu löschen. Wir blieben daher über Nacht liegen, um am 18. Februar noch den Rest der Ladung. für Longji an Land zu schaffen. Erst gegen $11 \mathrm{Uhr}$ konnten wir wieder abdampfen. In Plantation, einer kleinen Handelsniederlassung, welche wir von Longji aus bereits mit Leichtigkeit sehen konnten, wurde wieder angehalten. Hier gab es wieder einen grofsen Cargo auszuladen, so dafs mir der Kapitän sogleich erklärte, dafs er nicht ror Mittag des nächsten Tages abfahren könne. Ich ging an Land. Da in den letzten Jahren sich der Kautschukhandel der Südküste hauptsächlich nach Plantation gezogen hatte, bot der Platz einiges Interessante für mich dar. Ich erfuhr hier Näheres über die Distrikte, aus denen der gröfsere Teil des Kautschuks zu kommen schien, sowie über die Behandlung des gekauften Produktes. $\mathrm{Zu}$ meiner Freude hörte ich, dafs auch hier der gröfste Teil des Produktes in kleinen Stücken exportiert werde, nachdem er vorher noch gereinigt und getrocknet sei. Dem ist es wohl auch zum grofsen Teile zuzuschreiben, dafs der Kautschuk der Südküste im allgemeinen einen besseren Preis auf dem europäischen Markte erzielt, als der vom Kamerun-Flusse exportierte. Nach allem, was ich hier vernahm, scheint ein nicht geringer Teil des von der Südküste stammenden Kautschuks aus weiter Entfernung von der Küste zu .kominen, besonders aus der Gegend hinter Ekbolowa im BuliLande, welche gar nicht sehr weit von dem oberen Dja entfernt sein kann. Über diesen Ort Ekbolowa dürfte wohl auch in späterer Zeit, wenu wir erst das Hinterland von Kamerun mehr geöffnet haben werden, sich ein nicht unbedeutender Handel mit den NgokoRegionen entwickeln. Dafs bereits einige Artikel auf diesem Wege 


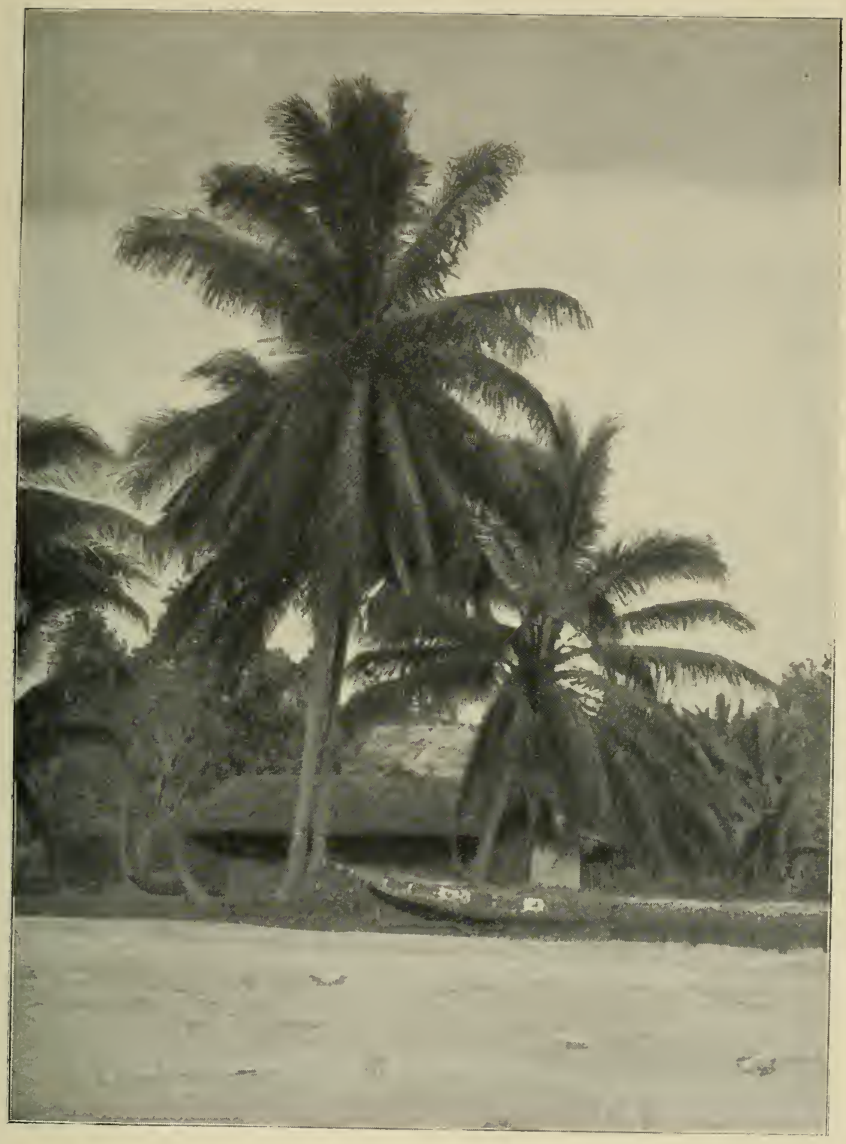

Cocos-Palmen in Gr. Batanga. 

von Hand zu Hand bis in die Ngoko-Regionen vorgedrungen sind, ist durch ein Gewehr erwiesen, welches Dr. Plehn aus Kunabembe erhielt, das nachweislich von einer Firma an der Südküste in den Handel gebracht worden war.

Wie unser Kapitän versprochen, fuhren wir gegen Mittag am 19. Februar von Plantation ab. Bei Kribi dampften wir vorbei und warfen vor einer sehr kleinen Niederlassung, Wasserfall mit Namen, Anker. Von Kribi aus hatte man bereits den Dampfer bei Plantation gesehen und als den englischen erkannt, daher waren einige Herren zu Fufs von Kribi nach Wasserfall gelaufen, um dort ihre Post an Bord des Dampfers zu empfangen. Wir erhielten infolgedessen am Nachmittage reichlichen Besuch. Unter anderen erschien auch Herr Mager, der Vertreter des Herrn K ̈̈derling, welchen ich vor allen Dingen zu sehen wünschte, da es meine Absicht war, die Plantage der Firma K üderling \& Co. in Campo zu besichtigen. Mit Herrn Mager arrangierte ich natürlich sofort das Nötige, um eventuell ohne Zeitverlust nach Campo zu kommen. Da Herr Mager noch am späten Abend an Land ging, verabredeten wir, dafs wir uns am nächsten Tage in Grofs-Batanga wiedersehen wollten, wo mich Herr Mager von dem Dampfer abholen sollte. Herr Mefsner, der Vertreter der Firma Lübke \& Co., war so freundlich, mir in Grofs-Batanga in seinem Hause Unterkunft anzu. bieten.

Als ich am Morgen des 20. Februar erwachte, lagen wir bereits vor Grofs-Batanga. Herrn Mager mit seinem Boote konnte ich auch kurz darauf erspähen. Schon um $7 \mathrm{Uhr}$ fuhr ich mit dem Schiffsdoktor und Herrn Mager an Land, wo ich mich der Verabredung gemäls bei Herrn Melsner einquartierte. Grols-Batanga hatte ich schon früher einmal, als ich auf der Reise nach dem Congo war, betreten, doch jetzt entrollte sich vor meinen Augen ein ganz anderes Bild als damals, als ich nur für eine Stunde in der Woermaunschen Faktorei mich aufgehalten hatte. Erst jetzt lernte ich die verschiedenen Faktoreien kennen, von denen allerdings die, in der ich wohnte, die stattlichste und bedeutendste schien. Am Nachmittage machte ich mit Herrn Mager und Herrn Mefsuer einen Rundgang längs des Strandes in den verschiedenen Faktoreien. Wir hatten beschlossen, noch am Abend desselben Tages nach Campo aufzubrechen, mufsten diesen Plan aber aufgeben, da die zu diesem Zwecke engagierten Leute nicht erschienen. Um denselben Übelstand am nächsten Tage zu verhüten, lielsen wir den alten Häuptling des Dorfes bei Grofs-Batanga rufen und trugen ihm nun ernstlich auf, bei Zeiten für die Leute zu sorgen, welche uns nach Campo rudern sollten. Als dieselben dann auch wirklich am Nach- 
mittag erschienen, wurden sie bis zu unserer Abfahrt in der Faktorei zurückgehalten.

Vor Jahren hatte Herr Küderling in Grols-Batanga einige Manihot Glaziovii-Stämme ausgesät, die unterdessen zu einer bedeutenden Gröfse herangewachsen waren. Da mir daran lag, zu erfahren, wie sich dieser Kautschukbaum in den südliclıen Distrikten unseres Schutzgebietes bewähren dürfte, zapfte ich die vorhandenen Exemplare an. Die Nilch, welche ich erhielt, flofs ziemlich reichlich und enthielt bedeutend mehr Kautschuk als in Victoria, ja - sogar so viel, dafs ich glaube, eine Anlage im gröfseren Stiele dürfte sich hier bezahlt machen. Ich setze dabei natürlich voraus, dals eine solche Anlage in der von mir bereits häufig vorgeschlagenen Art bewirtschaftet würde. Anzapfungen mit dem Pickierapparat, wie ich sie hier versuchte, dürften sich an heifsen Tagen, wenn die herausquellende Milch schnell koaguliert, am besten bewähren. Ich bin davon überzeugt, dafs man durch wiederholtes richtiges Anzapfen von den etwa sieben Jabre alten Stämmen im Jahre ein Pfund Kautschuk gewinnen könnte. Wie mir Herr Mager erzählte, hatte Herr Küderling selbst einmal derartige Anzapfungsversuche gemacht, ohne dabei zu guten Resultaten zu gelangen, hatte aber später sich darüber wundern müssen, dafs Eingeborene, welchen er die Erlaubnis gegeben, die Manihotstämme anzuzapfen, gröfsere Quantitäten Kautschuks gebracht hätten.

Am Abend des 21. Februar konnte ich endlich zusammen mit Herrn Mager die Reise nach Campo antreten. Da der Weg längs der Küste nur bei Ebbe zu gebrauchen und sonst auch infolge des tiefen Sandes sehr beschwerlich ist, zogen wir es vor, in einem Boote die Strecke bis Campo zurückzulegen. Da wir hofften, in der Nacht eine günstige Brise zu haben, beschlossen wir, erst spät am Abend abzufahren. Die See war ziemlich unruhig; als wir abfuhren, so dals wir gezwungen waren, sogleich möglichst weit in die See hinauszufahren, um vor den vielen Felsen, welche in der Nähe von Grofs-Batanga längs der Küste liegen, sicher zu sein. Die ersehnte Brise stellte sich zu unserer Enttäuschung aber nicht ein, und wir machten nun, da die Leute rudern mufsten, nur sehr geringe Fortschritte. In der Hoffnung, am Morgen in Sicht von Campo zu sein, legten wir uns im Boote nieder zur Ruhe, waren aber nicht wenig enttäuscht, als wir wieder erwachten, noch nichts von Campo sehen zu können; offenbar hatten unsere Leute im Boote die Gelegenheit benutzt, möglichst faul zu sein. Erst gegen Mittag kam die Landspitze vor dem Campo-Flusse in Sicht, doch begann die See nun auch so hoch zu gehen, dafs wir mehrmals glaubten, in unserem kleinen Boote von einer herannahenden Welle 


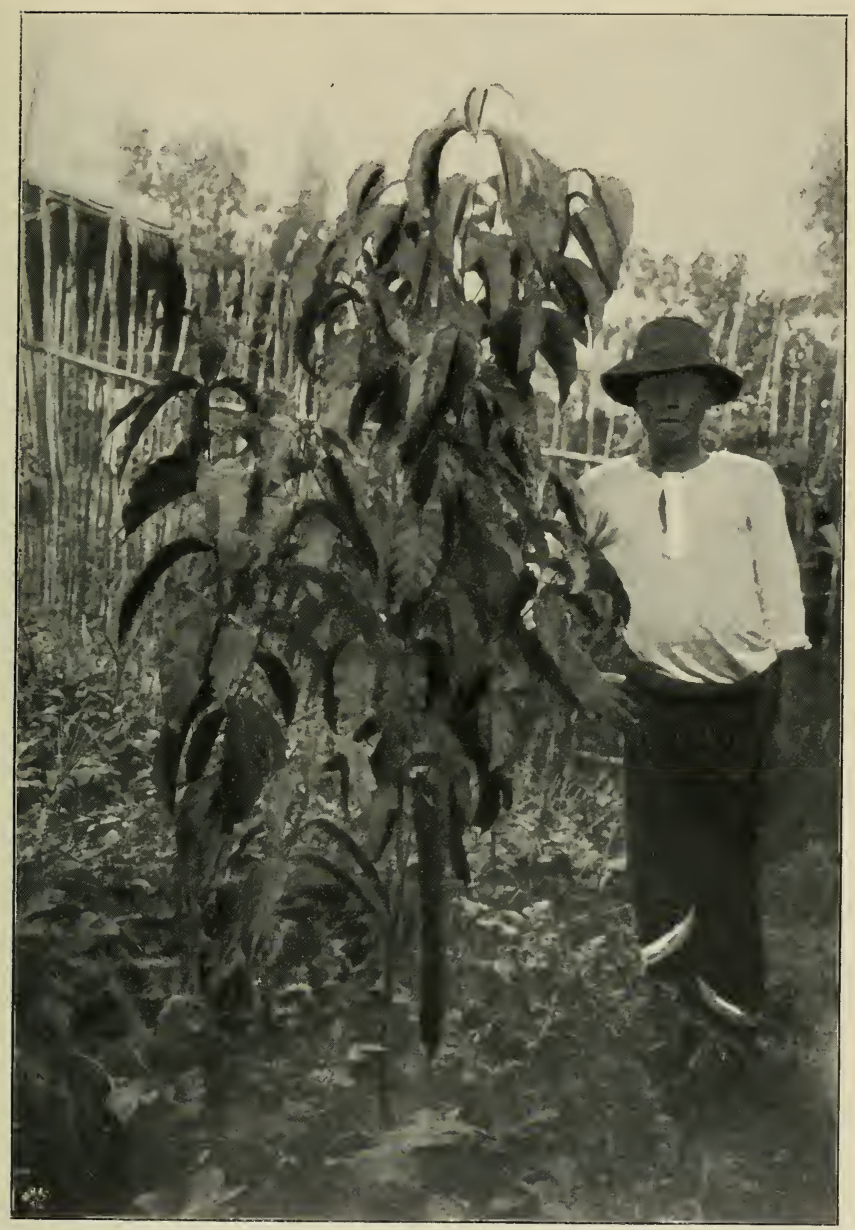

II Monate alte Kickxia auf der Campo-Plantage. 

überschwemmt zu werden. Unsere Lage wurde am Nachmittage sogar so unangenehm, dafs wir Europäer vorzogen, am Lande anzulaufen, um dann über Land den Marsch fortzusetzen. Einen meiner beiden Jungeu nahm ich mit, den anderen liefs ich zurück, damit er dafür sorge, dafs mein Gepäck nicht zu stark von den hereinschlagenden Wellen, denen das uns nachfolgende Boot ausgesetzt war, durchnäfst werde. Der Marsch am Strande entlang war infolge des losen Sandes recht beschwerlich, wurde aber unerträglich, als erst die Flut stieg und wir immer vor den böher steigenden Wellen auszuweichen hatten. Am allerschlimmsten aber wurde unsere Situation, als die Nacht hereinbrach und wir nun zwischen Gebüschen und dem Wasserniveau unseren Weg suchen mufsten. Am späten Abend war schliefslich das Wasser derartig gestiegen, dafs wir gezwungen waren, Schuhe und Socken auszuziehen und mit aufgerollten Hosen im Wasser am Strande entlang unseren Weg suchen mufsten. So angenehm auch die Kühle des Seewassers war, so unangenehm wurde unser Zustand, wenn wir mit den nackten Füfsen auf eine Muschel oder eine hervorstehende Holzspitze traten, denn die Nacht war so dunkel, dafs man fast seine eigene Hand nicht sehen konnte. Herr Mager, welcher kurzsichtig war, lief wiederholt direkt derartig in Büsche und umgefallene Bäume hinein, dafs wir uns wundern mufsten, endlich gegen 1 Uhr beide unversehrt in Campo einzutreffen. In der stattlichen, dort von Herrn Küderling errichteten Faktorei fanden wir alles verschlossen; wie wir hörten, war der Europäer gerade abwesend, um im Innern auf einigen Zweigfaktoreien Inventar aufzunehmen und Kautschuk und Elfenbein aufzukaufen. Zum Glücke hatte der farbige Verwalter des Ladens Schlüssel für einige der Zimmer, so dafs wir noch unter Dach und Fach ein Lager fanden.

Am frühen Morgen war das Boot mit unseren Sachen auch in Campo angelangt und alles bereits auf der Veranda der Faktorei zum Trocknen ausgelegt, als ich um $6 \mathrm{Uhr}$ aus meinem Zimmer heraustrat. Die sämtlichen Lasten waren furchtbar durchnälst. Am Nachmittag fuhr ich zusammen mit Herrn Mager nach der dicht oberhalb am Campo-Flusse gelegenen Plantage des Herrn Küderling, um dort die Kickxia-Anpflanzungen in Augenschein zu nehmen. Die Plantage war recht schön sauber gehalten, nur fiel mir auf, dafs die Schattenbäume fehlten und dafs infolgedessen viele der jungen Triebe an der Spitze verbrannt erschienen. Die Bäumchen trugen sehr reichlich Früchte und wuchsen recht gut, solange sie im Schatten der Bananen standen, welche zur Ernährung der Arbeiter angepflanzt waren. Es wäre sehr wünschenswert, dafs hier in Zukunft viele Schattenbäume beim Schlagen des Waldes 
stehen bleiben, denn das schon an und für sich viel trockenere Klima bedingt nach meiner Ansicht entschieden noch mehr Schatten für Kakaokulturen als das am Fufse des Kamerun-Gebirges hei Tictoria. Herr Küderling hatte, wie bekannt, für seinen Kakao aus dieser Campo-Plantage einst den höchsten Preis bekommen, der je für Kamerun-Kakao erzielt worden ist.

Auch hier in der Campo-Plantage hatte man eine Anzahl ron Manihosttämmen angepflanzt, welche übrigens beim Anzapfen gleichgünstige Resultate lieferten wie die in Grofs-Batanga wachsenden. Aufser einigen mehrere Jahre alten Baumchen von

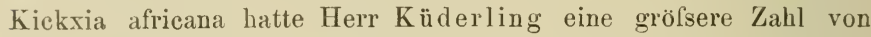
Pflänzchen der Kickxia elastica auspflanzen lassen. Von den Samen, welche er im Januar 1899 von Dr. Preufs erhalten hatte, waren nur drei Pflanzen aufgegangen, welche man nun an Ort und Stelle in dem samenbeete hatte stehen lassen; dieselben hatten sich derartig entwickelt, dals ich ihr Wachstum als ausuahmsweise günstiges bezeichnen mufs. Die jetzt einjährigen Pflanzen waren bereits höher als ein gro!ser Neger. Auf der Campo-Plantage befanden sich viele sumpfige Flächen, die vielleicht mit Hevea brasiliensis bepflanzt werden könnten, dewn in solchen sumpfigen Lokalitäten dürfte die Негеa rielleicht einen reicheren Erfolg liefern als in dem trockenen Boden, in dem sie im botanischen Garten zu Victoria steht. Die ror einigen Monaten ausgepflanzten Kickxien, welche aus Samen rom Mungo gezogen waren, hatte man in gröfseren Abständen in der Kakaoplantage ausgepflanzt. Meiner Ansicht nach dürfte dieser Standort für die Kickxia, welche doch eine Waldpflanze ist, nicht sehr günstig sein, da die Stämme sich dann wahrscheinlich schlecht entwickeln werden und nur kurz bleiben, wie nan das ïbrigens auch schon an den vorhandenen Exemplaren von Kickxia africana beobachten konnte.

Am Abend kehrten wir zur Faktorei nach Campo zurück, um am nächsten Morgen eine Canoefahrt bis zu den Schnellen des Campo-Flusses zu unternehmen, wo Herr Küderling noch eine zweite Plantage hatte anlegen lassen. Wir brachen sehr zeitig auf, um noch vor Beginn der heifsen Tageszeit an unseren Bestimmungsort anzulangen. Anfangs waren die Ufer des Flusses nur mit Mangroven und Avicennien bedeckt, allmäblich traten dann noch andere Pflanzen hinzu, bis schliefslich die Mangroven ganz verschwanden, um hauptsächlich Calamusgestrüppen Platz zu machen. Gegen 9 Uhr kamen wir bei der Plantage an. Dieselbe war in derselben Weise angelegt worden wie diejenige bei Campo. Der Boden schien noch typischerer Laterit zu sein als dort, grofse Glimmerschiefer-Blocke erhoben sich bis ïber die Oberfläche an 
verschiedenen Stellen. Auch hier hatte man leider fast gar nicht für Sichattenbäume gesorgt, und daher konnte ich auch wieder dieselbe Erscheinung wahrnehmen wie auf der Plantage bei Campo: die Spitzen der jungen Triebe schienen von der Sonne verbrannt zu werden. Kickxien hatte man aucb hier angepflanzt, dieselben standen recht gut und versprachen, vorzüglich anzugehen. Im übrigen bot diese Plantage nichts, das ich nicht schon auf der weiter unten bei Campo gelegenen gesehen hatte. Am Nachmittage fuhren wir nach der anf der französischen Seite des Flusses gelegenen Plantage eines Franzosen, der sich dort mit seiner Familie angesiedelt hatte. Es war daselbst aufser Kakao noch Kaflee und Tanille angepflanzt worden, doch machte die ganze Anlage gerade einen recht verwahrlosten Eindruck, den ihr Besitzer der bereits seit längerer Zeit herrschenden Dürre zuschrieb. Die Vanille stand sogar sehr schlecht. Noch gegen Abend kehrten wir dann nach Campo zurïck.

Am nächsten 'Tage fuhren wir nun wieder in einem Boote nach Grofs-Batanga zurück. Da wir eine günstige Brise bekamen, welche uns gestattete, die Segel anfzuspannen, hatten wir eine bedeutend günstigere Fahrt und erreichten Batanga schon am Abend desselben Tages.

Da ich auf keine andere Gielegenheit hoffen konnte, schnell nach Kamerun zurückzukehren, hatte ich beschlossen, am 27. Februar per Boot dorthin abzufahren. Den einen Ruhetag, welchen ich somit hatte, benutzte ich dazu, die Manihotstämme noch einmal anzuzapfen und Samen derselben zu sammeln, deren ich einige tausend erhielt. Als ich am frïhen Morgen des 27. Februar die Bootsleute zur Abfahrt zu rufen auf die Veranda trat, sah ich zu meiner Freude, dafs ein englischer Dampfer, der nach Kamerun gehen sollte, dicht bei uns vor Anker lag. Natürlich liefs ich sofort mein ganzes Gepäck an Bord bringen, um diese Gelegenheit nicht zu versäumen. Gegen $9 \mathrm{Uhr}$ verlief́s ich dann auf der "Boma" diesen Ort, in dessen Umgegend ich mich gern noch länger aufgehalten hätte. Die Fahrt lief sehr glïcklich ab, denn bereits um $5 \mathrm{Uhr}$ warf die "Boma" vor Kamerun Anker, so dafs ich noch an demselben Abend wieder zur Faktorei der Firma Jantzen \& Thormählen übersiedeln kounte.

Bis zum 2. März verblieb ich noch in Kamerun, um dann zusammen mit Herrn Geheimrat Wohltmann, welcher von Edea dort eingetroffen war, auf der "Nachtigal" nach Victoria zu fahren, wo wir der Sitzung des "Vereins Kameruner Pflanzer" beiwohnen wollten. In einem kurzen Vortrage legte ich daselbst den Herren, welche sehr vollzählig erschienen waren, meine Erfahrungen und 
Ansichten noch einmal vor, und versuchte noch einmal, zu einer möglichst energischen Inangriffnahme der Kautschukkultur anzuregen, worin mich Herr Geheimrat Wohltmann, dessen letzte Bedenken nun, da es mir gelungen war, die Kickxia auch auf Basaltboden nachzuweisen, geschwunden waren, sehr energisch unterstützte.

Am 4. März nachmittags erschien der deutsche Postdampfer

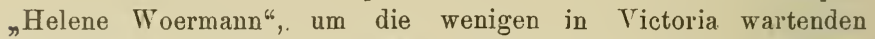
Passagiere noch abzuholen. Mit diesem fuhr ich dann nach Togo ab. Nur ungern nahm ich Abschied von Kamerun, unserer schönsten Kolonie in Afrika, der bei der immensen Fruchtbarkeit, welche fast allenthalben im Gebiete herrscht, sicher eine glänzende Zukunft berorsteht, wenn mit demselben Interesse und derselben Energie wie in den letzten Jahren an ihrer Entwickelung weiter gearbeitet wird. 


\section{Kapitel.}

\section{Togo-Reise und Heimreise.}

Während unserer Fahrt von Kamerun nach Togo hatten wir trotz des vorzüglichen Wetters gleich am Tage nach unserer Abreise von Victoria leider den Tod eines unserer Mitpassagiere zu beklagen, der bereits in sehr bedenklichem Zustande Kamerun verlassen hatte. In Lagos trafen wir am Morgen des 6. März ein und rerblieben daselbst bis zum späten Nachmittag. Als ich am folgenden Tage an Deck erschien, waren wir bereits vor KleinPopo. Herr Wöckel, welcher Herrn Geheimrat Wohltmann auf seiner Rückreise nach Europa noch Lebewohl sagen wollte, kam hier zu uns an Bord. Von ihm erfuhr ich interessante Thatsachen über die Manihot Glaziovii-Anpflanzungen, welche er als Leiter der Plantage Kemme hatte anlegen lassen. Nach kurzem Aufenthalte in Klein-Popo dampften wir nach Lome weiter. Von Herrn Geheimrat Wohltmann nahm ich dort Abschied und begab mich mit meinem gesamten Gepäck an Land, wo ich in der Bremer Faktorei, den vorherigen Abmachungen gemäls, bereits eine vollzählige Trägerkolonne zu meiner Verfügung zu finden hoffte. Herr Luther, der Agent der Firma, nahm mich sehr liebenswürdig auf und erklärte mir nun, dafs er, soweit es möglich war, alles vorbereitet habe, auch Träger seien da, welche bis Misahöhe mitgehen sollten. Ich liefs daraufhin sofort die Leute zusammenrufen und antreten. Mir schien die ganze Geschichte von Anfang an nicht sicher genug. Nach einigem Palaver einigten wir uns schliefslich, doch kam es mir so vor, als ob einige der Leute unwillig seien, mit einem ihnen unbekannten Europäer zu gehen. Der Sicherheit halber sagte ich den Leuten, dafs sie am Abend noch einmal antreten sollten.

Am Nachmittage machte ich Besuch bei dem stellvertretenden Gouverneur, Herrn Assessor Heim. Man bezweifelte damals sehr stark an der Küste, ob es mir gelingen würde, in der kurzen Zeit, welche mir zur Verfügung stand, bis nach Boëm hineinzukommen, wo ich das von Herrn Assessor Hupfeld für Herrn Sholto 
Douglas angekiufte Terrain besichtigen wollte. Da ich selbst mir wohl bewufst war, dals ich keine Zeit zu verlieren habe, wäre mir eine Verzögerung meiner Abreise von Lome äulserst unangenehm gewesen, daher geriet ich in nicht gerade die beste Stimmung als bereits am Abend von den Trägern verschiedene fehlten: sie seien bereits wieder in ihre Heimat zurückgekehrt, liefs es. Da wir diese entlaufenen Leute schwerlich wärden ersetzen können, erwartete ich schon mit Schrecken die Dinge, welche ich am nächsten Tage würde auszufechten haben, da ich doch durchaus aufbrechen mufste.

Wie ich es nicht anders erwartet hatte, erschienen am nächsten Morgen \& Leute statt der 15, welche eigentlich zur Stelle sein sollten. Ich liefs nun nach allen Seiten in der Stadt herum wach Trägern suchen, denn so viel sagte ich mir, dals der ganze Tag verloren sein würde, wenn ich nicht bis Mittag unterwegs sein könnte. Nach verschiedenen Stunden Wartens hatte ich denn glücklich 12 'Träger beisammen, aufser meinern Jungen, Afue, und einem „Headman", den ich mir unter den Trägern ausgesucht hatte. Um 10 Uhr endlich konnte ich aufbrechen. Noch in Lome sellost kam mir der Gourernementsgärtner, Merr Warnecke, welcher den Versuchsgarten bei Lome leitete, entgegen und bat mich, doch in dem Garten eine kurze Zeit zu verweilen, da er eine Anzahl Wardscher Kästen mit Kautschukpflanzen nach dem Ag'u zu senden habe, welche er gern unter Schutz eines Europäers abschicken würde. Ich erklärte mich bereit, die Kästchen nach der Douglasschen Plantage am Agu mitzunehmen, vorausgesetzt, dals er die Träger stellen könte. Da auch diese Frage ron ihm bereits erledigt war, nahm ich die vier 'Träger mit den Pflanzen an Versuchsgarten mit in meiner Karawane auf. Die Vegetation bei Lome macht auf jeden Nichtbotaniker anfang's einen recht dürftigen Eindruck, denn wo nicht von Menschenhand Kokospalmen gepflanzt sind, bringt der schmale Sandgürtel, welcher sich längs der Küste hinzieht, nur kleine Sträucher und dürftige Kräuter hervor, die an feuchteren Stellen mit einer kurzen, halophilen Vegetation abwechseln, wie wan sie an der Meeresküste sämtlicher tropischen und subtropischen Regionen allgemein kennt. Hat man diesen sandigen Küstenstreifen durchzogen, so gelangt man zunächst in ein Terrain, das sich nur sehr langsam etwas hebt und fast ausschliefslich aus einem roten, ziemlich sterilen Laterit geisildet wird. Dafs sich auf diesem Boden nicht bedeutende Kulturen entwickeln werden, wie man sie im Inwern häufig antrifft, liegt klar auf der Hand. Aber dessenuugeachtet sollte die Regierung darauf hinarbeiten, dals auch diese 
ausgedehnten Teile zur Verwertung kommen. Das könnte aber nur durch Aufforstungen oder durch Anpflanzungen von nützlichen Gewächsen geschehen, welche für eine derartige Buschsteppe geeignet sind. Bei der Frage der Aufforstung kämen hauptsächlich australische Acacia- und Eucalyptus-Arten in Betracht, deren Holz sich dann auch noch gut verwerten liefse, was für Lome, das jetzt schon mit Holz sehr schlecht bestellt ist, von grolsem Nutzen sein würde. Von anderen nützlichen Pflanzen, welche sich aufserdem hier in den Steppen hinter Lome als auch besonders im Innern gut bewähren dürften, möchte ich auch noch Acacia Verek erwähnen. die durch Lieferung eines guten Gummi arabicum in Senegambien zu den hauptsächlichsten Nutzpflanzen zählt. Ein anderer Weg; die Steppen Togos nutzbar zu machen, würde durch Anpflanzungen vón Manihot Glaziovii angebahnt werden. Die Samen derselben wären leicht aus nächster Nähe zu beschaffen und könnten in den Steppen, besonders da, wo diese durch vorgelagerte Waldungen oder Ḧ̈gelketten vor zu starken Winden geschützt sind, von Eingeborenen ausgestreut oder eventuell in gewissen Abständen in den Boden gesteckt und sich dann völlig selbst überlassen werden. so würde man mit geringen Kosten allmählich eine gewisse Aufforstung der Gebiete erzielen, aus denen dann nicht unerhebliche Quantititen Kautschuk gewonnen werden könnten. Wie mir Herr Wöckel versicherte, wächst Manihot bei Kpeme derartig schnell und verbreitet sich dort in solchem Mafse, selbst ohne Pflege, dafs man sich dort längst daran gewöhnt habe, es als Unkraut zu betrachten. Ich weil's, dals mir hierauf geantwortet werden könnte, dal's die Pflanze nur wenig Kautschuk gebe und aufserdem bei Stïrmen sehr leicht umgebrochen werde. Darauf möchte ich erwidern, dais derartige Pflanzungen, so dicht gewisse Strecken bedeckend, dem Winde wohl genïgend Widerstand entgegensetzen würden, dafs aufserdem aber die zur Aufforstung der Steppen nötigen Kapitalien so gering sein w ̈̈rden, wenn dieses mit Manihot geschieht, dals selbst ein sehr geringer Ertrag der Stämme gewinnbringend sein mülste; zum Überflusse aber ist nicht zu vergessen, dafs eine Aufforstuug dieser Steppengegenden auf die klimatischen Verhältnisse des Landes auch einen nicht unbedeutenden Einflufs ausüben würde, wenn sie in gröfserem Mafse betrieben würde. Ganz besonder's geeignet für derartige Anpflauzungen halte ich die Steppen zwischen Assaun und dem Agome-Gebirge, sowie die der Landschaft Agotime, soweit sie nicht an zu grofser Bodenfeuchtigkeit leiden. Sind einmal grölsere Gebiete in dieser Weise bepflanzt, so könnten dieselben leicht in Parzellen gestellt werden, welche dann an einzelne Negerfamilien 
von der Regierung verpachtet werden müssten. Diese Leute würden dann schon selbst dafür sorgen, dafs sie nicht von unberufener Hand geschädigt werden. Um aber ein zu rabiates Anzapfen seitens der Pächter zu verhüten, könnte man Inspektoren in diesen Distrikten herumschicken, welche alljährlich einige Male deu Zustand der Pflanzungen in Angenschein nehmen und, wo es nötig ist, in irgend einer Weise gegen Beschädigung der Bestände einschreiten müfsten. In dieser Weise betrieben, dürfte sich eine Plantage voll Manihot Glaziorii sehr wohl bewähren, und so allein scheint mir ein derartiges Unternehmen rentabel zu sein. Bei den durchaus nicht ungünstigen Arbeiterverhältnissen in Togo, mit Ausnahme der Küstenbezirke, dürfte es rler Regierung ein Leichtes sein, die verschiedenen Stationsleiter zur Anlage solcher Manihotpflanzungen zu bewegen. Die dem Lande auch sonst viel Unheil bringenden Grasbrändr müfsten in der Nähe dieser Bestände natürlich strengstens verboten werden. Für die Kolonie wären derartige Bestände von immensem Vorteil, und deshalb sollten von der Regierung oder von einem gemeinnützigen Komitee Schritte gethan werden, eine derartige Aufforstung der Steppengebiete anzubahnen. Da wir glücklicherweise in Togo derartig zu den Eingeborenen stehen, dafs in den meisten Distrikten eine Aufforderung seitens der Stationsleiter genügt, um die Dörfer zur Stellung von Arbeitern zn veranlassen, so dürften die Kosten einer solchen Anpflanzung sich als sehr geringe Summen erweisen, weun man bedenkt, welchen Nutzen die Kolonie in späteren Jahren darans ziehen könnte.

Herr Warnecke begleitete mich noch eine kurze Strecke durch die Buschsteppe, um mir daselbst einige ihm interessant erscheinende Pflanzen zu zeigen, dann sprengte ich auf meinem netten Pferdchen, welches früher Herrn Mischlich aus Kete-Kratschi gehört hatte und den Ruf grofser Zähigkeit und Ausdauer genofs, meinen Leuten nach, welche num bereits eine gute Strecke vorausmarschiert waren. Als wir uns weiter von der Küste entfernten, nahm die Buschsteppe allmählich einen etwas anderen Charakter an. Die höher aufschiefsenden Sträucher bewiesen, dals der Boden etwas fruchtbarer wurde, auch einjährige Kräuter zeigten sich häufiger, und hier und lort salı man auch schon etwas Gras. Gegen 2 Uhr liefs ich eine kurz. Rast machen, als wir bei einigen Markthütten vorbeikamen, um den Leuten \%eit zu geben, sich einige Nahrungsmittel zu kaufen. Bevol wir nach Akeppe kamen, hatte die Buschsteppe sich allmählich vollständig verändert, Gräser traten in grofsen Mengen auf, der berleutend fruchtbarere Boden trug viele Ölpalmen, von denen übrigens ein nicht geringer Teil von den Eingeborenen gepflanzt 
wurde. Zu beiden Seiten des Weges lagen viele Farmdörfer. Fs war hier interessant zu sehen, welche plötzliche Umwandlung der Vegetation in diesen Steppen ein Regen zur Folge hat. Etwa eine Woche ror meiner Ankunft in Togo war nämlich in dem MisahöheDistrikte mul einem Teile des Lome-Bezirks ein Gewitterregen gefallen, weleher sich aber nicht südlicher als etwa eine Stunde vor Akeppe hinzog. Während das ganze Gebiet südlich dieser Küstenzone vollständig dïrr aussah, war in ılem gesamten Gebiete nördlich davon der prächtigste Graswuchs zu finden, aus dem sich häufig die bis 5 Fufs hohen Stengel der Eulophia (Lissochilus) eristata mit ihren prächtigen Blüten hervorhoben. Die Sträucher und Bämms waren zum grofsen Teile in Blütenflor, die ganze Landschaft bot einen überaus frischen und für das Auge eines Botanikers äulserst fesselnden Aublick dar. Dieses Gebiet vor Akeppe wird von ren Einwohnem dieser Gegenden recht eifrig bearbeitet. Es ist sehr interessant zu sehen, mit welchem Eifer die Leute daselbst ihre Palmenplantagen anlegen und ihre Maniokfelder bestellen. Ich will ührigens hier gleich erwähnen, dafs ich nur äulserst selten in Westafrika Ölpalmenplantagen gesehen habe, bei weitem ıler gröfste Teil des in ilen Handel kommenden Palmenöles und der Palmenkerne wird, entgegen einer offenbar verbreiteten Ansicht, dals ،lie Ölpalme nur noch kultiviert orler verwildert in Afrika vorkomme, von vollständig wilden Exemplaren gewonnen. An einigen wenigen Stellen vor Akeppe sah ich schon Baumwolle angebaut, aber noch recht spärlich und ohne viel Verständnis angepflanzt. In Akeppe zogen wir gegen 4 Uhr nachmittags ein.

In der Nacht wurle ich durch einen grofsen Lärm aufgeweckt, welchen meine Lente machten. Als ich mich nach der Ursache desselben erkmudigte, hörte ich, dafs sie ron Ameisen überfallen seien; nun gewahrte ich auch zu meinem Schrecken, dafs auch in meinem Hause anf dem Boden Ameisen in grofser /ahl umherliefen; dafs die Tiere mich noch nicht angegriffen hatten, war dem etwa $1 \frac{1}{2}$ Fufs über dem Frdboden erhabenen Feldbett zu verdanken. Un sie zu verscheuchen, liefs ich nun, nachdem ich das ganze Haus tüchtig hatte auskehren lassen, zwei grofse Fener anmachen, die dann auch den gewünschten Erfolg brachten.

Schon früh am Morgen des 9. März liefs ich wieder aufbrechen. Etwa nach einer halben Stunde Marsch, teils durch Gebüsch, teils durch Steppengebiet, gelangten wir nach Noeppe. Die Steppen sind von hier ab mehr oder minder dicht mit Bäumen bervachsen und erhielten dadurch einen Anblick, welcher mich sehr an ähnliche Bammsteppen in Transvaal nnd besonders Mozambique erinnerte, 
ein Eindruck, der noch dadurch erhöht wurde, dafs dic Vegetation sich zmn grofsen Teile aus verwandten Pflanzen zusanmensetzte. In Noeppe liefs ich eine kurze Rast machen, um zu versuchen, einen andern Träger zu erwerben als Ersatz für einen Mam, weleher mir in ter Nacht entflohen war. Leider sah ich aber ball ein, lals ich in diesem Dorfe nieht die geringste Anssicht anf Erfolg haben wïrle, und zog daher bald wieder ab. Von Noeppe an hatten wir eine riesige Baumsteppe vor ms, welche nur an len jetzt noch trockenen, in der Regenzeit aber ziemliche Dimensionen annehmenten Wasserläufen von dichten Gebüschen oder schmalen Waldstreifen durchzogen war. Da viele der Kräuter unı Bäume zur \%eit in Blüte staurlen, war mir diese Steppe sehr interessant. Die grofsen weifsen Bhïten eines Cyenium waren sehr hänfig zu sehen. Hier und da rrhob sich einer jener wunderschönen Stengel der Enlophia cristata aus dem Grase, nicht selten in Gemeinschaft mit den grïngelben tütenförmigen Inflorescenzen ainex Amorphophallusart. Unter den Bäumen traten besonters Terminalia-Arten unel eine Bignoniaces mit zierlichen Trauben rosenroter Blüten hervor. Weiterhin gesellte sich zu diesen noch der Butterbaum, der schliefslich immer häutiger werden sollte, je melu wir in das Land hineinkamen. Inmitten dieser Steppen traf ich ganz merwartet mit eincr grölseren Trägerkolonm zusammen, an deren Lasten ich sofort erkemnen komnte, dafs ein Europäer in ter Nähw sein müsse, unel richtig, balel darauf traf ich mit dem Regierungsarzt Herm Dr. Wentlland zusimmen. Ton ihm konnte ich rinige Erkundigmugen äher dlen Kustand ler Wege unt die augenblicklichen \%ustämle an Agu- nut AgomeGebirge einziehen, von denen 'r eben zurïekkehrte. \%u meiner Freude lörts ich auch, lals die Wege immer besser werten sollten, je weiter man sich ron Lome entferne. Ciegen 11 Uhr erreichten wir Badja, ein Dorf ron ziemlicher Ausdehnung, wo ich meinen Lesuten \%eit zum Mittagessen greben wollte. Unter schönen Fiensbäumen lagertens wir mos. Anch hier in Batja hatte ich keinen brfolg im Anwerlex von Trägern. Häte ich allerelings damals die \%ustäule in 'Togo so gekannt wio später, als ich wieder durch Barlja zog, damn wäre ich wohl sicher in meinen Bemïhumgen rrolgreicher gewesen. Hirre gab es anch etwas frumera-Korn als Futter für mein P’orel zu kanfen, tas sich selhneller daran zu gewöhnen sehien, als an den Mais. Nach etwa dreistïndiger Rast brachen wir wieder auf. Die mächtige Bamnsteppe setate sich linter Badja weiter fort, die Vegetation blieb dirselbe wie zuvor, hier und dort gesellten sich zur Eulophia cristata noch andere auffallende Orehidaceen derselben (iattung, wie \%. B. 
die wundervolle Eulophia dilecta und die kleine Eulophia flava. Die Gräser bestanden meist aus niedrigen Arten, die fast alle ein gutes Viehfutter abgeben würlen. Es stimmte mich oft traurig, wemn ich sah, dafs in diesen Gegenden kein Grofsvieh gehalten werden kann, da die Tsetsefliege die Bestände in kurzer Zeit vernichten würde. Es kam mir damals unwillkürlich der Gedankr, dals es doch von riesigem Nutzen für die Kolonie sein mülste, wenn ein tüchtiger und erfahrener Tierarzt zum Zwecke des Studiums der durch die Tsetse hervorgerufenen Krankheit und der Verbreitung. dieses Übels nach Togo entsendet werden würde, damit mns nun endlich einmal Näheres über diese für die fernere Entwickelnng dles Landes äufserst wichtigen Punkte bekannt würde. Welel ein kolossaler Vorteil läge zmm Beispiel schon allein darin, wenn wir einmal im stande wären, von Lome bis zum Agnt- und AgomeGebirge statt durch teure und unzurerlässige Träger die Lasten in Ochsenwagen oder Manltierwagen $\mathrm{zu}$ befördern. Das Jand ist mit Ansnahme einiger Wellungen vollständig ehen und wïrıle sich zur Anlage einer Falırstrafse vorzüglich eignen, zudem wäre Futter für die Zugtiere in reichem Mafse in den Steppen rorhanden. Wenn wir dereinst die genane Verbreitung der Tsetsefliege von Togo kennen werden, die sicher in vielen fegenden des Schutzgebietes eine äufserst lokale ist, damn werden wir wahrscheinlich Zugtiere, wie Ochsen, Pferde und Maultiere, in Togo mit grofsem Erfolge verwenden können und vielleicht auch einmal so weit kommen, dafs das Land den ganzen Bedarf sellıst decken kamm. Während meiner Reise nach dem Agu-Gebirge, von Lome ans, habe ich gerarle mit grofsem Interesse die Möglichkeit der Anlage einer Falıstralse rerfolgt und habe an keiner Stelle bedeutende schwierigkeiten gefunden. Es werden einige Wasserläufe zu überbrücken sein und einige Sümpfe trocken grelegt oder umgangen wertlen müssen, doch das wären nur sehr geringe Arbeiten im Verhältnis zu dem Nutzen, den eine solche Strafse für den Handel der Kolonie bringen würde. Im Bezirke Misahöhe sind jetzt schon mit Ansnahme kleiner Strecken die Wege südlich des Agone-Gebirges in so vorzüglichem Zustande, dafs man sie auf weite Strecken mit Wagen befahren könnte. An einigen wenigen Stellen befanden sich wieder kleine Wäldchen in den Steppen hinter Badja, in denen dam gröfsere Bäume anftraten, während sonst anfser den Affenbrotbäumen, die in Togo nicht weit ins Innere vordringen, die Steppenbäume selten über $10 \mathrm{~m}$ hoch waren. Für das Nachtquartier hatte ich den Ort Kewe ausersehen, bei dem anch wieder ein Logierhaus für Europäer vorhanden sein sollte. Als wir uns 
gregen 5 Uhr am Nachmittage Kewe näherten, wich die Steppe allmählich einer dichteren Buschvegetation, deren Vorhandensein wahrscheinlich auf ehemalige Kultivierung des Geländes zurückzuführen ist. Die Eingeboreneu waren zur Zeit geratle damit beschäftigt, neue Farmen für die kommende Regenperiode anzulegen und die rorhandenen Ölpalmenanpflanzungen zu säubern. Kewe selbst ist nur ein kleineres Dorf, das auch wohl von geringerer Bedeutung ist als das in der Nähe liegende Assaun, in dem sich besonders die Schmiede und Töpfer niedergelassen haben. Wir hatten kaum unsere Lasten in dem geräumigen Rasthause untergebracht, als ein starker Gewitterregen losbrach, der für den Rest des Abends sich ohne Unterbrechung fortsetzte und in einen allgemeinen Landregen auszuarten schien. Als der Regen dam gegen Mitternacht auflıörte, war bald der feuchte Boden um das Haus herum von Hunderten von Ameisen bedeckt, so dafs ich schliefslich gezwungen war, mein Pferd, welches an einem der nahestehenden Bäume angebunden war, in einem in der Nähe aufgebauten Stalle unterzubringen, in lem es wenigstens ron dieser Plage befreit war.

Wie es häufig nach derartigen Gewitterregen der Fall zu sein pflegt, hatten wir am nächsten Tage einen wundervoll kühlen und hellen Morgen, llen ich dadurch auszunutzen versuchte, dafs ich bereits ım 5 Uhr das Signal zum Eimpacken ertönen liefs. Da wir das Zelt nicht einzupacken hatten, erfolgte schon kurze Zeit nach diesem Signal gewöhnlich das zweite, welches für die Lente das Zeichen zum Aufbruch war. Sobald wir uns etwas von Kewe entfernt hatten, traten wir wierler in die uns nun so wohl bekannte Baumsteppenformation ein. Infolge des Regens vom vorherigen Abend waren die Wege stark aufgeweicht und, da sie über lehmiges Terrain führten, nicht selten so schlüpfrig, dafs die Leute mit ihren Lasten nur langsam vorwärts kommen kounten und ich auf tlem Pferde auch gehörig aufjassen mufste, dannit das Tier nicht ausglitt. Etwa eine Stumde nach unserem Abmarsch aus Kewe passierten wir das Dorf Assann, dessen Umgebung auch wieder mit dichtem Gebüsch bedeckt war, in dem ich ïbrigens wiederholt Strophanthus beobachtete. Schier endlos setzte sich hinter Assaum nun die Baumsteppe fort. Dieselbe bot, la sie sich immer noch aus denselben Crewächsen zusammensetzte, wenig Iuteressantes für miclı lar. Der Butterbaum war hier schon hedeutend häufiger geworlen und trat an einigen Stellen bereits charakterbildend auf. In einem schmalen Waldgürtel, welcher sich am Rande einer Kette von Wasserlöchern gebilılet hatte, sah ich dir ersten Fxemplare riner Kantscluk liefernden Liane. Dio wenigen Exemplare waren 
leider nicht in Blüte, so dals ich nicht feststellen komnte, welche Art ich vor mir hatte. Auch Bossassanga-Pflanzen (Costus) gab es an solchen Lokalitäten in Fülle. Um 11 Uhr kamen wir in dem Dorfe Tove an. Da mir daran lag, noch am Abend bis Gbin zu kommen, gab ich den Trägern nur eine Stunde Zeit zum Kochen ihrer Mahlzeiten. Als ich dann aber die Signalpfeife zum Eimpacken ertönen liefs, weigerten sich die Leute, offenbar vou den Einwohnern des Dorfes dazu anfgestachelt, weiter zu marschieren, da der Weg bis Gbin zu weit sei; einige erschienen sogar nicht einmal. Da ich schon früher auf meinen Reisen erfahren hatte, clafs ein Nachgeben hier nur Bummelei bei den Lenten zur Folge haben würde, mufste ich hier ein Exempel statuieren. Ich gab den Leuten daher tüchtig meine Meinung zu hören, woranf sie sofort ihre Lasten ergriffen und alomarschierten. Als diejenigen, welche nicht erschienen waren, von ihren Verstecken aus sahen, dafs sie mit mir sich derartige Späfse nicht erlauben düritten, kamen auch sie sofort herbeigelaufen und nahmen ihre Lasten auf, um auch damit aufzubrechen. Sobald ich darauf zu Pferde die Karawane wieder eingeholt hatte, liefs ich in der Steppe die Leute anhalten und befahl denjenigen, welche auf mein Signal nicht erschienen waren, vorzutreten. Nachdem ich deren Namen aufgeschrieben hatte, kündigte ich ilmen an, dafs ich diese Unverschämtheit durch Abzug eines Tagelohmes von dem Trägerlohne eines jeden bestrafen werde. Diese Mafsregel wirkte besser als ich selbst gehofft hatte, denn während des uns num bevorstehenden Marsches zeigten die Lente mehr Eifer denn je zuvor. Bis gegen Abend hatten wir wieder durch Bammsteppen zu ziehen, die nichts Nenes darboten. Vor uns sahen wir bereits deutlich das Agu-Gebirge liegen, als wir gegen 6 Uhr in Gbiu einmarschierten. Zu meiner Freude fand ich hier ein sehr reinlich gehaltenes Rasthaus aufgebaut. Die Nacht, welche diesem Tage folgte, war herrlich. Der Mond stand in seiner ganzen Pracht am Firmamente und ergofs sein wundervolles Licht über das stille Dorf. Lange noch blieb ich vor dem Rasthanse sitzen, nachdem ich meine laufenden Arbeiten, wie Tagebuch schreiben und Pflanzen einlegen, erledigt hatte, um nach dem sehr heilsen Tage in der Steppe diese prachtvolle kühle Nacht zu geniefsen.

Der kurze Marsch, den wir am nächsten Tage noch bis zur Sholto Douglassehen Plantage am Agn-Gebirge zurückzulegen hatten, führte uns erst auch durch ebenes Steppengebiet, das aber bald einem dichten Waldstreifen weichen mufste. Die nun häufigen Hügel waren zum Teile sehr felsig, so dafs ich wiederholt das Pferd führen lassen mufste. Da, wo die Flora wieder ihren 
Steppencharakter annahm, zeigten sich nicht selten Pflanzenformen, welche ich vorher auf der Reise noch nicht beobachtet hatte. Nachdem wir über verschiedene Hügelrücken gestiegen waren, stiegen wir in lie Ebene direkt am Fufse des Gehirges hinab, in der wir bald das Dorf Atigbe erreichten. Hier liefs ich mir einen Fülırer vom Häuptling des Dorfes geben, der mich nach der Douglasschen Plantage hringen sollte. In Atigbe sah ich die ersten Exemplare rom Ficus Togelii in Togo. Anzapfungen, welche ich an Ort und Stelle rornahm, zeigten, daf's dieser Bam auch hier dieselbe nicht unbrauchbare Masse gab wie in Yoruba-Lande. Von Atigbe weiter marschierenıl, kamen wir balı zu dem Dorfe Tafie, in dem ich auch wieder eine Anzahl von Exemplaren des Ficus Vogelii fand. Wie im Toruba-Lande, werden diese Bäume hier in Togo von den Eingeborenen allenthalben auf den freien Plätzen der Dörfer angepflanzt, und mnter ihnen versammeln sich anch hier bei Beratungen und sonstigen Gelegenheiten die Mämner der Dörfer. Nur eine kleine Strecke hatten wir noch hinter Tafie durch ein an Ölpalmen reiches Gebiet zu marschieren, bis wir die Häuser der Douglasschen Pflanzung dicht vor uns sahen. Die beiden Herren, welche damals auf der Plantage angestellt waren, Herr 'Thienemann, der Leiter, nnd Herr Rohmer waren über mein Eintreffen gewissermalsen erstaunt, da sie sich ansgerechnet hatten, dafs ich unter günstigen Umständen erst am 12. März bei ihnen eintreffen könnte. Da ich eigentlich meine Träger nur bis zur Tafie-Plantage engagiert hatte, forderte ich dieselben auf, mich noch bis Misahöhe zu begleiten, da hier schwer neur Träger zu bekommen waren. Mit Ausnahme von dreien, welche ich als Fufskranke nicht gebranchen konnte, waren alle bereit dazu. Ich liefs nun den Häuptling von Tafie rufen und forderte ilın auf, mir für die drei zurückbleibenden Leute am nächsten Tage drei neue Träger bis Misahöhe zu stellen. Gegen ein kleines Geschenk war der Mann bereit, dieses zu thun, und somit war die Trägerfrage fürs Erste erledigt.

Auf der Besitzung des Herrn Douglas, deren Bearbeitung erst seit kurzem in Angriff genommen war, hatte man bisher nur einige Saatbeete angelegt, in denen die von Kamerun bezogene Kakaosaat eben aufzugehen begann, und ein grölseres Stïck Landes, welches für Baumwoll- und Tabakkultur in Anssicht genommen war, urbar gemacht. Es war also sonst wenig für mich zu sehen. Die Kautschukpflanzen und Bambusasämlinge, welche ich vom Versuchsgarten bei Lome mitgebracht hatte, waren in vorzüglichem Zustande angekommen. Herr Thienemann, welcher mich von hier an auf meiner Reise nach Boëm begleiten sollte, traf nun mit mir 
die Vorbereitungen zur Abreise, die ich am nächsten Tage vornehmen wollte. Herr Rohmer sollte während der Zeit unserer Abwesenheit allein anf der Plantage verbleiben.

Trotz meiner wiederholten Betonung dem Häuptling von Tafie gregenüber kamen die versprochenen Leute natürlich nicht um 6 Uhr, sondern erschienen erst nach 8 Uhr am nächsten Tage, so daf's sich unsere Abreise etwas verzögerte. Zurückgehend über Tafie, marschierten wir num dureh Abegame nach Abesia durch ein Gebiet, das an Ölpalmen sehr reich war. Die Steppenvegetation war hier wohl infolge ehemaliger und noch vorhandener Kulturen für grölsere Strecken verschwunden, un einer dichten Buschregetation Platz zu machen. Ton Abesia gelangten wir zunächst nach Tove, wo wir wieder in die Steppe eintraten. Nach kurzem Anfenthalt in Tove ging es nach Agome-Palime, dem Haupthandelscentrum für die Agrome-Region, einem Dorfe von ziemlicher Ausdehnung. Bei den hier anwesenden Vertretern deutscher Kanfmannshäuser, den Herren v. Bruch und Meyer, machten wir nun eine längere Rnhepause, während der unsere Leute sich mit Proviant versehen sollten, len sie hier, da gerarle Warkt alıgehalten wurle, reichlich kaufen komnten. Es ist hier in Togo wie auch in den benachbarten Ländern allgemein Sitte, dal's die Träger der Europäer sich selbst zu beköstigen hahen. Die Leute bekommen zu diesem Zwecke täglich 25 Pfennige (oder $3 \mathrm{~d}$ ) als Subsistenzgelder. Ganz besonders dem reisenden Europäer wird dadurch die z. B. in Kanerun oft recht lästige Terpflegungsfrage der Lente bedeutend erleichtert und ihm riel Ärger erspart. Hier in Togo ist eine derartige Regelung der Verpflegungsfrage schon darhureh vereinfacht, dafs das ganze Land ziemlich dicht bevölkert ist, was in Kamernn durchaus nicht ler Fall ist, wo aufserdem noch infolge der dichten Urwälder die rerschiedenen Völkerstämme unter sich sehr wenig miteinander rerkehren, sondern sich sogar recht häufig feindlich gegenüber stehen. Am Nachmittage brachen wir wieder von Palime auf. Da meine Lente eine gute halbe Stunde vor nns abmarschiert waren, ritt ich im Galopp hinterher, ohne sie noch vor der Station Misahöhe erreichen zu können. Der Weg von Palime nach dem Agome-Gebirge, auf dessen halber Höhe die Station liegt, war in wundervollem Zustande. Schon von weitem konnte man die Station mit ihren aus Steinen erbauten massiven Gebäuden erkennen, alles zengte hier von grofser Ordnung. Als ich zur Station einritt, kam mir Herr Dr. Gruner, der bereits von meiner Ankunft durch die vorhermarschierten Träger nnterrichtet war, entgegen und empfing mich in der ihm eigenen liebenswürdigsten Weise. Herr Thienemann erschieu auch kurz darauf in seiner Hängematte. 
Da ich mich nun hier in Misahöhe mit neuen Trägern zu versehen hatte, machte ich von der gütigen Einladung rles Herrn Dr. Gruner, einige Tage bei ihm zu verweilen, sehr gern Gebrauch, wufste ich doch auch, dafs ich von ihm, dem besten Kenner unseres Schutzgebietes Togo, sehr viele interessante Anfklärungen erhalten würde, die für die Reise nach Boëm für mich von grof'sen Werte sein mufsten.

Da Dr. Grumer schon längst die Absicht gehabt hatte, in Quamikrum eine Station zu bauen, hatte er bereits zu dem Zwecke eine Anzahl Soldaten ausgesucht, die mich zugleich auf der Reise nach Boëm begleiten sollten. Mit Hülfe des Herrn Dr. Gruner erhielten wir hier bald nene Träger. Die Lente, welche ich von Lome und Tafie hatte, lohnte ich nun ab und liefs sie nach ihren Dörfern zurückkehren. HerT Thienemann behielt von seinen Trägern nur sechs Leute zmräck, welche er als erprobte Hängrmattenträger kannte.

Trotz seiner noch nicht überwundenen Krankheit liefs es sich Dr. Gruner, der erst seit einem Tage sich wieder von einem schweren Schwarzwasserfieber einigermaisen erholt hatte, doch nicht nehmen, alle Schwierigkeiten, welche die Expedition haben könnte, zu beseitigen, so dafs ich ihm wirklich nie genng Dank wissen kann für die Unterstützung; die ich bei ihm gefunden. Diese Tage, welche ich noch im Laufe der nächsten Wochen in seiner Gesellschaft zu verbringen den Vorzug hatte, werden stets zu den angenehmsten und lehrreichsten meines Lebens zählen. Teh bedautrte nur, dals Dr. Gruner infolge seiner Krankheit verhindort war, mit mir zusammen, wie er ursprünglich beabsichtigt hatte, die Reise nach Boëm zu machen.

In den Versuchsgärten, welche Dr. Gruner bei der Station hatte anlegen lassen, wnrden anch einige Kautschukpflanzen gezogen. Manihot Glaziovii, Hevea brasiliensis und einige Ficusarten waren vorhanden mul schienen gut zu gedeihen. Die Exemplare waren noch zu jung, um an sich experimentieren zu lassen. Unterhalb der Station am Fufse des Gebirges hatte Dr. Plehn, welcher auch früher einmal Teiter dieser Station war, eine Kola-Anpflanzung begonuen, die aber wahrscheinlich infolge der zu feuchten Bodenverhältnisse uur sehr langsam heranzuwachsen schien.

'Zusammen mit Herm Thienemann unternahm ich am Morgen des 13. März eine Besteigung des François-Passes, wo Geheimrat Wohltmann Kickxia-Fxemplare gesehen zu haben glauhte. Es yelang mir mun auch thatsächlich, hier in den Bergwäldern Kickxia ausfindig zu machen, aber welche Enttäuschung — es war die falsche. 
Dessenungeachtet gab ich die Hoffnung damals natürlich noch nicht auf, noch erfolgreich zu sein, hatte ich doch in BakossiGebiete die falsche und die echte Kickxia nebeneinander gesehen. Die auf dem Erdboden umherliegenden Fruchthülsen liefsen mich keinen Augenblick mehr im Zweifel, dafs wir es hier mit Kiekxia africana zu thun haben. Da ich diese Früchte nie vorher gesehen und nun wirklich zu urteilen im stande war, freute ich mich, dafs anch meine letzten Bedenken geschwunden waren, dafs die Arten wirklich voneinander verschieden seien. Einige junge, dünne Landolphien fand ich damals auch in den Wäldern; dieselben waren aber noch $\mathrm{zu}$ schwach, $\mathrm{um}$ an ihrem Milchsafte feststellen zu kömmen, ob sie Kautschuk liefernden Arten angehörten orler nicht. Als wir die Höhe des Passes erreicht hatten, wendeten wir uns dem Gipfel des Hausberges zu, nach welchem auch ein guter Weg hinaufgelegt ist. Oben hatte man ein Häuschen errichtet, in dem Europäer, die als Rekonvaleszenten hier hinaufkommen wollten, es sich gemütlich einrichten können. Von dieser Bergspitze aus genossen wir eine prachtvolle Aussicht über das Land südlich des Agome-Gebirges sowohl als anch über die nördlich dlavon gelegenen Crebiete.

Von dieser Exkursion zurückgekehrt, trafen wir am Nachmittage noch einige Vorbereitungen für unseren am nächsten Morgen bevorstehenden Aufbruch. Die meisten Lasten waren schon vorher fertig gepackt worden, so dafs auch das bald erledigt war, zumal sowohl meine Lente als auch diejenigen, welche Herr Thienemann mitgenonmen, erprobte und alte Europäer-Begleiter waren, denen wir viele Sachen zur Besorgung anvertranen komnten. Den Abend verlebten wir noch in Dr. Gruners angenehmer Gesellschaft.

Am Morgen des 13. März war alles zum Aufbruch fertig. Herr Franke, der Stationsassistent des Herrn Dr. Gruner, hatte die Liebenswürdigkeit, mir viele kleine mit dem Aufbruche solcher Expeditionen zusammenhängende Arbeiten abzumehmen, so dafs wir schon früh die Träger, deren wir 25 hatten, unter Begleitung eines von Herrn Thienemann mitgenommenen zuverlässigen Aufsehers, vorausschicken konnten. Mit unseren Jungen und den Soldaten, welche von einem äufserst intelligenten Togo-Mann, dem StationsHülfsassistenten Amusso Bruce, geführt wurden, folgten wir der Träger-Karawane etwa eine Stunde später nach. Auf den FrançoisPasse ging es über das Agome-Gebirge hinunter nach dem kleinen Dörfchen Agome-Tongbe, dicht vor dem wir auf einer breiten Holzbrücke den Tii-Bach überschritten. Ohne uns in Tongbe aufzuhalten, setzten wir den Marsch fort. Zunächst gelangten wir in ein meln 
oder minder kultiviertes Gebiet, in dem Maniok, Baumwolle und Cajanus indieus gepflanzt waren. Allmählich wurde jedoch das Terrain bergiger und der Weg schmaler, wir stiegen in die KameSchlueht hinab. Vorher hatten wir noch Gelegenheit zu sehen, dafs auch hier in Togo die Hensehreekenplage nieht unberlentende Dimensionen anzunehmen vermag; gegenüber dem Dorfe AgomeTongbe hatten wir einen riesigen Heuschreekensehwarm zu durchzieheu, der die Felder des Dorfes arg bedrängte. Durch Rauch und Lärm suchten die Eingeborenen die Tiere zu versehenchen. In der romantischen Kame-Schlucht durchzogen wir noeh eimmal den Bach und stiegen dann wieder empor, dem Dorfe Kame zu. In den dichten Wäldern, welche das Thal bedeckten, war Kickxia africana in Unmengen vorhanden, von der Kautsehuk liefernden Kickxia elastica aber auch hier nichts zu sehen. Auch in Kame wurde nicht erst angehalten, war doch das nun gar nicht mehr weite Dörfchen Liati die Heimat meiner Träger und Trägerinnen, wo dieselben doch sieher noch einmal von ihren Verwandten und Bekannten Absehied nehmen wollten. Hinter Kame hörte der Wald wieder auf. Das hügelige Terrain war mit Gras und Sträuchern bewachsen, und an geeigneten Stellen waren gröfsere Flächen von den Eingeborenen urbar gemacht und mit Baumwolle, Maniok und Cajanus bepflanzt. Bohnen und Bataten sah man nur sehr selten. In Liati liefs ich die Leute zusammentreten und sonderte die sehwächsten derselben aus, denn es waren mehr Träger ersehienen, als wir nötig hatten. Jann bezahlte ich den Leuten ihre tägliche Subsisteuz von $25 \mathrm{Pf}$, damit sie sich noch möglichst viele Lebensmittel mitnelımen könnten, und machte die Gesellschaft darauf aufmerksam, dafs sie sämmtlich sich an unserem Lagerplatze einzufinden hätten, sobald meine Signalpfeife dreimal langgezogen ertöne. (Ich hatte für den Koch und den Leibjungen älmliche, aber kurze Signale.) Wir verblieben hier in Liati ungefähr eine Stuncle. Schon vorher hatten die meisten der 'Trägerimmen sich eingefunden, als das Signal aber ertönte, wurde es merkwürdig lebendig in dem Dorfe. Von allen Seiten strömten Träger und 'Trägerimnen herbei, begleitet von ihren Angehörigen, die ilmen noch allerlei Lebensmittel heransehleppten. Fs war äufserst interessant, diese einfachen, zufriedenen Lentehen in ihrer familiären Harmlosigkeit zu beobachten. Da zwei der Leute fehlten, mufste ich den Häuptling anfordern, sofort zwei andere zu stellen. Als auch las erledigt war, setzte sich unser Kug in Bewegung. Auf der ganzen Reise behielt ich nun dieselbe Marsehorduung bei. Frst hatten die Träger und Trägerimnen vor nus zu marsehieren, nicht selten geführt von Herm 'Thienemann, dahinter 
kam ich selbst mit ein oder zwei Jungen, welche etwaige notwendige Gegenstände zu tragen hatten. Amusso Bruce marschierte gewöhnlich neben meinem Pferde her, denn ich unterhielt mich gerı mit ihm, da er mir viel von den Expeditionen Kundt und Tappenbeck, bei welchem Ersteren er Diener gewesen war, zu erzählen wufste, auch selbst vorzüglich die verschiedensten Verhältnisse Togos kannte und ein recht gesundes Urteil über dieselben zu fällen wufste. Er sprach deutsch vollständig fliefsend. Hinter meinem Pferde kam die Hängematte Amussos und hinter dieser die zwölf Soldaten, geführt von ihrem Unteroffizier. Dicht hinter einander hatten wir die Dörfer Sagba, Pekehi und Dafong zu passieren. Dieselben bestanden zumeist aus wenigen Hütten und lagen inmitten ler Buschsteppe. Hinter Dafong wurde das Land stellenweise offener, doch im ganzen begleitete uns der Busch bis nach Fodome, wo ich Nachtquartier zu machen beschlossen hatte. Unter der Hitze hatten wir alle an jenem Nachmittage furchtbar zu leiden. Ein typischer Harmattan hatte sich über die Steppe ausgebreitet und infolgedessen eine Hitze hervorgerufen, die fast unerträglich wurde. Mit Freuden begrülste die Karawane daher gegen 4 Uhr unser Fintreffen in Fodome. Unter einem schattigen Ficusbaum liefs ich sofort hier mein Zelt aufstellen und erlaubte den Leuten, sich Nachtquartiere zu suchen. Da las Zelt zu klein war, hatten wir beide Europäer es so arrangiert, dafs ich nach dem Abendessen, das vor meinem Zelte eingenommen wurde, in demselben zur Ruhe ging, während Herr Thienemann eines der Hänser im Dorfe für die Nacht mietete.

Auf dem Marsche von Dafong nach Fodome hatte ich am Nachmittage eine überschenkeldicke Kautschuk liefernde Liane gesehen, von der Anıusso mir erzählte, dafs von ihr der sogenannte Kpando-Silkrubber gewonnen werde. Ich werde später noch Gelegenheit haben, auf diese Pflanzen zurückzukommen, und erwähne daher ihr Vorkommen hier nur des Standortes wegen, weil dieser der südwestlichste mir bekannt gewordene ist.

Wir waren kaum in Fodome eingezogen, als auch schon verschiedlene Leute kamen, um mich zu bitten, für sie Palaver zu schlichten. Da das nicht meine Sache war und ich mich nicht in Angelegenheiten hineinmischen wollte, welche mich nichts angingen, so liefs ich den Leuten sagen, dafs sie damit warten mülsten, bis Dr. Gruner käme, oder sie mülsten sich nach Misahöhe begeben, wo der "Doktor" ihnen Recht sprechen würde. Tief betrübt zog die Gesellschaft von dannen. Ein Weib, das durchaus von ihrem Manu getrennt werden wollte, machte noch einen verzweifelten Versuch, bei Herm Thiene- 
mann Recht zu bekommen, doch wies auch dieser sie natürlich ab. Gegen Abend wurde hier ein Verstorbener beerdigt. Mit ihr' $n$ langen Steinschlofsgewehren versehen, zog die Sehar der trauernden Männer und klagenden Weiber mit dem Leichnam in den Busch, wo er beigesetzt werden sollte. Unter nnaufhörlichem Abknallen ihrer Gewehre und dem grauenhaften Klagen der Weiber wurde die Leiche beerdigt. Während die tranernde Schar nun sich ruhig in ihre Hänser verfügte, $z \circ g$ die Witwe des Terstorbenen unter ekelhaftem Gewimmer von Haus zu Haus, um sich eine Beileidsgabe zu erbetteln. Alles, was sie erhielt, wanderte in einen Sack hinein, den sie bei sich trug.

Gegen $5 \frac{1}{2}$ Uhr gab ich anı Morgen des 15 . März das Signal zum Sammeln. Schon nach einer weiteren Viertelstunde verliefsen wir Fodome, nachdem ich noch von dem Häuptling ein kleines Gesehenk von Hühnern und Yams erhalten, wofür ich natürlich das ïbliche Gegengeschenk zu machen hatte. Von Fodome nach Fodome-Oue gebrauchten wir kaum eine Viertelstunde. Ton FodomeOue aus zogen wir teils durch ausgedehnte, spärlich mit Bäumen bedeckte Grassteppen, teils durch Busehwälder, die sich dureh Reichtum an Kickxia afrieana auszeichneten, nach dem kleinen Dörfchen Atabu. Nach wenigen Minuten Rast ging es damn weiter dureh Steppengebiet, das aufser einigen an einem Wasserloche wachsenden, offenbar wirklich wilden Bambusen, nur für den Botaniker in Form einiger seltener und unbekannter Pflanzen Interessantes darbot. Diese im mittleren Togo offenbar ziemlich verbreitete Bambusart scheint sich nicht besonders verwenden zu lassen, da das Rolır zu brüchig ist. Selbst dünne Stöckehen, welche ich mir häufig als Reitgerte schneiden liefs, brachen bei der geringsten Gelegenheit. Von Atabu nach Djakke und dann nach Akokhoë führte der breite Weg auch durch Steppen, die aber nur selten Bäume anfwiesen, sondern hauptsächlich etwa mannshohe Sträucher. Da es hier auch gnt geregnet hatte, zeigten sich viele Blumen im Grase, doeh fing infolge der letzten sehr heifsen Tage und des Harmattans, der bereits seit einigen Tagen regelınäfsig am Nachmittag ersehien, die Vegetation bereits in bedenklicher Weise an, noch vollständig unentwickelt dahinzuwelken.

In Akokhoë angekommen, liefs ich eiue Rast von zwei Stunden machen. Nachdem die Träger ihre Subsistenzgelder erhalten hatten, zerstreuten sie sich im Dorfe, um einen Platz zu suchen, wo sie ihre Nahrungsmittel kochen könnten. Der Häuptling des Dorfes erschien nun mit seinen Geschenken, welche auch wieder aus Yam und Hähnerı bestanden. Als (iegengeschenk schien diesen Leuten Tabak grofse Frende zu hereiten. Amusso, der mit diesem Häupt- 


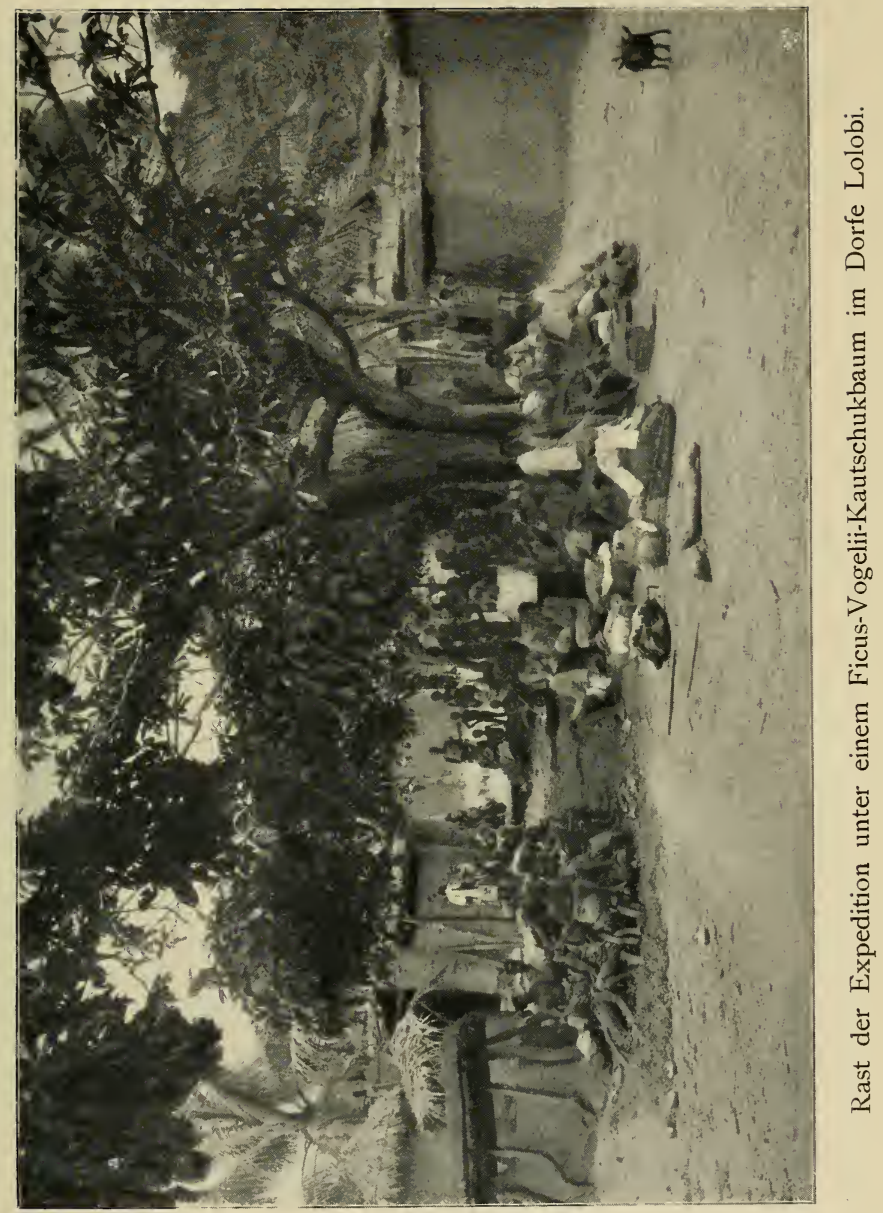



ling noch verschiedene Streitfragen und sonstige Geschäfte in Dr. Gruners Auftrage zu erledigen hatte, liefs ich hier mit neun Soldaten zurück, als wir gegen $11 \mathrm{Uhr}$ wieder abzogen, bis er seine Sachen erledigt habe. Durch ein heifses Buschsteppen-Gebiet zogen wir in der Mittagshitze weiter. Meinen Trägern lief der Schweils rom Körper derartig herunter, wie ich es sonst selten gesehen. Doch was half das alles, ich hatte mir vorgenommen, die Nacht auf dem Beika-Berge zuzubringen, und so mufsten wir noch einen langen Narsch am Nachmittag machen. Gegen 1 Uhr trafen wir im Dorfe Lolobi ein, las dicht am Dai-Flusse gelegen ist. Hier sah ich zum ersten Male die in Boëm verbreiteten Häuser mit vollständig flachem Dache. Diese Hänser sind am Tage furchtbar heifs, und fast ist es unmöglich für einen Europäer, sich in denselben aufzuhalten, doch sind sie äufserst reinlich gehalten. Der Fufsboden ist gewöhnlich mit Lehm glatt ausgeschmiert und nicht selten wie die Wände weifs getüncht. Fast ein jedes Haus hat seinen eigenen Feuerplatz, der durch drei kleine konische Säulchen erkenntlich ist, welche dazu dienen, die Töpfe oder sonstige zum Kochen verwendeten Gefälse oberhalb des Feuers zu halten; ebenso besitzt jedes Haus seine kleinen aus Lehm hergestellten Hausgötzen, wie man sie auch sonst noch in gröfseren Darstellungen in Togo in den verschiedeusten Dörfern finden kann. Der Fetischglaube spielt auch hier eine grofse Rolle. Aufser den gröfseren ('ötzenhütten, unter denen nicht selten drei bis fünf aus Lehm hergestellte plumpe Nachahmungen des menschlichen Körpers in einer Reihe sitzend dargestellt sind, habe ich recht häufig auf Feldern oder an Wegen Miniatur-Nachahmungen dieser Götzen gesehen, die wohl die betreffenden Iokalitäten beschirmen sollen. Es wäre sehr wünschenswert, dafs man noch möglichst, viel Erkundigungen über die Einzelheiten dieser Fetisch- und Götzen-Religion einsammele, ehe gerade die interessantesten und eigenartigsten Gebräuche vor der vorschreitenden Kultur verschwinclen, und gerade hier in Togo, wo wir es mit einer viel intelligenteren Bevölkerung zu thun haben als in Kamerun, werlen diese Eigenarten schneller aufgegeben werden als in den neisten anderen Ländern.

In Lolobi machte ich unter verschiedenen wundervollen Exemplaren des Ficus Vogelii Halt und erlaubte meinen Leuten, sich eine Zeit lang auszuruhen, da wir den hohen Beika-Berg zu ersteigen hatten, der nun dicht vor uns sich erhob. Auch hier bekam ich wierler von dem Häuptling Geschenke an Yams.

Gegen 2 Uhr nalımen wir wieder unsern Marsch auf. Der Beika-Berg, welcher sich vor uns erhob, war dicht bewaldet; 
anfangs, d. h. soweit der Weg von den Einwohnern von Lolobi zu besorgen war, war er in ziemlich schlechtem Zustande, er wurde aber zusehends besser, als wir in das Gebiet von Beika eintraten. Landolphien gab es in diesen Wäldern zerstreut, Kickxia africana war in Mengen vorhanden und bildete einen nicht unerheblichen Prozentsatz der Urwaldbäume. Nach fast dreistündigem, für die Träger sehr ermüdendem Klettern langten wir gegen 5 Uhr auf der Spitze des Berges in dem Dorfe Beika an. Ich hatte anch den gröfsten Teil des Marsehes zu Fufs zurücklegen müssen, da der Weg zum Reiten zu steil war.

Das Dorf Beika ist vollständig auf Felsen erbaut. Unter einem grofsen Feigenbaume liefs ich zwar zuerst die Leute lagern, sah aber bald ein, dafs es unmöglich war, das Zelt irgendwo aufzustellen, und liefs daher für mich ein reinliches Haus suchen, in dem dann die Lasten untergebracht wurden. Da infolge der Hitze, die in den Häusern noch herrsehte, keiner von uns Europäern Lust hatte, länger als dringend notwendig in denselben sich aufzuhalten, liefs ich Tische und Stühle unter dem Feigenbaum anfstellen, wo wir auch beschlossen, zu Abend zu essen. Der Häuptling mit einem grolsen Trosse kam bald, um mir die obligaten Geschenke, bestehend aus Yams, Bergreis und Hühnern, zu überbringen, von denen wie gewöhnlich der Yams unter meine Leute verteilt wurde, der Bergreis ein gut verwendbares Futter für mein Pferdchen bildete, die Hühner aber in unsere Küche wanderten. Kurze Zeit darauf erschien der Häuptling wieder und beklagte sich darüber, dafs meine Leute durchaus zum Wasser gehen wollten, obgleich er ihnen verloten hatte, es zu thun. Mir lag der Grund zu diesem Verbot allerdings klar vor den Augen, denn zu dieser Zeit badeten sich ja gewöhnlich die Holden des Dorfes. Meine Leute konnten schliefslich anch nicht ohne Wasser bleiben, deshalb befahl ich dem Häuptling, für mein sämmtliches Personal Wasser heranschaffen zn lassen, und verbot meinen Leuten dann, selbst zum Wasser herunterzugehen. Damit waren beide Parteien sehliefslich befriedigt. Aus Dankbarkeit schickte mir der Häuptling sogar noch eine ganze Anzahl Yamsknollen, welehe ich num wieder verteilte. Einige der Träger mufste ich hier übrigens bestrafen, da dieselhen so unverschämt waren, einigen Trägerweibern die leichteren Lasten abzunehmen und ihnen statt dessen schwere aufzupacken. Diese Übelthäter hatten mehrere Tage hindurch die sehwersten Lasten zn tragen. Noch vor Eintritt der Dunkelheit kam Amusso mit den Soldaten in Beika an.

Da wir am 16. März wieder einen Berg zu erklimmen haben sollten, liefs ich schon 1 m 5 Uhr antreten. Es war interessant, des 
Morgens diese Scene zu beobachten. Gewöhnlich liefs ich mir gegen 4 Uhr morgens durch den Koch schon den Kaffee bringen und setzte mich dann noch bis $5 \mathrm{Uhr}$ zu schriftlichen Arbeiten oder einer Zigarre nieder. Nachdem mein Junge unterdessen meine Sachen etwas zusammengeräumt hatte, liefs ich in dem noch vollständig stillen Dorfe die Signalpfeife ertönen. Sofort entwickelte sich num ein reges Leben. Von allen Seiten strömten die Leute herbei, um ihre Lasten fertig zu packen, oder die Einwolner des Dorfes in grolser Anzahl, um beim Aufbruche zuzugaffen. Sah ich, dafs alles fertig war, wobei der Headman zur nötigen Eile anzutreiben hatte, lamn ertönte das zweite Signal, und in der bereits oben beschriebenen Ordnung setzte sich der Zug in Bewegung. Dasselbe Schanspiel wiederholte sich fast allmorgentlich.

Von Beika stiegen wir num auf einem für die beladenen Träger nicht gerade gefahrlosen Wege wieder in ein tiefes Thal hinab. Der Grund des Thales schien aus sehr fruchtbarem Boden zu bestehen, der übrigens mit Elefantengras reich bedeckt war. Allmählich stiegen wir ron dieser Ebene auf einem immer steiler ansteigenden Pfade zum Dorfe Tetemang empor, das ähnlich wie Beika inf einer dicht bewaldeten Bergkuppe lag, aber nicht so anf Felsen stand wie die letztere Ortschaft. Hühner und Eier konnten wir für unsere Küche anch reichlich einkaufen. Unser Koch Quodjo, welcher früher einmal der Junge des in Kamerun ermordeten Oberleutnants Dr. Plehn gewesen war, war in solchen Sachen äufserst geschickt und erfahren, so dafs wir ihm diese Einkäufe vollständig allein überlassen konnten. Dieser Mensch war überhaupt trotz seines Hanges zıиı Leichtsinn, wenn er unter strenger Zucht war, vorzüglich zu gebrauchen und als Dolmetscher für uns hier sehr wertvoll. Lügen komnte er übrigens in stamenerregender Weise, loch das war nicht Itnsere Sache, solange er uns nicht belog, und davor hütete er sich.

Nach Beendigung unseres Frühstücks verliefsen wir mit den Geiseln rlas Dorf Tetemang und stiegen wieder in ein tiefes Thal hinab. Durch ziemlich dichten, an Landolphien umrl falschen Kickxien sehr reichen Wald führte der teilweise steile, nicht selten mit Geröll bedeckte Weg der Hauptstadt Boëms, Borada, zu, wo wir, nachdem wir noch ein kleines Hügelland durchzogen hatten, gegen Mittag eintrafen.

Die Häuser in Borada waren, wie es mit wenigen Ausnahmen in ganz Boëm der Fall ist, in derselben Weise erbaut, wie die von Lolobi, dem Dorfe am Dai-Flusse, das man eigentlich nicht mehr zı Boëm rechnet, meiner Meinumg nach aber entschieden noch dảzu gehört. Auch die Dörfer Beika und Tetemang bestehen ans solchen 
Häusern. Im allgemeinen muls man sagen, dafs die Häuser hier in Boёm von den Eingeborenen sehr reinlich gehalten werten, derart sogar, dafs ein Europäer eigentlichr ohme Zelt umherreisen kamn, da er mit einem Nachtquartier, wie es ihm die Häuser bieten, vollständig zufrieden sein kann. Nicht selten haben diese BoëmHäuser, besonders diejenigen in Borada, eine Art Veranda an der Frontseite, welche an beiden Seiten durch die verlängerten Giebelwände und oben durch das überhängende Dach geschützt ist. Die in Boem verbreitete Sprache ist das "Schi", eine Sprache, welche westlich und nördlich der Landschaft eine gröfsere Verbreitung haben soll. Einen eigentïmlichen Schmuck sah ich übrigens hier in Borada und später auch in vielen anderen Ortschaften Boëms, nämlich weite Halsketten, die aus ovalen Gliedern bestanden und aus Eisen verfertigt waren. Die einzelnen Glieder waren gewöhnlich vierkantig im Durchschnitt und bis $3 \mathrm{~mm}$ stark. Mir wurde gesagt, dafs diese Ketten ron den Wora-Wora-Leuten gemacht werden, die allgemein als gute Eisenschmiede einen grofsen Ruf geniefsen.

Gegen Mittag wurden wir, als ich eben das Signal zum Packen gegeben hatte, durch einen starken Gewitterregen überrascht, der eine gute halbe Stunde andauerte und bald die Strafsen des Dorfes in ein Gemisch von Bächen und Wassertümpeln verwandelte. Meine sämtlichen Lasten, welche ich schleunigst im Zelte unterbringen liels, blieben glücklicherweise vollständig trocken. Als nach Beendigung des Regens der Aufbruch endlich erfolgen konnte, stellte sich heraus, dafs Akpanje noch verschiedenes mit Amusso besprechen wollte. J) ich mich dadurch nicht aufhalten lassen wollte, liefs ich ihn mit zwei Soldaten zurück und die Karawane aufbrechen. Wir durchzogen zunächst ein hügeliges, fruchtbares Savannengebiet, in dem die. Eingeborenen viele Farmen angelegt hatten. Später gelangten wir in einen dichten Buschwald, in welchem die falsche Kickxia in riesigen Mengen vorhanden war. Die Stämme derselben schienen von den Eingeborenen viel als Nutzholz verwendet zu werden; so waren die Pfosten der Hänser und Brücken, über welchr der Weg führte, vorzugsweise aus diesem Holze hergestellt. Dassolbe ist wie das der Kickxia elastica ziemlich weich, und daher sind die Bäume leicht zu fällen. Nach einem Marsche von $1 \frac{1}{2}$ Stunden erreichten wir das Dorf Kyasekang, das für Boëm das Centrum des Ackerbaues sein soll. Ier alte Häuptling schien ein recht vernünftiger Bursche zu sein und that alles für meine Leute, was in seiner Macht stand. Als Geschenk brachte er mir ein schönes Schaf und eine grolse Yahl Yamsknollen sowie Bergreis und Guinea-Hirse. Da das Dorf und die Bevölkerung mir sehr gut gefielen, beschlof ich, üher Nacht hier 
zu bleiben und liefs mein Zelt wieder unter einem Ficus aufschlagen. Das Dorf Kyasekang machte in vieler Hinsicht einen bedeutend angenehmeren Eindruck als Borada. Die Strafsen waren bedeutend reinlicher und die Häuser anch nicht selten weifs getüncht; dazu kam noch die Zuvorkommenheit der Berölkerung im allgemeinen. Herr Thienemann, der schon früher einmal hier gewesen war, wurde von einem alten Weibe, das noch ein Geschenk aus Errnüssen (Arachis) brachte, sehr freudig begrülst. Wie er mir sagte, hatte er der Alten früher einmal einen Gefallen erweisen können, für den sie ihn aus Dankbarkeit nicht im Stiche liefs. Herr Thienemann verstand es überhaupt ausgezeichmet, die Eingeborenen an sich zu fesselı.

Schon während der letzten Tage waren wir allentlalben mit Palmenwein von den Häuptlingen, deren Gebiet wir durchzogen, versehen worden. Auch heute erhielten wir wiederum eine grofse Kalebasse dieses Getränkes, das, in mälsigen Quantitäten getrunken, hier in ilem heifsen Klima entschieden eine erfrischende Wirkung hat, wenn es nicht abgestanden ist.

Am frühen Morgen des 18. März waren wir wieder auf dem Marsche. Die Steppe, welche mit dichtem Buschwalde abwechselte, gewann bald wieder einen trockenen Anblick. Der Weg war in tadellosem Zustande. An den Seiten sah man sogar nicht selten in den tiefer gelegenen Gegenden Wassergräben gezogen, die den Weg. trocken halten sollten. $\mathrm{Zu}$ meiner grofsen Freucle sah ich auch in der Nähe des Dorfes Versuche der Eingeborenen, Kaffee und Kakao zu kultivieren. Die Pflanzungen waren noch zu jung, als dafs man von etwaigen Erfolgen oder Mifserfolgen hier sprechen kömnte. Nach einer guten Stunde Marsches erreichten wir den kleinen Ort Guamang. Hier gab es ein reges Leben. Vor zwei Tagen hatte einer der Jäger des Dorfes einen Elefanten geschossen, dessen Fleisch 11 m hereingebracht wurde. Natürlich hätten meine Träger daher zu gern gesehen, dafs ich ihnen Zeit lassen würde, von diesem Elefantenfleische etwas zu kaufen, doch ich liefs, ohne Rast machen zu lassen, weitermarschieren, da ich wohl wufste, dafs die Leute von dem erlegten Tiere nichts verkaufen würden, denn das Dorf hatte eine ziemliche Anzahl von Einwohnern, für welche ein selbst grofser Elefant lange nicht genügen konnte. Nach einer weiteren Stunde Marsches durch ein Gemisch von kurzgrasigen Steppen und Buschwäldern erreichten wir das kleine Dorf Monda, wo ich eine Rast von 10 Minuten machen liefs. Dieser kleine Ort zeichnete sich durch besondere Reinlichkeit aus. Ficus Vogelii scheint auch in diesen Gebieten nicht selten zu sein, ich sah auf dem Wege von Guamang nach Monda 
sogar viele wilde Exemplare. Von Monda nach Kadyebi, dem in Aussicht genommenen Endziele meiner Reise, hatten wir auch wieder ein gemischtes Gebiet zu durchziehen, das kleinere Baumsteppen und Urwälder besafs. In allen diesen Wäldern ist die Kickxia africana sehr verbreitet, ja man könnte fast sagen, der häufigste Urwaldbaum; doch trotz meines sehr eifrigen Suchens habe ich von der brauchbaren Kickxia elastica keine Spur entdecken können. Ich schnitt täglich eine grosse Zahl von Bäumen an, 1 m zu sehen, ob etwa an einigen Lokalitäten diese Kickxia africana doch Kautschuk greben könnte, gab diese Hoffnung aber bald auf. Die Bodenverhältnisse hier in Boem sind ganz ähnlich denen, unter welchen im Yoruba-Lande die Kickxia elastica auftritt. Ich bin daher fest davon überzeugt, dafs Ampflanzungen der letzteren sich hier vorzüglich entwickeln werden. Landolphien sind übrigens auch hier in den Wäldern vorhanden, doch stellen die Eingeborenen ihnen sehr nach, so dafs dieselben schon selten geworden sind. Gegen 10 Uhr trafen wir in Katlyebi ein. Ich liefs daselbst unter einem FicusBaume sogleich mein Zelt aufschlagen, da ich die Absicht hatte, erst am nächsten Tage das Dorf wieder zu verlassen. Der Häuptling des Dorfes schien ein machtloser alter Herr zu sein, der sich von seinen Verwandten offenbar viel gefallen lassen mufste. Auffallend lemutsvoll kam er zu mir, un mir sein Geschenk zu bringen, dabei betonend, dafs er zu arm sei, un mehr als Hühner, Reis und Yams greben zu kömmen. Die Leute hatten hier sowohl wie in den letzten ron uns passierten Dörfern kleine Kornspeicher, die gewöhnlich walzenförmig nnd nit konischen Dächern überdeckt waren. Nur wenige Häuser hatten die für Boëm typischen flachen Dächer. Die zu beiden Seiten abfallenden Strohiächer waren entschieden vorherrschend.

Zusammen mit Herrn Thienemann unternahm ich kurz nach meiner Ankunft in Kadyebi eine Exkursion, um mir das von Herm Bergassessor Hup feld für Herm Sholto Douglas angekaufte Terrain anzusehen, besonders auf Anbaufähigkeit für Kickxia elastica und andere Kautschukpflanzen. Wir hatten anf einem nicht schlechten Pfade etwa $3 / 4$ Stunde zu marschieren. Längs des Weges vorgehend, untersuchte ich zunächst die Vegetation und fand dieselben Verhältnisse wie im Yoruba-Lande, nur mit dem Unterschiede, dafs die falsche Kickxia reichlich vertreten war. Auch Sanseviera war vorbanden, an einer Stelle sogar in grofsen Mengen. Von dem Wege in das Dickicht eindringend, sahen wir, dal's die Vegetationsverhältnisse dieselben blieben. An einer stelle, wo sehwerlich sich äufserliche Einflüsse hätten geltend machen können, entnahmen wir darauf 


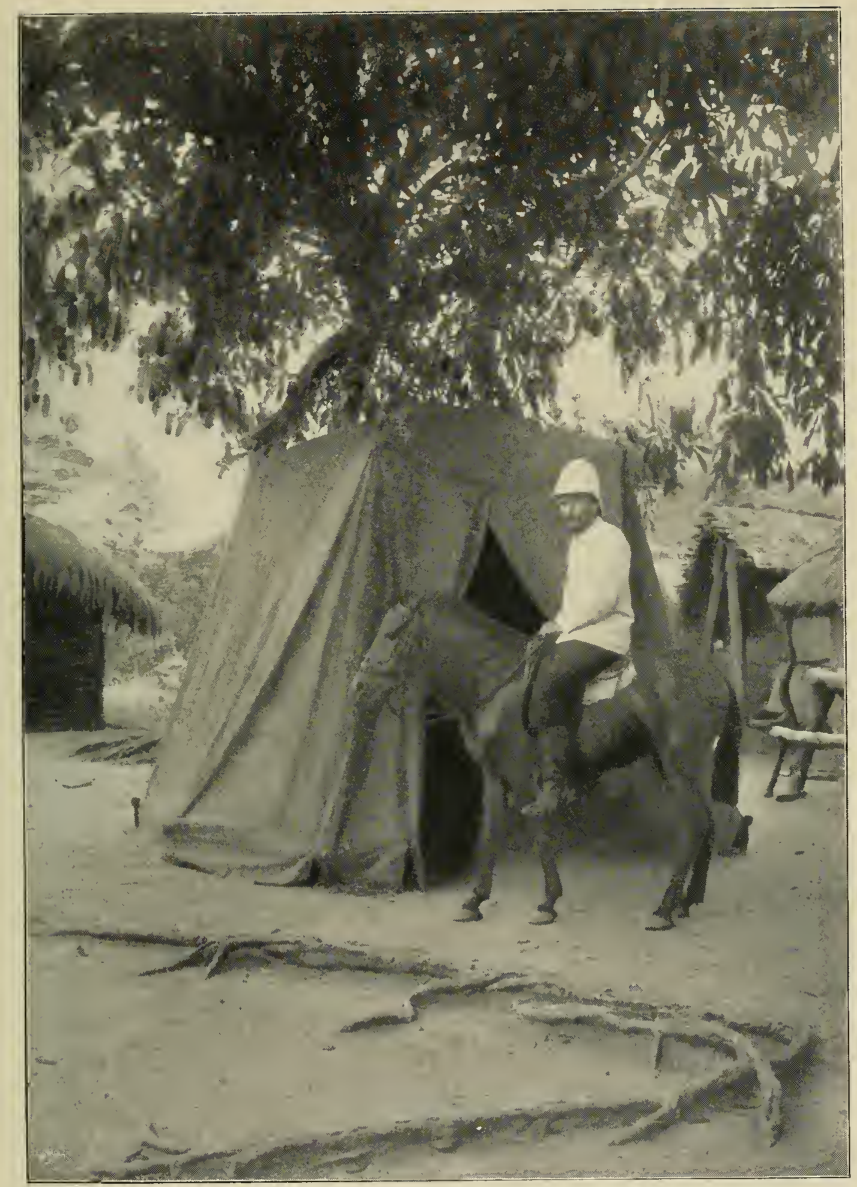

R. Schlechter vor seinem Zelte in Kadyebi. 

noch eine Bodenprobe, welche übrigens auf nicht schlechten Boden schliefsen liefs, in dem Kickxia elastica gut gedeihen würde. Für Tabak dürfte sich dieser Boden des Boëm-Waldgebietes wohl kaum bewähren, wenn er nicht alljährlich künstlich gedüngt würde, wohl aber für Baumwolle, an welche jedoch, solange die Transportkosten zur Küste dieselben bleiben werden, wohl nicht gedacht werden kann. Etwas anderes wäre es anch mit Kola, doch kemmen wir das Wachstum dieser wichtigen Pflanze bis jetzt noch viel zu wenig, um schon Schlüsse auf ihre Ertragsfähigkeit zu ziehen. Nach den Exemplaren zu urteilen, welche ich in Misahöhe gesehen, scheint diese Kultur nicht sehr aussichtsvoll für Plantagen, die in nicht zu langer Zeit doch mit einer gewissen Eimnahme heranskommen sollen, wohl aber als Nebenkultur möglicherweise vorteilhaft $\mathrm{zu}$ sein.

Aın Nachmittage kehrten wir nach Kadyebi zurück, wo ich für meine Leute einen Festschmaus gab, bei dem die Schafe von Borada und das vom Häuptling von Kyasekang erhaltene ihr Leben lassen mufsten.

In schellem Marschtempo verliefsen wir am Morgen des 19. März Kadyebi wieder, um anf demselben Wege, auf dem wir gekommen waren, nach Kyasekang zurückzukehren. In Honda und Gnamang liefs ich je eine Viertelstunde Rast machen, und dennoch trafen wir schon vor 10 Uhr in Kyasekang ein.

Ein alter Haussa-Malam, der hier ansässig war und mir schon bei neinem ersten Durchzuge durch das Dorf einige Yams und ein Huhn als Geschenk gebracht hatte, liefs es sich nicht nehmen, hier wieder mit einem Geschenke zu kommen. Er warf sich dabei immer in ehrfurchtsvoller Weise auf die Knice und berïhrte mit seiner Stirn den Borlen, dabei murmelte er alle möglichen Segenswünsche vor sich him. Es ist merkwürdig, dafs die Haussa, die sich doch sonst hier für höhergestellt halten als die Neger, einem Europäer gegenüber so unterwürfig sind, wie man es nie bei den anderen Eingeborenen sehen wird. Auch unter den Lenten, die mit Kantschuk aus dem Innern kommen, sind viele Haussa, welche dem Europäer sich entweder stets zu Füfsen werfen, oder aber stolz, kanm ein "Salaam“ wünschend, vorüberziehen.

Gegen 1 Uhr liefs ich wierler aufbrechen. Unser Weg fülute nun bedeutend mehr nach Westen. Anf einem vorzüglichen Wege, der auch wieder gut drainiert war, ging es zunächst durch eine Niederung und dann über hügelige Baumsteppen, allmählich emporsteigend nach Kyasekang-Akora, einem Schwesterdorfe des von uns eben verlassenen Kyasekang, das etwa $1^{1 / 2}$. Stunden entfernt lag. Auf einem grofsen Marktplatze liefs ich unter einem wundervollen Feigenbaum das Zelt 
aufschlagen, da wir erst am nächsten Morgen nach Quamikrum weitermarschieren wollten. Akora ist ein kleineres Iorf, welches etwa 200 Hütten besitzen dürfte. Die Eing'eborenen machten einen weniger günstigen Eindruck als die des von uns am Nachmittage rerlassenen Kyasekang. Bis in die Nacht hinein safs ich mit Herrn Thienemann zusammen bei Mondschein vor dem Zelte, über die verschiedensten Fragen unsere Ansichten und Gedanken anstauschend, bis ums doch die späte Stunde zur Ruhe mahnte, zumal da wir wufsten, dals wir am nächsten Tage bis Quamikrum einen langen Uarsch zu machen haben würden.

Am Morgen des 20. März waren wir schon zeitig wieder auf den Wege. Herr Thienemann und die Träger marschierten weit voraus, da ich mit Amusso und den Soldaten zurückgeblieben war, um den Häuptling von Akora zu sprechen. Durch einen ziemlich dichten Wald marschierend, in dem die falsche Kickxia und Landolphien viel vorhanden waren, gelangten wir nach etwa einer stunde zu dem Dörfchen Tomegbe, das nur aıs wenigen Hütten bestand und nach Angabe der Fingeborenen erst seit kurzer Zeit erbaut sein soll. Hier wartete Herr Thienemann mit den Trägern auf mein Eintreffen. Nach kurzer Rast ging es weiter durch dichten Wald, der nur hin und wieder von kleinen Savannen unterbrochen war. Die Wege waren schmal und nicht selten durch gefallene Baumstämme versperrt oder von hohen Wurzeln überlaufen, so dass ich auf dem Pferde tïchtig anfzupassen hatte, damit das Tier nicht zu Falle komme. An den Lianen und dünnen Baumzweigen hing hier in dem Walde nicht selten eine epiphytische Orchidacee, die gerade einen reichen Flor grünlicher Blüten darbot. Sonst war hei ter Art museres Zuges durch diesen botanisch sicher hochinteressanten Wald recht wenig zu sehen, da wir unsere ganze Aufmerksamkeit dem Wege zuzuwenden hatten. Hin und wieder blieb ich rtwas zurück, ım an den Kickxien Anzapfungsversuche zu machen, hatte aber keinen Frfolg mit denselben; immer wieder ergaben die Untersuchungen jene klebrige, wertlose Masse, welche anch bei vielen Ficusarten zu finden ist. Einige Landolphien lieferten g'uten Kantschuk, doch da Blüten und Früchte nicht zu finden waren, liefs sich leider die Art nicht feststellen, aufserdem sah ich mit wenigen Ausnahmen nur dünne Stämme derselben; die dickeren schienen alle hereits von den Eingeborenen ansgeschlagen worden zu sein.

Gegen 9 Uhr erreichten wir ein kleines Farmdörfchen, welches uns die daselbst wohnemlen Eingeborenen als "Indzimaqua" bezeichneten. Anch dieses war erst seit kurzer \%eit erbaut worden. Cinsern etwa 1\%: Stunden währenden Aufenthalt daselhst benutzte 
ich dazu, un mir die Farmen der Leute anzusehen. Es wurden Manihot utilissima, Baumwolle, etwas Mais, Cajanus indicus und Yams gebaut. Für die Yamsknollen erbauen die Lente ans dünnen Stangen luftige Häuschen, in denen die Knollen, welche äufserst leicht faulen und daher sehr vorsichtig behandelt werden müssen, teils an den Wänden einzeln aufgehängt, teils auf einem ebenfalls aus Stangen hergestellten Tische liegend, aufbewahrt wurden. Auf liese Weise trocknen dieselben nach Regen sofort durch den Wind oder sonstigen Luftzug wieder ab und sind daher besser vor Fäulnis greschützt. Dieselbe Art von Yamsspeichern sah ich auch zwischen Liati und Fodome, hatte damals aber keine Gelegenheit, sie näher zu besichtigen. Auf unserm Weitermarsche zogen wir über gröfsere Savannen, welche teils ziemlich regelmälsig mit zerstreuten Bäumen besetzt, teils von kleinen Busch- und Baumgruppen unterbrochen waren. Die Flora auf diesen Savannen war schon interessanter, da nach einigen Grasbränden verschiedene Kräuter erschienen waren. Aufser der über das ganze südliche und mittlere Togo weit verbreiteten Eulophia cristata waren Vernonien, eine Helichrysumart, Cycnium, Striga, Oldenlandia, Acalypha und der prachtvolle Haemanthus Kalbreyeri sehr verbreitet. Besonders der letztere war ein wundervoller Schmuck der saftig-grünen Steppen. Iuf den Bäumen, unter denen besonder's Terminalen, Combretumarten und Butterbäume häufig waren, wuchsen nicht selten Loranthus- oder Viccumarten und eine epiphytische Orchidacee, welche zwar nicht in Blüte war, aber wohl sicher zu Polystachia golungensis gehört, die in Afrika eine merkwürdig weite Verbreitung zu haben scheint. Nach einem Marsche von etwa zwei Stunden erreichten wir den Mkunsu-Flufs, welcher sich hier ein sehr tiefes Bett gegraben hat; derselbe führte zur Zeit nicht viel Wasser, soll aber zur Regenzeit nicht umbedeutende Dimensionen annehmen. Nachdem wir den Mkunsu überschritten hatten, sahen wir balıl larauf das Dorf Quamikrum vor uns liegen; wo ich Amusso mit len Soldaten zurïcklassen sollte.

Das Dorf Quamikrum soll früher eine nicht unbedentende Ortschaft gewesen sein, in der sich hauptsächlich Haussa-Leute anf der Durchreise von dem Inneru zur Küste längere Zeit aufzuhalten pflegten. Als wir damals dort eintrafen, fanden sich mur wenige Familien daselbst, von denen der gröfsere Teil auch durchziehende Hanssa waren. Die Hütten waren zum grofsen Teil stark im Verfall begriffen oder sogar schon vollständig umbewohnbar. Auf lem Marktplatze liefs ich sofort mein Zelt aufschlagen und den Platz umher etwas reinigen, da derselbe wüst nit śchmutz und 
Unkraut bedeckt war. Anch liefs ich sogleich einige der Wege zu beiden Seiten reinigen, da dieselben hänfig nur aus einem schmalen Pfade bestanden, der zu beiden Seiten derartig mit stachligen Amarantusbüschen bedeckt war, dafs man beim Betreten derselben von den Stacheln arg gepeinigt wurde. Auch Amusso liefs alsbald durch die Soldaten einen geeigneten Platz frei machen, auf welchem er die für die Station zı erbanenden Häuser aufzuführen gedachte, und komnte mir schon am Abend mitteilen, dafs diese erste Arbeit vollendet sei. Zum Bau der Häuser waren Einwohner umherliegender Ortschaften beordert worlen, welche am folgenden Tage eintreffen sollten. Am Nachmittage untersuchte ich die Wälder zu heiden Seiten des Mkunsu-Flusses, konnte aber anfser einigen Exemplaren des Ficus Vogelii, von der ührigens im Dorfe Quamikrum selbst verschiedene gröfsere Exemplare standen, nichts finden, das für mich von mehr als rein botanischem Interesse gewesen wäre. In letzterer Hinsicht war ich allerdings glücklicher. Eine interessante grofsblättrige Strychnosart, welche sich hoch in die Bäume hineinwand und in grofsen Guirlanden über den Mkunsu hinunterhing, war nicht selten. Auf den grasigen Hügeln bei dem Dorfe fand ich aufser einigen Scrophulariaceen eine für mich besonders interessante Asclepiadacee (eine Raphionacme) und die für die Steppen so typischen aufrechten Cissusarten, die aus grofsen unterirdischen Knollen entspringen. Am Abend erschienen noch verschiedene Haussa-Karawanen, leren Führer behaupteten, auf dem Wege nach Lome zu sein. Einige führten Kühe bei sich, welche aus Kratschi kommen sollten und nach Amussos Ansicht sicher nach Acra, nicht nach Lome gebracht wurden.

Am nächsten Morgen liefsen wir die Soldaten mit Amusso zurück und zogen nun auf der grofsen Strafse nach Kpandu in fast sïdliche Richtung. Das Gelände wurde etwas hügeliger und bot einen Anblick dar, der mich lebhaft an einige Gregenden in Natal erinnerte. $/ u$ beiden Seiten liatten wir Savannen, welche mit spärlichen Gesträuchen ołer kleinen Bäumchen bedeckt waren; später, nachlem wir ein kleines Farmdörfchen Adenkutschu passiert hatten, traten wir in einen Buschwald ein, in dem sich riesige Mengen der falschen Kickxia zeigten. Auch hier machte ich wiederholt Versuche, ein hrauchbares Produkt aus dem Milchsafte derselben zu gewimnen. Nach etwa dreistündigem Marsche erreichten wir das Dorf Wuropong. Dasselbe soll ungefähr 300 Hütten besitzen. Der Häuptling des Dorfes kam, uns zu begrüifsen, und brachte einige Kalebassen mit Palmenwein sowie einige Eier. Den Palnenwein verteilten wir zum grolsen Teile unter den Leuten, während wir für 
ıns einen kleinen Teil zurückbehielten, der, mit Cognak vermischt, uns vortrefflich schmeckte, da er erst soeben eingebracht und daher noch ganz frisch und kühl war. Bis gegen Mittag liefs ich hier in Wuropong rasten, dann setzten wir den Marsch weiter nach Süden fort. Die nun gut geschulten Träger marschierten jetzt vorzüglich, auch die Weiber blieben nicht zurn̈ck, so dafs die ganze Karawane sich gut geschlossen vorwärts bewegte. Herr Thienemann mit seiner Hängematte zog gewöhnlich voraus, ich beschlofs mit einem oder zwei Jungen den Zug, damit ich, ohne Störung zu verursachen, nach Belieben zu etwaigen Untersuchungen zurückbleiben könnte. Das Gebiet war anfangs hauptsächlich mit Buschwald bedeckt, wo es nicht von den Eingeborenen unter Kultur gesetzt worlen war, später wurden gröfsere Savannenkomplexe, in denen besonders eine Imperataart das vorherrschende Gras war, häufiger. Bald zogen wir durch das kleine Dorf Tapo und nach einer weiteren halben Stunde durch Antumda. Die Gebiete schienen hier fruchtbarer zu werden. Buschwald wechselte mit Elefantengras. Allenthalben waren auch von den Eingeborenen Farmen angelegt, die einen recht günstigen Eindruck machten. Aufser den bereits oben erwähnten Kulturpflanzen sah ich hier auch Hibriscus esculentus angepflanzt und sogar einige Tomaten. Ich glanbe, dals sich hier eine geeignete Gegend findet, die später einmal, wem sich erst der Baumwollban, zu dessen Hebung vom Kolonialwirtschaftlichen Komitee eine Expedition entsendet werden soll, besser entwickelt hat, bei einer gröfseren Anlage in Betracht gezogen werden dürfte. Das Land ist ziemlich eben und offenbar leicht zu bearbeiten. Gegen 2 Uhr nachmittag's erreichten wir das kleine Dorf Kadyevi und gleich darauf N'tschumuru, wo ich beschlossen hatte, Lager für die Nacht zu machen. Auf dem wunderschönen Marktplatze, der durch ein dichtes Dach von Ficusarten beschattet wurde, liefs ich zunächst die ganze Trägerschar einen grofsen Raum gehörig reinigen und dann das Zelt aufstellen. Für Herm Thienemann wurde wieder ein nahe gelegenes Haus gemietet. Nachdem ich meine laufenden Arbeiten erledig't hatte, machte ich einen Ausflug in die Umgebung, welcher aber infolge der dichten Elefantengrasdecke wenig anderes anfkommen liefs als vereinzelt stehende Bäume, unter denen besonders Wollbäume auffielen, und wenige Sträucher. In dem Dorfe selbst waren verschiedene Ficus Vogelii angepflanzt. Gegen Abend stattete mir der Häuptling des Dorfes einen Besuch ab. Als ich bei dieser Gelegenheit fragte, ob der Weg vor uns in gutem Zustande sei, sagte er, dafs er denselben noch schnell zu reinigen befohlen habe, denn seine Leute seien in den letzten 
Wochen viel auf den Feldern beschäftigt gewesen und daher habe sich Gras im Wege eingefunden.

Dafs die Ungebung hier allgemein fruchtbar sein müsse, schien schon aus den grosfen, dreifülsigen Kormspeichern hervorzugehen, welche wir hente in den meisten Dörfer'n sahen. Wir bekamen hier auch allenthalben Reis, Mais und Gruinea-Hirse für mein Pferd, das sich übrigens nicht viel ans denselben zu machen schien, sondern das saftige frische Gras vorzog. Bald erschien anch der Häuptling ron N'Kunya, um sich durch ein Geschenk von Yams, zwei Hühnern und einigen Kalebassen Palmenwein meine Freundschaft zu erwerben. Am Abend mufste ich unter meinen Trägern gegen einige sehr energisch anftreten, weil dieselben kamen und mich daranf aufmerksam machten, lafs ihre Heimat nun nm wenige Stunden entfernt sei und dals sie an folgenden Morgen dorthin zurïckkehren wollten. Fin solches Gelüste mufste ich den Lenten natürlich nehmen. Ich liefs sofort die Namen der Leute notieren mol ihnen nun sagen, dafs ich sie bestrafen würde.

Schon vor 4 Uhr war ich am nächsten Morgen wieder auf, um noch vor unserm Aufbruche einige schriftliche Arbeiten erledigen zu können. Um 5 Uhr gab ich dann das Signal zum Sammeln, so dals wir mit Tagesanbruch auf rlem Wege waren. Ich ritt hente voran. Am Kunya-Gebirge entlang führte unser Weg, zunächst durch Kunya-Klaba und weiter durch ein mit Elefantengras und Imperata hestandenes Savamnengebiet. Wie mir der Häuptling von N'tschmmuru versprochen, waren bereits eine grölsere Anzahl von Lenten dabej, den stark mit Imperatagräsern bewachsenen Weg zu reinigen unıl an feuchten Stellen zu drainieren. Von allen Seiten kamen inmer neue Leute hinzu, um bei dieser Arbeit zu helfen. Noch vor 6 Thr erreichten wir das Dorf Dafo, in dem eben ein kleiner Markt begonnen hatte. Um meinen Lenten Gelegenheit zu geben, hier billig Nahrungsmittel zu kaufen, liefs ich eine halbstündige Rast machen und zahlte ihnen bereits hier die Subsistenzgelder ans. Als wir dann wieder Dafo hinter uns hatten, traten wir in Savannen von ziemlicher Ausdehnung ein, die auch nicht unfruchtbar schienen. Auch hier war das Land etwas hïgelig, was ich der Nähe des Volta-Flusses zuschrieb. Da ich auf meinem Pferle vorausgeritten war, traf ich in rlem Orte Agbonohoe schon vor der Karawane ein. Ohme Rast ınachen zu lassen, ging es damn nach Fesi weiter, wieder durch fruchthare Elefantengras- und Imparatasavannen mit zerstrenten Bäumen und Stränchern. Da ıler letzte Teil des Weges ziemlich von Unkraut überwnchert war, liefs ich den IIäuptling von Fesi kommen und forlerte ilun auf, den Weg reinigen zu lassen, was 


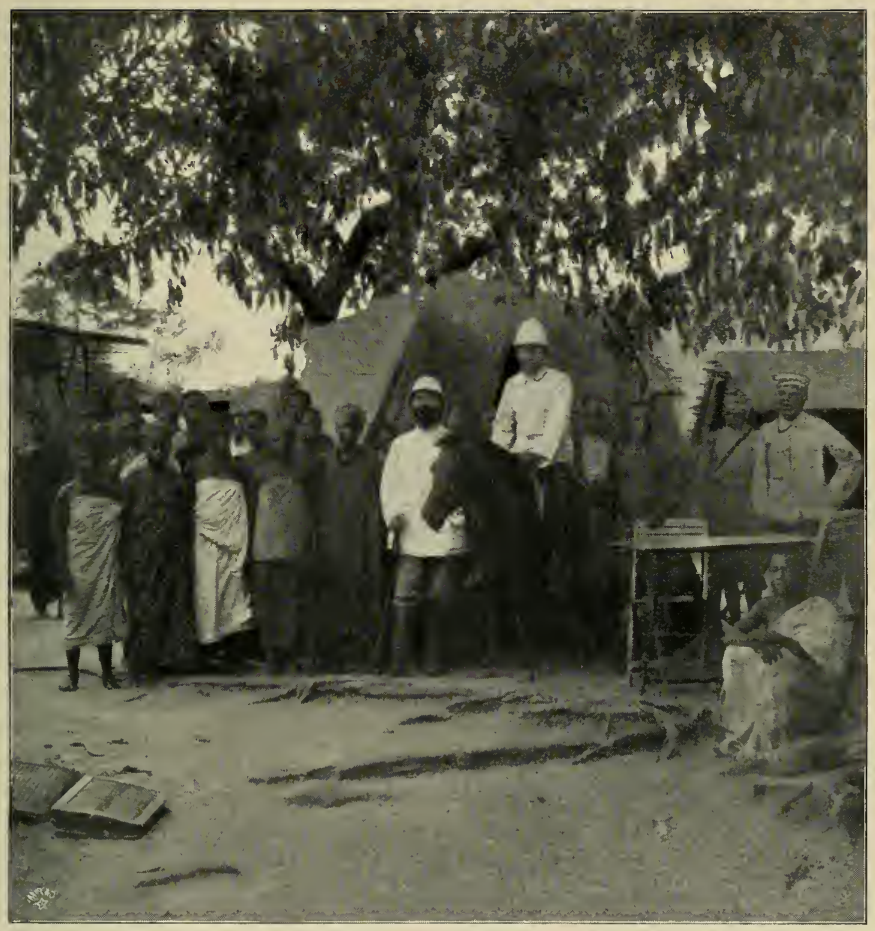

Die Expedition in Kadyebi. 

er sofort zu thun versprach, sobald seine Lente, die zu Arbeiten nach Kpandu gerufen waren, zurückkehren würden. Nachdem meine Karawane, welche unterdessen eingetroffen war, eine kurze Rast gremacht hatte und sich an Kokosnufsmileh gestärkt hatte, liefs ich wierler aufbrechen, um durch Abehung und Alöe nach Kpandu zu gelangen. Die Vegetation und die Bodenverhältnisse blieben dieselben bis kurz vor Kpandu. Erst als wir in die Ebene, in der Kpandu liegt, hinabstiegen, wurde der Boden steiniger und offenbar unfruchtbarer. Von der Missionsstation aus konnten wir das Dorf und, auf einem hohen Felsen oberhalb gelegen, die Regierungsstation Kpaudu bewundern. Ohne durch das Dorf hindurchzuziehen, liefs ich zur Station hinaufmarschieren, wo wir kurz nach $9 \mathrm{Uhr}$ anlangten. Da die Station nicht von Europäern bewohnt war und der farbige Assistent, dem die Verwaltung derselben übertragen war, in deu dahinterliegenden Arbeiter- und Soldatenhäusern seine Wohnm hatte, nahm ich mit Herm Thienemann von den beiden für Europäer bestimmten Räumen in dem Stationsgebäude Besitz. Unsere Lasten liefs ich ebendaselbst unterbringen. Die Träger und Trägerinnen wurden in verschiedene leerstehende Hänser des Stationshofes einquartiert. Bald sah es nun sehr lebendig auf der Station aus. Herr Thienemann und ich stärkten uns nach längerer Zeit einmal wieder an einem guten Glase Bier, das wir hier in Kpandu bekommen hatten. Ich liefs sofort das Essen fertigmachen, da ich die Absicht hatte, zur Volta hinüberzureiten, um auch das Thal des Flusses keunen gelernt zu haben. Gegen 11 Uhr ritt ich, gefolgt von einem Soldaten, der mir als Führer dienen sollte, zur Station linans. Unser Weg führte zunächst über den Hügelrücken, auf lem die Station gelegen ist. Von der Kante dieses Rückens, der plötzlich steil abfällt, hatten wir einen wundervollen Blick über das Thal der Volta, die sich in einiger Entfernung wie ein Silberfaden lahinschlängelte. Mit dem Pferde war der Abstieg in die Ebenen, welche sich unter uns hinstreckten, nicht leicht, besonders da der Weg an einigen Stellen mit Gerölle bedeckt war, auf dem das Tier keinen festen Halt hatte. Ieh mufste daher während des ganzen Abstieges das Tier sehr vorsichtig führen. Als wir in der Ebene angelangt waren, machte sich bald eine Hitze bemerkbar, wie ich sie vorher erlebt zn haben mich nicht erinnern konnte; es war gerade, als ob wir vor einem Backofen standen. Die ganze Ebene trug den Charakter einer typischen Togo-Banmsteppe; das Gras war niedrig, kaum n̈ber $1^{1 / 2} \mathrm{Fufs}$ hoch, von einigen Kräutern und Halbstränchern wie Vernonia, Acalypha, Sopubia, Cycnium, Striga, Eriosemma, Cryptolepis nigritana etc., durchsetzt und war von zerstreut stehenden Bäumen überdeckt. Ganz besonders fiel mir lier der 
Reichtum an Butterbäumen auf, von denen häufig behauptet worden ist, dafs sie ein brauchhares Guttapercha liefern, das aber, so viel ich erfahren, von sehr minderwertiger Qualität ist mud einen so geringen Preis bringt, dals es sich kaum verlohnen würte, dasselbe einzusammeln. Da die Bäume anfserdem nur einen kleinen Frtray geben, so würde die Arbeit, welche mit dem Einsammeln dieses guttaähnlichen Produktes verbunden ist, sich wohl schlecht lohnen, denn, wie ich hörte, werden am Niger, wo man das Gutta auf Teranlassung der Niger-Compagnie einsammelte, die Bäume erst gefällt. In einem Lande wie Togo, wo nur wenig Wälder vorhanden sind und der Bammuchs in den Steppen auch ein äufserst spärlicher ist, kamn uns gar nichts daran liegen, die wenigen Bäume umzuschlagen, nm dadurch eine Einnahme zu erzielen, die zu dem Schaden, der durch ein solches Torgehen herbeigeführt wird, in keinem Verhältnisse steht. Als wir uns nach etwa $1^{1 / 2}$ Stunden der Tolta näherten, hatten wir einige zur Zeit ausgetrocknete Bachbetten zu durchqueren, deren Ufer mit dichtem Gebüsch bedeckt waren. Die Vegetation einiger Sümpfe, die in der Nähe des Flusses lagen, liefs mich rermuten, dafs der Boden salzhaltig sein müsse, demn mit wenigen Ausnahmen traten dort nur ausgeprägte halophile Typen auf. Gegen 1 Uhr erreichten wir endlich die Volta selbst bei dem kleinen Flecken Dogbadja. Nach meiner Schätzung war der Flufs etwa $300 \mathrm{~m}$ breit. Inmitten desselben lag eine Sandbank, auf der sich vorübergehend Fischer angesiedelt hatten. Ich war erstamnt, den riesigen Verkehr hier zı sehen. Allenthalben sah man kleinere und gröfsere Canoes daherschiefsen, die ersteren durch Ruder, die letzteren durch grofse Segel fortgetrieben.

Nach kurzer Umschau an der Volta liefs ich mein Pferd wieder satteln und ritt damn zur Station Kpandu zurïck. Da ich mein Pferd gehörig zur Eile angetrieben, um endlich die heifse Steppe hinter nir zu haben, langte ich schon früh am Nachmittage daselbst wieder an. Da ich in dem Dorfe Kpandn noch verschiedene Einkäufe machen zu können hoffte, benutzte ich die noch übrige Tageszeit zu einem Ritte dorthin. Viel war hier allerdings nicht einzukaufen, doch wurden wir durch einige Dinge, wie Zucker, Bier und andere Kleinigkeiten, wieder aus momentaner Verlegenheit befreit.

In den Faktoreien, die übrigrens sämtlich unter Jeitung von Farbigen stanclen, sah ich hier die anch als Silkrubber gehenden Kautschukkuchen, die nicht, wie ich schon oben erwähnt, von einer Kickxia gewonnen werlen, sondern von der dickstïmmigen Landolphiaart, welche ich bereits beim Liati gesehen hatte. Auch an den Bergabhängen hinter Kpandu hatte ich dic Pflanze gefunden, 
aber auch hier ohne Blüten und Früchte, so dafs ich nicht die Art feststellen konnte. Auf dem Kunya-Gebirge ist nach Angaben der Kautschuksammler diese Liane noch häufig, wird aber auch dort jetzt in einer Weise ausgebeutet, dafs zu befürchten ist, dafs sie nur noch kurze Zeit daselbst vorhanden sein wird.

Gegen 6 Uhr verliefsen wir am Morgen des 23. März die station Kpandu, $и m$ im Dorfe die von mir am Tage vorher gekanften Sachen aufzunehmen; dann ging es unserem nächsten Ziele Misalıöhe entgegen. Gleich hinter Kpandu betraten wir wieder eine trockene Baumsteppe, welche auffallend eben sich weithin auszustrecken schien. Offenbar war der Boden hier weniger fruchtbar als zwischen Wuropong und $\mathrm{K}$ pandu, auch sah man von Eingeborenenkulturen recht wenig. In der sonnigen Steppe, wo das Laub der Schattenbäume fast gar keinen Schatten abgab, machte sich die Hitze des Tages bald unangenehm bemerkber, so dafs wir froh waren, als wir tas Dorf Sobuesante erreichten, in dem wir eine kurze Rast machen konnten. Der Hänptling erschien auch sofort mit einem Huhu und einigen Kalebassen Palmenwein, welcher uns nach dem Marsche lurch die trockene, heifse Steppe ganz besonders gut mundete. Nach kurzem Aufenthalt in diesem kleinen Dorfe setzten wir mit frischen Kräften unsern Marsch durch die Steppe fort, die denselben Charakter beibehielt wie vor Sobnesante. Es war ein heifser Tag, vielleicht einer der heifsesten, welche ich auf der Togo-Reise zu durchleben hatte. Die Träger und Trägerinnen mit ihren schweren Lasten kamen nur langsam vorwärts. Kurz vor Mittag erreichten wir den Ort Bevi, an dem der Daï-Flufs dicht vorbeifliefst. Auch hier kam der Häuptling mit einem kleinen Geschenke, um uns zu empfangen. Da die Hitze des Tages eine zu drückende war und ich befürchtete, dafs von meinen Trägern einige übernüdet werden könnten, liefs ich in Bevi eine zweistündige Rast machen, so dafs die Leute genügend Zeit hatten, ihre erhitzten Körper im Flusse gehörig abzukühlen. Der alte Hänptling schien ein sehr bescheidener Mensch zu sein und nicht viel Achtung zu geniefsen. Sobald er Geschenke mit mir gewechselt, setzte er sich in der Nähe unter einen Ficusbaum und betrachtete das Leben und Treiben ans ler Fintfernung. Zu allerdings unverschämten Preisen wurden hier meinen Leuten getrocknete und gedörrte Fische zum Kauf angeboten. Die Eingeborenen fangen dieselben im Daï-Flusse und benutzen sie im Tausche mit den durchziehenden Karawanen. Da ich aber hörte, dafs sie nuseretwegen die Preise hochgeschlagen hatten, befahl ich meinen Leuten, zu dem geforderten Preise keine Fische zu kaufen. Das half insofern, als nun die Lente von Bevi auch von ihren unverschämten Preisen Abstand nahmen und normale 
Preise forderten, zu welchen meine Lente verschiedenes erstehen konnten.

Während des Marsches von Bevi nach Vime wurde die Hitze in der ausgedörrten Steppe fast unerträglich. Erst als wir uns Vime gegen 4 Uhr näherten, gewamn die Gegend an Interesse. Der Boden wurde wieder fruchtbarer, hier und dort hatten dic Eingeborenen Farmen angelegt, auf denen wir wiederholt grölsere Komplexe mit Baumwolle bepflanzt sahen. Im Dorfe Vime, wo ich eine Rast vou etwa einer Viertelstunde machen liefs, sahen wir wieder verschiedene Prachtexemplare von Ficus Vogelii. In der Nähe unseres Lagerplatzes standen einige Kokospalmen und einige Stauden Zuckerrohr, welche sehr üppig aussahen. Nach weiteren 으 Minuten Marsch durch fruchtbares, ebenes Terrain gelangten wir nach We-Demme, wo ich mein Nachtquartier aufzuschlagen beschlossen hatte. Nach der Begrüfsung des Hämptlings, der mit seinem ganzen (iefolge vor meinem Zelte erschien, um seine Geschenke zu bringen, machte ich einen Rundgang durch das Dorf, wobei ich Gelegenheit hatte, einige Webereien in Augenschein zu nehmen. Die Leute könmen mit ihr^u Webstühlen nur schmale Streifen Zeug weben, die dann zn breiten. äufserst haltbaren Tüchern zusammengenäht werilen. D)as Drehen fler Fäden, das ich besonders in Boëm schon zu beobachten Grlegenheit hatte, bringen die Lente an einer Handspintlel mit grofsem Geschicke zu stande. Ist ein solcher Faden von der gewünschten Länge fertiggestellt, so wird er erst etwas angefenchtet mm dam gespannt, was entweder durch Umspannen zwischen zwei oler mehreren Bäumen geschieht oder dadurch, dals an den zusammengelegten Fäden ein gröfseres Gewicht aus Steinen angehängrt und darlurch die nötige Spannmng erzielt wirl. Die Weber arbeiteten hier sowohl wie in den benachbarten Häusern zumeist in Gesellschaft, in offenen Schuppen, die gewöhnlich zwei Webstühle umschlossen. Von den Eingeborenen werlen diese festen, in Lanrp selbst gewebten, allerdings anch bedeutend tenreren Stoffe den in Europa verfertigten meist minderwertigen Artikeln belleutend vorgezogen. In der Nähe des Dorfes sah ich anch hier in dem Busche wieder einige Exemplare der dickstämmigen Liane, welche den Kpandu-Silkrubber liefert. An Abend veranstaltete dex Häıptling von We-Demme vor meinem Kelte uns zn Ehren einen 'Tanz der' jungen Männer und Weiber, dem ich mit Herm 'Thienemann beiwohnte.

Gegen 6 Uhr früh am 24. März waren wir wieder anf dem Wege üher hïgeliges Trrain, das sich wegen seiner Fruehthark rit bei Anlage von Baumwollplantagen auch empfehlen dïrfte, und ganz besonders, da hier schou jetzt das Centrum der Baumwoll- 


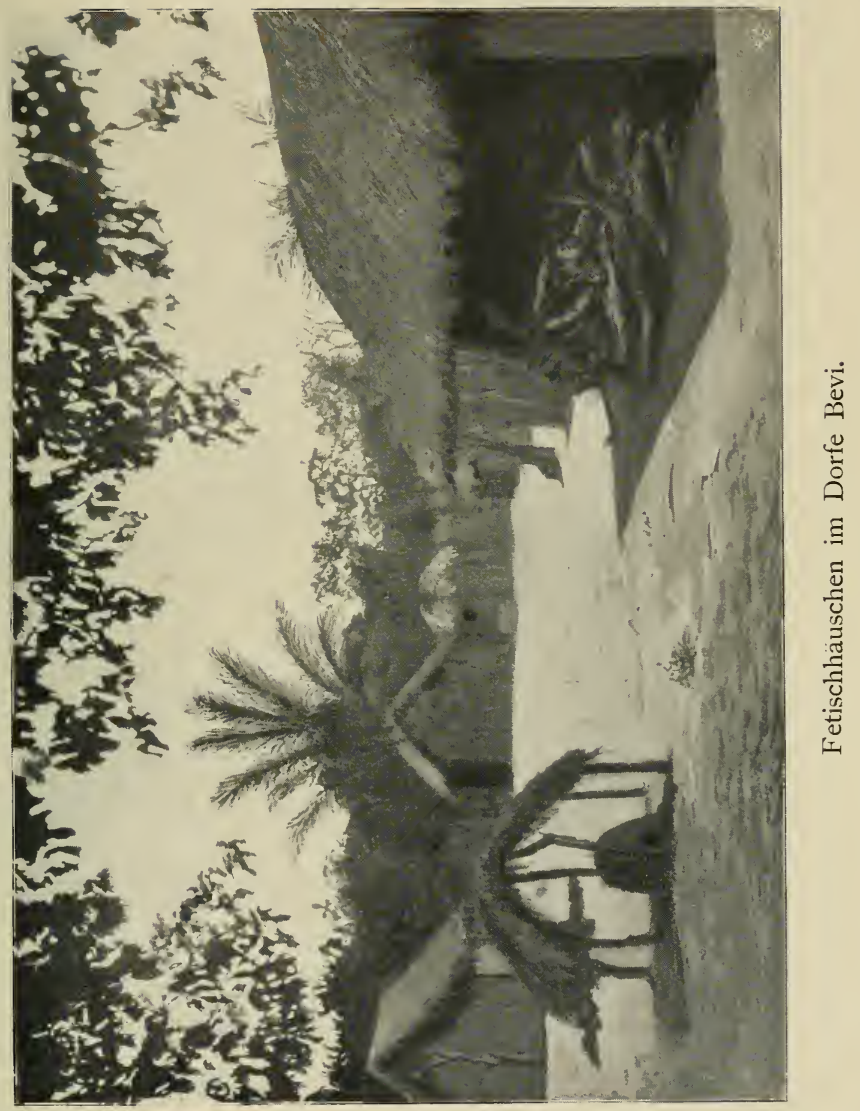



kulturen für die Agome-Region liegt. Wir marschierten durch die nahe bei eimander gelegenen Dörfer Leglebi-Fiapi und Leglebi-Duga und darauf, in bergigere, bewaldete Regionen eintretend, nach Kame, das uns ja schon von der Reise landeinwärts her bekannt war. Unsere Träger und Trägerinnen, welche hier in Kame viele Freunde umcl Verwandte hattén, gerieten anfser sich vor Freule, als sie wieder in die ihnen wohlbekannte Gegend eintraten. (rem hätte ich mit angehört, was sie den Kame-Leuten erzählten, denn diese rissen nicht selten vor Erstammen die Angen weit auf. Ganz besonders aber schien es unser Koch Quodjo zı verstehen, seine Erlebnisse auszuschmïcken, denn um ihn sammelte sich bald ein grofser Zuhörerkreis, in dessen Mitte er sich wie ein junger Gott bewundern liefs, nicht achtend auf das Kichern der Reisegenossen, die sich über die Erfindungsgabe des Burschen nicht genug amüsieren konnten. Nach kurzem Aufenthalte in Kame liefs ich bis Agome-Tongbe weitermarschieren, wo ich eine Frühstïcksrast machen liefs. Auf dem bereits beschriebenen Wege über den François-Pals gelangten wir dann alle frisch und munter gegen 11 Uhr wieder in Misahöhe an, wo mich Dr. Gruner aufs freundlichste aufnahm.

Da nun der Kontrakt mit meinen Trägern und Trägerinnen abgelaufen war, entliefs ich noch am Vormittag'e die ganze Gesellschaft, nachdem sie aufser ihrem Lohne noch den üblichen kleinen "Dash" erhalten hatten. Herr Dr. Gruner sorgte gütigst sofort wieder für neues Trägerpersonal, das er, da ich num nur eine kleine Rundreise im Agome-Gebirge unternehmen wollte und daher nur zehn Träger benötigte, aus Agome-Tongbe beorlerte. Herr Thienemann, welcher begierig war, zu sehen, ob auf der Agu-Plantage alles beim Rechten sei, brach am Nachmittag dorthin auf, nachdem wir vorher verabredet hatten, dals er bis zum Abend des nächsten Tages wieder nach Misahöhe kommen würde, sofern er sich kräftig genug dazu fühlte, dem sein Gesmulheitszustand erschien nicht sehr gut. Ich verblieb auf der Station, wo ich den Rest des Tages in Dr. Gruners und Herrn Frankes angenehmer Gesellschaft verbrachte.

Am Sonntag, den 25. März, ritt ich bald nach Frühstück nach Palime, wo ich hoffte, noch meine Lebensmittel durch Ankauf etwa dort vorhandener etwas ergänzen zu könmen. Fast in Palime angelangt, traf ich auch die Herren Meyer und v. Bruch, welche eben nach Misahöhe hinüberreiten wollten, um Herrn Dr. Cruner einen Besuch abzustatten. Als ich ihnen meine Absichten mitteilte, kehrten sie anch wieder nach Palime zurück, wo wir nun zusammensuchten, was an Efswaren abzugeben war, um dann gemeinsam nach Misahöhe zu reiten, wo wir gegen Mittag eintrafen. Ich liefs anı Nachmittag noch die verschiedenen Lasten zusammenpacken und 
bereit legen, welche ich auf der Rundreise im Agome-Gebirge zu henötigen glaubte. Den Abend verbrachten wir in sehr interessanter Unterhaltung mit Dr. Gruner und Herrn Martin von der Baseler Mission, der auch auf der Durehreise war und die Gelegenheit benutzte, mit Dr. Gruner über versehielene Fragen eingehende Rücksprache zu nehmen. Es war änfserst interessant zu sehen, wie genau Dr. Gruner in jedem Winkelchen seines Distriktes Bescheid wufste, mul wie er gewissermafsen die Seele des Distriktes war, ein jerler, grols und klein, kam, um sich bei ihm Rat zu holen, und überall wulste er zu helfen. Noch spät an jenem Abend kam ein Eilbote von Herrn Thienemann, welcher einen Brief desselben für mich brachte mit der Nachricht, dafs er erst am nächsten Morgen eintreffen werde.

Als Herr Thienemann gegen 7 Uhr am Morgen des 26. März erschien, war auch ich bereits fertig zum Aufbruch. Die 'Träger, unter denen wieder sieben Trägerinmen waren, waren der Aufforderung gemäfs sehon am Abend erschienen, und so stand unserem Aufbruche nichts mehr im Wege. Doch bald stellte sich heraus, dafs Herr Thienemann, der heftig fieberte, nicht im stande sein würde, die beschwerliche Reise, bei ler wir fast kaun Pferd oder Hängematte benutzen konnten, da die Wege ïber steile und felsige Bergrücken gingen, mitzumachen. Schwer folgte er Dr. Gruners und meinem Rate, zurückzubleiben und sieh tüchtig zu erholen. Ich hatte die Träger unter Leitung des Agu-Headmans bereits nach Tongbe rorausgeschickt und den Lenten einschärfen lassen, dafs sie sich wierler sammeln mülsten, sobald meine Signalpfeife in Tongbe erschallen würrle. Begleitet von dem Koch Quodjo und meinem Jungen Afue, verliefs ich die Station erst um 10 Uhr. Auf dem schon zweimal zurückgelegten Wege ritt ich nun über den FrançoisPafs nach 'Tongbe hinüber, wo ich die Trägertruppe zusammenrief, um ihnen die Subsistenzgelder zn geben, damit sie sich in ihrem Heinatsflorfe mit Efsvorräten versehen könnten. Da wir von Tonghe äber sehlechte Wege nach Ashanti-Kpoeta zu marschieren beabsichtigten, so schickte ich meinen Jungen Afue nit dem Pferde nach Leglebi-Abesia, wo ich ihm befahl, spätestens am nächsten Morgen einzutreffen, da ich grlaubte, in der Zeit ïber das Ciebirge dorthin zu kommen. Um 11 Uhr braeh ich damn mit meiner Karawane sellsst anf. Dicht hinter Tonghe stieg der Weg ziemlich steil an über einen grasigen Rücken. Hinige ebenere Teile dieses Gebietes und besonder's rinige der feuchteren Thäler dürften sich für Baumwoll- und 'Tabakkultur eignen, während die bewaldeten Rücken mir für Kickxiakultır wie gresehaffen erschienen. Es war eine gransam. 'Tour äher diese Berge und Thäler für die Lente mit 
ihren Lasten; steile Berge und tiefe Thäler wechselten beständig. Nur selten konnten wir über ebeneres Terrain marschieren. In den Wäldern waren falsche Kickxien und Landolphien, die guten Kautschuk gaben, häufig anzutreffen. Bei etwaigen Kulturanlagen hier in dem Gebiete, das zum gröfsten Teile Besitz des Herrn Sholto Douglas ist, wäre es wohl wünschenswert, dafs man diese Lianen möglichst schonte, denn wenn eiumal vorhanden, bedürfen sie gar keiner Pflege mehr und dürften bei vorsichtigem Anzapfen loch immerhin eine gute Nebeneinnahmequelle der Plantage bilden. Nach Überschreiten verschiedener Bäche, unter denen der AvhlivaBach der bedentendste war, gelangten wir an den Rand eines grolsen Thalkessels, in dem die Ḱpoeta-Dörfer zu sehen waren. Der Abstieg in diesen Kessel war recht beschwerlich und kounte nur langsam vor sich gehen. Unten angekommen, erreichten wir bald rlas Dorf Akhim-Kpoeta, in einer fruchtharen Ebene gelegen, und nach weiterem kurzen Marsche das heutige Endziel unserer Reise, AshantiKpoeta. Es war auffallend, dafs sich bei unserem Einzuge daselbst keine Menschenseele sehen liefs. Ich liefs ruhig unter einem grof'sen Lecaniodiscus-Baume einen Platz reinigen und forderte damn die Träger anf, sich mit den Kpoeta-Lenten anzufreunden und sich ein Nachtlager in den Hütten zu suchen. Da meine Träger aus der näheren Umgebıng. stammten und auch Bekannte unter den Kpoeta-Lenten hatten, war auch dieses bald gethan, doch immerhin blieb es merkwürdig, dafs die sämtlichen Leute in ihren Häısern verblieben. Ich schrieb lieses Verhalten nicht dem bösen Willen zu, sondern der Furcht vor len Weifsen, und wunderte mich daher auch nicht, als mein Koch und der Headman kamen, um mir mitzuteilen, dals die Leute mir weder Eier noch Hühner verkaufen wollten. Es ist unter den Negern Afrikas eine allgemein verbreitete Ansicht, dafs ein böser Zauberer im stande ist, jemandem Böses anzuthm, sobalıl er in Besitz eines Gegenstandes kommt, welcher dem Betreffenden gehört. So erklärte ich mir häufig auf meinen Reisen die Abneigung der Eingeborenen, lem Europäer irgend welche Artikel zu verkanfen, obgleich er doch häufig eine für seine Verhältnisse sehr hohe Bezahlung clafür bekommen würde. Hier in Kpoeta vermutete ich ähnliches. Wie ich elwartet hatte, hiefs es, niemand sei da. Den Nachmittag benutzte ich lazu, um das Terrain, auf dem die Kpoeta-Dörfer erbant sind, näher in Angenschein zu nehmen. Der grölsere Teil der Fläche bei AshantiKpoeta besteht aus sehr fruchtbarem Boden, der für ausgedehnte Kulturen wohl geeignet wäre. Die sämtlichen Wälıler des Agone-Gebietes sind fïr Kickxia-Anpflanzungen wohl ohne Zweifel sehr gut geeignet und infolge der einfachen Transportverhältnisse zur Küiste besonders für ein lerartiges Unternehmen zu empfehlen. (rearle 
die doch nicht unbedeutenden Transportunkosten sind es, welche bei irgend welchen kolonialwirtschaftlichen Unternehmungen fast alle Distrikte im Innern mit Ausnahme des Misahöhe-Distriktes ausschliefsen. Was würde es nützen, wemn wir wissen würden, dafs irgend welche landwirtschaftlichen Produkte im Innem reichlich vorhanden sind oder angezogen werden könnten, wenn sich die Transportunkosten höher stellen, als das betreffende Produkt wert ist. Mit Kautschuk und Kola wäre es nun allerdings etwas anders, da ersteres seines Wertes wegen einen Transport aus dem Innern wohl verlohnt, für Kolanüsse aber gute Absatzgebiete im Lande selbst rorhanden wären.

Später erschienen Kpoetaleute um mir Geschenke zu bringen, doch war ich erstaunt, dafs sich der Häuptling nicht sehen liefs. Als ich mich am Abend bereits schlafen gelegt hatte, kam endlich ein alter Neger mit einer ganzen Schar von Leuten, un mir Geschenke zu bringen. Da ich nicht die Absicht hatte, mich nochnals anzukleiden, liefs ich ihm sagen, er solle nur am nächsten Morgen zeitig wiederkommen, jetzt sei es schon zu spät.

Am nächsten Morgen, noch bevor die Sonne aufgegangen, kam die ganze Gesellschaft wieder mit ihren Geschenken. Der alte Mann bat nun um Entschuldigung, dafs man mir kein Huhn geschickt habe, doch es gäbe in letzter Zeit keinen richtigen Häuptling mehr bei ihnen, und daher labe niemand gewufst, wer die Sache übernehmen solle, nun seien sie gekommen, alles wieder gut zı machen. Ich bekam dann vier Hühner und eine Anzahl Yamsknollen sowie Reis als Geschenk, das ich durch ein Geschenk von Tabak zur grolsen Freude der Leute erwiderte.

Von Ashanti-Kpoeta un 6 Uhr aufbrechend, stiegen wir wieder langsam auf die Berge und gelangten dann in ein ziemlich zerrissenes, dicht bewaldetes Terrain, auf dem die falsche Kickxia wieder einer der hauptsächlichsten Urwaldbäume zu sein schien. Auch Landolphien und Strophanthus, besonders die erstere häufig, waren anzutreffen. Nachdem wir verschiedene Thäler überschritten hatten, gelangten wir auf ein zicmlich grofses, dicht bewaldetes Plateau, von dessen Rande aus wir eine wundervolle Aussicht über dir Jeglebi-Ebene bis hinter Kpandu und zum Kunya-Gebirge hatten. Ich liefs hier eine kurze Rast machen, um dann den sehr schwierigen steilen Abstieg zn beginnen, der für die Leute mit ihren Lasten nicht ohne Gefahr war. Der ganze steile Bergabhang war mit dichtem Buschwald bedeckt, der so niedrig war, dafs die Lasten der Leute nicht selten zwischen den \%weigen festsafsen, so dafs schon leshalb ein vorsichtiger Ahstieg geboten war. An vielen Stellen 


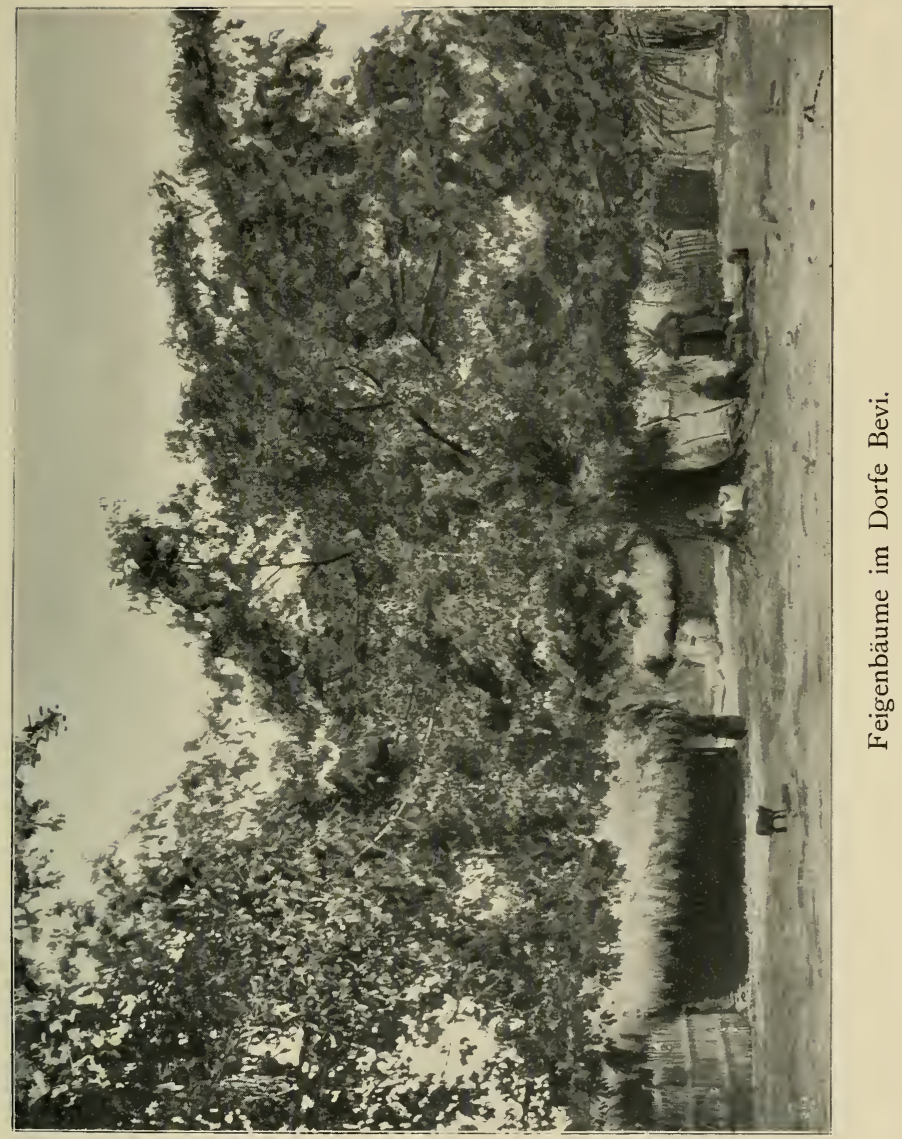



war der Pfad so steil, dafs ich mich wundern mulste, dafs alle Leute, ohne Schaden erlitten zu haben, schliefslich unten in der Ebene anlangten. Die Ebene, welche wir nun zu durchziehen hatten, bevor wir Leglebi-Abesia erreichten, war offenbar sehr fruchtbar, besonders in der Nähe des Gebirges. Da, wo nicht Wald das Terrain bedeckte, war es dicht mit den riesigen Halnen des Elefantengrases bewachsen. Überall zeigte sich eine wunderbare Üppigkeit. Kurz nachdem wir las ehenalige nun abgebrannte Dorf passiert hatten, zogen wir in dem neuen Leglebi-Abesia ein. Afue mit dem Pferde war bereits am frühen Morgen eingetroffen und hatte schon für ein schattiges Haus für mich gesorgt, da das erst in jüngerer Zeit wieder anfgebaute Dorf noch gar keine Schattenbäume besafs, unter denen man einigermafsen vor den Strahlen der Sonne geschützt gewesen wäre. Ich hatte mit Herru Thienemann verabredet, daf's er, falls eine Besserung in seinem Gesundheitszustande eintreten sollte, mir nach LeglebiAbesia nachkommen solle, doch war von ihm hier nichts zu sehen noch sonst eine Nachricht für mich eingelaufen. Ich machte hier einige kleine Ausflüge, um mich über die Kautschukverhältnisse der Wälder za orientieren, fand aber die Aussagen der Eingeborenen, lafs die Lianen meist schon ausgeschlagen seien, bestätigt. An Nachmittage setzten wir auch über kulturfähiges Land unsere Reise nach Leglebi-Fiapi fort und machten dann in Leglebi-Duga Halt, um unser Nachtlager daselbst aufzuschlagen.

Zeitig am Morgen des 28. März liefs ich wieder aufbrechen. Über Kame ging es in die Kame-Schlucht hinein, wo ich mich plötzlich über Hämmern und Schlagen in der Nähe wundern mufste. Als wir uns dem Tii-Flusse näherten, sah ich dann zu meiner Überraschung, dafs Dr. Gruner mit Tongbe-Lenten im Begriffe stand, eine Brücke über den zur Regenzeit nicht selten unpassierbaren Bach zu bauen. Auch er hatte mich noch nicht zurückerwartet. Ich liefs meine Leute nun hier rasten, um mit Dr. Gruner einige Zeit verweilen zu können. Herr Thienemann und Herr Franke erschienen auch bald auf der Bilılfäche. Ersterer sah furchtbar angegriffen aus. Die ungewohnte lange Boëm-Reise hatte ihn offenbar mehr angegriffen, als er sich selbst eingestehen wollte. Meine Karawante schickte ich gegen Mittag nach Tongbe voraus und folgte dam selbst nit Herm Thienemann am Nachmittage. In AgomeTongbe trafen wir mit den Herren ans Palime zusammen, die anf Ier Reise nach Kpandı waren, ım daselbst in den Faktoreien ihrer Firmen Inventar aufzunehmen. Um 3 Uhr liefs ich die Karawane wieder zusammentreten und nach Misahöhe aufbrechen, wo wir bald larauf eintrafen. Herr Dr. Gruner nnd Herr Franke erschienen kurz nach mus. Noch am Nachmittage lohnte ich meine 
Träger und Trägerinnen ab und schickte sie wieder nach Tongbe zurück, đla Dr. Gruner für die Reise nach der Küste hereits neue Leute für mich bestellt hatte.

Bei lem rastlosen Arbeiten des Herrn Dr. Gruner war es nach seiner Krankheit durchaus notwendig, dafs er sich eine kurze Erholung gönne und sei es nur für einige Tage. Ich setzte daher alle Hebel in Bewegung, um ihn zu bewegen, mich nach Amedjovhe zu begleiten, wohin er schon längst eine kleine Erholungsreise zu machen beabsichtigt hatte. Zu meiner Frende war er schliefslich doch dazı bereit, falls ich bis zum 30. März auf ihı warten würde. Gern willigte ich natürlich darin ein, denn eine Reise mit ihm mulste für mich von ganz besonderem Interesse sein. Śchon am Abend des 28. März kamen meine neuen Träger (fünfausgesucht starke Mämmer aus Kpime) an. Am 29. März ritt ich zusammen mit Dr. Gruner zur Kame-Schlucht, wo er den Brückenbau leiten wollte. Soweit dieses in meinen Kräften stand, half ich ihm dabei. Am Nachmittage war damn die Sache so weit gediehen, lafs wir die Eingeborenen allein die Arbeit fortsetzen lassen konnten.

Schon am Morgen des 30. März hatte ich die Träger vorausgeschickt, um dann selbst der Karawane nachzufolgen. Herr 'Thienemann blieb auf Misahöhe zurück, unı, sobald er wieder hergestellt sei, nach lem Agu zurückzukehren. Mit Dr. Gruner, welcher noch ror seiner Abreise sehr viel Amtsgeschäfte zu erledigen hatte, wollte ich in Agome-Palime wieder zusammentreffen. In Kussundu, einem Dörfchen vor Palime, holte ich meine TrägerKarawane wieder ein und zog nun mit derselben nach Palime, wo ich noch verschiedene Einkäufe machte, während ich auf Dr. Gruner wartete, der etwa eine Stunde später eintraf. Das ganze Gebiet un Agome-Palime herum würde sich zur Anlage von Baumwoll-Versuchsplantagen eignen. Vor allen Dingen würden von hier aus die Transportkosten nach der Küste nicht so bedeutend sein. Ich habe zwar die Überzeugung, dals wahrscheinlich die Umgebung der Leglebi-Dörfer noch geeigneter zu den Versuchen sein würde, da dort auch der Boden l.esser zu sein scheint, doch hätte man bein Transporte von dort nach ler Küste pro 30 Kilo einen Tagreslohn mehr für die Träger in Verrechmung zu bringen.

Die Reise des Herrn Dr. Gruner nach Amedjovhe war für die Eingeborenen sehr überraschend gewesen. Durch Folove und Kpalave marschierten wir lindurch und bogen dann von der Strafse nach $\mathrm{Ho}_{0}$ ab. Erst durch fruchthares Gröande marschierend, dann über pinen steinigen Hügelrücken steigend, grelangten wir, nachdem wir noch las Iörfchen Ahudju passiert, gegen 4\%/2 Uhr nachmittags nach Wuanme. Hior beschlossen wir üher Nacht zu bleiben. Jeh gah 
nun sofort den noch ungeschulten Kpime-Leuten Instruktionen im Aufstellen des Zeltes. Bald stand alles in bester Ordnung; meine Lasten wurden, wie gewöhnlich, in meinem Zelte nntergebracht. Dr. Gruner hatte für sich und seine Soldaten einige Häuser in der Nähe erstanden. Nachdem wir unser Abendessen eingenommen hatten, safsen wir beide Europäer noch gemütlich plaudernd bis 1 Uhr vor meinem Zelte.

Dr. Gruner hatte mich gebeten, das Signal zum Sammeln am Morgen zu geben. Ich rief daher die Leute $\mathrm{nm} 5^{1}, 2$ Uhr am folgenden Morgen zusammen, und nachdem die Lasten fertig gepackt waren, schickten wir die Träger nnter Leitumg eines Soldaten voraus. Dr. Gruner und ich folgten mit den Soldaten bald nach. Wir hatten zmnächst ein hügeliges Land vor uns, das bald in eine prachtvolle, fruchtbare Ebene abfiel, anf die ich hier ganz besonders aufmerksam machen möchte. Diese Ebene ist gnt bewässert und würde bei Anlagen von Baumwoll-, Tabak- und Sisalplantagen sicher einer näheren Beachtung wert sein. Besonders gutes Gelände durchzogen wir, nachdem wir Moendn passiert hatten. Anch vor Khonuta sahen wir wieder ganze Strecken, welche sich vorzüglich für bessere Kulturen eignen würden. In Khonnta warteten unsere Träger auf uns. Wir schickten das Gros derselben aber weiter nach Aflime und behielten nur wenige Lasten zurück, welche wir nötig. hatten, da wir hier eine kleine Frühstückspanse machen wollten.

Auch das Gebiet zwischen Khonuta und dem Fulse des Amedjovhe-Gebirges bei den Kpedje-Dörfern scheint recht fruchtbar und einer Beachtung wohl wert. In dem Dorfe Aflime gab es viele Kokospalmen, an deren Früchten sich unsere Träger ergötzten. Anch Dr. Gruner und ich liefsen uns einige Nüsse öffinen, um die erfrischende "Milch" derselben zu trinken. Un $11 \mathrm{Uhr}$ brachen wir wieder auf. Der Marsch auf das Gebirge war recht anstrengend für die Lente, da der Weg sehr steil war, wir mufsten auch von den Pferden hermnter, um sie hinauf führen zu lassen. Oben angelangt, traten wir in einen grofsen Wald, der sich über ılen ganzen Höhenrücken erstreckte. Nach etwas $3 / 4$ stündigem Marsche, welcher auch fast ausschliefslich durch ein an falschen Kickxien sehr reiches Waldgebiet führte, in dem die Eingeborenen leider bereits anfingen, gröfsere Strecken zur Anlage von Bananenpflanzungen niederzubrennen, gelangten wir an den Ful's der kleinen Bergkuppe, auf der $770 \mathrm{~m}$ über dem Meeresspiegel die Missionsstation Amedjovhe erbaut ist. Von dem Missionar, welcher die Station leitete, wurden wir äuf'serst liebenswürdig empfangen.

Da ich nicht Zeit genug hatte, mich länger hier aufzuhalten und llaher bereits am nächsten Morgen die Reise nach der Küste, welche 
ich auf Dr. Gruners Wunsch durch die Landschaft Agotime zurückzulegen beabsichtigte, antreten wollte, so unternahm ich noch unter ıer Führung unseres liebenswürdigen Wirtes am Nachmittage einen kleinen Spaziergang zur Besichtigung der Station. Landwirtschaftliches war weniger zu sehen. Vor allen Dingen war Kaffee angepflanzt, der sehr gut zu gedeihen schien und reichlich Früchte angesetzt hatte. Es waren zwei Arten hier in Kultur, die erstere, ler Liberia-Kaffee, stand zwar gut, doch erschien an den meisten Beeren kurz vor ihrer Reife ein Pilz, der dieselben damn in Kürze zerstörte und vollständig schwarz färbte. Anders war es mit iler zweiten Axt; dieselbe ging als Coffea arabica, schien mir aber von dieser verschieden zu sein; über nnd über waren die Bäumchen mit Blüten und Früchten schwer beladen. Auch schien die Frucht sehr gut zu sein, und das daraus hergestellte Getränk hatte einen sehr guten Geschmack und ein vorzügliches Aroma. Inwieweit sich die Kultur dieser Kaffeevarietät im grofsen lohnen würde, lälst sich nicht sagen, da meines Wissens nie Prohen dieses Kaffees zur Begutachtung nach Europa greschickt worden sind. Da die klimatischen und geologischen Verhältnisse des Amerljovhe-Gebirges denen des Agome-Gehirges vollständig gleichen, so kann wohl mit ziemlicher sicherheit angenommen werden, dafs diese Kaffeespezies auch dort sehr gut gedeihen werde. Mit grofsem Erfolge wurde hier auch Rinderzucht getrieben; vor allem gediehen die Kühe ausgezeichnet. Die Pferde, welche auch vorzüglich heranwuchsen, zeichneten sich durch guten, kräftigen Körperbau aus, wurden aber häufig von einer eigentümlichen Krankheit befallen, die nach den Schilderungen unseres Wirtes ıler Pferdekrankheit von Südost-Afrika ähnlich zu sein scheint. Auch lie Schafe sahen gesund aus, gehörten aber einer kleineren Art an, die sich wohl bei Vergrölserung der Zucht weniger empfehlen würde.

Fern wäre ich noch am nächsten Tage in Amedjovhe verblieben, um die Wälder der Umgebung näher kemnen zu lernen, doch bei derartigen Reisen mufs man mit Eventualitäten rechnen, die einem unterwegs manchmal ziemliche Keit rauben können; deshalb zog ich es vor, bei neiner ursprünglichen Absicht zı bleiben und wirklich abzuziehen. Dem von mir erhaltenen Befehle gemäfs, erschienen meine 'Träger auch um 6 Uhr morgens am 1. April aus dem nahe gelegenen Eingeborenen-Dorfe, in dem sie während der Nacht unteryeloracht worlen waren. leh schickte die Karawane voraus und folgte damn um 6 $6^{1} / 2$ Uhr selbst zu Pferde nach. Der Abschied vou Dr. Gruner, dem ich den glatten Verlauf meiner ganzen TogoReise zu verilanken hatte, wurde mir ordentlich schwer. In Salame, dem ersten kleinen Dorfe an Fulse des Gebirges, holte ich meine Lesute ain und marschierte num mit ihnen nach Aflime, wo 
ich noch einige Stämme des Ficus Vogelii anzapfte. Daranf ging es in schnellem Marsche bis Moëndu, wo ich meinen Lenten zwei Stunden Zeit gab, Essen zu kochen. Kaum hier angekommen, wurden wir von einem Eilboten des Herrn Dr. Gruner eingeholt, der mir noch einen Abschiedsgruls in Form eines Paketes Cigarren ïberbrachte, die mir hesonders willkommen waren, da ich vor einigen Tagen die letzte der meinigen anfgerancht hatte. Von Moëndu um Mittag abmarschierend, zogen wir fast direkt nach Süden, anf einem anf der Sprigadeschen Karte von Süd-Togo nicht aufgezeichneten Wege, der direkt nach Klave führt. Der Weg war nicht in besonders gutem Zustande, doch immerhin gut genug, dals man ihn zu Pferde zurücklegen konnte. Dicht hinter Moëndu überschritten wir zum ersten Male den Todjië-Bach, welchen wir noch häıfig sehen sollten. Die Vegetation des ersten Teiles zu beiden Seiten des Weges bestand aus Buschwald, der eine grofse Menge Ölpalmen leherbergte. In diesem Buschwalde war auch Ficus Vogelii ziemlich verbreitet. Nachlem wir etwa eine Stunde marschiert waren, trafen wir auf einen Trupp eingeborener Jäger, welche soeben drei Pinselohr-Schweine greschossen hatten. Ich verabredete mit den Leuten. dafs ich ilmen in Klave einen Teil eines Schweines abkanfen werde, falls sie sich beeilen würden, eines der Tiere dorthin zu bringen. Nachdem wir aus dem Buschwalde herausgetreten waren, kamen wir in eine steinige Baumsteppe, welche für mich, als Botaniker, manches Interessante geboten, wenn ich die Zeit gehabt hätte, mich dort aufzuhalten. In Klave liefs ich num eine kurze Rast machen, his die Eingeborenen mit dem erlegten Schweine erschienen, von dem ich für mich und meine Träger eine Hälfte erstand. Von Klave lis Shia war nur eine gute Marschstunde über ein Baumsteppengebiet, ähnlich dem zwischen Moëndu und Klave, aber weniger steinig. Ich liefs in Shia gar nicht rasten, da ich nicht wulste, wie lange wir noch bis Nyive zu marschieren haben würlen, wo ich das Nachtlager machen wollte. Anch hinter Shia setate sich anfangs die Steppe weiter fort, doch bald wurde das Land wieder fruchtbarer, als wir uns dem Todjië wieder näherten; denselben hatten wir vor Nyive noch zweimal zı überschreiten. Zu unserem nicht weringen Erstaumen mündete unser Fufsweg plötzlich in einen wundervoll rein gehaltenen breiten Weg, der uns über einen kleinen Hügel llirekt auf Nyive zu führte. Unterdessen hatte sich der Himmel belenklich rerdunkelt, so dafs ich meine Leute zu möglichster Eile antrieb, da ich jerlen Angenblick einen heftigen Gewitterregen erwartete. In Nyive angekommen, liefs ich sofort das Zelt unter einem wumlervollen Milletiabaum aufschlagen und die Lasten, da der Regen eben begann, hineinbringen. Dieser Gewitterregen mufs eine Wohl- 
that für die Umgebung gewesen sein, denn zwischen Klave und Nyive begannen die nach dem ersten Regen aufgesprossenen Kräuter bereits wieder zu welken. Der Regen danerte bis gegen 5 Uhr an nächsten Morgen in mehr oder minder leichten Schauem an.

Als ich am 2. April sah, dafs sich der Himmel klärte, lief's ich die Lente wieder antreten, und weiter ging es, ohne auf den Wunsch des Häuptlings zu hören, der mich bat, doch noch zu verweilen, da er mir ein Geschenk schieken wolle. Da wir den Weg von Nyive nach Atikpui nicht kannten, bat ich den Häuptling um eineu Führer dorthin. Ohne lange dadurch aufgehalten zn werden, erhielt ich einen jungen Mann, der uns führen komnte. Infolge des Regens war das Gras in den Steppen noch vollständig nals, so dafs ich, als ich vom Pferde abstieg, um einige interessante Pflanzen zn sammeln, total durchnälst wurde. Die Steppe wcchselte hier mit kleinen Buschpartien, zwischen deren nassen Büschen wir uns manchmal derartig hindurchwinden mufsten, dafs bereits einige der Lasten ganz durchnälst schienen; doch bald war dieser Schaden wieder geheilt, als die Sonne höher stieg und alles abtrocknete. In Atikpui hatte ich mich eine halbe Stunde aufzuhalten, da ich mir einen neuen Führer bis Nyitoe suchen mufste. Da von den umherstehenden Leuten keiner einwilligte, mufste ich erst den Häuptling rufen lassen, der mir dann sofort den gewünschten Mann stellte. Ein grofser Teil der Strecke, welche wir nun vor uns hatten, besonders nach Nyitoe zu, dürfte zu den fruchtbarsten Teilen der Landschaft Agotime gehören, soweit ich sie kennen gelernt habe. Anfangs hatten wir wieder eine sterilere Baumsteppe vor uns, doch nachdem wir den Todjië abermals überschritten latten, wurde das Terrain recht interessant. Hier dürften sich grofse Strecken für Baumwoll- und vielleicht auch für Tabakbau eignen. Besonders gut schien das Gebiet zwischen dem Todjië und dem Kedjo. Ich möchte hier jelloch, um Mifsverständnisse zu vermeiden, darauf aufmerksam machen, daf's ich, wenn ich von gutem fruchtbaren Gebiete schreibe, nur die Togo-Verhältnisse im Auge habe, da es sich hier nur um die eventuelle landwirtschaftliche Entwickelung dieser Kolonie handelt. In einem von der Natur so reich beschenkten Lande, wie dasjenige am Kamerun-Gel)irge, würden natürlich selbst die für Togo fruchtbar geltenden Orte als geringwertig angesehen werden. Ich möchte daher hesonders davor wamen, etwa die wirtschaftlichen Verhältnisse des Gebietes an Kamerun-Gebirge auf Togo zu übertragen, denn dies müfste notwendigerweise zu einem Fiasko führen, schon da, abgesehen von der sehr verschiedenen Beschaffenheit des Bodens, die meteorologisehen Verhältnisse ganz andere sind.

Kurz vor unserm Einzuge in Nyitoe überschritten wir noch den Kedjo, der sich hier mit rlem Todjië vereinigt. Wie fast alle Dörfer 
im südlichen Togo, hat auch Nyitoe seinen Fetischplatz, bevor man in die Stadt kommt. Eine besonders wichtige Rolle scheint an solchen Plätzen eine Jatrophaart zu spielen, welche man stets als Umrandung dieser Fetischplätze angepflanzt sieht. Die Form der Plätze ist sehr verschieden, ebenso die Lage derselben. Überall werden sie sehr reinlich gehalten. In Nyitae sah ich zum ersten Male die für Agotime charakteristischen merkwürdigen Thorhäuser, welche, gröfser als die anderen Häuser erbaut, den Eingang zum Marktplatze bilden. Auch ein Eisensehmied war dicht neben unsern Lager auf dem Marktplatze in voller Thätigkeit und bewies trot\% seiner recht primitiven Instrumente eine grofse Geschicklichkeit. Gegen 12 Uhr von Nyitoe aufbrechend, marschierten wir durch Sukpe, ein Dorf, das ebenso grofs wie Nyitoe und von diesem nur durch eimen schmalen Buschwaldstreifen getrennt ist. Allenthalben, wo ich mich hier in Agotime zu Pferde sehen liefs, liefen die Frauen und Kinder davon, als ob der Gottseibeiuns käme, und wurden erst wieder beruhigt und zutraulicher, wenn sie sahen, lafs auch meine Leute sich an das Pferd heranwagten. Interessant war übrigens, dafs in den sämtlichen Buschwäldern, welche wir südlich vom Amedjovhe-Gebirge durchzogen, keine Spur der falschen Kickxia zu finden war. Es scheint, dafs ihre Südgrenze etwa die fregend am Fufse des Amedjovhe-Gebirges ist. Landolphien waren hin und wieder zu sehen, doch selten in stärkeren Exemplaren. Ficus Vogelii ist allenthalben in den Dörfern von Süd-Togo wie Mittel-Togo als Schattenbaum auf Marktplätzen angepflanzt. Von Sukpe nach Apegame ging der Weg über ziemlich trockene Savannengebiete, die mehr oder minder spärlich mit kurzen Bäumen bedeckt waren, an einem kleinen Farmdorfe vorbei, für welches uns die dort wohnenden Leute den Namen Kpadjakho angaben. In der Steppe gab es sehr viele Borassuspalmen, deren Früchte von den Eingeborenen hin und wieder genossen werden. Die Kinder saugen gern die süfsliche, fleischige Pulpa aus, welche die Nüsse, deren stets drei zusammensitzen, umschliefsen. Als wir kurz hinter Apegame eben den Todjië wieder überschritten hatten, wurden wir inmitten der Steppe von einen sehr starken Regen überrascht, der uns bald vollständig durchnälste. Da wir bereits eine ziemliche Strecke von den letzten Häusern entfernt waren, war es unnütz, erst wieder umzukehren; ich liefs deshalb trotz des Regens, der übrigens bald vorübergezogen war, den Marsch fortsetzen. Die Savanne vor Bottoe war ziemlich steriler Natur und dürfte daher weniger für europäische Plantagenanlagen geeignet sein, würde aber doch zur Bepflanzung mit Manihot Glaziovii zı empfehlen sein. Etwa eine halbe Stunde vor Bottoe erreichten wir die unter Leitung. 
rines eingeborenen Negrers stehende Aufsenstation der Bremer Mission. In Bottoe kamen wir gegen 4 Uhr am Nachnittage an. Trotz des schlechten Rufes, welehen die Fingeborenen dieser Ortschaft haben, wurden wir daselbst sehr fremullich anfyenommen. Der Häuptling brachte mir ein Geschenk von drei Hühnern und etwas Mais. Ieh hatte währent der letzten Zeit vorzugsweise von Eiern gelebt, welche wir allenthalben in den Dörfern für Tabak reichlich kaufen konnten, da ich gegen Konserven und das ewige Hühnerfleisch eine furchtbare Abneigung bekommen hatte. Am Jorgen des 3. April brachen wir um 6 Uhr wieder auf. Der Häuptling des Dorfes hatte mir bereitwilligst einen Führer bis Batome bustellt, von wo aus ich damn einen neuen Führer bis Assahnn zu nehmen gedachte. Über eine sterile Savanne, welche sich wohl nu* zur Bepflanzung mit Manihot Glaziovii eignen dürfte, führte der Weg. Die infolge der ersten Regen hervorgesprossene Vegetation fing sehon wieder an bedenklich zu vertrocknen. In einem kleinen Farmdorfe, welches wir passierten, beklagten sich die Eingeborenen über die ausbleibenden Regen. Das Wasser hatten sie von ziemlicher Distanz herbeizuschaffen, da die sämtlichen Quellen und sonstigen Wasserplätze in der Ungebung ansgetroeknet waren. Etwa eine halhe Stunde vor Batome marsehierten wir dureh das Dorf Seva. In Batome machte sieh der Wassermangel erst recht benerkhar, wir hatten hier viel Geld für clas von den Fingeborenen herbeigeschaffte Wasser zu zahlen.

Von einigen Weibern kanfte ich hier eine Anzahl Finger- unı Armringe, ebenso gelang es mir, einige Exemplare oraler Messingringe zu erstehen, welche am Fufse über dem spame getragen werden. Die Fingerringe und ein Teil der Armringe waren aus Nickel verfertigt. Nach Angabe der Fingeborenen waren sie in Assahun hergestellt. Fs ist wohl nicht unwahrseheinlich, dafs ein Teil der nach Togo importierten Fünfpfennigstïeke zu derartigen Arbeiten verwendet wird. Um 12 Uhr liefs ich wieder auflorechen, diesmal ohne Führer. Es war in der trockenen Steppe drückenıl heifs, dazn sehien der Weg immer unkenntlicher zu werlen. An rinigen verlassenen Farmolörfern zogen wir vorbei, bis allmählich die (iegend emen interessanteren Charakter amahm. Hin uml wieder zeigten sich kleine Buschwäldchen, die immer hänfiger zı werden schienen, und dazwisehen lagen die Farmen der Eingeborenen. In Agorome floh die ganze Bevölkerung, als sie dex Weifsen auf dem Pferde ansiehtig wnrde, nur mit Mühe komnte ich rinige Lente bewegen, zurüekznkehren, nm mir den Weg zn zeigen. Nach etwa einer weiteren Stmude gelangten wir nach heve, wo ich für die Nacht geblichen wäre, wemn nicht die Einwohmer behauptet hätten, 
weder genügend Wasser noch Nahrung zu haben. Es blieb uns also nichts übrig, als den Marsch bis Assahum fortzusetzen. Etwa 20 Minuten vor Assahun kamen wir wieder auf die loreite LomeMisahöhe-Strafse und trafen dann mit Finbruch der Dunkelheit in Assahun ein. Ich liefs sofort das Zelt aufschlagen, um für die Nacht hier rasten zu können, meine Lente fanden Unterkommen in den Häusern der Eingeborenen.

Gegen $5^{1 / 2}$ Uhr rief an 4. April meine Signalpfeife unsere Schar wieder zusammen. Da ich die Absicht hatte, blols bis Badja zu marschierem, liefs ich heute nicht so zur Eile antreiben. In Kewe liefs ich am Logirhause eine halbe Stmole Rast machen und dann direkt nach Badja vorgehen, wo wir schon um 10 Uhr unter Ficus- und Affenbrotbäumen das Zelt aufstellen konnten. Es schien hier ein grofser Palavertag zu sein, denn in der Nähe meines Zeltes wurde eiue lange Gerichtsverhandlung vom Häuptlinge abgehalten. Ich wurde zwar aufgefordert, auch daran teilzunehmen, schlug diese Einlarlung aber ab, da ich mich nicht in die Angelegenheiten der Lente mischen wollte. Gregen Abend mufste ich den Häuptling rufen lassen, um ihn aufzufordern, für einen Polizeisoldaten, dessen Träger entlanfen war, einen neuen Träger zu stellen. Wie sich herausstellte, hatte eigentlich der Soldat selbst Schnld an der Sache, und deshalb waren die Badja-Lente gegen ihn aufgebracht, doch gelang es mir, den Streit zur Zufriedenheit beider Parteien beizulegen, so dafs sich der Häuptling verpflichtete, in aller Frühe am nächsten Tage den gewünschten Träger bis Palime zu stellen. Unsern Aufenthalt am Nachmittage in Badja benutzte ich dazu, die Steppen botanisch zu untersuchen, wobei es mir gelang, einige recht interessante Funde zu mathen. Am Abend begann ein sehr starker Regren, welcher die ganze Nacht hindurch nicht endete und unseru Aufbruch am uächsten Morgen bis $7 \mathrm{Uhr}$ verzögerte. Kaum waren wir anf dem Wege wieder in der Steppe, als der Regen mit erneuter Heftigkeit wiederum begann. Doch wollte ich mich dadurch nicht mehr in unserm Fortkommen behindern lassen und liel's nun unter diesen nicht gerade sehr angenehmen Zuständen den Marsch fortsetzen. Waren wir und die Lasten doch bereits vollstäulig ılurchnäfst, so kounte etwas Regen mehr oder minder weiter keinen bedeutenden Schaden anrichten. Die Wege waren allerdings infolge ilırer lehmigen Beschaffenheit so schlüpfrig, dals mehrere Male Träger mit ihren Lasten stürzten. Ebenso hatte ich mit meinem Pferde gut aufzupassen, denn anch das Tier konnte nicht sicher treten. Nachdem wir Noeppe passiert, trafen wir gegen 11 Uhr vollständig durchnälst in Akeppe ein. Zu unserm Glück hatte der Regen machgelassen, so dals wir in den nichts weniger 
als regendichten Rasthütten daselbst verbleiben komnten. Am Nachmittage klärte sich zu unserer Freude der Himmel auf, ja, die Sonne trat sogar hervor und gab uns somit Gelegenheit, eiuen Teil der Lasten zu trocknen. Leider gesellte sich eine neue Plage wieder zu uns, nämlich die Ameisen, die nun nach dem Regen unsern Lagerplatz zu Hunderten umschwärmten und, wo sie nur Gelegenheit fanden, ihre Wut an den nackten Füfsen der Träger ausliefsen. Auch ich machte am Abend, nachdem ich mir die hohen Stiefel abgezogen hatte, wiederholt ihre Bekanntschaft.

Am nächsten Morgen stand die Karawane schon um 5 Uhr reisefertig da. Um $7 \mathrm{Uhr}$ liefs ich noch eiumal bei einem Farmdorfe eine kurze Frühstücksrast machen und ritt dann nach Lome voraus, wo ich um $10^{1} / 2$ Uhr eintraf, während meine Karawane um 11 Uhr anlangte. Ich traf umgehend meine Vorbereitungen zur Abreise und erledigte einige mir von Dr. Gruner mitgegebene Aufträge. Den Abend verbrachte ich noch in einer gemütlichen Gesellschaft bei Herrn Dr. Wendland.

Pünktlich erschien gegen Mittag am 7. April der Dampfer „Eduard Bohlen“, der mich nach Europa bringen sollte. Gern wäre ich noch länger in Togo geblieben, wenn ich mir nicht hätte sagen müssen, dafs in Europa viele Arbeiten während der Monate meiner harrten, welche ich daselbst zu verbringen gedachte. Die Fahrt durch die Brandung verlief auch glücklich, obgleich dieselbe nicht ganz gefahrlos war. Um 2 Uhr lichtete der Dampfer die Anker, und fort ging es, der Heimat zu.

In den ersten Tagen der Heimreise verlief unsere Fahrt noch einigermafsen zu unserer Zufriedenheit, doch bald verringerte sich die Geschwindigkeit immer mehr, so dafs wir mit der Zeit unsere Ankunft in Europa immer weiter verschieben mulsten. Die Fahrt war keineswegs eine gemütliche und zufriedenstellende, so dafs alle Passagiere aufatmeten, als wir am 1. Mai mit einer fünftägigen Verspätung in die Elbe eindampften. 


\section{Kapitel.}

\section{Allgemeines und Untersuchungen.}

Als kurz nach der Entdeckung Amerikas nach Europa die Kunde gelangte, dafs die Eingeborenen von Haïti sich bei ihren Spielen kleiner elastischer Bälle bedienten, die aus dem Safte von Bäumen hergestellt wurden, da kounte wohl niemand ahnen, welche epochemachenden Entleckungen später noch von diesem regetabilischen Produkte abhängen sollten und welch ein begehrter Handelsartikel dasselbe noch werden sollte. Nach dem einheimischen Namen des Produktes Caú-cho bildeten sich in Europa bald die Worte Caoutchouc oder Kautschuk ans, und unter diesem Namen wurde es zunächst in Europa als Merkwürdigkeit bekannt. Nach(lem man dann seine Fähigkeit entdeckt hatte, Bleistiftstriche auf Papier auszuradieren, wurde es in England allgemein Rubber oder India-Rubber genaunt. Anch um Wasserdichtigkeit bei Stoffen zu erzielen, fand der Kautschuk schon vor Ende des letzten Jahrhunderts Verwendung; doch da noch nicht seine Vulkanisationsfähigkeit entleckt war, hatte man solche Stoffe vor Wärme und vor allen Dingen vor Sounenstrahlen zu schützen, da dieselben infolge der eintretenden Oxydation des Kautschuks klebrig wurden.

Anch in Indien und später in Afrika gelang es schliefslich, Bäume und Lianen ausfindig zu machen, aus deren Milch man Kautschuk herstellen konnte. Es würde zu weit führen, wenn ich hier näher auf die Entdeckungsgeschichte der einzelnen Pflanzen eingehen würde; sie ist schon wiederholt genauer behandelt worden.

Nach der Entdeckung der wunderbaren Fähigkeiten des Kautschuks wuchs natürlich der Bedarf in unerwarteter Weise und mit ihm sein Wert. Infolgedessen suchten die Kautschuksammler die ihnen zugänglichen Kautschukgebiete möglichst auszubeuten, und so kam es, dafs die Pflanzen in der rohesten Weise angezapft wurden, sogar derartig, dafs ganze Bestände allmählich dahinstarben. Allerdings wurden bei dieser gewissenlosen Ausbentungsmethode in den folgenden Jahren riesige Quantitäten in den Handel gebracht, doch zeigte sich sehr bald in den darauf von Jahr zu Jahr geringer werdenden Mengen das Endresultat. Mit Ausnahme des Congo- 
staates sind in Afrika die sämtlichen Kautschuk liefernden Kolonien in ihrer Produktion zurückgegangen. Bei dem Congostaate ist das entgegengesetzte Faktum nicht etwa in einer vorsichtigeren Behandlung: der Kautschukbestände zu suchen, wie man hänfig versucht hat, die Sachlage darzustellen, sondern ist einzig und allein durch das Erschliefsen immer neuer Gebiete zu erklären. Es werden zwar von der dortigen Regierung den übrigen Handelsgesellschaften, welche Kautschuk exportieren, gewisse Verpflichtungen auferlegt, wie z. B. Anpflanzen neuer Bestände etc., doch erstens werlen diese Verordnungen keineswegs sehr streng genommen, zweitens aber dürften lange nicht genügend Sämlinge beschaffbar sein, um die daselbst im Innern allgemein stattfindenden Verwüstungen wieder gut zu machen. Wenn man sieht, wie bereits seit Jahren z. B. in der Lagos-Kolonie der Engländer sowie an der Goldküste die Produktion von Kautschuk infolge des unverantwortlichen Vorgehens der Kautschuksammler zurückgegaugen ist, so muls man sich wundern, dals nicht schon lange durch Anpflauzungen dieser Schaden gut zu machen versucht worden ist. Dals man bei solchen Anpflanzungen vor allen Dingen Bäume, welche Kautschuk liefern, den Lianen vorziehen sollte, ist leicht dadurch zu begründen, dafs die Lianen erst nach langen Jahren anzapfbar sind und selbst daun nur geringere Quantitäten Kautschuk liefern; aufserdem aber lassen sich bei ihnen nicht so leicht Vorkehrungen treffen, um schadloses Anzapfen möglich zu machen. Der Abbau solcher Bestände wird daher stets ein mehr oder minder ausgeprägter Raubbau bleiben. Gauz anders liegen die Terhältnisse bei den Bäumen. Dieselben weisen ein viel schnelleres Dickenwachstum auf und geben entschieden viel gröfsere Quantitäten Kautschuk liefernder Milch. Es sollte aus diesem Grunde nicht allein von seiten privater Plantagengesellschaften alles versucht werden, ausgedehnte Kautschukplantagen zu schaffen, sonderı es sollten auch derartige Unternehmungen in jeder Weise von der Regierung unterstützt werden. An der Goldküste haben im letzten Jahre die Engländer begonnen, dieser Frage ein besonderes Interesse entgegenzubringen, und dort bereits ausgedehnte Kickxia-Anpflanzungen angelegt. Da nun gerade ron deutscher Seite viel, man könnte sagen am meisten zur näheren Kenntnis der für derartige Anlagen eventucll brauchbaren Kautschukbäume beigetragen ist, so wäre es doch recht betrübend für unsere Nation, wenn uns auch hierin wieder die Engländer zuvorkommen würden und so gewissermafsen wieder die Früchte deutscher Arbeiten und deutscher Forschungen geniefsen würden.

Betrachten wir einmal dic in Afrika heimischen Kautschuk liefernden Gewächse in Bezug auf ihre Anbaufähigkeiten. Bei 
weitem der grölste Teil des afrikanischen Kautschuks wird von Landolphia-Arten gewomnen. Da die Angaben der Sammler sich häufig widersprechen, ist man in vielen Fällen noch keineswegs genau unterrichtet über die Möglichkeit, aus dem Milchsaft einiger Arten wirklich Kautschuk zu gewinnen. Ganz besonders ist dieses der Fall bei den Arten mit grolsen Blüten, aus der Verwandtschaft der Landolphia comorensis, und es wäre daher sehr erwünscht, wenn die in Afrika lebenden Sammler grerade dieser Frage spezielle Aufmerksamkeit schenken und von den einzelnen Arten genau feststellen würden, ob sie Kautschuk lieferu oder nicht. AIs sicher Kautschuk gebend sind uns bisher aus Afrika die folgenden Arten bekannt:

1. Landolphia tomeutosa A. Dew. aus Senegambien, welche die gröfste Menge des dorther stammenden Kautschuks liefern soll.

2. Landolphia Heudelotii D. C., welche vielleicht von L. tomentosa nur als Abart verschieden ist.

3. Landolphia comorensis K. Sch. aus Ostafrika, von der löchst. wahrscheinlich die von verschiedenen Autoren als mit ihr identisch betrachtete, keinen Kautschuk liefernde Pflanze spezifisch verschieden ist.

4. Landolphia Kleinei Pierre aus dem Flufsgebiete des Congo.

5. Landolphia owariensis Pal. de Beauv. mit einer weiten Verbreitung über den westlichen Teil Afrikas und im Sudan. Mit dieser Art ist L. Klainei häufig verwechselt worden.

6. Landolphia Kirkii Th. Dyer aus dem südöstlichen Afrika.

Von diesen hier aufgezählten Arten ist der von Landolphia Klainei gewonnene Kautschuk der beste und wohl überhaupt der beste aus Afrika bisher bekannt gewordene. Von ihr wird auch das als "Kassai rouge" in den Handel kommende Produkt gewonnen. Im Congostaate hat aus diesem Grunde die Regierung auch da, wo sie Landolphia-Anpflanzungen begonnen hat, hauptsächlich diese Art heranziehen lassen. Es sind meines Wissens Resultate derartiger Anpflanzungen noch nicht bekannt, da dieselben alle viel zu jung sind, um einen Ertrag liefern zu können. Es wird auch noch eine lange Reihe von Jahren vergehen, ehe man mit dem Abernten der Lianen beginmen kann, ohne sogleich einen empfindlichen Schaden berbeizuführen. Ich bin persönlich der Ansicht, dals eine Liane etwa 15 Jahre alt sein mülste, ehe ihr Hauptstamm anzapfungsfähig ist. Bei dem immensen Längenwachstum, welches diese tropischen Lianen besitzen, ist es nicht $\mathrm{zu}$ verwundern, dals die Pflanze zu gleicher Zeit ein stärkeres Dickenwachstum nicht aufweisen kann. 
In Kamerun hat Herr Günther auf der Soppo-Plantage vor einigen Jahren eine Landolphia-Anpflanzung begounen, welche, als ich sie zum letzten Male zu sehen Gelegenheit hatte, recht gesund aussah, doch hatten die etwa $2^{1} / 2$ jälırigen Stämme noch nicht $1 \mathrm{~cm}$ im Durchmesser erreicht; einige derselben hatten dabei allerdings bereits eine Länge ron $5 \mathrm{~m}$ aufzuweisen. Die Kultur der Lianen wäre keineswegs zu verwerfen, wemn man aus irgend welchen Gründen gezwungen ist, Waldpartien in den Plantagengebieten stehen zu lassen, in denen bereits Kautschuklianen vorhanden sind. Da wäre durch jährliches Nachpflanzen die Möglichkeit vorhanden, mit der Zeit eine regelrechte Landolphia-Schonung zu erziehen, welche dann eine gute Nebeneinnahmequelle für die Plantage bilden würde. Ebenso ist es keineswegs zu übersehen, dals sich Landolphieu auch an den Schattenbäumen in den Kakaoplantagen anpflanzen liefsen. Da man, wenn die Pflänzchen erst einmal die Höhe ron einem Fufs erreicht haben, gar keine Arbeit mit ihnen hat, und die Anpflanzungen somit fast gar nichts kosten würden, so liefse sich eventuell auch diese Art von KautschukNebenkultur empfehlen. Die Früchte der am Kamerun-Gebirge einen guten Kautschuk liefernden Liane, welche fälschlich wiederholt als Landolphia florida bezeichnet worden ist, sind auf den Märkten der Baquiri unter dem Namen "Maniongo" in den Monaten Dezember, Januar und Februar mit Leichtigkeit in Mengen zu erstehen; Schwierigkeiten im Beschaffen der Samen lägen also nicht vor. Leider enthalten die Blätter und die jüngeren Teile der Landolphien keinen brauchbaren Kantschuk, sonst liefse sich ja eventuell in ähnlicher Weise, wie der Wurzelkantschuk im Congo- und AngolaGebiete hergestellt wird, aus ihnen das Produkt gewinnen, und dann würde allerdings eine Landolphiaplantage ein äufserst empfehlenswertes Unternehmen sein. Ich habe während meiner Expedition gerade dieser Frage der Möglichkeit des Ausziehens von Kautschuk aus den jüngeren Teilen der Kautschukpflanzen ganz besondere Aufmerksamkeit gewidmet und habe dabei inmermehr die Überzeugung gewonnen, dafs bei Landolphien und Kickxien dieses unmöglich sei. Die Kautschukpflanzen scheiden in sämtlichen jüngeren Teilen einen Milchsaft aus, aus dem sich kein brauchbarer Kautschuk, sondern nur ein deın Vogelleim ähnliches Produkt der Ficusarten gleiches Material herstellen läfst.

Inwiefern die amerikanischen Kautschukpflanzen, vor allen Dingen die Hevea, bei Gewinnung von Kautschuk aus den jüngeren Teilen in Betracht kommen können, habe ich bisher leider noch nicht Gelegenheit gehabt, feststellen zu können. Es wäre sehr wünschenswert, dafs auch mit dem Ceara-Kautschuk ähnliche 


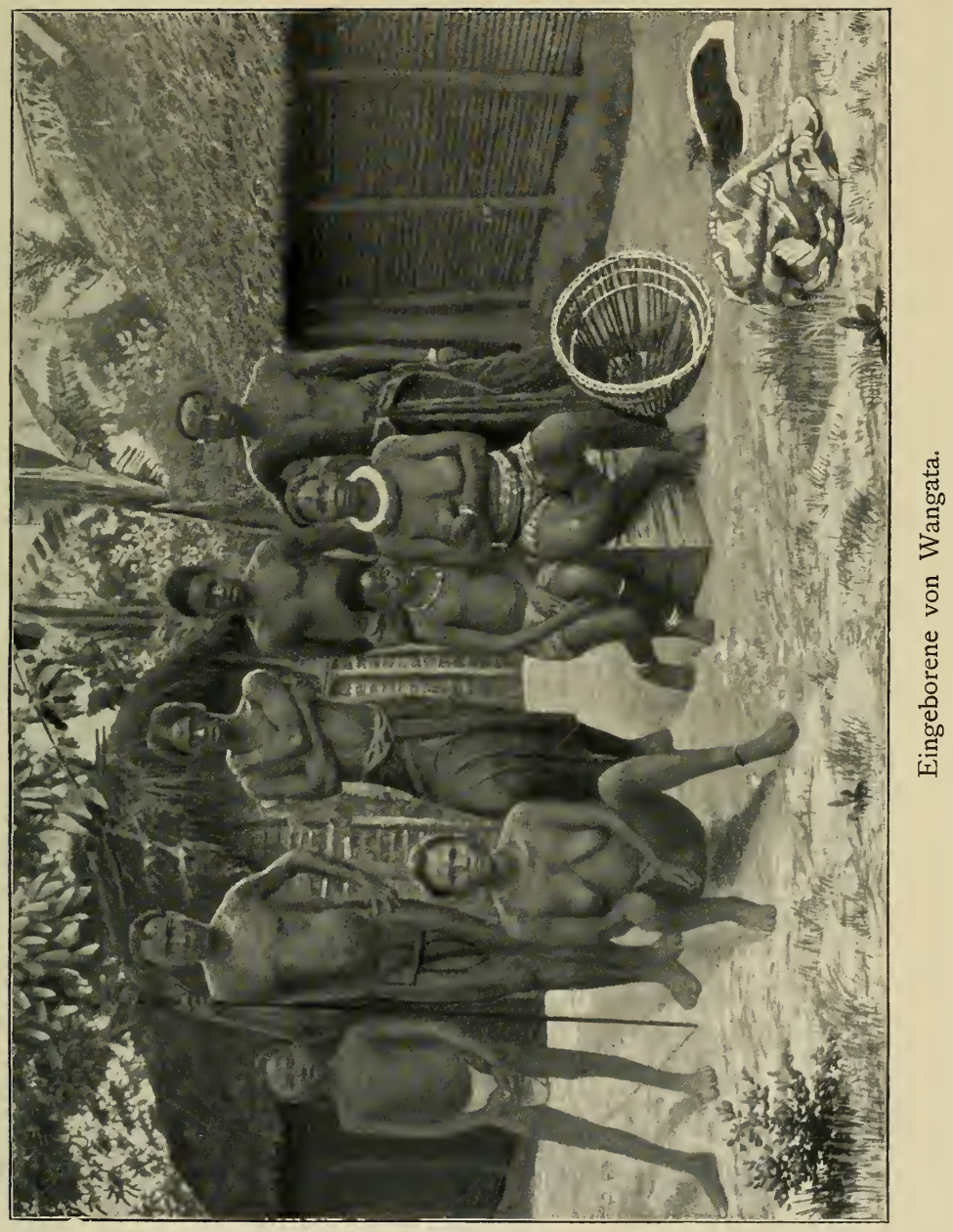



Versuche gemacht werden würdeu, da bei diesem die Kautschuk liofernde Latex höher in die jüngeren Teile hinaufsteigt als bei Landolphien und Kickxien. Die Terwandlung der Latex in solche, welche wirklich guten Kautschuk liefert, geht also innerhalb der Pflanze vor sich. Sollte sich da nicht ein sehr interessantes und vielleicht auch höchst erfolgreiches Studium für einen sich in den Kantschukgegenden Afrikas aufhaltenclen Chemiker darbieten? Aus der Verschiedenheit der chemischen Zusammensetzung der Latex in den verschieden alten Teilen der Pflanze liefsen sich da wahrscheinlich höchst wichtige Schlüsse ziehen, die uns der wirklichen Erkenntnis des Kautschnks um ein Beträchtliches näher bringen könnten. Ich entsinne mich übrigens auch, dafs bei Landolphia Kirkii die wirklich brauchbare Kautschnk liefernde Milch fast bis in die jüngsten Teile hinein steigt. Ich selbst habe aus den Fruchtschalen dieser Art im Hinterlande von Inhambane einen durchans brauchbaren Kautschuk herausziehen können. Also auch diese Art dürfte, wenn es sich darum handelt, ans den jüngeren Teilen der Pflanzen Kantschuk zu gewinnen, einer Beachtung wert sein. Ich würde vorschlagen, zu diesem Zwecke eine gröfsere Quantität der jüngeren Zweig’e mit ihren Blättern und Blüten zu einem Brei zu stampfen oder sonstwie stark zu zermalmen und dann vollständig zu trocknen. Zum Zwecke der Untersuchung wären mindestens 50 Pfund dieses Materials nötig. In Europa liefse sich dann mit Leichtigkeit der etwa in dieser Masse enthaltene Kautschuk auswaschen, und die Qualität und Quantität des gewommenen Produktes wäre dann leicht festzustellen.

Man hat in letzter Zeit den Gedanken in Erwägung gezogen, ob sich eine vorteilhaftere Kautschukgewinnung ergeben könne, wenn von Kickxien oder Manihot Glaziovii die Rinde geschält würde und dann aus ihr, sei es an Ort und Stelle, sei es in Europa, der darin enthaltene Kautschuk gewonnen würde. Dafs dieses Verfahren möglich ist, liegt anf der Hand. Ich bin auch der Überzeug'ung, dafs, obgleich beim Abschälen der Rinde eine enorme Menge des Milchsaftes verloren gehen würde, die in derselben bleibende Quantität eine grölsere Menge Kautschuk ergeben würde, als mall sonst bei einmaligenı Anzapfen erhalten könnte. Aber hiefsè dies nicht den Raubbau, gegen den seit Jahren versucht wird, anzukämpfen, da man bereits zur Genüge kennen gelernt hat, welche Folgen er nach sich zieht, noch bedeutend unterstützen? Welcher Gewinn läge darin, wenn wir allerdings bei einmaligem Abschälen des Baumes eine grofse Quantität des erwünschten Produktes gewännen, während nach mehrjährigem vorsichtigen Anzapfen derselbe Baum eine bedeutend grölsere Menge desselben geliefert haben würde? Es 
kann uns doch nicht daran liegen, möglichst schnell eine bedeutende Kautschukproduktion zu erlangen, sondern vielmehr sollte es meiner Ansicht nach unser Bestreben sein, eine danernde genügende Produktionsfähigkeit der Kautschukländer zu schaffen.

Meiner Ansicht nach kann nur da ein Abschälen der Rinde zum Zwecke der Kantschnkbereitung in Betracht kommen, wo infolge zu hohen Alters oder übermäfsiger Anzapfung durch Anschneiden der Bäume gar kein und nicht genügend Kautschuk gewonnen werden kann.

Von den Pflanzen, welche im Rufe stehen, den Wurzelkautschuk von Angola und vom Congo zu liefern, hatte ich nur Gelegenheit, Carpodinus lanceolatus K. Sch. kennen zu lernen. Diese Pflanze wächst in sandigen, kurzgrasigen Savannen, in denen sie während des ganzen Tages den vollen Sonnenstrahlen ausgesetzt ist. Für eine Kolonie wie Kamerun kann sie also als anbaufähig gar nicht in Betracht kommen. Der Kantschuk, welcher von ihr gewonnen wird, ist keineswegs ron so guter Qualität wie häufig geschildert wird. Überhaupt sind in nenerer Zeit die Angaben über die Güte dieses sowohl wie auch ähnlicher Produkte recht häufig übertrieben worden. Die Art der Gewinnung des Kautschnks von Carpodinus lanceolatus ist aufserdem eine solche, die viele Arbeitskräfte erfordert, und daher schon wäre der Verdienst für den Europäer zu gering, wenn er nicht die fertige Ware von dem Eingeborenen kaufen kann, der die zur Herstellung derselben nötige Zeit und Arbeit beim Verkaufe nicht rechnet. Was die Pflanze aber besonders für Kulturen ungeeignet erscheinen lälst, ist ihre auffallende Empfindlichkeit g'egen jede Wachstumsstörung. Selbst Wurzelstöcke ron bedeutender Länge sterben bei leichter Verletzung' bald ab, vielleicht an Verblutung durch Anstreten des Milchsaftes. Während meines Aufenthaltes in Dolo-Ebenen am Stanley-Pool habe ich diesbezüglich die verschiedensten Versuche gemacht. Selbst Pflanzen mit über fufslangen Wurzelstöcken starben trotz reichlicher Bewässerung in wenigen Tagen ab. Keinen besseren Erfolg hatte ich beim Ausstechen vou Rasenstücken mit Carpodinus, die etwa einen Fuf́s in Durchmesser hatten. Die darin enthaltenen Pflanzen siechten auch allmählich dahin. Anch einige nach Kamerun geschickte Rasen und Wurzelstöcke starben trotz guter Pflege in Victoria wie in Buea langsam ab. Fntgegen verschiedenen Behauptungen enthält der oberirdische Teil von Carpodinus lanceolatus keine Milch, die zur Bereitung eines guten Kautschuks verwendet werden kann. Ich habe denselben mit rlen verschiedensten Koagulationsmitteln beliandelt und komnte doch nie ein besseres Produkt herstellen als von den als nicht kautschukgebend bekannten anderen Apocynaceen. 
Ich also kann diese Pflanze für Kulturen irgend welcher Art nicht empfehlen. Das aus den Wurzelstöcken gewonnene Quantum Kautschuks ist aufserdem ein geringes und entspricht in keiner Weise der Mühe und Arbeit, welche zu seiner Herstellung erforderlich sind.

Nach den Angaben vou verschiedenen Reisendeu sollen im Kwango-Gebiete und Angola Wurzelkautschuk-Arten vorkommen, die ein wirklich gutes Produkt liefern, doch bin ich davon überzeugt, dafs es sich danu um andere Pflanzen handeln mufs als um Carpodinus lanceolatus. Einige getrocknete Wurzelstöcke des Carpodinus lanceolatus, welche ich im Berliner botanischen Museum untersuchte, zeigten auch nur geringe Spuren ihres Kautschuckgehaltes.

Von den übrigeu windenden Carpodinusarten, deren im Stromgebiete des Congo eine gröfsere Anzahl vorkommt, ist mir keine begegnet, welche brauchbaren Kautschuk liefert. Die Milchsäfte sämtlicher Apocynaceen und Asclepiadaceen enthalten eine gewisse Quantität Kautschuk, doch ist bei fast allen eine so grofse Menge von Harzen vorhanden, dafs die wirkliche Kautschukuatur der koagulierten Milch durch die zähen, klebrigen Harze vollständig verdrängt wird.

Mit Ausnahme der Ficus Vogelii sind bis jetzt aus Afrika noch keine Feigenbäume bekannt geworden, deren Milchsaft sich zur Kautschukfabrikation eignet. Bei allen diesen ist die Latex sehr stark mit Harzen vermischt, welche das durch die Koagulation gewonnene Produkt zu einem zähen Leim verwandeln, welcher sogar in einigen Gegenden Afrikas als Vogelleim verwendet wird. Hin und wieder werden von einigen Firmen der Westküste einige Tonnen dieses Stoffes nach Europa geschickt und finden dort, da sie ja selten kommen, in einigen Kautschukfabriken Absatz. Allerdings zu einem geringen Preise, da sie nur für wenige Artikel zu verwenden sind. So zum Beispiel, um Wasserdichtigkeit von Stoffen etc. zu erzeugen. Von einer unserer ersten Antoritäten in der Kautschukfabrikation erfuhr ich diesbezüglich, dafs es billiger sei, durch Hinzufügung von Harzen, wie z. B. Kolophonium zu guten Kautschuk, diese vogelleimähnliche Masse in Europa herzustellen, als sie von Afrika zu importieren, wo damn noch die Frachtspesen etc. bezahlt werden müssen. Es scheiut also, als ob für das Produkt jener Ficusarten kein grofser Absatz zu erwarten ist. Anders würde es allerdings sein, wenı nicht mehr genügend guter Kautschuk auf den Markt gebracht werden würde, dann mülste man natürlich auch diesen mit Harzen vermischten Kautschuk verwenden, um den besseren Kautschuk für besondere Artikel verarbeiten zu können. In einer Kautschukfabrik sah ich einst ganze Fässer dieses klebrigen 
Produktes der Ficusarten, und hörte damals, dafs dasselbe für die Herstellung verschiedener Artikel zu verwenden sei. Man hatte 1,50 Mark für das Kilo dieses Kantschuks bezahlt und teilte unir ruit, dafs sich bei diesem Preise eine Einfuhr nach Europa wohl bezahlt machen könnte. Wo also grenügend solcher Ficusarten vorhanden sind, so daf's von den in Afrika ansässigen Firmen diese Ware zum Preise von 75 Pfemigen pro Pfund auf den europäischen Markt gebracht werden kann, wäre es daher vielleicht empfehlenswert, dem Abban der Ficuswaldungen (wie z. B. im Hinterlande von Inhambane) einiges Interesse entgegenzubringen, doch vorher ist es erwünscht, festzustellen, wie viel dieser Ware absetzbar sein würde.

Bei Ficus Vogelii liegen die Verhältnisse etwas yünstiger. Diese Art liefert einen Kantschuk, der zwar nicht harzfrei ist, aber doch nicht klebt. Infolge seines doch noch bedeutenden Harzgehaltes hat dieser Kautschuk weniger Elastizität als der der Landolphien und Kickxia und kann nicht in derselben Weise verwendet werden. Er ist aber bedeutend besser als der anderer afrikanischer Ficnsarten. Nach den Angaben verschiedener Reisenden wird aus der Ficus Vogelii in den Gebieten sïdlich des Niger viel Kautschuk bereitet. Ich habe selbst nie während meiner Reisen gesehen, dafs Eingeborene aus dem reinen Milchsafte dieses Baumes Kautschuk anfertigten, noch labe ich von den Kanfleuten gehört, dafs dieser minderwertige Kautschnk auch nur die geringste Rolle im Handel spielte. Dafs häufig die Milch mit der der Kickxia elastica vermischt koaguliert wird und als reiner "Silk-Rubber" in den Handel kommt, haben mir die Eingeborenen, welche doch derartige Fälschungen selbst vornehmen, wiederholt eingestanden. Ob der „Silk-Rubber" durch diese Beimischung des Milchsaftes der Ficus Vogelii sehr leidet, habe ich nicht feststellen kömen, da ich keine Proben einer solchen Kautschukart gesehen. Die Kanfleute versicherten mir, dafs sie mit Ausnahme grober Fälschungen an dem "Silk-Rubber" nie Spuren gesehen haben, welche als derartige Milchsaftmischungen gedeutet werden könnten. Im Yoruba-Landle sowohl wie in unserer Kolonie Togo ist diese Ficusart sehr verbreitet, und laher wären leicht grölsere Quantitäten Milch zu erhalten. Es wäre laher wünschenswert, dafs von seiten dort lebender Interessenten Versuche dieser Art unternommen werden würden. Ich konnte dieselben nicht ausführen, da mir im Yoruba-Lande wie in Togo keine Kickxiamileh, wenigstens nicht in der nötigen Quantität, zur Verfügung stand.

Älınlich wie dieser Kautschuk von Ficus Vogelii ist der von «iner bei Buea wachsenden Ficnsart beschaffen, von der ich leider 
kein Fruchtmaterial besitze. Die Art gehört offenbar auch in die Verwandtschaft des Ficus Vogelii. Auch der aus ihr gewonnene Kautschuk: ist infolge seines Harzgehaltes sehr wenig elastisch und wenig klebrig und dürfte daher auch nur geringe Preise erzielen. Natürlich, zu Anlagen ausgedehnterer Art sind diese beiden Ficusarten nicht geschaffen, da das aus ihnen gewonnene Produkt in gröfseren Quantitäten auf dem europäischen Markte wohl schwerlich Absatz finden_dürfte. Wenn eine Vermischung mit dem Milchsafte der Kickxien oder Landolphien zulässig wäre, würden die Arten allerdings an Bedeutung gewinnen, da sie grofse Mengen Milchsaft geben. Als Alleebaum ist die Ficus Vogelii für Plantagen schon seines dichten Schattens wegen zu empfehlen. Die Buea-Ficusart habe ich nur epiphytisch auf Bäumen angetroffen, doch beweisen Exemplare, welche ich nach Victoria brachte, dafs anch sie in reinen Boden gedeihen würde. Für Kamerun scheint sich Ficus Vogelii dagegen nicht zu eignen. Das Klima scheint ihr zu feucht zu sein. Einige Stecklinge, welche ich von Lagos nach Victoria überführte, siechten, obgleich sie anfangs ganz gut anwuchsen, allmählich dahin. Auf Ficus elastica, welche auch in Kamerun angepflanzt ist, werde ich weiter unten (*elegenheit haben, näher einzugehen.

Als zuerst der Silk-Rubber von Lagos bekannt wurde, von dem es hiefs, lafs er von einem Baume herrühre, gelang es nach vielen Bemühungen, als Stammpflanze dieses Produktes die Kickxia zu ermitteln. Aufangs glaubte man stets, es hier mit der Kickxia africana zu thun zu haben. Bald aber wurden Behauptungen laut, dafs die als Kickxia africana von Bentham beschriebene Pflanze keinen Kautschuk gebe. Diese Behauptung wurde von Dr. Preufs sowohl wie von Monsieur Chalot, dem Direktor des botanischen Gartens zu Gabun, bestätigt. Trotzdem wurde von englischer Seite noch stets behauptet, dafs die Kickxia africana im Hinterlande von Lagos sowohl wie in der Grold-Coast-Colony guten Kautschuk liefere. Als ich damals aufgefordert wurde, die Kantschuk-Expedition zu führen, sollte eine der Aufgaben der Expedition sein, diese Frage endgültig zu lösen. Da, im Januar 1899, etwa 10 Tage vor meiner Abreise von Europa, traf Dr. Preufs aus Kanerun ein mit der Nachricht, dafs er die Frage bereits gelöst habe. Am Mungo in Kamerun habe er die Kautschuk liefernde Kickxia gefunden und feststellen können, dafs dieselbe spezifisch von der Kickxia africana verschieden sei; die Früchte sowohl wie die Blätter seien verschieden. Nun konnte auch festgestellt werden, dafs die bisherigen Abbildungen der Kickxia africana falsch seien. Man hatte gewöhnlich die Früchte der Kautschuk liefernden Art zusammen mit Zweigen und Blättern der Kickxia africana abgebildet. Dr. Preufs beschrieb dann im 
Juli-Hefte des Notizblattes des Königlichen Botanischen Gartens za Berlin noch in denselben Jahre die von ihm neu entdeckte Kickxia als Kickxia elastica und gab zugleich eine gute Beschreibung der beiden anderen bekannten Arten, der Kickxia africana Benth. unıl Kickxia latifolia Stapf, welch letztere besonders der Kickxia elastica nalie steht. Herr Dr. Stapf rom Kew Herbarium wies bald daranf hin, dafs die afrikanischen Kickxiaarten nicht mit der von Blume aufgestellten Gattung Kickxia kongenerisch seien, wie Bentham glaubte, als er die erste afrikanische Art, Kickxia africana, beschrieb. Auf Grund einer Anzahl vou ihm in Kew Bull. näher ausgeführten Merkmale trennte Dr. Stapf die afrikanischen Kickxiaarten ab und stellte die neue Gattung Funtuma auf, mit den drei Arten: F. africana, F. latifolia und F. elastica. Den Namen Funtuma leitete er voı dem Namen ıler Fantis für die Kickxia „ofuntum" ab. Wenngleich ich mit Herrn Dr. Stapf vollständig darin übereinstimme, dal's die afrikanischen Arten von der malayischen Gattung Kickxia generisch verschieden sind, so habe ich dennoch in dieser Arbeit wie in meinen Berichten den Namen Kickxia beibehalten, da die Pflanze unter diesem Namen schon weit bekamnt ist, während selbst in wissenschaftlichen Kreisen der Name Funtuma w enig Verbreitung gefunden hat.

Was nun die geographische Verbreitung der drei Kickxiaarten anbelangt, so ist Kickxia africana von Liberia an nach Osten vorgehend in den Wäldern bis Kamerun zu finden, von wo aus sie dann bis in das Gabnn-Gebiet nach Süden vordringt. Kickxia latifolia ist bisher nur aus dem Stromgebiete des Mittelcongo und seiner Nebenflüsse bekannt. Die weiteste Verbreitung scheint Kickxia elastica zu haben. Ihr Verbreitungsgebiet scheint mit dem der Kickxia africana im Norden zusammenzufallen. Nach Süden aher dehnt es sich bis in die äufserste Südostecke des KamerunGebietes am Sanga und Ngoko aus. Auch im Gabun-Grebiete in den Hinterländern von Corisko-Bai soll es letzthin geglückt sein, diese Art festzustellen. Im Congo-Gebiete sollen am Mungala-Flusse auclı Kickxiabestände vorhanden sein, aus denen ein guter Kautschuk zrewonnen wird, doch bedarf dieses Gerücht noch der Bestätigung. Aufserdem ist es nicht ausgeschlossen, dafs es sich in lem Falle um eine andere Art handelt als um Kickxia elastica. In Ostafrika soll in letzterer Zeit auch eine Kickxia aufgefunden worden sein, doch habe ich Exemplare dieser Art noch nicht zu Gesicht bekommen. *) Anffallend in der geographischen Verbreitung der Kickxia elastica

* Jiese Art ist zngleich mit einer fünften jetzt in nenester Zeit im Notizblatte des Königl. Botanischen Gartens zu Berlin von Professor Schumann als neu beschrieben worden.

Der Verfasser. 
ist ،ler Umstand, dal's es bis jetzt noch nicht grelungen ist, sie in Togo südlich von dem Kratsehi-Distrikte nachzuweisen. Ob die bei Kratschi von dem Herm Grafen Zeeh aufgefundene Kickxia wirklich zu Kickxia elastica zu rechnen ist, kann erst festgestellt werden, wenn Blüten vorliegen. Die an das Berliner botanische Museum gesandten Zweige, welehe ich gesehen habe, enthalten weder Blüten noch Früchte.

Von den drei Kickxiaarten, welche somit bis jetzt aus Afrika bekannt geworden sind, enthält nur die Kickxia elastica einen Milchsaft, aus dem guter Kautschuk gewonnen werden kann. Das aus der koagulierten Mileh der anderen beiden Arten gewonnene Produkt ist infolge seines sehr grofsen Harzgehaltes und seiner Klebrigkeit nur wie die Fieussäfte verwendbar, anf welche ich bereits oben aufmerksam gemacht habe.

Die einzigen Versuche, festzustellen, wie viel Milchsaft eine Kickxia im Jahre geben kamn, dürften wohl diejenigen sein, welche ich am Ngoko unternahm, als es mir gelungen, daselbst ganze Bestände dieses wichtigen Baumes aufzufinden. Ich liefs damals einen etwa siebenjährigen Stamm von einem Fanti anzapfen, welcher ein sehr gesehickter Kautsehuksammler war und schon von seiner Heimat her die Kickxia sehr wohl kannte. Die Anzapfung gesehah in der rohesten Art, loch so, dafs die Cambiumschichten unter der Rinde des Stammes nicht beschädigt wurden. Der Ertrag war ein solcher, dafs ich damals meine kühnsten Hoffinmgen übertroffen sah. Es gelang, nicht weniger als gegen $3400 \mathrm{ccm}$ Milchsaft von dem einen Baume zu gewimen, aus denen sich gegen $2000 \mathrm{~g}$ Kautschuk herstellen liefsen. Auf $150 \mathrm{ccm}$ Milchsaft erhielt ich im Ngoko-Gebiete stets etwa $90 \mathrm{~g}$ frischen Kautschuks. Durch gutes Austrocknen dieses Produktes würden etwa noeh 20\% Wasser entfernt werden, so dafs man aus 150 cem Milehsaft $70 \mathrm{~g}$ guten Kautschuks erhalten würde. Auf der Reise nach Enropa geht durch Oxydation und sonstige Schäden davon natürlich noch einiges verloren, doch wäre dennoch der Gewinn als ein recht vorteilhafter zu bezeichnen. Durch vorsichtigeres, wiederholtes Anzapfen wäre es nicht unmöglich, jährlich eine ebenso grofse Menge Milchsaft zu gewinnen, ohne dem Bamme dadurch besonderen Scharlen zuzufügen. Der von dem Fanti damals angezapfte Stamn, cler allerdings vorher noch vollständig: unversehrt war, hatte, als ich die Ngoko-Station etwa $1^{1 / 2}$ Monate später verliels, noch dasselbe gesunde Aussehen wie vorher. Ich mufs allerdings hier hinzufügen, dafs die Zeit infolge hänfiger Regen für das fernere Gedeihen des Baumes günstig grewesen war. Um zu sehen, wie viel Latex die Leute täglich einzusammeln im stande sein würden, schickte ich zwei Leute aus. Dieselben brachten nach 


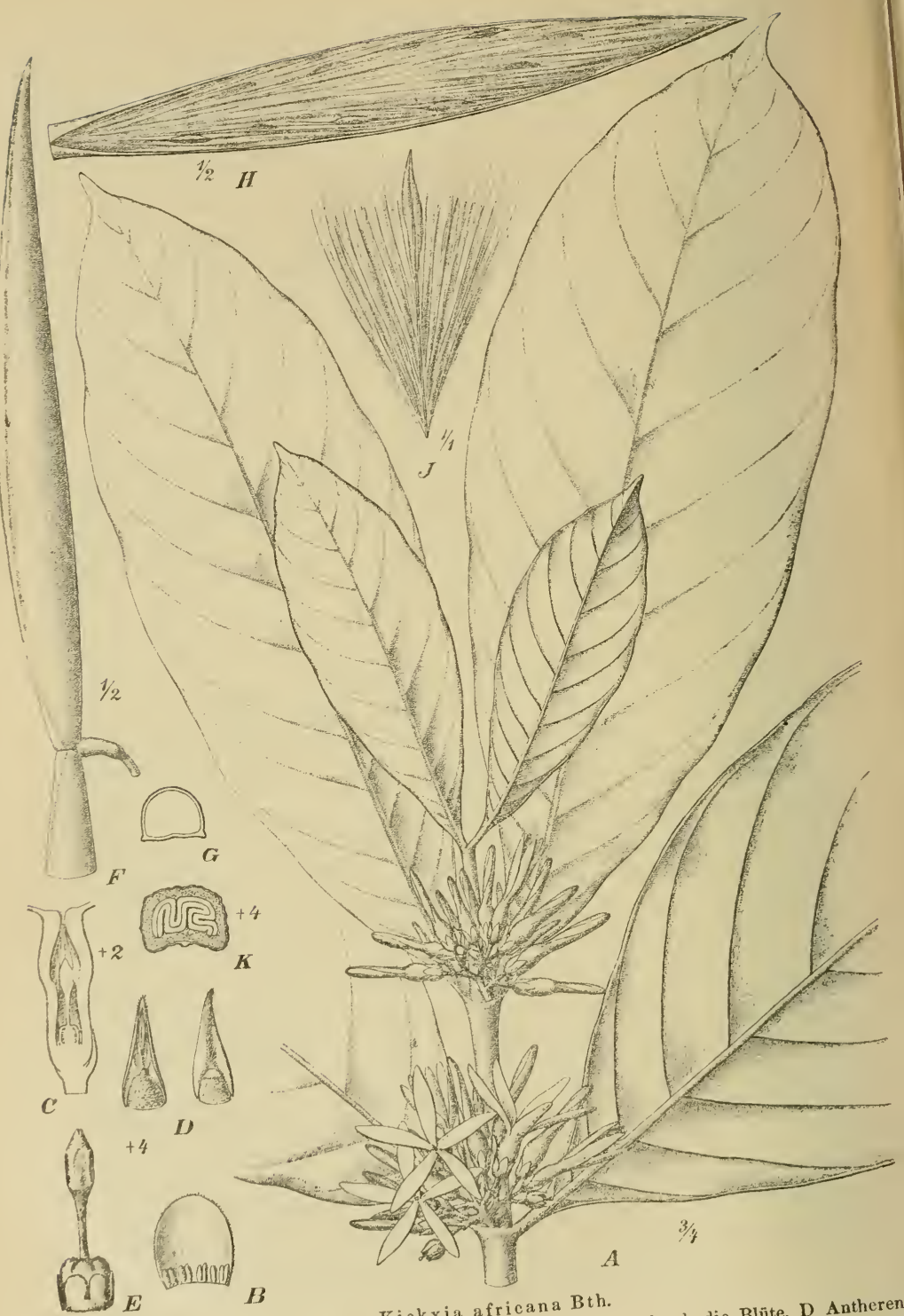

Kickxia africana Bth. att von innen, C Längsschnitt dureh dieselbe aufgesprungen, A Blühender Zweig, B Kelchblatt von G dieselbe im Querschn 
etwa neunstündiger Abwesenheit so viel Milchsaft ein, dafs ich ans ihm etwa $2500 \mathrm{~g}$. Kautschnk anfertigen konnte.

Über die Schnelligkeit des Dickenwachstums der Kickxia liegen bestimmte Angaben bis jetzt nicht vor. Ich habe versucht, einiges darüber festzustellen, konnte natürlich aber nur zu mehr oder minder vagen Vernutungen kommen. Unter den Leuten des Herrn Oberleutnant Dr. Pleln war es auch nur jener Fanti, welcher sich schon vorher in seiner Heimat mit Einsammeln von Kickxia-Kautschuk abgegeben hatte. Von diesem hörte ich, dafs etwa sechsjährige Stämme anzapfbar seien und etwa zehnjährige beim ersten Anzapfen den reichsten Ertrag lieferten. Das Alter der Anzapfungsfähigkeit stimmte mit meinen Vermutungen überein; erstaunt war ich dagegen über die Mitteilung, dafs ältere Bänme allmählich ganz aufhören sollten, Kautschuk zu lieferm. Sowohl den Angaben, welche ich im Yoruba-Lande gesammelt, wie meinen eigenen Beobachtungen in der Ngoko-Region widersprach dieses entschieden. Die vier-bis fünfjährigen Stämme von Kickxia africana, welche ich auf der Kürlerlingschen Plantage bei Campo gesehen habe, die aber wohl infolge zu starker Sonne sich mehr buschartig entwickelt hatten, hatten trotzdem Hauptstämme von einem halben Ful's Durchmesser. Wenn man nun bedenkt, dafs durch die unzähligen Seitenstämme und Zweige ein grofser Teil der Wachstumskraft vom Hauptstamme abgelenkt wird, so ist wohl anzunehmen, dafs bei regulärer Entwickelung die Stämme in diesem Zeitranm bedeutend dicker sein dürften. Hevea brasiliensis, eine Pflanze, welche anch anfangs mehr Längen- als Dickenwachstum aufweist, hat, nach den Exemplaren im botanischen Garten zu Victoria zu urteilen, auch nach fünfjährigem Wachstum schon recht ansehnliche Stämme rebildet. Ein solches Wachstum, wie ich es auf der Campo-Plantage bei den rlei bereits früher erwähnten elf Monate alten Bänmchen von Kickxia elastica gesehen und hier abgebildet habe, lürfte allerding's nicht normal sein, doch beweist es, welche. Wachstumskraft in der Pflanze steckt, sobald sie unter günstigen Verhältnissen aufwachsen kann.

Nach den Erfahrungen, welche uns jetzt betreffs Anlagen von Kickxia-Plantagen zu Gebote stehen, und das sind allerdings nur sehr geringe, scheint es, als ob die Pflanze durch Auspflanzen aus den Samenbeeten bedeutend leidet, und daher wäre es sehr wünschenswert, dals, sobald genügend Samen zu beschaffen sind, auch Versuche gemacht werden sollten, die Pflanze sogleich an Ort und Stelle auszusäen, ähnlich wie es jetzt anf vielen Kakaoplantagen mit der Kakaosaat gemacht wird. Die Pflanzen würden so nicht durch Verpflanzen in ihrem Wachstum gestört werden und schon früher genügend festen Fuls fassen, um besser äufseren Einflüssen Widerstand leisten zu können. 
Was die Anzapfungsmethoden für Kickxia anbetrifft, so sind in den Ländern, wo dieser Baum ausgebentet wird, bis jetzt nur zwei Arten der Gewinnung des Milchsaftes bekannt. Die eine derselben, das Umschlagen der Bäume, ist natürlich von vornherein verwerflich. In den Ländern, wo dieses geschieht, also hauptsächlich bei den Völkern im Osten und Nordosten des Kamerun-Gebirges um den Barombi-See hernm, werden die Stämme umgeschlagen und mehr oder minder ihrer Kronen beraubt. Durch untergeschobene Steine oder Holzblöcke wird dann der gefällte Stanm ein wenig über den Boden gehalten und in mehr oder minder grofsen Abständen (gewöhnlich von etwa einem Fufse) werden quer um den Stamm herum Ringe ausgeschnitten. Der infolge dieser Verwundungen austretende Milchsaft wirl in den unter den Ringen aufgestellten Gefälsen aufgefangen. Natürlich bleibt bei dieser Methode eine grofse Menge von Milchsaft in der dem Stamm noch anhaftenden Rinde zurïck, und selbst durch nochmaliges Anzapfen der unversehrten Teile kann nur ein geringer Teil desselben herausgezogen werden. Natürlich ist diese Art von Raubbau, bei welcher auf Kosten einer unzureichenden einmaligen Anzapfung ein ganzer Stanm getötet wird, lie verwerflichste Art der Kantschnkgewinnung, welche bekannt ist, und daher wäre es sehr wünschenswert, wenn von seiten der Regierung Schritte gegen ein derartiges unverantwortliches Vorgehen seitens der Kantschuksammler gethan und eventuell durch strenge Strafen die an den Tag kommenden Fälle dieser Art von Ausbeutung der in unseren Kolonien vorhandenen Schätze gerügt würden. Schon Dr. Preufs hat vor einigen Jahren darauf aufmerksam gemacht, dafs der Kautschukbanm in der Nähe der Barombi-Station infolge dieser rohen Art der Gewinnung des Produktes fast gänzlich verschwunden sei. Ich weifs selır gut, dafs mir auf meinen Vorschlag geantwortet werden könnte, dafs ein solches Vorgehen seitens der Regierung noch nicht möglich wäre, weil nicht genügend Enropäer im Lande seien, um die Aufsicht über die Eingeborenen zu führen. Das ist aber kein Grund, das Verbot des Abschlagens der Kickxiastämme nicht zu crlassen, denn wemn ein solches nicht existiert, ist ein jeder Neger berechtigt, öffentlich in frevelhafter Weise die Bäume zu töten, während im anderen Falle bei den eventuell zu Tage kommenden Fällen durch die Bestrafung der Übelthäter ein Exempel statuiert werden würde, das auf die Negerbevölkerung jener Gebiete nicht ohne Eindruck bleiben würde.

Die andere, jetzt schon weit verbreitete Anzapfungsmethode bei den Kickxien ist die aus Amerika stammende Methode des Grätenschnittes. Um die schlanken Stämme der Kickxia ersteigen zu können, bedienen sich die Fantis eines ebenso praktischen wie vorzüglichen 
Kletterapparates. Derselhe bestelit ans zwei Ringen, von denen der eine den Oberkörper des Hinaufklettermelen und den Bammstamm zugleich mmspant, der andere aber nur mon den stamm geschlungen wird. Ton heiden hängen in mgleicher Höhe gevissemalsen Steigbügel herah, wolche zur Sicherheit als Ruhepunkt tär die Fülse dienen. Durch abwechsehdes Emporschieben dieser beiden Ringe und der daran befindlichen steighögel crklettert drer Fanti mit herlentemder Geschwindigkeit selhst hole Bamnstämme, sofern er im stanrle ist, mit seinen Ringen dieselben zu unspannon. Oben brgimnend, wird zum Zwecke des (irätenschnittes zmü̈chst pine Längsrimme aus der Rinde ausgeschnitten, in welche tam dir verschiedenen zu beiden Seitem der Längsimme aufsteigenden, den Stamm von jeder Seite halb mospannenden Querrinmen eimmïnden. Wem man sielt diese Rimmen plastisch dargestellt denken wärde, so erhielte man also etwa das Bild eines Rückgrates mit den Rippen. In einem dicht oberhalb des (irmules des Bammstammes angeorachten Gefäfse wird dann die Wilch anfgefangen. Da die Fingehoronen beim Einschmeiden der Rimmen in die Rinde meist nicht vorsichtig genug zu Werke gehen und daher die unter der Rinde liegenden ('ambiumschichten versehren. gehen viele Exemplare der Kickxia sehon mach simmaligem Anzapfen zu Grmole. Dic Instrumente, welche jeh mitgrinommen hatte, d. h. die Messer mul Äxte, anf welche ich die Blechlı̈̈lsen aufsetzen komute, um ein zu tiefes Eindringen der Sehnojrle in die Rinde zu rerhüten, bewährten sich daher selır gut. Es ist allerdings bei Stämmen verschiedenen Alters nötig, diese Śchneiden zu ändern, da die jüngeren Bäume rine dïmnere Rinds laben als die älteren.

Eime dritte Methode, welche allerdings bis jetzt meines Wissens nicht versucht worden ist, aber empfehlenswert erscheint, ist die Pickiermethode. leh komnte persönlich in dieser Hinsicht nur sehwachr Versuche machen, da sich der Pickierapparat, welchen ich mitgenommen, an der zähen Kickxiarinde als zu schwach erwies. 1)a schon bei Stichen von geringer Tiefe der Saft reichlich fliefst, könnte man dnrch wiederholtes Pickieren jährlich eine nicht unbedeutende Menge Kautschnk gewinnen, ohne den Banm ernstlich zu verletzen. Der am Stamme hermnterlanfende Milchsaft könnte, wie es beim Gewimmen des Para-Milchsaftes häufig gehandhabt wird, unten Stanm durch eine Lehmrimme aufgefangen mul in ein Gefäls hineingeleitet werden. Das am Stamm koagulierte Produkt mülste dam natürlich extra abgewickelt werden. Geschieht diese Art der Ausbeutung jährlich verschiedlene Male, so dürtte sich wohl eine yute Ernte erwarten lassen, ohne dafs der Bam in seinem Wachstum ('mpfindlich gestört werden würde. Das Anzapfen der horizontal 
ahstehenden Äste lürfte mit grölseren Schwierigkeiten rerknüpft sein, als das der senkrechten Stämme, und es werden sich in diesem Fallo. wohl keine anderen Methoden ausfindig machen lassen, als das Auffangen des Milchsaftes in darmnter anfogehängte Gefäfse. K/n diesem Zwecke würle es am vorteilhaftesten sein, in gewissen Abständen die Äste zu rerwunden und unter jedler dieser Anzapfungsstellen ein Giefäfs zum Auffangen des Milchsaftes anzubringen. Wie ich schon weitrr oben angab, enthalten dic noch nicht verholzten Teile der Kickxia elastica keineu Milchsaft, ans dem sich branchbarer Kautschuk bereiten läfst. Es kommen beim Anzapfen der Äste und Zweige daher also nur die älteren in Betracht. An etwa senkrecht stehenden Ästen liefsen sich natürlich anch die an den Stämmen praktizierten Anzapfungsmethoden zur Anwentmo bringen.

Die Umwandlung des gewommenen Milchsaftes in Kautschuk kann in verschiedener Weise betrieben werlen. Nach den ron mir selbst im Sanga-Ngoko-Gebiete erprobten Methorlen dürfte sich das Kochen der Milch am besten empfehlen lassen. Zı diesem Zwecke mülste man sich irdene Gefälse anschaffen, da an den Metalltöpfen die sehr bald anhaftende Milch leicht anbrennt und dann eine schmelle Oxydation des Kautschuks zur Folge haben würde. Nachden die zu koagulierende Nilch, um ein zu schmelles Kochen nud Anbrennen zu verhüten, mit der drei- bis sechsfachen Menge Wasser vermischt worden ist, muls sie in den irdenen Töpfen mnter einem nicht zu scharfen Feuer langsam zum Kochen gehracht werden. Sobald sich damn ein zartes Häntchen anf der Oberfläche der kochenden Flüssigkeit bildet, muls sie stets durch Rühren in Bewegung gehalten werden, damit sich keine koagulierenden Teile an dem heifsen Topf ansetzen können und daselbst anbrennen. Bald wird sich die Flüssigkeit in ein helles, nilchiges Wasser und eine schneeweifse, flockige Masse gesondert haben, welche man nun behnfs Abkühlung in ein Bassin mit kaltem Wasser wirft. Durch weiteres Kochen des Rückstandes wird sich derselhe infolge weiterer Koagulation allmählich klären und noch weitere Partikel der flockigen Masse absondern, die dann der bereits entfernten hinzugefügt oder für sich gehalten werden können, da sie gewöhnlich rin offenbar weniger gutes, wenn auch noch vorzïglich verwendbares Produkt darstellen. Sind die flockigen Massen genügend durchgekühlt, so werden sie am besten möglichst stark zusammengeprefst und in wurstähnliche Formen ausgezogen, worlurch die gröfste Menge des noch eingeschlossenen Wassers ausgeprefst und somit ein gleichmäisiges Material erzengt wird. NachJem so aus dem Kautschuk das Wasser soweit als möglich entfernt ist, werden jene wurstähnlichen Stïcke zerschuitten und sollten dann eine geraume Zeit ausgetrocknet werden, ohe sie nach Europa ver- 
schifft werlen. Wenn es sich um Ausheutung von Plantagen handelt, wo man dann grölsere Quantitäten Kantschuks zur Zeit anfertigt, wäre es vielleicht selnr praktisch, nachdem die erkaltete Masse in Kuchenform geprefst ist, dieselbe behufs besserer Entwässerung durch eine Walze gehen zu lassen und damn die dadurch entstehenden Kautsehnkfelle hängend zu trocknen. Je dünner danı diese Fellı hergestellt würden, desto schncller und besser würden sie natürlich durchtrocknen ma dadmrch die Güte des Kautseluks berleutend erhöht werden, und desto besser würle sich der Kautsehuk bei seiner Verschiffung nach Europa lialten.

Ob es angehracht ist, beim Kochen rtwaige Koagulationsmittel, wie den Saft der Bossassangapflanze, oder sänren hinzuzufügen, mul's später die Praxis lehren. Die von mir nach Zusatz derartiger Koagulationsmittel angefertigten Proben unterschieden sich an Güte in keiner Weise von denjenigen, welche einfach durch Kochen hergrestellt worden waren. Bei meinen Versuchen fand ich dagegen, dal's es hesser sei, möglichst viel Wasser der Milch beizusetzen, bevor sir gekocht wirl. Der Kautschukgehalt bleibt ja llessemungeachtet in der Masse derselbe, und die koagulierenden Kantschukflocken sind weniger der Ciefahr ausgesetzt, amzubrennen.

Fine zweite Methode der Bereitumg des Kickxia-Kantschuks, welche sich vielleicht bewähren dürfte, ist die folgencle: Auf möglichst grofse Schalen, welche von unten gleichmälsig warm gehalten werden könnten, giefse man dir Kautschnkmilch aus und lasse die darin enthaltenen Wassemengen allmählich verdunsten. Natürlich dïrfen diese Schalen nie derartig erhitzt werden, dals sie die Milch zum Kochen hringen würden, da sonst sofort der sich bildende Kautsehuk verhrennen würde. Aneh in dieser Weise würde man dünne Kantschukfolle erhalten, welche dann schnell durchgetrocknet werden könnten.

Dieser letzteren ist eine Methode verwandt, für welche sich insofern einiges sagen läfst, da nur wenig Arbeitskräfte dazu nötig sind, doch ist sie ebenso wie lie eben beschriebene langwieriger als die des Einkochens der Milch. Ein grölseres Gefäl's mit trichterförmigem Boden, welcher dmrch eineu Abflufshahn geöffuet werden kann, fülle man mit der frischen Kickxiamilch und lasse es damn einige Tage ruhig stehen. Nach etwa acht Tagen werden sich dann die in der Milch enthaltenen Kautschukkügelehen nach der Oberfläche der Flüssigkeit zusammendrängen, und allmählich kann man das am Grunde des Gefäfses fast reine Wasser durch das verschliefsbare Abzugrolır herausfliefsen lassen, so clafs man nach etwa zwei Wochen nur die mehr oder minder zusammenlängende Kautschukmasse zurückbehält, welche dann durch Pressen von dem grölseren 
Teile der sich darin noch befindenden Wassermengen befreit werden kann. Die sich zuerst an der Oberfläche bildende Kautschukhaut scheint einen grol'sen Teil der Kantschukharze zu enthalten und kömnte deshalb, vielleieht gesondert, als andere Qnalität in den Handel gebracht werden. Leider ist es ohne Laboratorium nicht möglich, in Westafrika die Berechtigung dieser meiner Vermutung zu prüfen uml festzustellen, wie weit die Kautschukmasse von Harzen befreit ist, nachdem die sich zuerst bihlende obere Schicht entfernt worden ist. Auch mit Wasser kam man die Mileh verdünnen, doch scheint ladurch das Abscheiden der Kautschukkügelchen nicht eher ror sich zu gehen.

Während meines Anfenthaltes auf der Ngoko-Station in SüdostKamerun machte ich auch Versuche, Kickxia-Kantschuk nach der Para-Räuchermethode herzustellen. Ich liefs mir zu diesen Zwecki, aus hartem Holze eine ruderförmige Spatel anfertigen, ähnlich wic sie in Para gebränchlich ist. Leiøler standen mir damals keint Palmennüsse zur Verfügumg, so dafs ich gezwungen war, über einem einfachen Holzfener die Räucherversuche zn machen. Dieselben fielen durchans nicht zu meiner Zufriedenheit ans. Die Mileh der Kickxia koaguliert offenbar zu langsam, um sich fïr diese Methorle: zn eignen. Ich war trotz eifriger Arbeit nach mehreren Stunden rrst in stancle, eine kaum $4 \mathrm{~mm}$ dicke Kautschukschicht um die Spatel herumzulegen. Die Eingehorenen, welehe ich dam mit dieser Arbeit betraute, hatten schon gar keine Just dazu, da eine solche mülssame Methorle ihnen von Natur aus zuwider ist. Selbst wem man die Leute zu dieser Arbeit fände, dürfte sich doch das Resultat in kein Verhältnis zu dem Kostenanfwand an Arbeitermaterial stellen. Es ist wissenschaftlich interessant, lal's sich der KickxiaKantschuk in dieser Weise anfertigen lälist und auch von brauchharer Qualität ist, doch befürchte ich, dafs wir uns mit diesem Resultat zufriculenstellen müssen. Nach menen Wrfahrumgen ist also liese Methode für Westafrika nicht angebracht. Ob eventuell über rinem Fenter von Pahmennüssen ein hesseres Resultat herbeigeführt werlen kamn, muls ich noch dahingestellt sein lassen, doch glaulise ich, dafs ein solehes anch nicht hesonder's zu einer schnelleren Koagrulation fülnen wird, da die Kickxianilch, abweichend von den Vilehsäften der meisten amderen Kantsehukarten, gegen Winflul's von لیn gewöhnlichen Koagulationsmitteln vollständig unverändert bleibt, solange nicht ein grewisser Wärmegrad hinzutritt.

U'm anch die B iffensche Centrifugiermethode anwenden zu können, hatte ich auf der Experlition eine kleine Rahm-Centrifuge mitgeführt. Mit dieser Centrifuge stellte ich auf der Ngoko-Station auch Versuche a11. leh fand, lafs sieh die Kickxianilch leicht centrifugieren lälst, aber 
nur bis zu einem gewissen Grade. Man hatte die sich oben an den Tuben sammelnde flockige Masse stets wioder zn entfernen, um eino einigermatsen gute Scheidung d(r Kautschukkïgelchen zı erzielen, und democh enthielt schliefslich der Rückstand noch so viel Kantschnk. lafs ich gezwnngen war, die letzten Reste durch Kochen ausznzichen. Man hatte also trotz langwieriger Arbeit nachher noch dir zuerst geschilderte Methorle zu wiederholen, um das zu erreichen, was man dmeh Abkochen in wenigen Vinuten erreicht hättr. Ex scheint also, als ob das Centrifugiereu praktisch von geringeu Werte mol $11 m$ als wissenschaftliches Experiment interessant ist, da durchaus nicht alle Milchsäfte durch Centrifugieren in dieser Weiso. sich behandeh lassen. Ich mufs hier allerdings erwähnen, dats meine Centrifuge zu klein war, um Experimente in gröfserem Massstahe zuzulassen, doch ist kaum zu erwarten, dals hier, wo sich die loagulation in lieser Weise nicht einmal in kleinen lohnt, eine solche in gröfscrem Mafsstabe betrieben, zu anderen Resultaten fïhren wïrde.

Aus dem oben Gesagten scheint also hervorzugehen, dafs dir Methode des Einkochens der Kickxiamilch zur Koagulation derselben die empfehlenswerteste ist. lch wïrde ihr jedenfalls vor jeder anleren den Vorzug geben. Inwieweit die Methode des Eintrocknens sich bewähren wird, müssen weitere Versuche feststellen.

Ich habe bereits wiederholt Vorschläge üher Aulagen vou Kickxiaplantagen und deren Instandhaltung gemacht und bin stets dafür eingetreten, dals man möglichst hald dlieser Frage nähertreten solle. Es ist mir ja gelmngen, im Victoria-Geliete in Kamerum einige Plantagenleiter für eine solche Unternehmung günstig zu stimmen und sie zur luangriffualume des Planes zu bewegen. Doch his jetzt sind solehe Pflanzungern nur am lamerun-Giebirge entstanden, obgleich die Regionen süıllich des Kamerun-Flusses für derartige Untermehmungen auch durchaus gïnstig, wemn nicht sogar infolge ihres weniger schweren Borlens noch güustiger sind. Jedenfalls mülste das Projekt eine viel weitere Verbreitung finden.

Da bis jetzt das Beschaffen grofser Quantitäten ron Samen noch immer mit einigen Schwierigkeiten verkmüpft ist, so hatte ich bisher vorgeschlagen, dieselben erst in Saatbeeten anszusäen, damit möglichst wenig verloren gehen kömmen; doch wemn wir erst Verbindungen besitzen, durch welche die Samen in gröfseren Quantitäten leicht zu erhalten sind, so wäre es viclleicht ratsan, an Ort und Stelle einige derselben anszusäen, um dann die kräftigste Pflanze der aufgegangeneu stehen zu lassen, die anderen könnten ‘amn ja zum Ansfüllen etwaiger Lücken verwendet werden. Sind dio Pflanzen in Saatbeeten ansgesät, so müssen sie, antangs be- 
schattet, in deuselben verbleiben, bis sie vier his sechs Blättehen entwickelt haben. Dann könnten sie im Walde ausgepflanzt werden. Un len Pflänzchen in ihrer Jugend genügend Luft und licht angedeihen zu lassen, mufs der Wald zu diesem \%wecke etwas welichtet, 1. h. das Unterholz und die jüngeren Stämme, soweit sie mit wenigen Axtsehlägen zu fällen sind, entfernt werden. Eine solche Lichtung des Waldes zum Zwecke ron Kickxiaplantagen würde also nicht mit sehr grofsen Kosten verknüpft sein. Kusammen mit Herrn Stammler, Aem Leiter der Moliwe-Pflanzung, berechnete ich dir ladurch entstehenden Unkosten. Er hatte gefunden, ılafs er mit fïnfzig guten Arbeitern in der olven vorgeschlagenen Weise cin Hektar zur Aufnahme der jungen Pflänzchen in einem 'Tage herriehtın komnte. Da er zu diesem Zweckr die tenren 'Togo-Arbeiter varwendet hatte, welche alles in allem 1,35 Mlk. pro 'Tag'kosteten, so würden sich die Ansgaben für die Arbeiter sellıst auf 6 T Mk. 50 J’f. belaufen. Da zur Aufsicht dieser Arlseiter ein Europäer nötig ist, Aer einschliefslich seiner Beköstig'mng ungefähr 12 Mk. pro 'Tag' kosten würde, so ergäbe sich als Endresultat eines Kostenauschlages für rie Lichtung eines Hektars die Summe von 79 Mk. 50 Pf., also rum 80 Mk. In Abständen von etwa fünf Metern kömnten die Pflänzchen in den so gelichteten Wald eingepflanzt werden, da die Kickxia rin Baum ist, der nur eine kleine aufrechte Krone besitzt. Es wäre vielleicht sehr angebracht, wenn man die einzehnen samen in tiitenförmig aufgerollte, mit Erde gefüllte Kakaoblätter orler in kleine Körlschen aus Ölpahnen-Blattfiedern, in deren Anfertignng die Eingeborenen eine grofse Geschicklichkeit besitzen, ansiäen würle. in denen sie daun an Ort und Stelle übertragen werlen könnten, sobald sie das nötige Alter erreicht haben. Da das Kakaoblatt orler das Körbchen aus Palmen-Blattfiedern im Boden bald verfaulen würde, würden die Wurzehn keinen Widerstand an der ehemaligen Wanklung finden und somit gar keine Wachstumsstörung eintreten. Bei Kakao habe ich liese Methode nit grofisem Erfolgre zur Anwendung bringen sehen. Herr Stammler teilte mir mit, dafs zum Bepflanzen dines Hektares des so gelichteten Waldes auch wieder fünfaig Jente unter Anfsicht eines Europäers einen Tag thätig sein wärten. Die Bepflanzungskosten würlen sich mithin also auch ant 79 Mk. 50 Pf., also rund 80 Mk. holaufen. Fin elon mit Kiekxia Mastica bepflanzter Hektar würle sonit also einc Anslage von 159 bezw. 160 Mk. erforlern. Da hei eimem Ahstande von fünf Metern auf einem Mektar Lambes 400 P’fänzehen stehen wïrden, so würde rine Pflanze f) Pf. kosten. Wem man bedenkt, welche riesigent Unkosten das Urbarmachen des Landes bei Anlage einer Kakaoplantage arfordert, da nur rin verhailtnismälsig kleiner Teil der 
stärkeren Urwaldbäume stehen bleiben kann, so ist es leicht erklärlich, dal's eine Kakaopflanze, an Ort und Stelle ausgepflanzt, bedentend mehr kosten muls. Bis die so ausgepflanzten Kickxien (rine genügende Stärke erreicht haben, $m$ sich selbst überlassen zu werlen, d. h. bis zn Beginn ihres dritten Lebensjahres, mülste die Pflanzung in der Nähe der jungen Bämmchen genügend rein gehalten worden, damit dieselhen nicht von den aufspriefsenden Unkräntern überwuchert mol erstickt werden. In einem nur mäl'sig gelichteten Urwalde wird der Kampf gegen etwa anfspriefsende Unkräuter ein nicht so schwieriger sein als in einem offenen, somigen Terrain, daher dürfte eine Reinigmg der Plantage nur drei- oder viemal in Jahre nötig sein. Also anch hier wären die Unkosten nur geringe, denı zur Reinigmm des Hektars wïrden nach Herru Stammler etwa zehn Leute einen Tag lang beschäftigt verden müssen.

Vorausgesetzt num, dal's der Bamm erst nach sechs Jahren angezapft werden kamn, so stände der Bruttoertrag desselben, wenn er nur ein Kilo Kautschuk lieferte, in einem so holıen Verhältnisss zu den geringen Ansgaben, dafs man die Kickxiakultur nur als aine mingehener lohnende bezeichnen könnte.

Wem wir damn erst einmal so weit gekommen sind, dal's wir in den Plantagen Kantschuk gewinnen kömmen, dam werden sich anch noch viele Verbesserungen in der rationellen Anzapfungsmethorle der Bämme und in der Bereitung eines guten Kautschnks finden, denn dam kömmen an Ort und Stelle wichtige Tersuch gemacht werlen, für welche der Reisende nicht genügend Keit hat.

Ich möchte gérarle die Kickxia zum Anban in Westafrika hesonders empfehlen, da sie im Lande heimisch ist und deshall, sicher mehr Aussicht auf Erfolg zu bieten scheint, als die versehiedenen Kantschukbämme anderer Erdteile.

Bei Gelegenheit der schilderung meiner Togo-Reise habe ich bereits des Manihot (ilaziovii Erwähmmg gethan und Vorschläge fïr seine Anpflanzmng gemacht. Die Pflanze ist meiner Ansicht nach mit Tnrecht in letzterer Zeit hänfig als wertlos hezeichnet worden. Wenn sic nur richtig angepflanzt mud ansgebentet wird, lann wäre ein grölsere nit Manihot Glaziovii berleckte Fläche rine durchaus nicht zu verachtende Besitzung, welche sicher mehr rinbringen dürfte, als viele der afrikanischen Kaffeeplantagen, deren Unterhaltung ganz bedeutende Kosten verursacht. Ich möchte hier noch eimmal betonen, lals ich nur dann für die Anpflanzung dos Manihot Glaziovii eintrete, wem diese sowohl wie das Abernten der Bestände in der von mir vorgeschlagenen Weise betrieben wirl. śobald die Aulage gröfsere Kosten verursacht, kam Manihot 
(ilaziovii nicht als Kulturptlanze in Betracht kommen, dem bei den grringen Iengen Kantschuk, welche drr Baum liefert, wïrde sich ein regelrechter Plantagenhetrieb nie lohnen. Für die schr regren-

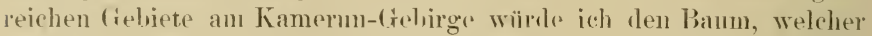
in seiner Heimat rine Steppenptlanz ist, nicht empfehlen. In den (iegenden, wo, wis z. I3, in den Steppen 'Togos, die Eingeborenen alljährlich ılas (iras nielerbrennen, müfsten die Brände natürlich iı der Tähe solcher Manihothestäude verboten und im Falle der Übertretung die den Brand rexursachenden Eingeborenen bestraft werden. Üherhaupt wäle es sehr wïnschenswert, dafs rliese rollständig nutzlosen Grasbrämle, dio besoulers in Togo, wo sehon an und für sich lir Bewaldung des Gebietes eine sebr spärliche ist, in den linumbeständen riesige Verheerungen anrichten, rerboten oder duch bedentend erschwert wïrlen. Fs wäre doch ein grofser Trimmpl europäischer Kultur, weun as uns gelänge, die sonst rollständig wertlosen immensen Steppengehietr dureh Bepflanzumg mit nïtzlichen Gewächsen wertvoll machen zu könneu. Manihot Glaziovii int eine Pflanze, dic bei dieser Frage grofse Beachtmog rerdient. Awch in anderer Hinsicht wäre ein Bepflanzen der Steppen mit diesem Kantschubaume von Wichtigkeit. Da bekanntlich der Bamm ziemlich grofse lanbhlïtter bositzt, die, wenn sie heral,fallen, allmählich den Borkn mit einer Humusschicht ïherlecken würden, so würde mit ler Keit der. Steppencharakter der mit diesem hepflanzten Gebiete vollstïndig rerloren gelıen und schon dadurch lere Wert der fieliete berlentend erhöht werilen.

Anch der Ficus elastiea habe ieh bereits Erwähmumg nethan. Entgegen der Manihot Alaziovii hahen wir in ilur eine Pflanze vor uns, welche zu ihrem Gedeihen einer fenchtren Atmosphäre bedarf. Demuch ist as nerkwïrdig, dafs die bisher in Kamerum vorhandenen Exemplare einen recht mindrewertigen Kantschuk liefern, ohgleich anch dort der Baum vorzüglich gedeilıt. Sollte dieses otwa in der chemischen Kusammensetzumg des Borlens liegen? Oder sollten die im Vietoriatiarten rorhandenen Exomplare ron einer hereits degeneriorten Pflanze abstammen? Es wird nötig sein, un diesep Frage auf den frumd zu gehen, mit möglichst guten Spielarten neur Versuche zu machen. Sehlagen auch diese nicht vin, damm diüftr wohl erwiesen sein, dafs die Pflanze in Kamerun nur rincu minderwertigen Kantselulk hervorzubringen im stande ist. Wir pinige aus Kairo entstammente, vou Ilerm Prof. S'cliweinfurth angefertigte Proben beweisen, liefern die dort angroapften Bänme ein wirklich vorzügrichrs Produkt, das wohl mit den beston Penang-Qnalitäten kunkurriorn könntr. Sollten sich Spiolarton dieser Firus finden 
lassen, welehe anch in Kanerun ein wirklielı gntes Produkt rrzengen, so sollte mit ihrer Anpflanzung nicht gezögert werlen.

Zur Zeit meiner Anwesenheit in Westafrika waren ron Castilho: elastica in Kamernu nur einige wenige, sehr junge Exemplare vorhanden, aus deren Alter uatïrlich gar nicht zu schliefsen war, ob sie sich gut bewähren wïrden oder nicht. Nach den letzthin vou Kamerun eingetroffenen Vachrichten sollen sich die Exemplare selu gut entwickeh. Inwieweit sich ein Kautschukertrag späterhin rentieren wird, mufs natürlich der Zukunft n̈berlassen werden zu entscheiden.

Im botanischen fiarten zn Victoria standen die einzigen Bämur ron Herea, welche bereits anzapfbar waren. Der Borlen, in dem diese Exemplare wuchsen, war ziemlich trocken, mud diesem Umstande ist es wohl zuzuschreiben, dafs die Stämme auffallend wenig Kantschuk gaben. Es ist durchaus nicht ansgeschlossen, dafs die Pflanze in fenchterer Lage orler in höherem Alter, wie es sich in Ceylon zeigte, einen bedentent besseren Ertrag bringen uml sich dam bezahlt machen würde. Anfserdem ist es noch nicht erwiesen, dafs die in Vietoria stehenden Bäume wirklich einer besseren Herea-Art angehören, die auch in der Heimat gröfsere Erträge liefert. Also auch über sie lälst sich, soweit Kamerum in Betracht koummt, noch nicht viel sagen. 


\section{Anhang I.}

\section{Denkschrift des Herru Prof. 0. Warburg zur Begriundung der Kautschuk-Expedition.**)}

Eine wie grolse Bedeutung der Kantsehnkhandel namentlich infolge der Entwickelung der Elektrotechnik und les Rarlsports arerreicht hat, ist bekannt genug. Es brancht nur darauf hingewiesen zu werden, dafs, während 1830 erst 230 Tons nach Europa eingeführt wurlen unt 1840 (im Jahre der Entileckung tler Vulkanisation des Kantschuks) 400 Tons (von Para kommend) den gesamten Welthedarf deckten, der Konsm im Jahre 1896 schon anf 31541 Tons grestiegren ist, welche Summe einen Wert von 200 Millionen Mark repräsentiert.

Nacheinantler wurten sämtliche tropische Gegenden für dir fiewinnung von Kantschuk in Anspruch genonmen, in den meisten Gegenden freilich in derart ruchloser Weise, dafs nach wenigen Jahren steigender Ausbeute die natürlichen Bestände so gut wir vernichtet waren. Centralamerika, die Heinat des schönen Castilloa-Kautschuks, liefert nur noch ganz geringe Mengen, so dal's man sich daselbst jetzt mit Energie auf die Kultur dieser Bäum, zи werfen beginnt. Der gesamte Export Süı- und Mittelaun rrikas, abgesehen von Brasilien, betrug $1896 \mathrm{mur} 1773$ Tons, d. h. nur ¡.6 pCt. der Totalprorluktion. Der nie sehr hedentend gewesenr. Kantschukexport Südasiens befindet sich seit Jahren in Abnahm. und betrug 1896 etwa 1393 Tons, d. h. 4.4 pCt. der Weltproduktion. Fïr Brasilien liegen die Verhältnisse insefern günstig, als im Amawonas-Gebiet den feinen Para-Kautschnk grofse Bänme (Hevea) liefern, die recht widerstandsfähig sint; aufserdem hat sich daselbst ein inmer nehr vervollkommnete Methode des Anzapfens ausgebild.t, so dafs die Protluktion dieses gewaltigen, zwei Drittel Europas gleichkommenden Gebietess stets wächst und rou 10018 Tons 1882/4:3 anf 22290 Tons (etwa 140 Millionen Mark) im Jahre 1896 gestiegr'n ist. Die im Amazonas-Gebiet lebenden Sachverständigen sind allيremein der Ansicht, daf's von einer Erschöpfung des Vorrates nowh fïr lange hinaus keine leede sein kann.

*) Die ausführliche Statistik sämtlicher für den Kautschukexport in Jietracht kommenden Länder siehe Warbnrg: Die Kautschukpflanzen und ihre Kultur, Berlin 1900, Kolonial-Wirtschaftliches Komitee, Unter den Linden fo. 
In aufsteigender Richtung bewegt sich angenblicklich anch noch die Kautschukausfuhr Afrikas, lie aber 1896 erst 9111 Tons, das sind 28.9 pCt. Gesamtproduktion betrug, wovon nicht weniger als 6933 Tons nach Liverpool gingen, und zwar 1890 Tons von der Nordwestküste (Senegambien, Liberia, Gold-, Elfenbein- und Sklavenküste), 2352 Tons aus Lagos, 975 Tons aus Sierra Leone, 1716 Tons von Marlagaskar und Mozambique. Dazu kommen 501 Tons vom Congostaat, meist nach Antwerpen gehend, und 67.5 Tons der deutschen richutzgehiete, meist nach Hamburg gehend.

Was die deutschen Kolonien in Afrika betriftit, so bildet der Kautschuk zwar einen der bedentendsten Ausfuhrartikel Kameruns und Ostafrikas, und auch Togo exportiert nicht unheträchtliche Quantitäten; die Zeit des Aufschwunges in Bezng auf liesen Artikel ist aber schon für msere Kolonien vorbei, Togo nmol Kamcrun zeigen schon wieder beträchtliche Almahmen, in Ostafrika hat zwar noch im letzten Jahre die Quantität etwas zugenomnen, aber nur noch sehr wenig und wahrscheinlich nur infolge ler vermehrten Anfuhren aus Portugiesisch-Ostafrika; es dürfte kaum einem Zweifel unterliegen, dafs sich auch hier schon in einem der nächsten Jahre ein bedeutender Minderexport zeigen wird.

Kamerun exportierte

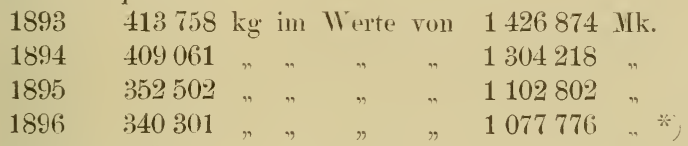

Togo exportierte:

\begin{tabular}{|c|c|c|c|c|c|c|c|}
\hline 1893 & 28637 & $\mathrm{~kg}$ & im & Werte & ron & $9925 t$ & IIk. \\
\hline 1894 & 30582 & $"$ & .. & . & 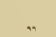 & 115621 & .. \\
\hline 1895 & 87498 & " & $"$ & . & " & 306123 & * \\
\hline 1896 & 82645 & 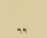 &. & m & $n$ & 297524 & $n$ \\
\hline 1897 & 66156 & " & . & . & " & 245369 & 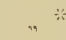 \\
\hline
\end{tabular}

Deutseh-Ostafrika exportierte:

1893499994 engl. Pf. im Werte von 232598 Dollar

$1894 \quad 415429$

$1895 \quad 503320$

$1896 \quad 611446$

$1897619 \supseteq 64$

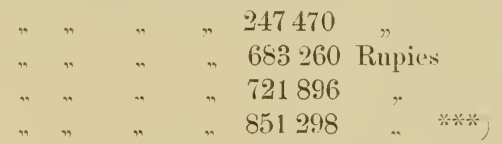

* Im Jahre 1897 wurden $372273 \mathrm{~kg}$ im Werte von $887572 \mathrm{Mk}$. exportiert.

**) In den beiden letzten Jahren fand folgender Export statt:

$\begin{array}{ll}1898 & 87277 \mathrm{~kg} \text { im Werte vou } \\ 1899 & 68239169 \mathrm{Mk} .\end{array}$

***, In den beiden letzten Jahren fand folgender Export statt: $1898 \quad 186891 \mathrm{~kg}$ im Werte von 970109 Rupies $1899267505, \quad, \quad$, $\quad 1337181$ 
Noch schlimmer ist der Rückgang in anderen afrikanischern fiegenden, und zwar gerade in solchen, wo der Kautschuk zuerst in gröfseren Mengen exportiert wmrle. So betrug der Grsamtexport lesherïhnten altbekamnten Na d a gaskar-Ka u tschuks im.Jahre 1896 mur noch 5:36 is: Fres., mul del Jlozambique-Kautschuk, ron lem schon lsĩ $445567 \mathrm{~kg}$ exportiert wurlen, war 1894 und 1895 schon anf 2501 säcke, 1896 auf 2000 säcke zurückgegangen, währenl

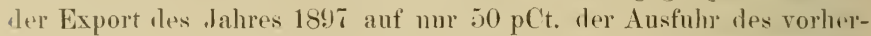
grhenden Jahres angegehen wird. Dabei besteht (Kolonialblatt 1s!s \. 359) ,fast (i) pCt. der Gummiausfuhr aus sogenanntem gekochten finmmi, desisen Qualität sich von Jahr zu Jahr rersehlechtert hat. -1) daf's derselhe kamm noch einen Wert für len emropäischen Markt lresitzt". Auch an rler Coldküste, von wo 1893 für 218162 Pf. Niterl., 1894 sogar für 322070 Pf. Sterl. Kantschuk exportiert wurlell, lat sich lir Ausuhr 1896 etwas verringert (Kolonialhlatt 1898 s. 14\%), ebenso in französischen ('ongo, ron wo der Frport betrug

$\begin{array}{llllllllllllll}1895 & . & . & . & . & . & . & . & . & . & . & 574 & 546 & \mathrm{~kg} \\ 1896 & . & . & . & . & . & . & . & . & . & . & 546 & 555 & \\ 1897 & . & . & . & . & . & . & . & . & . & . & 518 & 270 & \end{array}$

Auch in Angola scheint sich jetzt schon ein Rïckgang oder wrnigstens pin Stillstand rorzuboreiten. Während der Kantschnkxport von 14 (b) $\mathrm{kg}$ im Jahre 1870 anf $2105771 \mathrm{~kg}$ im Jahre 1895 gestiegen war; hetrug der Export im Jalme 1896 erst $2285.995 \mathrm{~kg}$. also nur seln weng melur, mol von den sildlichen Provinzen ist sogar

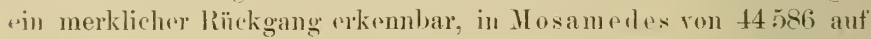
$12740 \mathrm{~kg}$, in Amliriz von $4186 \mathrm{~kg}$ anf $2094 \mathrm{~kg}$ in dron heiden Jahren 1894 mal 1895 .

Fiir Britisch-('eutralafrika, welches $189: 3$ 539) englische Pfuml (393 l’f. Sterl.), 1894 noch 144 englische Pf. (i Pf. Sterl.) exportierte, wirl liautschuk jetzt gar nicht melı erwähnt, vom Niger coast Plotretorate kommt nur gelegentlich otwas Kautschuk.

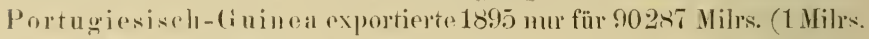
"twa :3 .11k.). Shellost in Lagos, welches infolge der Entrleckumg.

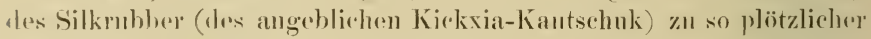
Berleutung grelangte, dafs 1895, ๙. h. ein Jahr nach der EntA leckmm, 5069504 englische Pfund in Werte vou 26!) 8!2 Pf. Sterl. 2xportiert wurlen, ist seitslem infolge der mafslosen und ungeregelten Ausbentung ler dortigen Kautschukbäume die fimmmigewinnung wisler auf einnu kleinen Botrag zosammengesehmolzen. (Kolonialhatt 1897 s. (i:37.)

Dire rimgige errofse Kmmahme zeight der ('ongostant, wir aus folgender 'Tahell, laevoreceht (Kolonialblatt 1895 s. 20): 


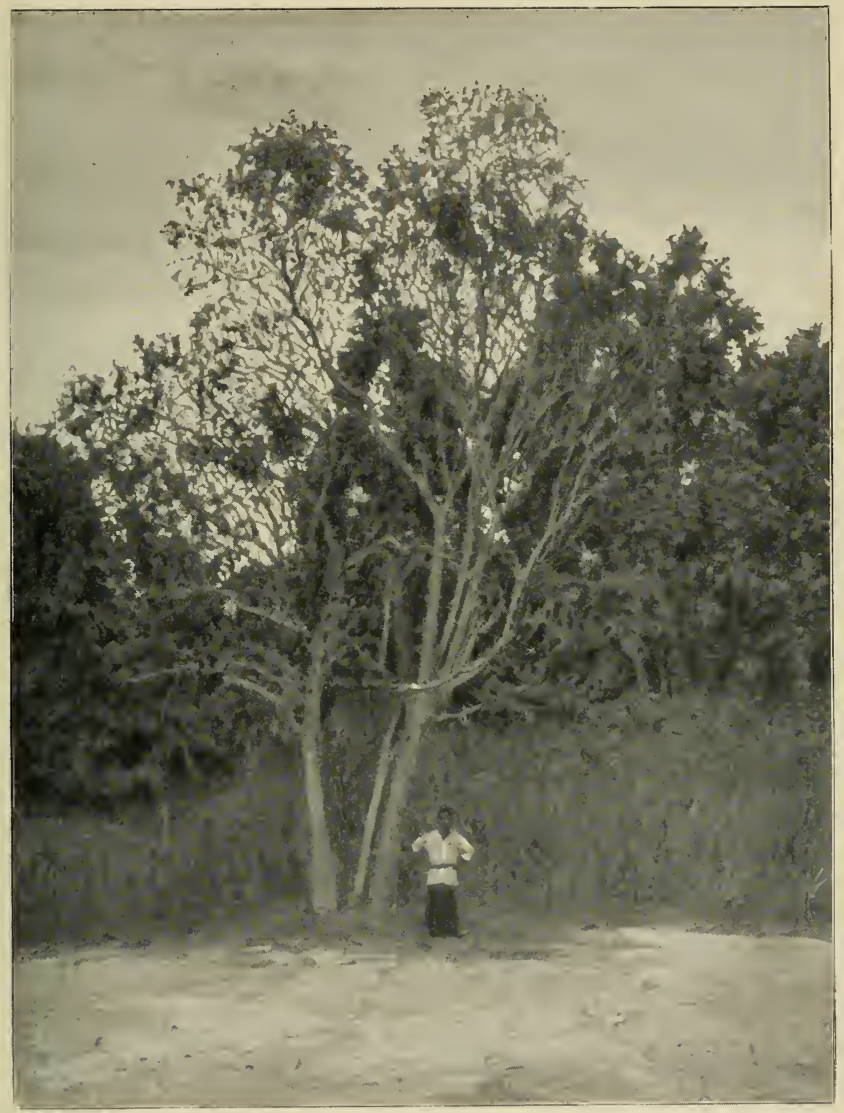

Ceara-Kautschukbaum in Gr. Batanga. 



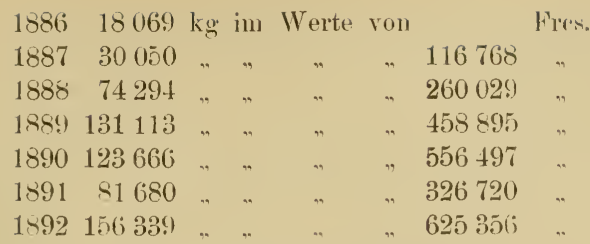

Damn stieg (ler Export rapide, hetrug 18!). sehon üher .000000 kg (im Werte voll „882585 Fres.) mml 1896 bereits $1195000 \mathrm{~kg}$. Für 1597 wird der Export auf $1500000 \mathrm{~kg}$ (1500 Tomen) geschätzt. Man erwartet sogar für die Zukunft einen Export von 4000 'Tommen pro Jahr' aus dem (Congostaat. *)

Die Trsachen der anffälligen Erscheimmg der Ahnahme des Kautschuks in den meisten Teilen Afrikas gegenüber der Zunahme in Brasilien sind in der unvernünftigen Ausbentung durch die Eingeborenen Afrikas zu suchen; wobei freilich zuzugehen ist, dafs es viel schwieriger ist, Lianen (wie in Afrika) rationell anzuzapfen, als die grofsen, den Para-Kautschuk liefermden Bäume. Aber anch wo es sich $n$ Bämme handelt, wie heim silkrubber in lagos, lut man in Afrika (elenso wie in Centralanerika anch die Castilloa) lie Bäume in kurzer Zeit vernichtet. Der ('ongerstaat ist bisher von ler Abmahme des Exportes an Kantschuk verschont geblieben, einerseits, weil die Ausbentmog rlort noch zu jumg ist und jetzt erst anfängt, weiter ins Laud hineiu vorzudringen; dam aber auch, weil die Regierung bemülst ist, dureh Belehrung und Strafen (ane rationelle Ausbeutung zu erzwingen. Namentich ist hierdurelı teilweise eine Güte des Produktes erzielt wie fast nirgends in Afrika, am allerwenigsten in unseren Schutzgebieten, so dafs manche Kautschuksorten des Congo-Gebietes nemerdings dem guten Para-Kautschuk an Wert kaum nachstehen sollen.

Von welcher Bedentung diese enorme Zunahme der Kautschukausfuhr des Congostaates für das belgische Mutterland ist, sieht man an dem zumehmenden Kantschnkhandel Antwerpens, welcher Platz jetzt auch sogar schon heginut, Kantschuk anderer Provinzen (z. B. der Goldküste und Angolas) an sich zu ziehen. Der Kantschukimport Antwerpens betrug:

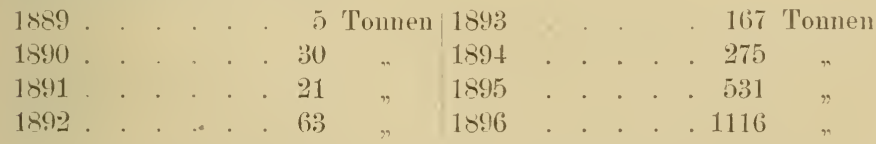

* In der That betrug der Export 1897 schon $1662380 \mathrm{~kg}$ in Werte von 8311900 Fres. und stieg 1898 sogar auf $2113465 \mathrm{~kg}$ im Werte von 15850987 Fres 
Nach Hamburg wurden an Kantschuk eingeführt:

18944771 Tonnen in Werte von 16148120 VIk.

$18955424 \quad . \quad . \quad . \quad . \quad \ldots 18819850$

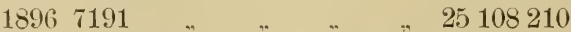

so dafs also unser grofses Emporium angenblicklich einen mehr als sechsfach so bedentenden Kautschukhandel hat als Antwerpen und fast ein Viertel der gesimten Weltproduktion nach Hamburg welangt.

Weit weniger erfreulich steltt sich aber die Sache dar, wem wir den Herkunftsländern des in den Hamburger Handel gelangenden Kautschnks nachgehen. Nicht weniger als 3832 Tonnen, also über die Hälfte der gesamten Einfuhr, gelangt erst über andere europäische (nicht dentsche) nud nordamerikanische Häfen nach Hamburg, darunter 2895 über Grofsbritannien, 209 über Belgien, 174 über Frankreich, 117 über Portngal, 138 über die Niederlande, 131 über die Vereinigten Staaten etc. Ans Brasilien kommen nur 69 Tonnen direkt, aus Afrika lagegen ‘2864, d. h. fast ein Drittel der gesamten afrikanischen Ausfulır, darunter

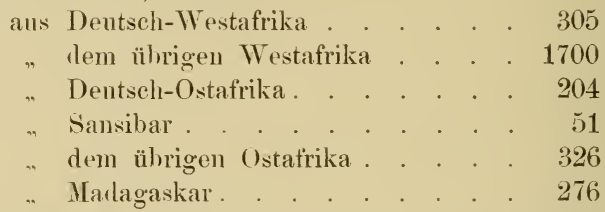

Es wird hierdnreh also die auch sonst geltende Regel bestätigt, dafs cler Handel der Flagge folgt; nur Westafrika teilweise, sowie Madagaskar, wo grerade viele dleutsche Häuser ansässig sind, machen darin eine Ansnahme; schon Sansibar exportiert trotz der vielen dort ansässigen deutschen Hänser den gröfsten Teil nach England, mud nur von den dentschen Schutzgebieten geht der gröfste Teil $\left({ }^{2} / 3\right.$ bis $\left.{ }^{3} / 4\right)$ direkt nach Deutschland.

Wir sehen also ans diesen Erörterungen, dafs

1. der Kantschukhandel stetig und rapide wächst,

2. Deutschland im Kantschukhandel eine hervorragende Stellung einnimut,

3. der Kautschukhandel sich im allgemeinen nach der Flagge des Landes richtet,

4. der Kautschukexport Brasiliens stetig zunimmt,

5. der Kautschnkexport in Afrika nur noch im Congostaat beträchtlich zunimumt, in den meisten Ländern hingegen abnimmt,

6. der Kautschukexport Deutsch-Westafrikas schon bedeutend abnimmt, derjenige Ostafrikas kaum mehr zunimmt. 


\section{Anhang II.}

fintachten ïber die rou Lagos eingesandten Kantschnkprohen des chemischen Laboratorimms fiir Handel und Indıstrie (Dr. Rob. Henriques). Berlin.

Die ron Herm schlechter am 1. März übersandten Proben, bestehend aus:

1. Mileh einer Ficusart von Lagos,

2. daraus gewonnener Kantsehnk, kalt koaguliert,

3. " " knchend koaguliert,

4. kleine Probe Kickxiamilch ron Lages,

habe ich mit folgendem Resultat untersucht:

Zu 1. Die Ficusmilch stellte eine dünne, leicht bewegliche Flüssigkeit vom sperifischen fiewicht 0.98 dar. Eingesandt waren $75 \mathrm{ecm}$.

Die Milch koaguliert heim Ansäuern mit Essig- oder Mineralsäure nicht in der Kälte, wohl aber rasch in der Wärme, wobei sich der Kautschuk in Form eines Klumpens in bräunlich gefärbten Serum ausscheidet und ans diesem herausgenommen und gewaschen werden kann. Es wurden so gewonnen ans $50 \mathrm{ccm}$ : $13.5 \mathrm{~g}$ feuchtes $=9.3 \mathrm{~g}$ trockenes Rohprodukt.

Gehalt des trocknen Rohprodukts an Asche: 0.18 pCt.,

"Kautschukharzen : $22.6 \mathrm{pCt}$.

Der entharzte Ficus-Kautschnk war zwar kein erstklassiges Produkt, immerhin aber ein echter, mäfsige Elastizität zeigender Kautschuk. Die sogenannten Kautschukharze bildeten eine weifse, anscheinend krystallisierte, in heifsem Aceton lösliche feste Masse.

Die Proben sub 2 und 3 ergaben:

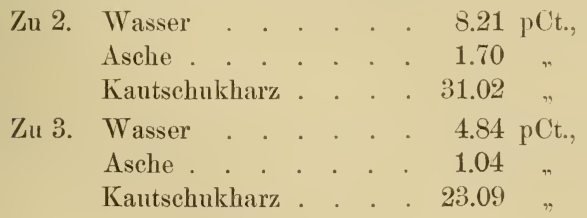


Die Prohs 3 (kochend koaguliert) stimmte mithin mit dem von mir ans der Mileh erhaltenen Produkt im wesentliehen überein. Die Ficusmileh durch Verdunstenlassen an der Juft zu koagulieren (wie No. 2), empfiehlt sich mithin nicht. Dor aus 2) und 3 gewomene entharzte Kautschuk stimmte miter sich uml mit dem aus der Milch newonnenen völlig überein.

In Anbetracht dessen, dafs das Entharzen eines solehen FicusKantschuks sich technisch sehr wohl ausführen läl'st und dals das damn gewommene Prodnkt ein weit brauchbarerer Kantschuk ist als der aus guten Flakes um derartigen Waren herzustellende, möchte ich den erentuellen Wert einer Rohware wie No. 3 auf etwa t.50 Mark pro Kilo normieren. Kantschukhändler und -fabrikanten werden ihn aber wahrscheinlich etwas niedriger taxieren. Was die Taxen ron dieser Seite betrifft, so möchte ich noch darauf hinweisen, dals gröfsere Mengen von den Eingeborenen kaum so trocken hergestellt werden könnten wie diese kleinen ron Herm Schlechter koagnlierten Mengen. Nasse Rohware von einem so grofsen Harzgehalt wie der rorliegende repräsentiert sich aber sehr schlecht und wird rorerst recht niedrig hewertet werden.

trollte sich diese Lagos-Ficus auch in unseren Kolonien finden, so wären die Eingeborenen zu einem fleifsigen Sammeln und Verarbeiten des Saftes anzulalten, der immer ein billiges, für Sekundawaren wohl verwendbares Produkt liefern würle. Einen derartigen Baum aber plantagemmälsig anzupflanzen, lazı kömnte ich nicht raten, selbst wenn die Ficus, worüber wohl nichts bekannt ist, besonclers rasch anzapfungsfähig wäre. Für Anbau und Kultur sollten vorerst meines Erachtens nur solche Pflanzén in Frage kommen, die ein gutes, elastisches, auch ohne weitere Reinigung wenig Harz enthaltendes Produkt geben.

$\mathrm{Ku} 4$. Die nit eingesehickte kleine Probe Kickxiamilch reichte uben hin, um daraus etwas Kantsehnk zu koagulieren und mit dem der P'reufsschen Kickxiamileh von Kanerun zu vergleichen. Die Lagos- und Kamerum-Jileh verhielten sich, betreffend die Art des Koagulierens, völlig gleich, und auch die darans gofertigten Kautsrhukproben waren von gleicher Vorzïglichkeit.

Die wichtigsten der ron Herm Schlechter ans Westafrika mitgehrachten Kautsehuk- und Kautschuksaftproben habe ich nummehr untersucht, und erlaube ich mir, larïher folgenden Bericht zur Verfïgung zu stollen:

1. Landolplia ron Ngoko.

Sprevies unlestimmt. An 21. Oktober 18.99 an Ort und Stelle koaguliert: tis cem der Milch wurlen mit elsenso viel Wasser verdünnt und nach /usatz you $5 \mathrm{ccm}$ Bossassangasaft gekocht. Fr- 
haltener Kautschuk: $16 \mathrm{~g}$. - Aussehen: Wurstförmiges Stück, sehr elastisch. Trocken mul gut. Weils mit rlunkeler Aufsenschicht.

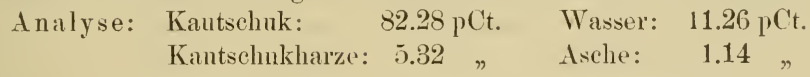

\section{Landolphia von Bonga am sanga.}

Spezies unbestimmit. Am 16. Angust 1899 an Ort und Stelle koagnliert. Aus 20 cem erhalten $12 \mathrm{~g}$ Kautschuk. - Aussehen: Kleiner Kuchen von gleicher Farbe wie 1. Ebenfalls sehr elastisch unrl gut; wenn auch stark wasserhaltig, doch erstklassiges Prorlukt.

Analyse: Kantschuk: $\quad 72.43 \mathrm{pCt}$. Wasser: $21.20 \mathrm{pCt}$. Kautschukharze: $1.06 \%$ Asche: 0.31 ,

\section{Kickxia elastica.}

a) Milch derselben. In Ngoko direkt von dem Bamm abgelassen und $700 \mathrm{ccm}$, versetzt mit $35 \mathrm{~cm}$ Salmiakgeist ( $30 \mathrm{pCt}$.), in eine sofort versiegrelte Weinflasche gefüllt. Trotz dieser Vor'sichtsmalsregeln ist die Milch nicht unverändert in meinen Besitz gekommen. Ein grolser Teil Kautschuk war freiwillig koaguliert. Ton diesen wurle die Milch abgegossen, von der noch $300 \mathrm{ccm}$ isoliert werden konnten; diese verhielt sich genan wie die im vorigen Jahre von mir untersuchte Kickxiamilch von Dr. Preuls (siehe "Tropenpflanzer" 1899, S.257 unt „Gummizeitung", XIII, 1899, No. 26). Spezifisches Gewicht: 0.990. Weder Mineral- noch organische Säuren fällen Kautschuk aus, ebenso wenig gelingt es mit dem zum Koagulieren der Landolphia verwendeten Bossassangasaft, die Kickxiamileh zum Koagulieren zu bringen, man mufs viehmehr, wie ich schon früher schrieb, den Saft zum Kochen bringen (was sich auch mit dem Verfahren der Eingeborenen deckt) und gewinnt dann unter Rühreı der mit Wasser verdünnten Wilch, angesäuert oder nicht, den festen Kickxia-Kautschuk.

Über die eigentümlichen Koagulationserscheinungen, die dabei die Milch zeigt, soll an anderer Stelle berichtet werden. Der fertig koagulierte Kantschuk wurle in Stücke geschnitten, ordentlich gewaschen und an der Luft getrocknet. Zerschneiclet man die grölseren Stücke mit Scheren in kleinere (vielleicht Würfel von 2 bis $3 \mathrm{~cm}$ Seitenlänge), so grelingt es, selbst hier bei warmer Witterung in acht bis zehn Tagen den Kantschuk anf etwa 10 pCt. Wassergehalt zu trocknen, olıne dafs man eine Oxydation zu befürchten hätte, besonders wenn man die trocknenden Massen öfter mmschanfelt. Dies Verfahren dürfte sich zur Einführung bei den Wilden empfehlen, die oftmals monatelang trocknen, um eine trockene, bessere Ware zu erzielen. 
Die 300 e'm Milch - es wurlo mur eine gemessene Menge verarbeitet - enthalten $104.5 \mathrm{~g}$ Kantseluk von ler Zusammensetzung:

\begin{tabular}{|c|c|c|}
\hline $\begin{array}{l}\text { Kautschuk: } \\
\text { Kautschukharze: }\end{array}$ & $\begin{array}{l}82.17 \mathrm{pCt} . \\
6.72\end{array}$ & $\begin{array}{l}\text { Wasser: } \\
\text { Asche: }\end{array}$ \\
\hline
\end{tabular}

Der freiwillig koagulierte Kautschuk aus ier Mileh wog mach den Waschen und Trocknen $217 \mathrm{~g}$ und enthielt:

\begin{tabular}{|c|c|c|}
\hline $\begin{array}{l}\text { Kautschuk: } \\
\text { Kantsclukharze: }\end{array}$ & $\begin{array}{c}82.39 \mathrm{p}^{\mathrm{Ct}} . \\
6.35 \%\end{array}$ & $\begin{array}{l}\text { Wasser: } \\
\text { Asche: }\end{array}$ \\
\hline
\end{tabular}

Es ergaben also $700 \mathrm{~cm}$ Mileh $321^{1} / 2.2$ Verkanfsware mit rum $10 \mathrm{pCt}$. Wasser $=$ rund $46 \mathrm{pCt}$. rom Milehvolum.

b) 1.628 I Kickxiasaft, ron S'chlechter an 13. September 1s!! in Ngoko durch Kochen der vertünnten Milch koaguliert, gahen $870 \mathrm{~g}$ Kantschuk folgenter Kusammensetzung:

$\begin{array}{lcll}\text { Kautschuk: } & 84.86 \mathrm{pCt} . & \text { Wasser: } & 9.99 \mathrm{pC} \text { t. } \\ \text { Kautschukharze: } & 4.96 \mathrm{~m} & \text { Asche: } & 0.19 \%\end{array}$

Diese sowie die folgenden Sorten c) und d) dürften aber zur Zeit der Wägung betlentend wasserreicher gewesen sein, als sie es in dem Zustand waren, wo sie analysiert wurlen. Tergl. die Ausbeute aus Milch (llesselhen Baumes) und Schlechters Angaben.

c) 1.575 I Kickxiasaft, am 10. September 1899 von S'chlechter durch Kochen mit Bossassangasaft koaguliert. Erhalten $835 \mathrm{~g}$ Kautschuk.

I)ie Analyse ergali:

$\begin{array}{lclc}\text { Kautschuk: } & 82.56 \mathrm{pCt} . & \text { Wasser: } & 11.19 \mathrm{pCt} . \\ \text { Kautschukharze: } & 5.80, & \text { Asche: } & 0.45\end{array}$

1) $130 \mathrm{ccm}$ derselben Milch wurden (13. 'September 1899) anf Lrhm ausgegossen, der Kantschuk nach zwei Tagen gesammelt. Frhalten $7 \pm \mathrm{g}$.

Die Analyse rrgab:

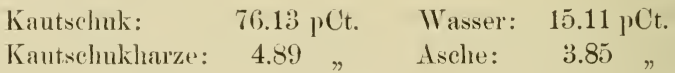

1) Ein Kantschukstück ('mullich, das Schlechter am 14. September in Ngoko nach Art ter Para-Kantschuk-Ciewimmmg räucherte (rewicht: $215 \mathrm{~g}$ ), rrgab folgente Kahlen:

\begin{tabular}{|c|c|c|c|}
\hline & $80.20 \mathrm{pCt}$ & Wasserl: & $13.53 \mathrm{p} \mathrm{Ct}$. \\
\hline Kautsehukharze: & 4.75 & Asche: & 1.52 \\
\hline
\end{tabular}

Praktischen Wrert hat das Verfahren für den Kickxia-Kautschuk natälich nicht; es bestätigt sich nur so eine Vermutumg, die ich ehenfalls früher äufserte ("Tropenpfl." 1898, S. 259), dafs sich der Kirkxia-Kantselunk wahrscheinlich gout räuchern liefse. 
Die Proben b) lis d) von Schl echter waren zmmeist cylintrische S'tïcke von durchschnittlich 4 c'm l)urehnesser mul $2 \mathrm{~cm}$ Höhe, ebenfalls an der Oberfläche gel,räunt, mit weifsem Kern, wie die kleiner gerschnittene Ware, die ich aus der Milch gewinnen komnte. Der Kantschuk stellt sich den besten C'ongo-Sorten zur Seite, soweit man larüler nach Laboratoriumsversuchen urteilen kann. Fabrikationsversuche müssen entscheiden, wie sich der Kickxia-Kautschnk dabei lewährt, demn zwei von verschiedenen Pflanzenfanilien stammende Kautschnke sinel nicht chemisch ilentische Körper, sondern nur nahe Verwanilte und kömnen sich dhemisch gewaltig unterscheiden, so auch bei der Vulkanisation ein recht rersehiedenes Verhalten zeigen. Vorsicht bei der Einführung nener Sorten ist also zu empfehlen.

Der Bossassangasaft, der Saft verschiedener Cactusarten, der ïlerall in Congo-frebiet zum Koagulieren der Laulolphiamileh rerwendet wirl, erwies sich, wie zu erwarten stand, als stark saurer Pflanzensaft (100 cemSaft neutralisiert mit $19.75 \mathrm{ccm}_{2}^{\mathrm{n}}$ Alkali). Yon ¿liesen Käuren sind nicht ganz ein Fünftel mit Wasserdänpfen leicht Hüchtig und zeigen den Charakter der Essigsäure, der nicht flüchtige Rest besteht aus lochmolekularen Sämren, sowic ans niechrigermolekularen rom Charakter der Oxalsäure, deren Kalksalze mit Chlorcalium aus dem Saft fallen. Die nähere Untersuchung des Saftes, er'schwert dadurch, dal's leicht Zersetzungen durch schimmelpilze in dem olne Zusitze tramsportierten Material eintreten, steht noch aus. 


\section{Kapitel.}

\section{Die botanischen Ergebnisse der Expedition.}

In den nachstehenden Zeilen habe ich versucht, eine kurze Schilderung der Vegetationsverhältnisse der von mir auf meiner westafrikanischen Reise durchzogenen Gebiete zu geben. Da diese Reise sehr beschleunigt werden mufste und vor allen Dingen die botanische Erforschung der Gebiete erst in zweiter Linie in Betracht kam, so ist es natürlich, dafs manche Eindrücke, welche ich bei einem so flüchtigen Durchzuge gewonnen habe, nicht durchaus die richtige Beurteilung treffen werden. Um eine pflanzengeographische Skizze eines (iebietes aber geben zu können, dazu gehört meiner Ansicht nach mehr als ein Aufenthalt, der so kurz bemessen war, wie ich ihn leider nur hatte.

Unter den nördlicheren von mir bereisten Gebieten mufs Togo vor allen Dingen das Interesse des Pflanzengeographen in Anspruch nehmen, da die Zone an der Küste und im Innern mehr Verschiedenheiten aufweist als die der angrenzenden Gebiete. Es wird eine interessante Frage in der Zukunft sein, zu erforschen, welche Ursachen die Steppengebiete in Togo so weit bis zur Küste vorgeschoben haben, während doch die Nachbargebiete mit Ausnahme eines Teiles der Goldküste einen viele Meilen breiten Urwaldgürtel an ler Küste aufweisen. Die Kenntnis der Flora dieses Schutzgebietes liegt bei uns noch recht in Argen, und steht weit hinter jener zurück, welche wir bereits über die der Küstenländer von Kamerun erlangt haben.

Dem Reisentlen, welcher von der Küste kommt, fallen drei verschiedene Vegetationszonen auf, welche in kurzen Abständen hintereinander folgen. Die erste dieser Zonen ist ein schmaler Buschsteppengürtel, welcher sich längs der Küste hinzieht, llarauf folgt die gemischte Gras- und Baumsteppen-Zone, die dureh das zum Teil bewaldete Agome- unl Agu-Gebirge unterbrochen wirl, und schliefslich die Waldzone, welche aber keine regelmäfsige Ausdehnung hat.

I ie Buschsteppe der Küste hat einen ausgesprochen xerophytischen Charakter und ist ror allen Dingen gekennzeichnet durch das Fehlen 


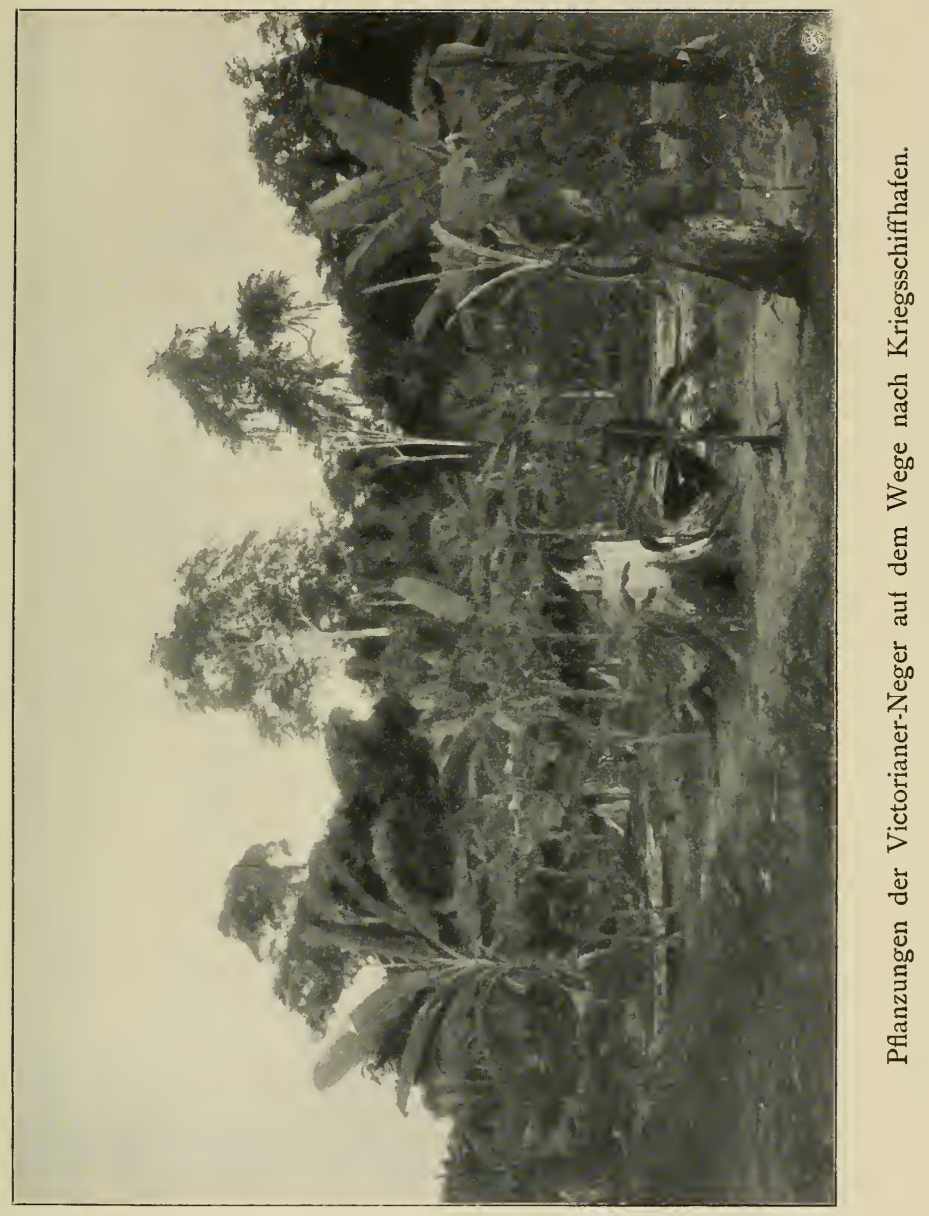


Aler Ölpalme und die auffallende Spärlichkeit der Gräser. An der Stelle, wo ich diese Zone durchschritten habe, wies sie nur eine Breite von etwa drei Marschstunden anf. Die Vegetation setzt sich zunächst nur aus mannshohen Büschen oder aus noch kleinerem Gesträuch zusammen. Nur hin und wieder zeigt sich ein verkrüppelter Baum, oder, wenn wir tiefer in diesen Buschgürtel eingerlrungen sind, eine Sänle, welche selbst den' stärksten Stürmen Trotz bietet, ein Baobab (Aılansonia digita). Die Sträucher gehören vorzugsweise den Euphorbiaceen und Rubiaceen an, unter welch letzteren die Gardenia Thunbergia durch ihren sparrigen Wuchs und ihre stark duftenden, anfangs weifsen, später gelblichen Bln̈ten besonders ins Ange fällt. Nicht selten finden sich die fleischigen Zweige von Sarcostemma aphyllum R. Br. oder anderer Asclepiadaceen; dickstämmige Senecio-Árten winden sich über die Sträucher hin. Auch die Tiliaceen-Grattung Grewia in sehr sparrigen Formen zeigt hin und wierler ilne gelben Blüten im Verein mit stacheligen Akazien. Uns ist über die Flora gerade dieser Küsten-Buschsteppe noch recht wenig bekannt, da keiner der wenigen Sammler des Gebietes derselben Interesse entgegengebracht zu haben scheint. Ich selbst durchzog diesen Teil des Landes zu einer Zeit, als nach langer Dürre die mit Staub dicht bedeckten Gelsüsche gar keine Blüten zeigten. Nach dem Regen sollen auch einige kleinere Kräuter auftreten, doch sind uns dieselben und ihre Verwandtschaften noch gar nicht bekannt.

Eine viel weitere Ausdehnung besitzt die zweite, die Gras- und Baumsteppen-Zone. Dieselbe begann anf meiner Reiseroute bei dem Dorfe Akeppe. Ölpalmen treten in dieser lıänfig auf. Yor allen Dingen alıer charakteristisch für sie sind die weiten Grasflächen, welche mit einzelıen Bäumen bedeckt sind. Da wo die Läufe der nur periodisch fliefsenden Bäche es zulassen, halıen sich wohl auch kleine Buschwaldgruppen gehildet, welche für den Botaniker stets eine Fülle interessanter Formen bergen. Ich bin fest clavon überzengt, daf's sich die Flora dieser Grassteppen, wenn sie erst besser bekannt sein wird, als sehr reichhaltig erweisen wird. Aufser einer Fülle von Gramineen und Cyperaceen finden wir hier besonders riele scrophulariaceen. In kleinen Büschen leuchtet allenthalben das prachtvolle Cycnium camporum Engl. mit seinen grofsen weifsen Blüten aus dem frase hervor. Striga ist in melneren Arten vertreten, unter denen besonders diejenigen mit scharlachroten Blüten unser Auge fesselu. Sopubia Dregeana bildet kleine Büsche mit Trauben rosenroter Blüten. Compositen sind nn schwach vertreten. Besonders sind es die Aspilien, welche uns mit ihren weilsen oder gelben strahlblüten auffallen. Hier und dort 
prhelot sich anch eine schlanke Coreopsis oder eine seltene Aedesia, die mit ihren langen, grasïhnlichun Blättern bei ob^rflächlicher Betrachtımg alles andere hinter sich rermuten lälist, als eine Composite. Nächst den Scrophulariaceen sind es die Rubiaceen, welche lirr sich durch Formenreichtum anszeichnen, und mnter ihnen besonders die Oldenlandien, ron denen mus die rerschiedensten Typen von der schlanken $O$. virgata $W$. bis zu der zierlichen O. Heynei Oliv. begegnen. Anfsertem fallen dem flüchtig D)rchreisenden noch Euphorbiaceen, Gentianaceen, kleine Leguminosen, hesonders ('assia und Indigofera-Arten, sowie Malvaceen und Asclepiadaceen anf. Unter den letzteren finclen sich einige Typen, die mit Fornen ler ost- und südafrikanischen Steppen verwandt sind. An Nonocotyledonen fehlt es anch nicht. Tor allen Dingen müssen unter liesen die Orchidaceen erwähnt werden, welche mit ihren prachtvollen schlanken Blütenständen der Steppe zur Zierde gereichen; unter diesen sind es besonders Eulophia-Arten (F. cristata Stend. und E. dilecta Schltr.), welche sich anszeichnen. Selten lugt aus dem Grase eine weifs- otler grünblütige Habenaria oder an schattigeren Stellen eine Nervilia hervor. Zwei andere sogleich ins Ange fallende Pflanzen möchte ich hier nicht unerwälınt. lassen. Die Anchomanes-Arten, welche durch ihre gefleckten, stachligen Stengel und div hellgrünen oder violetten spathen auffallem, sind sehr verbreitet, obgleich sonst Araceen nicht zu den hänfigeren Repräsentanten der Steppenfloren gehören. Fine andere auch nicht selten anzutreffencle Pflanze ist ıle merkwürlige Tacea pinnatifida. Fs würde mich zu weit führen, wollte ich hier in dieser kurzen Skizz» alle die interessanten und schömen Pflanzen erwähnen, welche i in jenen steppen beobachtet habe.

Die Baumvegetation setzt sich vorzugsweise aus Leguminosen, Stereuliaceen, Euphorbiaceen mil vor allen Dingen CombretumArten umd Bassiastänmen zusammen.

Da, wo sich längs der Wasserläufe Buschwald gebildet hat, finden wir eine Flora, welche der der dritten \%one auffallend ähnlich ist. Nur eines ist mir in jenen Buschwäldern südlich des Agome-Gelirges anfgefallen, nämlich das vollständige Fehlen dr Kickxia africana.

Wie ich sehon oben erwähnte, hat die dritte Tegetationszonc, die Urwaldzone, eine sahr mregelnälsige Ausdehmung. Diese Frscheinung ist wohl zum grofsen Teile auf die ausgedehnten Wald- und Grasbrände zurïckznführen, welch, von den Eingeborenen gewolnheitsgemäls angesteckt werden, teils nm das Wild aus seinen Verstecken hervorzujagen, teils um nenen fruchtbaren Boden für dir: Aupflanzungen zu gewinuen. 
In difsem Walde finden wir aine ziemlich dichte Enterholzvegetation, so dafs wir denselben fast als Buschwald bezeichnen müssen. Nicht selten ist der Boden über weite Strecken hin mit Alpinien, die häufig Mameshöhe erreichen, bedeckt. An lichteren Stellen gesellen sich zu diesen die Costus-Arten, und hier und dort läfst clie Sanseviera ihre schön marmorierten, breiten Blätter aus dem Dickicht hervorleuchten. In der Bildung des Unterholzes spielen die Rubiaceen und Euphorbiaceen die Hauptrolle. CissusArten, zierliche Asclepiadaceen und Apocynaceen mud seltener Menispermaceen bedecken diese Büsche häufig rollständlig; an den Stämmen aber winden sich die riesigen Lianen empor, welche ihren Blïteuflor in den hohen Baumkronen entwickeln.

Der ganze Buschwald ist mehr orler minder dicht bestanden mit Kickxia africana und anderen kleineren Bäumen aus den Familien ¿er Apocynaceen, Rubiacen, Euphorbiaceen, Combretaceen ete. Diese wiederum werden ïberragt durch die Waldriesen, welche über sie noch ein Sehutzdach bilden. Die letzteren setzen sich zusimmen ans Leguminosen, Moraceen (Chlorophora), Euphorbiaceen und Combretaceen. Über die einzelnen Arten dieser Familien ist noch viel zu erkumden, da es sehr schwer ist, von ihmen Blüten und Frïchte zu erlangen.

Dem Waldgebiet Togos ist dasjenige der Hinterländer von Lagos sehr ähnlich, doch bildet die Wallzone daselbst einen breiten Gürtel, welcher direkt an der Küste beginnt. Erst hinter diesem Gürtel erstreckt sich dann die Graszone in einer Finterunng von mindestens $60 \mathrm{~km}$ von der Küste. Die Flora des westafrikanischen Waldes ist auffallend arm an Formationsverschiedenheiten, es sei denn, dafs solche durch hohe Gebirge oder sonstige klimatische Einflüsse in ihrer Entwickelumg begünstigt werden. Anch in den Wäldern des Yoruba-Landes finden wir dieselben Pflanzen wieder, welche wir hereits aus Togo kemuen gelemt haben. Häufiger sind daselbst die Leguminosen und Apocynaceen; statt der Kickxia africana Bth. ist Kickxia elastica Preuls verbreitet. Da die Urwaldkomplexe einen bedentend gröfseren Umfang besitzen, haben sich mehr Baumriesen erhalten: vor allen Dingen sind Ceiba- und Bombax-Arten, sowie andere Sterculiaceen in riesigen Exemplaren verbreitet.

Das Grasgebiet, welehes anf der von mir begangenen Route kurz vor Ibadan begimnt, zeigt einen melır hügeligen Charakter als die Steppen von Togo, und hänfiger als dort finden wir Unkränter, welche wohl durch die Mensehen über weite Regionen des NigerGebietes verbreitet sind. Zu ihnen zählen die verschiedenen Amarantaceen mul Compositen, Acalypha-Arten, Malvaceen umd Tiliaceen. 
Jit Ausnahme der wenigen ans dem Sudan bis in die YorubaLänder herabsteigenden Arten ist die Flora jener Steppen denen ron Togo sehr ähnlich, aber entschieden erheblich ärmer an Arten.

Von dem Waldgebiete Kameruns habe ich nur die Gegenden ann Kamerun-Gebirge kennen gelernt und dann die riesigen Välder ler Sanga-Ngoko-Region. Wie es bei einem Gebirge ron derartigen Dimensionen rorauszusetzen ist, hat das Kamerun-Gebirge einen höchst bemerkenswerten Einflufs auf die Niederschläge jener Regionen, und diesen sowolıl wie der Elevation des Terrains ist es zu verdanken, dafs wir hier eine äufserst üppige Flora vorfinden, welche sehr reich an bisher noch nicht aus anderen Gegenden des Schutzgebietes bekannt gewordenen Arten ist. Vor allen Dingen ist es der Reichtum an Farnen und Epiphyten aller Art, welcher das Auge des Forschers hier entzückt. In den Regionen zwisehen 100() und $2000 \mathrm{~m}$ Höhe finden wir sogar Baumfarnen. Die Epiphyten gehören aufser zu den Farmen (Polypodium, Aspidium, Darallia, Trichomanes, Hymenophyllum und den interessanten Platycerien) rorzugsweise den Orchidaceen an. Die in diesen Gebiete auftretenden epiphytischen Orchidaceen nehmen ihrer Zahl nach einen sehr umfangreichen Platz in der Zusammensetzung der Flora ein. Hauptsächlich sind es die Gattungen Angraeeum (Mystacidium, Listrostachys), Bubbophyllum (Megadinium), Polystachya, Eulophia (1 Art), Aneistroehilus (1 Art) und Liparis, welche hier auftreten. In den Humus der Wälder finden wir anfserdem eine grofse Zahl terrestriseher, zum Teil saprophytischer Arten. Die Tegetation, welche sich im tiefen Schatten dieser Wälder rerbreitet hat, besteht vorzugsweise aus Rubiaceen, unter denen die Poychotria-Arten eine sehr bedentende Rolle spielen, aus Acanthaceen mit prachtroll gefärbten Blïten. Dorstenien mit ihren eigenartigen Inflorescenzen, schattenliebende Gräsern und Cyperaceen stellen ein anderes nmfangreiches Kontingent. Die sonst mehr oder minder epiphytischen Culcasia-Arten kriechen nur an feuchteren Stollen über weite Flächen am Borlen hin und scheinen ein recht behagliches Dasein zu führen, aber seltener Blüten zu entwickeln. An felsigeren Stellen zeigen sich häufig kleine Scrophnlariaceen und Cyrtandreen (Streptocarpus) und hier und da auch einige Labiaten (Coleus) mol Begonien.

Längs der Gebirgsbäche finden wir ror allen Dingen eine äufserst üppige Flora. Nicht nur Ejpiphyten sind an den überhängrenden Ästen mud Zweigen der Bämme in besonders reicher Zalıl anzutroffen, sondern auch eine grolse Zahl teils unter Wasser wachsender Pflanzen, unter denen besonders das praelitrolle Crinum natans mit seinen schneeweifsen Blüten brwähnung verdient. Höchst 
beachtenswert sint ferner jenc Gewächse, welche während riner mehr oder minder kurzen Zeit in Jahre bei dem hohen Wasserstande von den Fluten erreicht werden. Zu diesen gehören anfser Araceen, Cyperaceen und Urticaceen vor allen Dingen die prachtrollen Impatiens-Arten, welche in ilnen Blüten interessante, an Orchidaceen erinnernde Formen aufweisen. Die Leguminosen, welche hier weniger reichlich vertreten sind, werden durch die A eschynomeenund Desmodium-Arten repräsentiert. Melastomaceen suchen die Ränder der Bäche mit Vorliebe auf, da sie tort die ihnen zusagende Feuchtigkeit und genügend Licht finden.

Die Urwallbäume setzen sich aus ähnlichen Elementen zusammen wie die des Yoruba-Waldes, nur treten hier bedentend mehr Arten hinzu, und die Entwickelmmg derselben ist eine üppigere. Besonders Legmminosen sind vorherrschend. Für den Botaniker liegt gerade in der Ermittelnug der Urwaldbäume noch ein grofses Arbeitsfeld ror.

Da in der Ngoko-Region meine Zeit durch andere Arbeiten sehr stark in Anspruch genommen war, konnte ich dort der Flora nicht die Anfmerksamkeit schenken, welche ich ihr gern entgegengelıracht hätte. Nach meineı oberflächlichen Beobachtungen scheint sie der des Yaunde-Gebietes sehr ähnlich zu sein, doch treten bei ilır einige Arten hinzu, deren Hanptverbreitungsgebiet eigentlich in dem grofsen Urwalde des Congo-Beckens liegt. '/n diesen gehören hanptsächlich die anf die Flufsränder und die, dem Congo-Becken eigenen, Sumpfwälder beschränkten Arten.

Entgregen den Ansichten vieler Botaniker nöchte ich glauben, dafs die Congo-Flora sehr arm an endemischen Arten ist. Endemismen finden sich hauptsächlich in der ersten von mir oben erwähnten Tegetationszone des Gebietes. Diese erstreckt sich ron der Küste bis zum Stanley-Pool einerseits mul dem Kassai-Kwango-frebiete andererseits. Im Süden geht die Zone rollständig in die Angola-BenguellaFlora über. Wemn ich einerseits hier den Stanley-Pool als Grenze, angebe, so meine ich damit nur die politische Grenze des Congostaates, demn nach Norden geht das Gehiet so weit in die französisehen Besitzungen hinein, wie die Ansläufer der von Angola kommenrlen Sierra do Crystal, also fast bis in das Ogowe-Gebiet.

Die Vegetation dieser Zone, welche sich durch hügelige Physiognomie auszeichnet, ist mit der Flora der Angola-Hochländer eng verwandt, und viele, ja ich möchte sagen selır viele Arten treten hier noch auf, welche ursprünglich ron dem Hnilla-Plateau bekannt geworden sind. In den Thälern, zwischen den Hügeln oder längs der Flufsläufe haben sich Galerie- und Buschwälder gebildet, deren Elemente teils, wie in den Galeriewäldern des unteren Congo, der Flora des Congo-Beckens entstammen, teils dieselben Arten aufweisen, wie die Buschwälder von Angola. 
Auf den grasigen Hügeln finclen wir ein reiches fiemisch von Arten der verschiedensten Familien. Aufser Gräsern mul cyperacesn begegnen wir besonders Leguminosen (nit vielen Indigofera-mul Crotalaria-Arten) Compositen (besonder's Vernonien und sogar Helichrysum-Arten), Rubiaceen, Gentianaceen, vicle Ścrophulariaceen etc., kurzum eine typische afrikanische (irassteppenflora, wie wir sie aus Transvaal, Angola und Ostafrika bereits selur wohl kenuen. In den Sümpfen oder am Ramde derselben fehlen werler Utricularien noch die Eriocaulonaceen, sonst wirderholen sich.dieselhen Erscheinungen, Rubiaceen, Scrophulariaceen, Irisaceen, Araceen, Orchidaceen und die prachtvollen Melastomatacern, alle Familien sind vertreten.

Als ich in den sandigen Whenen bei Dolo am Stanley-Porol sammelte, war ich über die Flora im höchsten Mafse überrascht, fast glaubte ich mich in die Hoogeveld-Steppen von Transval zurückversetzt, so ähnlich war die Flora derjenigen, welche ich im Sommer 1893/94 dort beobachtet hatte. Hier liegt ein nener Beweis für die Terwandtschaft der Floren ähnlicher Gebiete in Afrika ror. Die Arten sind zwar in demselben verschicelen, loch kann man lessenungeachtet eine wirklich auffallende Gleichförmigkeit dler Steppenfloren sowohl wie der typischen Urwaldfloren konstatieren. Westafrika besitzt gewifs mit seinen bedeutenden Niederschlägon eine recht typische Flora; doch sind die Hauptvertreter mit den ostafrikanischen Typen immer mehr oder minder nahe verwandt.

Die zweite Vegetatiouszone, welche ich im Congo zu beohachten Gelegenheit hatte, möchte ich als typische Flora des Congo-Beckins bezeichnen. Sie bildet im allgemeinen die Flora des sogenannten Äquatorialwaldes und der Ufer des Congo und seiner Nebenflüsse. Oben habe ich bereits angerleutet, wie arm diese Flora an typischen Artell ist.

Wenn wir annehmen, dafs die Flora des Congo-Beckens noch jüngeren Alters ist, so wird diese ihre Armut leichter erklärlich, und es lassen sich einige recht interessante beispiele ler binwanderung versehiedener Arten noch hente feststellen. Leider ist es nir nicht möglich, im Innem des (iebictes, vor allen Dingen nach Osten, die Grenzen dieser Florenzone auch nur ammïherud foxtzulegen, da ich nicht weit genug ins Innere desselben gekomums hin, und leshall, wäre es sehr wünschenswert, wenn wir dlereinst von kompetenterer Seite etwas darüber erfahren könuten.

Die Flora des Congo-Beckens liesitzt sehr ausgesprochenr Anklänge an die Flora des Kancrun-fiebietes und des französischen Congo. Ieh halte es daher für sehr wahrscheinlich, dal's von dort aus die gröfsere $/$ ahl des Pflanzen eingewandert ist. Noeh hente 
finden wir gegenüber der Jündmug des Sanga, loxi lukulela, eine Urwaldflora, welche sich durch eine merkwürdige Reichhaltigkeit und Verwandtschaft oder Gleichheit mit Sülkanerun-Typen auszeichnet. Wemm wir nun in Betracht ziehen, dafs eine nicht unerhebliche Menge des rom Sanga in den Congo Hiefsenden Wassers aus jenen Gegenden entstammt, so glaube ich diese Florenverwandtschaften darauf zurückfülıren zu kömmen. - Ebenso finden wir am Unterlanfe des Kassai und in der Nähe der Mündung desselben eine erhebliche Anzahl von Arten, deren Lrsprumg anf die süıllich gelegenen Gebiete zurückzuführen ist. Leiıler kann ich mir kein Urteil rrlauben über die Gehiete östlich der Stanley-Fälle, doch bin ich fest lavon überzengt, dafs ein grolser Prozentsatz der Pflanzen des CongoBeckens von dorther stammt. Ein anderes Verhälnis darf ja anch in einem Stromgebiete ron der geringen Eleration des Congo-Beckens nicht erwartet werklen. Alljährlich zur Zeit des hohen Wasserstandes werden, ähnlich wie im (iebiete des Amazonas, lie Wälder mehr orler minder hoch vom Wasser überspült.

Diesen Verhältnissen passen sich eine Anzahl von Bäumen an, indem sie ihre Stämme wie die Pandamusarten durch Stützwurzeln über den Borlen emporheben. Wie schon oben bemerkt, besteht die Urwaldflora fast ausschliefslich aus Gewächsen, welche im KamerunUrwalle anzutreffen sind. Anders dagegen setzt sich die Flora der Flulsufer zusammen. Häufig finden wir dort noch im Wasser stehemıl Impatiens- und Aschynomene-Arten und eine als „Bubandja“ bekannte Euphorbiacee. Calamus-Arten bilden am Waldrande oft undurchIringliche Gestrüppe, in deren Schatten sich mit Torliebe AlpiniaArten ansiedeln. Besonders typisch für die Flufsufer sind unter den Bämmen Copaifera-Arten mol Irvingia Smithii Hk. f., die sich sehr gern mit Orchidaceen bekleidet.

In der folgenden Aufzählung bin ich dem Englerschen System gefolgt, sowohl in der Anordnming der Familien wie der Gattmoren. Die einzelnen Arten sind alphabetisch anfgezählt.

Allen den Herren, welche sich an der Bestimmung meiner Sammlungen beteiligt haben, vor allen Dingen Herrn Geheimrat Professor Dr. A. Engler, welcher mir stets in liphenswürdigster Weise die Benutzung des reichen Berliner Herbarimms gestattete, spreche ich hiermit meinen besten Dank aus.

\section{Gramineae. (1)et. R. Pilger.)}

$$
\text { Andropogon L. }
$$

1. A. brevifolius sw. ?

In paludibus prope Leopoldrille pone stanley-Pool (Congo). VI. 18.99 - No. 12514 . 
Authephora Schreb.

1. A. elegans Schreher rar. africana Pilger n. var.

In arenosis prope Leopoldrille pone Stanley-Pool (Congo). VI. 1899 - No. 12508.

Melinis Beaur.

1. M. gracilis Pilger n. sp.

In collihus arenosis inter Ibarlan et Abeokuta (Yoruba-Land). III. 1899 - No. 12338.

$$
\text { Panicum I. }
$$

1. P. bongaënse Pilger n. sp.

In fruticetis prope Bonga, ad ostimm fluminis Sanga (Congo français). VIII. 1899 - No. 12647.

Zur Sektion Ptychophyllum gehörig.

2. P. brizanthmm Hochst. ?

In fruticetis prope Bonga ad ostium fluminis Sanga (Congo français). VIII. 1899 - No. 12663.

3. P. ovalifolium Porir.

In planitie arenosa prope Dolo pone Stanley-Pool (Congo). VI. 1899 - No. 12496.

4. P. uncinatum Rardi.

In cultis prope Bibundi (Kamerun). IV. 1899 - No. 12419. Olyra L.

1. O. brevifolia Sehum.

In fruticetis ac arl margines silvarmm juxta flumen Ngoko (Kamerum). IX. 1899 - No. 12750.

1. L. conchifera Hack.

$$
\text { Leptaspis } \mathrm{R} \text {. Br. }
$$

In silvis primaevis prope Ikorodu' (Toruba-Land). III. $1899-$ No. 12998.

1. S. Molleri Hack.

$$
\text { Sporobolus R. Br. }
$$

In arenosis pone Leopoldville (Congo). VI. 1899 - No. 12552.

2. S. strictus Frauch.

In planitie arenosa prope Dolo, pone Stanley-Pool (Congo). YI. 1899 - No. 12448.

1. M. setacea $\mathrm{R}$. Br.

$$
\text { Mierochloa R. Br. }
$$

In apertis prope Leopoldville pone Stanley-Pool (Congo). VI. 1900 - No. 12585.

1. I. chinrnsis Nees.

$$
\text { Leptochloa beanv. }
$$

In fruticetis prope Bonga ad ostium fluminis Sanga (Congo français). VIII. 1899 - No. 12680. 
1. E. ciliaris Lk.

Eragrostis Host.

In fruticetis prope Leopoldville pone stanley-Pool (Congt). VI. 1899 - No. 12680.

2. E. pilosa P. B.

In collibus graminosis inter Ibadan et Abeokuta (Yoruba-Land). III. 1899 - No. 13018.

3. E. plumosa Retz.

In collibus graminosis prope Ibadan (Yornba-Lant). III. 1899 - No. 12328.

4. E. sabulicola Pilger n. sp.

In dunis maritimis prope Cape Lopez (Congo français). Xll. 1899 - No. 12817.

5. E. tremula Hochst.

In umbrosis prope Leopoldville pone Stanley-Pool (Congo).

VI. 1899 - No. 12507.

1. S. crinita P. B.

$$
\text { Streptogyne Beaur. }
$$

In silvis primaevis juxta flumen Dja (Kamermu). X. 1899No. 11778.

1. C. lappacea Deso.

$$
\text { Centhotheca Desr. }
$$

In fruticetis prope Kriegsschiffhafen (Kamerum). IV. 1899 No. 12395 . In planitie arenosa prope Dolo pone Stanley-Pool (Congo). VI. 1899 - No. 12499.

$$
\text { Guaduella Franch. }
$$

1. G. marantifolia Franch.

In silvis primaevis juxta „Muni-River" pone Corisco-Bay. XII. 1899 - No. 12827.

Cyperaceae. (Det. K. Schumann.)

1. C. amabilis Vahl.

Cyperus Michx.

In sabulosis prope Leopoldville pone Stanley-Pool (Congo). VI. 1899 - No. 12533.

2. C. caracasanus H. B. et Kth.

In collibus gramin osisinter Ibadan et Abeokital (Yoruba-Land). III. 1899 - No. 13017.

3. C. cuspidatus H. B. et Kith.

In arenosis prope Leopoldville ad Stanley-Pool (Congo). VI. 1899 - No. 12517.

4. C. diffusus Vahl.

In silvis prope Coquilhatville (Congo). VII. $1899-$ No. 12605. 
j. ('. rotumelus L.

In humilis propelkorodn (Yoruba-Land). III. 1899- No.12 297. In arenosis prope Leopoldville pone Stanley-Pool (Congo). VI. 1899 - No. 12515.

6. C. radiatus Tahl.

In paludibus prope Noki (Congo). V. 1899 - No. 12 439; In humidis prope Leopoldville, pone stanley-Pool (Cougo). VI. 1899 - No. 12513.

7. C. Smithianus Ridl.

In fruticetis prope Coquilhatville (Congo). VII. 1ऽ99 -No. 12608.

S. C. mubellatus C. B. ('?.

In collibus graminosis inter Ibadan et therkuta (Yoruba-Lanı). III. 1899 - No. 12336.

9. C. spec.

10. C. spec.

In humirlis prope Irebn (Congo). TII. 1899 - No. 12641.

In humidis prope Leopolilville, pone "Stanley-Pool" (Congo). VI. $1899-$ - No. $1257 \%$.

11. (. spec.

In humidis prope Leopoldrille, pone „Stanley-Pool“ (C'ongo). VI. 1899 - No. 12 511.

1. K. humilis Michx.

$$
\text { Killingia Rottl. }
$$

In humislis prope Irebu (Congo). VIl. 1s99 - No. 1264:.

๖. K. pumila Michx.

In collibus arenosis inter Lbadan et Abeokuta (Yoruba-Land). III. 1899 - \o. 12348 . In arenosis prope Coquilhatville (Congo). VII 18.99 - No. 12603.

3. K. triecps Rottb.

In humidis prope Irebu (Congo). VII. 1s!) - No. 12642.

1. S. lrarbatus.

\section{Scirpus Tournef.}

In avenosis liumidis prope Stanley-Pool (Congo). V1. 1899 - No. $1256 \%$.

2. S. spere. $110 \mathrm{x}$.

In insulis sabulosis in flumino Congo, locostanley-Pool appellato. ง I. 1899 - No. 12569.

1. H. diphylla Tahl.

$$
\text { Fimbristylis Tahl. }
$$

In collilus graminosis inter lbalan et Abeokuta (Yoruba-Land). III. $18 !) !$ - To. 12346. 
2. F. philosa Vahl.

In clivis graminosis montimm Agome alt. e. $300 \mathrm{~m}$ (Togo). III. 1900 No. 12967.

3. F. spee:

In arenosis inter Ibadan et Aberkuta (Yoruba-Land). IV. 1^?9. - No. 12347.

t. F. spee.

In insulis fluminis Congo, loco Stanley-Pool appellato. VI. 1899 - No. 12558.

\section{Hypolitrum L. C. Rich.}

1. H. nemorosim P. de Beauv.

In umbrosis prope Leopoldville pone Stanley-Pool (Congo). VI. 1899 No. 12583.

Araceae. (1)et. A. Engler.)

Culcasia Beanv.

1. C. scamlens P. Beaur.

Ad trunces arborum seandens in silvis prope Ikorodn (YorubaLand). III. 1899 - No. 12304. In silvis primaevis prope Kriegsschiffhafen (Kamerun). IV. 1899 - No. $123997 . \quad$ In umbrosis prope Leopoldville pone Stanley-Pool (Congo). IV. 1899 - No. 12561.

2. U. striolata Engl.

Ail truncos arborum in umbrosis prope Leopoldville (Congo). VI. 1899 - No. 12 522; No. 12581.

3. C. tenuifolia kngl.

Ad truncos arborum scandens prope Leopoldville pone StanleyPool (Congo). Vl. 1899 - No. 12565.

$$
\text { Anchomanes Seliott. }
$$

1. A. dubius Schott.

In graminesis inter Ibarlan et Abeokuta (Yoruba-Land). III. 1899 - No. 13028 .

1. H. Banmamii Engl.

$$
\text { Hydrosme schott. }
$$

In graminosis prope Barja (Togo). IV. 1900 - No. 12977. Nephthytis schott.

1. N. Poissonii Engl.

In silvis primaeris inter Mundame et Otam (Kamerun), alt. c. 200 m. 1. 1900 - No. 12886 .

1. A. Afzelii s'chott.

$$
\text { Anubias s'chott. }
$$

In rivulis prope Bilundi (Kamerum). IV. $1900-$ No. 12412. 
Eriocaulonaceae. (Det. Ruhlaud.)

syngonanthus Ruhl.

1. S. Schlechteri Ruhl. n. sp.

In sabulosis humidis prope Dolo pone stanley-Pool (Congo). VI. 1899 - No. $124 \% 3$.

Commelinaceae. (Det. K. Schumann.)

Pollia Thbg.

1. P. condensata C. B. Cl.

In silvis primaeris juxta flumen Ngoko (Kamerum). IX. 18!9 - No. 12753.

2. P. Mannii C. Bl. C.

In silris primaeris juxta flumen Dja (Kameruu). LX. $1899-$ No. 12768 .

$$
\text { Palisota Rehb. }
$$

1. P. acuminata C. B. Cl.

In fruticetis prope Coquilhatville (Congo). VII. $1899-$ No. 12613.

2. P. thyrsiflora Bth.

In silvis primaevis prope Ishagamo (Yoruba-Land). IV. $1899-$ No. 13007 .

1. ('. capitata Bth.

$$
\text { Commelina Glum. }
$$

In silvis prope Inundame (Kamerun). I. 1900 - No. 12930.

$$
\text { Polyspatha Bth. }
$$

1. P. paniculata Bth.

In silvis primaevis juxta flumen Sanga, inter Bonga et Wesso (Congo framęais). VIII. 1899 - No. 12714.

2. P. ? spec.?

In silvis primaevis juxta flumen Ngoko (Kamerun). XI. 1899 - No. 12741.

Aneilema R. Br.

1. A. beninense Kth.

In silvis prope Ikororlu (Yoruba-Land). III. 1899 - No. 12303.

2. A. ovato-oblongum P. de Beauv.

In silvis primaevis juxta flumen Dja et Ngoko (Kamerun). IX. 1899 - No. 12 761, 12 783. In umbrosis prope Leopolılville (Congo). 11. 1899 - To. 12530.

3. A. setulosa K. Stch. 11. sp.

In graminosis prope Badja (Togo). IV. 1899 - No. 12973. 


\section{Buforrestia C. B. Cl.}

1. B. imperforata C. B. Cl.

In silvis primaevis juxta flumen Dja (Kamerun). IX. $1899-$ No. 12761 .

1. F. Prenfsii K. Sch.

$$
\text { Forrestia A. Rich. }
$$

In silvis primaevis prope Kriegsschiffhafen (Kamerun). IV. 1899 - No. 12389.

1. F. africana C. B. Cl.

$$
\text { Floscopa Lour. }
$$

In silvis juxta flumen Sanga inter Bonga et Wesso (Congo français). VIII. 1899 - No. 12691.

\section{Amaryllidaceae. (Det. H. Harms.)}

Haemanthus Tourn.

1. H. cinnabarinus Dene.

In silvis primaevis prope Ishagamo (Yoruba-Land). III. 1899 No. 13005.

1. C. natans Bkr.

$$
\text { Crinum L. }
$$

In rivulis lapidosis prope Muea (Kamerun) alt. e. $600 \mathrm{~m}$, I. 1900 - No. 12851.

1. D. Preussii Pax.

Dioscoreaceae. (Det. H. Harms.)

Diocorea Plum.

In fruticetis prope Wesso all flumen Sanga (Congo français). VIII. 1899 - No. 12722.

2. D. Schlechteri Harms n. sp.

In fruticetis prope Leopoldville ad Stanley-Pool (Congo). Vl. 1899 - No. 12548.

Ist mit D. Dusenii Uline verwandt, verschieden durch schmälere Blätter.

1. C. cordifolinm.

Cyanastraceae. (Det. A. Engler.)

Cyanastrum Oliv.

In silvis inter Ibadan et Aheokuta (Yornba-Land). III. 1899.

Iridaceae. (Det. R. Schlechter.)

Gladiolus Tourn.

1. G. spec. aff. brevifolio Jaeq.

In planitie arenosa prope Dolo juxta Stanley-Pool (Congo) VI. 1899 - No. 12445. 
Zingiberaceae. (Det. K. Schumann.)

Amomum L.

1. A. granum Paradisii L.

In silvis prope Ikorodu (Yoruba-Land). III. 1899 - No. 12993.

Burmanniaceae. (Det. R. Schlechter.)

Gymnosiphon Bl.

1. G. squamatus Wright.

Saprophyt auf faulendem Laube in clen Urwäldern bei Corisco Bay (Gabron). XII. 1899 - No. 12831.

Orchidaceae. (Det. R. Schlechter.)

Platanthera L. C. Rich.

1. P. pleistophylla Schltr.

In graminosis prope Kinchassa pone Stanley-Pool (Congo). XI. 1899 - No. 12 797.

Brachycorythis Leopoldi Krzl., welche sich in keiner Weise ron Brachycorythis pleistophylla, dem Typus der vorliegenden Art, unterscheidet, gehört auch hierher.

1. H. Guingangae Rehb. f.

$$
\text { Habenaria W. }
$$

In graminosis humidis prope Cape Lopez (Congo français). XII. 1899 - No. 12816.

H. Poggeana Krzl. kann ich spezifisch von dieser Art nicht trennen. Die Blüten sind orangegelb.

2. H. macrandra Ldl.

In silvis primaevis juxta flumen Sanga (Congo français). XI. 1899 - No. 12991.

Nach genauen Untersnchungen an lebendem Material kann ich die Rolfesche Gattung. Porlanilia nicht annehmen. Wir müfsten sonst die Gattung Habenaria in viele kleine Gattungen zerlegen.

3. H. stenoloba Schltr. n. sp.

In collihns graminosis prope Libreville (Congo français). XII. 1899 - No. 12824.

$$
\text { Disperis Sw. }
$$

1. 1). togoensis Schltr. n. sp.

In rupibus montium Agome prope Ashanti-Kpoeta (Togo). III. 1900 - No. 12990.

1. N. umbrosa Schltr.

$$
\text { Nervilia Geaud. }
$$

In graminosis prope Kewe (Togo). III. 1900 - No. 12947.

In fruticetis prope Atikpui (Togo), IV. 1900 - No. 12984.

Pogonia umbrosa Rehb. f. P'. viridiflava Rehl,. f. seheint anch nimht verwhinlen. 


\section{$-\quad 275--$ \\ Vauilla Sw.}

1. V. africana Ldll.

Juxta rivum Leandja (Kannerun), alt. $6000 \mathrm{~m}$. I. 1900 No. 12862 .

Ieh kamn V. encullata Krel. nicht von dieser Art getremnt halten. Das im Berliner Herbar vorhandene Original stimmt mit V. africana Lell. vollständig äberein.

2. V. spec.

In silvis juxta flumen Sanga inter Bonga et Wesso (Congo français). VIII. 1899 - No. 12. 701.

Ein Exemplar ohne Blüten.

1. E. nutans Rehb. f.

$$
\text { Epipogon (tmel. }
$$

In silvis primaevis prope Mafura (Kameruı), alt. $400 \mathrm{~m}$. I. 1900 - No. 12910.

Auxopus Schltr. u. gen.

1. A. kamerunensis Schltr.

In silvis primaevis inter Nyoke et Mundane (Kamerun), alt. c. 200 m. I. 1900 - No. 12875 .

Eine sehr interessante neue Gattung, welehe mit Didymoplexis verwandt ist, sich aber durch freie Petalen und die Columna unterscheidet. Die Blütenstiele der winzignen Blüten verläng('rn sich bis zur Fruchtreife sehr bedentent.

\section{Zeuxine LdI.}

1. '\%. Batesii Rolfe.

In silvis primaevis prope Buea (Kameruu), alt. e. 600 m., I. 1900 - No. 12839.

2. \%. elongata Rolfe.

In silvis primaevis prope Lukulela (Congo). VII. $1899-$ No. 12644.

1. C. lepida Rolfe.

$$
\text { Cheirostylis Bl. }
$$

In silvis primaevis supra Buea (Kamerum), alt. e. $1100 \mathrm{~m}$ I. 1900 - No. 12845 .

Ich neige der Ansicht zn, dafs diese Pflanze richtiger bei Zenxine verblieben wäre. Mir selbst ist die Gattung Cheirostylis zu wenig bekannt, um mir ein endgültiges Urteil bilden zu können.

\section{Hetaeria Bl.}

1. H. Mannii Rehb. f.

In silvis primaevis prope Victoria (Kamerun), alt. e. $100 \mathrm{~m}$. II. 1900 - No. 1294 i. 


$$
\text { Maniella Rehb. f. }
$$

1. M. Gustari Rehb. f.

In silvis primaevis prope Victoria (Kamermn), alt. c. $200 \mathrm{~m}$. II. 1900 - To. 12945.

Corymbis Thou.

1. C. Welwitschii Rehb. f.

In silvis prope Kriegsschiffhafen, alt. $20 \mathrm{~m}$ (Kamerum). IT. 1899 No. 12381.

1. II. stelidostachya Rehb. f.

\section{Microstylis Nutt.}

In silvis primaeris juxta flumen Mungo (Kamerun), alt. c. 100 m. I. 1900 - No. 12944 .

Abweichend von den anderen Microstylis-Arten, ist hier das Labellum nach unten gekehrt.

2. I. guineensis Lill.

$$
\text { Liparis L. C. Rich. }
$$

In collibus graminosis prope Libreville (Congo français). XII. 1899 - No. 12825 . In paludibus prope Cape Lopez (Congo français). XII. 1899 - No. 12810.

1. L. epiphytica Schltr. n. sp.

Epiphytica in arborilus juxta flumen Sanga prope N'Kundi (Congo français). VIII. 1899 - No. 12 694; juxta flumen Ngoko et Dja (Kamerun). IX.-X. 1899.

$$
\text { Polystachia Ldl. }
$$

1. P. Adansoniae Rehb. f.

In ramis arbormm in silvis primaevis propo Bilmmli (Kamerum). IV. 1899 - No. 12 409.

P. albo-violacea Krzl. und P. Dusenii Krzl. siml von dieser Art nicht verschierlen.

2. P. bifida Ladl.

In arboribus silvae supra Buea (Kamerun). I. 1900 No. 13043.

Die vorliegende Pflanze wurde von Kränzlin als P. farinosa heschrieben, doelı muterscheidet sie sich nur durch etwas stärkeren Wuchs ron den Originalexemplaren der P'. bifida. Dic Blütenteile beider sind vollkommen gleichgestaltet.

3. P. caloglossa Rehb. f.

Epipleytica in ramis arbormu prope Bilundi (Kamermu). IV. 1899 - No. 123.59 .

4. P. coriscensis Rehh. f.

In arborihus juxta "Wuni-River" (Coriseo Bay). XII. 1899 No. 12829 .

P. higlandulosa Kr\%l. gehört hicrher. 
5. P. erassifolia sehltr. n. sp.

Epiphytica in arboribus prope Moliwe (Kamerum), I. 1900 No. 12.281.

Eine merkwürdige Novität, welche sieh von allen anderen Arten durch die dicken Blätter und die sitzenden Blüten unterscheidet.

(i. P. cultriformis sprgl.

Epiphytica in arboribus prope Nyassosso (Kamerun). I. $1900-$ No. 13044 .

I)ie Verbreitung dieser Art ist sehr interessant. Ursprünglich wurde sie aus Madagascar beschrieben, dann auf dem östlichen Teile des afrikanisehen Kontinents anfgefunden, num liegt sie sogar aus Westafrika vor. P. Kirkii Rolfe ist mit ihr identisch, ebenso P. gracilenta Krzl. Die Behauptung des letzteren Autors, dafs sich P. gracilenta von P. cultriformis durch doppelt längere Bläten unterscheide, ist dadurch erklärlich, dafs sich die Ovarien bei unserer Art nach der Befruehtung bedeutend verlängern.

7. P. dolichophylla Sehltr. n. sp.

In arboribus prope Buea (Kamerun), alt. с. $800 \mathrm{~m} . \quad$ I. 1900 - No. 12837.

8. P. elastica Lull.

In arboribus prope V'ictoria (Kamerun), alt. e. $50 \mathrm{~m}$. І. 1900 No. 12833.

9. P. cucullata Dur. et Schinz.

In ramis arborum prope Nyassosso (Kamerum), alt. $800 \mathrm{~m}$. I. 1900 - No. 13045 .

10. P. golungensis Rchl. f.

In arboribus prope Mnndame (Kamerun), alt. c. $150 \mathrm{~m}$. 1. 1900 - No. 12880.

11. P. laxiflora LAll.

In arboribus prope Bibundi (Kamerun). IV. 1899 - No. 12 422.

12. I'. leonensis Rehb. f.

In arboribus juxta flumen Mungo (Kamermu), alt. c. $100 \mathrm{~m}$. I. 1900 - No. 12943.

13. I'. nitidula Reehlo. f. var.

Epiphytica in arboribus in silvis primaevis juxta flumen Ngokn (Kamerum). IX. 1899 - No. 17 734.

Die vorliegenden Exemplare unterseheiden sich ron dem Original der P. nitilula dlurch deutlicher ansgehildete seitenlappen des Labellums.

14. P. Plehniana Schltr. n. sp.

Epiphytica in arboribus juxta flumen Ngoko (Kamerum). IX. 1899 - No. 12748. 
Fis ist mir ein grofses Vergnïgen, diese Art dem Andenken lles Leiters der Ngoko-Station, dles Oberlentnants Dr. R. Plehn, widmen zı kömnell.

15. P. polychaete Krzl.

In arboribus prope Buea (Kamerum). I. 1900 - No. 12 842.

16. P. puberula Ldl.

In arboribus prope Bibundi (Kanermu). IV. $1899-$ No. 12431. In arboribus in silvis primaevis juxta flumen Sanga (Congo français). XI. 18.19 - No. 12793.

P. odorata Lindl. kann ich von der vorliegenden Art nicht trennen.

17. P. ensifolia Ldl.

Epiphytica in fruticetis prope Muea (Kamerun), alt. c. $700 \mathrm{~m}$. I. 1900 - No. 12852 .

P. pyramidalis Ldl., P. rhodoptera Rchb. f. und P. sulfurea Brogn. gehören alle zu dieser Art.

18. P. elastica Ldl.

P. expansa Ridl. sowohl, wie P. Victoriae Krzl. gehören zu dieser Art.

19. P. ramulosa Ldl.

In arboribus juxta flmmen Dja (Kamerun). IX. 1899 No. 12 77. In arboribus juxta flumen Sanga inter Bonga et Wesso (Congo français). VIII. 1899 - No. 12695.

20. P. Stuhlmannii Krzl.

In arboribus juxta flumen Ngoko (Kamerun). IX. $1899-$ To. 12740.

Sehr interessant ist die Verbreitung der sowohl in Ost- wie in Westafrika vorkommenden Pflanze. P. Ridleyi Rolfe gehört auch hierher. Das Originalexemplar der P'. Stuhlnamuii Krzl. ist in Herb. Schweinfurth wie im Herb. Berol. von Kränzlin selbst als P. polychaete Krzl. nachträglich bestinmıt worlen, loch ist die Art von P. polychaete durchaus versehieden.

21. P. Supfiana Sehltr. n. sp.

In arborilus prope Bibumdi (Kamerum). IV. 1899 - No. 12415.

Ich erlaube mir, diese Art zu Ehren des Herm Supf, Torsitzenden des Kolonialwirtschaftlichen Komitess, zu beneunen.

22. P. tessalata lud.

In arboribus juxta flumen Simga inter Bonga et Wesso (Congo français). VIII. 1899 - Bo. 12711. In arhoribus inter lrebu et Lukulela (Congo). No. 12 6iss. In arboribus pone Stanley-Pool (Congo). V1. $1899-$ To. 12501.

23. P. spere.

In silvis primatevis prope Bibundi (Kamerun). IV. 1899Tก. 12416. 
Ancistrochilus Rolfe.

1. A. Thomsonianum Rolfe.

Culta in Horto botanico Gabunensi, com. Chalot. XII. 1899 No. 13040 .

Ich führe diese Pflanze mit auf, da ich später am Mungo wiederholt Exemplare angetroffen habe.

$$
\text { Eulophia R. Br. }
$$

1. E. antennisepala Schltr.

In paludibus prope Kinchassa pone Stanley-Pool (Congo). XI. 1898 - No. 12806.

Von Reichenbach fil. als Lissochilus antemisepalus beschrieben. Die Pflanze ist mit E. Lindleyana Schltr. (Lissochilus Lindleyanus Rchb. f.) nahe verwandt.

2. E. cristata Steud.

In collibus graminosis inter Ibadan et Abeokuta (Yorubaland). III. 1899 - No. 12351.

3. E. cyrtosioirles Schltr. n. sp.

Saprophytica in silvis prope Lukalela (Congo). VII. 1899 No. 12643.

Mit E. galeoloides Krzl. verwandt.

4. E. dilecta Schltr. (Lissochilus dilectus Rehb. f.)

In graminosis prope Gbin (Togo). III. 1900 - No. 12 951;

In graminosis prope Kinchassa pone Stanley-Pool (Congo). XI. 1899 - No. 12805.

var. $\beta$. minor.

In graminosis prope Badja (Togo). IV. 1900 - No. 12970 , Lissochilus Büttneri Krzl. gehört hierher.

5. E. gigantea N. E. Br.

In paludibus prope Ukaka Beach (Corisco Bay). XII. 1899 No. 12826 . In paludibus prope Libreville (Congo français). IV. 1899 - No. 12432.

Die Prachtpflanze ist in den Salzsümpfen an der westafrikanischen Küste das ganze Jahr hindurch in Blüte zu finden.

(6. E. gracilis LAll.

In silvis prope Ikorudu (Yorubaland). III. 1899 -- No. 12995. In umbrosis prope Kinchassa pone Stanley-Pool (Congo). XI. 1899 - No. 12798.

Eulophia Laurentiana kírzl. gehört hierher.

7. E. Lindleyana Schltr.

In paludibus prope Kinclıassa (Congo). XI. 1899 - No. 12800.

Mit E. Buchanani Bol. nahe verwandt. Von Reichenbach fil. als Lissochilus Lindleyanns beschrieben. 
s. E. Iuciela Ldl.

In arboribus prope Buea (Kamerun), alt. 700 m. I. 1900

No. 12 838; In truncis prope Borassorum prope Irebu (Congo). VII. 1899 - No. 12634.

9. E. lutea Ldll.

In graminosis prope Badja (Togo). IV. 1900 - 12771.

10. E. porphyroglossa Bol.

In paludibus prope Kinchassa (Congo). XI. 1899 - No. 12811. In paludibus prope Coquilhatville (Congo). VII. 1899 No. 12593.

11. E. Saundersiana Rchb. f.

In silvis primaevis prope Ishagamo (Yorubaland). III. $1899-$ To. 13006.

12. E. tuberifera Krzl.

In graminosis prope Kewe (Togo). III. 1900 - No. 12948. Genyorchis Schltr. n. gell.

1. (i. pumila Schltr.

In arboribus juxta flumen Ngoko (Kamerun), IX. 1899 To. 12 737. In arboribus juxta flumen Sanga prope Likilenuba (Congo français). VIII. 1899 - No. 12702.

Ich sehe mich gezwungen, hier eine neue Gattung anfzustellen, welche ich einstweilen bei den Bolbophyllinae unterbringe. Von den anderen Gattungen daselbst muterscheidet sie sich wesentlich durch die beiden Pollinien, welche einem mit einer Klebscheibe versehenen Stipes ansitzen. Ton Polystachia wird sie durch die sehr stark reduzierten Petalen und die basilare Infloreszenz untersehieden. Aufser der obigen, von Swarz Dendrobium pumilum genannten Pflanze gehörten noch hierher (t. micropetala Schltr. (Bulbophyllum micropetalum Ldl.).

Bolbophyllum Thou.

1. B. aurantiaeum Hk. f.

In arboribus prope Nyassosso (Kameruu), alt. 800 m. I. 1900 - No. 13041.

2. B. (§ Megaclinium) Bakossorum Sehltr. n. sp.

In arboribus prope Nyassosso, in terra Bakossormm (Kamerun), alt. c. 800 m. I. 1900 - No. 12898 .

3. B. barligerum Lill.

In arboribus juxta flumen Dja (Kamerun). X. $1899-$ No. 12787 .

t. B. bifarium Hk. f.

In ramis arborum prope Bibundi (Kamerun). IV. 1899 No. 12418 . In arboribus prope Nyassosso (Kamermin), alt. $800 \mathrm{~m}$. I. 1900 - No. 12896. 


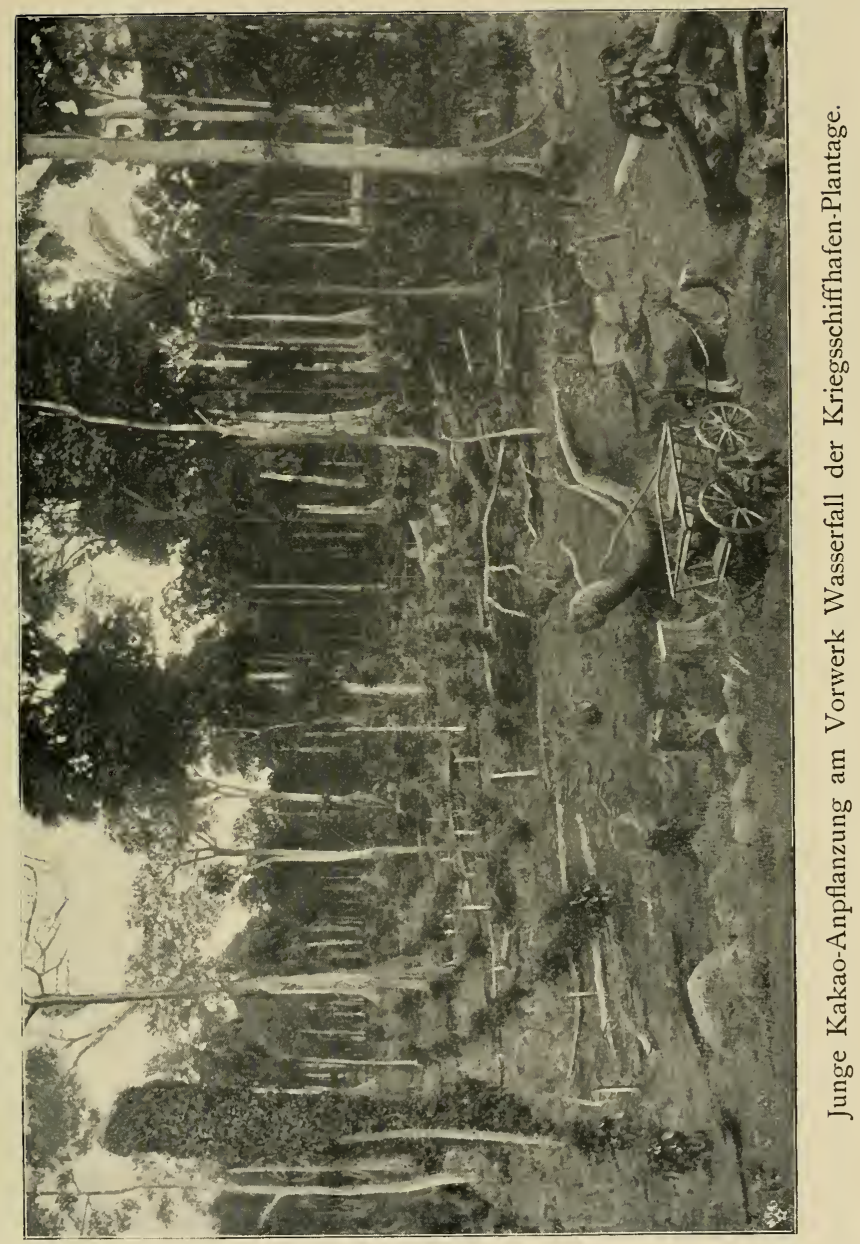



5. B. Calamaria Ldl.

In arboribus prope Nyassosso (Kamerun), alt. $800 \mathrm{~m}$. I. 1900 - No. 12 934. In ramis arborum juxta flumen Ngoko (Kamerun), LX. 1899 - No. 12725.

6. B. ealyptratum Krzl.

Epiphytica in silvis prope Victoria (Kameruin). IV. 1899 No. 12369.

7. B. cocoinum Batem.

Epiphytica in arboribus prope Bibundi (Kamerun). IV. 1899 - No. 12361.

Ich kann B. porphyroglossum Krzl. spezifisch von dieser Art nicht trennen.

8. B. (\$ Megaclinium) congolanum Schltr. n. sp.

In ramis arbor'um juxta flumen Sanga prope N'Kundi (Congo français), VIII. 1899 - No. 12693 . In ramis arborum juxta flumen Ngoko (Kamerun). X. 1899 - No. 12781.

Ich habe diese Art im ganzen Flufsgebiete des Congo sehr hänfig beobachtet.

9. B. (\$ Megaclinium) decipiens Schltr. n. sp.

In arboribus juxta flumen Ngoko (Kamerum), X. 1899No. 12789.

10. B. filiforme Krzl.

Epiphytica in arboribus prope liriegsschiffhafen (Kamermu). IV. 1899 - No. 12 400. In arboribus juxta flumen Mungo prope Nundame (Kamerun), alt. c. 100 m. I. 1900 - No. 12941.

11. B. fuscum Ldl.

In arboribus prope Victoria (Kamerun). I. 1900 - No. 12834.

12. B. (\$ Megaclinium) galunnense Schltr. n. sp.

In arboribus prope Cape Lopez (Congo français). XII. 1899 - No. 12819.

13. B. (\$ Megaclinium) kamerunense Schltr. 11. sp.

In arboribus prope Bibundi (Kamerun). IV. 1900 - No. 12430.

14. B. (\$ Megaclinium) leptorrhachis Schltr. n. sp.

In ramis arbormu prope Moliwe (Kamerun). I. 1900 No. 12992.

15. B. (\$ Megaclinium) longibulbum Schltr. n. sp.

In ramis arborum prope Nyassosso (Kamcrum), alt. с. $800 \mathrm{~m}$. I. 1900 - No 12893.

16. B. lupulinum Ldl.

In ramis arborum prope Buea (Kameruu), alt. c. $800 \mathrm{ml}$. I. 1900 - No. 12844.

Mit der vorliegenden Pflanze ist P. Urbanianum Krzl. in allen Punkten identisch. 
17. B. Mannii Hk. f.

In arboribus prope Buea, alt. c. $800 \mathrm{~m}$. (Kamerun). I. 1900) - No. 12836.

1^. B. Oreonastes Rehb. f.

Epiphytica in arborihus prope Buea (Kamerun), alt. $900 \mathrm{~m}$. IV. 1900 - No. 1237 .

19. B. oxfehilum Sehltr. n. sp.

In arboribus prope Mafura (Kamerum), alt. 400 m. I. $1900-$ No. 13042.

20. B. (\$ Megaclinium) oxypterum Rehb. f. In arboribus prope Bibundi (Kamerun). IV. 1899 - No. 12428.

21. B. Rhizophorae Ldl.

Epiphytica in arboribus prope Victoria (Kamerun). IV. 1899 - No. 12373.

22. B. Sangae Schltr. n. sp.

In arboribus juxta fiumen Sanga prope N'Kundi (Congo français). VIII. 1899 - No. 12687.

23. B. stenopetalum Krzl.

Epiphytica in arboribus prope Bibundi (Kamerun). IV. 1899 - No. 12358.

24. B. teretifolium Schltr. n. sp.

Epiphytica in arboribus prope Bihundi (Kamerun). IT. 18!99 - No. 12362.

25. B. spec.

In arboribus prope Mundame (Kamerum), alt. 200 m. I. 1900 - No. 12879.

26. B. spec.

In arboribus prope Bibumdi (Kanerun). IV. 1899-No. 12 4.27.

Angraecum Thou.

1. A. affine Sehltr. n. sp.

Epiphytica in arboribus juxta flumen Ngoko (Kamerum). IX. 1899 - No. 12744.

2. A. areuatum Ldl. var. Chailluamm (Hk.) Sichltr.

In arhoriluns prope Cape Lopez (Congo français). XII. 189)! To. 128:0; in arboribus juxta flumen Dja (Kameruu). IX. 1899 - No. 12764 ; in arboribus juxta flumen Nogok (Kamerun). 1X. 1899 - No. 12735 .

Ich mufs Lindley vollständig Recht geben, wemn or diese westafrikanische Pflanze als Varietit des A. areuatum Ldl. betrachtet. A. arcuatum scheint eine derjenigen afrikanischen Orchidaceen $z u$ sein, welche in vielen Varietäten üleer ein sehr grofses fichicet verbreitet sind. 
3. A. ashantense Ldl.

In arboribus juxta flumen Samga prope Wesso, (Congo français). VIII. 1899 - No. 12 720; in arboribus juxta flumen Ruki pone Coquilhatville (Congo). YIII. 1899 - No. 12668.

4. A. Batesii Schltr.

In arboribus juxta flumen Ngoko (Kamerum). IX. 1899 No. 12 747.

Von Rolfe als Mysticidium Batesii beschrieben.

5. A. calanthum Schltr. n. sp.

In arboribus juxta flumen Sanga prope Likilemba (Congo français). VIII. 1899 - No. 12700 ; in ramis arborum juxta flumen Ngoko (Kamerun). [X. $1899-$

6. A. eapitatatum Ldl.

In arboribus prope Irebu (Congo). VIII. 1899 - No. 12 639.

7. A. clandestinum Ldl.

In arboribus juxta flumen Dja (Kamerun). X. 1899- No. 12788.

var. $\beta$. Durandianum Schltr.

In arboribus juxta flumen Nóko (Kamerum). IX. 1899 No. 12736.

Von Kränzlin als eigene Art beschrieben worden.

Var. $\gamma$. stenophyllum Sehltr. n. var.

In arboribus prope Buea, alt. e. $900 \mathrm{~m}$ (Kamerun). I. 1900 No. 12843 .

8. A. clavatum Schltr.

In silvis prope Quamikrum (Togo). III. 1900 - No. 12952.

In arboribus in silvis inter Tbarlan et Abeokuta (Toruba-Land). III. 1899 - No. $123 \% 4$.

Listrostachys clavata Rendle mufs hier untergebracht werlen. Die Pflanze ist ein guter Beweis für die höchst unnatürliche Zerteilıng der Gattmo Angraecum in Listrostachys, Mystacilium und Aeranthus. Nach den Pollinien gehörte A. clavatum zu Mystacidium, wo Rolfe sie anch untergebracht hat, während das selır nahe verwandte $A$. affine Schltr. ein Listrostachys wäre. Es giebt rlerartiger ähnlicher Beispiele noch sehr viele.

9. A. curvipes Sehltr. n. sp.

In arboribus juxta flumen Ngoko (Kanerum). X. 18.19 - No. 12784.

10. A. dactyloceras s'chltr.

Epiphytica in arboribus prope Bnea (Kamerun). al. c. $900 \mathrm{~m}$ [T. 1899 - No. 12378.

Von Reichenbach als Listrostachys dactyloceras beschrieben. Kränzlins Listrostachys foreipata ist spezifisch nicht verschieden. 
11. A. Ilistichum LdI.

In arboribus juxta flumen Sanga (Congo français). XI. 1899 - No. 12 790 .

In ganz West-Afrika weit verlsreitet.

12. A. Eichlerianm Krol.

In arboribus juxta Muni-River (Corisco Bay). Xll. 1s!!!) - No. 12 829.

13. A. filifolium schltr. 11. sp.

In arboribus juxta flumen Sanga (Congo français). XI. 189!) - So. 12 791.

14. A. filipes Sehltr. n. sp.

In arboribus juxta flumen Bumbesse, in regione Ngoko (Kamerun). LX. 1899 - No. 12757.

15. 1. fimbriatum Rendle.

In arboribus prope Cape Lopez (Congo français). XII. 1899 - No. 12 818 .

Die Pflanze besitzt eine merkwürdige geographische Verbreitung.

16. A. lepidotum Rehb. f.

In arboribus juxta Humen Ngoko (Kamerum). IX. 190.) - No. 12743; in arboribus juxta flumen Ruki pone Coquillaatville (Congo). VII. 1899 - No. 22 619.

17. A. ichneumonemun Rehb. f.

In arboribus prope Bokabo (Congo). XI. 1599 - No. 12714.

18. A. imbricatum ldd.

In silvis inter Ibarlan et Abeokuta (Yoruba-Land). III. 1899 - No. 13022 ; in arboribus juxta flumen Ngoko (Kamerum). IX. 1899 - No. 12755 .

19. . infundibulare Ldl.

In arboribus juxta flumen Ngoko (Kamerui). IX. 1899 - No. 12 724.

Ls giebt auf iem afrikanischen Festlande wohl keine Art, wrolche gröfsere Blüten besitzt, als die vorliegenden. An uächsten mit ilır rerwandt ist $\mathrm{A}$. Eichlerianum Krzl.

20. A. marerorhynchium Sehltr. u. sp.

In arboribus juxta flumen Dja (Kamerum). X. $1899-$ No.12 785.

21. 1. micropetalum Schltr. 1r. sp.

In arhoribus prope Eko-Keyoke, alt. c. 400 w (Kameruiı). I. 1900 - No. 12892 ; in arboribus juxta flumen 1)ja (Kamerun). IX.-X. 1899 - No. $12779 ;$ No. 12786. 
22. A. oeonioides Schltr.

In arboribus juxta flumen Ngoko (Kamerun). IX. 1899 - No. 12752.

Hierher gehören Angraecum clavatum Rolfe und Saccolahiun oeonioides Krzl.

23. A. pellucidum Ldl.

In arhoribus juxta flumen Ngoko (Kamermn). IX. 1899 - No. 12733.

24. A. Plehnianum Schltr. n. sp.

In arboribus juxta flumen Ngoko (Kamerun). X. 1899-No.12 780.

25. A. rhipsalisocium Rehb. f.

In silvis primaevis inter Ibadan et Abeokuta (Yoruba-Land). IV. 1899 - No. 13031 ; in arboribus prope Vietoria (Kamerun). I. 1900 - No. 12835.

26. A. scandens Schltr. 11. sp.

Inter frutices et ramos arhorum scandlens juxta flumen Ngoko (Kameruu). IX. 1899 - No. 12739.

27. A. subulatum Ldll.

In arboribus juxta flumen Mungo, alt. c. $100 \mathrm{~m}$. (Kamerum). 1. 1900; in arboribus juxta flumen Ngoko (Kamerun). IX. 1899) - No. 12749.

28. A. tridactylites Rolfe.

In arboribus prope Buea (Kamerun), alt. e. 900 m. I. 1900 - No. 12 840; in arboribus prope Nyassosso (Kamerun). I. 1900 No. 12935 .

29. A. vesicatum Iull.

In arboribus juxta flumen Ngoko (Kamermu). IX. 1899 - No. 12732.

30. A. Woodianum Sehltr.

In arboribus juxta flumen Ngoko (Kamerun). IX. 1899 - No. 12726.

31. A. Zenkeri Schltr.

In arboribus prope Nyassosso (Kamerun), alt. e. $800 \mathrm{~m}$. I. 1900 - No. 12900; in arboribus juxta flumen Ngoko (Kamerum). IX. 1899 - No. 12745.

3.2. A. spec.

Epiphytiea in arhorihus juxta flumen Ruki prope Coquilhatrille (Congo). VII. 1899 - No. 12 620.

Hierher gehören: Listrastadigo \%enkeri Krat. I. Batesii Rolfe \& L. iridifolia Rolfe.

33. A. spee.

In arboribus juxta flumen Mungo (Kimerun), alt. c. $100 \mathrm{~m}$. I. 1900 - No. 12942. 
Ulmaceae. (Det. A. Engler.)

Trema Leur.

1. T. guineensis Engl. var. parvifolia Engl.

In fruticetis inter Ibadan et Abeokuta (Yoruba-Land). III. 1899 - No. 13019.

Moraceae. (Det. A. Engler.)

Dorstenia $\mathrm{I}_{2}$.

1. D. ciliata Engl.

In silvis primaevis prope Eko-Keyoke (Kamerun), alt. $400 \mathrm{~m}$. l. $1900-$ No. 12891 .

‥ 1). Harmsiana Engl. n. op. In silvis primaevis inter Mundame et Mafura (Kamerum), alt. c. 300 mI. 1. 1900 - No. 12888 .

3. D. frutescens Engl.

In silvis prope Eko-Keyoke (Kamerum), alt c. 400 m. I. 1900 - No. 12890 .

4. D. intermedia Engl.

In silvis primaevis prope Victoria (Kamerun). IV. 1899 - No. 12368 .

5. D. mundamensis Engl. n. op.

In silvis primaevis prope Mundame (Kamerun), alt. e. $200 \mathrm{~m}$. I. 1900 - No. 12883.

(j. 1). scabra Engl.

In silvis prope Coquilhatville (Congo). ITl. 1899- No. 12607.

7. D. subtriangularis Engl.

In silvis primaevis prope Victoria et Bihundi (Kamermu). IV. 1899 - No. 12375 ; No. 12424.

8. D. tennifolia Engl.

In silvis primaevis inter Mafura et Mundame (Kamerun). I. 1900 - No. 12920.

(). I). turbinata Engl.

In silvis primaevis inter Nyoke et Nundame (Kamerun). I. 1900 - No. 12871.

Trymatoeoceus Poepp d Endl.

1. 'T. africanus H. Baill.

In silvis primaev is inter Nyoke et Mlundame (Kamerun). I 1900 No. $1287 \%$.

Urticaceae. (I) et. A. Engler.)

1. F. interrupta Ciamul.

Fleurya (iandich.

In fruticetis prope Leopoldvill, pone Stanley-Pool (Congo). V1. 1899) - No. 12537. 
1. P. guineensis Bth.

$$
\text { Pouzolzia Gaudich. }
$$

In collibus juxta flumen Ngoko (Kamermu). LX. 1899-No. 12729.

$$
\text { Olacaceae. (Det. A. Engler.) }
$$

\section{Olax L.}

1. V. Durandii, Engl.

In silvis primarvis juxta flumen Sanga, inter Bonga et Wesso (Collgo franęais). VIII. 1899 - No. 12705.

\section{Balanophoraceae. (Det. A. Engler.)}

Thonningia Vahl.

1. T. sangninea Vahl.

In silvis primaevis juxta flumen Sanga, prope Wesso (Congo français). VIII 18!9 - No. 12 721; in umbrosis juxta flumen Congo prope Kinchassa (Congo). XI.18!9 - No. 12 80:3.

Amarantaceae. (Det. Lopriore.)

$$
\text { Celosia L. }
$$

1. C. argentea $\mathrm{L}$.

In cultis prope Coquilhatville (Congo). VII. 1899 No. $1260 \%$.

2. C. laxa Sichum. et 'Thomn.

Ad margines silvarum inter lbarlan et Aherkuta (YorubaLand). III. 1899 - No. 13039.

\section{Amarantus L.}

1. A. spinosiss $\mathrm{L}$.

In collibus cultisque juxta flumen Dja (Kamerun). IX. 1899 - No. 12772.

$$
\text { Alternanthera Forsk. }
$$

1. A. repens O. Ktze.

In collibus argillaceis inter Ibadan et Abeokuta (Yoruba-Land). III. 1899 - No. 13033.

2. A. sessilis $\mathrm{R}$. Br.

In humillis prope Bonga, ad ostium fluminis Sanga (Congo francais). VIII. 1899 - No. 12672.

1. I. portulacoides Mog.

$$
\text { Iresine } \mathrm{P} . \mathrm{Br} \text {. }
$$

In rupibus in litore maris prope Bibundi (Kamermu). IV. 1899 - No. 12420. 


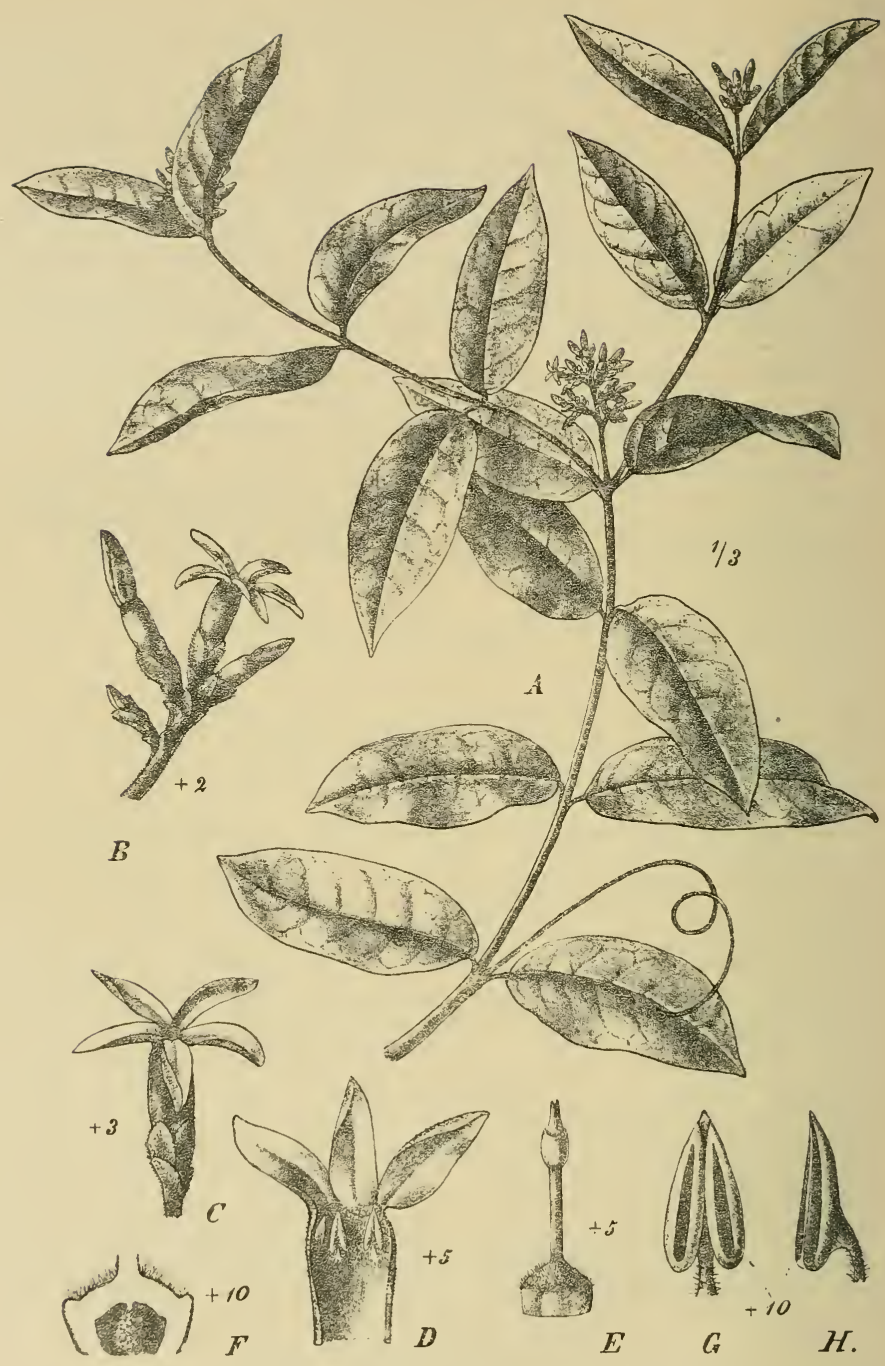

Landolphia humilis K. Nielt. 11. sp.

A Zweig, B Blütenzweig, C Blüte, D dieselbe geöffnet, E Fruchtknoten mit Griffel, fF Längsschnitt durch den Fruchtknoten. Fr Anthere von vorn. $H$ dieselbe von der Seite. 
Phytolaccaceae. (Det. A. Engler.)

1. M. apetala Engl.

Vohlana Iart.

In silvis primaevis prope Ikororlu (Yoruba-Land). III. 1899 No. 13003.

\section{Caryophyllaceae. (Det. A. Engler.) \\ Drymaria Willd.}

1. D. cordata Willu.

In fruticetis prope Neanlja (Kamerun), alt. c. $700 \mathrm{~m}$. I. 1900.

- No. 12858.

1. P. depressum Rohlb.

$$
\text { Polycarpon Loefl: }
$$

In insulis sabulosis fluminis Congo, in lacu Stanley-Pool itppellato (Congo). III. 1899 - No. 12556.

Menispermaceae. (Det. A. Engler.)

Cissampelos $\mathrm{I}$.

1. C. Perreira L. subspec. owariensis (Beauv.).

Inter fruticides scandens prope Ikororlu (Yoruba-Land). III. 1899 - No. 12302.

Cruciferae. (Det. A. Engler.)

Cardamine L.

1. C. trichocarpa Hochst.

In graminosis fruticetisque inter Ngusi et Mafura (Kamerun), alt. c. 400 m. I. 1900 - No. 12904.

Capparidaceae. (Det. E. Gilg.)

Cleome L.

1. C. cilitia Schunn. et Thomı.

In cultis prope Victoria et prope Kriegsschiffhafen, satis frequens (Kamerum). III. 1899 - No. 12391.

Podostemaceae. (Det. R. Schlechter.)

Dicraea Wedd.

1. Dicraea spec.

In lacu Stanley-Pool prope Leopoldville (Congo). VI. 1899 - No. 12574.

Crassulaceae. (Det A. Engler.)

Kalanchoe Adams.

1. K. crenata Harv.

In fruticetis inter Ngusi et Mafura (Kamerun), alt. c. $400 \mathrm{~m}$.

I. 1900 - No. 12911.

R. Schlechter, Westafrikanisohe Kantschuk-Expedition. 
Rosiceae. (Det. A. Engler.)

Parinarium Juss.

1. P. curatellifolimm Planch.

In collibus graminosis prope Kinchassa, juxta stanley-Pool (Congo). IX. 1899 -- No. 12 796.

Connaraceae. (Det. E. (tilg.)

Rourea Aubl.

1. R. aliantoicles (iilg.

In fruticetis prope Bonga ad ostium fluminis Sianga (Congo français). VIII. 1899 - No. 12712.

2. R. coccinea Hook. f.

In fruticetis inter Ibatan et Abeokuta (Yoruba-land). III. 1899 - No. 13030.

3. R. Dinklagei Gilg.

In collibus juxta flumen 1)ja (Kamerun). IX. 1899. No. 12765.

Agelaea soland.

1. A. obliqua Raill.

In fruticetis prope Bonga, ad ostium fluminis Sanga (Congo français). VII. 1899 - No. 12653.

\section{Cnestis Juss.}

1. C. iomalla Gilg.

In fruticetis prope Leopoldville ad "Stanley-Pool" (Congo). VI. 1899 - No. 12550.

2. C. oblongifolia Bkr.

In fruticetis prope Leopoldville arl "Stanley-Pool" (Congo). V. 1899 - No. 12545.

Leguminosae. (Det. H. Harms.)

Albizzia Durazz.

1. A. Brownei Oliv.

In silvis inter Ishagamo et Thadan (Yoruba-Land). III. 1899) - No. 12315.

1. II. asperata 1 .

$$
\text { Mimosa L. }
$$

In ripis fluminis Congo art "Stanley-Pool" (Congo). VI. 1899 - No. 12512.

$$
\text { Cynometra I. }
$$

1. C. Schlechteri Harms n. sp.

In ripis fluminis Congo ar "Stanley-Pool“ (Congo). VI. 2899 - No. 12659 . 


\section{$-291+$ \\ Cassia L.}

1. C. Sieberiana D. ( :

In silvis inter Ibarlan of Alrokuta (Yorubat-Lannl). III. 1899 No. 12342.

1. A. ramiflorus 'l'aub.

$$
\text { Angylocalyx 'T'aul. }
$$

In silvis primaevis prope Ikororlu (Yoruba-Land). III. 1899) No. 12994.

$$
\text { Crotalarial. }
$$

1. C. lanceolata E. Mey.

In graminosis prope Dolo juxta "Stanley-Iool" (Congo). VI. 1899 No. $12476 ;$ No. 12482.

๖. C. onouriges Bth.

In frutieetis prope Coquilhatville (Comgo). VII. I89!9 No. 12625.

3. C. retusa $\mathrm{L}$.

In collibus arenosis prope Ibarlan (Yoruba-Ianul). III. 1899 No. 12326.

4. C. striata D. C.

In campis arenosis prope Dolo juxta "Stanley-Pool" (Congo). VI. 1899 - No. 12497 ; In apertis fruticetorum prope Coquilhatville (Congo). VII. 1899 - No. 12621 .

1. I. eapitata Kotschy.

$$
\text { Indigofera } 1 \text {. }
$$

In planitie arenosa prope Dolo juxta „Stanley-Pool“ (Congo). VI. 1899 -- No. 12470

2. I. erythrogramma Weber.

In planitie arenosa prope Dolo juxta „Stauley-Pool" (Congo). VI. 1899 - No. 12470 .

3. I. macrocarpa Lep.

In collibus graminosis prope Ibarlan (Yoruba-Land). III. 1899 No. 12329 .

4. I. oligantha Harms n. sp.

In planitie graminosa prope Bonga, at ostium fluminis Sanga (Congo français). VIII. 1899 No. 12666.

5. I. palysphaera Bkr.

In arenosis prope Libreville (Congo français). V. 1899 No. 12433.

I. Dewerrei Micheli in Bull. Soc. bot. Belg. XXXVI. 2 (1897) 54 et Illustr. fl. Congo t. 30 ist ron dieser Art nicht spezifisch zu tremmen. 
6. I. sall gatlia Harms ne sp.

In graminosis prope Bonga, anl ostimn fluninis Sanga (Congo français). VIII. 1899 - No. 12670.

7. I. tetrasperma s'chum. et Thom!n.

In collibus prope [badan (Toruba-Land). Ill. 18!99

No. 12333 ; In planitie arenosa prope Dolo juxta „Stanley-Pool" (Congo). VI. 1899 - To. $1247 \%$.

$\therefore$ I. trita l. f.

ln ripis fluminis Sanga, inter Bonga of Wesso (Congo fran(ais). VIII. 1899 -- No. 12713.

1. T. bracteolata $t i$. et Perr.

$$
\text { Tephrosia L. }
$$

In planitic sabulosa prope Dolo juxta Stanley-Pool (Congo). VI. 1899 - No. 12466.

2. T. elegans Schum. et Thomı.

ln collibus prope Libreville (Congo framçais). Y. $1899-$ No. 12 436; In planitie arenosa prope Dolo (Congo). VI. 1899 No. 12500 .

3. T. lıpinifolia D. C.

In dunio sahulosis prope Dolo juxta Stanley-Pool (Congo). V1. 1899 - No. 12467.

Diese Form der weitvorbreituten Pflanze ist besonders iuteressant durch ihre Hoterocarpie. Viele der Blütenstände dringen in den Sand ein, ähnlich wie bei Arachis, und bilden dort kurze 1-2 samige Hülsen.

4. T. Vogelii Hook. f.

In apertis silvarum fruticetorumque prope Wesso ad flumen Sauga (Congo français). VIII. 1899 - No.12717.

1. I. Thomuingii Bkr.

$$
\text { Millettia Wight d Arn. }
$$

In silvis juxta flumen Congo prope Irebu (Congo). VII. 1889 - No. 12 640; In silvis prope Wesso juxta flumen Sanga (Congo français). VIII. 1899 - No. 12718.

1. O. sennoides D. C.

$$
\text { Ormocarpum D. C. }
$$

In grantinosis apertis prope Kriegsschifflhafen (Kamernu). VI. 1899 - No. 12385.

$$
\text { Aeschynomene L. }
$$

1. A. brachyearpa Harms is. sp.

In sabulosis prope Leopoldville ad "Stanley-Pool" (Congo). V1. $18919-$ No. 12524. 
2. A. cristata Vatke.

In ripis fluminis Sanga prope Bonga (Congo français). VII. 1899 - No. 12648 .

3. A. pulchella Planch.

In elivis graminosis montium Agome, prope Aslanti-Kpoeta (Togo). III. $1900-$ No. 12958.

4. A. sensitiva Sn.

In fruticetis prope Dolo juxta Stanley-Pool (Congo). IJ. 1899 No. 12483.

5. A. Sehlechteri Harms n. sp.

In rivulis prope Dolo juxta Stanley-Pool (Congo). V1. 1899 - No. 12491.

6. A. spec.

In paludibus prope Irehu (Congo). K11. 1899 - No. 12 (i35.

1. C. stellaris Afz.

$$
\text { Cyclocarpa Afz. }
$$

In graminosis humidis prope Dolo juxta ,Stanley-Pool" (Congo). VI. $1899-$ No. 12484.

1. D. mauritianum D. C.

$$
\text { Desmorlium Dess. }
$$

In collibus prope Thatan (Tornba-Lami). HI. 18s9-No. 12330.

2. D. incanum D. C.

In apertis prope villam Kataku juxta flumen Ngoko (Kamerun). IX. 1899 - No. 12760. Prope villam N'Kunfla juxta flumen Sanga inter Wesso et Bonga (Congo français). VIII. 1899 - No. 12 708 .

3. D. triflorum D. C.

In collibus graminosis prope Iharlan (Toruba-Lamu). ПI. 1899 - No. 12335.

$$
\text { Uraria Dest. }
$$

1. U. picta Dest.

In fruticetis prope Dolo juxta Stanley-Pool (Congo). VI. 1899 - No. 12481.

1. R. delibis Hook. f.

$$
\text { Rhynehosia L. }
$$

Inter frutices scandens juxta rivulum Meanja (Kamerum), alt. c. 600 m. I. 1900 - No. 12856 .

1. E. glomeratum Hook. f.

$$
\text { Eriosema D. C. }
$$

In eampis arenosis prope Dolo juxta, stanley-Pool" (Congo). VI. 1899 - No. 12464 ; In paludibus prope I)olo juxta „Stan- 
lej-Pool" (Congo). VI. 1899 - No. 12473 . In fruticetis prope Leopoldville juxta "Stanley-Pool" (Congo). VI.1899-No.12588

(Meiner Ansicht nach liegen hier 3 verschiedene Arten vor. R. Schltr.).

1. V. micrantha Harms.

$$
\text { Vigua Savi. }
$$

In sabulosis inter Dolo et Kinchassa arl "Stanley-l'ool" satis frequens (Congo). V1. 1899 - No. 12592.

2. V. luteola Bth. var, villosa (Savi).

In fruticetis prope Leopoldville al Stanley-Pool (Congo). VI. 1899 - No. 12576; In fruticetis prope Bonga, ad ostium fluminis Sanga (Congo français). VIII. 1899 - No. 12657.

(Diese Form diurfte wohl spezifiseh von I. huteola Bth. verschiedlen sein. Die Blüten sind rosenrot gefärbt. R. Schltr:)

\section{Rutaceae. (Det. A. Engler.)}

Clausena Burm.

1. C. anisata Oliv.

Arl margines silvarum inter Ishagamo ef Ibadan (Yornba-Land). III. 1899 - No. 12318.

\section{Meliaceae. (Det. H. Harms.)}

Turraea $\mathrm{L}_{\mathrm{L}}$.

1. 'T. Vogelii Hk. f.

In fruticetis juxta flumen Dja (Kamerun). IX. 1899 No. 12771 ; In fruticetis arl ostium fluminis Sanga prope Bonga (Congo français). VII. $18.99-$ No. 12650 ().

2. T. aff. Vorgelii Hk. f.

In fruticetis juxta flumen Dja (Kamermu). IX. 1899 ำ. 12763.

Malpighiaceae. (Det. A. Engler.)

Acridocarpus Guill.

1. A. Sneathmanii Guill. et Perr.

In silvis primaevis prope florolu (Yoruba-Land). III. 1899 - No. 12300.

1. P. acicularis Oliv.

Polygalaceae. (Det. (Gïrke.)

$$
\text { Polygala } \mathrm{l} \text {. }
$$

In planitie arenosa prope Dolo, juxta „Stanley-Pool" (Congo). Vl. 1899 - No. $124 ! 4$.

2. P. arenaria Willd.

In collibus lapidosis juxta flumen Congo prope Noki. V. 1899 - No. $1243 \%$. 
3. P. congoënsis Gürken. sp.

Ad margines paludum prope Dolo juxta Stanley-Pool. XI. 1899 - No. 12809 .

Scheint nur selten unul stets vereinzelt aufzutreten.

1. C. alba Don.

$$
\text { Carpolobia Don. }
$$

In fruticetis prope Nyoke (Kamerun), alt. 200-300 ped.

I. 1900 - No. 12 864 .

2. C. lutea Don.

In fruticetis inter Ibadan et Aheokuta (Yoruba-Land). III. 1899 - No. 13 (030.

Euphorbiaceae. (Det. F. Pax.)

Phyllanthus. L.

1. P. capillaris Schum. \& Thoun.

In silvis juxta flumen Sanga, inter Bonga et Wesso (Congo français). VIII. 1899 - No. 12 699. In fruticetis prope Coquilhatville (Congo). VII. 18.99 - No. 12604.

๖. P. reticulatus Poir.

Juxta flumen Sanga inter Bonga et Wesso (Congo français). - No. 12 689. In silvis inter Mundame et Otam, alt. 20()$-300 \mathrm{~m}$. (Kamerun). Г. 1900 - No. 12887.

(Ich halte diese beirlen Nummern für spezifisch vorschieden. Schltr.).

3. P. spec.

In graminosis inter Ibadan et Abeokuta (Yorula-Land). [II. 1899 - No. 12345.

4. P. spec.

In collibus prope lbalan (Yoruba-Land). III. 1899 No. 13014 .

Antidesma L.

1. A. laciniatum M. Arg.

In silvis primaevis prope Victoria (Kamerun). IV. 1899 No. 12363.

2. A. venosum Tul.

In fruticetis ad ostium fluminis Sanga, prope Bonga (Congo français). VIII. 1899 - No. 12669.

1. C. lobatus $\mathrm{L}$.

$$
\text { Crotom L. }
$$

In collibus graminosis prope Ibarlan (Yoruba-Land). III. 1 s.99 - No. 12331. 
1. M. africanum M. Arg.

Mauniophyton M. Arg.

In fruticetis prope Coquilhatville (Congo). VII. 1899 No. 12615.

\section{Micrococa Bth.}

1. M. Mercurialis Bth.

In cultis prope Kriegsschiffhafen (Kamerun). IV. 1899 No. 12394.

1. E. aculeata Bth.

Erythrococea Bth.

In collibus prope Ibadan (Yoruba-Land). III. 1899 - No. 13012. Mallotus Lour.

1. M. oppositifolius M. Arg.

In collibus inter Ibadan et Abeokuta (Yoruba-Land). III. 1899 - No. 13025 . In collibus juxta flumen Dja (Kamerum). TX. 1899 - No. 12766.

2. M. subulatus M. Arg.

In silvis prope Bibundi (Kamerun). IV. 1899 - No. 12402.

1. A. penniculata Mig. Acalypha L.

In silvisjnxta flumen Ngoko (Kamerun). IX. 1899 - No. 12742.

1. D. ipomeifolia Bth.

$$
\text { Dalechampsia } \mathrm{L} \text {. }
$$

Inter frutices scandens prope Leopoldville pone Stanley-Pool (Congo). VI. 1899 - No. 12538.

1. B. spec.

Bridelia Willd.

In silvis primaevis inter Ibadan et Abeokuta (Yoruba-Land). III. $1899-$ No, 12356.

1. C. africanus Pax.

$$
\text { Chaetocarpus Thw. }
$$

In fruticetis prope Leopoldville pone "Stanley-Pool“ (Congo). Y\}. 1899 - No. 12554 (mas), No. 12546 (fem.).

In fruticetis prope Kinchassa pone Stanley-Pool (Congo). IV. $1899-$ No. 12802.

Sebastiania Sprgl.

1. S. Clamaemeles M. Arg.

In planitie arenosa prope Agome-Palime (Togo). III. 1900 No. 12965.

1. R. spec.

$$
\text { Ricinodendron M. Arg. }
$$

In silvis primaevis prope Iladan (Yoruba-Land). III. 1899 - No. 12321. 
Sapium L.

1. S. oblongifolium Pax.

In fruticetis prope Leopoldville, pone "Stanley-Pool" (Congo). VI. 1899 - No. 12540.

\section{Anacardiaceae. (Det. A. Engler:)}

1. I. Smithii Hook. f.

$$
\text { Irvingia Hook f. }
$$

In ripis fluminis Congo prope Irebn (Congo). VII. 1899 No. 12633; In ripis fluminis ('ongo prope Kinchassa (Congo). XI. 1899 - No. 12795.

Hippocrateaceae. (Det. Th. Loesener.)

1. H. Rowlandii Loes.

$$
\text { Hippoeratoa } 1 \text {. }
$$

In silvis prope Ikororlu (Yornha-LamI). III. 1899 - No. 13001.

2. H. velutina Afz.

In fruticetis prope Coquilhatville (Congo). VII. 1899-No. 12606 .

$$
\text { Salacia } \mathrm{L} \text {. }
$$

1. S. Schlechteri Loes. n. sj.

In silvis primaevis prope Victoria (Kamerum). [V. $1899-$ No. 12365.

Icacinaceae. (Det. A. Engler.)

Iodes Bl.

1. I. africana Webw.

In ripis fluminis Sanga, inter Bonga et Wesso (Congo français). VIII. 1899 - No. 12710.

$$
\text { Pyrenacantha Hook. }
$$

1. P. Standtii Engl.

In fruticetis prope Coquilhatville (Congo). VII. 1899 -No. 12601 .

1. A. Standtii Engl.

$$
\text { Aleodeiopsis Oliv. }
$$

In silvis primaevis prope Ibadan (Yoruba-Land). III. 1899 No. 13011 . In silvis primaevis inter Bonga et Wesso, juxta flumen Sanga (Congo français). VIII. 1899 - No. 12696.

Sapindaceae. (Det. E. Gilg.)

1. A. africanns P. B. ?

Allophylus L.

In fruticetis prope Bonga ad ostium fluminis Sanga (Congo français). VIII. 1899 - No. 12664. 
2. A. Welwitschii Gilg.

In fruticetis prope Bonga, arl ostium fluminis Sanga (Congo franęais). TIII. 1899 - No. 12674.

Deinbollia śchum. et Thonn.

1. D. leptophylla Gilg. n. sp.

In collihus graminosis inter Ibadan et Abeokuta (Yorubaland). III. 1899 - No. 13026 .

1. L. enpanioides Pl.

Lecaniodiseus Pl.

Culta in villa Atikpui (Togo). IV. $1900-$ No. 12985$)$

\section{Balsaminaceae. (Det. F. (iilg..)}

Impatiens I.

1. I. licolor Hook. f.

In silvis primaevis prope Xyassosso (Kamerun). I. $19100-$ No. 12937.

2. I. fulvo-pilosa Gilg n. sp.

In silvis primaeris prope Nyassosso (Kamerum). I. $1909-$ No. 12939.

3. I. hians Hook f.

In silvis primaevis juxta flumen samga, inter Bonga et Wesso (Congo franęais). VIII. 1899 - No. 12 (688.

4. I. Irvingii Hook f.

In umbrosis prope Leopoliville pone "Stanley-Pool“ (Congo). V'I. 1899 - No. $1252 \pi$.

5. I. macroptera Hook. f.

In silvis primaevis prope Meandja (Kamejun). I. 1900 No. 12860.

Vitaceae. (Det. E. (iilg.)

Cissus L.

1. C. Esaso Gilg.

In fruticetis juxta flumeu I)ja (Kamerum). 1X.1899- No.12 762 .

2. C. Guerkeana Gilg.

In planitie arenosa prode Dolo pone Stanley-Pool (Congoo). VI. 1899 - No. 12463.

3. C. producta Afz.

In ripis rivulorum inter Ngusi et Mafura (Kamerun), alt. c. 400 m. I. 1900 - No. 12 !108.

4. C. stenopoda Gilg. 11. sp.

In collibus gramiussis proper Quaniksum (Togo). III. 1900 - S1. 1295.5. 
Malvaceae. (Det. Gürke, p. p. K. S̈chumann.)

Wissarlula Medik.

1. W. hernandioides Garke.

In collibus inter Thadan et Aheokuta (Yoruba-Land). III. 1899 - No. 13038.

$$
\text { Sida } L_{\text {. }} \text {. }
$$

1. S. hrachyphylla K. Seh. n. sp.

In planitie graminosa prope Bonga, ad ostium fluminis Sanga (Congo français). VIII. 1899 - No. 12675.

2. S. linifolia Car.

In collibns graminosis prope Abeskuta (Yoruba-Land). III. 189!

- No. 12357.

3. S. rhombifolia L.

In arenosis prope Leopoliville (Congo). VI.1899-No. 12573.

4. S. rotundifolia L.

In arenosis prope Leopoldville (Congo). VI. 1899-No. 12562.

5. S. urens $\mathrm{L}$.

In fruticetis prope Leopoldville (Congo). VI. 1899 - No. 12575.

1. U. lobata L.

$$
\text { Urena } \mathrm{L} \text {. }
$$

In fruticetis prope Leopoldville(Congo). VI. 1899 - No. 12503.

Tiliaceae. (Det. K. S'chumann.)

Glyphaea Hk. f.

1. (t. grewioides Hk. f.

In umbrosis prope Bibundi (Kamerum). IV. 1899 - No. 12408.

$$
\text { Cephalonema K. sch. }
$$

1. C. polyandrum K. Sch.

In fruticetis et ad margines silvarum prope Coquilhatville (Congo) VII. 1899 - No. 12594.

1. L. multiflora K. Sch.

$$
\text { Leptonychia. }
$$

Ad margines silvarum prope Coqnilhatville (Congo). VII. 1899 - No. 12600 .

1. G. carpinifolia Juss.

$$
\text { Grewia L. }
$$

In silvis primaevis prope Ishagamo (Yoruba-Land). III. 1899 - No. 12314.

2. (r. microdelphys K. Sch. n. sp.

In fruticetis prope Bonga ad ostium fluminis Sanga (Congo français). VIII. 1899 - No. 12682. 
3. G. Schlechteri K. Sch. n. sp.

Ad margines silrarum inter Ishagamo et Ibarlan (YorubaLand). III. $1899-$ Co. 12316.

4. (.. spec.

In fruticetis juxta flumen Ngoko (Kamerun). IX. 1899 To. 12730 .

$$
\text { Triumfetta } \mathrm{L} \text {. }
$$

1. T. semitrilolsa I. rar. africana K. Sch.

Ad margines silvarum prope Coquilhatville (Congo). III. 1899 - No. 12611.

Sterculiacea. (Det. K. Stchmmann.)

Melochia $\mathrm{I}$.

1. М. corchorifolia L.

In arenosis prope Dolo, pone „Stanley-Pool" (Congo). VI. 1899 - No. 12498.

2. II. melissifolia Bth.

In hmmidis prope Ibadan (Toruba-Land). TV. 1899 - To. 12337.

$$
\text { Cola Sichott. }
$$

1. C. spec.

In silvis juxta flumen Nonoko (Kamerun). IX. 1899-No. 12 736.

Dilleniaceae. (Det. E. Gilg.)

Tetracera L.

1. 'T. alnifolia Wille

In ripis fluminis ('ongo prope Lukulela (Congo). VII. 18s9) - No. 12646.

I) Pflanze ist im Ufergebüsch des Congo und seiner NebenHüsse sehr verbreitet. Für eine längere Periode im Jalure steht sie daselhst nicht selten vollständig unter Wasser.

Ochnaceae. (Det. A. Eingler.)

Ouratea Anbl.

1. O. affinis Engl.

In fruticutis silvistue prope Leopoldville pone „Stanley-Pool" (Congo). VI. 1899 - No. $12535 ;$ No. 12584.

2. O. reticulata Engl.

In silvis inter Ihatan et Abeokuta (Yoruba-lanul). VI. 1899 - No. 13022 ; in fruticetis prope Wesse juxta flumen Sanga (Congo franeais). IX. 1899 - No. 12 719. 
Sauvagesia I.

1. S. congoensis Engl. 11. sp.

lu paludibus prope Dolo, pone „Ntanley-Pool“(Congo). VI. 1899 - No. 12443.

Violaceae. (I)et. A. Engler.)

Rinorea Aubl.

1. R. dentata O. Ktze.

In collibus prope Ibarlan (Yoruba-Land). III.1899- No.13013.

Ionidium L.

1. I. enneaspermum Vent.

In collibus prope Ilsadau (Yoruba-Land). Ill. 1899-No. 12334.

Turneraceae. (Det. J. Urban.)

Wormskiöllia Schum. \& Thoun.

1. W. lobata Urb.

Auf grasigen Ebenen am "Stanley-Pool" (Congo). VI. 1899 - No. 12567.

Passifloraceae. (Det. H. Harms.) Ophiocaulon Hk f.

1. O. cissampeloides Hook. f.

Inter frutices seandens prope Coquilhatville (Cougo). VII. 1899 - No. 12614.

$$
\text { Adenia Forsk. }
$$

1. A. lobata Engl.

In apertis silvarum inter Ishagamo et Ihadan (Yoruba-Laud). III 1899 - No. 12323 ; inter frutices scandens prope Bonga ad ostium fluminis Sanga(Congo français). VIII. 1899-No. 12686.

Begoniaceae. (Det. L. (xilg.)

Begonia L.

1. B. macrura frilg n. sp.

In silvis primaevis inter Mafura et Mundame (Kameruu), alt. c. 400 m. I. 1900 - No. 12918.

2. B. Schlechteri Gilg n. sp.

In silvis primaevis inter Mafura et Mundame (Kamerun), alt. c. $400 . \mathrm{m}$ I. 1900 - No. 12915 .

Thymelaeaceae. (Det. E. (tilg.)

Dicranolepis Plauch.

1. D. polygaloides Gilg n. sp.

In silvis inter Mundame et Malende, alt. c. 200 m. (Kamerun). 1. 1900 - No. 12889. 
2 D. vestita Fingl.

In silvis inter Ngusi et Mafura (Kamerum), alt, 400 n. I 1900 - No. 12907.

Combretaceae. (1)et. A. Eilngler.)

Combretum L.

1. C. exaurienlatum, Engl, et Diels var. Schlechteri Engl.

In collibus lapidosis prope Matati (Congo). XI. Is.9! - No. 12812.

2. C. latialatum Engl.

In silvis primaevis prope Kriegsschiffhafen (Kamerun). IV.1899

- No. 12382.

3. C. spec.

In fruticetis prope Leopoldville pone Stanley-l'ool (Congo). Y1. 1899 - No. 12509.

\section{Melastomaceae. (Det. F. ( $\mathrm{xil}$.}

1. O. congolensis Cogn.

Osbeckia $\mathrm{L}$.

In paludibus prope Leopoldville pone Stanley-Pool (Congo). VI. 1899 - No. 12564.

2. O. drepanosepala Gilg.

In planitie prope Dolo pone „Stanley-l'ool“ (Congo). VI. 1899 No. 12468.

3. O. saxicola Gilg.

In graminosis prope Bonga, ad ostium fluminis Sanga (Congo français). VIII. 1899 - No. 12677.

Tristemma Juss.

1. 'T. incompletum R. Br.

In campis apertis prope Bibundi (Kamermu). IV. 1899 No. 12 407; in humidis prope Leopoldville pone Stanley-Pool (Congo). VI. 1899 - No. 12542.

2. T. Schlechteri Gilg. n. sp.

In collibus juxta flumen Ngroko (Kamerun). X. 1899 - No. 12782.

$$
\text { Dirophora Bth. }
$$

1. D. spenueroides Bth.

All margines silvarum prope Kriegsschiffliafen (Kamerum). IV. 1899 - No. 12388.

1. D. gracilis Cognn.

$$
\text { Dissotis Btl. }
$$

In paludibus in planitie arenosa prope Dolo pone StanleyPool (Congo). VI. 1899 - No. 12461 ; in paludibus prope Leopoldville ad Stanley-Pool (Congo). VI. 1899 - No. 12555. 
2. D. multiflora Triana.

In fruticetis prope leopollvilla (Congo). VI. 1899 - No. 12579; in fruticetis prope Coquillatville (Congo). VII. 1r99-No. 12598; in silvis prope Irebu (Congo). VII. 1899 - No. 12629.

3. D. rotundifolia Triana.

In fruticetis prope Leopoldville pone "Stanley-Pool" (Congo). VI. 1899 - No. 12531.

4. D. Thollonii Cogm.

In planitic arenosa prope Dolo pone "Stanley-Poul“ (Congo). V. 1899 - No. 12459.

1. I. heterophyllum Gilg.

\section{Memecylon L.}

In ripis fluminis Sanga inter. Wesso et Bonga (C'cngo français). VIII. 1899 - No. 12697.

2. II. myrianthum Gilg.

In ripis fluminis Congo ad "Stanley-Pool“ (Congo). V1l.1899 - No. 12520.

Onotheraceae. (Det. A. Engler.)

Jussiaea.

1. J. linifolia Vahl.

In stagnis prope Leopoldville juxta „Stanley-Pool“ (Congo). VI. 1899 - No. 12510.

Myrsinaceae. (Det. E. Gilg.)

1. II. cordifolia Bkr.

$$
\text { Maesa Forsk. }
$$

In fruticetis prope Nyassosso (Kamerun), alt. e. $800 \mathrm{~m}$. 1. 1900 - No. 12901.

$$
\text { Ardisia sw. }
$$

1. A. Schlechteri Gilg. n. sp.

In silvis primaevis ad pedem montis Kamerunberg prope Bibundi (Kamerun), alt. c. $100 \mathrm{~m}$. IV. 1899 - No. 12417.

Primulaceae. (Det. R. Schlechter.)

Ardisiandra Hk. f.

1. A. sibthorpioides Hk. f.

In silvis supra Buea (Kamerun), alt. $1100 \mathrm{~m}$. I. 1900 No. 12846.

1. P. zeylanica L.

Plumbaginaceae. (Det. A. Engler.) Plumbago L.

In fruticetis prope Dolo, juxta Stanley-Pool (Congo). VI. 1899 - No. 12489. 


\section{- $304-$ \\ Oleaceae. (Det. E. Gilg). \\ Jasminum $\mathrm{I}$.}

1. J. pauciflorum Bth.

In fruticetis prope Akeppe (Togo). 11. 1900 - No. 12988.

Loganiaceae. (Det. (r. (rilg.)

Mostuea Didrichs.

1. II. Buchholzii Engl.

In silvis primaevis inter Nyoke et Malende (Kamerun), alt. e. 200 m. I. 1900 - No. 12876.

2. M. Schlechteri Gilg. n. sp.

In silvis prope Nyassosso (Kamerun), alt. e. 800 m. I. $1900-$ No. 12936 .

1. S. pungens solered.

$$
\text { Strychnos } \mathrm{l} \text {. }
$$

In planitie arenosa prope Dolo (Congo). VI. 1899 No. $1 \% 472$.

Ein kurzer, gredrungener steppenbaum.

2. S. eiliicalyx Gilg. n. sp.

Alte scandlens in silvis prope Quanikrum ('Togo). III. $1900-$ No. 12957.

Gentianaceae. (Det. E. Gilg.)

Exacum L.

1. E. quinquenervium Griseb.

In planitie arenosa prope Dolo juxta Stanley-Pool (Congo). VI. 1899.

Blüten hellblan.

Neurotheca Salisb.

1. N. loeselioides Bth. et Hk. f.

In planitie arenosa prope Dolo juxta Stanley-Pool (Congo). VI. 1899 - No. 12495.

2. N. exacoides Gilg n. sp.

In arenosis humidis prope Cape Lopez (Congo français). XII. 1899 - No. 12814.

Blüten hellblau.

Limnanthemum s. P. Gmel.

1. L. indicum Griseb.

In paludibus juxta flumen Congo prope Lukulela (Congo). VII. 1899 - No. 12645.

Apocynaceae. (Det. U. Schumann, p. p. H. Hallier.) Arduina $\mathrm{I}$.

1. A. edulis Vahl.

In fruticetis prope Atikpui (Togo). IV. 1899 - No. 12980. 


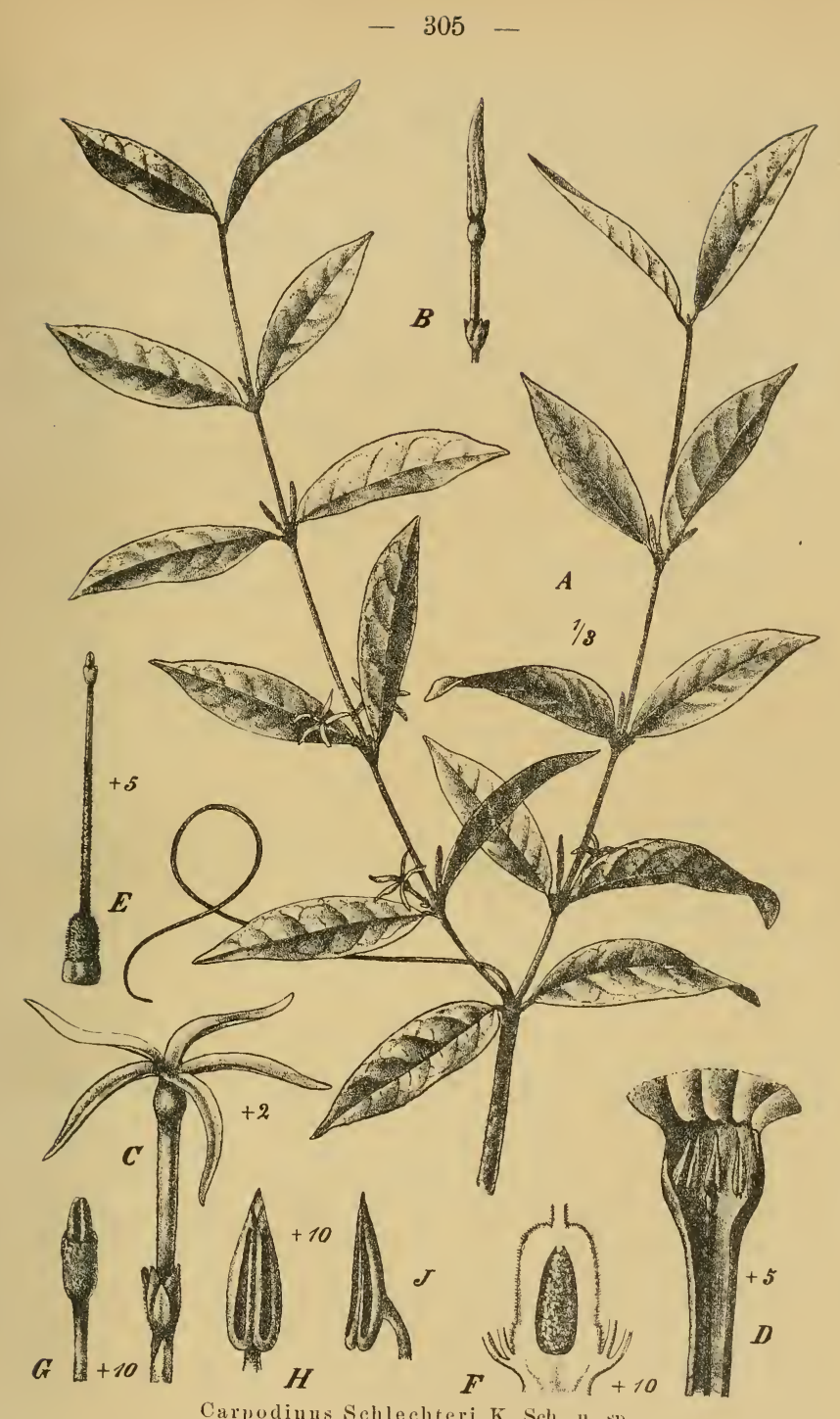

Carpodiuns Sehlechteri K. Sch. n. sp.

A Blühender Zweig, B Kunospe, C Blüte, D geöff̈nete Blütenröhre. E Fruchtknoteı mit Griffel, F Längssichnitt dureh den Fruchtkuoten. G Griffelkopf, H Anthere ron
vorn, J dieselbe von der Seite.

R. Schlechter, Westafrikanische Kantschuk-Expedition. 
Landolphia P. Beaur.

1. L. florida Bth. var leiantha Oliv.

Ad margines fluvii Sanga, prope Bonga (Congo français). VIII. 1899 - No. 12679.

2. L. humilis K. Sch. n. sp.

In graminosis prope „Stanley-Pool“ (Congo). VI. 1899 No. 12544.

3. I. Klainei Pierre.

In fruticetis prope Bonga, ad ostium fluminis Sanga. (Congo français). VIII. 1899 - No. 12660 . In ripis fluminis Sanga inter Bonga et Wesso (Congo français). VIII. 1899 No. 12698 . In ripis fluminis Dja (Kamerun). IX. 1899No. 12770.

1. C. lanceolatus K. Sch.

$$
\text { Carpodinus R. Br. }
$$

In planitie sabulosa prope Dolo, pone „Stanley-Pool“ (Congo). VI. 1899 - No. 12447.

2. C. Schlechteri K. Sch. n. sp.

In fruticetis silvisque prope Kinchassa pone „Stanley-Pool“ (Congo). alte scandens. XI. 1899 - No. 12804.

Holarrhena R. Br.

1. H. africana A. D. C.

In silvis primaevis prope Ikorodu (Yoruba-Land). III. 1899 No. 12 296. In fruticetis prope Badja (Togo). IV. $1900-$ No. 12969.

Blüten weifs. Habituell macht die Pflanze den Eindruck einer kleinen Kickxia.

\section{Alafia T'hon.}

1. A. Bartevi Oliv.

In silvis prope Jshagamo (Yoruba-Land). III. 1899 No. 12311.

$$
\text { Tabernaemontana } \mathrm{L} \text {. }
$$

1. T. Barteri Oliv.

In silvis primaevis prope Ikorodu (Yoruba-Land). III. 1899No. 12301.

Ein 1 bis $1^{1} / 2$ m hoher Strauch, mit schönen stark riechenden weifsen Blüten, welche an Gardenia erinnern.

Hunteria Rexb.

1. II. breviloba Hallier f. n. sp.

In silvis primaevis juxta flumen Sanga, inter Wesso et Bonga (Congo français). VIII. 1899 - No. 12706. 
2. R. obscura K. Seh.

In fruticetis prope Leopoldville pone stanley-Pool (Congo). VI. 1899 - No. 22534.

3. R. Prenssii Engl.

In silvis primaevis prope Mundame (Kamerun), alt. c. $200 \mathrm{~m}$. I. 1900 - No. 12929.

$$
\text { Ranwolfia L. }
$$

1. R. pleiosciadica K. Sch.

In silvis primaevis inter Abeokuta et Ihadan (Yoruba-Land). III. 1899 - No. 13037.

$$
\text { Motandra A. D, C. }
$$

1. M. rostrata K. Sch. n. sp.

Acl margines silvarum prope Ishagamo (Yoruba-Land). III. 1899 - No. 12 312.

Eine sehr reich mit weifsen Blüten bedeckte Liane.

1. K. africana Bth.

$$
\text { Kickxia Bl. }
$$

In silvis montis Amedjovhe (Togo). IV. 1899 - No. 12979.

2. K. elastica Preufs.

In silvis inter Ishagamo et Ibadan (Yoruba-Land). III. 1899 - No. 12319. In silvis primaevis juxta flumen Ngoko (Kamerun). LX. 1899 - No. 12746.

3. K. latifolia Stapf.

In silvis prope Coquilhatville (Congo). VII. 1899 - No. 12596.

Über die Verbreitung der einzelnen Kickxia- und Landolphiaarten sind nähere Angaben in den vorhergehenden Kapiteln zu finden.

$$
\text { Oncinotis Bth. }
$$

1. O. chlorogena K. Sch. n. sp.

In silvis primaevis prope Ikorodu (Yoruba-Land). III. $1899-$ No. 12996.

Eine Liane mit gelblichen Blüten.

2. O. subsessilis K. Sch. n. sp.

In silvis primaevis prope Ishagamo (Yoruba-Land). III. 1899 - No. 12310.

Blüten weifslich mit fünf purpurroten Streifen im Schlunde. Strophantus D. C.

1. S. Preufsii Pax et Engl.

In silvis prope Ishagamo (Yoruba-Land). III. 1899 No. 12313.

2. S. sarmentosus A. D. C.

Ad margines silvarum montium Agome (Togo). III. $1899-$ No. 12962. 
3. S. Schlechteri K. Sch. n. sp.

In silvis primaevis inter Mafura et Mundame (Kamerun), alt. 300 m. $\quad$ I. 1900 - No. 12919.

1. W. parviflora Bth.

$$
\text { Wrightia R. Br. }
$$

In silvis primaevis prope Ishagamo (Yoruba-Iand). III. 1899 No. 13008 .

$$
\text { Isonema R. Br. }
$$

1. J. infundibuliformis Stapf.

In fruticetis prope Coquilhatville (Congo). VII. 1899. No. 12602.

Asclepiadaceae. (Det. R. Sichlechter.)

$$
\text { Periploca L. }
$$

1. P. nigricans Afz.

Inter frutices scandens ad margines silvarum prope Libreville (Congo français). XII. 1899 - No. 12822.

1. C. sanguinolenta Schltr.

$$
\text { Cryptolepis R. Br. }
$$

In fruticetis scandens prope Akeppe (Togo). IV. $1900-$ No. 12986.

Diese Pflanze ist ursprünglich als Pergularia sanguinolenta beschrieben und abgebildet worlen. In nenerer Zeit scheint sie sonst nicht wierler anfgefunden worden zu sein.

2. C. scandens Schltr.

Inter fruticulos scandens in solo arenoso prope Dolo, pone Stanley-Pool (Congo). VI. 1899 - No. 12451.

Identisch mit Ectadiopsis scandens K. Sch. Die Blüten sind creamgelb gefärbt.

1. R. Browneana Scott Elliot.

$$
\text { Raphiacme Harv. }
$$

In collibus graminosis prope Quamikrum (Togo). III. $1900-$ No. 12956 .

$$
\text { Schizoglossum E. Mey. }
$$

1. S. togoense schltr. n. sp.

In graminosis prope Badja (Togo). IV. 1900 - No. 1297:. Wine sehr schlanke, zierliche Pflanze mit grünlichen Blüten.

$$
\text { Asclepias L. }
$$

1. A. lineolata Schltr.

In campis graminosis prope Dolo, pone Stanley-Pool (Cougo). XI. 1899 - No. 12807. 
2. A. dissoluta Schltr.

In campis graminosis prope Dolo, pone Stanley-Pool (Congo). XI. 1899 - No. 12808.

Ausgezeichnet durch kurze, dicke, undeutlich dreilappige Coronaschuppen. Von Schumann als Xyomalobium beschrieben.

\section{Cynanchum L.}

1. C. acuminatum K. Sch.

Inter frutices scandens, ad pedem montis Kamerunberg (Kamerun), alt. c. 100 m. IV. 1899 - No. 12413 . Inter frutices scandens prope Nyassosso (Kamerun), alt. c. $800 \mathrm{~m}$. I. 1900 - No. 12938 . In fruticetis prope Wesso, juxta flumen Sanga (Congo français). IX. 1899 - No. 12723.

Ursprünglich von Bentham als Cynocto num acuminatum beschrieben. Die Pflanze scheint sehr verbreitet zu sein.

2. C. schistoglossum Schltr.

In fruticetis prope Dolo, pone Stanley-Pool (Congo). VI. 1899 - No. 12484 .

\section{Tylophora R. Br.}

1. T. congoensis Schlt. n. sp.

Inter frutices scandens prope Leopoldville, juxta Stanley-Pool (Congo). VI. 1899 - No. 12551.

Ausgezeichnet durch die wenigblütigen Inflorescenzen.

2. T. dahomensis K. Seh. n. sp. (Mss. in Herb. Berol.)

Inter frutices scandens prope Akeppe (Togo), una cum Cryptolepide sanguinolenta Schltr. IV. 1900 - No. 12987.

3. T. silvatica Dene.

Inter frutices scandens prope Coquilhatville (Congo). VII. 1899 - No. 12610.

Sonst auch noch an verschiedenen anderen Lokalitäten in Congo-Gebiete von mir beobachtet.

\section{Marsdenia R. Br.}

1. M. latifolia Schltr.

Inter frutices scandens prope Ikorodı (Yoruba-Land.) III. 1899 - No. 13000 . Inter frutices scandens prope Libreville (Congo français). XII. 1899 - No. 12823.

Diese von Bentham zu Gongronema gestellte Art kaun ich generisch nicht von Marsdenia trennen. Die Gattung Gongronema bedarf ïberhaupt einer genaueren Durcharbeitung, da offenbar Verschiedenes dort untergebracht ist, was nicht zu ihr gehört. 
1. P. africana R. Br.

\section{Pergularia L.}

In silvis inter Ishagamo et Ikorodu (Yoruba-Land). III. $1899-$ No. $1231 \%$.

Brachystelma R. Br.

1. B. togoense Schltr. n. sp.

In graminosis ad pedem montium Agome (Togo). III. 1900 - No. 12961.

Die Blüten sind dunkelweinrot gefürbt und sitzen in Dolden an Ende der Zweige.

$$
\text { Ceropegia R. Br. }
$$

1. C. yorubana Schltr. n. sp.

Inter frutices scandens inter Ibadan et Abeokuta (YorubaLand). III. 1899 - No. 13016.

Neoschumannia Schltr. n. gen.

1. N. kamerunensis Schltr. n. sp.

Inter frutices scandens prope Kriegsschiffliafen ad margines silvarum (Kamerun). IV. 1899 - No. 12384.

\section{Borraginaceae. (Det. Gürke.)}

\section{Cordia.}

1. C. odorata Gürke.

In silvis prope Ikorodu (Xoruba-Land). III. 1899 - No. 12999.

Verbenceae. (Det. Gürke.)

Clerodendron $\mathrm{L}$.

1. C. yaundense Gürke.

In fruticetis prope Irebu (Congo). VII. 1899 - No. 1262 i.

2. C. scandens G. B.

In campis apertis prope Victoria (Kanerun). IV. $1899-$ No. 12372; In fruticetis prope Coquilhatville (Congo). VII. 1899 - No. 12612.

3. C. Schlechteri Gürke n. sp.

In fruticetis juxta Stanley-Pool prope Leopoldville (Congo). VI. 1899 - No. 12504.

4. C. splendens Don.

Ad margines silvarum prope Mundame (Kamerun). I. $1900-$ No. 12931 .

$$
\text { Kalaharia Baill. }
$$

1. K. spinescens (iürke.

In campis arenosis prope Leopoldville (Congo). VI. $1899-$ No. 12589. 
Labiatae. (Det. Gïrke.)

Leonotis Pers.

1. L. nepetifolia R. Br.

In fruticetis prope Bonga ad ostium fluminis Sanga (Congo français). VII. 1899 - No. 12655.

Leucas R. Br.

1. L. deflexa Hk. f.

All margines silvarmm viarumque inter Ngusi et Mafura (Kamermu), alt. c. 400 m. I. 1900 - No. 12909.

Achyrospermum Bl.

1. A. Schlechteri Gürke n. sp.

In silvis primaevis juxta flumen Dja (Kamerun). IX. 1899 No. 12 769. In silvis primaevis prope Mnea (Kamerun), alt c. 600 m. I. 1900 - No. 12850.

\section{Elsholtzia Willd.}

1. E. Schimperi Hochst.

Ad margines silvarum inter Mafura et Mundame (Kamerun), alt. 300 m. I. 1900 - No. 12914.

1. H. pectinata Poit.

$$
\text { Hyptis Jacq. }
$$

In arenosis prope Dolo juxta Stanley-Pool (Congo). VI. 1899 - No. 12478.

2. H. spicigera Lam.

In cultis et ad margines fruticetorum prope Leopoldville juxta Stanley-Pool (Congo). VI. 1899 - No. 12505.

1. A. rosmarinifolia Welw.

Alvesia Welw.

In collibns graminosis juxta Stanley-Pool prope Dolo (Congo). VI. 1899 - No. 12492.

$$
\text { Solenostemon Schum et Thonn. }
$$

1. S. ocimoides Schum et Thomn.

In axilis foliorum palmae Elaeis prope Kriegssehiffhafen (KameruI). III. 1899 - No. 12396.

$$
\text { Plectranthus L'Her. }
$$

1. P. ramosissimus Hk. f.

In fruticetis graminosisque prope Nyassosso (Kamermu), alt. c. 800 m. I. 1900 - No. 12897 .

2. P. Schlechteri Gürke n. sp.

In humidis prope Dolo juxta Stanley-Pool (Congo). VI. 1899 No. 12490 . 
3. P. spec. I.

In graminosis prope Atikpui (Togo). IV. $1900-$ No. 12982.

4. P. spec. II.

In graminosis prope Akeppe (Togo). IV. 1900 - No. 12989.

$$
\text { Platostoma Beauv. }
$$

1. P. africanum.

In cultis prope Bibundi (Kamerun). III. 1899 - No. 12421. In fruticetis juxta flumen Dja (Kamerun). IX. 1899 - No. 12776. Ad margines silvarum fruticetorumque prope Coquilhatville (Congo). VII. 1899 - No. 12623.

1. A. coeruleus Oliv.

Acrocephalus Bth.

Ad margines paludum prope Dolo juxta Stanley-Pool (Congo). VI. 1899 - No. 12446.

Blüten weisslich.

$$
\text { Geniosporum Wall. }
$$

1. G. congoense Gürke n. sp.

In palndibus prope Dolo juxta „Stanley-Pool“ (Congo). VI. 1899 - No. 12469.

Moschosma Behb.

1. M. polystachyum Benth.

In fruticetis prope Bonga ad ostium fluminis Sanga (Congo français). VIII. 1899 - No. 12668.

1. O. gratissimum L.

$$
\text { O cimum L. }
$$

In fruticetis prope Victoria (Kamerun). III. 1899 - No. 12370.

Solanaceae. (Det. U. Dammer.)

Solanum L.

1. S. togoense Dammer. n. sp.

Inter frutices scandens prope Badja (Togo). IV. 1900 No. 12974.

2. S. spec.

At margines silvarum prope Ishagamo (Yoruba-land). III. 1899 - No. 13004.

Die von Wright im Kew. Bull. veröffentlichten SolanumArten, sind so schlecht beschrieben, dafs es unmöglich ist, sie ohne Original zu erkennen. Verschiedene der Diagnosen würden auf ein Dutz'nul Arten passen. 
Scrophulariaceae. (Determ. A. Engler.) Lindernia All.

1. L. diffusa Wettst.

In humidis collium inter Ibadan et Abeokuta (Yoruba-Land). III. 1899 - No. 12341.

2. L. latibracteata Engl.

In paludibus prope Dolo, pone Stanley-Pool (Congo). VI. 1899 - No. 12440.

$$
\text { Bacopa Aubl. }
$$

1. B. alternifolia Engl. n. sp.

In arenosis humidis insularum in lacu Stanley-Pool (Congo). VI. 1899 - No. 12571 . In paludibus prope Bonga (Congo français). VII. 1899 - No. 12651.

Die Blüten sind hellblau gefärbt.

2. B. calycina Engl.

In arenosis lumidis prope Leopoldville, pone Stanley-Pool (Congo). VI. 1899 - No. 12559.

$$
\text { Artanema Don. }
$$

1. A. longifolium Wettst.

In paludibus prope Ishagamo (Yoruba-Land). III. 1899 No. 13009.

1. T. parviflora Hiern.

Torrenia L.

In collibus inter Ibadan et Abeokuta (Yoruba-Land). III. 1899 - No. 12339.

1. S. dulcis L.

Scoparia L.

In collibus inter Ibadan et Abeokuta (Yoruba-Land). III. 1899 No. 12337.

1. M. indicum Wettst.

$$
\text { Melasma Berg. }
$$

In apertis humidis inter Mafura et Mundame (Kamerun), alt. c. 300 m. I. 1900 - No. 12922 .

1. S. Dregeana Bth.

$$
\text { Sopubia Ham. }
$$

In clivis graminosis montinm Agome (Togo). III. 1900 No. 12959.

2. S. trifida Ham.

In graminosis prope Bonga ad ostium fluminis Sanga (Congo français). VIII. 1899 - No. 12667.

Var. ramosa (Hochst.).

In graminosis prope Dolo, juxta Stanley-Pool (Congo). VI. 1899 - No. 12487. 
Buechnera $\mathrm{I}_{\text {. }}$.

1. B. Buettneri Engl.

In graminosis prope Dolo, juxta Stanley-Pool (Congo). VI. 1899 - No. 12489.

2. B. eapitata Bth.

In planitie arenosa prope Dolo, pone Stanley-Pool (Congo). VI. 1899 - No. 12457.

1. C. camporum Engl.

$$
\text { Cyenium E. Mey. }
$$

In graminosis prope Kewe (Togo). III. 1900 - No. 12949.

1. R. fistulosa Bth.

$$
\text { Rhamphicarpa Bth. }
$$

In insulis sabulosis in lacu Stanley-Pool (Congo). VI. 1899 - No. 125\%7.

1. S. Baumannii Engl.

$$
\text { Striga Lour. }
$$

In collibus graminosis prope Quamikrum (Togo). III. $1900-$ No. 12954.

2. S. canescens Engl.

In collibus graminosis prope Quamikrum ('Togo). III. 1900 - No. 12953.

Acanthaceae. (Det. G. Lindau.)

Elytraria Dahl.

1. E. squamosa lindau.

Ad margines silvarum prope Kriegschiff'hafen (Kamerun). IV. 1899 - No. 12386.

Nelsonia R. Br.

1. N. brunelloicles $\mathrm{O} . \mathrm{K}$.

Juxta rivulos prope Ishagamo (Toruba-Land). III. 1899 No. 12 308; in arenosis fruticetorum prope Stanley-Pool (Congo). VI. 1899 - No. 12506.

1. B. Prenssii Lindan.

$$
\text { Brillantaisia P. Beanr. }
$$

In collibus juxta flumen Ngoko (Kamerun). IX. 1899 No. $1272 \pi$.

1. H. eiliata Lindau.

$$
\text { Hygrophila R. Br. }
$$

In humidis prope Bonga (Congo franęais). VIII. 1899 No. 12678. 
1. P. obliqua S. Moore.

Phaulopsis W.

In fruticetis prope Dolo (Congo). TI. 1899 - No. 12486.

2. P. oppositifolia Lindau.

In umbrosis prope Stanley-Pool (Congo). TI. 1899 No. 12541.

$$
\text { Paulowilhemia Hochst. }
$$

1. P. togoensis Lindau.

In fruticetis prope Muea (Kamerum), alt. c. 800 m. I. $1900-$ No. 12848 .

$$
\text { Dyschoriste Nees. }
$$

1. D. Perrottetii O. K.

In fruticetis inter Ibadan et Abeokuta (Yoruba-Land). III. 1899 - No. 13 035; in fruticetis prope Bonga (Congo). VII. 1899 - No. 12654.

Physacanthus Bth.

1. P. batanganus Lindan.

In silvis primaevis juxta flumen Muni River (Corisco-Bay). XII. 1899 - No. 12832.

Blüten wunderschön hellblau gefärbt.

Lankesteria Ldl.

1. L. elegans T. Aud.

In silvis primaevis prope Meandja (Kamerun), alt. c. $600 \mathrm{~m}$. I. 1900 - No. 12859 ; in silvis primaevis prope Nyassosso (Kamerun), alt. e. 800 m. 1. 1900 - No. 12902.

Blüten weifs.

$$
\text { Crossandra Salisb. }
$$

1. C. flava Hk. f.

In fruticetis prope Nyoke (Kamerun), alt. c. 300 m. - No. 12865 Blüten dunkel-schwefelgelb.

2. C. guineensis Nees.

In silvis primaevis juxta flumen Sanga, inter Wesso et Bonga (Congo français). VIII. 1899 - No. 12703.

Blüten hellblau.

$$
\text { Asystasia } \mathrm{Bl} \text {. }
$$

1. A. gangetica T. Aud.

In fruticetis inter Ibadan et Abeoknta (Ioruba-Iand). 111. 1899.

2. A. longituba Lindau.

In silvis primaevis prope Mnea (Kamerun), alt. $600 \mathrm{~m} . \quad$ I.1900No. 12854 .

Blüten hellblau. 
3. A. macrophylla Lindan.

In fruticetis prope Buea (Kameruu), alt. 900 m. [V. $1899-$ No. 12379 .

Blüten hellviolett.

1. G. pictum Lindan.

Graptophyllum Nees.

In silvis primaevis prope Nyassosso (Kamerun), alt. c. $\$ 00 \mathrm{~m}$. Ein Strauch im Urwalde mit wunderschönen, dunkel-purpurroten Blüten. Die Art ist sicher im Gebiete vollständig wild, daher ist ihr Auftreten in Papu-Asien sehr erstaunlich.

1. C. Büttneri Lindau.

Chlamydocardia Lindau.

In saxis rivulorum inter Mundame et Mafura (Kamerun), alt. c. 300 m. I. 1900 - No. 12925 .

\section{Psenderanthemum Radk.}

1. P. Ludovicianum Lindau.

Ad margines silvarum prope Mnea (Kamerun), 600 m. I. 1900 No. 12 853. In silvis primaevis inter Ngusi et Mafura (Kamerun), alt. 400 m. I. 1900 - No. 12905 .

Blüten weifs, mit blauen Punkten und Flecken am CorollaSchlunde.

2. P. nigritianum Radk.

In silvis primaevis prope Meandja (Kamerun), alt. c. $600 \mathrm{~m}$. I. 1900 - No. 12861.

Blïten ziegelrot.

1. R. Baumanuii Lindan.

$$
\text { Rungia Nees. }
$$

In cultis prope Bibundi (Kamerun). IV. 1899 - No. 12411. In humidis umbrosisque juxta flumen Dja (Kamerun). IX. 1899 No. 12777 .

1. I). alternans Lindau.

$$
\text { Dicliptera Juss. }
$$

In umbrosis inter Malende et Munlame (Kamerum). I. $1900-$ No. 12 s8t.

2. J). laxispica Lindau n. sp.

In silvis primaevis prope Nyoke (Kamerun), alt. c. $200 \mathrm{~m}$. I. 1900 - No. 12863.

3. D. spee. verosim. unbellata Juss.

In fruticetis prope Stanley-Pool (Congo). VI. 1899 - No. 12529.

1. H. cancellata Nees.

$$
\text { Hypoestes R. Br. }
$$

In fruticetis prope Stanley-Pool (Congo). VI.1899 - No.12551. 
2. H. violaceo-tincta Lindau.

In silvis primaevis prope Nyassosso (Kamerun), alt. e. $800 \mathrm{~m}$. I. 1900 - No. 12899 .

1. F. africana Lindau.

$$
\text { Filetia Mig. }
$$

In silvis primaevis juxta flumen Ngoko (Kamerun). IX. 1899 - No. 12759.

Rhinacanthus Nees.

1. R. parvittorus T. And.

In silvis prope Kriegsschiffhafen (Kamerun). [V. 1899 No. 12 383. In silvis primaevis iuter Mafura et Mundame (Kamerun), alt. e. $300 \mathrm{~m}$. 1. 1900 - No. 12921 . In silvis juxta flumen Sanga inter Bonga et Wesso (Congo français). VIII. 1899 - No. 12715.

Blüten weifs.

$$
\text { Durernoia E. Wey. }
$$

1. D. Buchholzii Lindan.

In silvis primaeris inter Mafura et Mundame (Kamerun), alt. c. 300 m. I. $1900-$ No. $1291 \%$.

2. D. robusta Lindau.

In silvis primaevis prope Mundame, alt. e. $200 \mathrm{~m}$. (Kamerun). I. $1900-$ No. 12928.

Oreacanthus Bth.

1. O. Mannii Bth.

In silvis umbrosis inter Malende et Mundame (Kamerum), alt. c. $200 \mathrm{~m}$. I. $1900-12882$.

1. J. flava Tahl.

$$
\text { Justicia L. }
$$

In fruticetis juxta flumen Ngoko (Kamerun). IX. $1899-$ No. 12758 .

2. J. grandis Lindau.

In silvis primaevis inter Malende et Mundame, alt. ‘. $200 \mathrm{~m}$. (Kamerun). I. 1900 - No. 12878.

3. J. insularis T. And.

In fruticetis prope Stanley-Pool (Congo). VI.1899- No.12526.

4. J. Paxiana Lindau.

In silvis inter Ilundame et Otam (Kamerun), alt. 200-300 m. I. 1900 - No. 12885 .

Rubiaceae. (Det. K. Schumann.) Oldenlandia $L$.

1. O. angolensis K. Sch.

In arenosis prope Leopoldville, pone Stanley-Pool (Congo). VI. 1897 - No. 12532. 
2. O. asperuliflora K. Seh. n. sp.

In arenosis prope Coquilhatville (Congo). VII. 1899 No. 12597.

3. O. corymbosa $\mathrm{L}$.

In arenosis inter Ibadan et Abeoknta (Yoruba-Land). III. 1899 - No. 13036.

4. O. Crepiniana K. Sch.

Inter frutices scandens prope Coquilhatville (Congo). VII. 1899 - No. 12622.

5. O. Heynei Oliv.

In insulis sabulosis fluminis Congo, in lacu "Stanley-Pool“ (Congo). VI. 1899 - No. 19572.

6. O. lancifolia Schweinf.

In collibns sabulosis inter Ibadan et Abeokuta (Yorulsa-Land). III. 1899 - No. 12344.

7. O. virgata D. C.

In graminosis prope Badja (Togo). IV. 1900 - Ko. 1297. Hekistocarpa Hk. f.

1. H. minutiflora Hk. f.

Ad margines silvarum prope Nyoke (Kamerun), alt. c. $300 \mathrm{~m}$. I. 1900 - No. 12860.

1. V. multiflora Sn.

Virecta sm.

In paludibus prope Leopoldville, pone „Stanley-Pool“ (Congo). VI. 1899 - No. $12553 . \quad$ In humidis prope Coquilhatrille (Congo). VIl. 1899 - No. 12599.

2. V. procumbens Sm.

In humidis prope Bibundi (Kamerun). IV. 1899 - No. 12404. In paludibus prope Leopoldville (Congo). VI. 1899 - No. 12528. 3. T. setigera Hiern.

In silvis prope Bibundi (Kamerun). IV. 1899 - No. 12405.

4. V. suffruticosa K. Sch. n. sp.

In rupilous rivulormm inter Mafura et Mundame alt. c. $300 \mathrm{~m}$ (Kameruu). I. 1900 - No. 12926.

1. O. dilatata Hiern.

$$
\text { Otomeria Benth. }
$$

In paludibus prope Dolo, pone Stanley-Pool (Congo). VI. 1899 No. 12462.

2. O. guinernsis Bth.

In arenosis cultisque prope Leopoldville pone „Stanley-Pool“ (Congo). VI. 1899 - No. 12516.

3. O. micrantha K. Sch.

Aıl margines silvarum juxta flumen Dja (Kanerun). IX. 1899 - No. 12773. 
1. S. sambucinns K. Sch.

Sarcocephalus Afz.

In collibus graminosis prope Kinchassa, pone Stanley-Pool (Congo). XI. 1899 - No. 12779.

$$
\text { Pentaloneha Hook. fil. }
$$

1. P. humilis Hk. f.

In graminosis prope Bonga, ad ostium fluminis Sanga (Congo français). VIII. 1899 - No. 12661.

1. U. hirtellum Bth.

$$
\text { Urophyllım Wall. }
$$

In silvis primaevis prope Kriegsschiffhafen (Kamerum). IV. 1899 - No. 12380.

1. S. calycina Bth.

$$
\text { Sabicea Aubl. }
$$

In fruticetis inter Ibarlan et Abeokuta (Yoruba-Land). III. 1899 - No. 13024 .

2. S. venosa Bth.

In fruticetis prope Bonga ad ostimn fluminis Sanga (Congo français). VII. 1899 - No. 12658.

Tarenna Gaertn.

1. T. platyptera K. Seh. n. sp.

In silvis inter Nyoke et Malende, alt. $200 \mathrm{~m}$ (Kamerun). I. 1900 - No. 12868 .

1. R. acuminata Btt.

\section{Randia Linn.}

In fruticetis prope Irebu (Congo). VII. 1899 - No. 12628.

2. R. malleifora Bth.

Ad margines silvarum juxta flumen Sanga inter. Bonga et Wesso (Congo français). VIII. 1899 - No. 12708.

1. M. longistyla Hk. f.

$$
\text { Macrosphyra Hk. f. }
$$

In silvis inter Ibadan et Ishagamo (Yoruba-Land). III. 1899 - No. 12320.

1. O. speciosus D. C.

$$
\text { Oxyanthus P. De. }
$$

In fruticetis prope Badja (Togo). IV. 1900 - No. 12975.

Bertiera Aubl.

1. B. aethiopica Hiern.

In fruticetis prope Coquilhatville (Congo). VII. 1899 No. 12617.

2. B. macrocarpa Hiern.

In fruticetis prope Bonga ad ostiun fluminis Sanga (Congo français). VII. 1899 - No. 12652. 
Heinsia Dan.

1. H. pulchella K. Sch.

In fruticetis prope Bonga ad ostium fluminis Sanga (Congo français). VIII. 1899 - No. 12656 . In collibus apertis juxta "Stanley-Pool“, pone Leopoldville (Congo). VI. 1899 No. 12587.

1. Y. canthioides Bth.

$$
\text { Vangueria Juss. }
$$

In silvis inter Ibadan et Abeokuta (Yoruba-Land). III. 1899 - No. 12 322. In fruticetis prope Leopoldville, juxta StanleyPool (Congo). VI. 1899 - No. 12543.

$$
\text { Plectronia Linn. }
$$

1. P. strychnoides K. Sch. n. sp.

In fruticetis prope Badja (Togo). IV. 1900 - No. 12976.

$$
\text { Cremaspora Bth. }
$$

1. C. africana K. Sch.

In fruticetis prope Bonga, ad ostium fluminis Sanga (Congo français). VIII. 1899 - No. 12676.

1. C. divaricata K. Sch.

$$
\text { Coffea Linn. }
$$

In fruticetis silvisque montium Agome (Togo). III. $1900-$ No. 12963.

2. C.? spec.

In silvis primaevis prope Mundame (Kamerun), alt. c. $200 \mathrm{~m}$. I. 1900 - No. 12932.

1. 1. riparia Hiern.

$$
\text { Ixora Linn. }
$$

In fruticetis prope Bonga ad ostium fluminis Sanga (Congo français). VIII. 1899 - No. 12665.

1. P. Baconia Hiern.

$$
\text { Pavetta Linn. }
$$

In silvis prope lkororlu (Yoruba-Land). III. 1899 No. 12299.

2. P. bidentata Hiem.

In silvis primaevis inter Nyoke et Mundame (Kamerun). I. 1900 - No. 12872.

$$
\text { Rutidea D. C. }
$$

1. R. Loeseriana K. Sch.

In silvis primaevis inter Mafura et Mundame (Kamerun). 1. 1900 - No. 12923.

2. R. Schlechteri K. Sch. n. sp.

In fruticetis prope Irebu (Congo). VII. 1899 - No. 12632. 
3. R. tomentosa K. Sch. 11. sp.

In silvis primaevis prope Ikorodu (Yoruba-Land). III. 1899 - No. 12298.

1. P. brachyantha Hiern.

$$
\text { Psychotria L. }
$$

In silvis prope Kriegsschiffhafen (Kamerun). IV. 1899 No. 12 387. In silvis primaevis inter Mafura et Mundame (Kamerun), alt. c. 300 m. I. 1900 - No. 12913 . In umbrosis prope Leopoldville pone Stanley-Pool (Congo). VI. 1899 No. 12566.

2. P. cardiophylla K. Sch. n. sp.

In silvis prope Bibundi (Kamerun). IV. 1899 - No. 12426.

3. P. cataractarum K. Sch. n. sp.

In silvis primaeris prope Bibundi (Kamerun). IV. 1899 No. 12406 .

4. P. latistipula Bth.

In silvis prope Victoria et Kriegsichiffhafen (Kamerun). IV. 1899 - No. 12374 ; No. 12390.

j. P. mierothyr'sus K. Seh. n. sp.

In silvis primaevis inter IIundame et Otam (Kamerun), alt. 200-300 m. I. 1900 - No. 12884 . In silvis primaevis juxta flumen Ngoko (Kamerun). IX. 1899 - No. 12731.

6. P. refractiloba K. sich.

In silvis prope Ilkorodu (Yoruba-Land). III. 1899 - No. 12305.

7. P. Schlechteri K. Seh. n. sp.

In silvis primaevis prope Victoria (Kamerun). 1V. 1899No. 12366.

8. P. Supfiana K. Sch. n. sp.

In silvis primaevis prope Muntame (Kamerun), alt. c. $200 \mathrm{~m}$. I. 1900 - No. 12933.

9. P. Vogeliana Bth.

In fruticetis prope Gbin (Togo). III. 1900 - No. 12950. In silvis inter Ibadan et Abeoknta (Toruba-Land). III. 1899 - No. 13034 .

10. P. spec.

In fruticetis prope Buea (Kamerun). IV. 1899 - No. 12376.

11. P.? spec.

In silvis inter Nyoke et Malende (Kamerun), alt. c. $200 \mathrm{~m}$. I. 1900 - No. 12873.

12. P. spec.

In ripis fluminis Congo prope Stanley-Pool. VI. $1899-$ No. 12547.

R. Seblechter, Westafrikanische Kautschuk-Expedition. 
13. P. spec.

In sil ris prope Victoria (Kanerun). IV. 1899 - No. 12364. Chasalia.

1. C. yorubensis K. Sch. n. sp.

In silvis inter Ibadan et Abeokuta (Yoruba-Land). III. 1899 - No. 13029.

2. C.? spec.

In silvis inter Mundame et Malende (Kamerun), alt. c. $200 \mathrm{~m}$. I. 1900 - No. 12877 .

\section{Uragoga L.}

1. U. sphaerocrater K. Sch. n. sp.

In collibus prope Ibadan (Yoruba-Land). III. 1899 No. 13015 .

1. G. paniculata Bth.

\section{Gaertinera Lam.}

In collibus juxta Stanley-Pool, pone Leopoldville (Congo). VI. 1899 - No. 12553.

2. G. plagiocalyx K. Sch. n. sp.

In fruticetis prope Leopoldville juxta Stanley-Pool (Congo). VI. 1899 - No. 12586.

Borreria G. F. W. Mey.

1. B. ocymoides K. Sch.

In cultis prope Bibundi (Kamerun). IV. 1899 - No. 12425.

2. B. oligantha K. Sch. n. sp.

In paludibus prope Cape Lopez (Congo français). XII. 1899 - No. 12913.

3. B. Rnellia K. Sch.

In arenosis inter Ibadan et Abeokuta (Yoruba-Land). III. 1899 - No. 12340.

4. B. stricta K. Sch.

In planitie arenosa prope Tolo pone Stanley-Pool (Congo). VI. 1899 - No. 12458.

5. B. tetradon K. Sch. n. sp.

In paludibus prope Dolo, juxta "Stanley-Pool“ (Congo). VI. 1899 - No. 12475.

1. M. verticellatus Vatke.

Mitracarpus Zuce.

In collibus arenosis inter Ibadan et Abeokuta (Yoruba-Land). III. 1899 - No. 12353. In collibus graminosis prope Ibadan (Yoruba-Land). III. 1899 - No. 12324 . In arenosis prope Leopoldville (Congo). VI. 1899 - No. 12591. 


\section{Cucurbitaceae. (Det. H. Herms.)}

Melothria L.

1. II. spec. aff. tridactylae Hook. f.

Inter frutices scandens prope Coquilhatville (Congo). VU. 1899 -- No. 12626.

$$
\text { Momordica L. }
$$

1. II. cissoides Planch.

Inter frutices scandens prope Ikorodu (Yoruba-Land). III. 1899 - No. 12307.

Campanulaceae. (Det. A. Engler.)

Cephalostigma A. D. C.

1. C. Perrottetii A. D. C.

In collibus lapidosis prope Noki (Congo). V. 1899 No. 12437.

Compositae. (Det. O. Hoffmann, p. p. R. Schlechter.)

Bothriocline Oliv.

1. B. misera O. Hoffm.

In arenosis prope Stanley-Pool ad villam Leopoldville (Congo). VI. 1899 - No. 12560.

Aedesia O. Hoffm.

1. A. Bammannii O. Hoffm.

In graminosis prope Agome-Palime (Togo). III. 1900 No. 12966 .

$$
\text { Vernonia Schoeb. }
$$

1. V. Biafrae O.\&H.

Inter frutices scandens prope Muea (Kamerun), alt. c. $600 \mathrm{~m}$. I. 1900 - No. 12849 .

2. V. Calvoana Hk. f.

In fruticetis inter Mafura et Mundame (Kamerun), alt. c. 300 m. I. $1900-$ No. 12912.

3. V. cinerea Less.

In sabulosis humidis prope Dolo pone „Stanley-Pool" (Congo). VI. 1899. - No. 12479.

4. V. glaberrima Welw.

In graminosis humidis prope Dolo pone „Stanley-Pool“ (Congo). VI. 1899 - No. 12452.

5. V. guineensis Bth.

In collibus graminosis montium Agome (Togo). III. $1900-$ No. 12964.

6. Y. undulata Oliv, et Hiern.

In graminosis humidis prope Dolo pone Stanley-Pool (Congo).

VI. 1899 - No. 12480. 
7. V. spec.

In fruticetis prope Meandja (Kamerum), alt. $600 \mathrm{~m}$. I. 1900 - No. 12855.

1. H. stellulifera Bth.

$$
\text { Herderia Cass. }
$$

Ad margines fruticetorum prope Ishagamo (Yoruba-Land). III. 1899 - No. 12309.

$$
\text { Elephantopus L. }
$$

1. E. scaber L.

In silris inter Nyoke et Malende (Kamerun), alt. $200 \mathrm{~m}$. I. 1900 - Yo. 12869.

$$
\text { Mikania Willd. }
$$

1. M. scandens Willd.

Inter frutices scandens pone Leopoldville pone Stanley-Pool (Congo). VI. 1899 - No. 125218.

1. D. latifolia D. C.

$$
\text { Dichrocephala D. C. }
$$

In humidis prope Bonga at ostium fluminis Sanga (Congo français). VIII. 1899 - No. 12662.

1. If. volubilis D. C.

$$
\text { Microglossa D. C. }
$$

In silvis inter Abeokuta et Ibadan (Yoruba-Land). III. 1899 - No. 13021 ; In ripis fluminis Sanga, inter Bonga et Wesso (Congo français). VIII. 1899 - No. 12079.

2. Ví. angolensis $\mathrm{O}$. et $\mathrm{H}$.

In planitie graminosa prope Bonga, ad ostimm fluminis Sanga (Congo français). VIII. 1899 -. No. 12673.

1. C. aegyptiaca Ait.

$$
\text { Conyza Less. }
$$

In graminosis prope Irebu (Congo). VII. 1899 - No. 12630.

1. L. alata Schulz Bip.

$$
\text { Laggera Schulz Pip. }
$$

In graminosis prope Irebu (Congo). VII. 1899 - No. 12631.

Helichrysum Gaertn.

1. H. congolanum Schltr. n. sp.

In graminosis prope Dolo pone Stanley-Pool (Congo). VI. 1899 - No. 12465.

2. H. Mechowianm Klatt.

In clivis graminosis montimn Agome ('Togo). III. $1900-$ No. 12960. 
Acanthospermum D. C.

1. A. hispidum D. C.

In cultis prope Atikpui (Togo). IV. 1900 - No. 12981.

1. E. alba Hassk.

$$
\text { Epaltes Cass. }
$$

In collibus prope Leopoldville pone Stanley-Pool (Congo). VT. 1899 - No. 12563.

1. ล. africanus Jacq.

$$
\text { Selerocarpus Jaeq. }
$$

In fruticetis atque ad margines silvarum prope Irebu (Congo). VII. 1899 - No. 12637.

Hoffmanniella Schltr. n. gen.

1. H. silvatica Schltr. n. sp.

In silvis primaevis juxta flumen Dja, locis humidis (Kamerun). LX. $1899-$ No. 12775.

\section{Aspilia Thou.}

1. A. helianthoides Oliv. et Hieru.

In graminosis prope Atikpui (Togo). IV. 1900 - No. 12983. In graminosis inter Ibarlan et Abeokuta (Yoruba-Land). III. 1899 - No. 12350 . Ad margines fruticetorum prope Libreville (Congo français). V. 1899 - No. 12435.

Strahlblüten weiss.

2. A. Kotschyi Pth. et Hk. f.

In fruticetis eultisque prope Leopolılville, pone Stanley-Pool (Congo). VI. 1899 - No. 12536.

1. S. nodiflora Grtu.

$$
\text { syuedrella Gaert. }
$$

In silvis ac juxta vias prope Ikorodu (Yoruba-Land). III. 1899 - No. 12997.

Chrysanthellum Rich.

1. C. procumbens Pers.

In arenosis inter Ibadan et Abeokuta (Yoruba-Land). III. 1899 - No. 12349.

1. G. crepidioides Bth.

$$
\text { Gyllura Cass. }
$$

In cultis juxta flumen Ngoko (Kamerum). IX. 1899 -No. 12277.

2. G. vitellina Bth.

In paludibus fruticetisque prope Nyassosso (Kamerun), alt. c. 800 m. I. 1900 - No. 12895 . 


\section{$-\quad 326$}

\section{Emilia Cass.}

1. E. integrifolia Bkr.

In planitie arenosa prope Dolo, pone Stanley-Pool (Congo). VI. 1899 - No. 12449.

Senecio L.

1. S. gabunicus Oliv. et Hiern.

In fruticetis inter Ibadan et Abeokuta (Yoruba-Land). III. 1899 - No. 13023.

2. S. Quartinianus Aschs.

In fruticetis prope Leopoldville pone Stanley-Pool (Congo). Vl. 1899 - No. 12502. 

35185000038446 


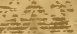

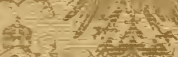

sil

as

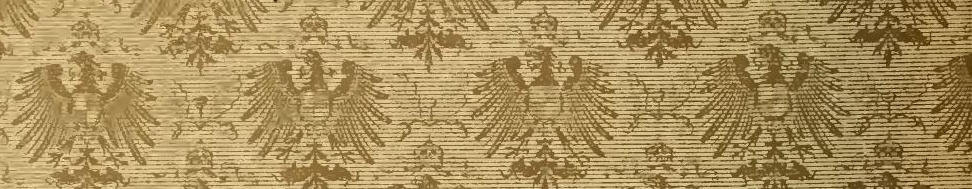

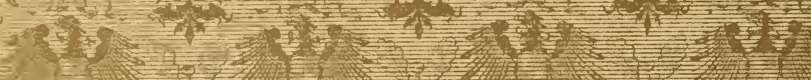

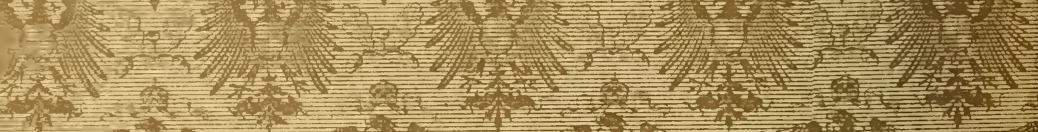
$3 \operatorname{lon}^{2}$

(1)

(2)

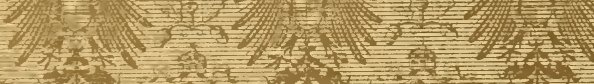

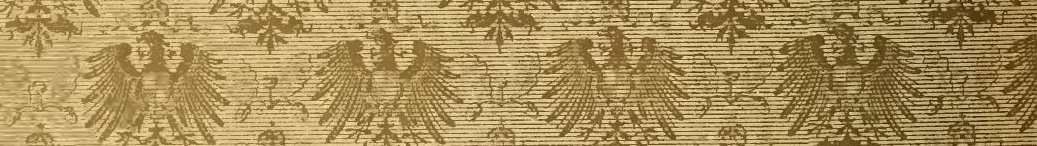

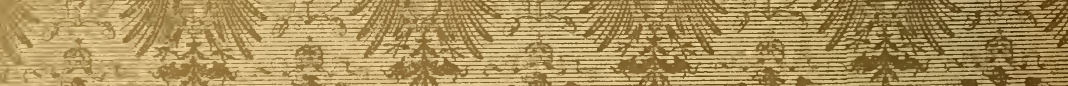

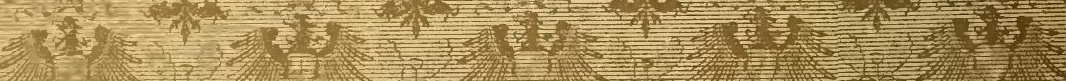

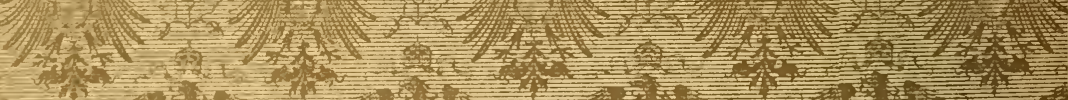
का

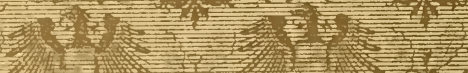

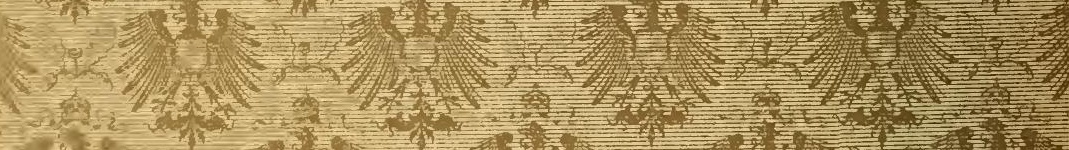

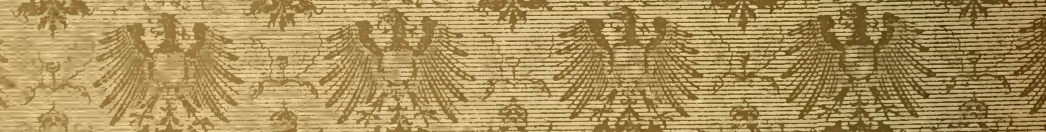

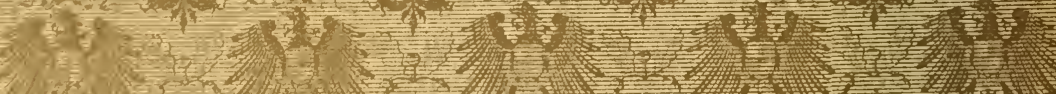

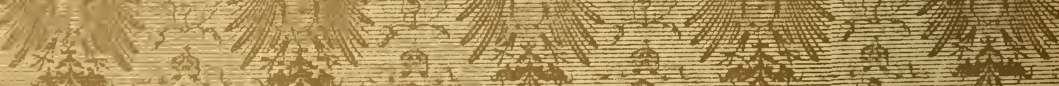

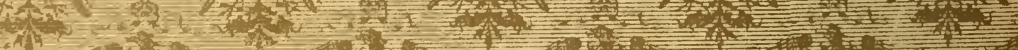

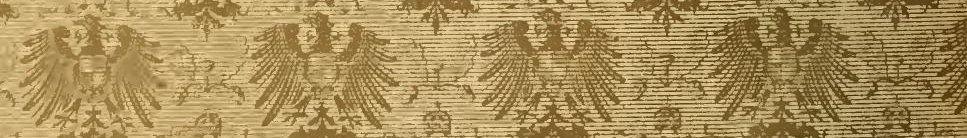

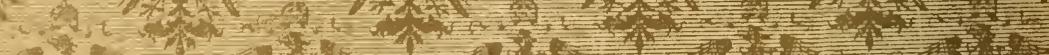

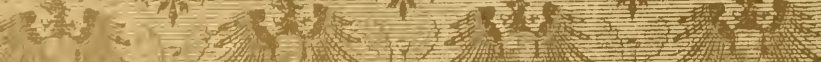

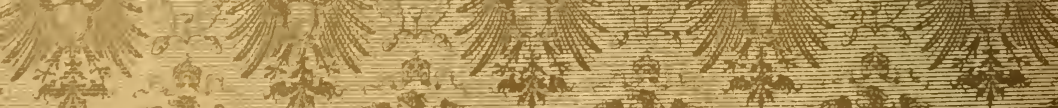

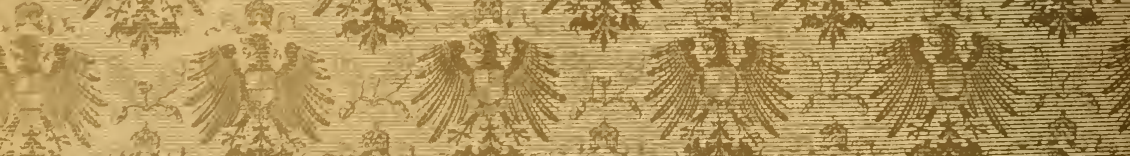

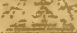




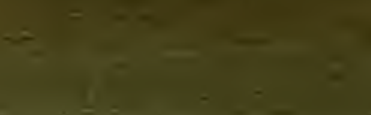

